\title{
BENSON AND BETTS
}

\section{AGRICULTURE}




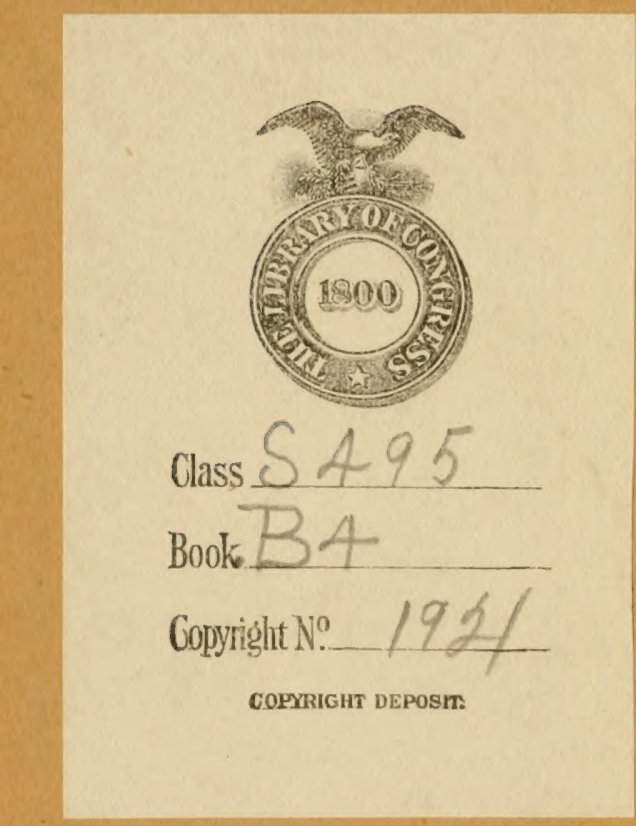





\title{
A G R I C U L T U R E
}

A Text for the School and the Farm

\author{
$B y_{0}$ \\ O. H. BENSON
}

AGRICULTURIST, UNITED STATBS DEPARTMENT OF AGRICULTURE

and

GEORGE HERBERT BETTS

AUTHOR OF THE MIND AND ITS EDUCATION BETTER RURAL SCHOOLS. ETC.

WITH ILLUSTRATIONS, CHARTS AND DIAGRAMS

I92I

INDIANAPOLIS

THE BOBBS-MERRILL COMPANY

PUBLISHERS 
Copyright 1915, 1921

The Bobbs-Merrilll Company

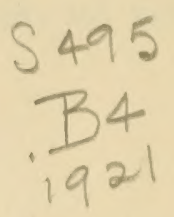

Printing and Binding by

pookwulter-Ball Printing Company Indianapolis, Indians

(घ)

MAY 181921

(a) Cl. $A 617054$ 
"I know of no pursuit in which more real and important service can be rendered to any country than improving its agriculture."

George Washingtom 


\section{AUTHORS' ACKNOWLEDGHENTS}

Acknowledgment is gratefully made to the Minister of Agriculture, Canada, for the illustration on page 209; the United States Department of Agriculture for the illustrations on pages $17,40,65,68,75,77,82,85,93,105,120,125$, I29, I47, I49, I51, I86, I89, 193, 194, 196, 198, 209, 213, $273,278,280,284,286,298,299,303,309,317,318,321$, $325,328,350,352,353,355,362,364,369,397$; the Poultry Department of the Massachusetts College of Agriculture, pages $357,364,366$; the Kansas State College of Agriculture, pages 42, 45; the Alabama Polytechnic Institute, page I73; the Washington State College of Agriculture, page 339; the Iowa State College of Agriculture and Mechanic Arts, pages I5, 19, 28, 55, I23, I39, 243; the College of Agriculture of the Illinois State University, pages 233, 239, 320, 323; the College of Agriculture of the University of. Wisconsin, pages 187, 190, 192, 195, 199; the College of Agriculture of the State University of Minnesota, pages 348,372 ; the College of Agriculture of the University of Ohio, page I29; ine Yakima Commercial Club of the State of Washington, pages I55, I82, 269, 338 ; the Crop Improvements Committee, Board of Trade Building, Chicago, page 39; Wallace's Farmer, Des Moines, Iowa, page 393; the Agricultural Department of the International Harvester Company of Chicago, pages $51,68,89,135,137,142,144,157$; the James Manufacturing Company, Fort Atkinson, Wisconsin, pages 239, 246, 4II ; the DeLaval Separator Company of New York City, page 383 ; the Lehigh Portland Cement Company, of Chicago, page 430 ; the Northern Pacific Railway, page $34 \mathrm{I}$; the Hoosier Manufacturing Company, New Castle, Indiana, page 380 , and the David McKay Publishers, Washington Square, Philadelphia, $\mathrm{Pa}$., pages 4I3, 4I 415 . 


\section{PREFACE}

The present volume attempts what has not yet been accomplished in elementary texts on agriculture-the combining of real practical information with concrete home and school projects to be carried out by the pupils. Agriculture, of all subjects, can not be taught from within a text-book. Nor, on the other hand, can it be well taught by the teacher who is not a specialist without a good text-book by means of which to unify the instruction and lead to an intelligent interest in the farm and its problems. Unless the pupils busy themselves with actual agricultural activities, the study becomes mere theory and of doubtful value. This 'ext is a guide to concrete work and interest on the farm, in the garden and about the home.

Yet the text is more than a laboratory guide. It gives a large amount of practical, scientific information wholly without technical terms. Further, this information is always so immediately related to definite farm projects as to have meaning and application. Scientific facts and their use go hand in hand. Theory and practise are never divorced. The old maxim, "Learn to do by doing," is constantly followed, and the doing made natural and worth while to the child by being connected with his home interests.

Hardly a day's assignment occurs in the book, therefore, that does not present some real project for the pupils to carry out in connection with the farm or home life. Nor are the problems set the child lacking the information and guidance necessary to their intelligent solution. The re- 


\section{PREFACE}

quired facts, principles and descriptions are always at hand, and the problem or project made the means of teaching some valuable lesson in concrete form.

The authors believe that the elementary features of agriculture can be successfully taught without technicalities. It has been their aim to present a treatment so clear that students from fourteen to eighteen years of age could read and profit by it even without a teacher. They have also tried to make the subject-matter so vital and helpful that all who are interested in agriculture, even practical farmers, will care to read it, and desire to carry out its lessons in practise.

Teachers will recognize and welcome the attempt to use the study of agriculture in bringing about a closer relation between the school and the home. Not only teachers, but county superintendents and agricultural agents will appreciate the many helpful suggestions concerning Demonstration Work, Play Contests and Agricultural Club Projects; for these are coming to occupy an important place in agricultural education. The great amount of care given to make the lessons teachable through the outlining of many definite and practical laboratory, field and home projects will appeal to all who use the text, and save much time for the busy teacher.

The authors gratefully render their acknowledgments fo: much cordial help received from the staffs of various state colleges of agriculture and the United States Department of Agriculture. Especially valuable have been the suggestions and material received from the colleges of agriculture of Iowa, Indiana, Illinois, Wisconsin, Ohio, New York, Massachusetts, Alabama, Minnesota, Kansas and Nebraska. 


\section{CONTENTS}

\section{PART I. FARM CROPS}

CHAPTER

I Corn Culture

Corn the king of crops-The "corn belt"-The corn plant -Determining the stand-Stand in the home field-Corn enemies-Topics for investigation-Saving the seed-Types of corn-The selection bed-Corn judging with score-card -Testing the seed-Problems and experiments-Preparing seed for the planter-Seed bed and planting-Cultivating the corn-Harvesting and storing-The silo-Uses of corn - Topics for investigation-Corn demonstrations-Corn play contests-Corn club projects.

II WHEAT

Bread the staff of life-Importance of wheat-The wheat states-Types of wheat-Topics for investigation-Growing the crop-Diseases and insect enemies-Treatment of fungous enemies-Treatment of insect enemies-Problems and experiments.

III OATS

Importance of oats as a crop-The oats region-Types of oats-Problems and experiments-Raising the crop-Harvesting and thrashing-Insect enemies and diseases-Topics for investigation-Wheat and oat demonstrations-Play contests-Club projects.

\section{The Potato}

Origin-Plant and tuber-Potatoes as a farm crop-The potato region-Growing the crop-Harvesting and storing potatoes-Seed selection-The "tuber-unit" method-Potato enemies-Problems and experiments-Potato demonstrations-Play contests-Potato clubs.

\section{Forige Crops}

The place of forage crops-Important grasses and legumes-Region and extent of forage crops-Uses to which the forage plants are put-Problems and experimentsDemonstrations-Club projects. 


\section{CONTENTS-(CONTINUED)}

Wide use of the clovers-Red clover-Study of the plant - Value of red clover on the farm-Raising red cloverSeed bed and seeding-Good seed-Harvesting-Enemies and their control-Other kinds of clover-Problems for investigation.

VII Alfalfa

Study of plant-Distribution of alfalfa-Alfalfa as a forage crof- As a renewer of the soil-Successful raising of alfalfa-Harvesting-Enemies-Topics for investigation.

\section{OtHer Legumes}

The cow-pea-Cow-peas as forage-As a soil renewerThe vetches-Varieties-Uses-Soy-beans-Uses and cultivation-Feeding value-The peanut.

iX Meadows and Pastures

Importance of meadows and pastures-Requirements of a meadow-Meadow grasses and legumes-Mixtures for meadows-Care of meadows-Problems for investigationPastures-Requirements-Seed mixtures-Care.

\section{PART II. HORTICULTURE}

$\mathrm{X}$ The Vegetable Garden

Importance of garden-Location and soil-Plan-Table of planting and maturing-Garden culture-The hotbedInsect enemics-Other enemies-Froblems and experiments -Garden demonstrations-Play contests-Club and canning projects.

KI The Frutt Garden . . . . . . . . .

Profits and satisfaction-Soil and location-Plan-A variety list-Care of fruit garden-Enemies and their treatment - Spraying-Problems and experiments-DemonstrationsPlay contests-Fruit clubs.

\section{The Tomato}

Importance of the tomato-Varieties-Raising the cropPruning and staking-llarvesting and marketing-Problems and experiments-Demonstrations-Play contests-Clubs. 


\section{CONTENTS-(CONTINUED)}

CHAPTER

XIII Garden AND ORCHARd SpRays . . . . . . 208

Indispensable in successful gardening-Bordeaux mixture - Use-Lime-sulphur-How made and used-Arsenate of lead-Mixing and applying-Paris green-Kerosene emulsion-How made and used-Resin-lime mixture.

XIV Home Canning of Fruits and Vegetables . . . 217

Value of home canned foods-Recipes for home canning -Time table for canning-Canning outfits.

\section{PART III. THE SOIL}

XV Nature of SoIL. 225

Origin of soil-Nature of soil-Organic matter-Texture and its effects-Structure of soils-Structure and tilthErosion-Problems and experiments.

XVI Soil Fertility and Plant Groivth . . . . . 236

Plant food and soil fertility-Loss of fertility-Maintaining fertility-Barnyard manure as a fertilizer-Preventing loss from manure-Application to soil-Green manuringCommercial fertilizers-Use of lime on soils-Crop rotation and fertility.

XVII SOIL MoIsture

Forms of soil water-Capacity of soils for capillary water-Tillage and soil water-Soil drainage-Surface and tile drains-Soil demonstrations-Problems and experiments -Soil play contests-Club work.

\section{PART IV. FARM ANIMALS}

XVIII Farm Animals and Agriculture

Work animals-Animals that supply food-Other animal products-Topics for investigation.

XIX Cattle

Dairy cattle-Profitable and unprofitable cows-The dairy type-Selecting dairy cows by milk tests-Dairy breedsFeeding for milk production-Producing clean milk-Beef breeds-Judging cattle-Tuberculosis in cattle-Experiments and problems - Demonstrations with cattle - Play contests-Club projects. 


\section{CONTLNTS--(CONTINUER)}

CII ATTER

XX HORSES

The horse-raising states - Classes of horses - Breeds Judging horses - Common defects of horses - Care and fraining-liceding: work rations- Topics for investigationDemonstrations with lourse:-l'lay contests-Club projects.

XII SWINE

l'ork region-Breeds of hogs-Care hog houses-Fieding: balanced rations-Diseases-Prevention and treatment of clolera- P'roblems and experiments-DemonstrationsPlay contests-Club projects.

Xill Simpr

Importance on farm-Breeds of sheep-Feeding: rations - Experiments and problems-Demonstrations-Play contests-Club work.

\section{PNULTRY}

Importance on farm-Extent of industry-Breeds of chickens-Producing chickens-Hens and incubators-l'est-

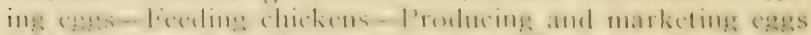

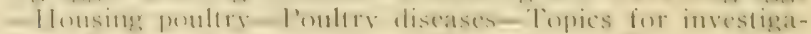

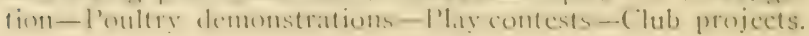

\section{I'AR'T V. FARM ECONOMICS}

\section{Farm and Home Management}

Planning the farm-Administration of farms - Farm accounts-lmportant rules-Ten commandments of agriculture-Topies for investigation-The farm house-Other farm buildings.

XXV THe Home Grounds and Woon Lot

Beautifying the home grounds-Trees-The lawn-The farm wool het Tree encmies-l'roblems and experiments - Demonstrations-l'liy contests-Tree and grounds club.

\section{XXVI line County Agricultural Agent}

Work of the county agent-Financial support-The county agent and the school-How to make use of the county agent. 


\section{CONTENTS-(CONTINUED)}

XXVII FARM IMPLEMENTS AND MEChaNics 408

Importance of implements and tools-Farm mechanicsUse of cement-Shop wrok-Kope tying and splicingProblems and experiments-Play contests-Club projects.

XXXVIII Road Building and Maintenance.

Importance of goorl roads-Types of roads-Location of a road-Qualities making a gord road-Construction of earth roads-Maintenance-Topics for investigation-Road demonstrations-Road clubs.

XXIX Birds ANd Other Insect Destroyers . . 432

Birds and their food-Birds helpful to agricultureI Iarmful birds-Protecting birds-Topics for investigation -Other insect destroyers.

XXX Miscellaneous Information . . . . . . 441

How to remove stains-Iocation of colleges of agriculture and experiment stations-Distance apart for planting fruits and vegetables-Quantity of seed per acre for planting.

INDEX 

AGRICULTURE 




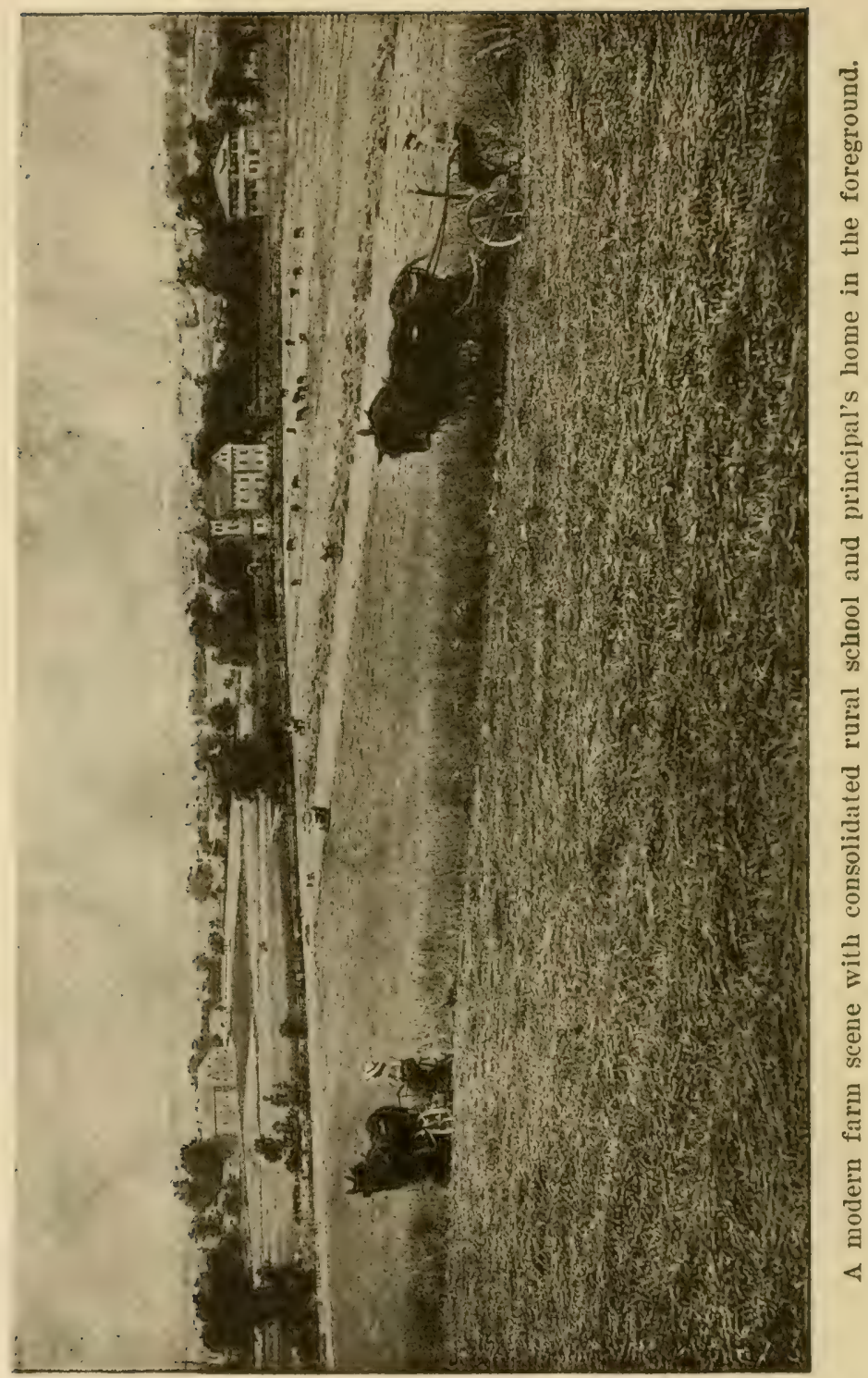




\section{AGRICULTURE}

\section{PART I. FARM CROPS}

\section{CHAPTER I \\ CORN CULTURE}

CORN is king of farm crops. The value of the corn crop is almost equal to that of cotton, wheat and oats combined, and totals more than a billion dollars annually. We feed our stock upon corn, eat it for our own food and use it in many other ways. The welfare and prosperity of millions of people are dependent on securing a good crop of corn.

Three-fourths of the corn crop of the world is grown in the United States. Each year we produce more than $2,500,000,000$ bushels. Should we load this enormous crop into wagons, fifty bushels to the load, and allow twenty feet for each wagon and team, the line would reach about eight times around the earth at the equator.

Taking the whole country together, the average yicld of corn per acre is slightly less than thirty bushels. The states best adapted to corn raising are Illinois, Iowa, Nebraska, Missouri, Kansas, Indiana and Ohio. These seven states, which are called the "corn belt" of the United States, raise nearly half of all the world"s corn. In them the yield is somewhat over forty bushels to the acre. This is a much smaller crop than could be raised if the soil were enriched, and greater care and skill used in growing the crop. A 
large number of corn club boys in different states have produced as much as one hundred fifty bushels from an acre, and not a few in the southern states have raised more than two hundred bushels. One of the things we shall try to learn in this book is how to raise a larger crop of corn from our fields.

\section{The Corn Plant}

Corn belongs to the grass family; that is, it is a member of the same group of plants as timothy, wheat, rye, or bluegrass.

In order to study the corn plant itself, each of the class will secure from a near-by field, or bring from home, a complete stalk of corn, taking care to save as much of the root as possible. Then use the text as a help in studying the plant.

The roots.-Examining the roots, do you find them tough and fibrous, or tender? Do the roots branch, or is there a central tap root? At earing time the roots of a vigorous plant may extend down several feet, and spread out so that they meet the roots from other hills. The ground of a corn-field may thus be completely filled with roots. In dry seasons the roots strike deeper than in wet seasons. Why? Would you expect the roots to run deeper in a black porous soil, or in a hard clay subsoil?

Are there roots branching from the lower one or two joints of the stalk, thus starting from above the top of the ground? Roots growing in this way are called brace roots. They act like the guy ropes of a tent pole, and hold the stalk erect in the winds. If these are broken off by close plowing, or lestroyed by worms, the corn is easily blown down.

The stem.-How long is the stem? What is its girth just above the root? How many leaves has it? From where do these start? How are they attached? Are the 


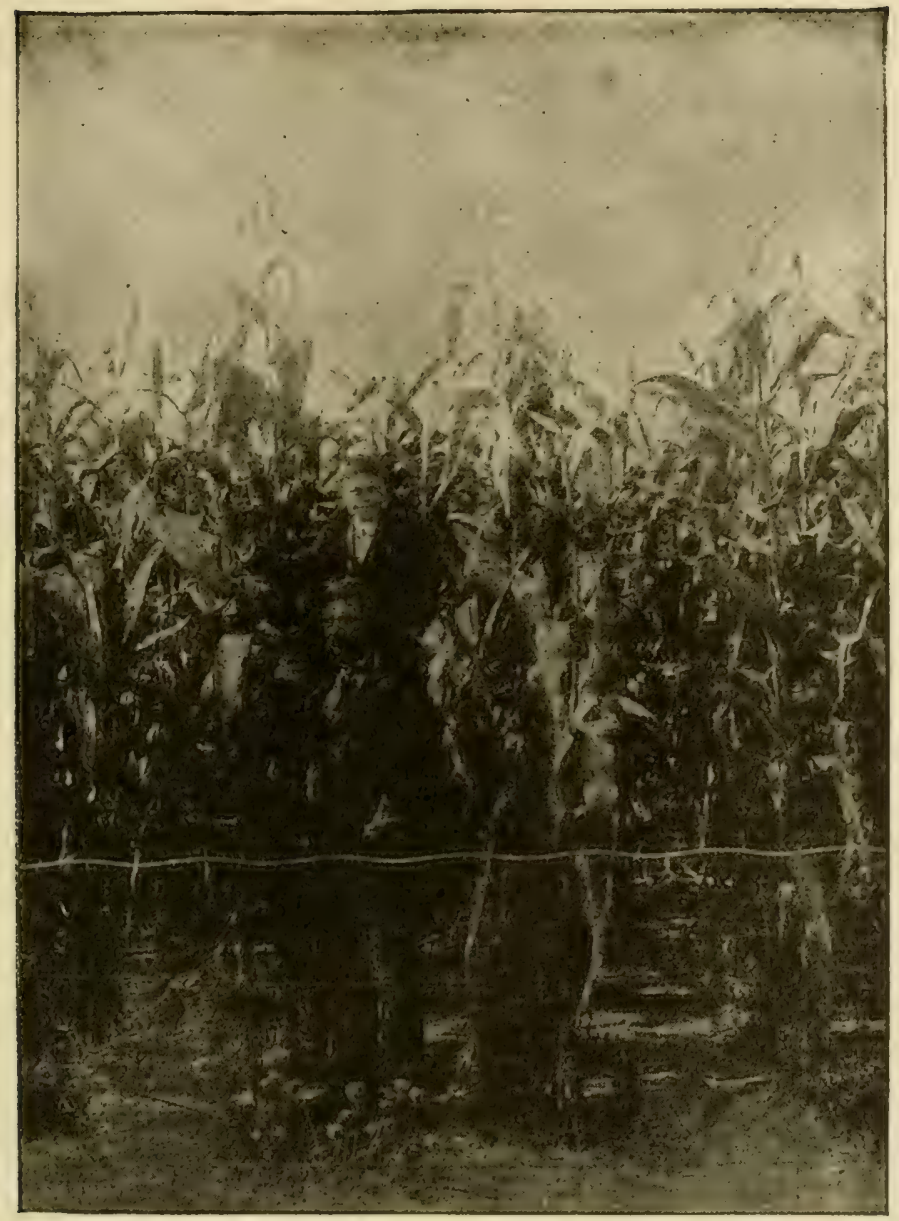

A good stand of corn. The yield was 105 bushels to the acre. The boy tested the seed. 
edges of the blades longer than the center? What proof have you?

The length of the stem varies with different varieties of corn, and because of differences in the season or the soil. The range is from two or three feet to fifteen or twenty feet. The stem is divicled by joints called nodes; the sections between these joints are called internodes.

Is the stem round, or flattened? Cut the stem across and note the structure. Unlike most other grasses, corn is not hollow. The spongy substance with which the haid outside shell is filled is called pith. The threads found running lengthwise through the pith add greatly to the strength of the stalk.

The leaves.-The leaves are important in the growth of the plant, since in them the plant food is worked over and assimilated, and through them the respiration, or breathing, of the plant is done. The leaves are large, and hence have to stand much tugging in the wind. Are they stronger hecause of their sheath-like form of atlachment? Will they tear as easily in a strong wind if the onter edges are slightly longer than the center? Large vigorous leaves indicate a healthy plant. In very dry weather, the leaves curl up from the edges. This is a useful habit, since the leaf when thus rolled up does not lose so much moisture as when fully open.

Tassel and silk.-Strip the husk carefully from an ear in the milk stage, without injuring the silks. How many silks are there? Where are the silks attached to the ear? While tassel and silk are borne on different parts of the plant, yet it takes both together to make the complete flower of the corn and produce the ear. The tassel represents the male part, and the silk the female part of the flower.

The work of the tassel is to proluce pollen. This sifts 
off in fine grains just as the corn is silking. A particle of pollen lodges on the tip of a silk, and a growth is carried through the center of the tiny thread to its root, where the kernel forms. The pollen in this way fertilizes the silks, one silk for each kernel of corn. If for any reason no fertilization occurs, no kernels will be formed.

The pollen grains are very light, and may be carried by the wind for many rods, thus fertilizing the silks of other plants than their own. This is called cross-fertilization. The reason different varieties of corn planted in near-by fields mix is because the pollen is carried from one field to the other.

Have you ever seen an ear with part of the kernels white and the rest red, or yellow? How is this to be explainer! : A small patch of pop-corn planted near field corn turned out to be wadly mixed, although the seed used was pure. How do you account for the mixture?

\section{Determining the Stand}

In order to raise a full yield of corn we must first of all have a good stand. Corn is usually planted in rows about three and a half feet apart each way. On good corn land three stalks seem to make the best hill. It is plain that if the hills have but one or two stalks each, or if whole hills are frequently missing, there can not be a full crop.

Importance of a good stand.-Farmers often lose much of their labor and a large amount of money because of a poor stand of corn. It requires as much work to prepare the ground and cultivate the corn for half or twothirds of a stand as if every hill was present and had its three stalks.

How is it with the farms in your own neighborhood? With your father's farm? What kind of a stand do the 
corn-fields show? The best way to answer this question is to go out into the fields and count the hills. This is the way the scientist works; he makes surc, and does not guess. ITe will therefore determine the stand on several plots selected from different parts of a field of corn and discover whether the farmer is losing labor and money because the stand is imperfect.

Preparing for field study.-Before going out to the field rule off four forms like the following in your notebook, eacl square to represent a hill of corn :

3. Record of Stand of Corn

, PLOT NO.

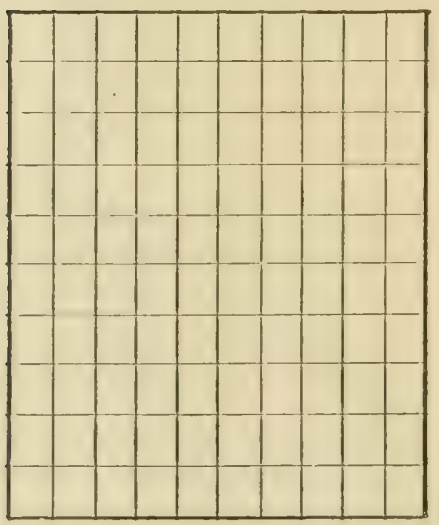

Counting stand in the field.-Now go to a near-by field and select what appears to be an average plot of corn, ten hills square. Go through the plot carefully, counting the stalks in each hill, and recording the number in the proper 
square on your record sheet. Hills having more than three stalks are to be recorded as having only three, as three stalks to the hill make the best stand on average soil, if planted three and one-half feet each way.

Having completed the count on this plot, select three other plots in different parts of the field, count the hills and make the record in your note-book for each plot separately. Tre are now ready to estimate the stand for the entire field. To do this, we shall need to work out the following problems, keeping the results in our note-books:

1. If every hill had three stalks, how many stalks would there be on each plot? How many on all four plots?

2. How many hills in each of the plots had three stalks? Two stalks? One stalk? No stalk? How many stalks altogether in each of the plots?' In all the plots combined?

3. What percentage of a perfect stand do all four plots average? If the entire field averages as good a stand as the plots, what percentage of a stand has it?

4. How many acres in the entire field? How many acres did the farmer plow and tend which, because of an imperfect stand, raised no corn?

5. What will this field probably yield to the acre? Suppose the ears would still average the same size, what would it yield with a perfect stand? At the market price of corn, what difference in value would this make per acre? For the whole field?

Counting stand in home fields.-After having made this study, you will naturally want to know about your home fields of corn. Therefore prepare other record sheets in your note-books, and count the stand on four different plots of your father's corn, making careful records as you did in the first study. Then work out the five problems for the home field as you did for the field studied at school. Show the results to your father, and talk with him about 
the cause of the imperfect stand. Also compare your results with the stand found in the home fields of other members of the class, and see if you can discover what produces the differences in stand. Barring bad weather at planting time, worms and other pests, at least a ninety-five per cent. stand should always be secured.

Barren stalks and suckers.-Merely having the right number of stalks in the field does not insure a crop, however. These stalks must bear ears. There are two classes of stalks that are of no use, barren stalks and suckers.

Strong and vigorous-looking stalks may be barren. Barrenness may be caused by weak seed, injuries to the roots by worms or insects, discases, poor soil, drought, or too thick planting. Suckers are but branches from the parent stalks, and have no root of their own. They are worse than useless, for they seldom bear ears, and are but a drain on the stalk which supports them. Suckers are caused by thin planting, especially in rich heavy land. There are also some strains of corn which, through heredity, are likely to grow suckers. Seed from sucker-bearing stalks should not be planted.

Counting barren stalks and suckers.-We shall now determine the percentage of barren stalks and suckers in a field. Take either the plots already counted for stand or new ones, and go over them, counting the ears. Nake a record sheet of squares as before. In these squares record (1) the number of stalks that has two ears, (2) that has one ear, (3) that has no ear. Do this for each of four plots ten hills square.

\section{Summing Up Results}

1. What percentage of the stalks bears two ears? One ear?

2. What percentage of stalks is barren? If this percentage holds for the entire field, how much is the yield 
reduced per acre, supposing the field as it now stands will yield forty bushels?

3. What percentage of the stalks bears suckers? How many of the suckers had ears?

4. What do you judge was the cause of the barren stalks? Of the suckers?

\section{Corn Enemies}

Plants, like animals, are subject to certain diseases. Corn is usually a healthy plant, and not affected by as many diseases as some of the other crops. The most serious enemies of corn are various insects, such as the cornroot worm, the corn-root aphis or louse, the cutworm, the ear worm; and such animals as gophers, squirrels and birds.

The corn-root worm.-This pest is responsible, over a large area of the country, for greater loss to the corn crop than any other cause except poor seed, and often probably inflicts more damage than all other insects put together. It has been estimated that its damage in the corn belt alone exceeds 200,000,000 bushels annually. Because the root worm is very small and does its work under ground, it is seldom seen, and probably could not be identified by many farmers to whom it has caused thousands of dollars of loss. It is present in some degree in almost every cornfield.

At full size the root worm is about one-third inch in length, and as large around as a pin. It is whitish in color, with its head and the first segment of its body brown. The root worm hatches in June or early July, and reaches its full growth by the first of August. Soon after this it goes into the pupa state, and in a few days comes out a small green beetle. This beetle lays the eggs, which remain in the ground over winter and hatch the next generation of root worms the following spring.

As soon as the young worms are hatched out they enter 


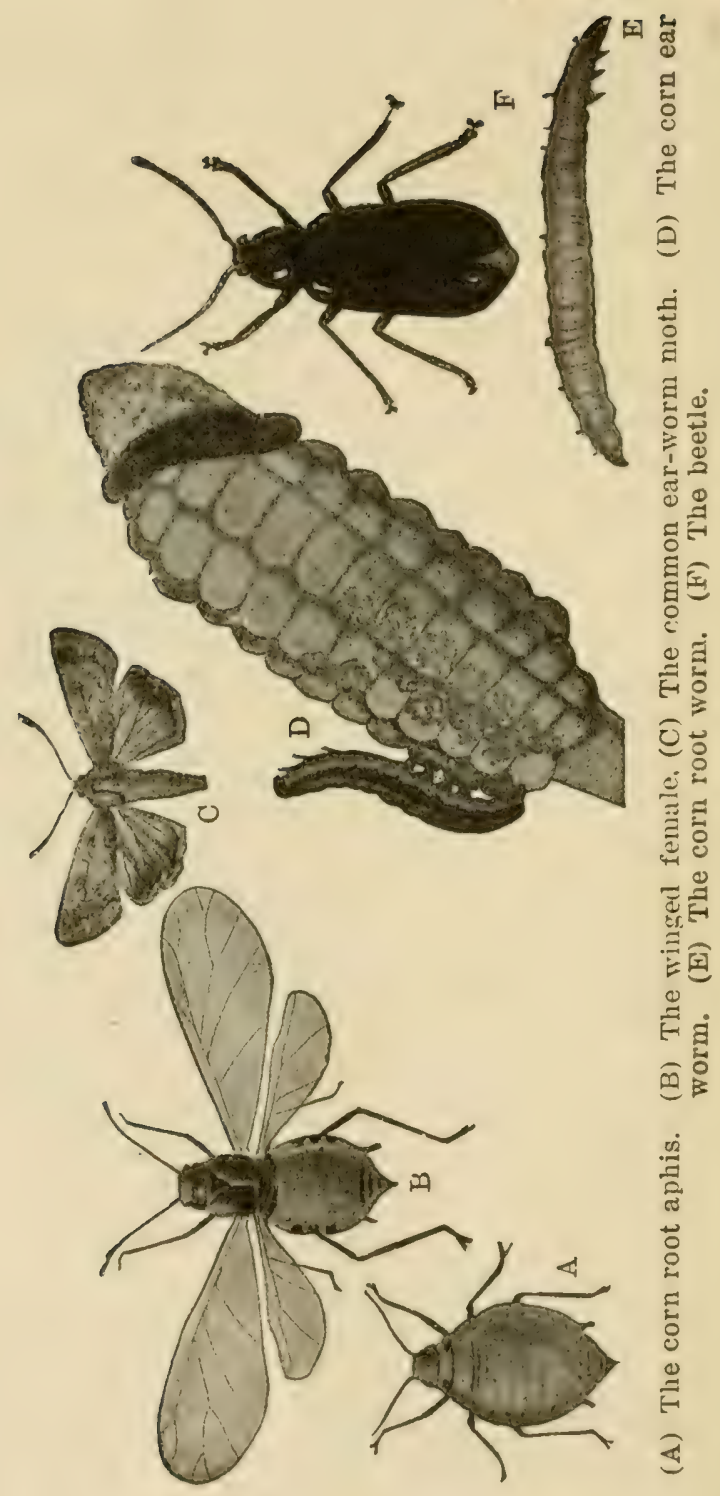


the roots of the growing corn, burrowing back and forth just under the outside covering. Half a dozen worms are sometimes found in the one root, and as many as two hundred in a single hill. The worm destroys the tender part of the root, which turns brown and rots off, leaving only the stubs of roots. As a result, the stalk of corn is deprived of its means of securing moisture and nourishment. It seems to stand still instead of making a vigorous growth, and fires badly during the dry weather of July and August. It is easily blown over, especially after a rain when the ground is soft. The yield is greatly reduced, and the ears are light and chaffy; many stalks are barren. The growth of the plant is retarded, and the crop is later in maturing.

There is no way of stopping these pests once they begin on a field of corn. But the remedy is simple for the next year-wherever possible plant the field to some other crop. For this will leave the young worms with no food, and they will all die. The field can then be planted to corn again, and should be free from root worms for at least the first year. Usually corn should not be raised for more than two years in succession on the same field. Especially if the corn goes down in spots in August, and if the roots show the working of these worms, should corn not follow the next season. If proper rotation of crops is practised, there will be little or no loss from the root worm.

The corn-root aphis or louse.-Second to the root worm, the worst enemy of corn is the corn-root aphis. This is a small louse, no larger than the head of a pin, and of a bluish-green color. These lice are found in groups on the roots of corn, from which they suck the juices intended for the growth of the plant.

The corn-root aphis is always found accompanied by ants. Indeed, it is the ants which carry the lice to the 
corn roots, or to the roots of certain weeds after the corn roots have become hard. The ants take this care of the aphis because it gives out a sweet substance called "honey dew," upon which the ants feed. The presence of many ants in the corn-field, especially ant-holes in the hill, is a sign of the root aphis.

The worst damage by the aphis is done while the corn is very young. The lice sometimes destroy the roots even before the plant comes up. The effect of their work on the corn roots causes the plant to turn yellow and take on a sickly appearance. If they are very severe in their attack, the tips of the leaves become purplish, and the stem reddish in color. The yield of the crop is greatly reduced, and its ripening delayed.

Rotation of crops is one of the surest remedies against this pest. Harrozering the field before the corn comes $u p$, or while it is small, interferes with the work of the ants, and hence checks the ravages of the aphis. Keeping the fields clean of weeds is also necessary, since the lice thrive on the roots of such plants as smartweed and foxtail.

Cutworms.-Cutworms do little damage except on sodl land which has been in meadow or pasture for a num. ber of years. They are a grayish-brown color, and grow to an inch or more in length. Cutworms work at night, cutting the young stalk of corn off just at the surface of the ground.

One remedy for cutworms is the fall plowing of soll. thus exposing the insects to the freezing of winter. This will greatly reduce their number. A shorter rotation of crops, leaving the field in sod but one or two years, will also tend to destroy the cutworms.

Wireworms.-Wireworms also make their home in sod, and hence are worst in newly broken ground. They 
are the larvæ of the click-beetle, whose eggs are laid in meadows and pastures in the fall. They hatch out as small reddish-brown worms in the early spring. The worms attack the sprouting kernel, and also bore holes through the young plant. Fall plowing and rotation of crops are the best remedies against the wireworm.

The corn ear worm.-The worm is usually found working in the tips of corn ears. It attacks not only corn, but cotton and many other plants.

The corn ear worm lives through the winter in the pupa stage, and comes out in the spring as a moth. There are several broods each season, but only the last does any great damage to the corn. The harm done by the ear worm is not great, except to sweet corn intended for canning. There is no certain remedy known, though fall plowing is thought to reduce their number.

Smut.-The most common disease affecting corn is smut. The smut masses seen on growing corn are produced by a small parasitic plant which lives on the juices of the corn plant. Smut spores, corresponding to seeds, live over winter in the soil, or may be distributed in manure spread on the field, or may even be blown •considerable distances from other fields.

The slimy black masses of smut are found on the stalk, leaves, tassel, or ear. Since smut must live off the strength of its host, it is evident that the corn plant is weakened and the yield reduced by the presence of this disease. There is no effective remedy for corn smut, though the burning of smut balls, keeping it from the manure used on the field, and the rotation of crops all tend to control it.

\section{TOPICS FOR INVESTIGATION}

1. The corn-root worm of the North can be found at 
work only from late June to early August. During late August and September the worm is found onl:- in the beetle stage. Go into a corn-field and secure several of these beetles. They are green, and about twice the size of a pinhead. Learn to recognize the insect at sight.

2. If possible secure a number of the pupæ of the cornroot worm. About the middle of August they can be found in great numbers around the roots of corn in a field where the worms have been at work. Keep the pupæ in warm moist soil in a box covered with netting or glass and watch for the beetles to come out.

3. Find hills of corn which have suffered from the corn-root worm. How do you discover where they have. been at work? Does the hill pull up easily as compared with a good hill? What is the condition of the ear?

4. Observe several fields that have been in corn for a number of years in succession. Do they show signs of the root worm? Compare with fields on which a rotation of crops has been grown.

5. Secure several ears of corn in which the ear worm has been working. How does the worm proceed in its attack? Nake a study of the worm, and become able to identify it at sight. Would you want to eat canned sweet corn from a field which had suffered from these worms?

6. Secure samples of corn smut affecting (1) the ear, (2) the tassel, (3) the stem, (4) the leaves. Does the stalk look healthy? Is the ear good? After the smut ball is dry, note the fine powder which flies from it. This is the spores which reproduce the plant for next year.

7. If possible, secure samples of the corn-root aphis, the cutworm and the wireworm. Learn to identify all these accurately and quickly.

8. Other such enemies to be noted are: the corn moth or caterpillar, the stalk borer, the white grub and the corn bill bug. If possible, secure specimens of these, learn to identify them, tell how they damage the crop and how to exterminate them.

\section{Saving the Seed}

The first care if we would secure a good stand of corn is the seed. We must have seed that will grow and show 


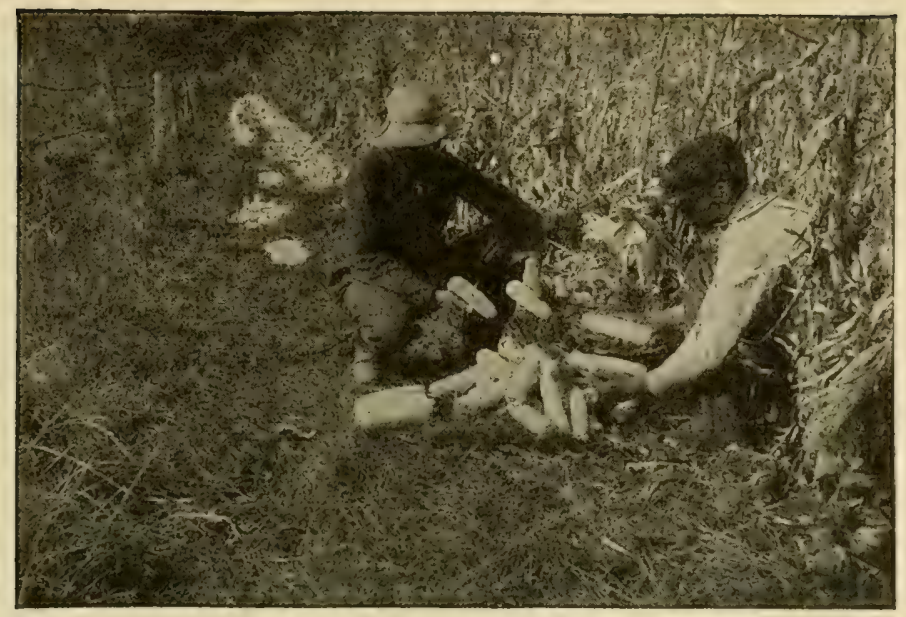

Gathering seed before it freezes.

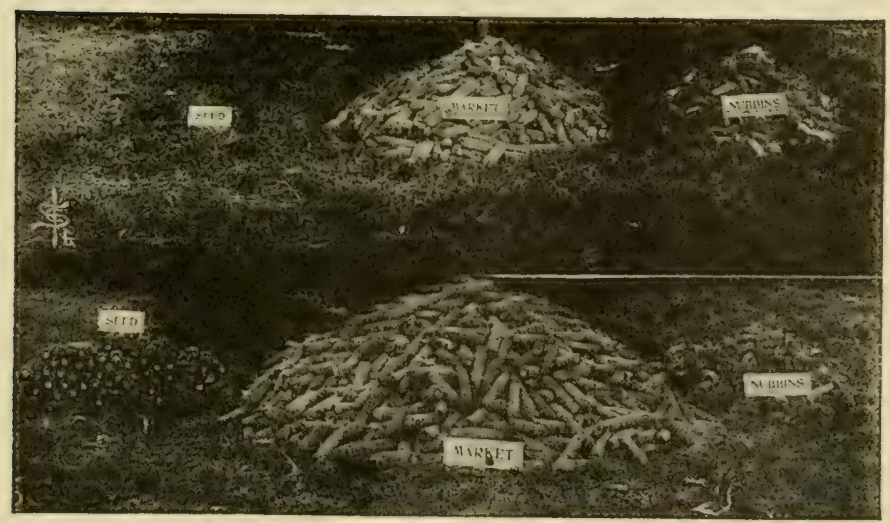

The difference between good seed and poor seed. Each picture shows the rield from one acre in adjoining fields. Upper picture, poor seed: yield, 22.5 bushels; marketable, $73.9 \%$; nubbins, $26.1 \%$; seed, none. Lower picture. good seed : yield, 66.5 bushels; marketable, $86.7 \%$; nubbins, $6.3 \%$; seed, $7 \%$. 
strong vitality. Most of the poor stands which we discovered in the fields we have just been studying no doubt came from seed that either failed to germinate, or else threw out plants so weak that they were unable to live through the cold damp weather of early spring.

The loss from poor seed.-The loss from the planting of poor seed is enormous. There are more than one hundred million acres of corn planted every year in the United States. This requires some sixteen million bushels of seel. But of these sixteen million bushels, it has been estimated by government experts that three million bushels fail to grow or produce barren stalks. Think of planting three million bushels of worthless seed corn each year!

Let us see what this great waste means. The average yield of corn to the acre in the United States is slightly under thirty bushels, or only one small ear to the hill. For, counting 3,556 hills to the acre, one ten-ounce ear to the hill would yield almost thirty-two bushels to the acre; and an ear weighing only ten ounces is little more than a nubbin. Our farmers are therefore averaging but one small ear to the hill in all their corn-fields. If they should increase the stand and improve the corn so that from each hill they get two medium-sized ears, each weighing twelve and one-half ounces, the yield will be eighty bushels to the acre instead of thirty bushels. Will it not pay to select good seed?

When seed corn should be gathered.-There is no more important work on the farm than the selection and care of seed corn for the next crop. Freezing before it is fully dry almost always injures the seed so that it either will fail to sprout, or else will produce a weak plant. Seed corn should therefore be gathered as early in the fa!l as it is well ripened. The time for saving seed in the "corn belt" is from September twentieth to October tenth. 


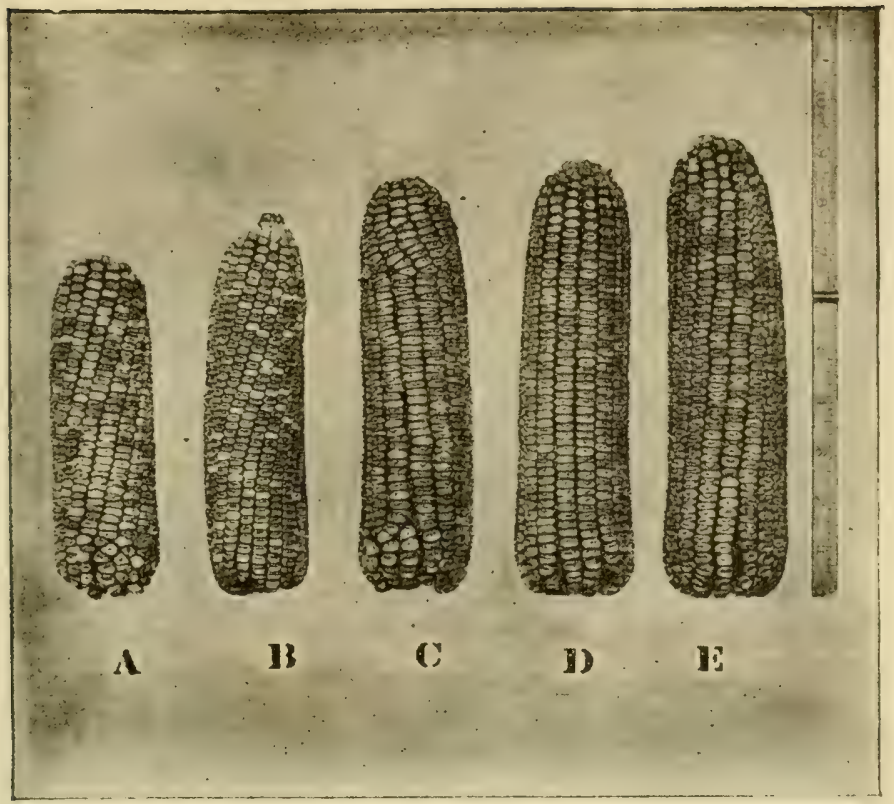

Illustration of the yield of corn per acre, allowing a single stalk for each hill of $31 / 2$ feet. (A) 28.8 bushels; (B) 30 bushels; (C) 40 bushels; (D) 45 bushels: (E) 50 bushels:

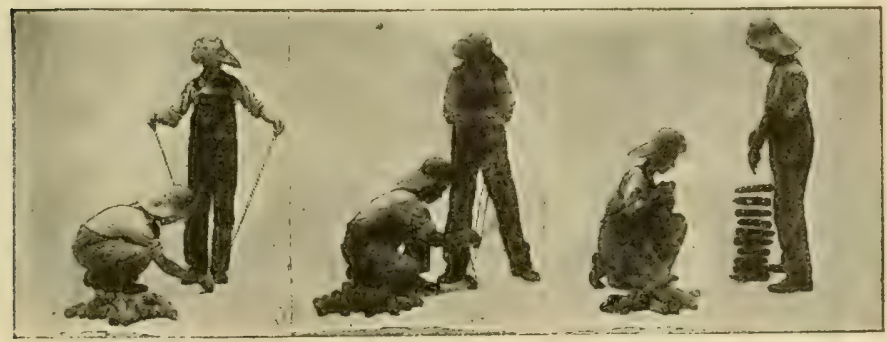

Stringing seed corn,- the tirst step. The second step. The string completed. 
How to gather seed corn.-Securing good seed requires that seed corn shall be gathered from the field before the general crop is harvested. The proper way to select seed corn is to pass through the best parts of the field, row by row, with a sack slung over the shoulder, examining each promising-looking ear from a good stalk and full hill, and taking the ear if it proves acceptable. This looks like a good deal of work, but when it is remembered that twelve to fifteen ears will plant an acre, and that the difference between a yield of thirty bushels or of sixty bushels to the acre may result from having good seed, it is well worth the time. From three to five bushels a day may be selected in this way-enough to plant from twenty-five to forty acres of next season's crop.

The right kind of seed hill.-In selecting ears for seed it is important to take into account all the surroundings of the plant. It is plain that ears grown on stalks which stand but one in a hill, or next to missing hills, have a better chance to grow large than those from full hills. A large ear grown under such favorable conditions might not produce so well as somewhat smaller ears grown under less favorable conditions. We want to be sure that the ear is good size because of something in the nature of the car itself, rather than from what has happened to it while growing. Mature good ears from hills having three stalks are desirable, for this condition promises a good yield. The stalk should be sturdy, not too tall, and have plenty of broaci îll leaves.

Curing the seed.-Caring for the seed after it is picked is as important as its selection. The great thing in caring for seed corn just picked from the field is to give it a chance to dry thoroughly. To do this, it must be where it can get plenty of circulating air. The ears should not touch one another, for then they will not dry evenly. Seed 


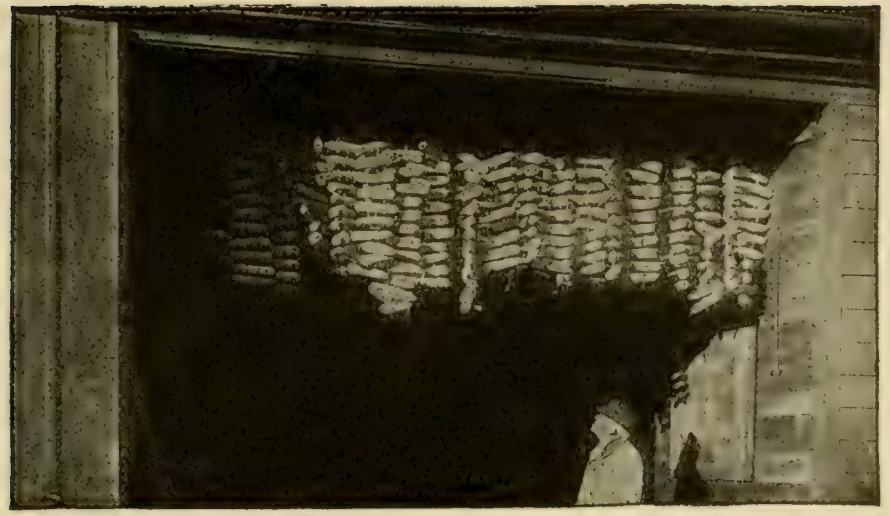

Seed corn hung up to dry.

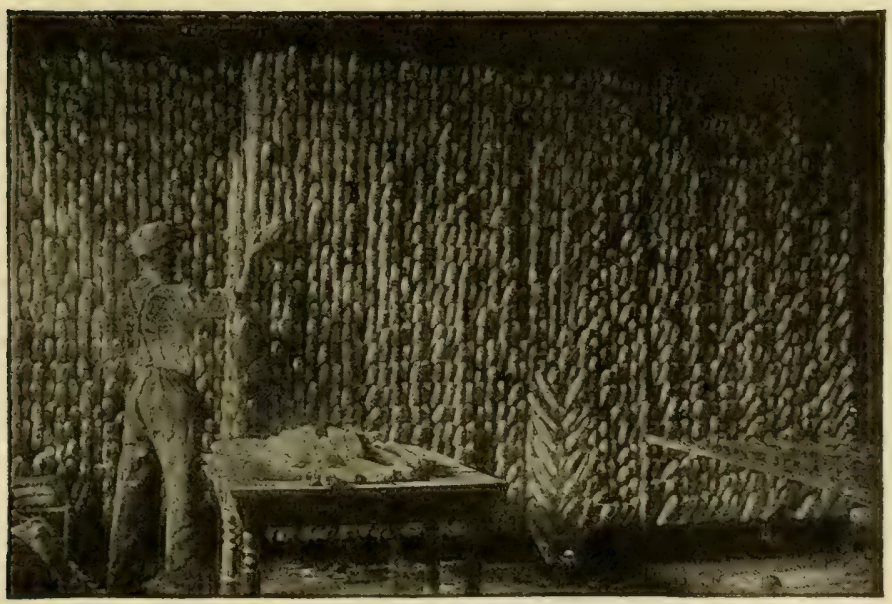

Another method of drying seed corn. 
corn should therefore never be stacked in piles or thrown into a crib after it is gathered, but should be hung up in some open place sheltered from the direct sun, if the weather is still hot, and from all rain or other forms of moisture.

One of the simplest and best ways to hang seed corn is by stringing it. By this method each string contains a dozen ears-almost enough to plant an acre. To hang corn in this way, cut a string of binding twine twelve feet long, and tie the ends together, thus forming a loop. One person should opcrate the string, and another handle the ears. Place the first ear in the strings, and pass one end of the loop through the other end, tightening down to the ear. Place the next ear in the same way, and keep on until the string has all been taken up. Hang the stringer of ears up in a uniformly dry place and it will need no more attention until time comes for testing the seed. This plan should be followed after each day's picking, not even allowing the corn to lie over night before being hung to dry.

Another plan of drying out seed corn is to lay the ears side by side on shelves, where there is free circulation of air, and where mice and rats can not reach the corn. Where this plan is followed, the shelves should be made of slats, and not of solid boards, so as to allow the air to get to all parts of the ear.

Hanging the ears by tying a part of the husks works well, but takes more time, and also takes up more room than to use the twine loop for hanging a dozen ears in one string. Still another method is to drive ten-penny finishing nails four inches apart in a post, sticking the butt of the ear on the nail.

\section{Types of Corn}

There are altogether seven different types of corn. These are: (1) pod corn, (2) soft corn, (3) sweet corn, (4) 
pop-corn, (5) Kafir corn, (6) flint corn, and (7) dent corn.

Pod corn.-Most of those who will study this book have never seen pod corn grown. It has a thin husk around each separate kernel. This type of corn is of interest chiefly because it is thought to be the oldest type, from which all other types have developed. The chaff or scale at the base of the kernels of our common varieties is probably a remnant of the kernel husk of the old pod corn. Pod corn will grow in almost any temperate region.

Soft corn.- Soft corn, like pod corn, is not grown as a staple crop in the United States. This is the Mondamin of the American Indians, and was favored by them because it was very easily ground. Its softness is caused by the fact that its endosperm is all of soft white starch, wholly lacking the horny starch of the other types. Little of this type is grown except in the South.

Sweet corn.-Sweet corn is widely grown for human food. It is used green as "roasting-ears," and is canned while green and kept in this state for almost any length of time. Sweet corn does not produce so large a yield as some other kinds, and hence is not grown for feeding stock. It is grown throughout the corn territory.

Pop-corn.-Pop-corn is distinguished for the hardness of its kernel. It is just the opposite of soft corn, and has an endosperm nearly all of hard horny starch. When the kernels are heated and the moisture in them expands, an explosion occurs which we call popping. Pop-corn can be raised in all parts of the corn region.

Kafir corn.-Botanically Kafir is not really a member of the corn family, but belongs to the sorghums. For agricultural purposes, however, Kafir may be considered a type of corn. Its medium-sized seeds grow in a cylindrical or oblong head instead of on an ear. Kafir is grown 
in the semi-arid regions of the Southwest. It is a good substitute for corn in the ration of all farm animals.

Flint corn.-Flint corn is the prevailing type yet raised in New England and in New York. It is to be recognized by the long slender ear, and by the hard flinty kernel, which contains a large amount of horny starch. Flint corn does not require so long a season as dent corn, and hence is preferred in northern regions where there is danger of the crop being caught by the frost before it is ripe. As earlier varieties of dent.corn are being developed, they are displacing flint corn in many regions.

Dent corn.-This is the principal corn raised in the great corn producing regions of the United States. In fact it supplies the greater part of the world's corn crop. It is called dent corn because the soft starch of the crown shrinks slightly in ripening, thus causing a depression in the top of the kernel. It is the type grown almost exclusively for feeding stock, and all the commercial corn products, such as glucose, starch, sirup, etc., are made from it. Dent corn has two varieties: (1) single car, or one ear to the stalk, as grown in the corn belt; and (2) prolific, or many ears to the stalk, as grown in the South.

Types and varieties.-Each different type of corn may have many iaricties. As a matter of fact, however, the types that are most grown have the largest number of varieties, or strains. Varieties of corn are produced in three different ways: (1) by selecting some exceptional or peculiar ear, and using it for seed, picking out for seed each year the ears most nearly like the original parent ear until the varicty is established; (2) by cross breeding; and (3) by selecting each year for planting the best ears, - the earliest ears, the largest ears, the best shaped ears, or ears that possess whatever quality is wanted in the new variety. If this same quality is selected year after year, the variety 


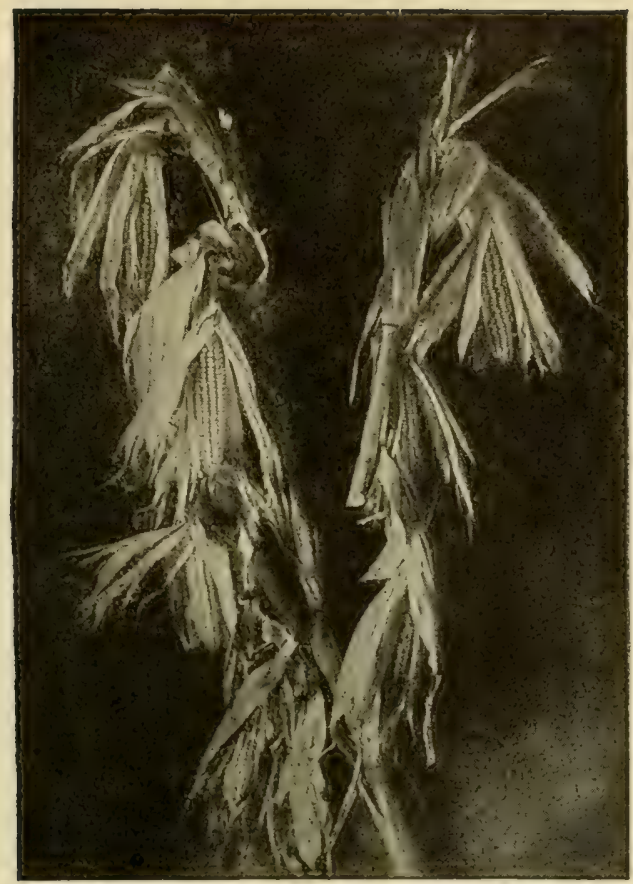

An illustration of the prolific corn common in the southern states. It will grow 2 to $\mathrm{S}$ ears of corn on each stalk. It requires a subtropical climate, copious rainfall and a long season.

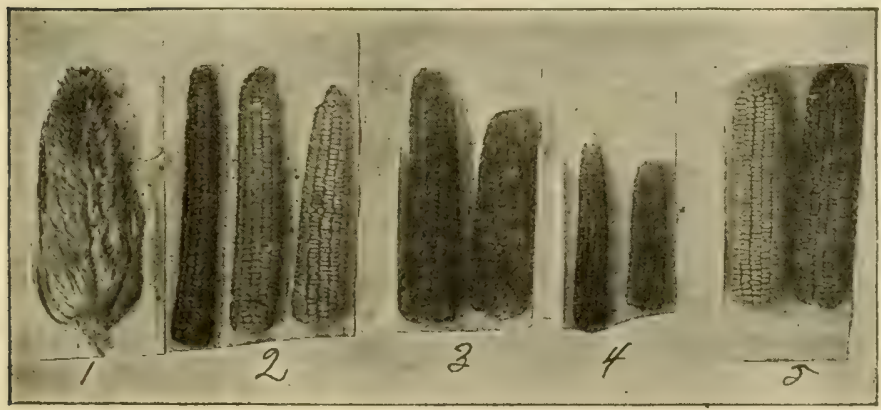

Types of corn. (1) pod corn; (2) three strains of flint corn; (3) two strains of sweet corn; (4) two strains of pop-corn; (5) two strains of dent corn. 
will after a time have a tendency to "breed true"; that is, all to be like the ears selected for seed.

Selecting the best variety.-Different varieties are suited for different climates and for different soils. It is therefore important in selecting a variety of corn to know whether it is adapted to the conditions under which it is to be raised.

\section{TOPICS FOR INVESTIGATION}

1. How many of the seven different types of corn have you ever seen? How many are grown in your region? (Be sure to distinguish type from variety.)

2. Bring to school a sample of as many different types as you can find. What three can you easily secure if you live in the Middle West? What ones can you secure if you live in New England? If you live in Oklahoma or Alabama?

3. Examine these different types for the size of the ear; for the shape; for the shape of kernel; for color; for proportion of corn to cob; for the parts of the liernel.

4. Is the corn raised on your father's farm a truc varicty, or is it mixed? If true, what is the variety?

5. How many varicties of corn do you know? Join with your classmates in making as large a collection of samples of different varieties as can be found in the neighborhood. Comparing these ears for the different qualities by which ears are judged, what are the differences you note? Which seems to you the best variety? Does it yield best? Does it ripen? Does it have good feeding and selling qualities?

\section{Raising Seed in a Selection Bed}

The first step necessary in improving corn is to improve the seed. Not only must we make sure that the corn selected for seed will grow, but it must be as nearly perfect in every way as possible. For heredity works in plants as well as in animals. We select the best stock for breeding; we should do the same in choosing the seed we plant. Good, strong. well-formed ears will tend to produce corn of the 
same kind, while small, irregular, or weak ears will breed the characteristics of their kind.

Choosing the selection bed.-So important is the matter of the very best corn for seed, that many farmers are now using what is called the sclection bed for the raising of

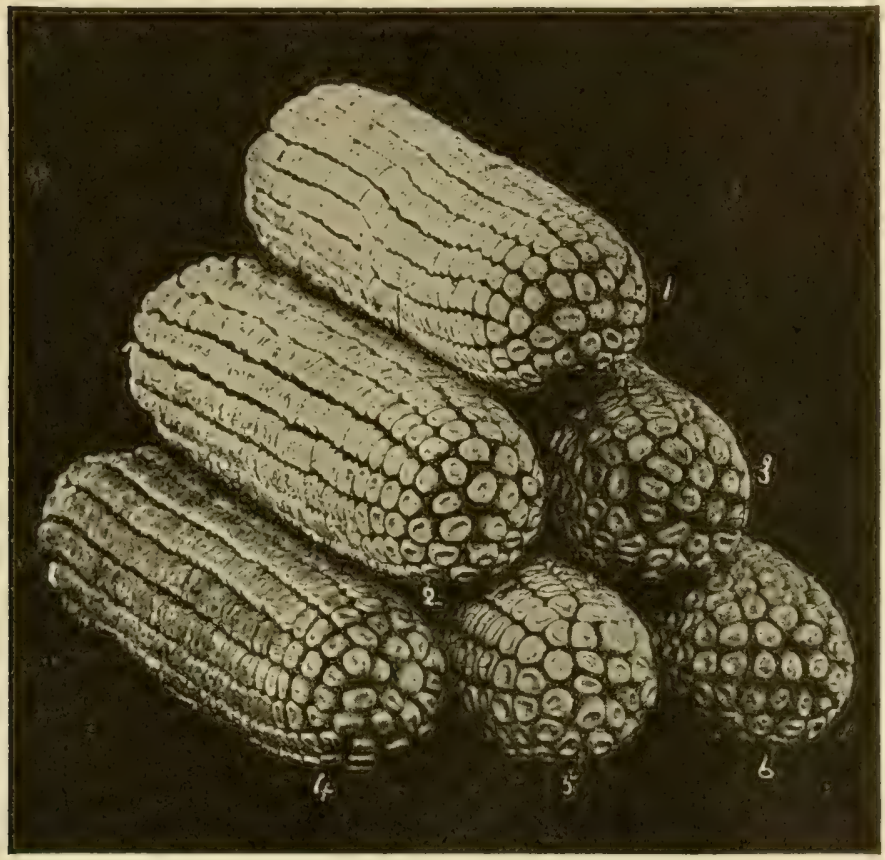

A sample of corn showing good tip ends.

seed. The selection bed should be a choice plot of ground of from one to three acres, depending on the size of the farm. This plot is specially prepared, planted with the choicest seed, tested for growth and vitality, and is given the best of care.

The selection bed should be by itself if you want pure 
seed. It may be a part of the general field, if located at the south or southwest side, so that the prevailing summer winds may carry the pollen to all parts of the plot, and even to the remainder of the field. This plot should never be placed where it will receive the pollen from some neighboring field of different variety, of mixed, or poor grade corn.

Care at tasseling time.-At tasseling time the selection bed requires special attention. As already explained, this is because the tassel, which is the male flower of the corn, bears the pollen necessary to fertilize the silk, which is the female flower. There is one silk for each kernel. The silk has to be fertilizcd by a single grain of pollen falling upon it. If pollen from a different variety of corn fertilizes the silks, the result is a mixed breed. If the pollen comes from weak or faulty stalks, the ears formed are imperfect, or the stalk may remain barren.

In the selection bed, as in the remainder of the field, there will be found weak stalks, barren stalks and suckers, all of which may bear tassels, and hence produce pollen. But the pollen from these faulty stalks should not be allowed to fertilize the ear-bearing stalks. To prevent this, it is necessary to go into the selection bed when the first tassels begin to appear, and cut out all the faulty stalks, so that their pollen may do no damage. This is a very important matter in raising good seed, and should never be neglected. ITeak parentage in corn, as in stock, should be prevented.

Taking seed from selection bed.-The same care should be observed in selecting seed from the selection bed as from the general field. Each year the choicest and strongest ears should be used in planting the selection bed. In this way, almost any variety of corn can be improved, and much larger and better yields obtained. 
Home-grown seed the best.-As a rule, home-grown seed is best, provided it is carefully selected, and kept improving from year to year. It takes corn shipped in from another region several years to adapt itself to the new conditions so that it will do as well as in its home place. Corn does not "run out," as many farmers believe, but is run out by farmers who are careless in the selection of seed.

\section{TOPICS FOR INVESTIGATION}

1. Has your father ever used the selection bed, or "seed patch" for the raising of his seed corn? How many of the farmers in your neighborhood so use it?

2. Good seed corn from a favorite variety sells at from two dollars to as much as ten dollars a bushel. Suppose that you should plant a selection bed of two acres, and secure sixty bushels per acre, one-third of which is suitable for seed. If cribbed corn is worth fifty cents a bushel, and seed corn three dollars, what is the return from the two acres? How much greater is the return than if the corn had all been sold for feed? All corn club boys and ambitious farmers should raise seed corn of the improved strains.

3. Talk with your father about planting a seed club acre next year, and allowing you to manage it, select the seed, and care for the patch at tasseling time. About how many ears would be required to plant a three-acre bed? Have you satisfactory seed from which to select for the bed, or would you have to secure seed from a neighbor? What variety does your father favor? What are the other varieties that might be considered?

\section{Corn Judging with Score-Card}

What qualities, together, make a good ear of corn? We are now ready for a somewhat more careful study of the ear to answer this question. For this purpose we shal judge a sample of ten ears by the use of the score-card. The score-card requires that we grade the ear on each of 


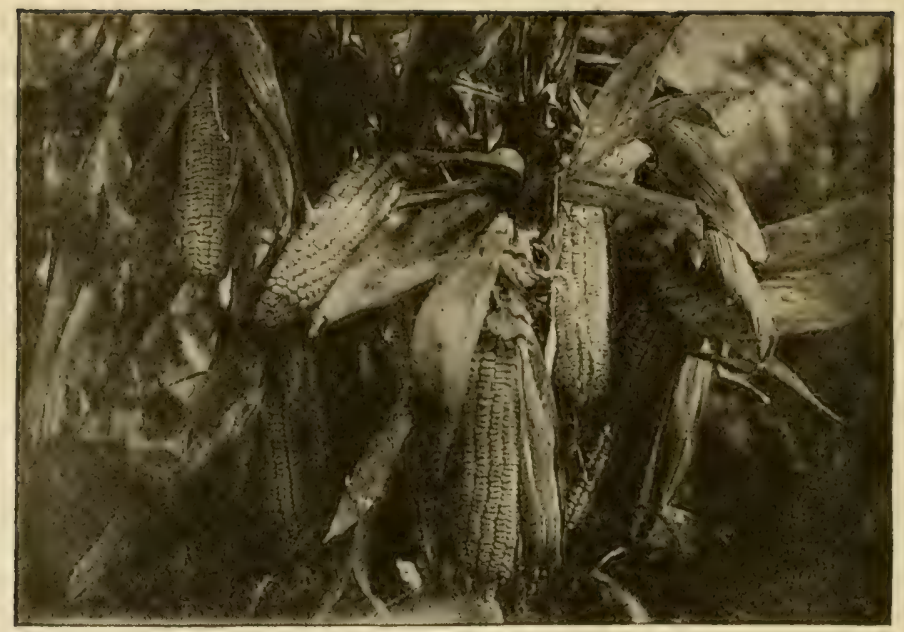

A three-stalk hill with six gool eal's of silver Ílng, on an Iowil firlu.

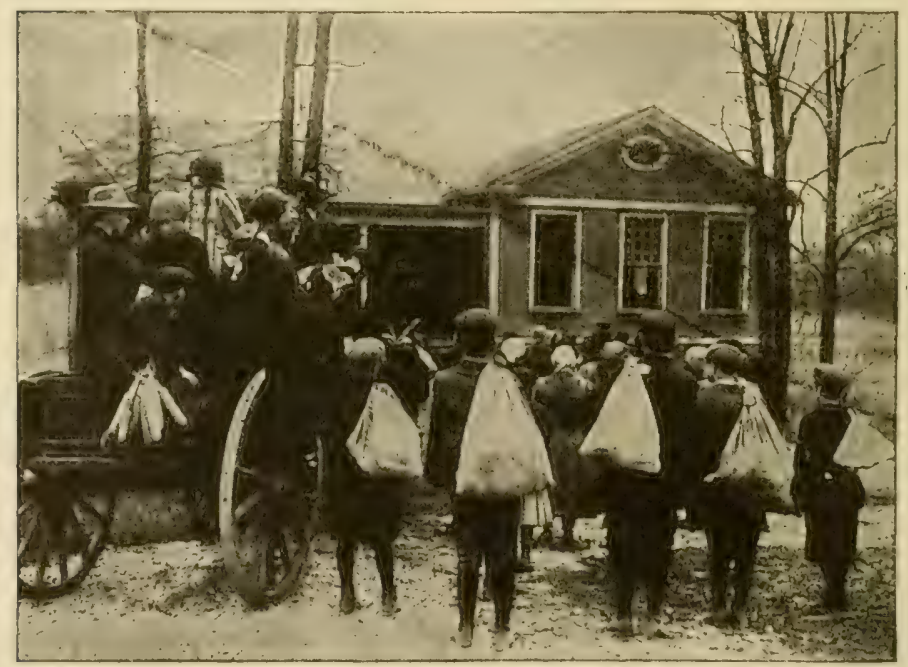

Boys and girls bringing corn to school fur judging aud testing in a Cook County rural school. 
its different qualities, and then sum these markings all together for the final "standing" or value of the ear.

This method of judging corn is much more accurate and scientific than estimating the value of an ear in an offhand way. It is the method used by most of the corn experts.

All ears to be judged as if for seed.-No matter for what purpose corn is to be used, it is always best to judge the ears as if they were intended for sced. This is because the ear that is best for seed is also best for every other purpose. The ear which would show best in an agricultural exhibit, the one which would be best for yield, or feeding, or any other use is the one which grades highest as a seed ear.

Preparing the samples for judging.-To supply corn for judging with the score-card, each pupil will bring from home the best ten ears of corn he can find either in the field or the crib. There should be altogether as many as from five to ten sets of ten ears each. Each ear must be labeled or numbered so as to show (1) what set it belongs to, and (2) its number in the set. For this purpose prepare pieces of tough cardboard one-half inch square. For the first set of ten, label the ears A1, A2, A3 and so on. For the next set, label the ears B1, B2, B3, etc. Do this way for each of the different sets, so that any ear can be placed in the set where it belongs. The labels can be tied to the ears, or can be attached to the butts by pushing a small nail through the card and into the butt of the ear. The sets can now be placed together on a table without danger of getting them mixed.

The four qualities on which the ear is judged.-The score-card is arranged to judge the corn on four different qualities, each quality, if perfect, being counted as twenty- 
five points, one hundred points therefore being a perfect score.

The first great question about an ear is: Will it yield well; has it a good constitution, so that it will do well even under unfavorable conditions? The second question is: Will it ripen, and not get caught by the frost and so produce a crop of soft corn? The third question is: Will it grow, is it of good vitality, so that it will give a good stand, and strong plants? The fourth question is: Does it show improvement; that is, is it a clear type that will breed true, and not show mixed breeds?

Let us study these four points a little more in detail, and then we shall be ready to score our samples according to the points of the score-card. (Sample score-cards should be secured for the class from the state agricultural college or the United States Department of Agriculture.)

Will the ear yield?-The chief factors in the yield are the size of ear, depth of kernel, filling at tip and butt, and reasonably close set rows. The size of the ear must be adapted to the locality. Much larger ears can be raised in Missouri, for example, than in Minnesota, because of the difference in length of season.

Will the ear ripen?-In general, ears that have a large circumference are slower in ripening than slender ears. Long kernels also indicate late maturity, as do large, coarse, pithy cobs. Such characteristics are therefore not adapted to regions having short seasons.

Will the ear grow?-In an ear of good vitality the grain is of a bright and cheerful appearance, and the germ and embryo of clear whitish color, somewhat shiny from the oil it contains. And discoloring or signs of molding indicate lack of vitality.

Dhes the corn show improvenient?-In corn that is improving instead of running out, the color is clear and 
free from mixture, true to the variety represented. Both ears and kernels should be constant in shape, and conform to the variety type.

How to judge with the score-card.-Place your ten ear samples on the table with the butts toward you. Begin with ear number 1, and study each ear with great care, point by point, taking time to decide each grade mark. Put these down in the proper place on the score-card. Do not be afraid to mark off for defects. It takes a good ear to score ninety points when carefully graded.

Finally, add together the marks for each ear given under each of the four grade points, and place the sum in the proper place in the summary on the score-card. Add these results for each ear. This will give you the final score for each ear of the set.

Comparing scores.-After thus completing your own sample of ten ears, exchange with one of your classmates, and score his sample, while he at the same time scores yours. Do this as carefully as the first set, without referring to the grading given by the other person. When both have finished, compare the scores, and discuss the differences in the markings. It is not to be expected that the scoring will agree in all particulars, but where there are wide differences, the reasons for each score given should be carefully gone over to correct any false judgment.

\section{Testing the Seed Corn}

No seed corn should ever be planted that has not been tested ear by ear to see whether it will germinate, and produce a strong growth. For, even if the seed is carefully selected and cared fər, there are always some ears that will fail to grow, or else produce plants so weak as to be barren or raise but worthless nubbins. 


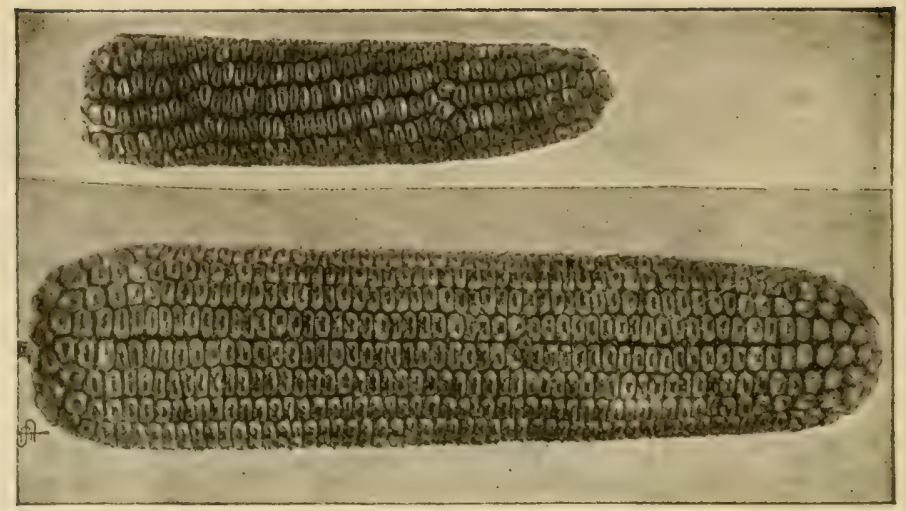

The small ear grows in extreme northern portion of Minnesota and the larger ear in central and southern Minnesota. The two illustrate the effect of climateand the influence length of season has.on corn production.

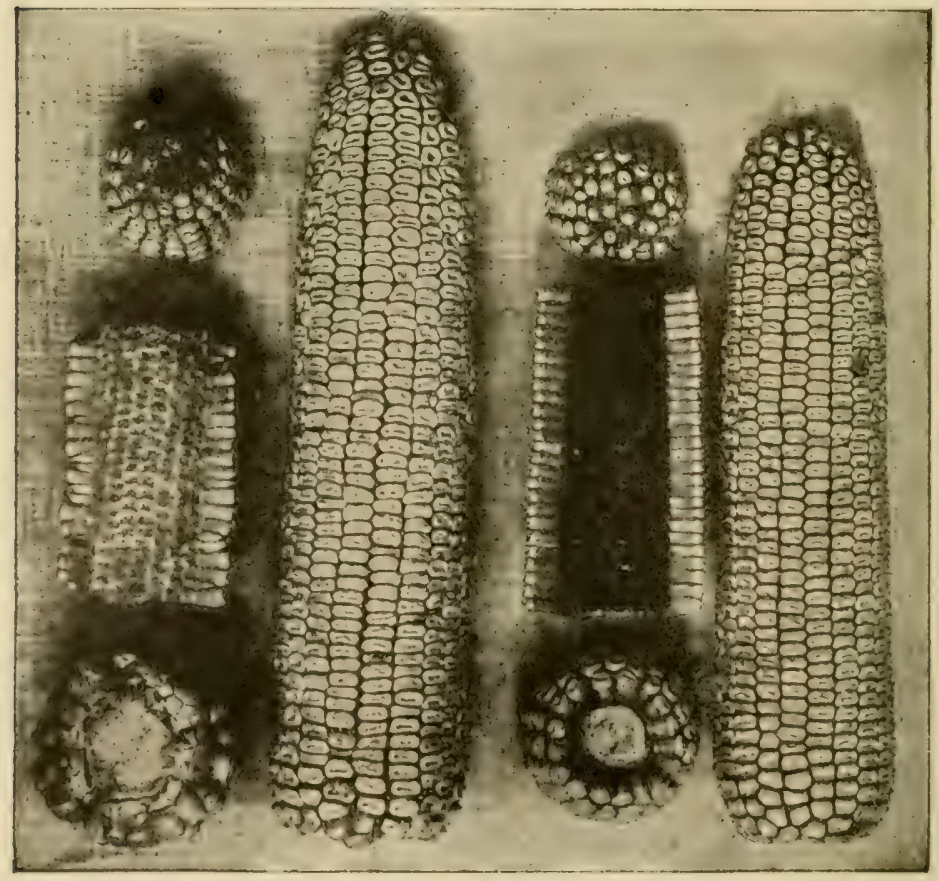

A good ear and a poor ear of corn. 
Since it takes but a dozen or fiftcen ears to plant an acre, and since an acre of average ground should yield at least sixty bushels, each ear of seed represents from four to five bushels of crop. The farmer's time can be spent in no more profitable way than in making sure that every ear of seed corn planted is sure to grow. The testing should be done late in the winter, or in the early spring before the farm work opens.

Preparing for testing.-Testing the seed corn costs practically nothing but a little time, care and attention. For, while there are several excellent seed-corn testers on the market, none is superior to one that can easily be made at home.

The sawdust germination box may be prepared as follows: Construct a box thirty inches square and four inches deep. Put some sawdust in a bag and soak it in warm water until it is well saturated. Fill the box half full of the sawdust, packing it well. Take a piece of good white cloth and rule it off in two-and-one-half-inch squares, making one hundred squares in all, and numbering them from one to one hundred. Place the cloth on the sawdust so that there will be a margin of at least two inches between the sides of the box and the squares. Tack cloth to the edges of the box.

Now take one hundred ears of the corn to be tested and lay them out in a row on a table or planks. Drive a nail into the table every tenth ear, separating the entire lot into ten groups of ten ears each. Number the ears from one to one hundred to correspond with the squares in the tester. This may be done by numbering the places on the edge of the table if care is taken not to change places with the ears.

Making the test.-Remove one kernel from near the butt, one from near the midlle, and one from near the tip of the ear; turn the ear over and remove three kernels from 
corresponding positions on the other side of the ear. These six kernels are to be placed, germ side up and tips all toward one side of the box, in the squares over the sawdust, those from ear No. 1 in square No. 1 , and so on, until six kernels lave been taken from each of the one hundred ears and placed in the tester.

After the kernels are all in position, thus filling the one hundred squares, lay a piece of cloth over them, taking care not to disturb their positions. Sprinkle this cloth well with warm water. Now lay over this another cloth about twice the size of the box. Fill in on top about two inches of damp sawdust, packing it down very firmly. Then fold the edges of the cloth over the sawdust, covering it so that it will not dry out.

The germination box is now ready to set away for the kernels to sprout. The box should be kept in a fairly warm place, and must not be allowed to freeze. The kernels should be allowed from six to eight days for sprouting, depending on the temperature. It is not enough that the germination has merely started; it must be allowed to go on for some days to show whether the new plant has good vitality.

The number of germination boxes required will depend on the amount of seed to be tested. Several can be used at the same time, stacking one on top of another as they are fillerl. The ears must, of course, remain in their original positions on the tables until the results of the test are determined.

Reading the test. - It the cnd of the germination period the cover must be removed withont disturbing the kernels. This can be done by carefully rolling up the top pad of sawdust in its cloth. The sprouts will be some two inches long, and may in some cases have grown through the first cloth covering. 


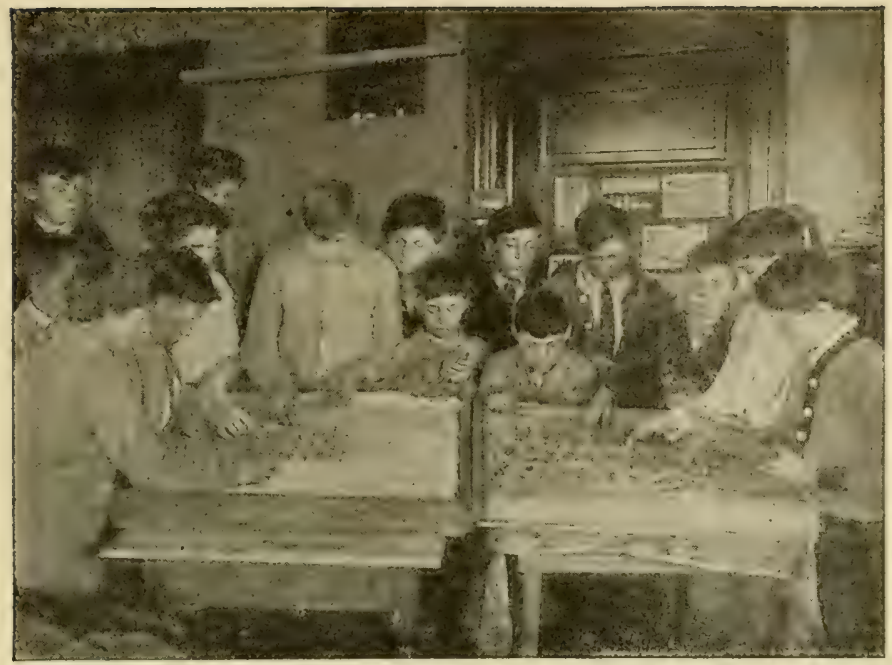

School texting seed corn in s:molust rermination boxes.

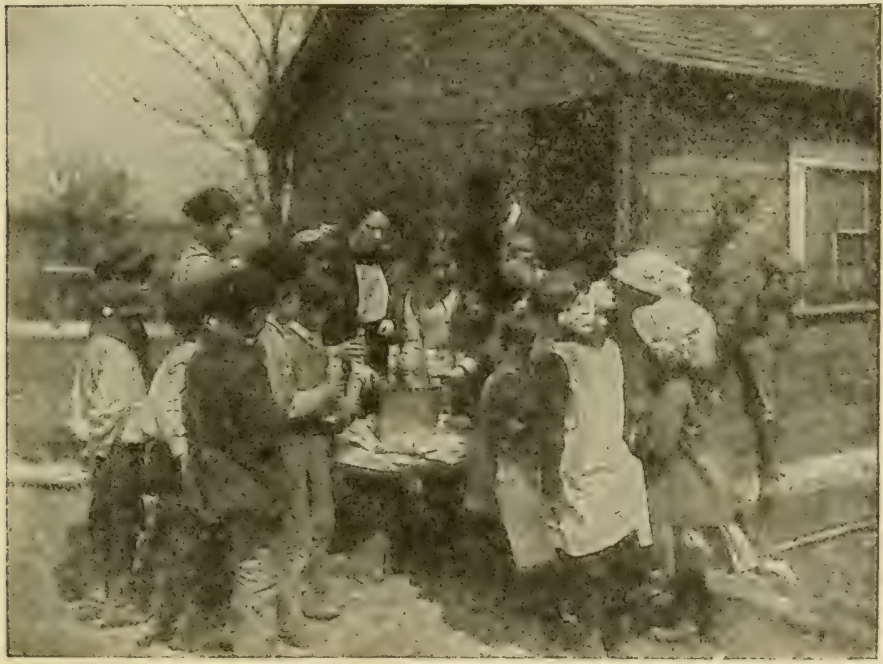

Putting the rang dolls into a bucket, which is then wrapued in old newspapers and kept in a safe place until the kernels of corn have snrouted. 
It is easy now to tell which are the good and which are the bad seed ears. An ear should be rejected if even one of the six kemels failed to sprout. For a loss of one out of six means sixteen and two-thirds per cent. of the crop gone if all ears were of this kind.

Ears whose six kernels may all sprout, but which start weakly, should also be thrown out. For it is these weak plants that later turn out to be barren, or prove an easy prey to dry wcather or some insect enemy. If only those ears are planted whose six kernels all produce strong vigorous sprouts in the germination box, the greatest obstacle in the way of a perfect stand will have been removed.

The "rag-doll" tester.-A very simple and effective tester is made of a strip of cloth and is called the "rag doll." To make this form of tester, use nine-inch strips of muslin five fect long. Draw a pencil line lengthwise down the middle of the strip, and draw cross lines every three inches, leaving about fifteen inches at each end of the strip with no lines. Number the spaces. W'et the cloth thoroughly, and place the kernels in the spaces as in the sawdust tester. Roll the strip up from either end, and tie a string around the roll. Now stand the roll, with the tips of the kernels down, in a bucket of tepid water for several hours. Place the roll in a box or under an inverted bucket so that the moisture will not dry out. Of course as many of these rolls may be used as are required for the amount of corn to be tested.

Commercial testers.-Several forms of commercial testers are now available, and most of them are fairly satisfactory. There is little need, however, for buying testers when they can be so easily made at home, and when the home-made testers are so simple and effective. 


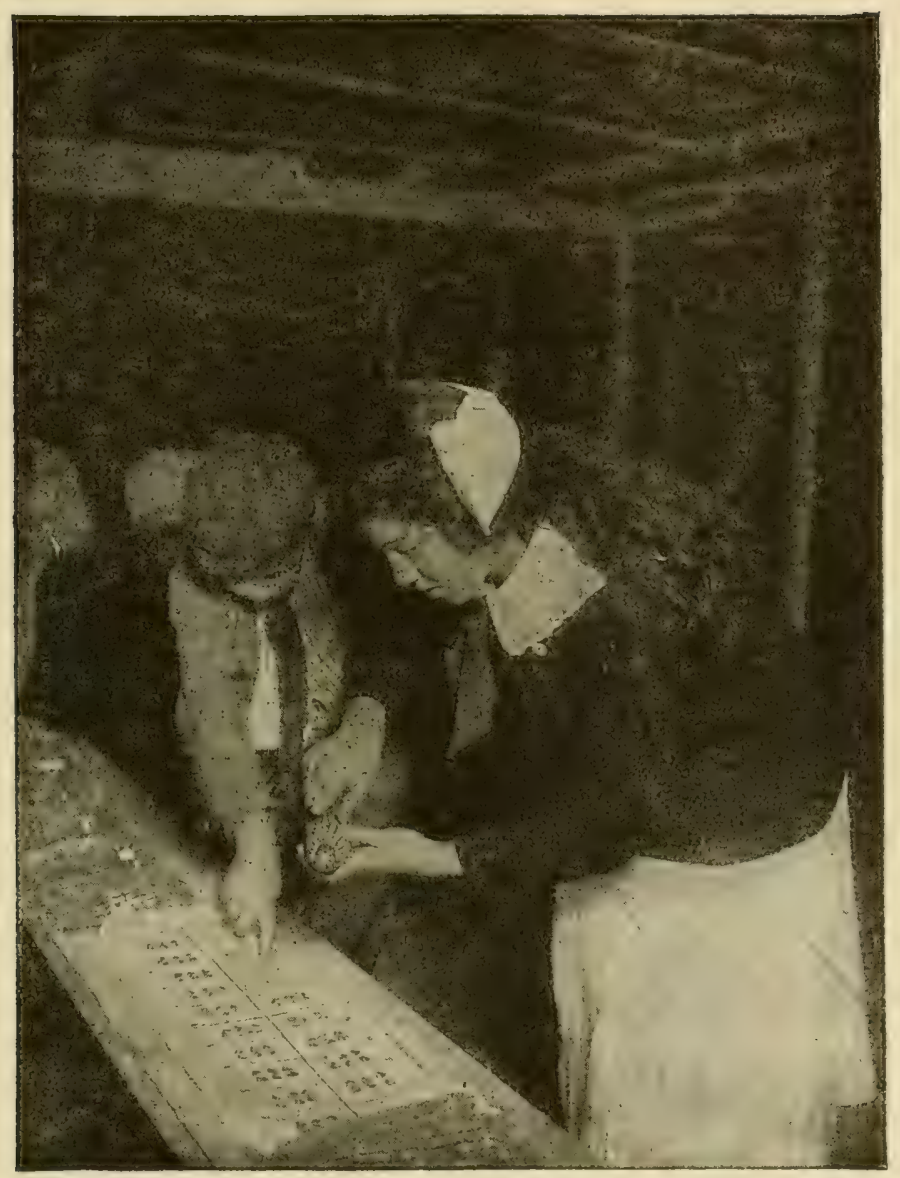

Placing the kernels in the "rag-doll" tester. 


\section{TOPICS FOR INVESTIGATION}

Let the class join in making a germination box for the school as described in the text. Sawdust may be obtained from wood-piles, icehouses, or meat markets.

1. Each pupil will bring to school enough ears of seed corn so that the class will have one hundred ears for testing.

2. Arrange the ears as directed, numbering them from one to one hundred. Take six kernels from each ear and place them in the box. Make arrangements to keep the box reasonably warm. The "rag-doll" tester may be used by some of the class. Compare results from the two forms of tester.

3. At the end of a week uncover the box and read the test. How many ears had one kernel that did not grow? Two kernels? Three kernels? Four kernels? Five kernels? Six kernels?

4. What would have been the percentage of stand if all the ears had been planted, and the germination in the ficld been equal to that of the box? It is estimated that to hire the labor for testing will cost about sixteen cents an acre. Would this pay? Compare this report with your record from counting stand on page six.

5. How many ears will grow, but produce plants so weak that they will probably be barren or produce nubbins? How many of the one hundred ears should be discarded as seed?

6. Tell your father about this test, and join with him in testing the home seed for the next crop.

\section{Preparing Seed Corn for the Planter}

Aiter testing the seed, the next step is to girde it for the planter. This means to divide the seed corn into lots according to the size of the kernels. It is impossible to secure a regular drop, with the planter muless the kernels are of fairly uniform size. And no matter how gool the seed, if one hill receives two lernels and the next four or five, the stand will be irregular and the crop reduced. 
Grading seed corn.-The grading of seed corn can be done in the winter when general farm work is slack. It may wcll follow immediately after the testing, or even be carried on in connection with it.

The first step in grading is to shell off the butts and tips by hand. The end liernels are always more or less

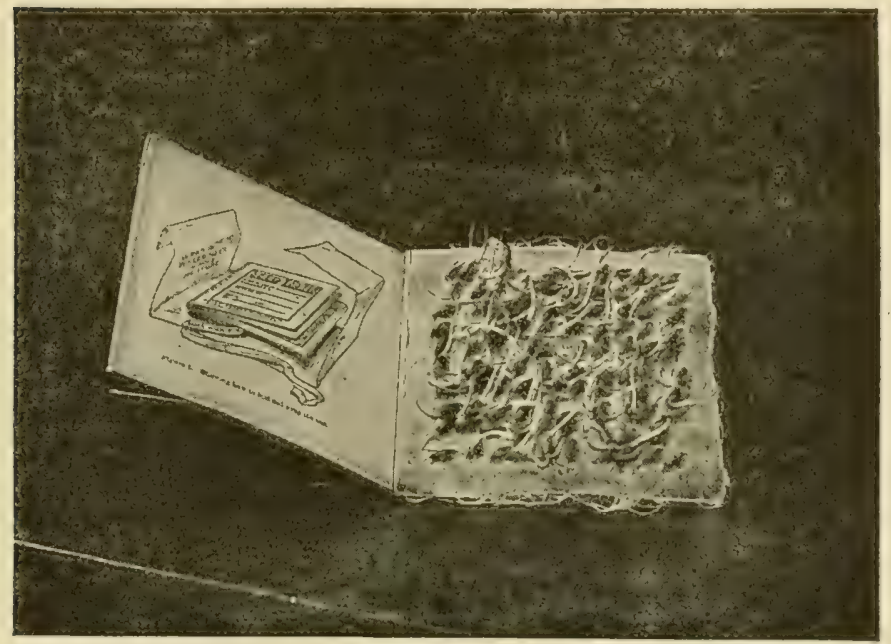

The blotter seed tester. An excelleut type for school use.

irregular, and differ in size from the remainder of the ear. They should never be planted.

The ears are then to be shelled, one at a time, and the kernels inspected to determine whether they are large or small; if the variation is great, it will be well to have also a medium grade. As each ear is shelled, the seed is put into its proper grade; when the shelling is completed, the supply of seed will therefore be in either two or three lots, based on the size of the kernels. All ears with exceptionally 
large or exceptionally small kernels should be rejected, as they will fit neither grade.

Hand picking the seed.-But eren after the most careful grading by ears, there will still be a surprisingly large number of irregular, broken, diseased, or imperfect kur-

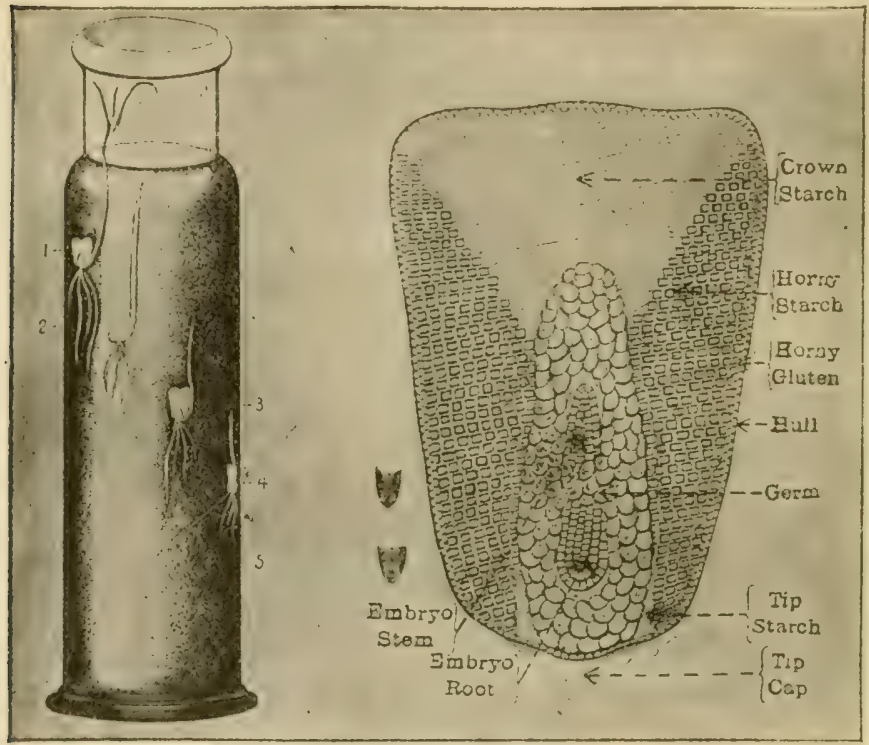

Experiments showing re:tlits of plinting corn at different depths. Diagram of kernel of corn.

nels. To remove these, the corn should be spread out on a table, a few handfuls at a time, and all the imperfect liernels thrown out. Running the seed through a "sorter" saves time in the hand picking. The seed-corn sorter consists of a sieve with large oblong meshes.

Caring for the shelled seed.-After the seed has been tested and graded it must be given good care to prevent 
it from becoming damp and molding, or getting too dry as from artificial heat. It should be placed in sacks holding not more than half a bushel each, and hung in a protected place, such as an attic. The sacks should be labeled to show the grade that each contains.

Testing the planter.-Before planting time, the planter should be carefully tested for each grade of seed, and the right size of plates determined. This is done by placing a quantity of each grade of seed in the planter boxes in succession, throwing the drop by hand, and keeping accurate count of the number of kernels dropped each time for at least a hundred hills.

In well graded seed it should be possible to secure a drop of three kernels more than seventy-five per cent. of the time. Whether whatever variation there is should be chiefly in the direction of two, or of four, kernels will depend on the richness of the soil. If the seed has been carefully tested, the effort should be to plant three kernels to the hill in just as many cases as possible.

\section{TOPICS FOR INVESTIGATION}

Let each member of the class bring to school a number of ears of corn suitable for seed so that the class will together have a lot of at least fifty ears.

1. Shell off the butts and tips, comparing the size of the kernels. Will the shape of the kernel have anything to do with the number the planter will drop to the hill?

2. Shell all the ears, one at a time, dividing the kerncls into three lots according to size. How many ears go into each grade? Are there any ears with kernels too large or too small for either grade?

3. Now let each pupil take a pint of shelled corn from each of the three grades and hand pick it. How many kernels are very small, irregular, or chaffy? How many broken? How many moldy or black at the tip? How many have you rejected from each lot? Count the good 


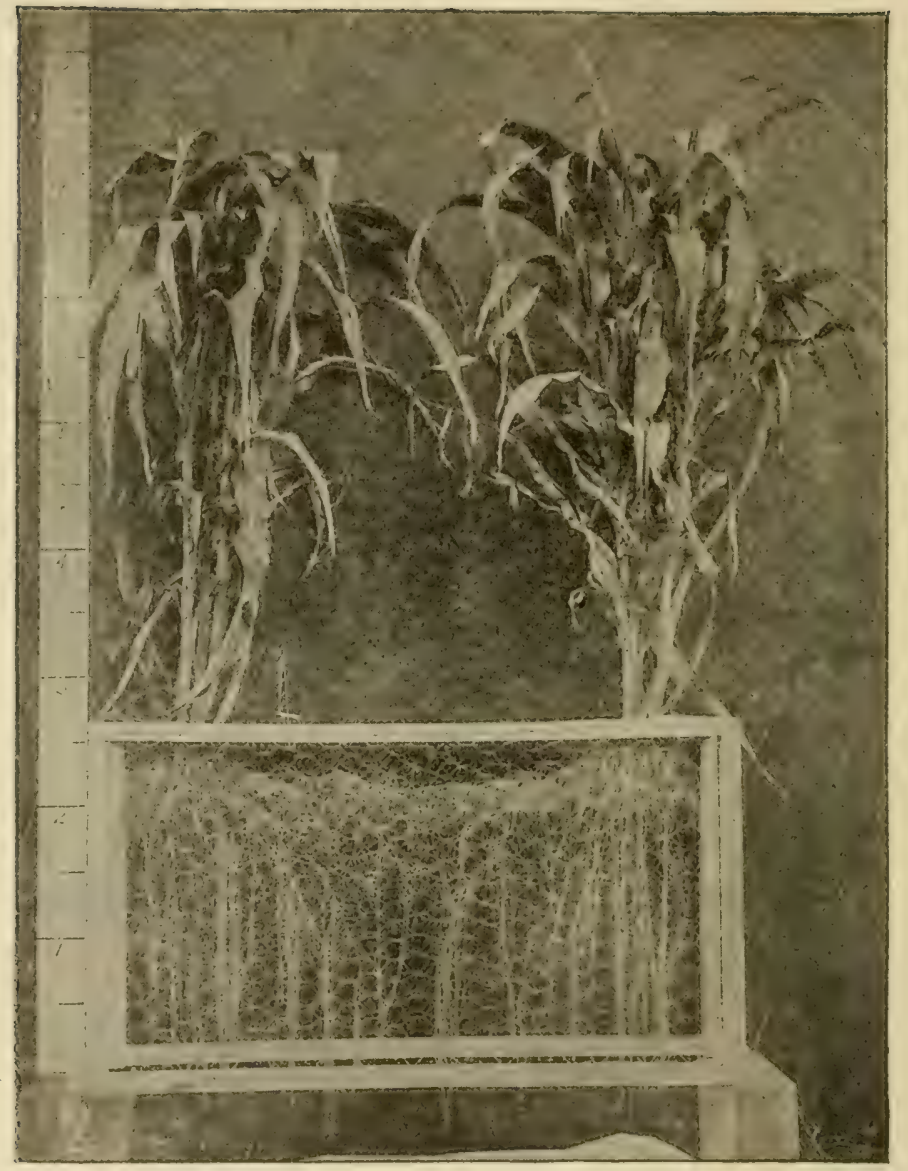

Corn roots at time for last plowing. The stallis are albont i fert high aud stand :31/e feet aluart. Note how all the intervening space is filled with roots. 
kernels in each lot and figure the percentage rejected through hand picking.

4. If there is a corn planter near at hand, draw it to the school and test it for the drop on each of the different grades of seed, keeping count for at least one hundred hills on each side of the planter. What percentage of the time are you able to secure a drop of three kernels?

5. Mix together a few pints of the three grades in the proportion they bear in the whole amount shelled. Test the planter with this mixture, keeping track of the drop for one hundred hills on each side of the planter. What do you conclude as to the wisclom of grading seed corn for the planter?

\section{The Seed Bed and Planting}

The roots of growing corn require, besides the nutrients of the soil, heat, air and moisture. Let any of these fall short, and the crop is injured. Loose soil absorbs both moisture and air better than hard soil. Loose soil also holds its moisture better than hard soil, since it does not favor such rapid evaporation. And, since evaporation is always accompanied by a loss of heat, hard soil loses heat more rapidly at night or during cold spells. The supply of heat, air and moisture therefore depends on having the soil loose and finely pulverized.

How corn roots grow.-Corn roots grow by pushing the root tip out through the soil, drawing food from the tiny particles of earth, and drinking the film of water that surrounds each particle of soil. If the ground is hard or soggy, the root tips can not easily push through it, nor can they get enough air. If it is coarse and full of clods, the roots can not reach across the open places between the clods. In soil of this character roots also suffer from lack of moisture, for they must be packed about by fine particles in order to drink in the water. Even if the soil be so wet as to have water standing around the roots, they 
can not use water in this form. Indeed, water standing around the roots will injure them by keeping them too cold, and by shutting the air from them. Not until water is absorbed by millions of minute particles of fine soil is it ready for plant roots to drink.

Preparing the seed bed.-Ground is plowed in order to loosen it. Fall plowing is usually best for corn. Fall plowed ground presents a rough surface which holds the snow better, and it also takes in and retains a larger supply of moisture. Fall plowing also has plenty of time to settle, so that it is in better condition for the crop than spring plowing, and allows earlier planting. Spring plowed ground, not having much time to settle, dries out more easily than ground plowed in the fall. Especially should sod land be plowed in the fall, so that the sod may have a chance to rot and settle down on the subsoil. There is also less danger from cutworms in fall plowed, sod land. Stubble ground should usually be plowed early, and sod late in the fall.

Ground should not be plowed while it is wet, for most soils, if turned while wet, have a tendency to bake and form into clods that are hard to pulverize. Fall plowed ground should not be harrowed until spring, but should be disked or harrowed as soon as oats seeding is done. This will kill young weeds, and save the moisture from drying out. Spring plowing should usually be harrowed within a few hours after it is turned, for it is then much more easily pulverized than after it has dried. In very fine and mellow soil this may not be necessary, but many farmers harrow what they have plowed at the close of each half-day.

Spring plowing should be disked and harrowed enough to press the loosened soil down on the furrow bottom, so that it will make good connection with the subsoil. This will do much to prevent drying out. In fact, it is impos- 


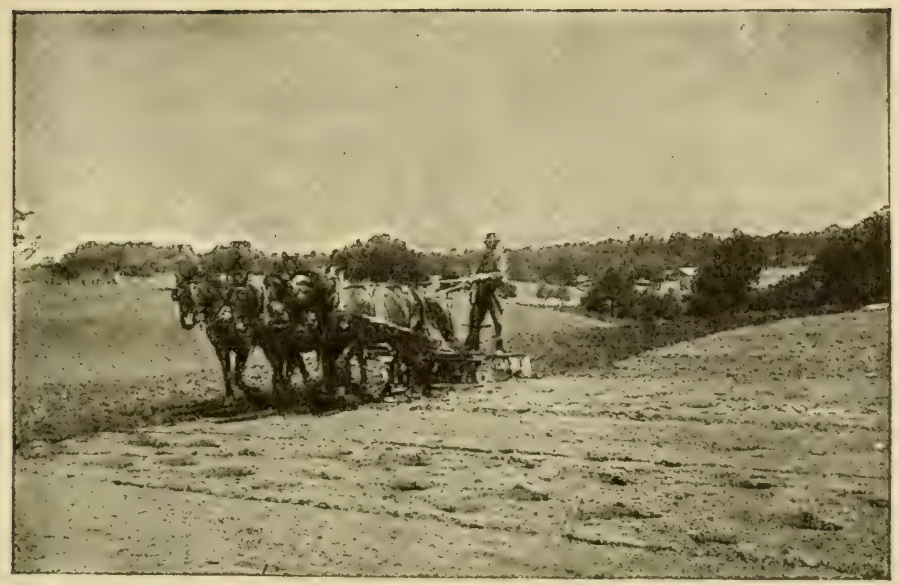

A well prepared seed bed.

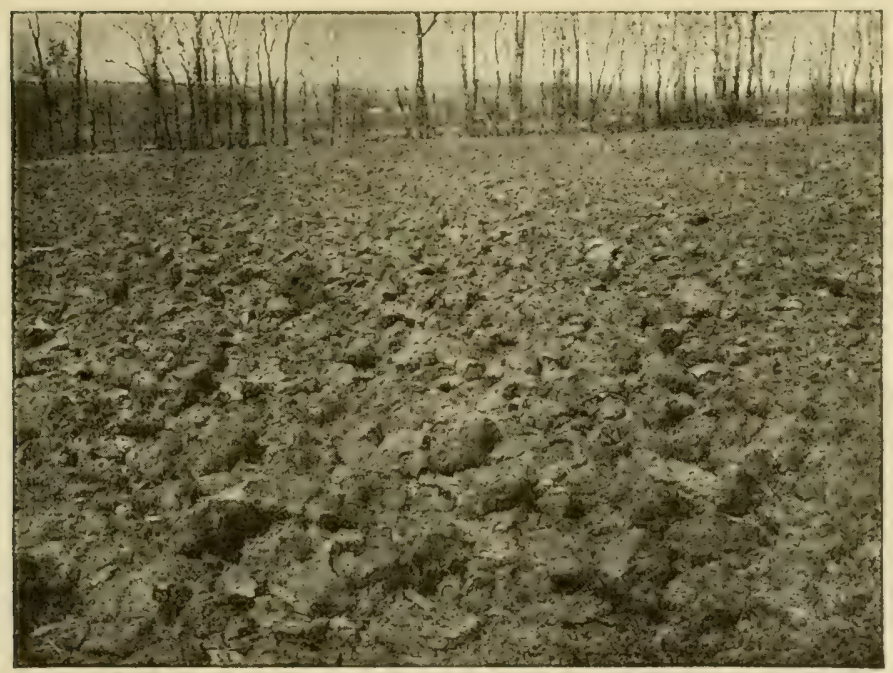

A poorly prepared seed bed. 
sible to work spring plowing too much in this way. Much harrowing packs the soil thoroughly, makes a loose bed for the seed, and provides a fine mulch to prevent loss of moisture through evaporation. Thorough disking or harrowing of fall plowing is necessary to loosen the soil and prepare the bed for the seed.

Killing the weeds.-It is well to harrow just before planting, as this kills the spronting weeds, and allows the corn to gret started ahead of them. Fy far the easiest time to kill weeds is when they are just starting, and a few harrowings early in the season will save much trouble with weeds later on. From two to four harrowings, or their equivalent in disking, wili usually pay on average fields.

Time for planting.--Corn should be planted as early in the spring as the ground can he made ready and the soil is warm enotigh. The average date of planting varies from the eleventh of March in Floricla to the twenty-sixth of May in Maine. The first two weeks of May are the cornflanting time in the states of the great middle region of the United States. The average air temperature at which corn is planted is about fifty-five degrees. The Indians hat a rule that corn should be planted when the leaves of the maples were as large as squirrels' ears.

Depth of planting.-A mistake is often made in planting corn too deep. Some say that by planting deep they give the roots a deep setting. This, however, is not the case. For, no matter how deep the seed is planted, the roots adapt themselves to conditions. If the planting is 100 deep, the permanent roots finally start out nearer the surface, and time has been lost and energy wasted in compelling the plant to readjust itself.

Corn should uswally not be planted more than one and a half incles deep, and frequently not more than an inch. ispecially in cold weather or in wet soils, should the plant- 
ing be shallow. Careful experiments have been made by the agricultural colleges of many states as to the best depth for planting corn, and they have found that almost universally the shallow planting is best. The only exception is for a very dry soil, or a dry season.

\section{TOPICS FOR INVESTIGATION}

1. Have you seen corn planted in a seed bed that was hard and full of clods? Did the corn do well? Have you seen corn with water standing about the roots? How did the corn look? What caused this appearance?

2. What percentage of corn land in your neighborhood is plowed in the fall? Why is not more of it plowed in the fall? Ask your father about this. Which is the busier season, fall or spring? In which season is it necessary that the work be done at just such a time?

3. Have you seen ground plowed when it was wet? Did it bake in clods? Do the farmers you know harrow their spring plowing the day it is plowed? Have you seen weeds get a good start ahead of the corn? How can this be prevented?

4. Have you seen spring plowing planted when the soil was so loose that the planter wheels settled several inches in the ground? What is the danger in planting a seed bed in this condition? What should be done to it? Suppose spring plowing has been rained on until it is very hard. What is the best way to prepare a seed bed for planting?

5. What is the earliest date of planting in your vicinity? The average date? The latest safe date for common varieties of corn?

6. Make the following test to discover the best depth for planting corn: Put one inch of dirt in the bottom of a quart glass jar. On this, near the side, plant a kernel of corn, and cover it with an inch of dirt. On this layer plant another kernel, and so on until the lower kernel is covered with six inches of dirt, and the top with one inch. Place the kernels so that one will not 'je directly above another. Let the seeds sprout, and watch the growth for ten days. From 
this experiment what do you conclude is the best depth? Ask your father how deep he plants his corn.

\section{Cultivating the Corn}

Why corn needs to be cultivated.-Corn is to be cultivated after planting for three main purposes: (1) to kill the weeds, (2) to admit air to the roots, and (3) to preserve the moisture of the soil.

From the time germination begins the growth of the plant must be unchecked if a full crop is to be secured. When corn has become yellow and spindling from being choked by weeds, or from the baking of uncultivated soil around it, it is permanently injured and will never fully recover. Only the rich green color and sturdy stock of the rapidly growing plant give promise of a full yield.

When to begin cultivation.-Cultivation should begin early. Lnder average conditions, two harrowings should be given before the corn comes up. This will keep the soil from baking, and keep the weeds down until the plants are large enough to cultivate. The time to kill weeds is just as they are starting. Let them once get well rooted, and they are hard to keep down. The spring tooth weeder is sometimes user? instead of the harrow for early cultivation. It is valuable where there are many stones or ruts in the field.

The shovel or disk cultivator should be started as soon as the corn is well up, so that the rows can be easily followed. Even if the weeds do not seem to be starting, they are surely taking root. Cultivation will also break up the crusted soil, and admit air to the growing roots. And this must be done or their growth will be checked.

Methods of cultivation.-Four or five cultivations are usually enough after the corn comes up, though this must depend on the claracter of the soil, the weeds and the 
amount of moisture. The present tendency is toward shallow cultivation, thongh this also must depend on whether the soil seems to pack heavily and become hard underneath. If it does, the first should be of some depth. The important thing is not to break or injure the growing roots. For a broken root always means loss of vitality and food to the plant.

From thirty to sixty days after planting, the roots have often spread so far that they meet between the rows, thus occupying all the ground. Especially is this true if the season has up to this time been rather wet. For in wet anu loose soils the roots spread out near the surface, while in dry soil they spread less and run deeper into the ground.

It is evident that deep cultivation after the roots are well spread is injurious. The old method of setting the shovels deep and "hilling up" the corn the last time through is no longer followed in scientific farming. The cultivations should be shallow. Cultivation may continue with advantage up to the time the corn is tasseling if care is taken not to break the roots. In dry seasons this late cultivation is a very great advantage, because it keeps a loose soil mulch, which does much to prevent evaporation of the sub-surface moisture.

\section{TOPICS FOR INVESTIGATION}

1. Examine three different farmers' corn-fields, and see if you can tell whether the last plowing was deep or shallow. How can you tell? Did they "hill up"? Are the fields weedy? If so, what was the cause?

2. How many times does your father cultivate his corn? At what date does he lay it by? Does haying get in the way of late cultivation of the corn?

3. Suppose that next season proves to be hot and dry. How should the corn in your vicinity be cultivated? Suppose the season should be wet. How, then, should the corn be cultivated? 
4. Why does keeping the soil pulverized and loose on top prevent loss of moisture? What causes the corn tc look yellow and stunted when the ground becomes baked?

5. Suppose a careless boy covers up five hills out of every hundred in plowing a field of forty acres of corn. The crop yields thirty-eight bushels to the acre. How much would it have yielded if he had covered up none? How much did his carelessness cost if corn is worth fifty cents a bushel?

\section{Harvesting and Storing the Corn}

Corn is harvested in three principal ways: (1) it is husked from the standing stalks and the ears stored in cribs; (2) it is cut while partially green and either shocked in the field or stored in a silo; and (3) stock, especially hogs, are turned into the field to do the harvesting for themselves.

Field husking.-By far the greater part of the corn produced, especially in the great corn belt, is husked in the field from the standing stalks. This is the method used when corn is raised for the grain, and the fodder, or stover, is a secondary consideration.

Ficld lutsking is the cheapest and quickest way of securing the grain. In good corn, from sixty to more than one hundred bushels a day can be gathered by one man with a team, at a cost of from three to four cents a bushel. Machines for husking from the standing stalls are also in use on many large farms. Corn can be picked by a husking machine at the rate of from seven to eight acres a day, and, where the acreage is large, at a cost per bushel slightly less than for hand picking. No machine yet invented does the husking as satisfactorily as by hand. The machine misses some cars, breaks others, shells off more or iess corn, and pulls up or breaks many stalks. The corn-picking machine is not always a complete success. 


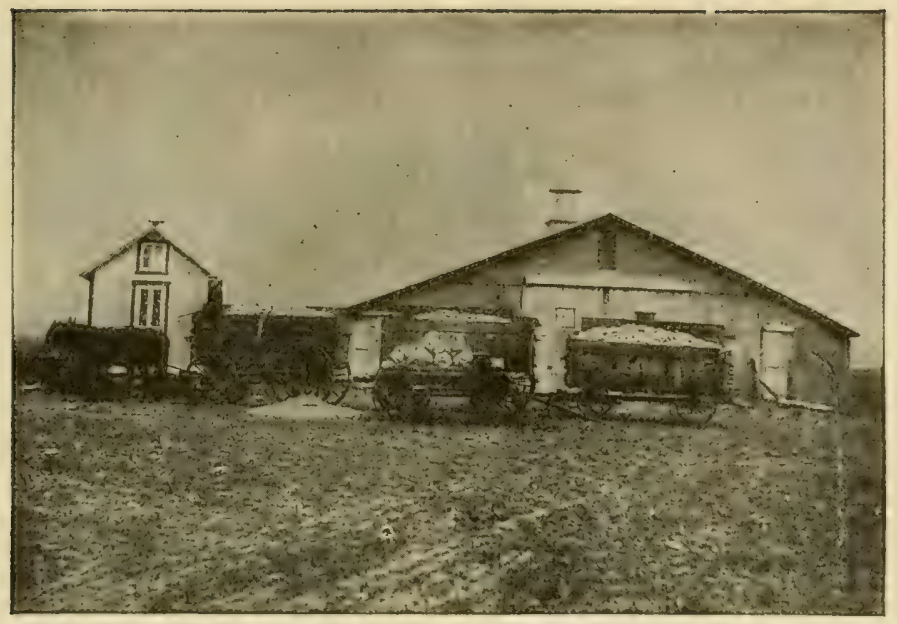

Yield from one acre raised by a Douglas County, Illinois, corn club boy, 150 bushels; three loads for market, one load for seed.

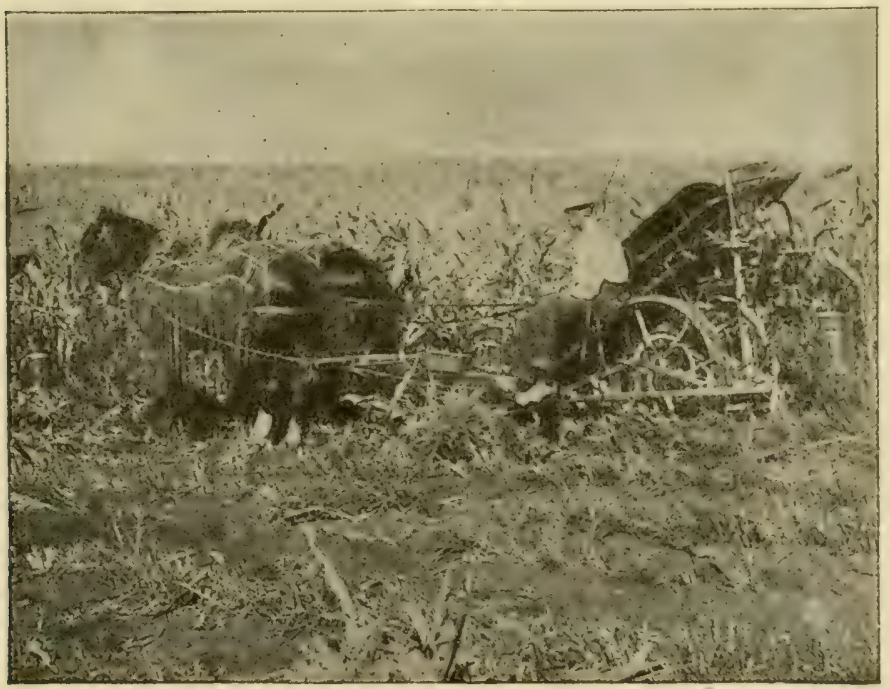

Corn harvester at work. 
One advantage of field husking is that the harvesting can be delayed until the fall rush with other crops is over. The ears should be well cured before being cribbed, or there is danger of molding. This is especially true if the fall and winter should happen to be warm and moist.

Corn shotld be stored in well protected cribs. The use of rail or other forms of uncovered cribs is a source of great loss. The grain may seem to keep well during the winter in the open crib, but when shelled and sold to the elevators in the spring it often heats and spoils. This tends to reduce the price of corn, and has caused a prejudice in European countries against American corn as a food. No rain or snow should reach the corn after it is cribbed, for it is sure to injure the quality of the grain.

Harvesting by cutting.-In average corn the ear supplies about sixty-four per cent. of the food value and the plant thirty-six per cent. Thus the stover in a field is worth for feeding purposes more than half as much as the grain. If the corn is cut just as it is becoming well glazed the stover is worth from five to ten dollars a ton.

The time for cutting corn depends on the use to which it is to be put. If the corn is grown chiefly for the grain, it should not be cut until the kernels are well dented and the husks partially dry. The stover will still make good feed if it is properly cared for. After a heavy frost, or after most of the leaves have become brown, the stover will not pay for the expense of cutting and feeding. Cutting while the corn is in the roasting-ear stage makes a more palatable stover, but the feeding value of the crop is considerably less than if cut in the glazing stage.

The corn binder.-The corn binder is widely used in northern states. It works successfully in corn from five to nine feet high. In regions where the stalks grow from ten 
to twelve feet in height, the binder does not meet with favor, since it is not yet built to handle corn of this size.

On account of the expense of owning and operating a corn binder, it is doubtful whether it pays to purchase one unless at least twenty acres per season are to be cut. From seven to eight acres a day can be harvested with the corn binder, at a cost of about one dollar and a half an acre for cutting and shocking:

The corn shocker.-The corn shocker cuts the corn and forms it into a shock carried on the machine. When the shock is completed it is tied by hand, and lifted from the machine by a crane and set on the ground. From four to five acres per day can be harvested with a shocker at a cost of about a dollar and ten cents an acre.

Shocking the corn.-No matter how the corn is cut, it should be shocked so that it will stand erect and keep the fodder dry. Fallen and twisted shocks result in the loss of millions of dollars worth of stover, and not a small amount of grain as well. Shocks should be tied as soon as they are made, and then tightened in a week or ten days. Binding twine makes a convenient tie. The band should be within about two feet of the top, so that the shock may turn the rain.

Fodder should not be left in the shock longer than necessary to become well cured. It should then be stored in ricks or barns. The practise of leaving shocks in the field over winter can not be too severely condemned. For the rains and wind destroy the most palatable and nutritious part of the plant and rob it of a large part of its food value.

The silo.-The silo has come into general use on the best managed farms. Although it will preserve any green, succulent growth such as clover, sorghum, cabbage, sugar 
beets, etc., the silo is employed almost wholly in this country for the storing of corn without curing.

For silage, the corn, when cut, should be ripened enough so that it has somewhat glazed, well-dented kernels, and the husks and leaves should have begun to die. If cut much earlier than this a great proportion of the feeding value of the crop will be lost. If cut much later, it will not pack well in the silo, nor be so palatable.

Storing green corn in a silo is like canning fruit. In fact, the silo is nothing but a large jar, air tight except at the top. When the green silage is put in, it soon begins to decay, and thus generates a great deal of heat. This process uses up all the air in the silage, producing a large amount of carbon dioxide. Finally, the heat and the lack of air stop all decay, and the silage will keep for almost any length of time. Several inches of the silage on the top is certain to spoil, for it has sufficient air to keep up the decay. Decay will also take place where there is any leakage of air through the walls of the silo.

Advantages in use of silo.-There are many advantages in the use of the silo. Even the harder and coarser parts of the stover, because cut when green and shredded into small pieces, are eaten. Probably about double the feeding value can be taken from an acre of corn by putting it into a silo rather than by shocking and feeding it from the field. This will allow nearly twice as much stock to be kept on a farm by use of the silo. Animals also need such a laxative food as silage provides.

Stock relish silage better than dry fodder, eat more of it, and thrive better on it. Cattle prefer it to clover hay, and eat it greedily even when fresh from good pasturage. Many farmers who make a business of dairying are coming to feed silage all through the summer as a supplement to 


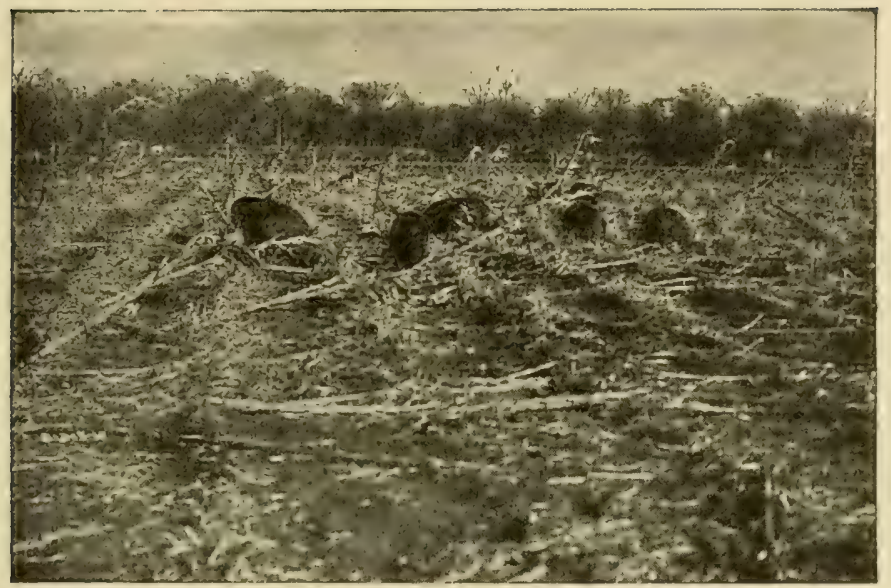

Marvestiug corn by "hogging luwn."

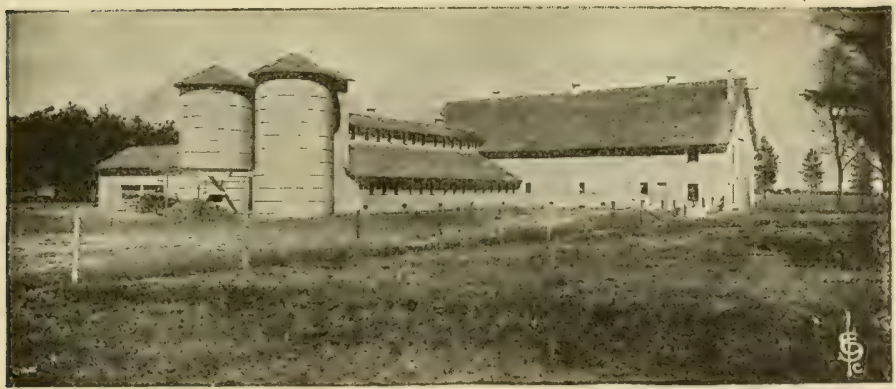

Well arrauged silos and barns. 
pasturage. This has been found to pay because of the increased supply of milk produced.

Size of the silo.-The size of the silo must depend on the number of the herd to be fed from it. Silage exposed to the air decays rapidly, especially in warm weather. In order to avoid waste it is necessary to feed from one and one-half to two inches daily from the surface of the silage. If the herd is small or the silo too great in diameter, this is impossible.

Owing to the closer packing, silage is better in quality as the depth increases. It is therefore better to build a silo of considerable height rather than low and of greater diameter. Moderate-sized silos are built from thirty to forty feet deep. Silos are now being constructed with a water-tank in the top into which water for house and barn use is pumped by a windmill. This gives the necessary pressure without the cost of building a tower for the tank.

The following table shows the size of silos required for herds of different sizes (allows each cow forty pounds a day for one hundred eighty days):

Number of Estimated Capacity Silo Diameter Silo Height

$\begin{array}{cccc}\text { Cows } & \text { in Tons } & \text { in Feet } & \text { in Feet } \\ 7 & 26 & 10 & 20 \\ 14 & 51 & 10 & 32 \\ 21 & 73 & 12 & 32 \\ 27 & 101 & 14 & 32 \\ 33 & 119 & 16 & 30 \\ 43 & 155 & 16 & 36 \\ 54 & 196 & 18 & 36\end{array}$

An average acre of corn will yield from eight to twelve tons of silage. Hence, knowing the capacity of the silo in tons, it is easy to compute the acreage of corn required to fill it.

Harvesting by "hogging down."-Under certain conditions corn may be profitably harvested by "hogging down." 
This means that at the proper time a drove of hogs are turned into the field and allowed to feed themselves upon the corn. This method will work well only in cases where there is a drove of considerable number, and when the fields of corn are not too large. The field should be all cleaned up in from two to four weeks after the hogs are turned in, since rain and mud are likely to injure corn left too long on the ground.

It has been found by farmers who have made careful tests of feeding corn in this way that more pork can be produced per bushel of corn when the hogs are allowed to feed themselves from the field than when they are hand fed. The labor of gathering and feeding the corn is also saved, and manure evenly distributed over the field. Fences are usually set up to divide the larger fields into small corn lots. Twenty-six-inch woven wire is suitable for this use. The wire is attached to well set, corner posts, and tightly stretched. It is then tied to the corn stalks for posts. This type of fence will last as long as is required for cleaning up the field.

\section{TOPICS FOR INVESTIGATION}

1. Good corn, if cut when glazing, should yield about ten tons of silage to the acre. A ton of silage occupies fifty cubic feet in the silo. If a silo is made to hold fifteen acres of corn, and is built thirty feet high, what must be its diameter?

2. If a cow requires forty pounds of silage a day, and the feeding season is one hundred and eighty days, how many tons must be stored for twenty-five cows?

3. If the corn yields twelve tons of silage to the acre, how many acres will be required for twenty-five cows?

4. How many silos are there in your school district? if what are they constructed? What height and diameter are they? Do any of them have a water-tank in the top? What did each of them cost? Draw a silo. 
5. If a boy in husking twenty acres of corn yielding forty bushels to the acre averages missing the throw-board of the wagon once out of each fifty throws, estimating one hundred throws or ears to a bushel, what is the value of the corn lost at fifty cents a bushel, supposing the stalks are sold to a neighbor?

6. Either from observation or agricultural bulletins, gather facts and write a description of a corn harvester; of a corn shocker; of a silo.

7. If a bushel of corn will produce ten pounds of pork, which is more profitable, to sell the corn or to feed it to hogs, providing pork is selling at seven cents a pound and corn at fifty cents a hushel? What would be the difference on one thousand bushels of corn?

\section{The Uses of Corn}

Corn as human food.-Corn is a native of America. It was cultivated by the Indians before the coming of white men. Corn was the principal grain food used by the Indians and was also widely used by the carly colonists. Its use as a human food has now spread throughout almost the entire world, but it is still most widely used in this country. Corn-meal is the principal food product derived from corn, but hominy, hulled corn, corn grits, flalied corn and other specially prepared breakfast foocis are also eaten. Corn starch is also a common food product. The unripe ears are extensively used and the canning of green corn has become an important industry.

Corn as food for animals.-By far the larger part of the corn crop is used, however, as food for animals. Corn is the basis of the great meat producing industry of the United States and along with grass constitutes the chief food of the animals used for meat. Farmers have found it more paying to fatten stock with corn and then sell the stock than to sell the corn itsclf. One reason for this is that it costs less to ship the meat produced by a bushel 
of corn than to ship the corn itself to a central market. One bushel of corn will produce from ten to twelve pounds of pork, which can be shipped more cheaply than could the bushel of corn.

Commercial uses of corn.-Besides its t1se as a food for man and beast, corn is employed in manufacturing some thirty or forty different products. For example, from corn are made several different kinds of glucose used by refiners of table sirups, by brewers, by leather manufacturers, by jelly makers, by fruit preservers, and by apothecaries. Corn also produces four different kinds of crystal glucose used in making candies and two kinds of grape sugar used by brewers and tanners. From corn there is made a sugar used in the manufacture of ale and beer. The pearl starch used by cotton and paper mills is made from corn, as is powdered starch used by the manufacturers of baking powcler and by the cotton and paper mills. Florine used by flour mixers, and clextrins used in the making of white fabrics, paper boxes, and the manufacture of mucilage and glue come from corn.

From corn there is also manufactured a substitute for rubber which is extensively used commercially. Corn is the chief source of the mantifacture of all alcohol and whisky and is the cheapest material now available for the making of denatured alcolol, which is used for heating, lighting and other commercial purposes.

Uses of the corn stalk.-Even the corn stalk has numerous uses. For example, from its pith comes the cellulose used for packing in war-ships. The corn pith has the quality of expanding when wet and hence will immediately swell and close any small hole in the vessel cansed by the enemy's shot. Corn stalks are also used in the manufacture of paper pulp and in various kinds of stock foods. Corn cobs are used in the making of corks and pipes. A special 
variety of corn with a large cob is raised in Missouri for the manufacture of pipes. It is estimated that approximately fifty million bushels of corn are used annualiy for various corn products in addition to those intended as food for people and animals.

The importance of corn as a food is increasing and scientists are discovering new ways of manufacturing or zooking it to make it both palatable and digestible. The very worst use that can be made of corn is to manufacture it into spirituous liquors since the use of alcohol as a beverage injures those who drink it and brings sorrow, disgrace and poverty to the user.

\section{TOPICS FOR INVESTIGATION}

1. Teacher and class should join in making a collection in small uniform bottles of all the different corn products available that are used for the table. (Certain companies will supply samples of their products free of cost.)

2. In how many different forms is the corn ear, or grain, fed to stock in your vicinity? In how many different forms is the stover fed?

3. How many of the different commercial products of corn have you ever seen? What foods have you recently eaten in which one or more of these products was used?

4. Enumerate the uses to which you have seen the corn stalk and cob put. Soak some dry pith in water for a few minutes. What happens?

5. How could you keep records or bookkeeping in connection with the corn crop? Make out a debit and credit book account covering a season's work on an acre of corn from planting to harvest. (See Farmers Bulletin No. 511, "Farm Bookkeeping," and Farmers' Bulletin No. 572, "Farm Cost Accounting.")

6. Sketch a map of the United States and locate in this the corn states. Indicate by different colors the first, second and third best corn sections of the country. From the crop report bulletins secure the figures of the last year's corn crop and the average yield for each state for the year 
as well as for the last ten years. Compare the yield of the last season with the yield of ten to twenty years ago.

\section{Corn Demonstrations}

"Demonstrations" are now becoming common in agricultural work. The purpose of a demonstration is to teach others some definite and well-known truth. The agricultural experiment seeks to discover some truth concerning the work of the farm, while the demonstration seeks to show others how to put this truth into practise.

Demonstrations by the school.- -Such demonstrations as the following may be conducted by the school for special exercises, evening programs, club meetings, district, county or state fairs, or special farm festivals:

1. Demonstrations in making and preparation of a seedcorn test box, a rag-doll tester, and how to make the test.

2. Demonstrate how to make a seed tray, a seed drying rack, and how to hang or place the seed corn.

3. Seed corn stringing demonstration.

4. Field demonstrations in plowing, cultivation, seed selection, hand pollenizing, etc.

5. Home economics demonstration showing how to make corn food products, valuable dishes, hominy, corn mush, bread, etc.

\section{Corn Play Contests}

Play contests are one of the most interesting means of learning certain facts connected with agriculture. The games and contests in connection with various farm activities add interest, develop skill and furnish a great deal of real fun besides.

Suitable play contests.-The teacher and pupils can organize such contests as the following in connection with the regular school activities, for the playgrounds at recess 
or at public events, such as literary programs, fairs or festivals:

1. Seed corn stringing contest.

2. Variety or strain naming contest.

3. Corn-bread baking contest.

4. Corn judging contest.

5. Corn guessing game.

6. Corn picking race. This picking race is handled something like the old-time potato race where you place the ears of corn from thrce to ten feet apart and the contestants are to gather twenty-five ears of corn and place the same in a box or receptacle in the shortest time.

7. Corn husking contest.

S. Oral corn recipe giving contest to determine who can give the largest number of corn recipes in a stated time of five or ten minutes.

All of these contests should be judged in general on speed, skill, condition of finished product, accuracy, etc. (See Bureau of Plant Industry Circular 10t, U. S. Department of Agriculture, Washington, D. C., for further instruction and score-cards on all corn contests.)

\section{Corn Club Work}

Three hundred thousand farm boys and sirls are now enrolled in agricultural and home-economic clubs, most of which are connected with the schools. Club work is the performance of a definite farm, garden or home enterprise, and is based on the best known farm and home practises. Club work in connection with the school may consist of a number of enterprises, such as corn, garden, market garden, poultry, sugar beet, cotton, alialfa and canning projects.

The corn club.-One of the most interesting club 
projects is the growing of an acre of corn on a husiness basis. Boys and girls ranging in age from ten to nineteen are eligible and the pupils may be divided into two classes, an $\mathrm{A}$ class from ten to fifteen years inclusive, and a $\mathrm{B}$ class from fifteen to nineteen. The basis of award for corn club work' should be :

1. Greatest yield per acre_..-_-_-_-_- 30

2. Best showing of profit on investment__._._._._._._. 30

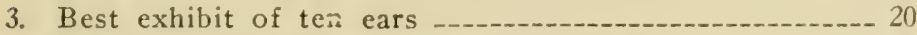

4. Crop report record and story of club work_...........- 20

Total score

Plan of work.-The following plan should govern the conduct of the work: It should be considered a legitimate means of extension service for the school,--a part of regular school work by which plants, soils, insects, plant diseases, crop management, labor income, farm management, etc., may be studied systematically for an entire cropping season. This necessitates making use of the district, state and national club leaders who always stand ready to help organize clubs and oversee the work.

Report blanks.-Every club should have a crop report blank making a record of observations, receipts and expenses at the beginning of the season and another on which to make a complete report at the close of the season. These blanks are furnished free by the United States Department of Agriculture. Definite credit for this club work should be given in connection with the class work in agriculture and other related subjects in the school. 


\section{CHAPTER II}

\section{WHEAT}

READ is the staff of life. Whatever else we may have B on our tables, we usually have bread. It is so common and necessary an article of food that we describe poverty by saying, "Not a crust of bread in the house,"

Iet the bread that you and I eat, wheat bread, is really a rather recent addition to the world's food. True, wheat has been known for many centuries,-so long that no one knows when or where it originated. But. not until the last few generations ha: it been found possible to raise enough so that the great mass of people can have it daily for food.

But iven yet wheat as a common article of food is almost unknown in many nations. Probably more than half the people living in the world to-day have never tasted wheat bread such as we eat daily. Either wheat is not grown, or it costs more than other foods and can not be afforded by the common people. In its stead they eat rice, barley and other foods.

\section{Importance of Wheat as a Crop}

The United States raises more wheat than any other nation, and approximately half as much as all Europe combined. We supply about one-fifth of all the wheat grown in the world. Our annual crop is nearly $700,000,000$ bushels, enough if loaded into cars to make two solid trains, one reaching from New York to San Francisco, and the other from Regina to New Orleans. 


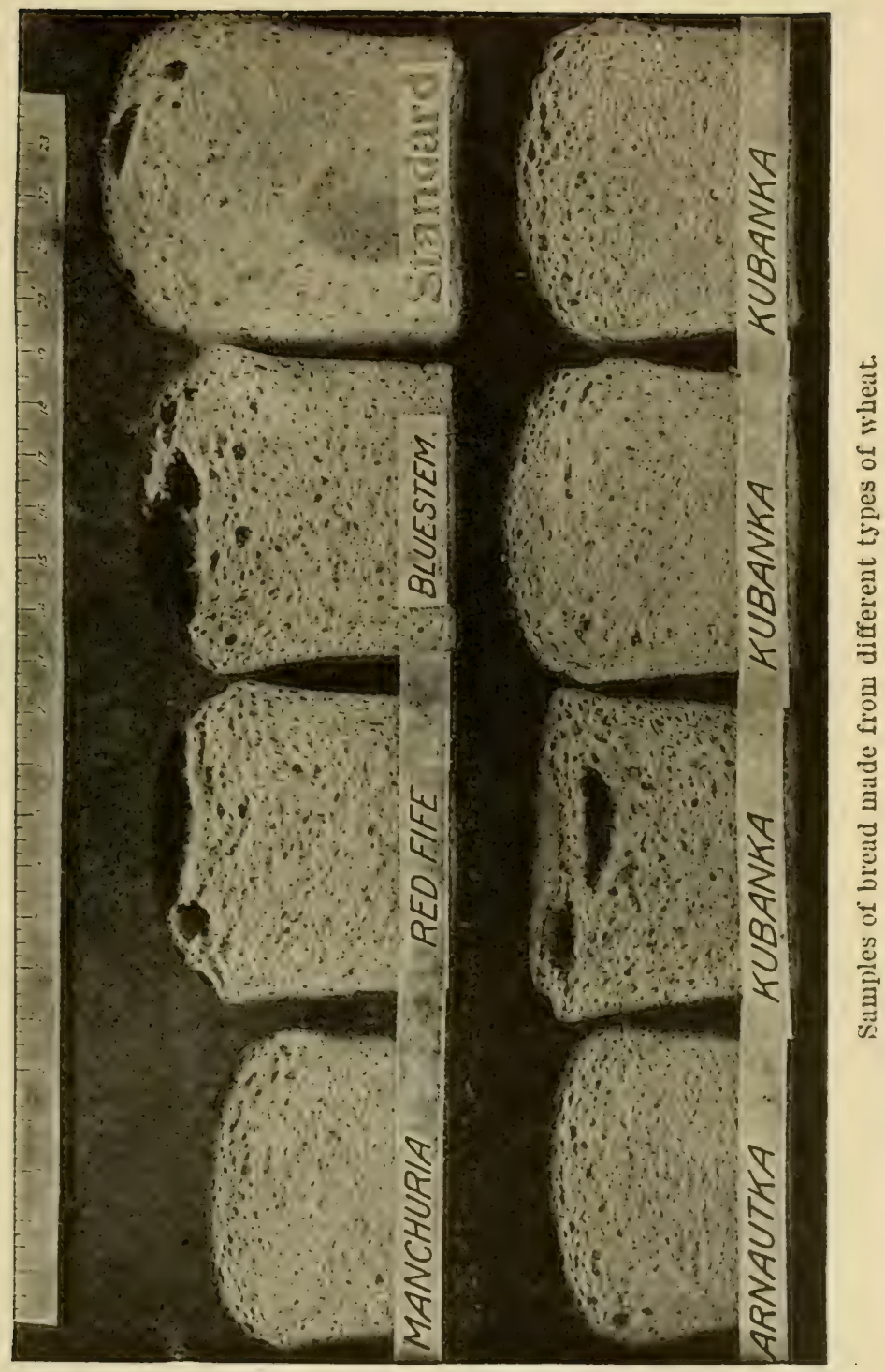


The wheat belt of the United States.-The best wheat producing regions are in the Middle West and North. Kansas, North Dakota and Minnesota produce not far from one-third of all the wheat grown in the United States. If to these we add the following twelve states, Nebraska, South Dakota, Indiana, Illinois, Ohio, Washington, Missouri, Pennsylvania, Oklahoma, California, Michigan and Oregon, we shall have the fifteen states that produce more than four-fifths of all our wheat.

The yield of wheat.-The average yield of wheat for the entire country is about half what it is for corn, or fourteen bushels to the acre. The states that produce the largest amount of wheat are not necessarily the ones that show the largest yield per acre. Taking the average for ten years, the ten states producing the largest amount of wheat rank in the following order in the yield per acre: Washington, first; Nebraska, second; Ohio, third; Illinois, fourth ; Indiana, fifth; Missouri, sixth; Minnesota, seventh; Kansas, eighth; South Dakota, ninth; North Dakota, teinth.

The average yield of wheat is gradually increasing, but all too slowly. With still better methods of farming and with better selection of seed and improvement of the soil much larger crops of wheat can be raised. And this means cheaper bread, and more profit in farming.

\section{Types of Wheat}

Wheat is classed as zwinter wheat or spring wheat, depending on whether it is planted in the fall or the spring. It is also classed as llard or soft in accordance with the quality of the grain.

There are three more or less distinct types of winter wheat, and three of spring wheat, as follows:

1. Soft winter wheat.

2. Semi-hard winter wheat.

3. Hard winter wheat. 
1. Soft spring wheat.

2. Hard spring wheat.

3. Macaroni wheat.

These types furnish a great many different varicties, so many that it would be a hopeless task to try to learn them all. The United States Department of Agriculture and the state experiment stations have tested as many as one thousand different varieties since 1895 .

Climate and type.-In general, the more humid climates produce the soft wheats and drier climates the hard wheats. The introduction of hard wheats has opened up vast western regions to wheat raising which were too dry for the soft varieties.

Better flour is made from hard than fiom soft wheat, though a very excellent grade is made by mixing the two. Macaroni wheat is the hardest type, and is chiefly used in the manufacture of macaroni, though some of this type is now being used for flour. Macaroni can not be successfully made from the soft wheats.

Winter wheat.-Winter wheat is planted in the fall, lives through the winter, and ripens the following summer. It requires about one hundred days to mature after growing weather has come in the spring.

About two-thirds of all the wheat grown in the United States is of winter varieties. In regions where winter wheat will withstand the extremes of temperature it is preferred to spring varieties, since it (1) yields more, and (2) is more free from disease and from injury by the various insect pests.

Kansas and Nebraska are the great centers for the hard winter varieties, while east of the Mississippi River the softer winter varieties are chiefly grown. More than sixty per cent. of all the winter wheat grown in the United States is raised in the states of Kansas, Indiana, Nebraska, 


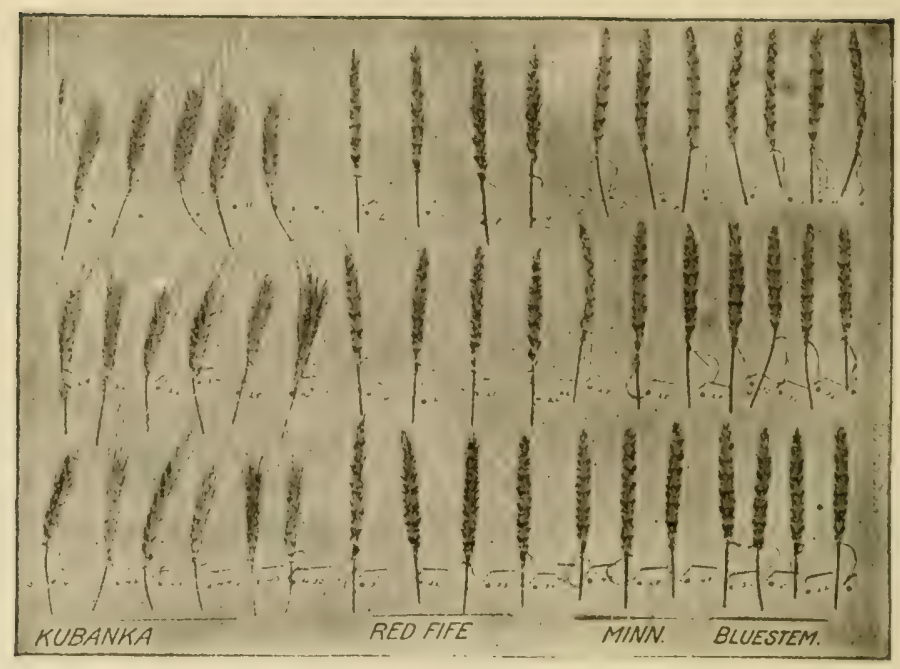

Common varieties of whent.

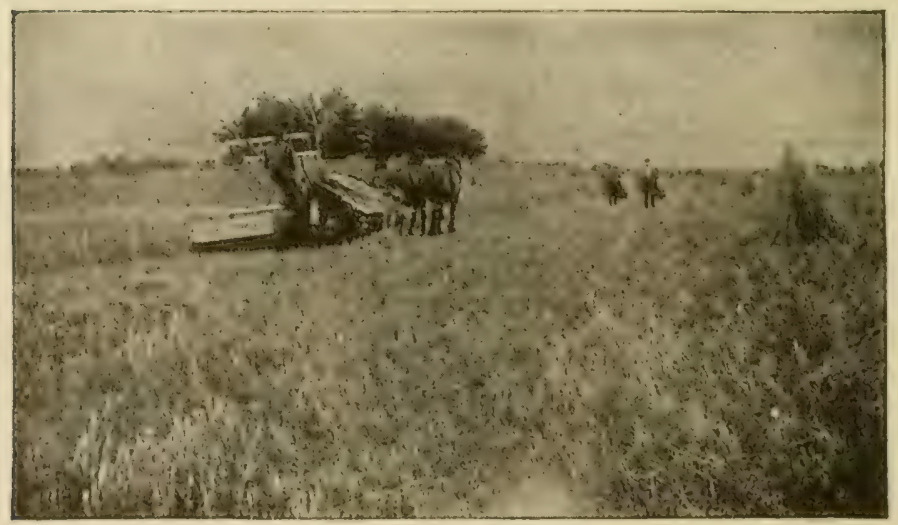

Harvesting wheat with a modern binder. 
Illinois, Ohio, Missouri, Pennsylvania, Oklahoma and Texas.

Spring wheat.-Spring wheat is adapted to localities where climatic conditions are not favorable to winter varieties. About one-third of our wheat comes from the springsowed crop. Most varieties of spring wheat require from one hundred to one hundred and twenty-five days from the date of pianting to mature.

Minnesota, North Dakota and South Dakota are the principal spring wheat regions of the country. These three states supply seventy per cent. of all the spring wheat grown in the United States.

\section{TOPICS FOR INVESTIGATION}

1. What proportion of the tilled land of your vicinity is devoted to wheat? Is this proportion increasing or decreasing?

2. What type of wheat is chiefly grown, winter or spring? Hard or soft? Do you know what are the chief varieties to be found in your neighborhood? Are the varieties bearded or beardless?

3. What is the average yield of wheat to the acre in your region? How does this compare with the yield for the state? (Consult your state agricultural college for the yield of the state.)

4. It is estimated by the United States Department of Agriculture that the average cost of producing an acre of wheat in the United States is about eleven dollars, including rental or interest value of land. Talk with your father about what the different items of expense cost in your vicinity (such as fertilizer, preparing land, seed, planting, harvesting, thrashing, marketing, rental). Make a detailed list of these expenses, and compare with the average cost for the country.

5. In similar manner figure what it costs to raise an acre of corn. Then find the market value of the grain from an acre of corn and from an acre of wheat, based on 
the average yield for your vicinity. Which crop pays the better, and by how much per acre?

\section{Growing the Wheat Crop}

Wheat grows best on virgin soil, or on land that has been renewed by means of clover, manure, or some other form of fertilizer. The new regions opened up in the West at first produce large crops, but soon fail in yield if wheat is raised continuously without rotation with other crops.

Preparing the seed bed.-Since wheat is one of the crops that can not be cultivated after planting, the seed bed should be prepared with especial care. The ground should be plowed, and then disked or harrowed until it is well packed and finely pulverized. The preparation for the fall and spring seeding is essentially the same. If the ground is new, the plowing may be shallow. The older soils require deeper plowing.

Spring wheat is sometimes disked in on corn land without first plowing the ground. This, however, is a careless method of farming, and has been proved by careful experiments not to secure so large a yield as from plowe t land.

Selecting and preparing the seed.-As in the case of corn, the best seed for wheat is usually that grown near home. New varieties and seed grown at a distance should not be used for the general crop until carefully tested by agricultural experiment stations and found adapted to the locality.

Wheat selected for seed should possess the following qualities: (1) A plump bright grain of good wheat; (2) a stiff straw, able to withstand adverse weather; (3) a compact head, ripening early, and not easily shattered; (4) good bread qualities; and (5) ability to resist insect enemies and diseases.

Once the type and variety selected for seed are decided 
upon, the wheat should be run through a fanning mill. This will select the heaviest and plumpest grains, as well as remove the seed of noxious weeds. If care is taken thus to secure the best of the crop for seed each year, there need be no fear of the seed "running out." On the contrary, the variety may actually be improved.

Methods of planting.-The method formerly used in planting wheat was to sow it broadcast on the plowed ground, and then harrow it in. This is a very wasteful way of planting, however, since some of the wheat fails to be covered, and is picked up by the birds; some of it is covered too shallow, and fails to secure good roots; and some of it is covered too deep, and grows imperfectly.

The method now used in all successful farming is to plant the wheat with a drill. This sets the seed at a uniform depth, and gives it a moist fine bed of soil. Numerous experiments have shown that the best depth to plant wheat for average years is from one and a half to three inches. Wheat, like corn, loses both time and strength by being planted too deep.

Wherever possible, wheat should be drilled in rows running east and west. In dry regions, the prevailing winds then blow snow and dirt into the drills instead of out of them, as is the case when the rows run north and south. In east-and-west rows the drill also tends to shade the roots of the plant, and so protect them from the frequent thawing and freezing which occur in the case of winter wheat when the sun shines directly into the drill. Because of these uses of the drill ridges, the ground should not be harrowed after the wheat is sown.

Harvesting the wheat.-Except in the semi-arid regions of the West where practically no rain falls during the harvest season, wheat should be cut as soon as it is ripe enough. Many farmers allow their wheat to become so 
ripe as to shatter, and much loss results. It may he cut while the grain is still soft, so that it can be crushed between the thumb and finger. This will not injure the quality of the grain, and the straw will be of much greater value if cut slightly green. Early cutting also reduces the risk of storms.

In regions where the grain can be allowed to stand without shattering until it has become fully ripe and dry, the cutting and thrashing are often accomplished in one process. This is done by a combination harvester and thrasher lrawn by from twenty to thirty horses, or by a tractor engine.

Wheat cut with the harvester should be carefully shocked, ustrally in nine-bundle shocks, eight bundles standing firmly on the ground in the form of a circle, and the ninth used for a cap-sheaf. Careless shocking is responsible for much loss from weathering.

When the wheat is well dried in the shock, it should at once be thrashed, or else stacked in well-built stacks. Wheat is too valuable to leave standing long in the field waiting for a thrashing machine. If once put in stacks, it should be allowed to stand for several weeks hefore thrashing in order that it may "pass through the sweat."

\section{Discases and Insect Enemies of Wheat}

Wheat is the prey of many different diseases and insect enemics, which sometimes almost totally destroy the crop. Many of these are coming to be better understood, and remedies for them derised. Three principal diseases attaching wheat are scal, rust and smut. These are all caused by the growth of fungi on the wheat plant. A fungus is a tiny plant organism that grows upon some other plant. or on animal tissue, and (lraws its living from its host. IVe call 
any organism that gets its living off another organism in this: way a parasite.

$\mathrm{Scab}$ in wheat.-Scab is the least common of the three

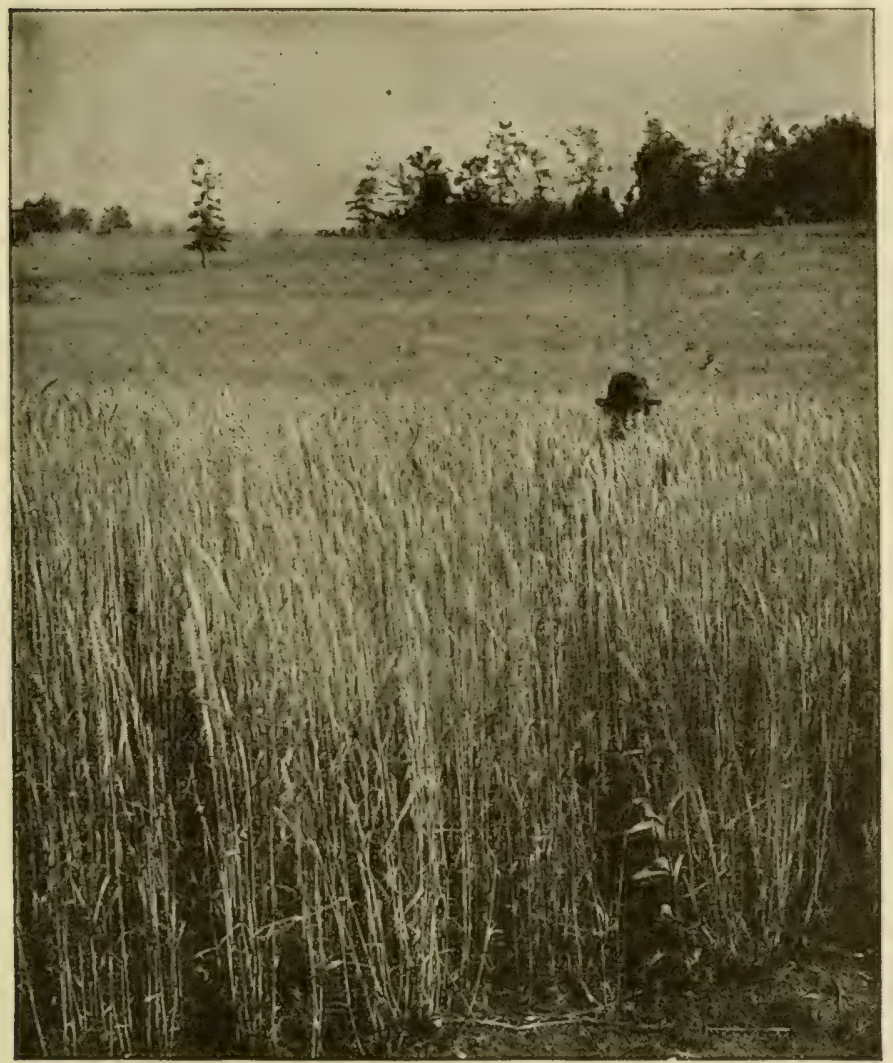

A good stand of wheat, raised by a Georgia club boy.

diseases mentioned, yet it sometimes causes much loss in certain localities. It attachs the glumes, or chaff, which surround the kernels of wheat in the head. The entire head 
is scldom destroyed, only a few of the glumes being affected. Scab results in a shrinkage of the kernels, and hence a reduction in the yield and an injury of the quality of the wheat. No cure has yet been discovered for wheat scab. A second crop of wheat should not follow wheat that has been affected with scab. If this is necessary, however, the stubble of the first crop should be burned to destroy as much of the scab as possible.

Rust in wheat. $\rightarrow$ Rust is one of the most serious encmies of the wheat crop. It is nearly always present in some degree, and has at times almost wholly destroyed the crop over considerable areas. There are two kinds of rust, one attacking the leaves and the other the stems of the plants. The stem rust is much more destructive than the leaf rust.

Rust may in some cases live over winter on the old plants, and be ready to attack the new crop if wheat is again planted on the field. Wheat rust also lives on other plants, especially the barbcrry, and is spread from them by birds or insects to wheat-fields. Laws have been passed in some states requiring the destruction of barberry hedges because of their part in spreading rust.

Moist seasons are more favorable to the ravages of rust than dry. Rust results in weakening the stem of the wheat plant, and reducing the size and quality of the grain. In some cases the heads even fail to fill, and the crop is a total failure. There is no known cure for rust, though certain varieties of wheat are better able to resist it than others. The carlier varicties are usually safer than the later.

Smut in wheat.-There are two kinds of smut that attack the wheat plant, loose smut and stinking smut. Loose smut usually destroys both the glumes and the kernels, leaving only the bare stem. Stinking smut grows inside the 


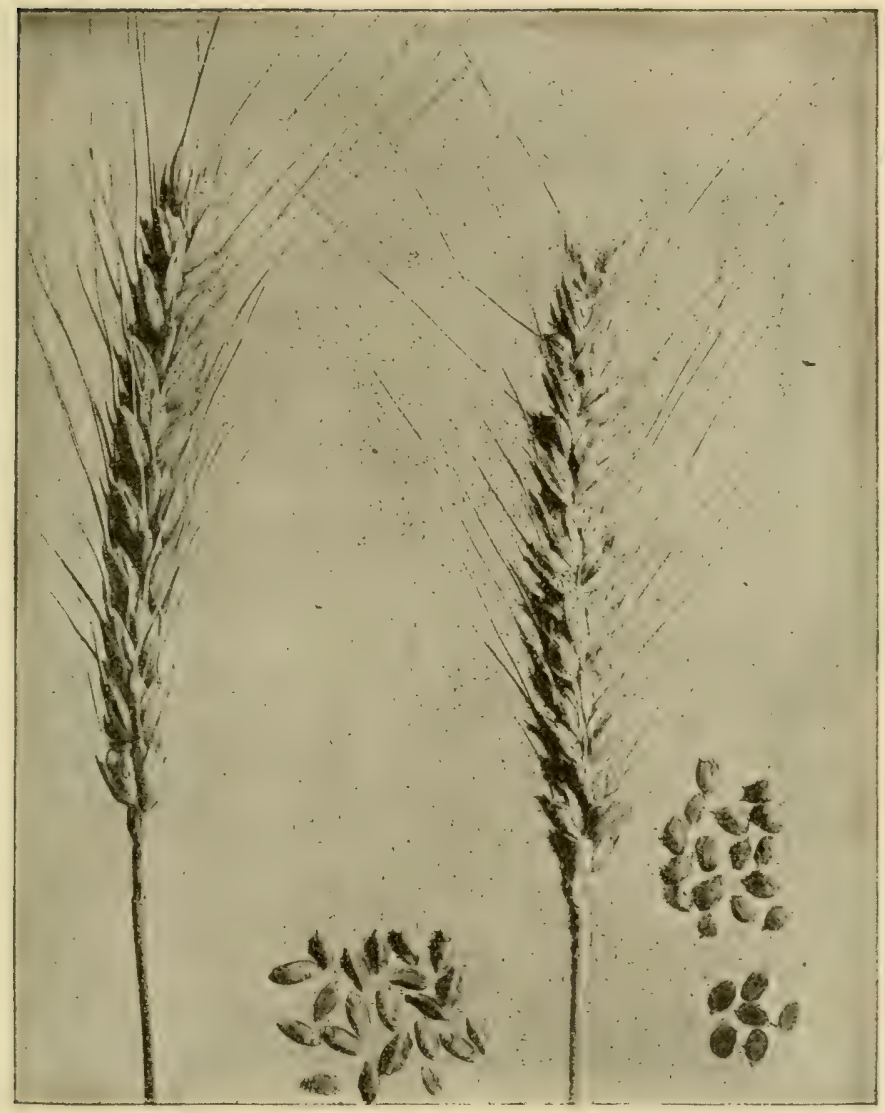

Stinking smut of wheit: smutted head and smut balls at right; sound bead and kertiels at left. 
glumes, destroying the kernel only, and taking its place. The spores from which stinking smut grows attach themselves to the kernels of wheat, and are therefore often sown with the seed. This fact makes it possible to combat this type of smut by treating seed wheat in such a way as to kill any smut spores that may be present.

One of the surest and cheapest ways of treating the seed for stinking smut is by the application of a solution of formalin. One pint of forty per cent. formalin mixed in forty-five gallons of water will treat one hundred bushels of wheat. The wheat may be spread out thin on a tight floor and sprinkled with the moisture, shoveling it over so that each grain is sure to become dampened.

After it is well sprinkled the wheat should be covered with sacks or blankets to keep it from drying out too rapidly: After a few hours, it may be spread out, or stirred, to hasten the drying in preparation for sowing. Ten pounds of copper sulphate dissolved in twenty-five gallons of water may be used instead of the formalin.

Loose smut may be prevented by what is called the hotzuater treatment of the seed. The wheat is put into sacks and immersed in tubs of water warmed to a temperature of one hundred and twenty degrees Fahrenheit. When the wheat has become thoroughly warmed, it is taken out, drained, and again dipped in water, this time heated to a temperature of one hundred and thirty-five degrees. The sacks may now be dipped at once in cold water, which will serve to keep the kernels from swelling. The wheat should then be spread where it will dry quickly. The general use of these well tested remedies should make smut of rare occurrence.

Chinch-bugs.-Chinch-bugs are among the worst of the insect enemies of wheat. They are easily recognized as a small dark-colored insect, with white wing covers. 


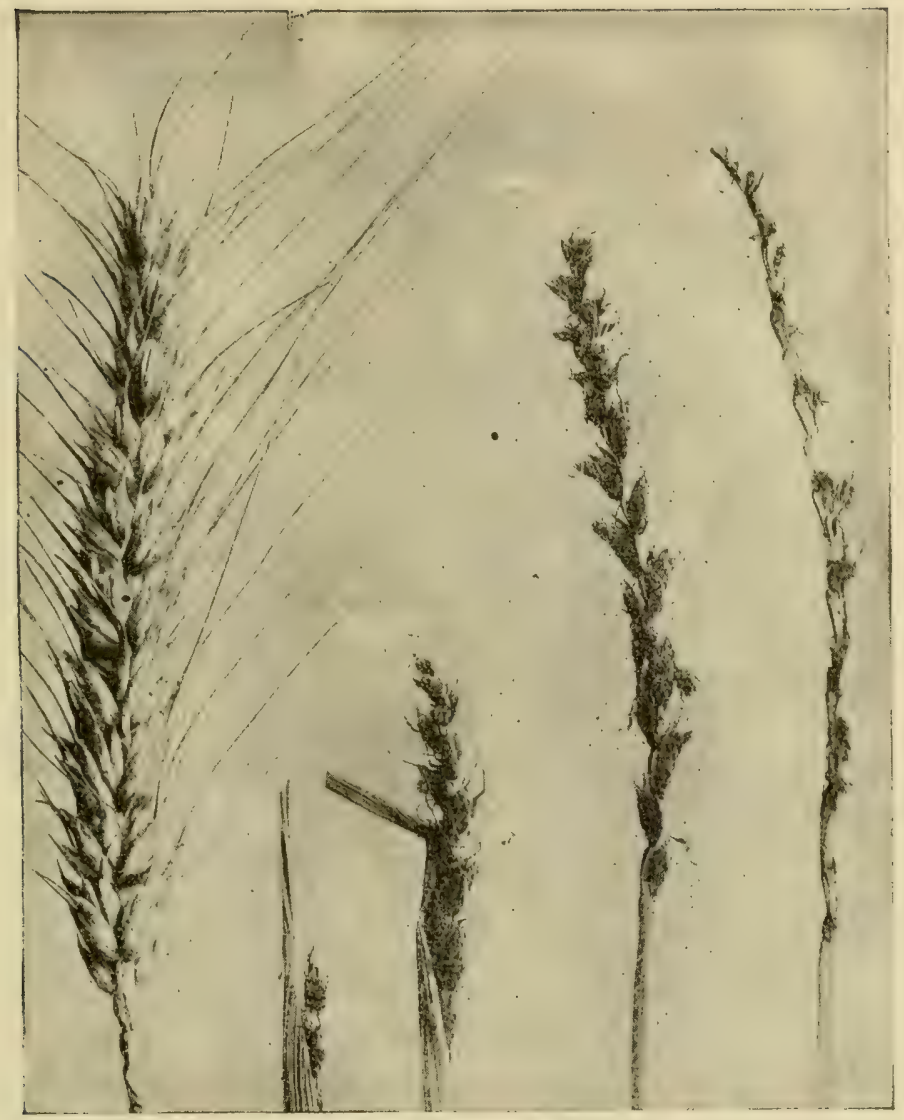

Loose smut of wheat. Sound head at left; different stages of smutted development at right. 
Chinch-bugs damage the wheat by sucking the sap from the plant, and thus checking its growth. The mature bugs live over winter, lay their eggs in the spring, and the young are soon hatched out, showing at first a reddish color.

No effective way of controlling chinch-bugs has yet been discovered. It is, however, helpful to burn the rubbish of any infected field in the fall, as this will destroy large numbers of the bugs, and leave the remainder without hiding-places.

The Hessian fly.-The Hessian fly is a small, mosquito-like insect that lays its eggs on the growing wheat. These eggs soon hatch, and the larvæ begin at once to suck the juices from the young plant.

One method of handling these pests is to turn under the first planting of wheat that has been attacked, and then sow another crop on the ground. This, however, is an expensive method of getting rid of them. The buming of fields in the fall, fall plowing, and rotation of crops are all helpful in checking their ravages.

Grasshoppers.-Grasshoppers are less to be dreaded now than in earlier years, though they occasionally do great damage to the wheat crop. The grasshopper lays its eggs in the summer, and they do not hatch until the following spring. It is possible greatly to reduce their number by late, deep fall plowing, which buries the eggs so deep that the young when hatched do not find their way to the surface. Poisonous sprays are also used to destroy the young hoppers.

\section{TOPICS FOR INVESTIGATION}

1. If winter wheat has been sown in your neighbor. hood, visit two or more fields and note (1) whether the seed was sown broadcast or drilled, (2) the direction of the drill rows, and (3) the evenness of the stand. 
2. Make a collection of all the different types of wheat available, and learn to identify them, (1) from the grain, and (2) from the head and straw.

3. Obtain samples of unthrashed wheat, and search for leaf rust; for stem rust. Compare the heads and kernels on the rusted stalks with those on healthy heads.

4. Find examples of stinking smut, of loose smut. What is the condition of the straw and grain in each case as compared with healthy plants?

5. Go out into fields of wheat and oats stubble and look under bunches of straw or rubbish for chinch-bugs. Bring specimens to school and examine them so that you can quickly identify them.

6. Secure a score-card for wheat, and judge from twenty-five to one hundred grains of wheat.

7. What is the best method for the testing of wheat for vitality? Look up instructions on the new blotter tester and a few of the commercial tray testers. Make a test of one hundred wheat seeds and judge for vitality, dividing the seed after germination into three classes, strong, weak and dead.

8. How would you keep a record or bookkeeping account of a field of wheat? Make out a debit and credit account covering a season's work with one acre of wheat. (See Farmers' Bulletins, 511 and 572.)

9. Sketch a map of the United States and locate the wheat producing states and sections. Insert the last census reports of wheat production for each state. Where are the leading wheat mills of the country?

10. Compare wheat bread with bread made from other products such as corn, rye, etc. What differences do you note?

11. How much wheat is exported annually from this country? How much wheat is imported?

12. What foreign countries produce wheat? Locate them on the map.

(See end of chapter on "Oats" for suggestions as to wheat demonstrations, play contests and club projects.) 


\section{CHAPTER III}

\section{OATS}

$\mathrm{O}$

ATS are one of the world's most important grain crops. Though not so old as wheat, oats have been grown in Europe for centuries. They were brought to this country by the early settlers, and are now raised in every state. The United States produces about one-fourth of all the oats grown in the world. Oats are chiefly valuable as a food for animals, yet they are also widely used as a human food.

\section{Importance of the Oats Crop}

Our oats crop is slightly more than a billion bushels a year, or a total yield of about one-third more than wheat. Because of the higher price of wheat, however, the value of the oats crop is only about half that of wheat. Among all farm crops, oats rank fifth in value, being surpassed only by corn, cotton, wheat and hay.

The oats region.-The great oats producing region of the United States extends from New York and Pennsylvania westward to Nebraska, Kansas and the Dakotas. Each state in this great chain plants more than a million acres of oats annually.

The following chart shows the thirteen states that produce about four-fiftls of all the oats raised in the United Sitates, with the per cent. of the total crop grown in each: 
lowa

Illinois

Minnesota

Wisconsin

Ohio

Indiana

North Dakota

Nebraska

Michigan

Kansas

New York

South Dakota

Pennsylvania

All others

The yield and profit.-The average yield per acre throughout the United States is about thirty bushels. 'The highest yields are in the far Northwest, where the rainfall is heavy during the growing season, or where irrigation is used. Here the crop not uncommonly runs from one hundred to one hundred and twenty-five bushels to the acre, and sometimes reaches one hundred and fifty bushels.

In the corn belt, oats are usually a less profitable crop than corn. The yield is less per acre, and the market price lower, while the cost of production is about the same. In Icwa or Illinois, the two leading states in the amount of oats produced, the cost of growing an acre of oats if we include the rental value of the land, will average from ten to twelve dollars. When oats are thirty-five cents a bushel, it is evident that a crop of thirty bushels to the acre leaves no margin of profit.

Thile oats do not pay so well as corn, it is necessary, nevertheless, to raise them, even in the corn region. For oats are needed, (1) to make possible the rotation of crops, and (2) as a food for stock, especially working horses. This crop, like corn and wheat, can easily be increased in 


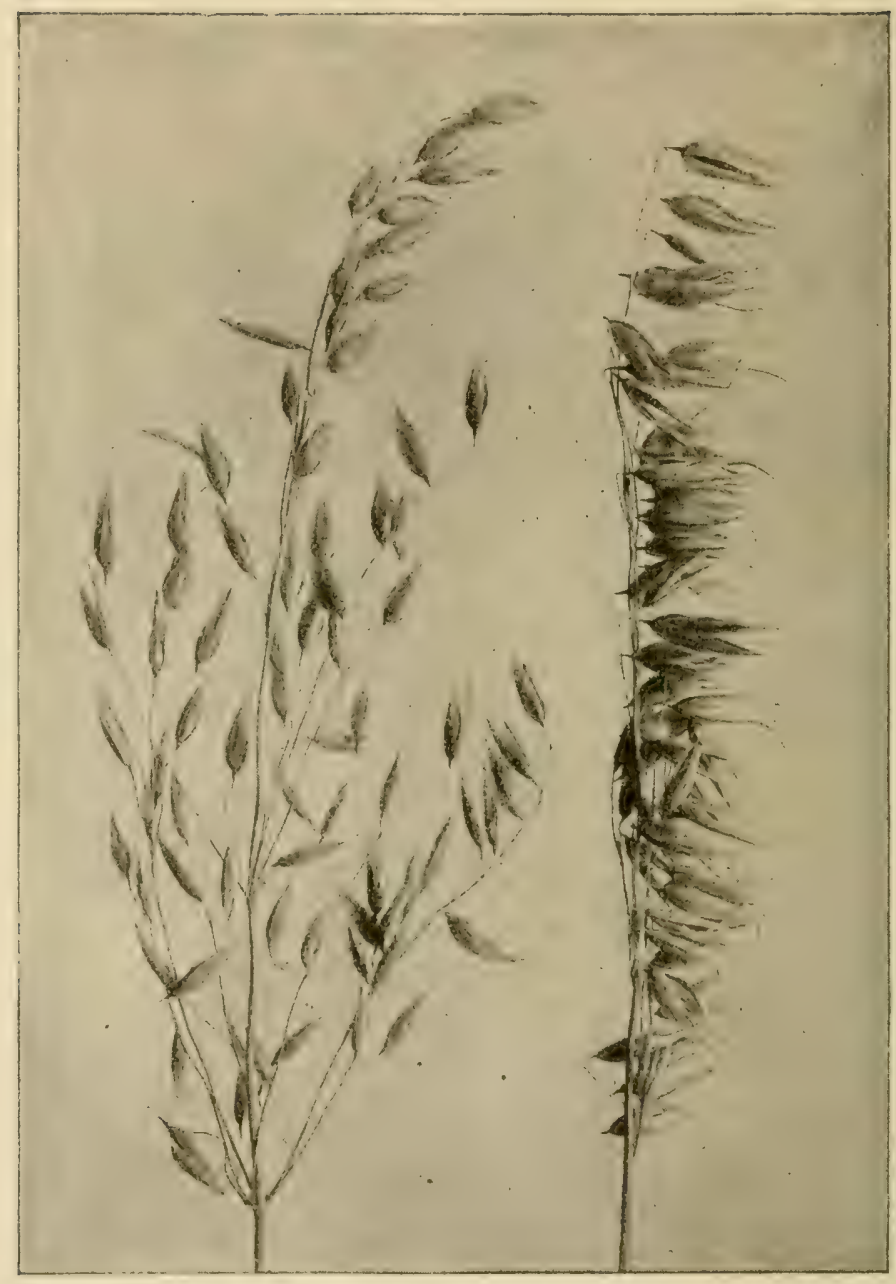

Two types of oat heals: spreading or panicled on the left; side or hor:se-mane on the right. 
yield and profit by improving the soil and employing better methods of seed selection and tillage. It is not impossible to secure an average yield of from fifty to seventy-five bushels to the acre throughout the oats region.

\section{Types of Oats}

Two general types or classes of oats are easily distinguished-the spreading, or panicled, and the side-bearing or horse-mane. The former has a spreading; bush-like head, branching from all sides of the central stem; the latter carries the grains on short branches, all of which are attached to one side of the stem.

Varieties for different regions.--It is impossible to tell how many different varieties of these two types exist. As in the case of wheat and corn, new varieties are being developed from year to year. Several hundred different varieties are now shown in the seed lists.

In New England, the northern tier of states and the Rocky Mountain region, white oats of rather latc-maturing, large-grained varieties are usually most successful. Examples of these varieties belonging to the spreading type are: Clydesdale, Big Four, Swedish Select and Lincoln; of the horse-mane type, White Russian and Tartarian are well known.

In the Missouri, Mississippi and Ohio River regions, extending as far south as Kansas, Missouri, Kentucky, Tennessee and Texas, and as far east as Ohio, small-grained, early, yellow varieties have proved the best. The Kherson, Silvermine, Big Four and Sixty Day are examples of these varieties.

Successful fall seeding of oats is possible only in the southern states. For southern fall seeding, Winter Turf and Red Rustproof are the varieties most used. For spring 
seeding in this region the Burt and Red Rustproof are satisfactory.

\section{TOPICS FOR INVESTIGATION}

1. How many acres in your father's farm? How many acres are cultivated this year? How many acres in grass

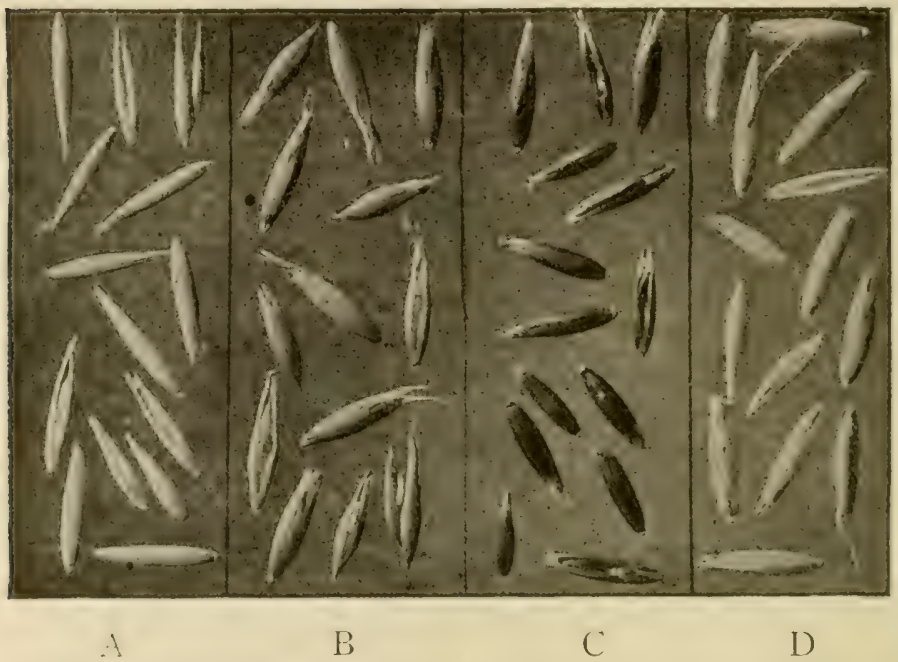

(A) Sixty Day, grain medium-sized, slenter, yellow: (B) Reel Iiustruroof, grain large. plump, reddish-brown; (C) North Finnish Blick, grain medium-sized, plump, black; (D) Swedish Select, grains white, large and plump.

land and pasture? How many acres in garden, orchard, lawn and barnyard?

2. How many acres are devoted (1) to corn; (2) to wheat; (3) to oats; (4) to other farm crops? What percentage is the acreage of each crop to all the land cultivated? To the whole farm?

3. Find how many acres altogether in the farms represented by the pupils in the school. Then answer each of the four questions asked in number "2" for all these farms summed together. How do the percentages for each 
crop raised on your father's farm compare with the percentages for the entire school district?

4. What was the yield of oats per acre on your father's farm this year? What is the yield of corn? Learn the

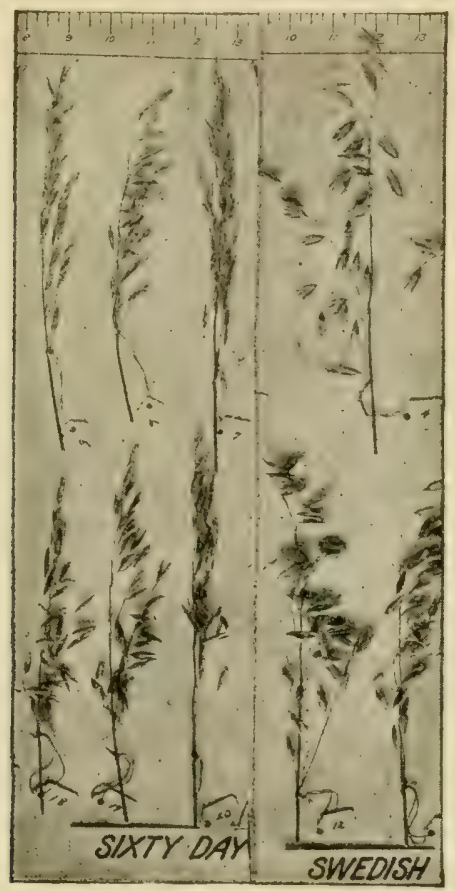

Two common varieties of oats.

market price of each grain, and figure the value per acre for each. Now ask your father to help you determine the cost of raising and harvesting an acre of each crop. Which is the more profitable crop, and by how much to the acre?

5. Which of the two types of oats is raised on your father's farm? What variety?

6. Make a collection of five or more different varieties of oats, study the kernels, and the entire plant if possible, 
and learn to identify quiclily the chicf varieties grown in your region.

\section{Raising the Crop}

Oats are usually planted with less care than any other crop. Where they follow corn in the rotation of crops, they are often sown broadcast on the corn land without previous cultivation or preparation of the ground. The field is then either disked or gone over with a cultivator and harrowed. This is a careless method of farming, and undoubtedly results in a diminished yield.

Preparing the seed bed.-When oats are sown after corn the seed bed should be prepared by plowing or two thorough diskings before seeding. The oats may then be covered by harrowing. The corn stalks should be broken down before disking. This can easily be done by means of a heary pole dragged broadside across the rows when the ground is frozen. A still better method is to cut the stalks with a corn cutter. If the growth of stalks and weeds is especially heavy on the field, it is best to rake and burn the rubbish to get it out of the way of cultivation.

It sometimes may not be necessary to plow the ground for oats following a well cultivated crop. Especially is this true if the plowing can not be done in the fall. One of the things most necessary in growing oats is to get the seed into the ground as early as it can be worked in the spring. And the seeding can be done more quickly by disking than by plowing. There is little or no danger to oats from freezing after they are sown, and the seed will sprout and grow in a much colder temperature than that necessary for corn.

Methods of seeding.-Oats are sown by two methods, (1) scattering the seed broadcast over the ground, and (2) drilling. The old method of broadcast seeding was to scat- 
ter the seed by hand from a sack slung over the shoulder. Machines for seeding have been devised which can be attached to the end-gate of a wagon. The seeder is driven by one of the rear wheels of the wagon by means of a sprocket wheel and chain.

Drilling usually results in a larger yield than broadcast

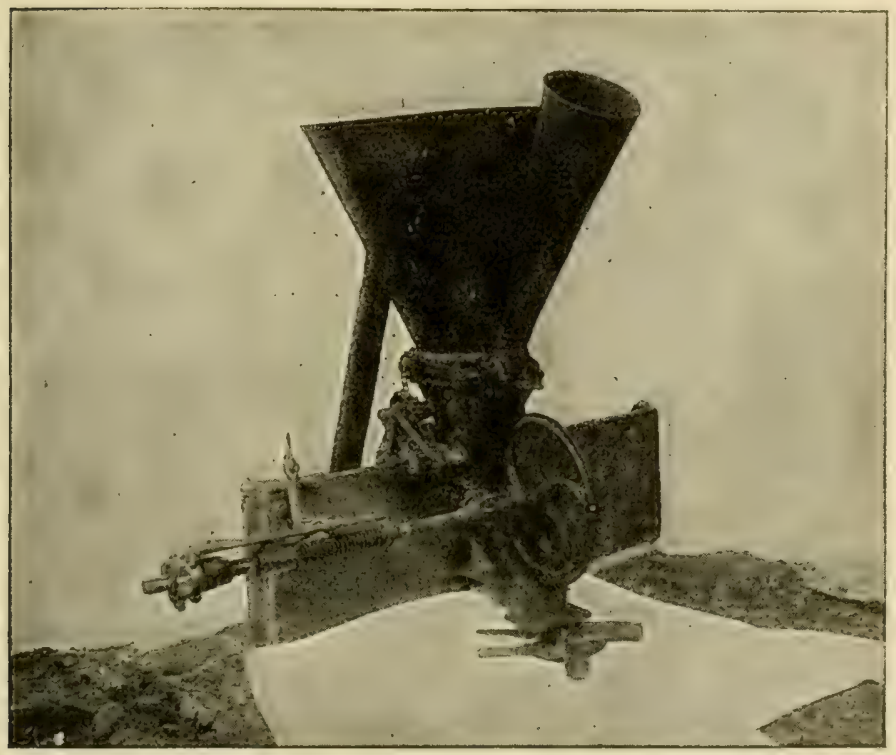

End-gate seeder for broadcast seeding of grain.

seeding. The drill plants the seed uniformly over the field and covers it well. The drilled crop comes up more evenly, and ripens more nearly at the same time than from broadcast sowing. Less seed is required when the planting is done with the drill, since practically all the seed is covered and given a chance to grow. This is impossible with broadcast seeding. 
I nistake is often made in planting oats too deep. The ground is usually moist when the planting is done, and depth is not required to secure moisture to start growth. Many agricultural experiment stations have tested different depths of planting, and recommend about one inch as the best depth for most regions.

Preparing the seed.-Seed oats should never be taken directly from the bin and sown, no matter how promising the grain looks. For oats ordinarily contain more dirt, weed seed and light grains than wheat.

The seed should always be run through the fanning mill. The current of air blows out the light grains and much of the rublish, and the smaller grains are removed by the sicves. This process of cleaning should generally exclude one-third or one-fourth of the oats run through the mill. If the seed is very light a still larger proportion will need to be rejected.

Careful tests have shown that seed prepared in this way will yield several bushels to the acre more than if sown directly from the bin. Many of the light grains fail to sprout, and most of those that grow produce weak plants that yield little or nothing. It will well pay every farmer to take time in the winter to prepare his seed oats.

Improvement of the seed.-It is possible greatly to improse a variety of oats by careful selection of the seed. This may be done by going into the field just before the (rop) is harvested, and gathering, head by head, the strongcit, larsest grained and best yielding plants, also giving preference to those that are freest from disease. From a peck to a bushel or more thus selected is thrashed out, the small, light or imperfect grains rejected, and the choice seed sown on a special seed plat to raise seed for the coming year's crop.

Harvesting the cro?.--Oats are harvested with the 


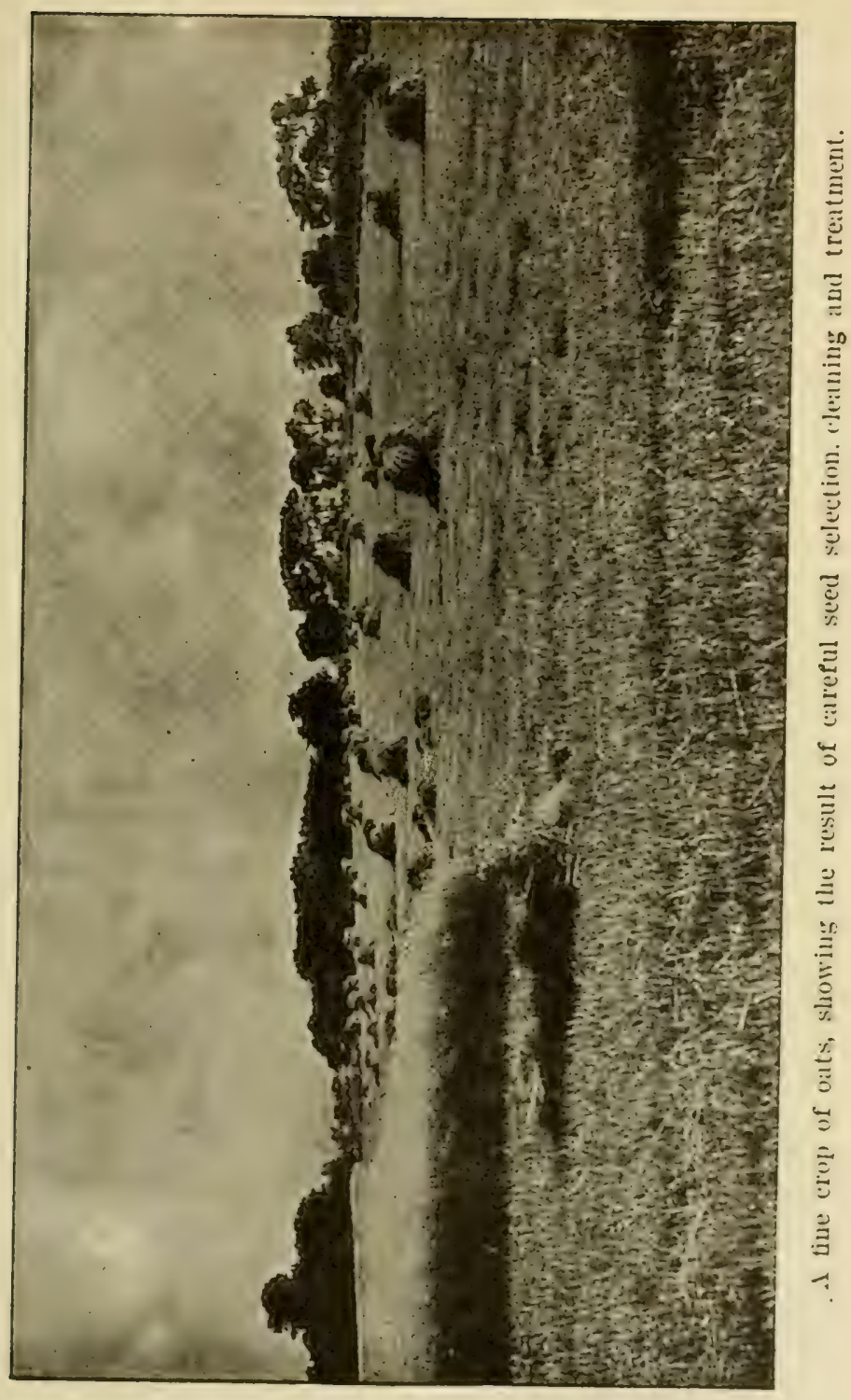


grain binder, the header, the mowing machinc, and the combined harvester and thrasher. By far the greater part of our oats crop is cut with the binder.

The best time for cutting oats is just as they are passing out of the hard-dough stage of ripening. On account of the fact that they shatter rather easily when ripe, it may he necessary, especially if the acreage is large, to begin when the grain is passing out of the milk stage. Cutting too early leaves the grain slightly lighter and of a greenish color.

The best method of shocking oats depends on the ripeness of the crop when harvested. If the oats are in the hard-dough stage when cut, they should be shocked in well built, round shocks. If the grain is green and the straw heavy or full of weeds, the long shock is better, since it allows freer curing. Either type of shock should be capped, except in regions where the winds are usually strong enough to blow a cap sheaf off, in which case it takes damage from lying on the ground.

Thrashing.-Oats may be thrashed from the shock, or stacked and thrashed any time during the fall. A somewhat better grade of oats is obtained by stacking and allowing the oats to "go through the sweat" before thrashing. The straw is also worth more for feed when the oats have cured in the stack.

The custom followed by careless farmers of leaving grain standing for weeks in the shock exposed to the weather while waiting for the thrashing machine can not be too strungly condemned. A period of hot wet weather is almost certain to start the oats to molding, or sprouting in the shock. On the other hand, if the weather is very dry, the oats shatter, and many bushels are lost in handling. If the thrashing machine can not be secured as soon as the oats have dried sufficiently to thrash, they should be stacked 
in well-built round stacks so constructed as to turn the rains.

\section{Insect Enemies and Diseases}

Oats are, on the whole, subject to fewer diseases, and the prey of fewer insects than wheat. The crop is, therefore, less liable to total failure from these causes.

Insect enemies.-Chinch-bugs attack oats, as well as wheat, though they usually do much less damage to oats than to wheat. They can be controlled only as already described in the case of wheat.

In some seasons the army worm has caused much loss to oats, but usually not over extensive areas. There is no satisfactory method known of controlling its ravages. What is known as the grecn bug, a grain aphis, is one of the most prominent enemies of oats. Grasshoppers occasionally consume the greater part of the crop in relatively small areas.

Diseases of oats.-The chief diseases attacking oats are rusts and smuts. These are of the same general character as the rusts and smuts of wheat, fungous growths feeding on the growing plant.

The rusts are of two chief types: (1) leaf rust, which is of a reddish-brown color, and attacks the leaves, and in some degree the stems, of oats shortly before ripening time; and (2) stem rust, which is to be recognized as tlack spots appearing on the stems and leaves of oats just before they ripen.

Stem rust is less common than leaf rust, but when present is far more injurious to the crop. The rusts are more serious as an enemy of oats in the South than in the North, appearing in the South almost every year, and greatly reducing the yield. Rust is far worse on moist hot seasons than on dry seasons. No sure cure has been discovered 
for rust in oats, though some varieties are more able to resist its attack than others.

Smut ordinarily causes more injury to oats than any other disease. It has been estimated that from two to three per cent. of the entire crop is destroyed every year by smut, causing a loss of from $\$ 6,000,000$ to $\$ 10,000,000$.

The smut of oats is easily recognized a little time before the crop is ripe. Instead of the kernels are found small masses of smut dust which have taken the place of the grain. Sometimes these smut balls are covered by the chaff, much as the kernel should be, and other times the chaff is lacking and the smut fully exposed.

While there are two kinds of smut in oats, both will yield to the same treatment. Smut may be wholly prevented by treating the seed with formalin, as described for the treatment of wheat. It will also be effectually prevented by the hot-water treatment. In either treatment the method is practically the same as for the seed wheat. With so simple and sure a remedy for smut, every farmer who lives in a smut region should treat his seed before sowing. It costs almost nothing, and may result in an increase of several bushels of oats to the acre.

\section{TOPICS FOR INVESTIGATION}

1. How did your father prepare the ground for oats last spring? Were they sown on corn land? If so, were the stalks broken down, or pastured close? Was the ground disked before the oats were sown? If so, how many diskings? If more than one, was the second disking across the first, or by lapping? Which is the better way? How many harrowings did the oats receive?

2. At what date are oats usually sown in your region? When does harvest begin? How many days, then, are recuired for the crop to mature? How much seed does your father use to the acre? 


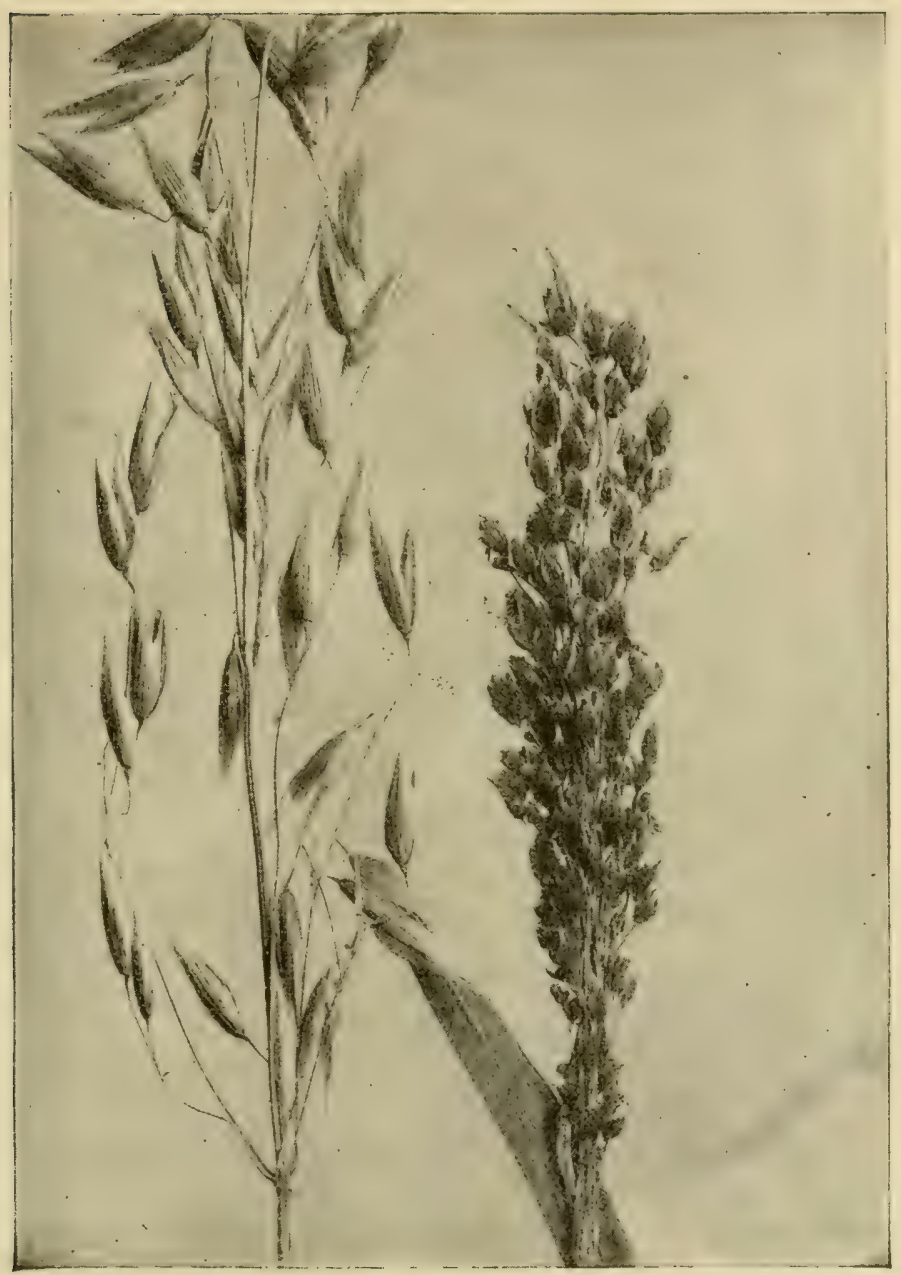

Smut of oats; smutted head at right; sound head at left. 
3. Collect samples of unthrashed oats, and examine (1) for each kind of rust; (2) for each kind of smut. If it is not possible to find unthrashed oats, examine straw for rust and evidences of smut.

4. Did rust or smut damage the crop in your region last season? Does your father treat his seed oats for smut? If so, by what method? Suppose your crop was reduced two per cent. by smut, how much did you lose per acre? How much on the entire crop? Would this not more than pay for treating the seed?

5. Does your father always run his seed oats through a fanning mill to select the better grains and remove weed seed? How long will it take to run one hundred bushels through a fanning mill? Suppose it results in an increase in yield of two bushels per acre, how much profit would there be from the cleaning?

6. Have you seen oats left in the shock until they were damaged, either by wet weather, or by shattering? About how much per acre does it cost to stack oats? Suppose there is a loss of one bushel to the acre by allowing the grain to stand in the shock; will it pay to stack? (Consider also the better quality of grain and straw.)

7. Make out a debit and credit sheet showing the proper method of keeping an account with a crop of oats covering the entire season, beginning with plowing and closing with harvesting, thrashing and marketing of the oats.

8. Test one hundred grains of seed oats for vitality by the use of the rag-doll tester or blotter tester, and estimate the percentage of strong, weak and dead seed. From this base your estimate on the loss of crop if all the oats sown in your home field are of the same standard of vitality.

9. Secure a copy of a score-card for oats and judge twenty or thirty grains of oats.

10. Sketch a map of the United States and locate the oat producing states. From the last crop census record the number of bushels of oats produced in each state. What foreign countries produce oats? 


\section{Wheat and Oat Demonstrations}

1. Demonstrate the making of a vitality test for wheat and oat seed.

2. The method of separating chaffy wheat or oats and weed seed from the better grade seed.

3. How wheat and oats may be used for the table. The girls can work out a number of recipes.

4. In the field demonstrate the proper method of seeding and, when equipment is available, the methods of pieparing seed bed, disking, fertilizing, etc.

5. Demonstrate how to select individual wheat and oat heads for seed.

\section{Wheat and Oat Play Contests}

Plan and carry out the following contest games:

1. Variety naming contest.

2. Wheat and oat judging contest.

3. Recipe giving contest.

4. Bread baking contest.

5. Oral descriptions by ciass members of a thrashing day at home.

\section{Wheat or Oat Club Project}

A wheat or oat club makes an interesting method of studying the economic production of these cereals. The members of the club should arrange to grow from one to five acres, studying carefully the system of "follow-up" instruction provided by the managers of such clubs in your county and state, and keeping a complete record of all observations, receipts and expenditures.

The girls can grow a small plat, say one square rod, with a view to studying the life history of the plant, its cul- 


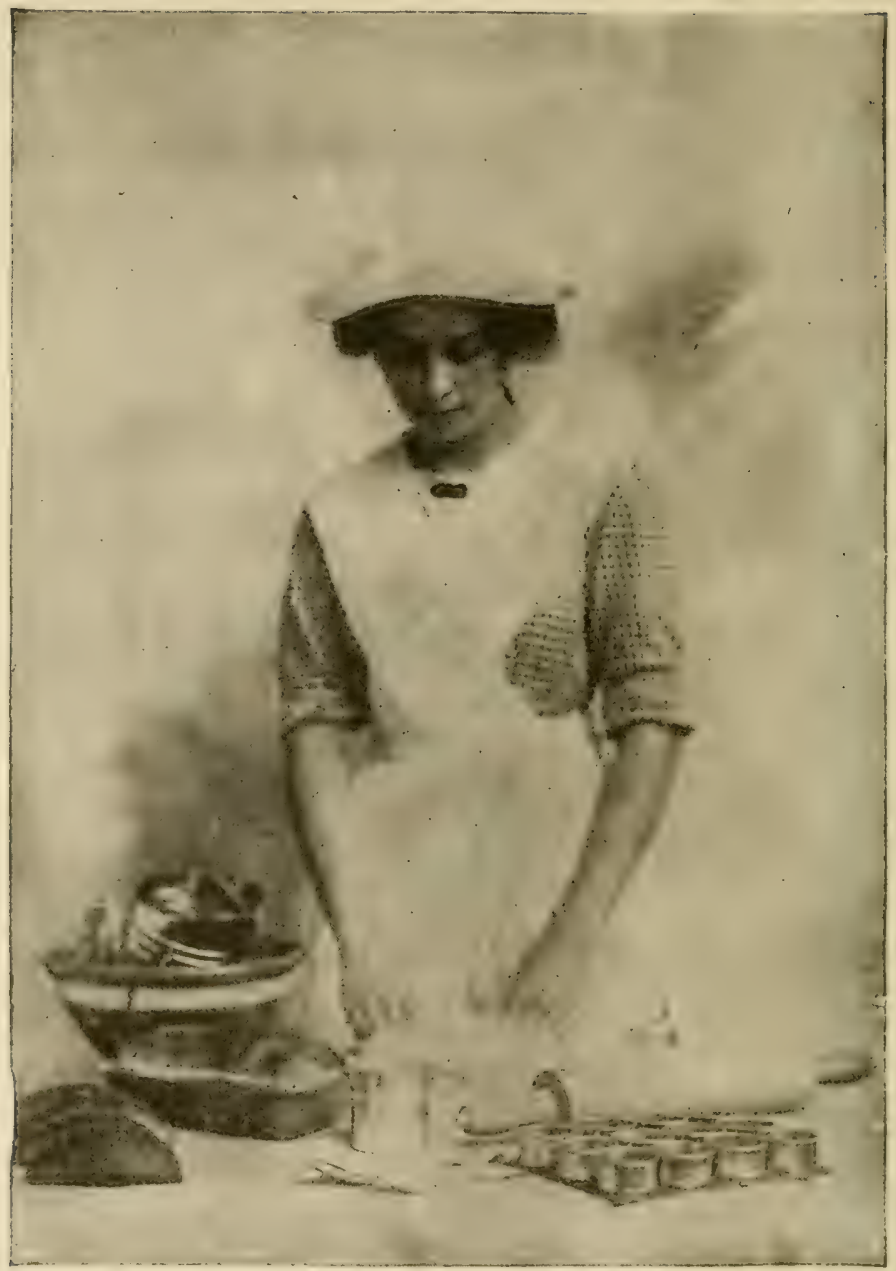

A club girl with her baking of bread. 
tural methods, and its use for food products. In connection with domestic-science work, the girls can prepare for exhibit purposes the various dishes possible from the oat and bake a loaf of wheat bread for the school exhibit each month. This makes an interesting demonstration for Friday afternoon programs.

For a basis of award in prize contests or for credit ratings on home projects and the club work, we suggest that you secure recommenlations of your Supervisor of Agricultural and Home Economic Education in your state, and also get help from your State Learler of Boys' and Girls Extension Work. In the absence of their aid, the following will be helpful:

\section{Home and Club Project Score Card}

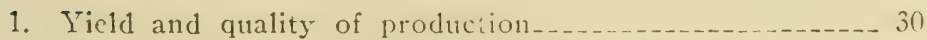

2. Net profit on investment

3. Exhibit of grain and materials_____

4. Crop records and story of work-__..._- 20

Total score, if perfect

\section{Suggestions}

Have members of the class outline a set of ten demonstrations with "oats," five play contests. Have them stage and carry out some of the demonstrations and contests. See suggestions of demonstrations and play contests with "corn" and other chapters. 


\section{CHAPTER IV}

\section{THE POTATO}

TE common white, or Irish, potato is a native of South 1 America. It was brought to North America by the early Spanish settlers. Potatoes are now so important an article of food in almost every country that little more than one-twentieth of the world's supply is grown in the United States.

\section{The Potato Plant}

Secure, if possible, a complete potato plant, including the roots and tubers. What is the shape of the stem? The nature of branching? The type of leaves? The flowers? Do potatoes bear seed? Are potatoes raised from sced? Why not plant potato seed instead of the tubers? Are the tubers a part of the root system, or do the roots only bear the tubers as the stems of tomatoes bear the fruit? Compare a potato plant and a tomato plant.

The plant.-The potato plant varies from two to four or five feet in height, though it does not show this great a height owing to its spreading habits of growth. The terminal clusters of flowers bear seeds, from which new varieties are often developed. For practical purposes the plant is reproduced from the tubers.

Though both plant and roots die upon the ripening of the seed and tubers, the potato is a perennial through the tuber which reproduces the plant. Since the tubers are 
destroyed by freezing, they are harvested before frost. Potatoes are annuals in all regions where the soil freeze: during the winter.

Tubers.-Examine a tuber. Note the distribution of the "eyes." These contain the buds from which the new plants are produced. The end at which they are thickest is called the "seed" end, and the other the "stem" end. At which end is the tuber attached to the roots of the plant? Are some potatoes more deeply indented at the eyes, and more irregular in shape than others? Which are more desirable for cooking? Why? Which have the better market demand?

Though there are hundreds of wild plants belonging to the same genus as potatoes, comparatively few of these are known as cultivated plants. Among the most closely related cultivated plants are the tomato and tobacco, which belong to the same family.

\section{Potatoes as a Farm Crop}

After corn, cotton, hay, wheat and oats, potatoes are one of our most valuable crops. They are raised in every state, though the chief potato region consists of ten or fifteen northern states reaching from the Missouri River eastward to the Atlantic. More than three million acres are planted to potatoes in the United States each year. The annual crop is nearly three hundred and fifty million bushels, or about four bushels to every inhabitant.

The potato region.-The following are the fifteen states which, according to federal statistics, produced the largest amount of potatoes for the period 1902-1911, together with the percentage of the entire crop of the United States grown by each: 


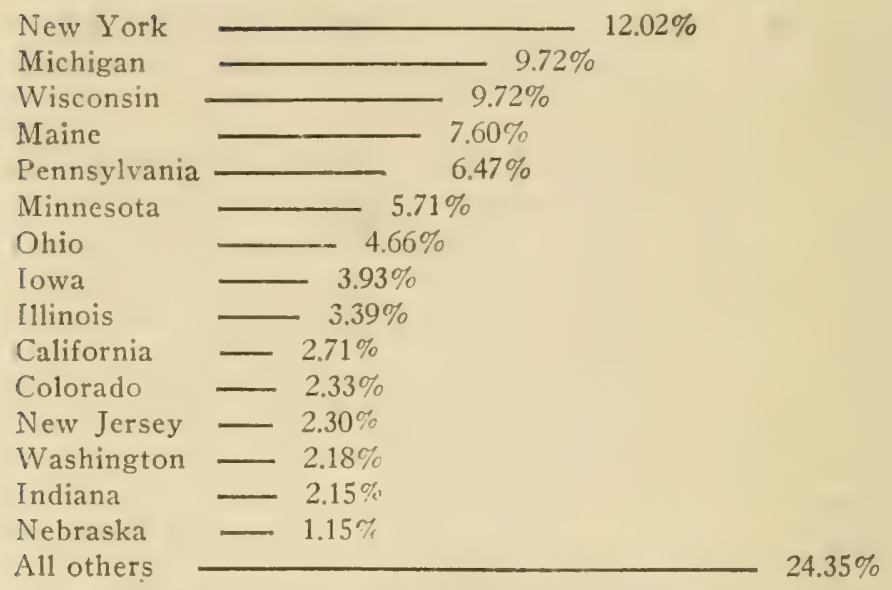

The yield.-Potatoes, like other crops, vary greacly in yield owing to differences in the fertility of the soil and the care taken in raising the crop. The average for the United States during the last ten-year period has been about ninety-six bushels to the acre. It is somewhat humiliating to know that, in spite of our improved machinery and scientific knowledge of the soil and plant diseases, we are now securing only about the same yield of potatoes that was produced at the close of the Civil War. Experts tell us that this yield car easily be doubled, with comparatively small expense and trouble.

\section{Raising the Crop}

The soil.-Potatoes thrive best in a rich sandy loam containing a good supply of humus. Hard stiff soils or heavy clay are not well adapted to potato raising. The best soil $\mathrm{cn}$ the farm should be devoted to the potato field, both becanse potatoes demand a better soil than most other crops, and because the value of potatoes per acre is greates than almost any other common crop. 
Ground that hąs recently raised clover, alfalfa or some other legume is especially suited to potatoes. While barnyard manure will greatly increase the yield, it will also favor the ravages of scab and other potato diseases, and so lower the quality of the crop. It is usually a mistake to plant potatoes on a freshly manured field. If manure is used, it is better to follow a heavy manuring with a crop of corn, and then plant potatoes for the next crop in succession.

Green manuring, that is, the plowing under of green crops such as clover or alfalfa, will add greatly to the yield. If the sod is old, it is usually better to grow one crop of corn before potatoes are planted on the field. Commercial fertilizers can be used to advantage for potatoes on most soils.

The seed bed.-Potatoes should have an especially well prepared seed bed. The plowing shouid be deeper than for most crops, since the seed is planted deeper and loose soil must be had for the roots and tubers. In average soils the plow should be set to a depth of not less than eight inches.

The seed bed must be well pulverized and thoroughly packed. Usually not less than four harrowings and diskings are required for the best results. Experiments have shown that the difference in yield caused by harrowing part of a field four times and the remainder of it but twice may be as much as twenty per cent. of the crop in favor of the better preparation.

The planting.-Potatoes should be planted not less than four inches deep. I.ess than this depth does not give room for the tubers to grow without protruding from the ground. This is sure to result in injury from sunburn. Most potato growers drill the seed, dropping single pieces of seed from twelve to fifteen inches apart in the row. In 
some regions potatoes are planted in cross rows like corn, with three cuts of seed to the hill.

The date for planting differs in various regions, but the greater part of the crop in the northern states is planted during the last half of May. From twelve to twenty bushels of seed are required for an acre, depending on how the tubers are cut for planting. Where crops of any considerable size are raised, the dropping is usually done with a horse planter, some makes of which are arranged to distribute commercial fertilizer at the same time.

Cultivating the crop.-Potatoes demand good cultivation. Harrowing should be done before the potatoes are up. From one to two harrowings may be given after the plants appear. Throughout the growing season a fine soil mulch should at all times be maintained by means of frequent cultivation. Especially after a rain should the soil crust be broken. The cultivation should be rather shallow, and potatoes should not be hilled up as is so often done.

Harvesting the crop.-When the vines have died the potatoes have stopped growing and the crop is ready to harvest. In the case of small fields, potatoes are often harvested by being plowed out with an ordinary plow, the tubers being picked up by hand, and the field afterward harrowed to uncover any that have been missed.

In regions where potatoes are grown in large quantities the digging is done with machines, several kinds of which are now on the market. The average machine will turn out about three acres in a day, and will require from five to ten pickers to keep up with it.

Storing the crop.--In order to keep well, potatoes must be stored in a cool place. The house cellar is usually too warm for them, and they also give out an unpleasant odor that permeates the house. A common type of vegetable cellar to be found on many farms is built 
with concrete or stone walls, the excavation being made on a side hill. It is covered with a shingle roof, and has is board floor on a level with the ground at the upper side. thus making an excellent tool and machinery house over the space used for vegetables.

\section{Improvement Through Selection of Seed}

One of the first factors in successful potato growing is the securing of good seed. Without this, fertility of soil and careful cultivation are largely wasted.

Good seed will possess the following qualities: It must (1) be pure, that is, free from mixtures of varieties; (2) be takęn from producticic plants, or "hill selected"; (3) be uniform in size and shape; (4) be firm and sound, not shrunken or decayed; (5) be entirely free from disease; (6) not wholly mature when harvested; (7) have sprouts just showing at time of planting.

It has been estimated by experts that attention to these points would add at least ten per cent. to the potato crop each year. This would mean an increase of nearly thirtyfive million bushels, worth about $\$ 21,000,000$ annually.

Pure seed.-Mixed varieties present several disadvantages in potato growing. The crop will not mature evenly. Thus, when the earlier variety has ripened and is ready for the market or table, the later one will have the 1 statoes just setting, and unfit for use. Nixed varieties do not cook evenly, and when baked or broiled together some will be overdone before others have softened. General mixture of varieties in potatoes as in other crops tends to degeneration and running out of the breed.

Seed from productive plants.--Seed should be taken only from the strongest and most productive plants, no matter what the variety. This can not be accomplished by 
selecting seed fiom the potato bin, any more than the best seed corn can be selected from the crib or wagon. For a certain tuber may itself be of good size and look promising, but have come from a plant that produced but one or two potatoes, or that grew only one tuber of fair size, with several culls.

The most successful method of developing high-grade seed potatoes is what is called the tuber-unit method. This consists of selecting from the seed bin a quantity of the most perfect tubers, each to weigh from six to eight ounces. These are cut for planting by splitting the tuber into four quarters, from seed end to stem end.

The tuber-unit method.-The four pieces of each potato are planted in succession twelve inches apart in the row. A longer space is left between the sets of fours, thus making it possible to watch the outcome of each tuber by itself. Before the plants begin to die, careful inspection is made, and any mixtures, imperfect or weak plants are marked for rejection. Only the most promising and uniform are reserved for the selection of seed.

When the crop is harvested, each set of four is dug by itself A further selection is made by rejecting the total product if any one of the four plants has failed to produce uniform, desirable tubers. The potatoes produced by each set of four selected for seed are put into separate sacks and kept for further examination.

Second season of tuber-unit planting.-Finally, the contents of each sack are inspected for the weight of marketable and unmarketable tubers, and other desirable qualities of the type. From each of the four-plant units the best ten tubers are to be selected for the next year's planting. This selected seed is planted the following year in the same way as the first season, thus giving forty plants to the unit instead of four. The product from the best forty- 


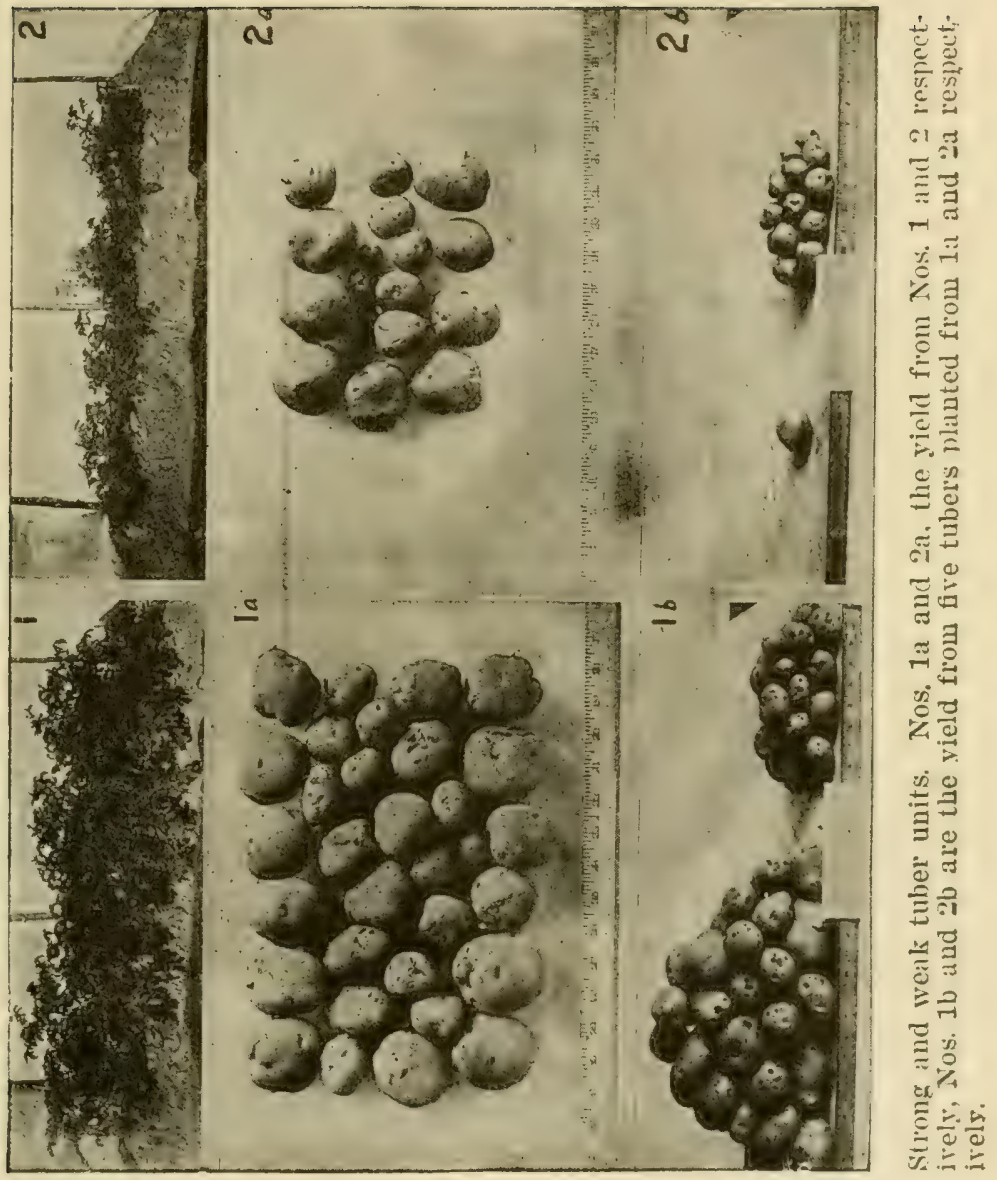


hill rows is kept for seed for the general crop for the following year. By thus keeping a breeding plat for seed, potatoes can be greatly improved, and the yield much increased.

The tuber-unit method can be rendered even more effective by making the first selection from the field instead of the potato bin. This is done by going into the field before the vines begin to die and marking a number of the most vigorous and desirable plants. These are harvested separately before wholly mature, and seed taken from the best hills.

The practise of planting for seed the small and unmarketable potato culls can not be too strongly condemned. It lessens the yield, lowers the quality of the crop and causes the variety to deteriorate.

Cutting seed potatoes.-Whether it pays better to cut potatoes for seed or plant the whole tuber has been much discussed. It is believed by many potato growers that under average conditions the yield will be greater when quarters are planted than when pieces with single eyes are used, and that halves will produce more than quarters. It is not sure that whole tubers will produce a larger yield than halves. The weight of experience seems to favor planting halves.

Immature seed.-For vitality, high yield and good markec qualities, potatoes intended for seed should be harvested before entirely ripe (by hill selection) that is, before the vines have died. Many experiments have shown that immature seed will produce a considerably higher yield than seed allowed to ripen before digging.

Home-grown seed not always best.-Contrary to the rule with most farm crops, seed brought from another region often produces a better crop of potatoes than home- 
grown seed. Especially is this true when northern grown potatoes are taken farther south. Not only is the yield increased, but the time required for maturing is shortened by securing seed trom colder regions. Great care should be taken in importing seed tubers not to introduce new forms of potato diseases.

\section{Potato Enemies}

Potatoes have many enemies, and the number seems to be increasing, owing to diseases being brought in from other countries.

Scab.-Scab is one of the most wide-spread and destructive of potato diseases. It causes a rough, pitted, scabby condition which may attack the tuber in patches, or extend over the entire surface. Whether scab is caused by a fungous growth or a species of soil bacteria is not certain. It is fortunate, however, that a very simple and effective remedy is known. This consists in treating seed potatoes before planting.

There are several mixtures used for this purpose, the cheapest and most easily applied of which is a formalin solution. This is prepared by mixing one pint of formalin with thirty gallons of water. The seed potatoes are soaked in the solution for two hours, and then planted without allowing them to come into contact with bags or utensils in which scabby potatoes have been kept.

Leaf, or early blight.-Leaf blight is another common potato disease. It attacks the leaves and stems, first showing about the time that the tubers begin to form. Its presence may be detected by the presence of grayish brown spots on the leaves, the part of the leaf attacked soon becoming hard and brittle. Within three or four weeks the leaves are all killed, and the stem is also affected. The tubers 


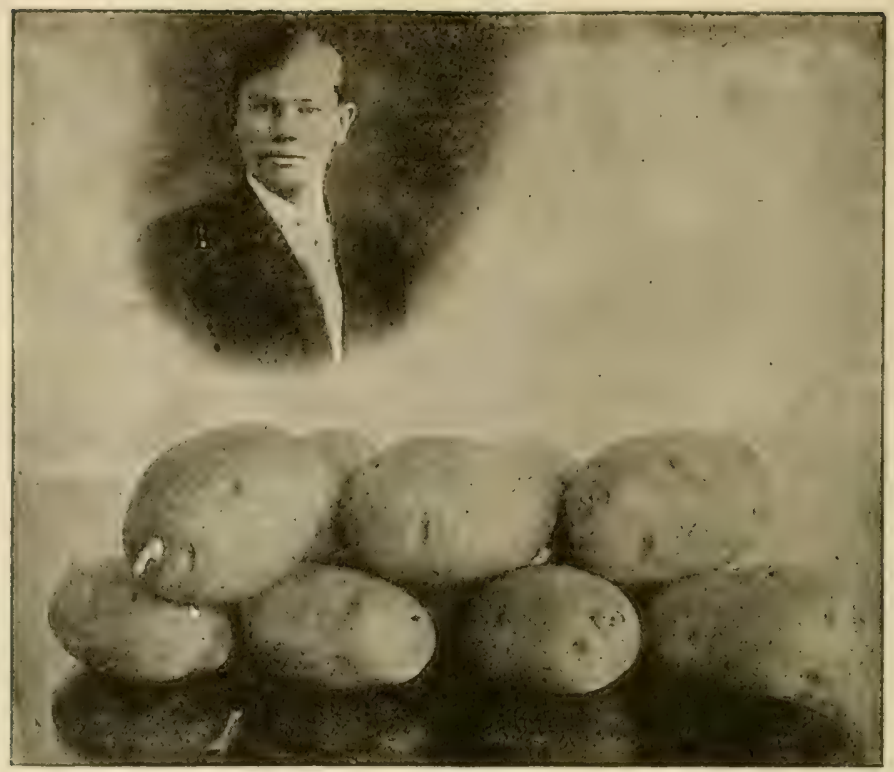

Club boy, and prize seed potatoes, sprouted enough for planting.

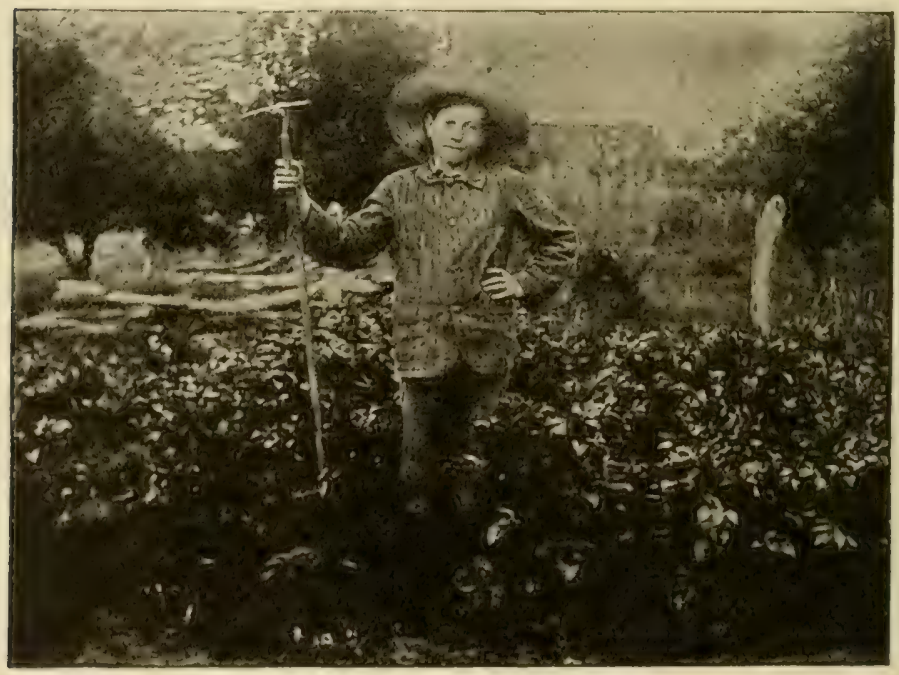

A potato club boy from Massachusetts. 
grow but little after the leaves are first attacked; hence the crop is ruined unless the blight can be checked.

The ravages of leaf blight can be almost if not wholly prevented by spraying the plants with the Bordeaux mixture (see page 208). This solution is applied with a spraying machine at the rate of about fifty gallons to the acre. From three to five sprayings during the season are required when leaf blight threatens. One pound of Paris green to the acre at the first spraying, and the same amount later in the season will also destroy the potato beetles, which often prove such a pest.

Late blight, or rot.-The blotches and blackish streaks often seen running through tubers are caused by late blight, or potato rot. This disease first attacks the leaves and stems, causing them to soften and decay, producing a bad smell. Late ilight often appears suddenly, and spreads through a field with great rapidity. A green. healthy-looking field may turn almost black in a day or two.

The treatment for late blight is the same as for leaf blight, and should never be neglected in regions where blight is common. It is far better to begin the spraying before either form of blight begins to appear, for this is the easiest time to prevent it.

\section{TOPICS FOR INVESTIGATION}

1. What is the acreage of potatoes raised on your home farm this season? If you are not certain, go out and measure the field carefully. Compare the acreage of each of the farms represented in the school.

2. What is the yield of your potatoes per acre? How does this compare with the other farms of your vicinity? With the state? With the United States?

3. Select two medium-sized potatoes, one regular, smooth and with shallow eyes, and the other irregular and with deep-set eyes. Weigh each. Pare both potatoes, as 
nearly the same as possible. Now weigh the pared tubers. Which lost the larger percentage in paring? Which is easier to pare? Which looks more pleasing for the table? Which would be the better to select for seed?

4. Bring a sample of as many different varieties of tubers as can be found in your neighborhood. Learn to recognize the chief breed characteristics so as to identify the different varieties, such as Early Rose, Bliss Triumph, Early Ohio, Gold Coin, Burbank, Rural New Yorker, Walter Raleigh. What are the principal early varieties? Late varieties? Do you find mixtures in which it is impossible to determine the varieties?

5. Select tubers of the same size from different varieties, such as Early Rose and Rural New Yorkers. At your homes try boiling them together. Do they cook in the same time? Try baking, frying, etc.

6. How deep does your father plow the ground for potatoes? How deep does he plant? Does he use commercial fertilizers? Does he manure the field for potatoes? If so, is the crop scabby?

7. What plan is used in selecting seed for your potato crop? Are culls ever used for seed? Is there any more reason in using small potatoes for seed than in taking seed corn from nubbins?

8. Suppose that seed potatoes are seventy-five cents a bushel, and that when quartered twelve bushels are required to plant an acre; also suppose that by planting halves instead of quarters the yield is increased twenty bushels per acre, and that the new crop sells at sixty cents a bushel. Which way of cutting seed is best, and by how much an acre?

9. Bring samples of potatoes affected by scab; by rot. Study the effects of each on the tuber. Secure if possible samples of plants affected by blight, and learn to identify the disease. What is the most troublesome potato disease in your region? What is the remedy?

10. After talking with your father about it, itemize the cost of raising an acre of potatoes. Compare this with the cost of producing an acre of corn; an acre of wheat or oats. Now, taking the average yield of each crop, compare the profit of potato raising with that of other crops. 
Would it not be possible to double the yield of potatoes per acre in your region? How would you go at it?

11. Illustrate how to keep a book account of an acre of potatoes from the preparation of the seed bed to the harvesting and marketing of the products. Include items of expense in regard to yield, selection of seed potatoes, grading, crating, marketing, and use of a special brand or label.

12. Make a map study of the United States, showing the location of the potato sections and insert the last census crop report on potato production in these states.

\section{Potato Demonstrations}

1. Demonstrate how to select seed potatoes from the hill.

2. How to prepare seed potatoes by cutting for seed.

3. How to manufacture potato starch out of culls and injured tubers.

4. How to grade and crate potatoes.

5. How to prepare potatoes in various ways for use in the home.

\section{Potato Play Contests}

1. Potato race.

2. Potato paring contest, based on time, skill and weight of peeling, using twelve uniform tubers.

3. Potato judging contest.

4. Variety naming contest.

5. Oral recipe contest. How to use the potato for home diet.

\section{Potato ᄃlub Project}

One of the most interesting field or garden crop projects is in connection with the production and management of a plat of potatoes. This can be taken up uniformly by both boys and girls, using not less than one-eighth acre as a basis. 
The club.-The study and practise in the work are to be based on the entire management of the club plat, including treatment for diseases and insects, grading, crating, marketing, manufacturing of potato starch, study of the life history and the relation of the potato to the various activities and studies of the schoolroom.

Club festival.-A potato club festival, covering all the interests of potato culture in the community, with the exhibits of both fresh and cooked products, lectures on potato culture, etc., can be made one of the big events of the fall term, to which all the patrons of the school can be invited. The Award.-The basis of award should be as follows :

1. Yield - -

2. Net profit on investment_________-_._- 30

3 Exhibit of products (fresh and cooked)

4. Crop report and story

Total Score 


\section{CHAPTER V}

\section{FORAGE CROPS}

UR study so far has dealt mostly with the cereals--the crops raised chiefly for their grain. We now come to study the distinct types of forage crops, or those grown for their leaves and stems, which are fed to stock. Besides serving them as food for animals, certain forage crops are of great value in enriching the soil and causing it to produce larger yields of cereals.

When the forage plants are fed green by grazing, we call the crop pasture; if cut, and at once fed green without allowing time to cure, it is called a soiling crop. If the crop is cut and allowed to cure before feeding it, it is called hay, straw', fodder, or stower as the case may be. We have already noted that a forage crop, cut and stored so that it will keep green, is called silage or ensilage.

\section{Important Forage Crops}

The most important forage crops may be divided into two broad classes, grasses and legumes.

Grasses.-The grasses are among the most widespread and important of our plants. They include an almost endless variety, many of which grow without cultivation, or even special seeding, the seed being carried by the wind, birds and in many other ways.

Among the most important grasses grown in the northern states are timothy, blue-grass, the millets and red-top. Common to the southern states are Bermuda grass, carpet grass, Lespedeza, Johnson grass, orchard grass and bromegrass. 
It must not be forgotten that our great cereals, corn, wheat, oats, barley, rice, rye, etc., also belong to the grass family.

While there are so many varieties of grasses, they possess certain characteristics in common. For example, practically all grasses bear their seeds either (1) in a spike, like wheat, barley or timothy; or else (2) in a panicle, like oats or blue-grass. Most of the grasses have hollow stems, with nodes, or joints, dividing the stem into sections.

Some of the grasses are anmuals; that is, they make their growth, raise seed and die all in one season, as oats, corn, or wheat. Other grasses are perennials; they live on from season to season without replanting, as timothy, blue-grass, or Bermuda grass.

Legumes.-The legumes differ from grasses in that they bear their seeds in pods, like beans and peas. These pods vary in form from the close, nearly straight pod of the pea to the curled pod of alfalfa. When the seed is ripe, the pod splits open, and the seeds scatter. Most legumes branch more freely than grasses and also send their roots more deeply into the soil.

Some of the most important legumes are the clovers, alfalfa, soy-bcans, coimpeas, the retches, and the ordinary garden peas and beans.

The legumes differ widely in their manner of growth, ranging all the way from small herbs like clover, to various vines, shrubs and even trees. Some of the legtimes are annuals, some are biennials, and others perennials.

\section{Importance of the Forage Crops}

Forage crops in the United States rank next in value after corn and cotton. The total acreage of improved pastures and harvested forage crops is considerably more than all the grain crops combined. 
The forage producing region.-The most important forage producing region of the United States is found in the north central states, reaching from Michigan and Ohio on the east to Kansas and Nebraska on the west. The last federal census shows the percentage of forage crops of the United States produced by each of the states of this region as follows:

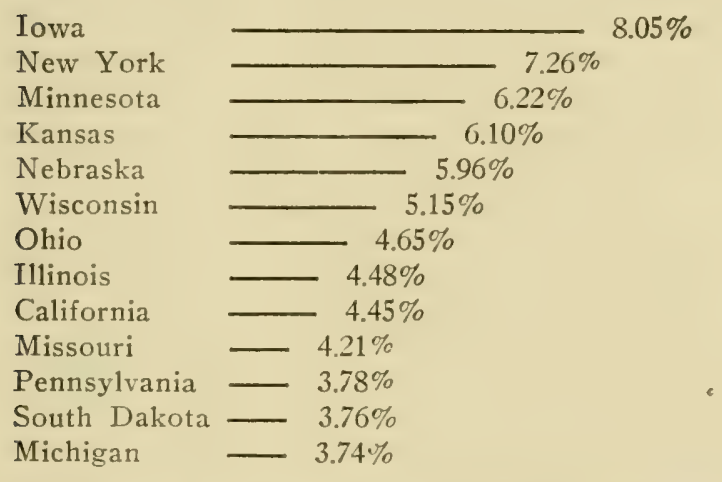

Uses of grasses and legumes.-Grasses and legumes have two principal uses: (1) they supply the most important part of the food of farm animals, and (2) they aid in building up the soil, making it productive for other crops. They are also serviceable in saving the soil from washing and blowing.

A great proportion of our cattle, horses, sheep and hogs are raised with forage as their chief food. Where good pasturage is available, little or no grain is fed to growing stock, and often none even to milk cows. And wher grain is used to fatten stock, or to give strength, as in the case of work horses, forage is required to supply the volatile oils as well as bulk and coarseness necessary to digestion.

Both grasses and legumes tend to improve the soil. 
Their decaying roots, stems and leaves form an important part of the soil, called humus. This vegetable matter not only enriches the soil, but makes it lighter and more porous, so that air can better get to the roots of growing plants. It also favors proper drainage in damp soils.

Legumes and the nitrogen of the soil--Legumes, however, enrich the soil in a special way, and are widely cultivated for this purpose. In order to understand how legumes do their work of improving the soil, it must be known that plants demand certain foods from the soil. One of the most necessary plant foods is nitrogen. If this is lacking in the soil, the crop does not grow well, and the yield is reduced. For example, wheat takes much nitrogen from the soil; this is the main reason why wheat can not be grown on the same land year after year. The nitrogen becomes exhausted. The soil is "worn out." It is estimated that a twenty-bushel crop of wheat removes about thirtyfive pounds of nitrogen from each acre.

Nitrogen may be returned to the soil in several ways. One of the most common ways is by means of barnyard manure, which is rich in nitrogen. Another way is through commercial fertilizers, such as sodium nitrate, ammonium sulphate, or dried blood saved from slaughter-houses. But the amount of manure is limited, and the commercial fertilizers are expensive. And this is where the legumes come in to help. Legumes are able to gather nitrogen from the air and deposit it in the soil.

There are millions of pounds of nitrogen in the atmosphere resting on every acre of ground. But the plants can not make use of this nitrogen in the form in which it exists in the air. It has to be made over for them. This is accomplished by bacteria which have their homes in the tubercles or nodules found on the roots of leguminous plants. 
In the small tubercles to be seen on the roots of clover, alfalfa, soy-beans or cow-peas are millions of bacteria, each able in the process of its own growth to take nitrogen from the air, change it into the form needed by growing plants, and leave it in the soil for the next crop. In this way the legume is able not only to secure its own growth, but to leave the soil richer through the action of its bacteria friends. The raising of legumes is therefore one of the best and most economical ways of enriching the soil. So important is the group of legumes that a separate chapter will be given the most important ones.

\section{TOPICS FOR INVESTIGATION}

1. What are the chief grasses used for pasturage in your neighborhood? For hay? For lawns?

2. What are the principal legumes cultivated in your vicinity? Which are annuals? Which are perennials?

3. Make a collection of the principal grasses found on your father's farm. Study their method of growth. Compare stems, leaves, roots, and method of seed bearing.

4. Make a similar collection and study of the common legumes.

5. Secure the roots of clover, of alfalfa, of peas, beans and any other available legumes. Make a study of the tubercles, comparing size and number. The bacteria are too small to be seen except with a powerful microscope. The tubercles are most plentiful in the early part of the growing season.

6. Illustrate how a bookkeeping record can be kept of the various types of forage crops, such as alfalfa, cowpeas, red and crimson clover, blue-grass, etc.

7. Nake a study of the map, locate the principal forage territories, and indicate the various types of grasses and forage crops that are being produced in the different sections. Indicate in each state the acreage allotted to each type of forage.

8. Indicate what kind of stock thrives best on certain forage crops, and tell why. 


\section{Forage Demonstrations}

1. Demonstrate how to prepare and make exhibits of the various types of grasses, legumes, plants, etc.

2. How to make a grass seed test.

3. The difference between a good and a poor grass seed head.

4. Show how grass seed should be sown and what constitutes a good stand.

5. Demonstrate how tú make different things in connection with the forage crops, such as haycocks, stacks, and how to cut hay with the scythe.

\section{Forage Crop Club Project}

In many schools it will be practicable for boys and girls to organize into clubs for the purpose of growing and demonstrating the possibilities of profitable farming in alfalfa, red clover, crimson clover, cow-peas, beans, etc. The age requirements should be the same as in other clubs. The area of the plot should not be less than one acre and may be more, depending on the size of the field available for club work.

The award.-The basis of award should be:

1. Average yicld per acre-_-_-_- 30

2. Net profit on investment_._._. 30

3. Exhibit of products (hay and seed)

4. Crop report and story-_-_._._. 20

Total score - -

For most localities the four most important forage crops in which to organize clubs would be alfalfa, clovers, cowpeas, and blue-grass sod for the lawn. 


\section{CHAPTER VI}

\section{THE CLOVERS}

CLOVERS are the most widely grown family of legumes among the farm crops. There are many different types of clover, such as red clover, white clover, alsike clover and crimson clover. By far the most important of these is the red clover, especially throughout the northeastern quarter of the United States. The great red-clover section reaches from Maine to Virginia, and as far west as the Missouri River. Either alone, or mixed with grasses for hay and pastures, red clover claims from one-eighth to one-third of all the cultivated land throughout the eastern and north central states. It is now also being successfully grown in Montana, Washington, Oregon and in the far Southwest.

\section{The Red-Clover Plant}

Red clover is so common a plant that it can usually be studied near at hand in the field. Every pupil should therefore examine the growing plant, and bring a complete specimen, including the root, to school for further reference. Also secure a plant of timothy, the grass that is commonly grown with red clover.

\section{TOPICS FOR INVESTIGATION}

Study of the red-clover plant.-Compare the clover and timothy plants (1) as to root systems, (2) stem and mode of branching, (3) mode of flowering and seed bearing. 


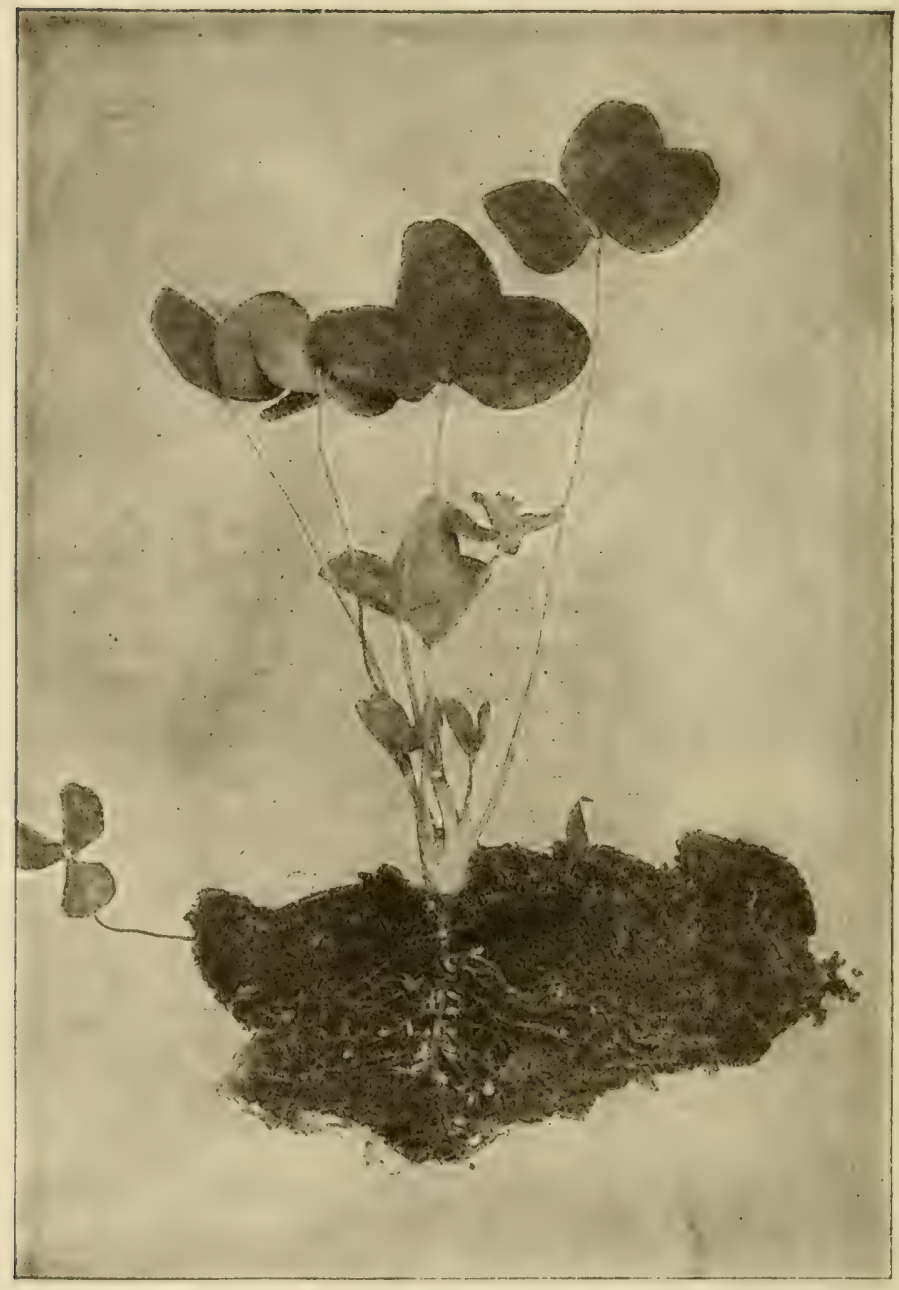

A Jouug red-clover plant, showiug the characteristic nodules on the roots. 
1. Which has the longer roots? Which will make the denser sod? Why? Do you find any tubercles on the roots? Is the stem of either hollow? Jointed? Which stands more erect? Why? What is the difference in their leaves? Which bears the larger number of seeds to the head? The larger seeds?

2. After red clover has been cut, from what part of the plant does the new growth start? How many cuttings a season can usually be made of red clover? Which cutting is used for the production of seed?

3. What is the shape of the individual flower of the red clover? How many flowers to the average head? How many seeds does each flower bear? What is the shape of the seed? Learn to identify it when mixed with the weed seeds most commonly found in red clover, such as trefoil, curled dock, wild mustard, dodder, or others.

4. Write an accurate description of the red-clover plant, so that one who has never seen the plant could identify it from your description.

\section{Value of Red Clover on the Farm}

Red clover as forage for stock.-Red clover makes an ideal forage crop for all classes of farm stock. Besides being highly palatable, it contains a large proportion of protein, one of the most necessary elements of food for animals. So essential is protein for the growth of animals and the production of milk and butter, that bran, oil meal, and cottonseed-meal are commonly fed to supply this element. Where red clover can be successfully raised it largely takes the place of these more costly foods, and at the same time supplies the roughage needed by all animals. When grain is fed, as to chickens, hogs or cattle, red clover, either green or cured, forms a most valuable item of food.

The worth of clover as an animal food has not been fully understood. It has been computed by experts that a ton of red-clover hay has almost two-thirds as much feed- 
ing value for farm stock as a ton of wheat bran, and more than two-thirds the feeding value of a ton of shelled corn.

Red clover as a soil renewer.- $\Lambda$ s a soil stimulant and fertilizer red clover is almost without a peer except alfalfa. By its use in the rotation of crops, it is possible to keep the supply of nitrogen and humus almost undiminished in the soil, throughout years of cropping. The bacteria living in the root tubercles transform atmospheric nitrogen into soil nitrogen and leave it for other crops. The roots and stems, decaying, add to the humus.

At the average price for commercial fertilizers often used to enrich land, a ton of clover is worth nearly ten dollars to plow under as a fertilizer. Fields which have been in red clover frequently produce ten bushels more of grain to the acre than before the clover was grown.

In the use of clover as a fertilizer it must be remembered, however, that clover adds to the soil chiefly nitrogen and humus; and that if the crop is all removed each year, none being plowed under and no manure returned the amount of nitrogen humus in the soil is increased but very little. Potash and phosphorus, two other plant foods often failing in worn soils, must be supplied either by the use of commercial fertilizers or barnyard manure.

\section{The Raising of Red Clover}

Red clover will grow successfully on any soil that will raise corn. Soil that is wet and heavy or lacking in humus will not produce a satisfactory stand of clover. Red clover has a remarkable root system, sending its main roots down as deep as six or eight feet in favorable soil. This enables plants which have received a good start to withstand considerable drought.

The seed bed.-The seed bed for clover should be 


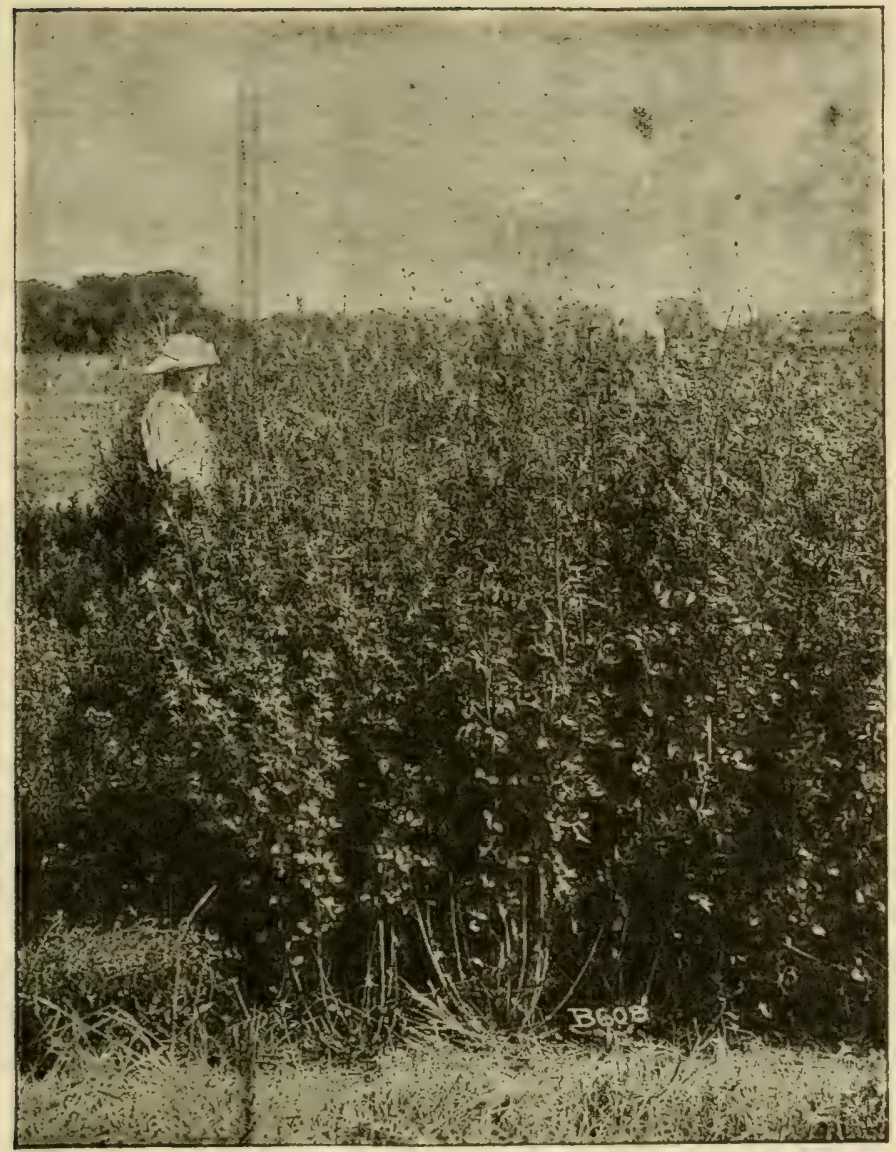

Sweet clover on an Iowa farm. 
fincly pulverized, hut well packed. If sown on freshly plowed land, it is necessary to harrow until the ground becomes firm, else a poor stand is sure to follow. The ground should be clean, as clover is not a good fighter of weeds.

Red clover may be sown in the early spring on fields of winter wheat. In this case no preparation of the seed bed is required. The covering of the seed may be accomplished by weathering. A more certain way is to harrow the wheat after the clover has been sown, or even both before and after the seeding of the clover. This does not injure the wheat. Red clover is also often sown in the spring with oats as a nurse crop.

Another common method of seeding red clover is in standing corn just following the last cultivation. This plan has worked successfully, especially in the New England states. If the crop of corn is heavy enough to shade the ground, or if the fall happens to be dry, a successful stand is uncertain.

Time of sowing.- In the larger part of the red-clover region, it does not seem to matter greatly whether the clover is sown in the spring or the fall. Which time is better depends on the season. Young clover plants do not easily withstand drought. If a dry season follows the seeding, the stand will not succeed no matter when the planting is done.

In spring seeding with a nurse crop of winter wheat, the clover shuthld be sown at the carliest possible moment. If the gromul is not to be harrowed to cover the seed, it may be sown on a late fall of snow. This gives the clover plants the advantage of a start before the moisture is out of the soil, and also before the nurse crop gets large enough to shade the young plants.

If the seeding is done in the fall, the crop should be 
sown early enough that the clover plants attain a growth of from four to six inclies before freezing weather comes

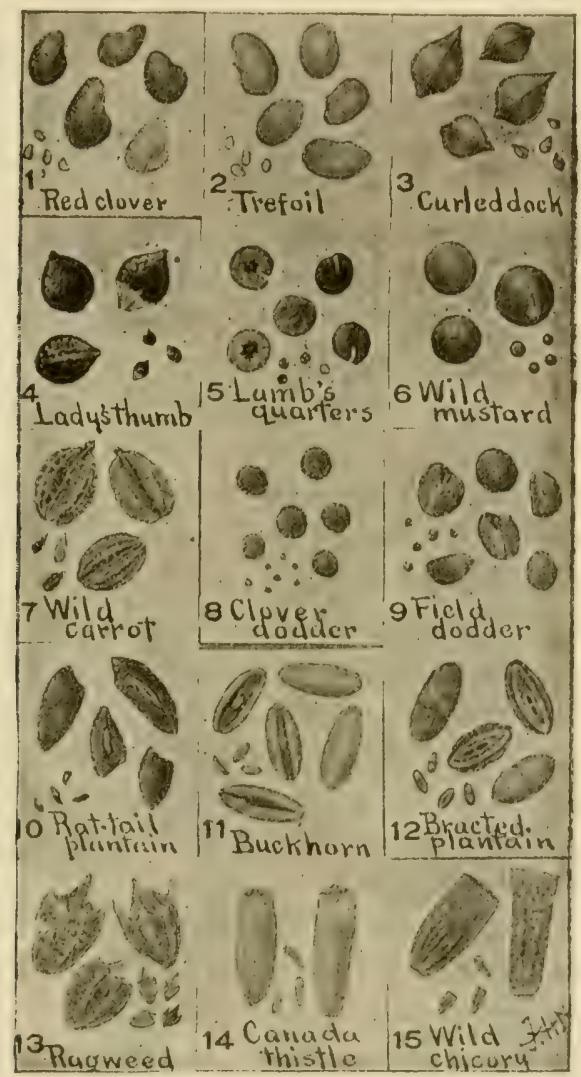

Seeds of red clover and common impurities.

on. ()therwise they may not be able to live through the winter, especially in the northern states. Secling after August fifteenth is unsafe in the northern states. 
Clover seed.-A great deal of the trouble found in securing a good stand of red clover comes from poor seed. Good red-clover seed should (1) be plump, and not shriveled; (2) look bright instead of dull; (3) vary in color from violet to light yellow, but not be a dull brown; (4) show individual seeds medium to large size; (5) be free from all weed seed and rubbish; (6) be free from what is called "hard" seed. By hard seed is meant grains whose seed coat is such that the seed absorbs moisture but slowly and hence may not germinate for several weeks or even months. The seed of very new varieties may contain as much as fifty to sixty per cent. of hard seed.

As is the case with most other farm crops, it is safer to secure clover seed from near home than from a distance. In this way one may be sure that the variety is adapted to the vicinity, and that the seed does not contain noxious weeds and other impurities.

Cleaning red-clover seed.-Ordinary red-clover seed contains many different kinds of weed seeds. Some of these look enough like clover grains that they may pass unnoticed. Sowing clover mixed with weeds not only reduces the stand of clover, but compels the clover to divide its moisture and food with its worst enemies, besides rendering the ground foul for other crops.

Screening red-clover seed through a sieve with twenty meshes to the inch will remove all the smaller weed seeds, while retaining the medium-sized and larger clover grains. Seeds of wild carrot, ragweed, thistles, buckthorn, wild chickory, and several other weeds bearing large seeds are not removed in this way. Clover seed should first of all be selected from a field that is as free as possible from weeds. Even then, screening will pay, however, for the removal of the smaller clover and weed seeds. 


\section{Harvesting the Red-Clover Crop}

Red clover should be cut for hay just as it is past full bloom. If cut much earlier than this the entire food value of the plant is not obtained; if it is allowed to stand too long the leaves begin to fall, and the stems become dry and stiff. If the second crop is to be cut for seed, it may be necessary to cut the first somewhat early.

The care of clover hay.-In stacking or mowing the hay in a barn, the important thing is to avoid exposure to the weather, or becoming dry enough so that the leaves crumble and are lost. For the leaves of red clover, while they are only about forty per cent. of the weight of the plant, contain almost two-thirds of the protein of the whole plant. Clover hay that has become too dry is also very dusty, and not so good for feed.

Red-clover hay does not shed rain so well as the grass hays, and should therefore be stored in a barn where possible. If it must be put in stacks, these should be built with the greatest care, keeping the middle of the stack full and well tramped. The top should be covered with canvas, or with a coating of grass or straw.

Care must be taken not to put red clover into the barn or stack when it is damp from dew or rain, as it has a tendency to heat. This heating not only damages the hay, but not infrequently sets fire to the stack or barn and burns it down.

Harvesting red clover for seed.-Red-clover seed is usually secured from the second crop of the season, the first being harvested for hay. The clover is cut either with a mower or a special header, and run through a clover huller. By special adjustment an ordinary thrashing machine may be used for hulling the seed. Clover straw still possessis good feeding value after the seed is removed. 


\section{The Enemies of Red Clover}

In the starting of the clover crop, the two principal enemies to be encountered are drought and hard winters. A stand not infrequently fails from one or the other of these natural causes, which can not be guarded against, except to sow the crop at proper times, and according to proper methods of seeding. Red clover is so valuable, however, that an occasional failure to secure a stand should only spur the farmer to try for better success.

Insect enemies.-Various insects seem to find red clover highly palatable, and hence feed upon it. Yet only a few of these do the crop any great damage.

One of the worst of these pests is a small species of beetle known as the clozer root-borer. This beetle is of a brownish color, and grows about one-sixth of an inch in length. The larvæ of this insect attack the roots of the clover, usually during the second year of the crop. They have done the most damage in regions east of the Mississippi River, especially in Michigan, Indiana and Ohio. The only remedy so far found is to plow the damaged field as soon as the hay is removed. The larvæ are then without food and soon die, leaving the field free of their kind for a future crop.

The seed-bearing qualities of red clover are often seriously damaged by the clover-seed chalcis fly. This is an insect shaped like a wasp, and about the size of a seed of red clover. Just before the clover seed begins to harden this fly lays its eggs in the growing seed. As the larvx develop they use the seed for food, entirely destroying it by the time they secure their growth. The chalcis fly is responsible for much of the poor yield of clover seed. It is one of the worst clover crop pests in the United States. It is thought that light pasturing in the early spring, or even 


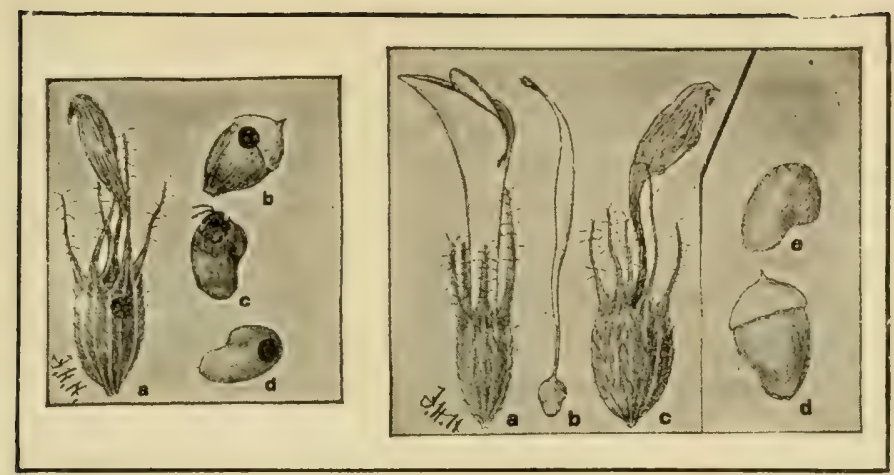

Effect on clover seed of the chalcis fly.

Stages in development of red-clover seed: (a) flower; (b) immature seed vessel ; (c) flower ripe; (d) mature seed ressel; (e) seed.

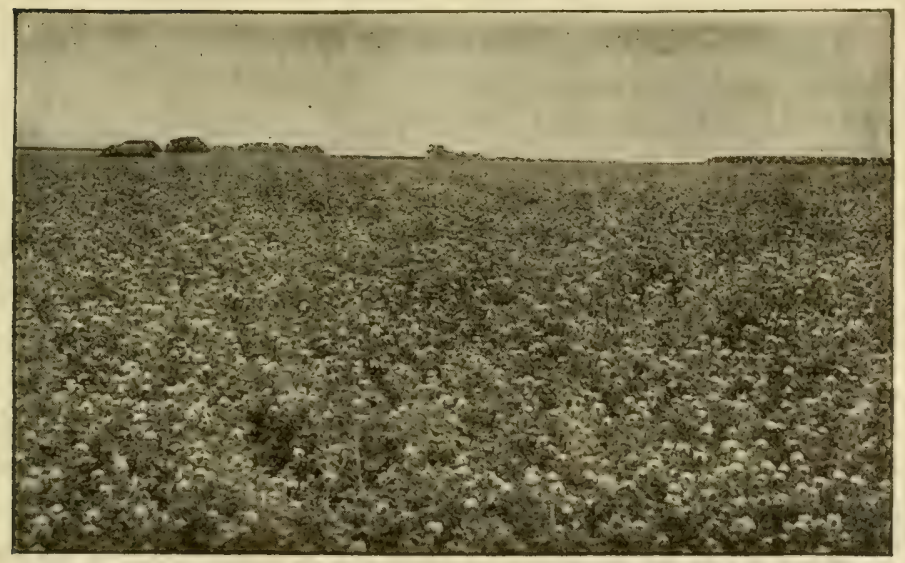

Second crop of red clover nearly ready to cut for seed. The first crop yielded $21 / 2$ tons to the acre. 
mowing the clover soon after it starts will do much to reduce the danger.

Clover has at least one enemy that works after the crop is stacked or mowed; this is the clover-hay worm. It usually works in the bottom of the stack or mow, eating the softer portions of the plant, but also damaging the feeding qualities of the hay by its excrement and a web that it leaves. Salting the hay near the bottom of the stack or mow will do much toward stopping the work of this pest.

While the botanists tell us that red clover is a perennial, it is seldom able to maintain a stand for more than three or four years, when it must be re-seeded. Red clover is usually followed by a grain crop before clover is again grown.

\section{Other Types of Clover}

None of the other clovers compare with red clover in their general value to the northern and central farms. Yet a few other types are of great importance in other sections.

White clover.-White clover is well known over most of the red-clover region. It differs in its manner of growth from red clover, being of a creeping habit, and therefore not well adapted to use as a hay crop. White clover is very hardy, and will often work its way into a pasture without seeding, the seeds being carried by winds and the birds. It makes an excellent pasture grass, and is also often used in lawn mixtures.

Alsike clover.-Alsike clover is named from a town in Sweden, where it is said to have originated. It resembles red clover but is of a finer, more delicate type, and therefore does not yield so well. While red clover will produce two crops each season, alsike clover will grow but one. This clover is esnecially suited to wet heavy soil 
which will not grow red clover, and in such regions proves a valuable crop.

Crimson clover.-This clover, whose cultural methods are similar to those of red clover, differs from the other clovers in being an annual. It is a relatively new crop, having recently been brought to this country from Europe. It is grown chiefly in the southeastern part of the United States, where it assumes the same importance that red clover has farther north. Crimson clover does not demand so rich a soil as red clover or alfalfa, but is of great importance in the southeast and southwest of the United States.

\section{TOPICS FOR INVESTIGATION}

1. How many acres of red clover are now growing on your father's farm? Make a comparison for all the farms represented in the school. What other legumes are raised at your home? Is the red clover grown alone, or with timothy?

2. How long have your father's clover-fields been down? Ask your father whether red clover that has been down two or three years begins to die out? What is the oldest field of red clover in the vicinity?

3. Secure several samples of red-clover seed. These may be taken from the supply intended for sowing, or from the barn floor where red clover is fed. Study these samples with reference to the qualities named in the text for clover seed. What proportion of the seed turns out to be weed seed instead of clover? Can you identify the different weeds represented?

4. Make a seed tester out of two plates and pieces of Canton flannel. Place one hundred seeds of red clover beiween the plates, dampen the cloth and keep warm for four or five days. How many of the seeds have sprouted? What percentage failed to grow? Is it probable that some of the seeds were "hard"?

5. If red-clover seed such as you tested is selling at eight dollars a bushel, what would the good seed in your sample really cost the purchaser? Would a farmer better 
pay nine dollars a bushel for pure seed, ninety-five per cent. of which will grow, or seven dollars a bushel for dirty seed, seventy-five per cent. of which will grow? Have in mind also the fact that the farmer can not afford to sow weed seed with his clover. Will it pay to test the rerdclover seed before planting?

6. Secure specimen plants and samples of seeds of all the other clovers to be found in your region. Learn to identify both plant and seed. 


\section{CHAPTER VII}

\section{ALFALFA}

\section{The Alfalfa Plant}

$\mathrm{F}^{\text {IRST }}$ of all secure, if possible, samples of growing I alfalfa plants. Go into the field and dig up several plants of different sizes, one year old, two years old, and three years old. Try to obtain the entire root system of at least one good-sized plant. This may be hard to do, as the roots usually extend from eight to ten feet down in the soil, and under favorable conditions more than twice this depth.

Study of the alfalfa plant.-Study the plant, noting the mode of branching, the system of leaves, the method of flowering, and the arrangement of seeds and pods. Look for the tubercles on the roots. These are most plentiful in the spring. Later in the season they fall off and decay in the soil. If the roots are pulled up roughly, the nodules will be stripped off and remain in the ground. The individual bacteria can not be seen except with a powerful microscope.

\section{TOPICS FOR INVESTIGATION}

1. How many cuttings to the season are made of alfalfa? How many of clover? Of timothy?

2. What is the average cutting of alfalfa to the acre? Of clover? Of timothy? Compare, then, the total crop for the season of the three linds of forage?

3. What is the market value of alfalfa per ton? Of clover? Of timothy? Compare the value per acre for feeding purposes of each of the three hay crops. 
4. What does it cost to produce an acre of alfalfa and harvest it? Of clover? Of timothy? Find which is the most profitable crop based on market value of hay. ( It must, however, be taken into account that alfalfa is of greatest value in renewing the soil.)

\section{The Growing of Alfalfa}

Alfalfa is one of the oldest plants known. It was known in Greece five hundred years B. C., and raised in England before Columbus discovered America. It has been known in this country for more than a century, but only recently has it become of any great importance as a farm crop. And even yet, its value is but little understood, and the methods of its growth are not generally known.

Acreage of alfalfa.-At present barely one-tenth as many acres are deroted to alfalfa as to clover and timothy, and one-ninth as many as are put in wheat. IVe have twenty acres in corn to every acre in alfalfa. Yet the amount of land devoted to alfalfa is increasing every year, and it will soon become one of our principal forage crops.

The alfalfa region.-The alfalfa region of the United States at present lies principally west of the Mississippi River. Out of about five million acres of alfalfa raised in the entire country, Kansas grows one million acres, or onefifth of the crop.

Alfalfa is especially adapted to dry soils and climates, and is therefore of the greatest value in the semi-arid regions of the West. Utah, Arizona, Colorado, Idaho and other western states are using alfalfa to make fertile many acres of soil almost barren for other crops.

The great corn belt states are admirably adapted to the raising of alfalfa, but have as yet done little with it. For example, the following are the ranks of these states in the production of alfalfa in the I'nited States: Ohio, nine- 
teenth; Iowa, twentieth; Kentucky, twenty-first: Illinois, twenty-second; Wisconsin, twenty-third; Indiana, twentyfourth, and Michigan, twenty-ninth.

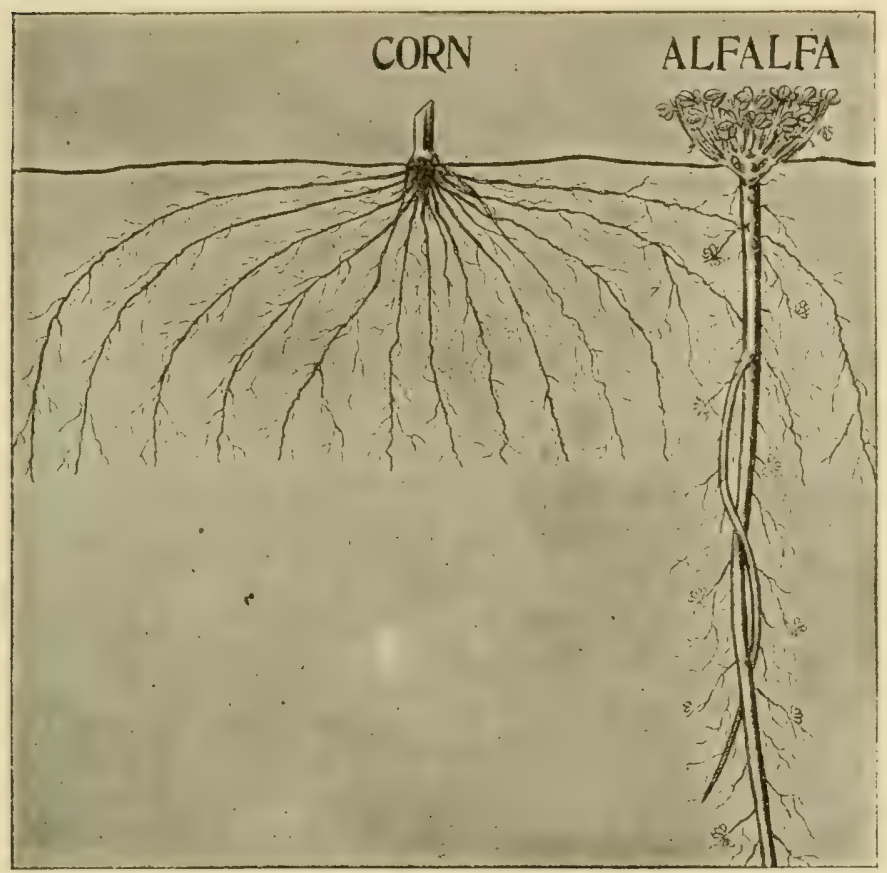

Comparison of corn and alfalfil roots, showing why alfalfa is a drought resister.

\section{Alfalfa as Forage for Stock}

Alfalfa is the most valuable forage crop known for the feeding of most kinds of farm animals. Like clover, it contains a high degree of that most important element of food, protein, which goes to make both bone and muscle. With such forage as timothy, corn, stover, or straw 
fed to stock, protein must lue supplied in the form of bran, or some other such feed. Alfalfa serves the same purpose, and is much cheaper to produce.

Feeding value of alfalfa.-The following table shows the feeding value of eight different kinds of feed, baserl on the digestible nutrient material in each: (Farmors' Bulletin, 339. These figures are only relative, since prices vary from year to year.)

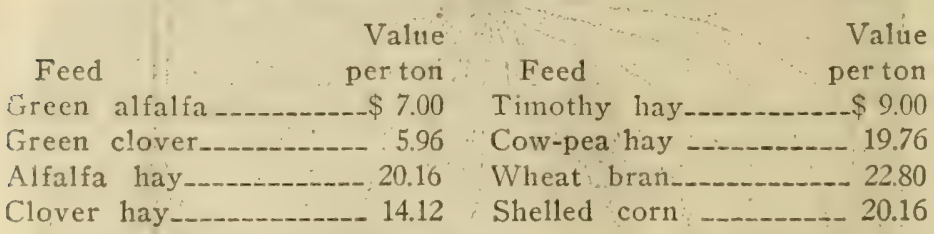

It is seen that the feeding value of alfalfa hay is more than double that of timothy. It is almost equal to wheat bran, and just equal to shelled corn. Alfalfa has an additional value for feeding stock because it is highly palatable to almost every farm animal, even to poultry and hogs.

Bran costs an average of about twenty dollars a ton; to raise alfalfa hay costs an average of about five dollars a ton. Why not grow the protein needed by the farm animals instead of buying it? As farmers learn more of the value of alfalfa this is what they will do.

\section{Alfalfa as a Revewer of the Soil}

Alfalfa is probably the best of the legumes as a soil renewer. The bacteria which grow in the root tubercle are able to take the nitrogen directly from the air and add it to the soil in such form that it can be used by other crops. The deep rooting system of the alfalfa plant also enables it to bring other minerals from the lower layers of the soil, depositing them near the surface where other plants can use them. The generous roots add much humus to the soil. 
In Colorado, Nebraska and Wyoming, farmers have found that almost double the yield of grain is produced from the same fields after they have been in alfalfa for sev-

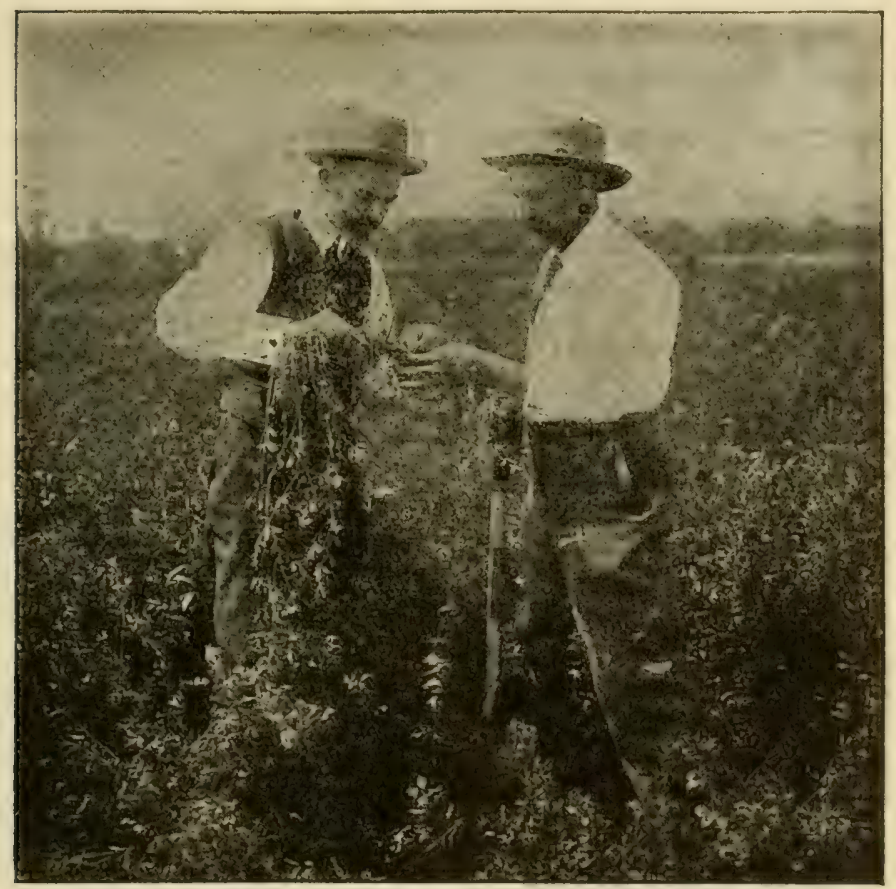

Examining the tubercles on alfalfa roots in a southern field.

eral years. Even greater results have been experienced in the South in the yield of cotton crops that have followed alfalfa.

Alfalfa can be used in the same way throughout the corn region to improve the soil for other crops. Besides being one of the cheapest and most effective means known of restoring certain clements to worn soil, it is also a crop 
which is in itself more profitable than almost any other crop that can be raised.

\section{Raising the Crop}

Soil requirements for alfalfa.-It is especially important in raising alfalfa that soil naturally wet shall be

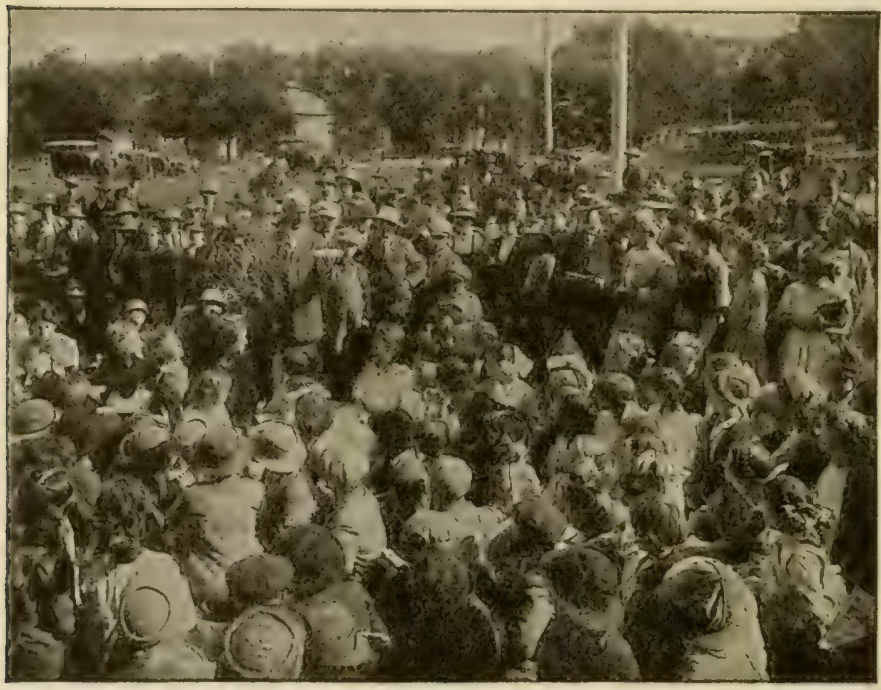

S'chool childrell in cook County, Illinuis, studying the relation of alfalfa to corn growing.

well drained. While alfalfa requires much moisture in growing, it will not stand the dampness of undrained soils; If submerged with water it will quickly die.

In heavy damp soil there is also likely to be more acid than is good for the alfalfa plant. Before sowing alfalfa it is, therefore, best to test the soil for acid. This can easily be done by taking a little of the soil when damp and plac- 
ing it upon blue litmus paper. If the paper turns to a pink color it indicates the presence of acid, and the soil

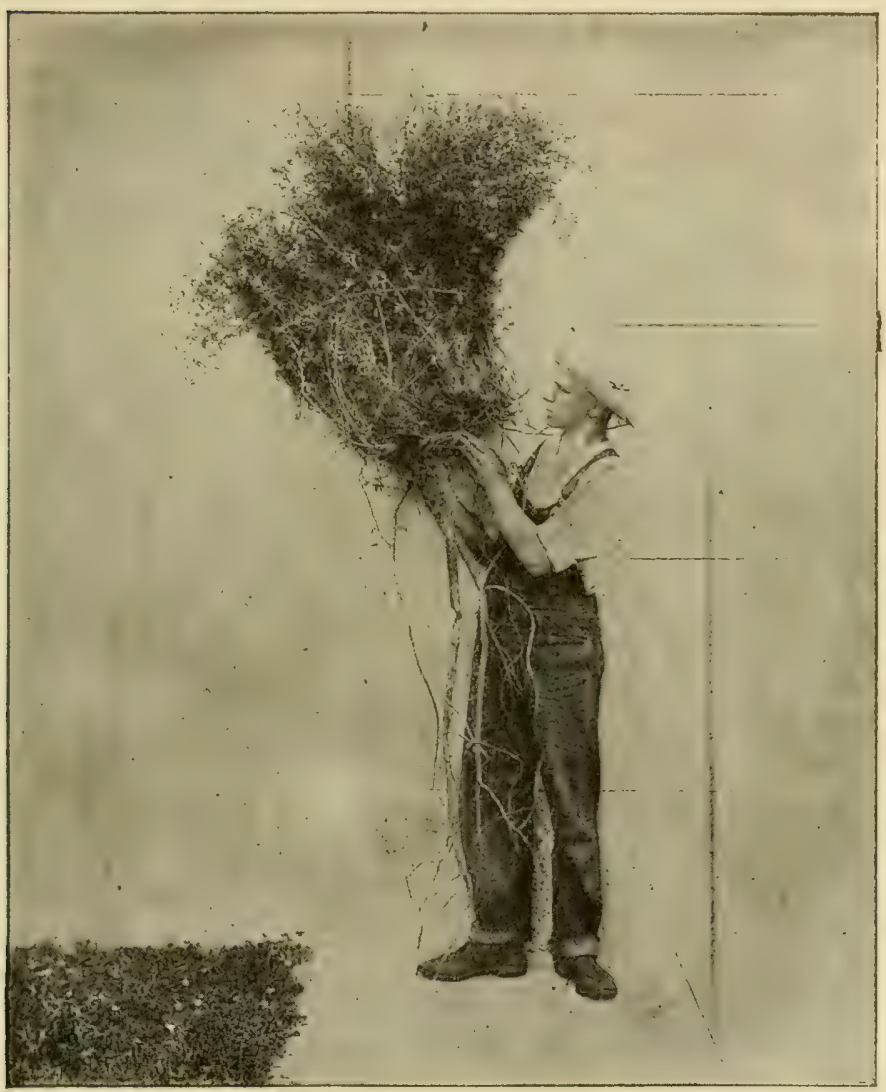

An alfalfa plant several years old. Note the generous root system and the size of the plant.

should then have an application of lime to counteract the acid. 
Starting alfalfa.-If proper methods are used it should be no harder to start alfalfa than clover. First of all, the seed must be most carefully selected, and should be tested before sowing. This can easily be done by means of a home-made tester, as in the case of clover.

Particularly should the seed be free from all noxious weeds or other impurities. For weeds are among the worst enemies of alfalfa. In some parts of the country the alfalfa crop is completely killed out of certain fields in a few years by the increase of weeds.

The seed bed should be more carefully prepared than for almost any other farm crop. After plowing it must be harrowed so thoroughly as to pack it well and leave a fine mulch on top. If the sced bed can be prepared some time ahead of the sowing so as to give an opportunity for several harrowings so much the better. The seeding may be done either broadcast or with a drill. It has been found best in most parts of the country not to sow alfalfa with a nurse crop, since the nurse crop deprives the young alfalfa plants of moisture, nourishment and light. It is of great advantage to manure the field before seeding to alfalfa.

Inoculating the soil.-It is usually best to inoculate the soil before sowing alfalfa. This means to put into the soil some of the bacteria which inhabit the root nodules. Almost any soil suitable for alfalia has some of these bacteria to begin with, so that alfalfa may often be started without inoculation. But where the supply of bacteria is very small, and where the soil is poor it will pay to inoculate. This may easily be accomplished by gathering the surface soil from a field on which alfalfa has been raised, and scattering it at the rate of one hundred to five hundred pounds to the acre over the field to be sown.

Similar results can be had by gathering soil in which sweet clover so commonly found along the roadsides has 
been growing. Care must be taken in gathering and scattering the soil not to allow it to be exposed to sunlight, as this will kill the bacteria. It is better therefore to secure the soil and spread it over the new field on cloudy days or in the late evening. The alfalfa seed should be sown immediately and harrowed in so that the bacteria may be covered, and be thus secure from the sunlight.

Time for seeding.-Late summer has been found the best time for seeding alfalfa in the East and the South, while in the Vest spring seeding is the rule. Spring seeding has also been found to work better in Minnesota, Wisconsin and the Dakotas. No general rule as to the time of seeding can, however, be given. The chief thing necessary is to seed as long as possible before the time of year that will be hardest on the plants. In the North this requires spring or early summer seeding in order that the plants may get sufficient growth before freezing to withstand the winter. Alfalfa plants less than six inches high do not ordinarily live well through the hard northern winters.

In some regions there is trouble in getting the plants started before drought comes on to check their growth. Throughout the corn belt late summer seeding should usually be practised. Alfalfa sown during August and the first week of September will have the best chance throughout this region.

\section{Harvesting the Crop}

Time for cutting.-Alfalfa makes the best hay if cut while in early bloom. A better means of determining the time for cutting is, however, to watch the start of the new shoots from the base of the plant. These shoots make the growth for the succeeding crop. When they are from one to two inches in length is the best time to harvest. In this way the new growth goes on without interruption. 
If the cutting takes place much earlier than this, there is a loss of growing time in waiting for the new shoots to derelop. If, on the other hand, the cutting is delayed until these shoots are too long, the mower will clip them off and they must begin all over again, thus delaying the next crop. Usually it is possible to secure three cuttings of alfalfa in the corn region and as many as eight, ten or even twelve in

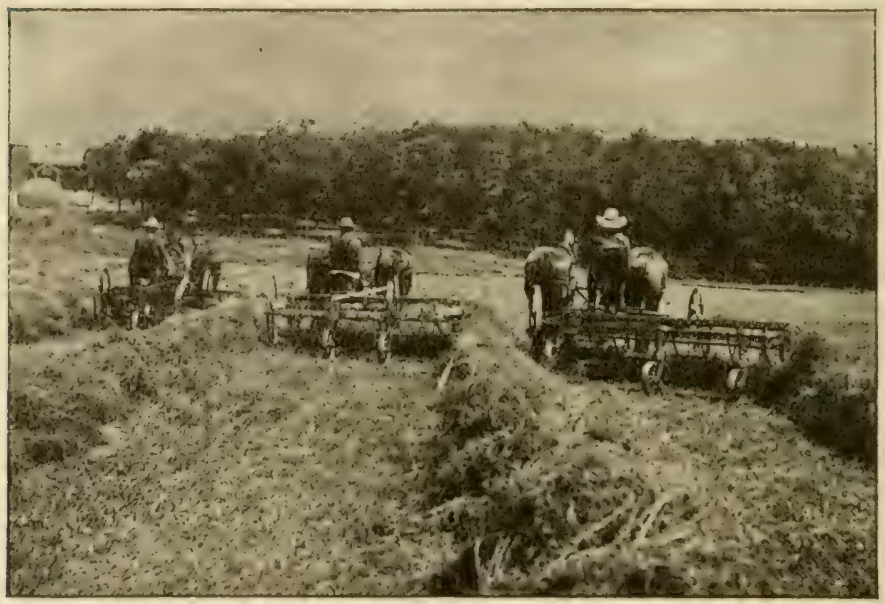

Side delivery ralier in au alfalfia field, yielding two tous to the acre on second cutting.

some of the irrigated regions of the West. It is evident that if the greatest number of cuttings is to be secured each crop must be cut as soon as it is ready in order to let the next get properly started.

Handling the hay.-Alfalfa, like clover, should be harvested so that the hay may reach the barn or stack with the least possible amount of handling or exposure to the weather. The alfalfa leaves contain a large proportion of 
the food value of the plant, and are easily crumbled and lost if the hay gets too dry.

Probably the best plan is to cock the hay when the stems are about half dry, stacking it when moisture no longer shows as a wisp of the plant is twisted by the finger. In regions where frequent rains are the rule during the haying season, it pays to have haycock covers consisting of squares of muslin to the corners of which weights are attached, or pins to thrust into the hay or the ground.

\section{Enemies of Alfalfa}

Weed enemies.-Undoubtedly weeds are the worst cnemies of alfalfa in most parts of the country. This is particularly true throughout the West and Southwest. Among the weed enemies are ivitch-grass, crab-grass in the West, bluc-grass and fortail throughout the Middle West and the barlcys in the far West. Cultivation with the spring-tooth harrow or disk is the best means of killing most of the weeds.

An especially troublesome weed among alfalfa is dodder. Dodder is a plant which twines itself about the alfalfa seedlings, soon attaching its threadlike stems firmly to the alfalfa plant. The dodder stem then withers away near the ground and the dodder continues to live as a parasite on the alfalfa. It is almost impossible to exterminate dodder when it has once secured a foothold in an alfalfa field. Turning sheep into the field to graze is one remedy for this pest. Another is to cut the alfalfa very low or even remove it entirely on any spots in the field where dodder starts.

Insect enemies.-Alfalfa does not have so wide a range of insect enemies as some of the other farm plants. The alfalfa weevil and grasshoppers are probably the worst 


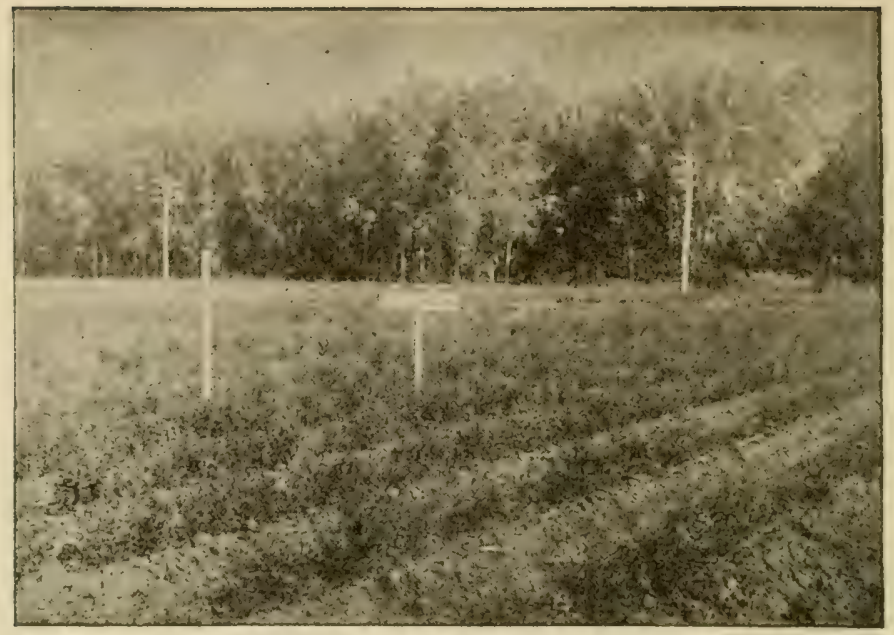

A six-weeks-old field of alfalfil in North Dakota.

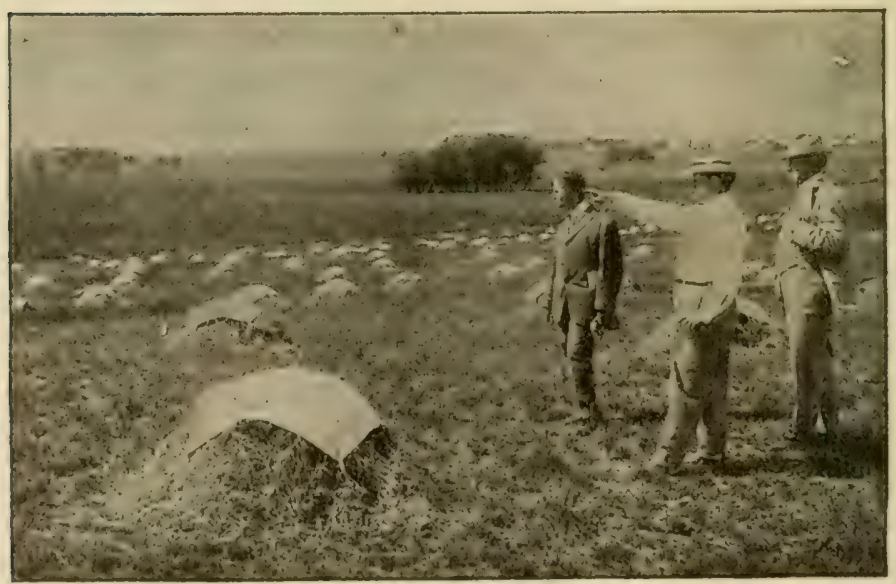

Alfalfi curing under cover. 
enemies of this kind, particularly in the regions of the West. It has been found that disking an alfalfa field late in the fall in the northern states and mid-winter in southern states exposes the weevil and grasshopper young to freezing and the attacks of birds, and thus reduces their number.

\section{TOPICS FOR INVESTIGATION}

1. How many acres of alfalfa are grown on each farm represented in the school? How long has alfalfa been raised in the vicinity? Why is not more grown, since it is one of the most profitable crops known?

2. Out of one hundred successful alfalfa growers in the corn belt, eighty-five testified that they had planted according to the following program: Manured the ground, fall plowed, summer fallowed the next season (surface cultivated without crop), limed, inoculated, seeded about August first. Make an inquiry among the alfalfa growers in your vicinity. How many did all these things? Which did they omit, if any? How did they succeed?

3. Collect samples of field soil taken several inches below the surface from each of the farms represented in the school. Moisten the soil, roll it into a ball, cut the ball into halves, and place between the halves a piece of litmus paper, leaving it a few moments. Does it turn pink? If so, this is an indication of acid or sour condition of the soil. What treatment should an acid soil receive before being sown to alfalfa?

4. If there is no alfalfa grown on your father's farm, talk with him about the crop, and join with him in starting a small field. Would your field need liming? Would you know where to secure soil for inoculating? If there is no alfalfa near, is there not sweet clover along the roadside? 


\section{OTHER LEGUMES}

WHILE red clover and alfalfa are the most important leguminous plants for large portions of the United States, there are several other legumes that deserve attention. Chicf among these are the cort-pca, grown chiefly in the South; the vetches, the soy-bcan, the pcanut ficld beans and pcas, and several others of lesser importance. These are procluced (1) for forage, (2) for soil renovation, and (3) for their seeds.

\section{The Corw-pea}

The cow-pea is to the South what red clover and alfalfa are to the West and North. It grows successfully on almost any kind of soil found in the cotton belt, and its cultivation is being rapidly extended throughout this region.

The plant.-The cow-pea was but recently introduced into this country, coming from China. The plant resembles the ordinary garden bean in appearance and manner of growth. It reaches a height of from one to nearly five feet. The smaller varieties stand nearly erect, the taller varieties spreading out vine-like on the ground.

The leaves are broad, and grow in clusters of three. The flowers resemble those of the garden pea, and are greenish-yellow in color. The pods, which are cylindrical in shape, grow from two to some seven inches in lengtli. The roots, which penetrate deeply into the soil, bear tubercles, which are the home of nitrogen-gathering bacteria. 


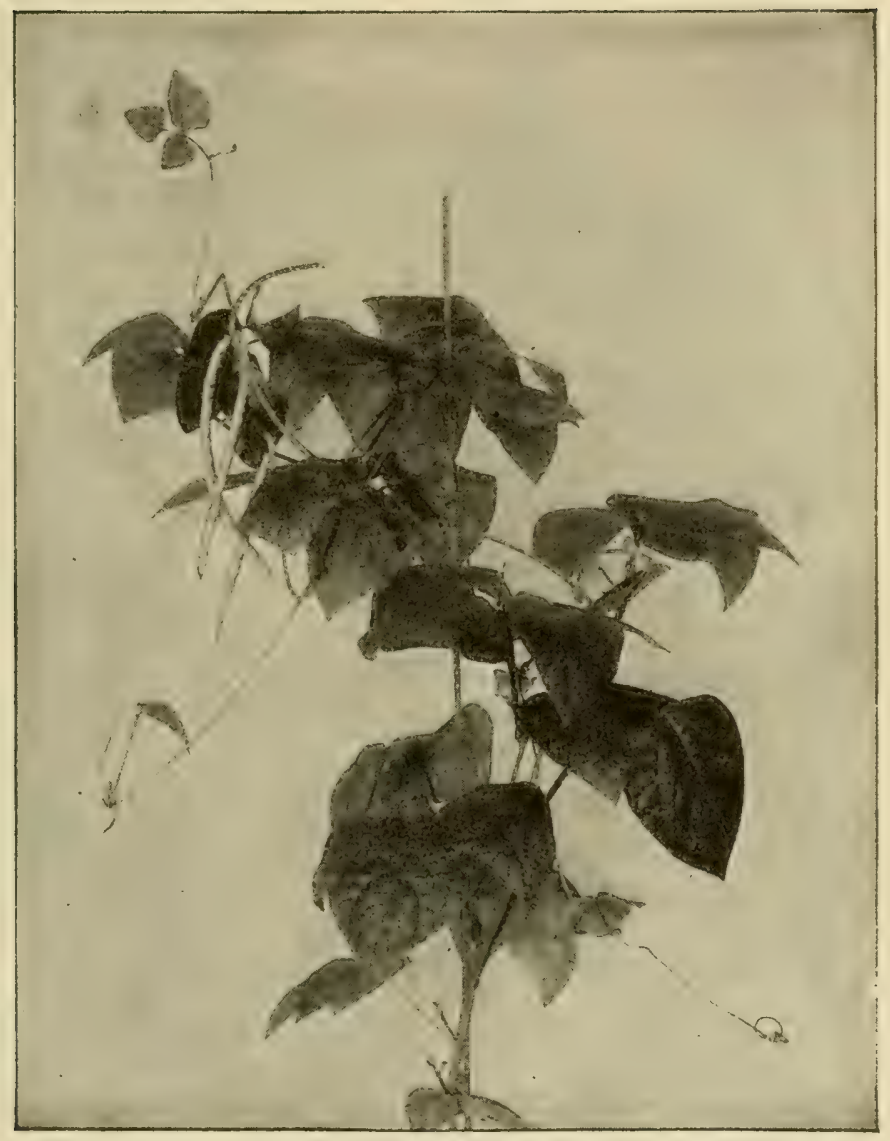

The cow-pea. 
Cow-peas as forage.-Cow-peas, when harvested for hay, yield from two to three tons to the acre. The feeding value of cow-pea hay is fully equal to that of red clover, and nearly equal to alfalfa or wheat bran. It has been fuund a better forage feed for working animals in the Sotith than grass hay. It is rich in protein, and therefore an acceptable substitute for corn or cottonseed-meal in the fattening of stock.

Since the cow-pea is an annual, it does not lend itself to the making of permanent meadows or pastures as cloes aliaifa. Cow-peas sowed in corn are profitably used as pasturage for hogs, the gain in weight being in some cases more than twice as fast with a mixed feed of cow-peas and corn as when corn alone is fed. Cattle also do well on a pasturage of cow-peas. Bloating is likely to occur, however, if grazing is allowed when the cow-peas are wet.

The cow-pea as a soil renovator.-The cow-pea improves the soil in two ways: (1) like other legumes, it is able through its root bacteria to gather nitrogen from the air and transfer it to the soil; and (2) its many roots, coarse stubble and stems, especially when the latter are plowed under as green manure, add much humus to the soil, making it more porous.

In many parts of the South cow-peas are coming to be largely used in crop rotation with cotton the principal crop. The field is planted to cotton either two or three years in succession, then a crop of corn and cow-peas grown, and then a return to cotton. In Missouri, Arkansas, Tennessee, Alabama and other states of this region, cow-peas are being successfully used in rotation with wheat and oats. An increase of from fifty to more than one hundred per cent. in other crops following cow-peas is net uncommon. 


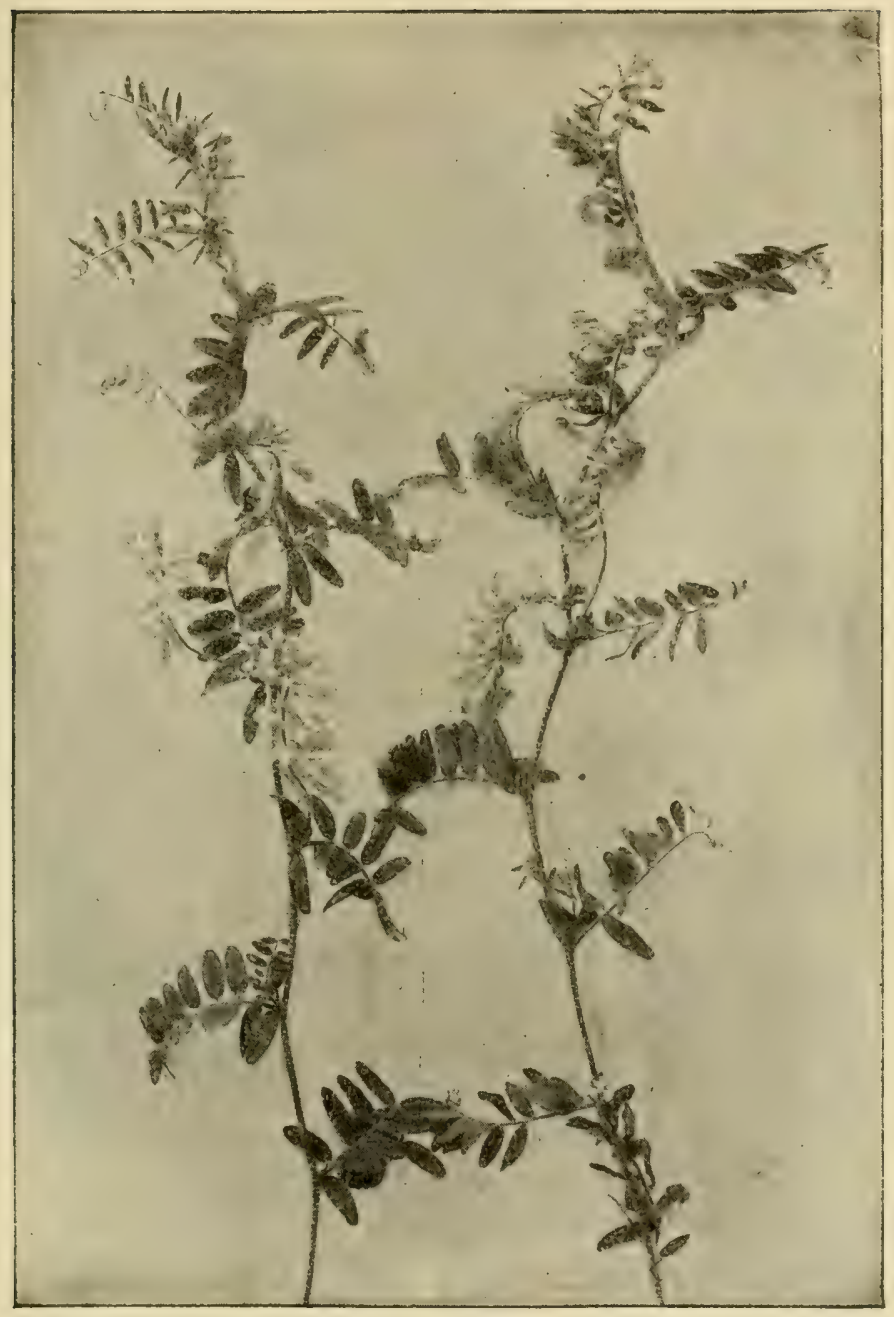

Hairy retch. 


\section{The Vetches}

The vetches are another group of legumes, grown most extensively on the Pacific Coast, less commonly in the South, and hardly at all in the North. Although more than one hundred different varieties of vetch are known, but two are commonly grown in the United States, common vetch and hairy vetch.

Common vetch.-Common retch is an annual, closely resembling the garden pea. Its stems are very slender, and grow from three to five feet or more in length. There are many different varicties of common vetch, of which the gray-seeded is most commonly grown in this country.

Low temperatures are fatal to common vetch; it can not be successfully raised in regions where the thermometer goes lower than about fifteen degrees Fahrenheit. Since the vetches have a long weak stem, they are usually planted with a crop of small grain to support them. Common vetch is largely grown for hay in the extreme West, where it is sown in the fall with wheat or oats. In the South, oats, rye or barley often are grown with vetch.

Hairy vetch.- Hairy vetch is much more hardy than common vetch, and may be raised in almost any portion of the United States. It finds its greatest use in supplying a legume for forage and improving the soil where red clover or alfalfa does not succeed, or where a short rotation crop is desired.

Hairy vetch has great power to resist drought, and does well on a sandy soil. It will also thrive on a soil so alkaline that most legumes refuse to grow on it.

\section{3.. Soy-Beans}

Soy-beans are native to Asia, where they have been grown from time immemorial. In China, India and Japan, 


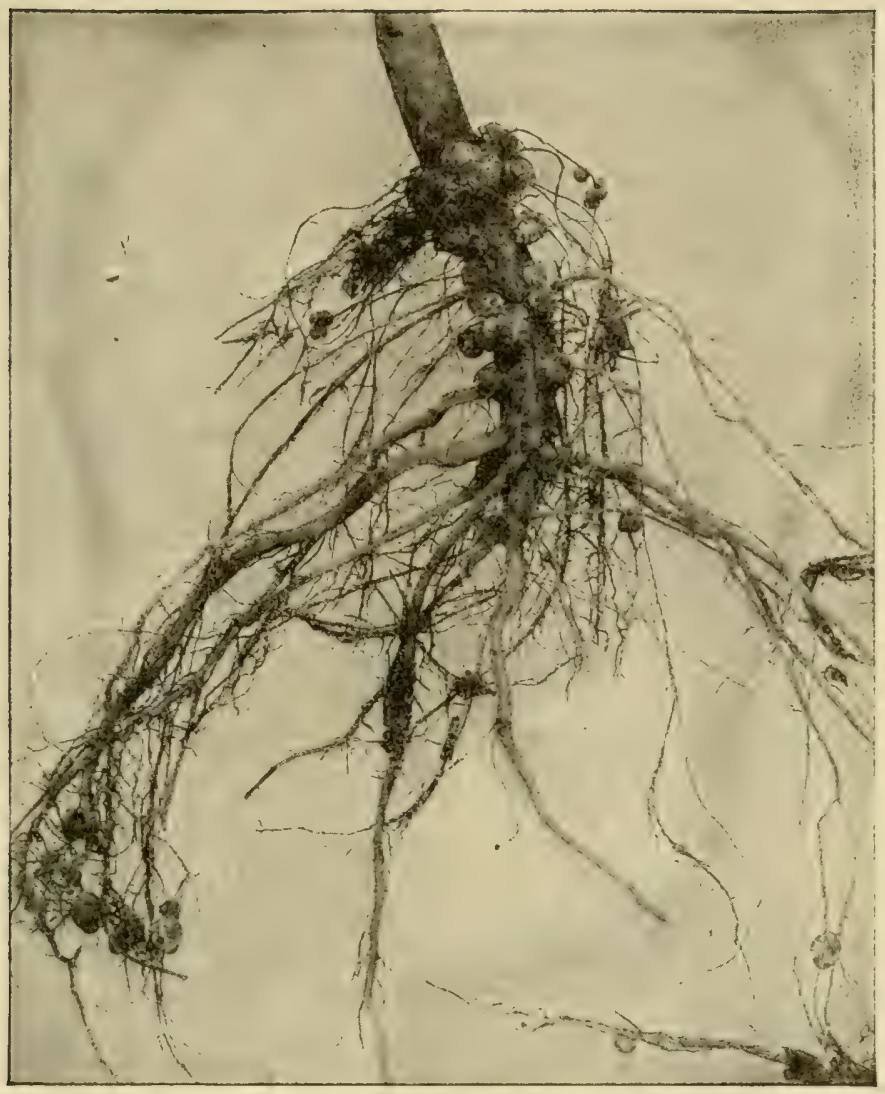

Root of a soy-beàn, showing bacteria-inbabited tubercles. 
some two hundred varieties are cultivated for human food, furnishing a staple article of diet in many regions. They have not proved palatable to Americans, however, and are raised in this country chiefly as a forage crop.

Where red clover or alfalfa can be successfully grown, soy-beans will have little place, since they are less profitable. They are especially adapted to the cotton belt, however, and to the southern portion of the corn belt. Since soybeans are drought resistant, they also grow well in the semiarid regions of the West. They have as yet made little headway as a crop in this region because of the ravages of the rabbits, which find their foliage a savory delicacy.

Feeding value.-The soy-bean has as great feeding value for stock as alfalfa, and is worth more than cottonseed-meal as a food for hogs, sheep or cattle. The straw, after all the grain has been removed, is as valuable as timothy hay, and even more palatable to most farm animals.

Like other legumes, the soy-bean adds to the fertility of the soil in which it grows, and therefore possesses a double value to the farmer.

\section{The Peanut}

Peanuts are grown in this country chiefly in the south Atlantic region. The plant produces stems from one to two and one-half feet in length. It has rather small leaves, growing three in a cluster. After flowering, the stems penetrate into the soil, where the pods or nuts are produced beneath the surface.

Uses of peanuts.-Peanuts are produced largely for their use as human food. Besides the roasted nuts sold on nearly every street corner, large quantities are made into peanut butter, oil, etc. The vines make an excellent forage for stock. Certain varieties are grown in the South exclusively as forage for hogs. 


\section{TOPICS FOR INVESTIGATION}

1. Secure if possible a complete specimen of each of the legumes described in the chapter. If they are not grown in your vicinity, write your agricultural college as to how they may be obtained. Study each different plant, and learn to identify it.

2. Secure seed of each of the legumes discussed. Learn to identify the seed. Plant in the school garden or at home, and watch the development of the plant.

3. Which of these legumes could be grown in your region? Would they be profitable? Talk with your father about this. If they would not pay, is it because of unfavorable climate, unsuitable soil, or because more profitable legumes can be grown? If you are not sure on any of these points, write your agricultural college. 


\title{
CHAPTER IX
}

\section{MEADOWS AND PASTURES}

\begin{abstract}
ATHOUGH meadows and pastures claim more than A half of all the farm land of the United States, they receive far less attention than any other part of the farm. About one-fourth of the acreage from which hay is harvested is native wild meadow; this is chiefly located in the newer portions of the West. Pastures are often used from year to year with no care taken to improve them. Yet in many cases meadows and pastures well repay the time and expense necessary to make them more productive.
\end{abstract}

\section{Meadores}

Requirements of a meadow.-Meadows are commonly used for a double purpose-the production of hay, and providing the rotation of crops required to maintain the fertility of the soil. It is necessary therefore to select such plants for the meadow as will serve both of these ends. This is possible with our wide range of grasses and legumes from which to choose.

Meadow plants should possess the following qualities: (1) yield well; (2) be palatable; (3) tend to improve the soil; (4) grow strong and thick enough to keep down the weeds; (5) produce an even firm sod free from high tufts or bunches.

The surface of the meadow should be smooth and free from obstructions that will interfere with the harvesting of the hay crop. 
Meadow grasses and legumes.-Most of our meadows are mixtures of grasses, or of grasses with legumes. Alfalfa seems to thrive best alone, but most meadow plants grow well in company with some other variety. Red or crimson clover and timothy, for example, are commonly found growing together.

Several advantages come from planting mixed meadows: the different plants draw their nourishment from various

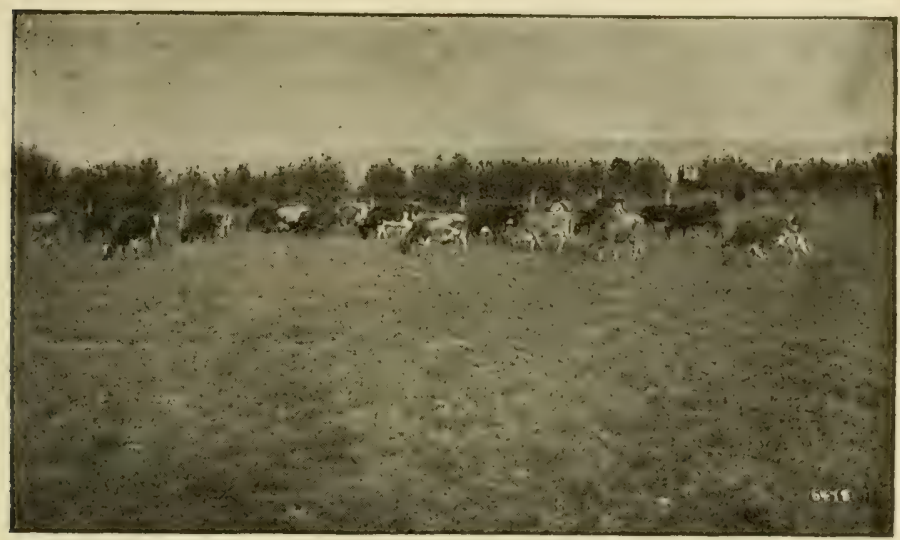

Two profitable western industries-dairying and fruit-raising (Washingtou).

depths of the soil, thus using its full strength more completely and increasing the yield of hay; mixtures accommodate themselves to peculiarities of seasons, sometimes one grass and sometimes another thriving better; mixed forage provides variety for stock, making the feed more palatable and affording a wider range of food elements.

When hay is raised for market instead of being fed on the farm, however, it is often best to devote the meadow to one plant alone, thus producing what is called a "pure" 
hay. Timothy is the favorite meadow grass for pure hay, and leads the market in all the great hay-buying centers. For working horses, timothy is thought by many to be superior to clover or to mixed forage. Pure red clover or alfalfa is often desired for fattening stock.

Meadow mixtures.-The mixture to be used in seeding a meadow will depend on the climate, soil and use to which the forage is to be put. Red clover and timothy are the most common mixture found throughout the northern states, the proportion of seed used being about threefifths timothy and two-fifths clover. For damp undrained soil, alsike clover is substituted for red clover, or mixed with it. A very common mixture for average soils is the following ảmounts per acre:

Timothy 15 pounds

Red clover

Alsike clover 4

This combination will produce about a half-and-half mixture of hay the first year, with timothy predominating the second year, and pure timothy thereafter. On very wet soils, red-top may be sulstituted for the red clover If the soil is also strong in acid, it is best to omit both clovers, and use the red-top with the timothy.

In southern regions. where clover, alfalfa and timothy are not successi' 1 in meadows, Jolnnson grass is the leading meadow plant, with red-top frequently used as a mixture. Brome-grass is impertant in many regions of the Northwest.

Care of meadows.- Under our system of rotation of crops meadows are usually not left down more than from two to four years, with sometimes a year or two of pasturing before the sod is broken up for other crops. Most of our meadows are therefore new, and must be constantly remade. 
One of the chief enemies of meadows is weeds. They not only hinder the newly seeded meadow from getting a good start, but injure the value of hay, reducing the market price. If allowed to grow in the meadow from year to year, the weeds will also leave the soil foul for the crops that follow when the meadow is again tilled.

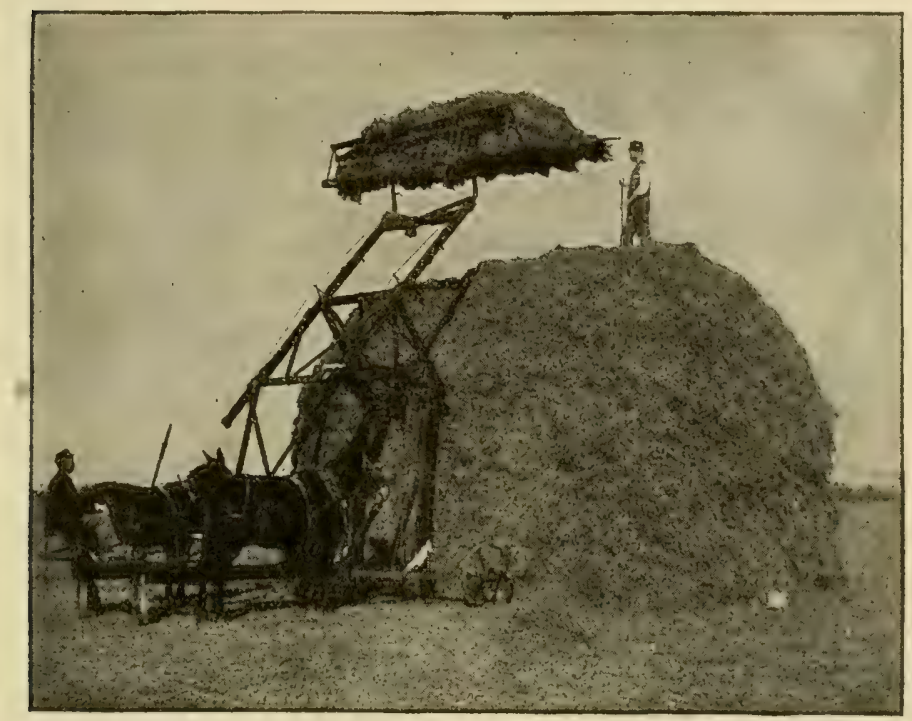

Stacking by meaus of modern machinery saves much labor.

It is no uncommon sight to see meadows grown up with ragweed, dock, smartweed, foxtail and other weed pests. If weeds appear after the crop of hay has been harvested, they should not be allowed to go to seed, but should be cut down with the mower while in bloom.

Spring seeded meadows should not be pastured the following fall even if the plants look thriving. This is sure to reduce the yield of hay the following season, and may cause the plants to winter kill by exposing the roots. The 
aftermath, or second growth, on older meadows may be pastured, though it does not pay to feed them close. Especially should new meadows not be trampled by stock while wet.

Permanent meadows.-Many meadows are located on wet ground, or on soil that for some reason is not cropped. In other cases there is neglect to rotate the meadow land with the remainder of the fields in the crop series. It is often found that meadows that are thus left for a number of years have a tendency to "run out."

The yield of hay on almost any meadow left without attention for several years decreases from one-third to onehalf. Weeds begin to appear, and patches here and there become thin or die out. The less desirable grasses crowd ont the better ones. Such a meadow is highly unprofitable. If tillable, it should be plowed up and put into other crops. If not, it should be improved and its quality kept up.

It is not hard to keep permanent meadows in a state of high production, but it requires some labor and expense. The following treatment will do much to keep permanent meadows in good condition: (1) No weeds are to be allowed to go to seed; (2) if the soil is run down, the field should be manured or other fertilizer used on it; (3) the soil should be loosened and the sod-bound condition relieved by disking; (4) fresh pure grass seed should be scattered, especially over thin or weedy places.

\section{TOPICS FOR INVESTIGATION}

1. What proportion of your father's farm is in meadow? In pasture? Compare with all the farms represented in the school.

2. How many different meadows on your home farm? How long has each been down? Which are the more successful, the older or the newer ones? 
3. Make a collection of the different meadow plants produced on your home meadows. How many different kinds of grasses? How many legumes? Do you find any grasses that were not sown, but which have come in of their own accord? Learn to identify each different grass and its seed in your meadows.

4. Make a collection of the most troublesome weeds found in your meadows. Learn to identify both plants and seeds. How many farmers in your region cut down the weeds on their meadows to keep them from going to seed?

5. Go out into some meadow near by and examine it for the five qualities specified for meadows. What was the yield per acre? Is red-top as palatable for stock as timothy? As clover? Does timothy improve the soil?

6. Examine some meadow just seeded. Identify the plants. Is the stand good? Is the field free from weeds? Is it reasonably smooth?

7. Are there any old meadows near at hand that are run down? If so, what do they need to improve them? How much do they yield? What is the quality of the hay produced?

\section{Pastures}

More improved farm land is devoted to pastures than to any cultivated crop. Pasturage supplies the greater proportion of the feed for the production of milk, butter, beef, mutton and wool and is an important factor in the production of pork. The annual value of our pasturage is more than that of any other crop raised.

Requirements of a pasture.-Pastures should possess in general the same qualities as meadows. They should (1) yield well; (2) have such grasses as will start early and continue to grow late; (3) be palatable and nutritious to stock; (4) form a firm tough sod that will stand trampling; (5) have fine rather than coarse grasses; and (6) be free from weeds.

Pasture grasses and legumes.-The best meadow grasses are not always the best pasture grasses. For ex- 
ample, timothy, the queen of hay grasses, is too coarse when used alone for the best pasture grass, and does not stand trampling so well as some others.

Pastures should usually be made of a mixture of plants. This will provide some varicties that start earlier than others, root at different depths, adjust themselves to various kinds of seasons, supply variety for stock, and endure longer

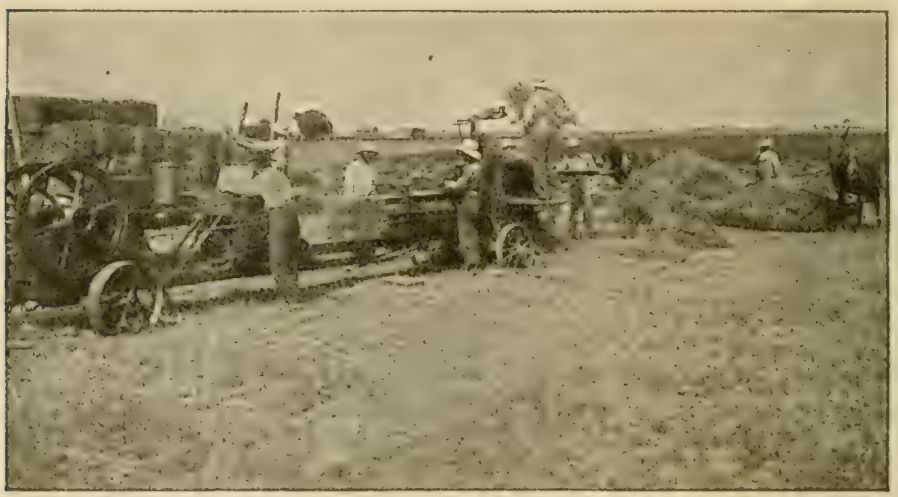

Baling hay in the West directly from the meadow.

without running out. Pasture mixtures should contain a much greater variety than meadow mixtures.

Pasture mixtures.-Over the greater portion of the United States north of the cotton belt and the region west of the Missouri River, Kentucky blue-grass and white clover are the most common and valuable pasture grasses. No matter what mixture is sown, one or both of these grasses is sure soon to make its appearan e, and gradually force most other grasses out. When blue-yrass and white clover have taken possesion of a pasture they grow reasonably well together, though in some seasons one of them will predominate, and again the other. 
Throughout the South, Bermuda grass is the chief pasture plant, though it is commonly mixed with Rhodes grass for dry soils and with orchard grass for wet regions. Red-top is successful on wet heavy soil.

For starting a pasture on good land in northern regions, a mixture may be made of something like the following proportions :

Timothy 10 pounds

Red clover 3 “"

Alsike clover

White clover

Kentucky blue-grass

Brozne-grass

Meadow iescue

Orchard grass

This will make sufficient seed for one acre. If the pasture is on very wet, undrained land, the red clover may be omitted and red-top substituted in its stead. Even though timothy will soon be driven out by blue-grass and white clover, it should head the mixture as it roots more quickly than the others, and acts as a cover while the slower grasses are getting started.

Care of pastures.-If permanent pastures are to be kept up to a high state of efficiency they demand even more care than meadows.

On fairly good soils, pastures do not usually require manuring, though a light coat of manure will increase the yield of any pasture. Nearly every pasture needs the assistance of a mower to keep down the weeds. This is because stock do not find most weeds palatable, and so eat the grass, leaving the weeds to flourish. Many pastures are thickly sprinkled with weeds which not only rob the soil but prevent cattle from eating the grass growing 
close to their roots, thus adding to the waste. Weeds should be cut from the pasture each year before they bear seed.

Grazing stock not only reject the weeds for the more palatable grass, but also have their preference among grasses. All have noted that the uplands in a pasture are grazed close, while low wet areas are hardly touched. In many cases the low parts of a pasture are almost wasted, because the red-top and other wet-soil grasses are less palatable than the blue-grass and clovers which thrive only on well drained soil. Such marshy places should be drained; the better pasture grasses will then soon take possession.

Pastures, like meadows, may become sod-bound. Almost any old pasture can be improved by disking or cultivating with a knife-toothed harrow. When this is done, fresh grass seed should be scattered on thin places, or a desirable new variety added to the plants already established.

After being grazed, pastures grow better if they have a rest from trampling and cropping. It is therefore best to have two pastures, using them alternately, instead of feeding the one continuously throughout the season. Such an arrangement usually requires only the expense of a partition fence, which the increased yield from the pasture will well repay.

\section{TOPICS FOR INVESTIGATION}

1. What is the age of the different pastures on your father's farm? What is the predominating grass? What other grasses are in the mixture?

2. Is there a pasture near by consisting of both upland and marsh land? If so, which is the more closely cropped? Secure samples of the grass from each part; what grass predominates in each case? Would it not pay to drain the wet portion? 
3. Make a study of the pastures represented at the school for the weeds growing in them. What proportion of the pastures may be called weedy? What weeds predominate? Are they ever mowed?

4. How many of the farmers in your vicinity follow the plan of dividing their pasture, so that the one part may rest while the other is being used? If this is not done at your home, figure the cost of running a division fence so that it would be possible. Talk with your father about the cost of the fence.

5. Are any of the pastures in your region ever disked to loosen the sod? Is new seed ever sown on them? Do you think any of them are sod-bound. How can you tell?

6. What is the cost per rod of laying field tile in your vicinity? Investigate any wet areas on your home pasture where the grass is rejected by the stock, and determine how many rods of drainage would be required to make the soil tillable. Suppose draining would double the feeding value of such an area, would the drain pay good interest on its cost? Figure this all out and talk with your father about it. 



\title{
PART II. HORTICULTURE
}

\author{
CHAPTER $\mathrm{X}$
}

\section{THE VEGETABLE GARDEN}

THE plan of every farm, village or suburban house I should include a good vegetable garden to supply the home table. Not only are vegetables a highly necessary food, but they are much more palatable when taken from the garden fresh as needed instead of bought in a market. Nor is a well stocked market easily available to most of our homes. Hence, unless the home raises its own supply of vegetables, those who surround the table are likely to suffer from lack of variety and the absence of certain food qualities required for health. Without vegetables the table is also more expensive because of requiring more of the high priced foods such as meats and bread.

The vegetable garden can be made the most profitable part of a farm. Half an acre of ground planted to a suitable variety of garden crops will, if properly cared for, yicld over one hundred dollars' worth of vegetables each season for the family table. This is from ten to twenty times what the same amount of ground in farm crops will produce. Although the garden requires considerable attention, the labor demanded is not great compared with the returns in profits, good health and human efficiency. 


\section{TOPICS FOR INVESTIGATION}

1. Measure your home garden and find the amount of space devoted to vegetables this season. Make a comparison with other members of the class. Compute the average size of vegetable gardens for the neighborhood.

2. Make a list of all the different vegetables raised in your home garden this year. How many different kinds? What proportion of the space was devoted to each? Compare the number of different kinds and the proportion of each with the garden plan shown on page 170.

\section{Location and Soil}

The location.-There is a double advantage in having the vegetable garden near the house: the vegetables can then be taken from the soil as needed, without loss of time; and spare moments free from other work or chores can be given to the care of the garden. Where the soil is suitable it is best to have the garden only a few rods from the kitchen door.

The soil.-Most vegetables require a well drained soil. Ground on which the water stands after a rain is not adapted to garden use. A slight slope to the south and east will favor the early maturing of the crops.

\section{Plan of the Vegetable Garden.}

The regetable garden should be carefully planned before time to begin planting, and a diagram made allotting to each crop its location and proper amount of space. This will save time in putting in the crop and insure a better arrangement.

The plan.-A well planned garden provides (1) for a succession of crops supplying the table with fresh vegetables from early spring to late fall, with storage varieties for winter use. This can be accomplished by selecting a 
reasonably wide range of crops and successive plantings of certain kinds.

(2) The right proportion of space should be allowed for each vegetable, depending on the tastes of the family and allowing for the canning of a supply for home use. As a result oi careless planning an over-supply of one vegetable often results in waste, while some other crop runs short.

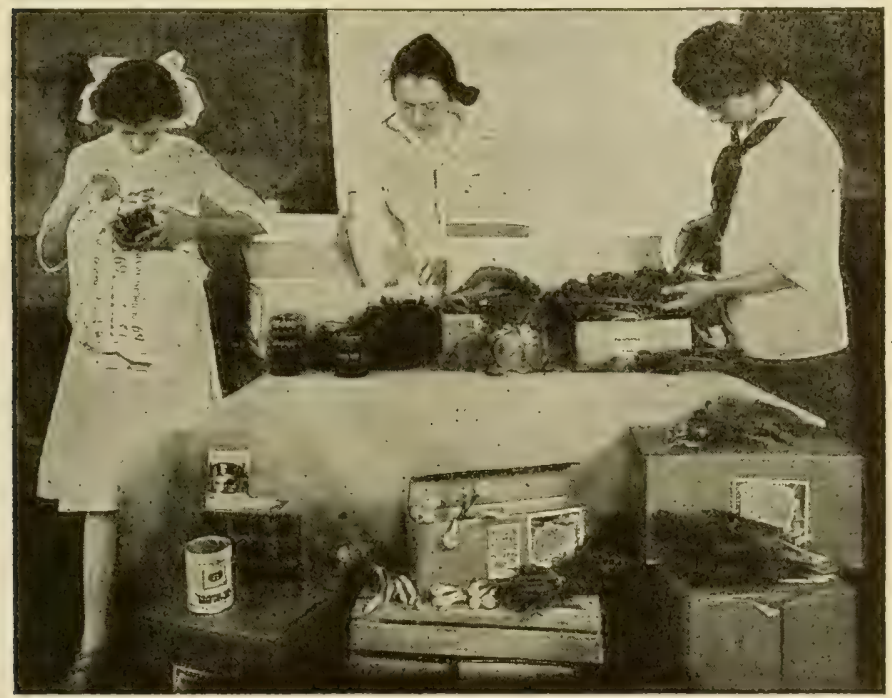

Members of National Market Garden Club packing fresh vegetables for parcel-post shipment.

(3) The crops should be arranged in the order of their time of planting, so that the planting can begin at one side of the garden in the early spring, and proceed across until all are in. This arrangement saves much labor in cultivation without interfering with crops already planted.

(4) If the cultivation is to be done with horse implements, as it should be in all larger gardens, the rows stould 
run the long way, ano a turf turning ground be left at each end. It also pays to place in each row plants that require the same kind of cultivation and that mature in about the same time so that together they will get out of the way of later plantings.

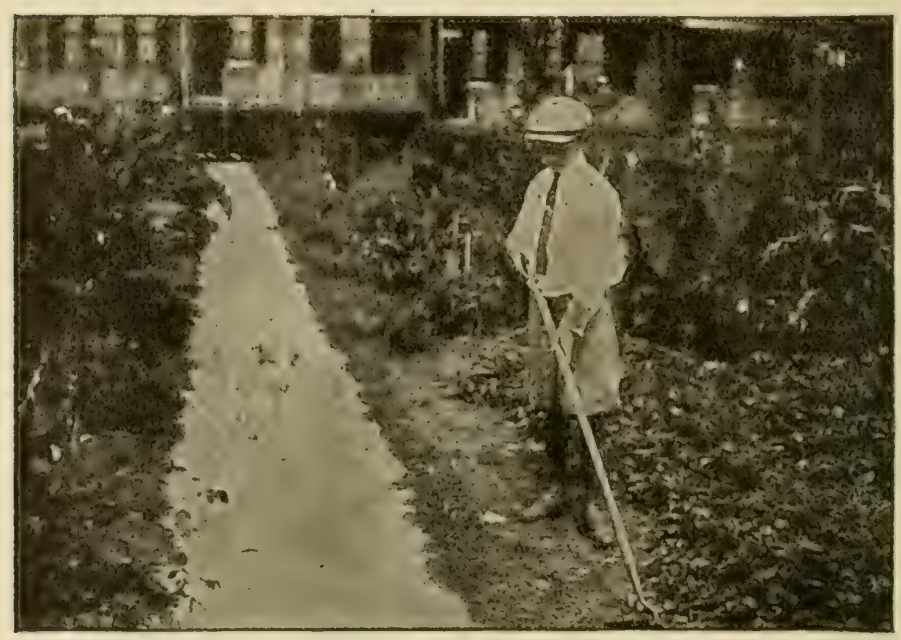

The boy with a hoe. Back-yard gardening.

The arrangement shown, which will, of course, need to be modified to meet personal requirements, presents a seasonal order of planting. In the latitude of Indiana, Illinois, Iowa, Farsas and Nebraska the first ten rows can be planted about April first; rows eleven to fourteen, inclusive, the last week in April; and the remainder about May fifteenth.

Planting time and maturity.-The time required for growth and the date of planting the common garden vegetables recommended by the United States Department of Agriculture are as follows: 
TIND OF

VEgetable

Asparagus

Beans, bush

Beans, pole

Beets

Brussels sprouts

Cabbage, early

Cabbage, late

Carrots

Cauliflower

Celery

Corn, sweet

Cucumbers

Eggplant

French endive

Horseradish

Lettuce

Melon, muskmelon Feb. to Apr.

Melon, watermelon Mar. to May

Onions, seed

Onion,sets

Peas

Peppers

Potatoes, Irish

Pumpkins

Radishes

Rhubarb, plants

Salsify

Squash, bush

Squash, late

Swiss chard

Tomatoes

Turnips

\section{SoutII}

IIME of PLANTING

Fall or early spring

Feb. to Apr. Apr. to July

(Aug. to Sept.)

Late spring

Feb. to Apr.

(Aug. to Sept.)

Jan. to July

Oct. to Dec.

June and July

Mar. Apr. Sept. Apr. to June

Jan. Feb. June Apr. to June

Aug. to Oct.

Feb. to Apr.

Feb. Mch. Sept.

Feb. to Apr.

Aug. to Oct.

Early spring

Sept. to Mar.

Oct. to Mar.

Early spring

Sept. to Apr:

Early spring

Jan. to Apr.

April and May

Sept. to Apr.

\section{Spring}

Spring

Feb. to Apr.

Dec. to Mar.

Aug. to Oct.

NoRtII

Early spring

Apr. to June

Early spring

April to June

April to June

Apr. to Aug.

April (July)
May and June 50 to 80 days

Apr. to Aug. 60 to 80 days

May and June 90 to 120 days

Mar. and Apr. 90 to 130 days

May and June 90 to 130 days

75 to 110 days

100 to 130 days

120 to 150 days

60 to 100 days

60 to 80 days

100 to 140 days

100 to 130 days

1 to 2 years

March to Sept. 60 to 90 days

May and June

120 to 150 days

100 to 120 days

Apr. and May 130 to 150 days

Fall, Feb. to May90 to 120 days

March to June 40 to 80 days

May and June 100 to 140 days

March to June 80 to 140 days

May to July 100 to $140^{\circ}$ days

March to Sept. 20 to 40 days

Fall or spring. 1 to 3 years

May and Jine
120 to 180 days

60 to 80 days

120 to 160 days

60 to 80 days

100 to 140 days

60 to 80 days 
The following plan of a garden ninety feet wide and two hundred and forty feet long suggests how to carry out the principles just stated:

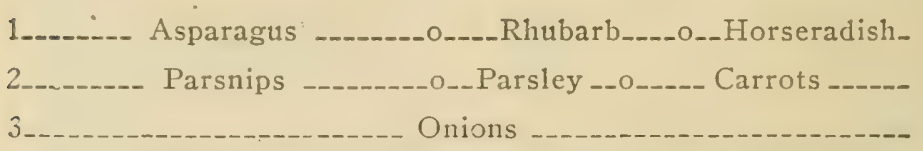

4_-______Early Beets__o___Swiss Chard__o__- Salsify

S_-_ettuce (fol. by celery)_o_Radishes (cel.)_o_Onion sets_(follow by celery)

6_-_Early Turnips (fol. by cel.)_o_Spinach (cel.)_o_Onion sets (follow by celery)

7._._. Farly Peas (follow by celery)__-_o_._String beans (cel.) 8---------Early potatoes (followed by turnips)

9-_-_-_-_Early potatoes (followed by turnips) 10---_-_-_-_Early potatoes (followed by turnips)

11 -

12_-_Early cabbage_-_-_o_-_-_Cauliflower_--_o_Brussels sprouts_ 13_--_-_-_-_-_-_Summer cabbage-_-_-_-_-_-_-_-___String beans_14__-__-_Early sweet corn (followed by greens)

15 -

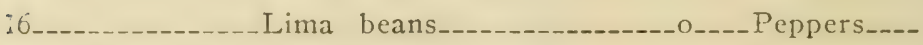

iᄀ -

18_--Late swect corn (followed by lettuce and radishes)_-----

19._-_Late sweet corn (followed by lettuce and radishes) -.--$20 \mathrm{x} x \mathrm{x} x$ (1)!@ $@ x \mathrm{x} x \mathrm{x}$ (1)!@@@@ $@ \mathrm{x} x \mathrm{x} x$

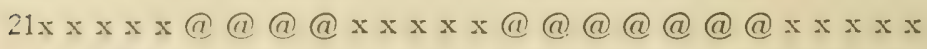
Cucumbers Early Late Watermelons Muskmelons $22 \mathrm{x} \times \mathrm{x} \times$ (1) (1) (1) (1) $\mathrm{x} \times \mathrm{x} \times \mathrm{x}$ (1) (1) (1) (1) (1) (1) (1) $\mathrm{x} \times \mathrm{x} \times \mathrm{x}$ Squash Squash

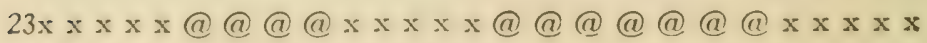




\section{Culture of the Garden Crops}

Most of the vegetables named in the preceding section can be raised without technical training in their cultivation. A few, however, must have special treatment if they are to succeed, and if there is not time to give them this extra attention they would better be left out.

Garden crops requiring rich soil and much tillage.Although the whole garden should be much richer than for the field crops, the following vegetables require an especially rich soil ; cabbages, cauliflower, Brussels sprouts, eggplant, celery, onions and melons. Melons may have the hills well manured and the remainder of the area no richer than the rest of the garden. A sand loam, rich in humus, is considered best for most vegetables.

In general it may be said that the plants which demand a very rich soil also need a greater amount of tillage than the remainder of the garden.

Vegetables that require transplanting.-The season required for certain vegetables to mature for the table is so long that in the North they must be started under glass in the latter part of the winter and transplanted when the weather is warm enough. The common plants belonging to this group are cabbage, celery, cauliflower, Brussels sprouts, tomatoes, eggplant, pepper, sweet potato. Lettuce and muskmelons may also be transplanted to good advantage.

The hotbed.-For small gardens the plants that are to be transplanted are often started in shallow boxes. The more common method is, however, to use a hotbed.

A hotbed is made as follows: Select a sunny place sheltered by a building or fence from the north winds, and make a bed of coarse manure from the horse stalls eighteen inches deep, eight feet wide, and any multiple of three feet 
long. The manure must be fresh and contain a good amount of straw. Pack the bed well by thoroughly tramping.

Place on top of the bed a board irame six feet wide, twelve inches high at the north edge and six inches at the south. The frame may be as long as required. After placing the frame in position, put in it a rich garden loam to the depth of three to six inches, packing and smoothing it well. Cover the frame with glazed sash.

If the manure is in good condition it will begin heating almost at once, and will soon raise the temperature of the soil. Do not plant the seeds until the heating has been well tested and the temperature has begun to go down. This will be in about three days. The hotbed is now ready to receive the seed.

In raising the hotbed crop care must be taken to lift the sash during the warm part of bright days, and also to water sufficientiy. Watering should be done in the morning on sunny days, else the cooling may chill the plants. If the temperature grows too high the sash must be lifted, or the plants will be destroyed.

Transplanting.-When the time comes for transplanting to the open soil care must be used or the change may kill the tender plants or greatly check their growth. To avoid this hotbed plants are often transplanted to another bed, called a cold-frame, covered with glass but not heated. This is known as the "hardening off" process. Transplanting almost any plant is of great advantage since it causes the multiplication of many small roots which add to its growth.

Vegetables that require special treatment.-The larger and later varicties of peas grow so high that they require support, else they spread out on the ground and the 
pois rot. Where an abundance of brush is available, rods may be stuck in the ground for them to run on. Woven chicken wire is an excellent substitute and takes much less time. Lima beans also need poles. Because of this, bush varieties are sometimes grown in their stead.

Celery requires bleaching to produce the best results. To accomplish this, the plants are usually set at the bot-

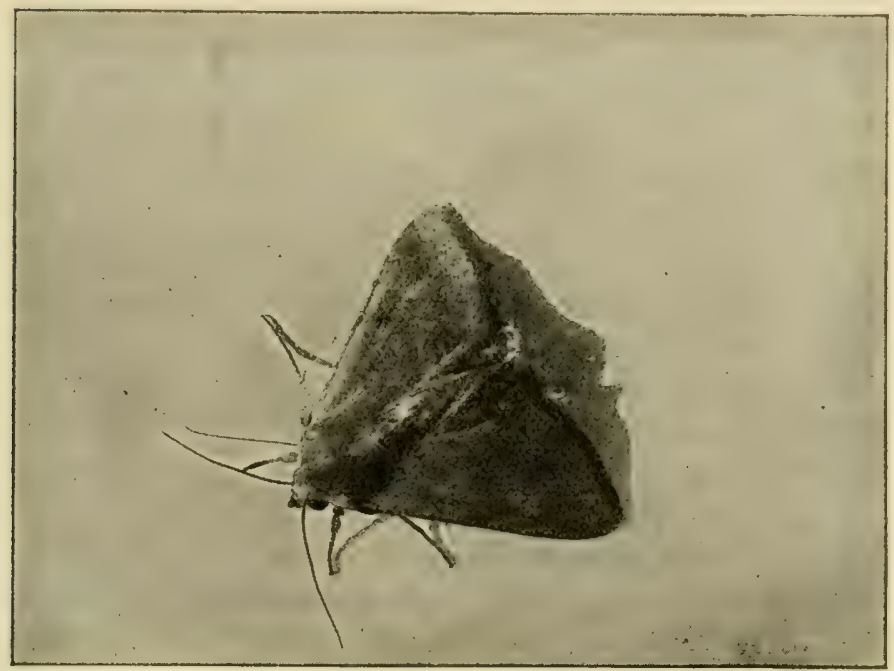

Moth (Heliothis obsoleta); the caterpillars from this species attack many garden plants, also cotton, corn, etc.

tom of a trench which is gradually filled in as the plants grow. At the end of the season the rows may be hilled up so that the plants are covered to the top.

Cauliflower and French endive are vegetables that need to be bleached. When the plants are well grown, the leaves are brought together and tied over the top, thus protecting the inner portion from the sun. 


\section{Insect Enemies of the Vegetable Garden}

Fortunately, most of the garden vegetables are not sub. ject to great injury from insects. Certain plants are, how. ever, special targets for these pests, and must be protected or they will almost certainly be destroyed.

The most common enemy of calbage and cauliflower is the cabbage-worm, which is the larvæ of the common white butterfly seen about the cabbage patches. The most effective remedy is spraying with the arscnate of lead preparation, made by mixing three pounds of the paste with fifty gallons of water. To this should be added a mixture of resin and lime, or soap, to cause the insecticide to stick to the leaves.

The cucumber beetle.-The worst enemy of cucumbers is a small striped beetle which eats the leaves of the young plants. When only a few hills are raised they may be kept off the plants by making a small wooden frame over which is stretched wire mosquito netting, and placing these boxes over the hills. These pests can also be controlled by spraying with the arsenate of lead compound. The roots of the plants are sometimes attacked by the larvae of the bettle. Tobacco dust sprinkled on the roots is an effective remedy.

The cucumber beetle is also the most troublesome enemy of squash, muskmelons and watermelons. These plants may be protected in the same way as the cucumber.

The aphis.-The aphis, a small green fly, is a sucking insect that attacks lettuce, peas and other green leaf crops. It is also frequently found on flowering shrubs. It may be controlled by spraying with a mixture of soap and water, or with a nicofume preparation mixed according to directions on the package.

The cutworm.-The cutworm attacks a number of 


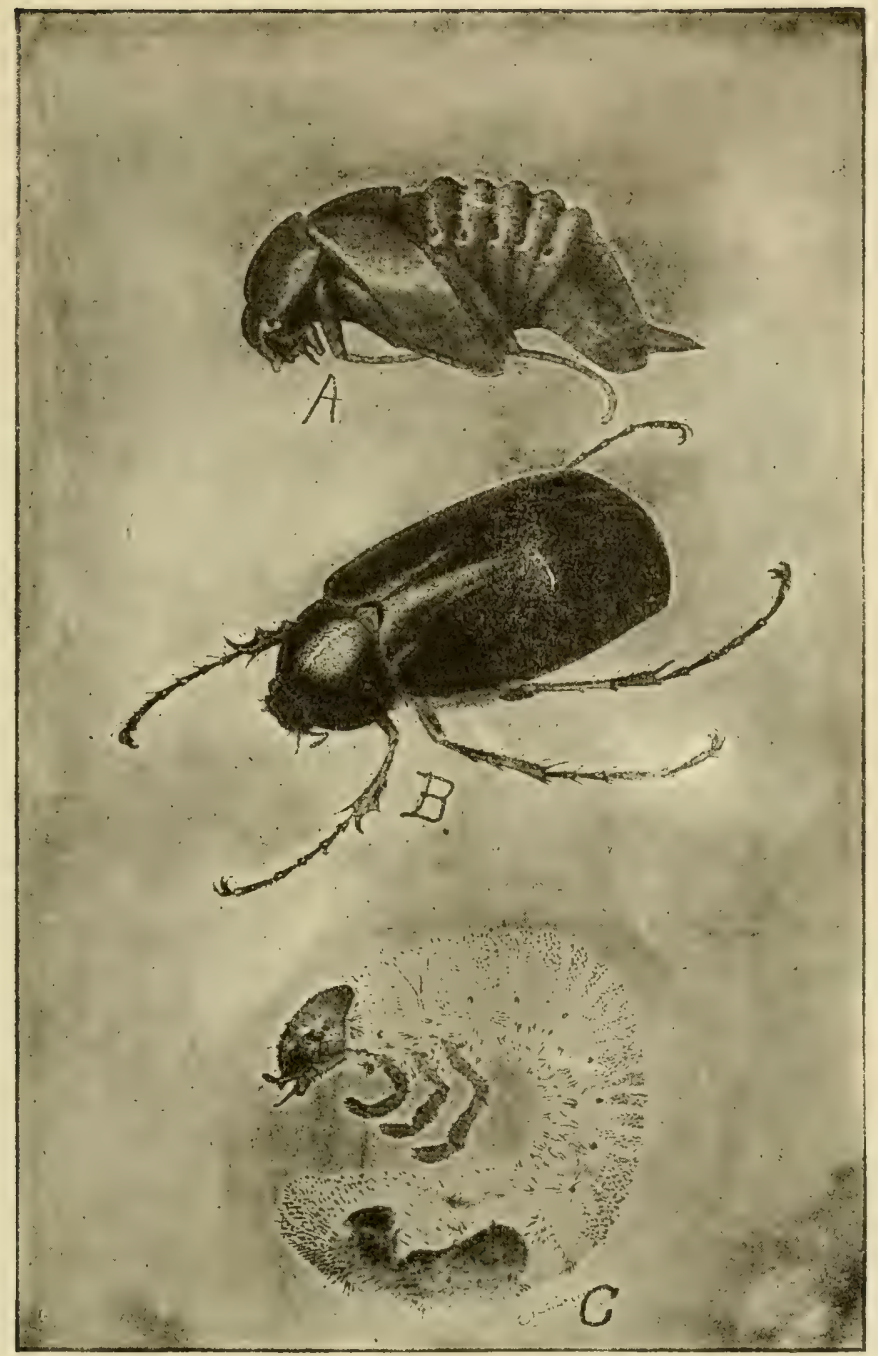

The white grub: (A) pupa; (B) beetle; (C) larva. 
different vegetables, cutting them off just at or near the surface of the ground. The remedy is fall plowing, and poisoning. An effective method of attracting to the poison is to dip clover blossoms in Paris green, or add Paris green to a mixture of bran and molasses, and strew around the roots of the plants.

\section{TOPICS For INVESTIGATION}

1. Make a careful diagram of your home garden plot, showing its exact length and breadth. Now make a plan for this plot similar to the one shown on page 170 , being careful to preserve the planting order from one side to the other. What plants would you add which are not shown in the sample garden? IN .ld you leave any out?

2. How many pla ings of radishes were made in your garden? Of lettuce? Of peas? Of beans? Of sweet corn? Of cabbage?

3. Is your garden manured every year? Is the soil in good condition and free from weeds? Is rubbish allowed to remain on the garden over winter, thereby making a harbor for insects?

4. Which of your garden crops have been most attacked by insects? Have you used any of the spray compounds as a remedy? If so, what ones, and for what insects? Was it successful? Do you know how to mix and apply the more common insecticides?

5. Talk with your father and mother and plan your home vegetable garden for next season. Bring your plans to school, and compare the different plans presented to determine the best.

6. Prepare a plan and specifications for a small hothouse which can be heated with an old stove or from the house heating plant.

7. Show how to keep a garden account for a season; at least six different kinds of products should be included in the items.

8. Make a map of the United States and show the two most important vegetables grown in each section. Compare the vegetable garden products of the Pacific Coast with those of the Atlantic Coast; the northern tier of states with the cotton belt states. 


\section{Garden Demonstrations}

1. Demonstrate how to prepare, pack and ship vegetables by parcel post.

2. Show how to make different types of boxes for marketing products.

3. Demonstrate how to make a home-made canning outfit, by using wash boiler, garbage bucket, pail and tub.

4. Show how to can regetables by the cold-pack method. (See Farmers' Bulletin 521.)

5. Demonstrate how to mix garden sprays and how to use them.

6. Demonstrate how to make vegetable dishes and how to serve them.

\section{Garden Play Contests}

All contests with garden products should be a combination of play with helpful practise and instruction.

1. Vegetable judging contests.

2. Story contest. Tell origin and life history of different vegetables.

3. Vegetable spelling contest.

4. Vegetable drawing contest. Place on stand before contestants a number of vegetables and have them draw them.

5. Vegetable canning contest.

6. Paring, labeling and packing contests.

\section{Home Garden and Canning Club Projects}

One of the most interesting of club projects in connection with the public schools is the work of the home garden and canning club. This can be undertaken in much the same way in both city and rural territory. The club plat should be operated on a business basis, and should be 


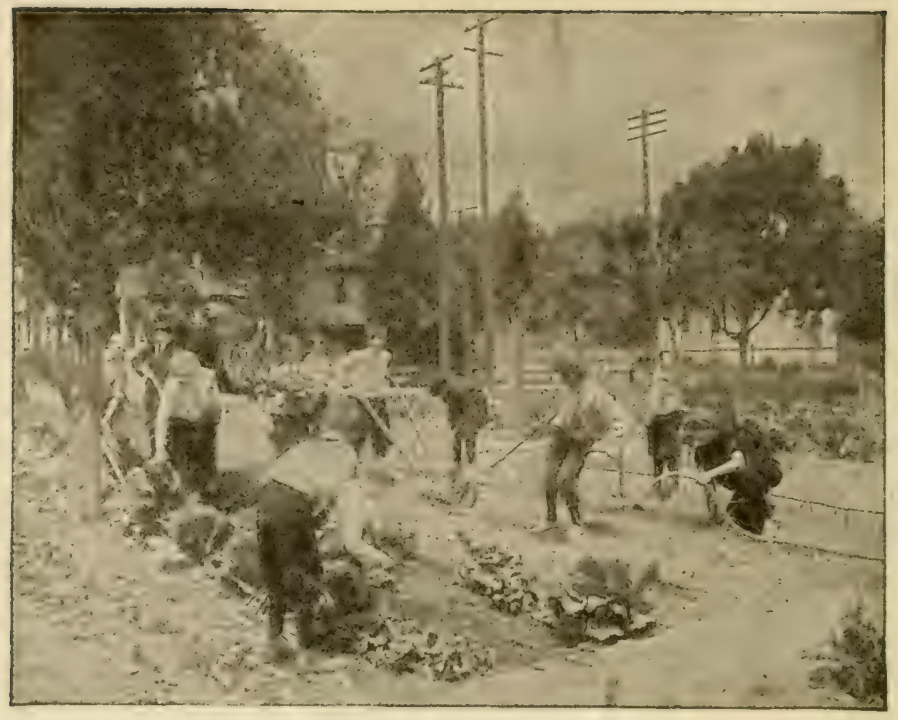

A Pasadena, California, school regetable garden.

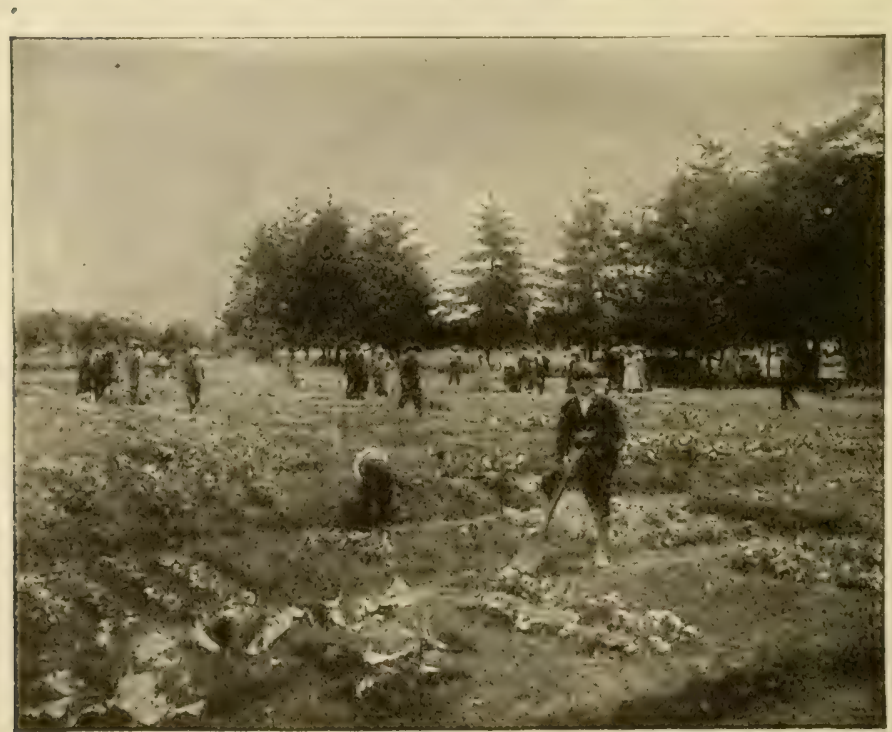

Public school garden in Portland, Oregon 
large enough to make possible an attractive net profit on the investment of time, moncy and cncrgy of the member. Club members should range in age from ten to eighteen years, inclusive, and be divided into two classes denominated as senior and junior gardeners. The basis of award should be as follows:

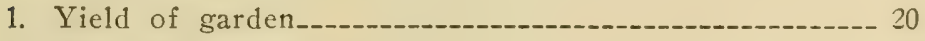

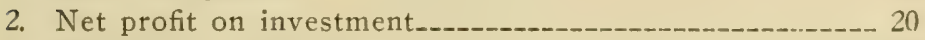

3. Variety of vegetables_-_-_- 20

4. Exhibit of products, fresh and canned-_-_-_-_-_ 20

5. Record and story, "How I Made My Crop"--_-_-_-_-_-_ 20

Total score-_._-_-_-_-_- 


\section{CHAPTER XI}

\section{THE FRUIT GARDEN}

THE fruit garden is not less desirable and profitable 1 than the vegetable garden. Fruit is universally palatable, and a highly necessary article of food. And because of the high cost, the remoteness of markets and the ease with which fruit wilts and decays, most of it must be raised at home or the family go without.

1. Measure accurately the space devoted to all kinds of fruit in your home garden. Make a diagram of the garden showing the location of each different fruit. What proportion of ground is devoted to each?

2. Make a table showing the number of each kind of fruit tree, bush and vine. Compare diagrams and tables with other members of the class and seek the cause for the differences. Just what is the distinction between vegetables and fruit?

Soil and location.-The soil and location suitable for the vegetable garden will in most cases be adapted to fruit raising as well. Heavy, damp clay soil needs to be drained and manured. The ground must be rich. As a matter of convenience and economy of time in caring for it, the fruit garden should be near the house.

\section{Plan of the Fruit Garden}

Since the plants set in the fruit garden are perennials and remain more or less permanently where they are first 
placed, the arrangement should be well planned from the start. The order in the fruit garden will depend chiefly on convenience, economy of space, and the adaptability of certain plants to grow in one another's company.

The plan.-The home fruit garden, like the vegetable garden, should be planned for cultivation by means of horses. The rows should therefore run the long way of the garden. The fruit garden may well join the vegetable garden, and be approximately the same size, about ninety by two hundred and forty feet for a farm garden. The entire plat will then contain approximately one acre of ground.

It is impossible to specify the different allotments of fruit that should go into the home garden, since individual taste and the adaptability of certain fruits to the locality will need to be taken into account. The following plan, providing for a garden ninety by two hundred and forty feet, will, however, be suggestive:

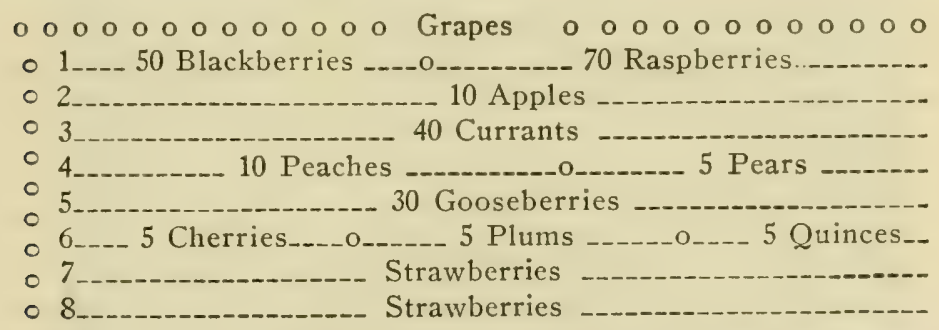

In regions where the climate will not permit the growing of peaches, pears or quinces, hardy apples can be added in their stead. Several trees each of apricots and nectarines will make a welcome addition where they are adapted to the climate.

Varieties.-In selecting the varieties, care should be taken to secure both early and late kinds, so that the fruit 
season may be extended as much as possible. Apples may be chosen to begin ripening at harvest time, and continue till late fall for winter storing. Cherries and plums may be selected so that the crop will last during at least twc

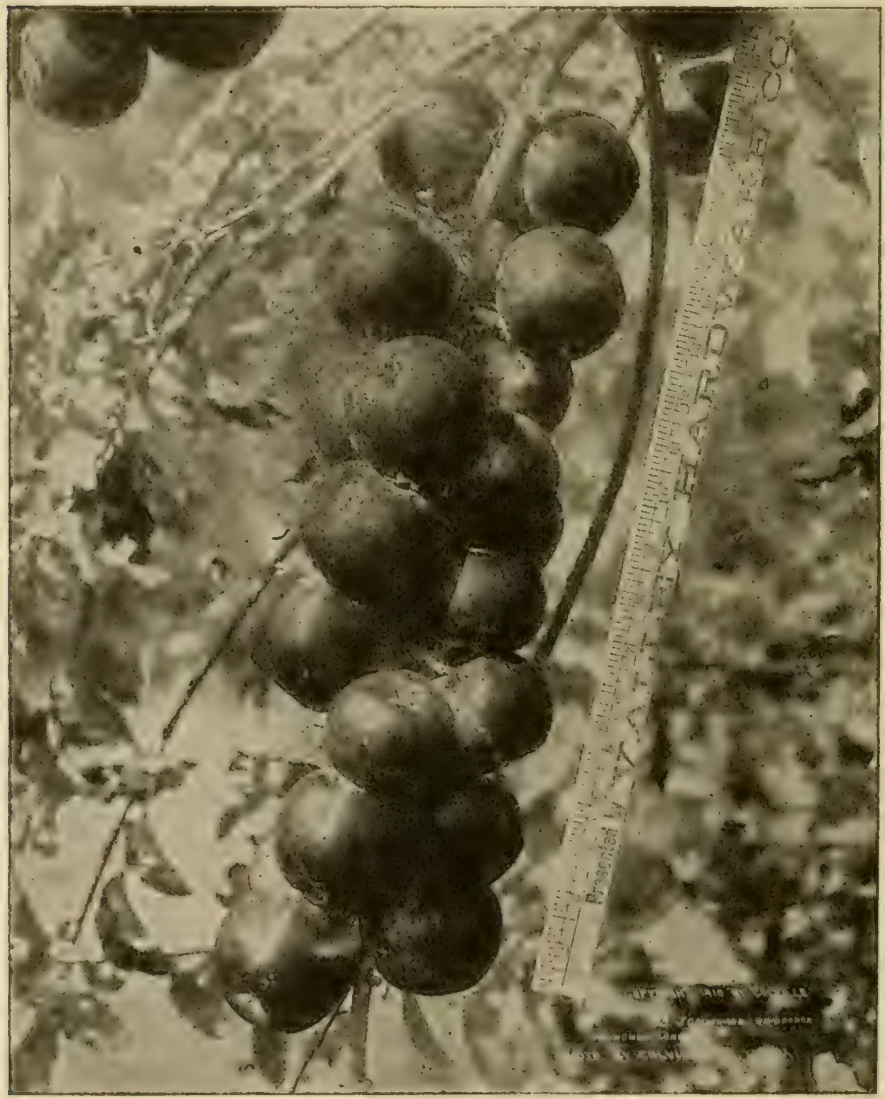

Apples growing in a Washington orchard.

months. The same is true with grapes and many of the berries. 
List of plants.-The following fruit garden list is recommended by the United States Department of Agriculture for regions of the latitude of northern Ohio:

Apples (10 trees).-Two Baldwin, 2 Grimes Golden, 1 Fallawater, 2 Red Astrakan, 1 Bonum, 1 Bough Sweet, 1 Transcendent Crab.

Peaches (10 trees).-One Alexander, 2 Rareripe (Yellow), 2 Early Crawford, 4 Late Crawford, 1 Stephens Rareripe.

Cherries (5 trees).-Two Early Richmond, 2 Black Tartarian, 1 Allen.

Plums (5 trees).-Two Green Gage, 2 Lombard, 1 Willard.

Pears (5 trees).-Two Bartlett, 1 Duchess, 1 Kieffer, 1 Seckel. Quinces.-Five Champion.

Grapes (50 vines).-Twenty-five Concord, 10 Niagara, 15 Brighton.

Raspberries (70 bushes).-Twenty-five Gregg, 10 Marlboro, 25 Cuthbert, 10 Golden Queen.

Blackberries (50 bushes).-Twenty-five Agawam, 25 Taylor.

Currants (45 bushes).- Twenty-five Wilder, 10 White Grapes, 10

Champion.

Gooseberries (30 bushes).-Ten Downing, 10 Industry, 10 Columbus.

Strawberries (200 plants).-One hundred Brandywine, 100 Gandy.

\section{Care of the Fruit Garden}

Cultivation.-The successful fruit garden must at all times be kept free from weeds, and all vines, bushes, shrubs and young trees be cultivated the same as any other crop. To allow them to become choked with weeds or bound by sod is to invite failure.

Mulching with coarse manure will serve the double purpose of helping to keep down the weeds and conserving the moisture. Care must be taken not to pack such a heavy coating over the roots as to deprive them of fresh air. Straw instead of manure should be used for the strawberry bed. 
Planting.-In the North all planting should be done in the spring: and as early as the ground can be worked. The plant should be exposed to the air as little as possible between the time of taking up and resetting. The roots should be full and plentiful, and all broken or injured portions cut away. In case a good supply of roots can not be obtained, the top should be cut back to correspond with the roots remaining. Unless this is done the growth will be greatly retarded, even if the plant does not die.

The holes in which the plants are to be set should be sufficiently large that the roots can be spread out in their natural form, and not bent or cramped. The earth should be loosened a number of inches below where the roots are to rest. The rich top soil should be used to pack about the roots, being thoroughly tramped to insure contact with every part of the root fibers. The plant should stand in its new position an incl or two deeper than in the nursery.

Pruning.-All garden fruits need pruning. This is for the purpose (1) of favoring the growth of sturdy trunks or stems, (2) removing the non-fruit-bearing parts so that the strength of the plant may go to the production of fruit, and (3) relieving the plant of old and useless stems and branches that no longer bear fruit.

The time and method of pruning different plants depend on their habits of growth and fruit-bearing, which must be known by the gardener. All cuts should leave a clean smooth surface, with no tearing of the bark or other injury.

Apples and Pears throw out in each season's growth short shoots or "spurs" from the sides of the branches that are one year or more old. It is on these spurs that the next year's fruit is grown. All pruning after the bearing age has been reached must be done with care not to trim back 
the spur-bearing branches to such an extent as to limit the crop. Pruning may be done at any time after the bearing season and before the new growth starts.

Peaches are borne directly on the wood of the preceding year's growth, and the branches may be headed in as much as required to limit the amount of fruit produced by the tree.

Grapes are borne on new shoots thrown out in the spring from the canes, or small side branches of the preceding season. Old wood is therefore of little value, and grapes will stand severe pruning. There are many different systems of pruning in use based on the form of the vine desired.

Raspberries and blackberries both produce their fruit on short shoots thrown out by the canes of the previous year's growth. The bushes may be cut back in the fall or early spring, and all old wood past the best bearing age removed.

Currants and gooseberries grow fruit on both old and new wood, the blossoms appearing in the axils of the shoots. All wood three years of age should be cut away.

Strawberries grow their fruit chiefly on the newer plants. The most fruitful plants are those only one year old. Plants over two years old do not produce enough to pay and should be rooted out to give place for new ones.

\section{Enemies of the Fruit Garden}

The fruit garden is prey to a variety of insect and other enemies. Unless the owner is willing to give time and attention to combating these pests there is little use to attempt fruit raising, for it is sure to be a failure. Spraying with some form of fungicide or insecticide is the only means of controlling them, and no one mixture will serve for all purposes. 
Insect enemies.-The insect enemies of the fruit garden are of two types: the biting insects, or those that actually eat portions of the plant; such as the larvæ of the codling-moth; and the sucking insects, or those that pierce the fruit, leaves, or bark with sharp beaks or bristles, and live off the juices of the plant. The latter group includes various plant bugs, lice and scale insects.

In general, the biting insects can be destroyed by spray-

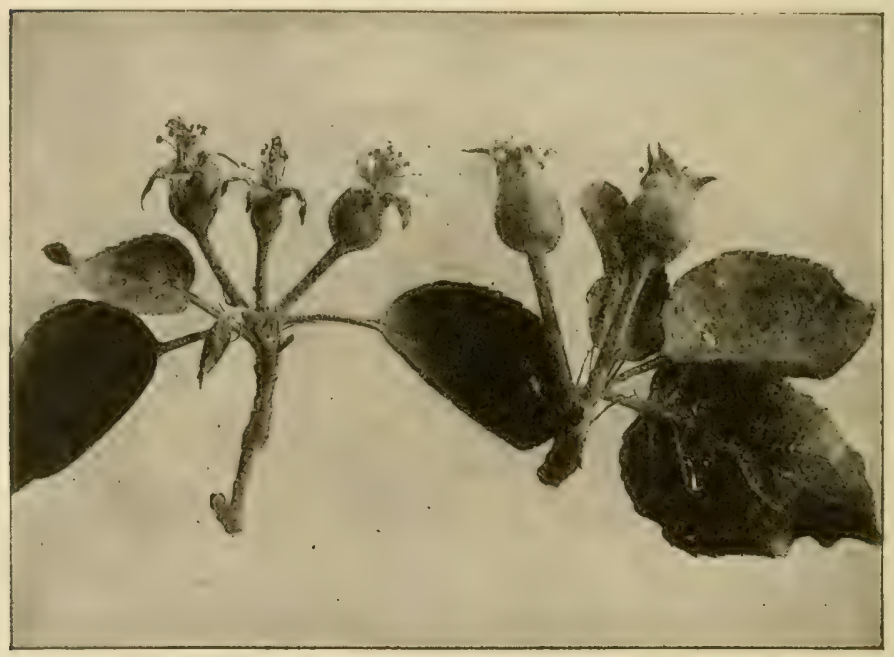

Apple clusters, on the left, with calyx lobes spread and in good condition for spraying; on the right, with calyx lobes closed and too late for effective spraying.

ing with some poison such as the arsenical compounds, which, if eaten, will kill them. The sucking insects can not be destroyed in this way, since the poison does not penetrate into the plant tissues whence they draw their food. For this group it is necessary to use some preparation that will either act on their bodies as a caustic, or that will smother 
them by closing their breathing pores, or that will fill the air with poisonous fumes.

Fungous enemies.-Almost every kind of garden fruit is a prey to one or more parasitic enemies in the form

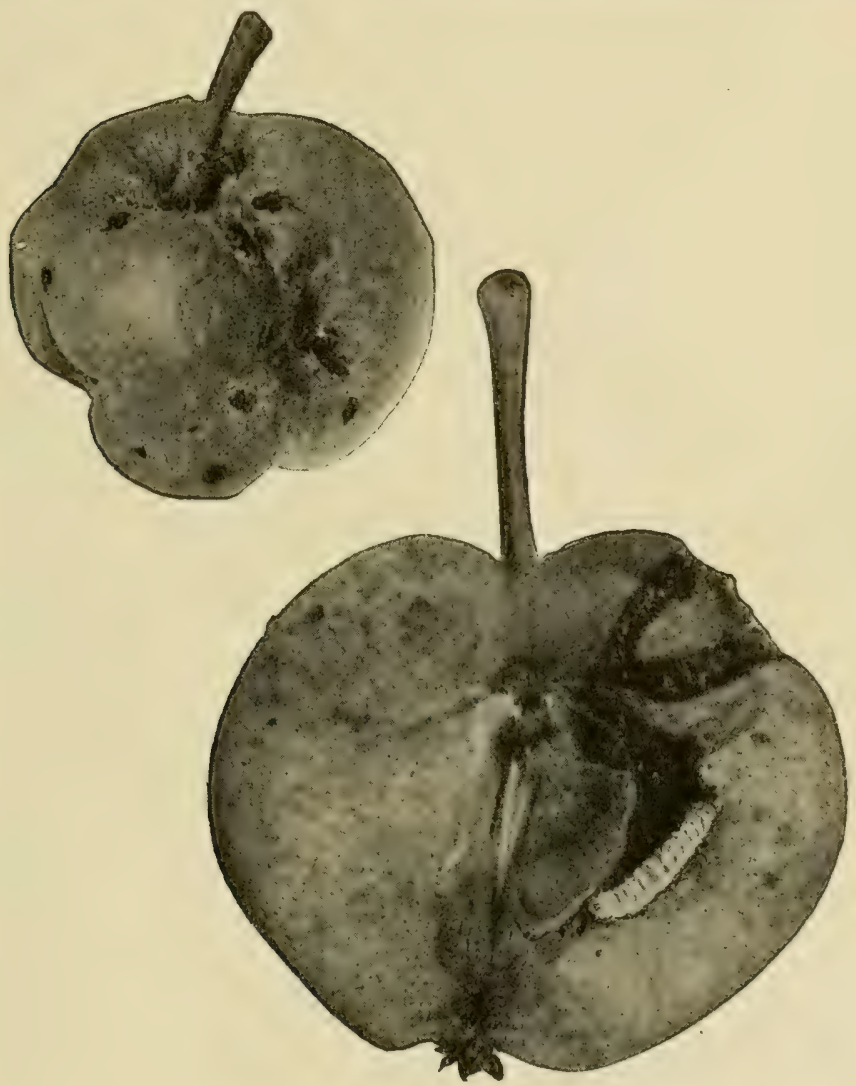

Two common defects of apples. The codling moth causes greater loss to many apple growers than all other insects com. bined, despite the fact that this pest can be controlled by proper spraying. 
of growths on fruit, foliage or branches. For these pests sprays are used that are fatal to the parasite but not injurious to the plant.

Scab, rust, rot, blight and mildew are examples of fungous enemies. In some cases tiie one variety attacks several different garden fruits, thus allowing the same spraying mixture to be used on all the various crops. In other cases, different fungicide compounds must be employed for the different fruits.

Spraying.-The composition of some of the different spraying mixtures is described in Chapter XIII. It is evident from the nature of the insects and diseases attacking fruit that no one remedy will serve all purposes. Apples, plums, peaches, pears and cherries are the special target of a wide range of insects and fungi. These plants will need several sprayings, using different insecticides and fungicides according to the pest threatening. Every fruit gardener must understand the nature and use of the required compounds.

All fruit trees should be treated with a dormant spray, applied some time during the dormant season, usually about March. The object is to kill the various scale insecis and mites which winter on the tree. Bordeaux mixture or limesulphur solution is effective. Bordeaux should not be used on plums or peaches.

A second spraying should be applied just after the leaf buds burst, but before the blossoms open. The mixture may be a combination of lime-sulphur or Bordeaux and arsenate of lead. This is to destroy the curculio, scab, leaf blight and similar enemies.

Apples should be given their third spraying immediately after the petals fall, but before the calyx tubes close. The chief purpose of this application is to destroy the codlingmoth, which is responsible for most of our wormy apples. The same mixture may be used as in the second spraying. 


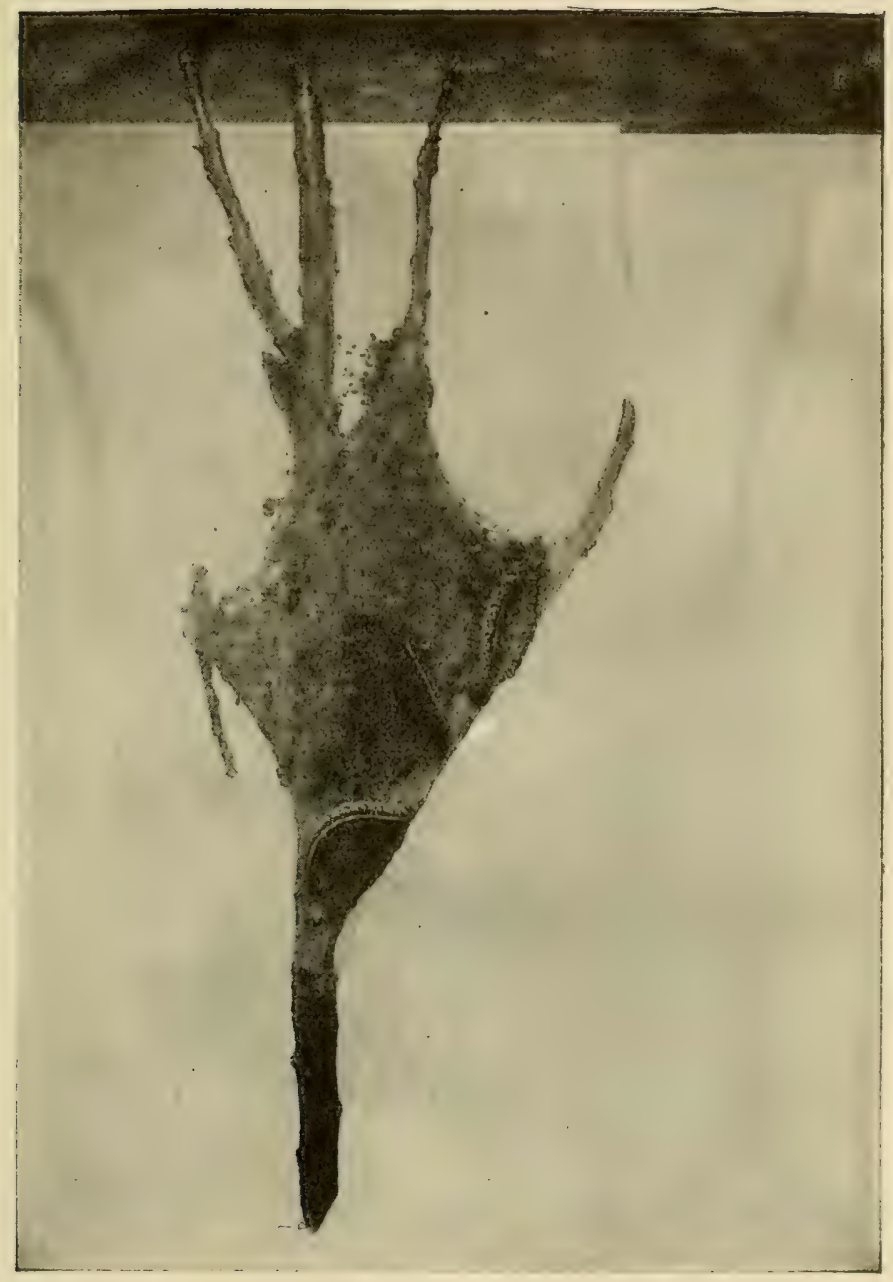

Nest and larra of the apple-tree tent caterpillar. 
Apples should be sprayed again several weeks after the petals fall, and at least once more during the season, probably in July, in all regions where the enemies are troublesome.

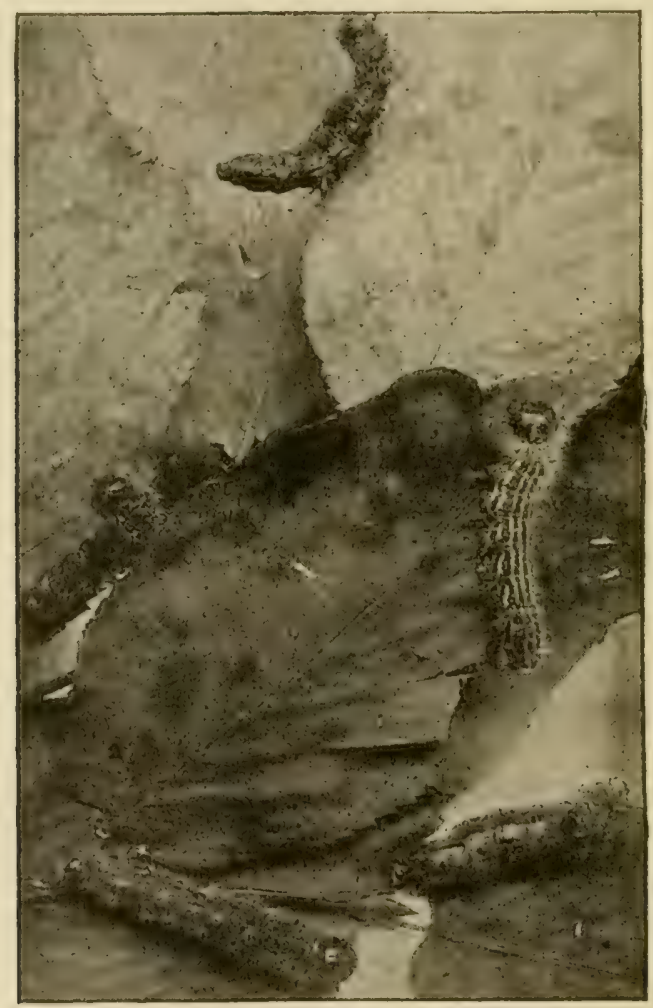

Yellow-necked caterpillars feeding. The caterpillar at the top shows characteristic pose when disturbed.

Pears should receive their third spraying just before the blossoms open, another as the petals fall, and a final spraying several weeks later. Peaches, plums and cher- 
ries must also receive several sprayings if the crop is to be free from worms, blight, rot and other troubles that threaten the final success of the crop.

Spraying machines.-While it seems that a great deal of trouble and expense are required to protect the farm fruit garden, it is really less than it appears if a good spraying pump is used. There are many different kinds of these, each suited for particular needs, and none is expensive. Whatever make of pump is secured, it must be powerful enough to drive a fine spray to every part of the largest tree.

\section{TOPICS FOR INVESTIGATION}

1. Compare the diagram of your fruit garden with the plan shown on page 181. Which is the better plan as to arrangement? Are any fruits shown in the plan which you do not have? Could they be successfully grown in your region? Do you have any not shown in the plan?

2. Compare the proportion of space given each fruit in the plan with the proportion shown in your diagram. What is your conclusion? Compare the proportion of space given each fruit in the different gardens represented at the school, and determine which garden is best balanced.

3. Make a list of all your home fruit by varieties, constructing a table similar to that on page 183.

4. Is your fruit garden well cultivated and free from weeds? Are any of the plants sod-bound? Is mulching used?

5. Learn to identify surely and quickly each of the different fruit trees, shrubs and vines, either when in foliage or dormant.

6. Go with your teacher or some expert gardener to some near-by fruit garden and learn how and why the different plants should be pruned. Is your home garden well pruned?

7. Bring specimen branches or stems of the different garden fruits and show where and how the fruit is borne. Make a drawing in each case.

8. Is your fruit garden regularly sprayed? What kind 


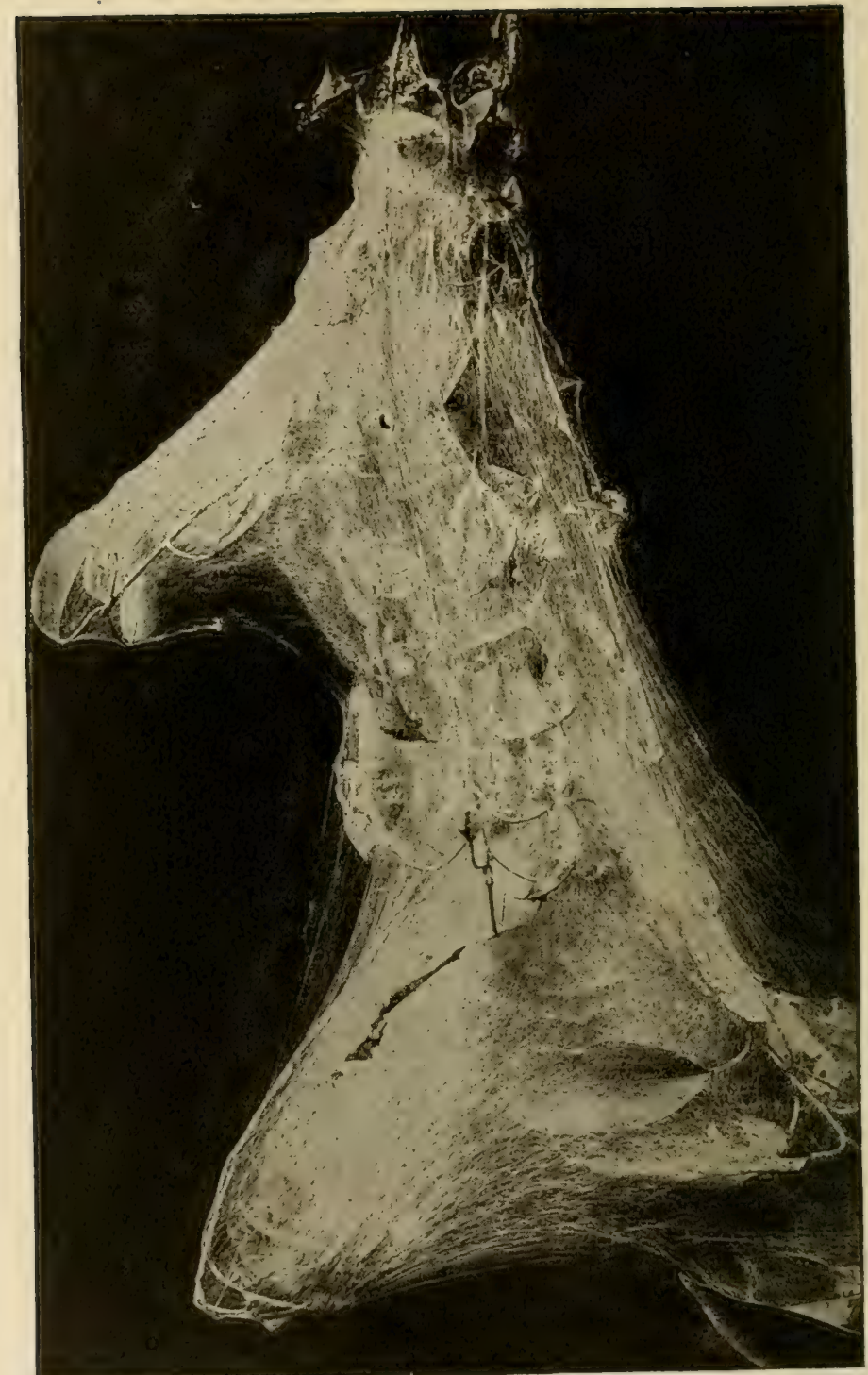

Nest of the fall web worm. The caterpillars work inside the web and not upon the outside as do the tent caterpillars. 
of spray machine is used? What mixtures? What enemies are most troublesome in the case of each fruit?

9. Make a collection of all the different insects and fungi you can find that damage fruit in your region. Learn to identify each. What spray is fatal to each?

10. Estimate the value of the fruit produced in your

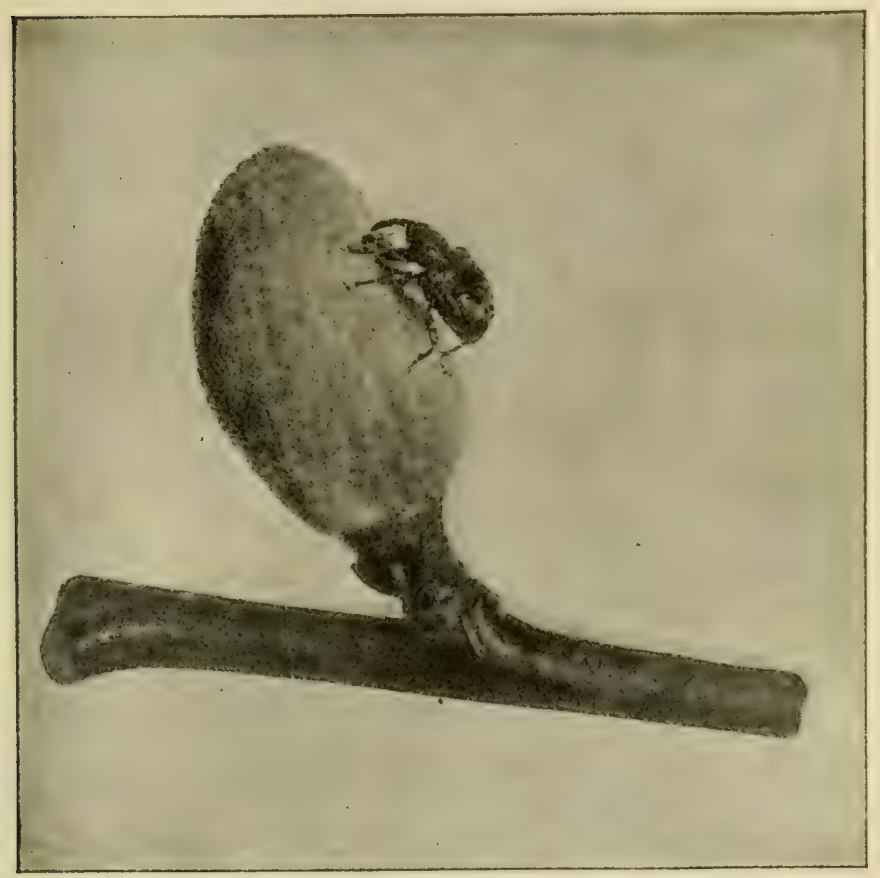

The plum curculio on a young peach.

home garden last year. Did it pay for the ground occupied and the time used? How can the amount of fruit and its net profit be increased? What are your plans in this direction for next year?

11. Show how to keep a debit and credit account of the fruit garden. It should contain the receipts and expenditures for at least three varieties of fruits. 


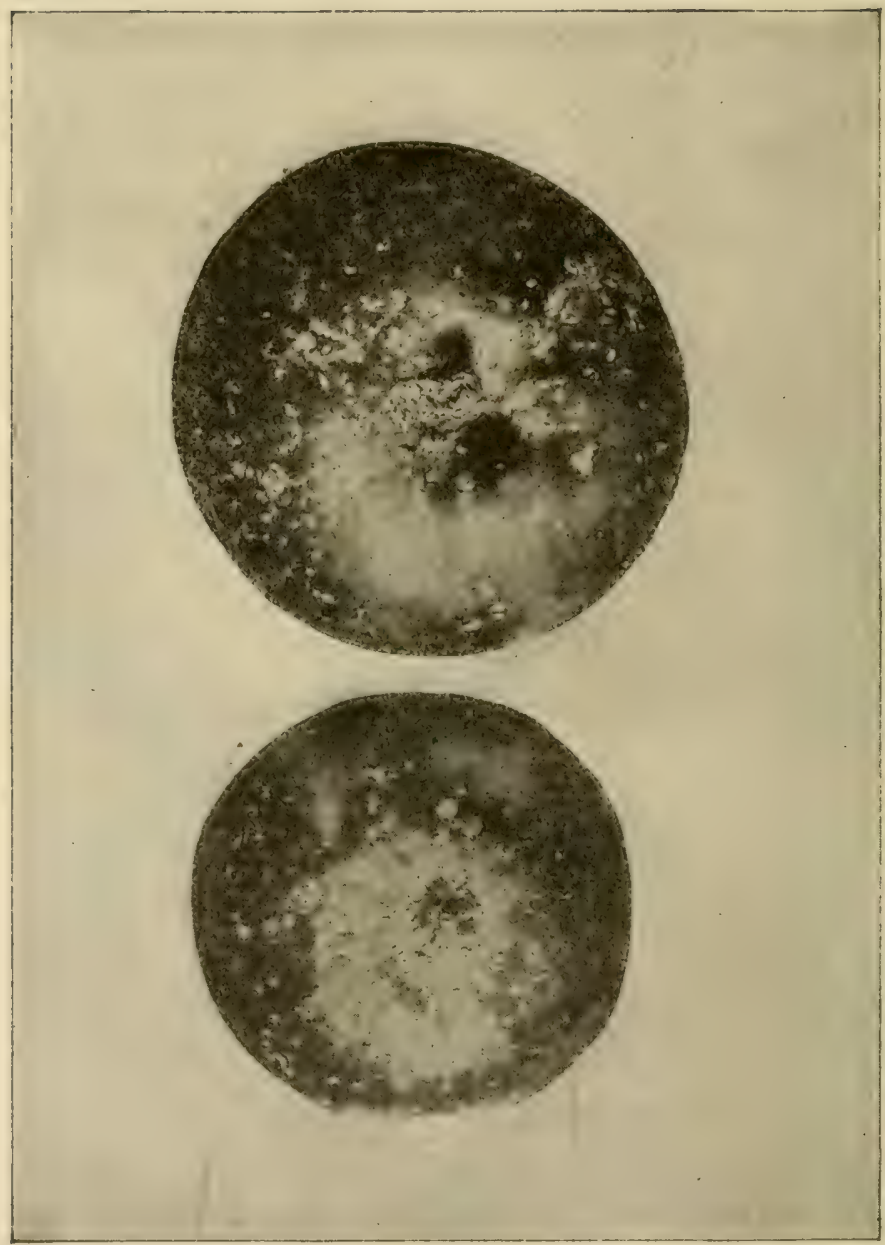

Baldwin apple badly infested with San Jose scale. 
12. Show upon the map the different fruit belts and estimate from the crop census records the crop production for the past season in the various states. Locate upon the map the citrus fruit states, the apple states, the small fruit states.

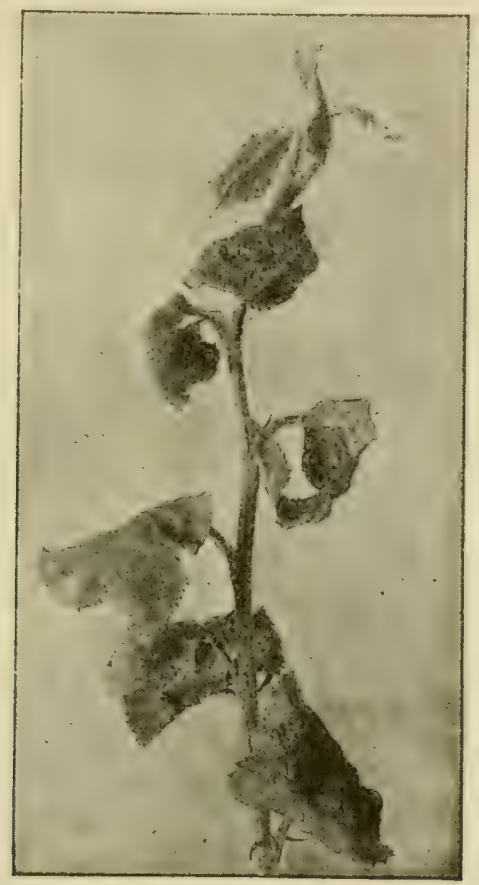

Twig showing appearance of leares infested with apple aphis.

\section{Fruit Demonstrations}

The demonstrations in connection with the fruit studies serve a double purpose: (1) to arouse definite interest of the school and community in fruit as a profitable crop for the farm and home, and (2) to show the relation of fruit to the daily diet. 


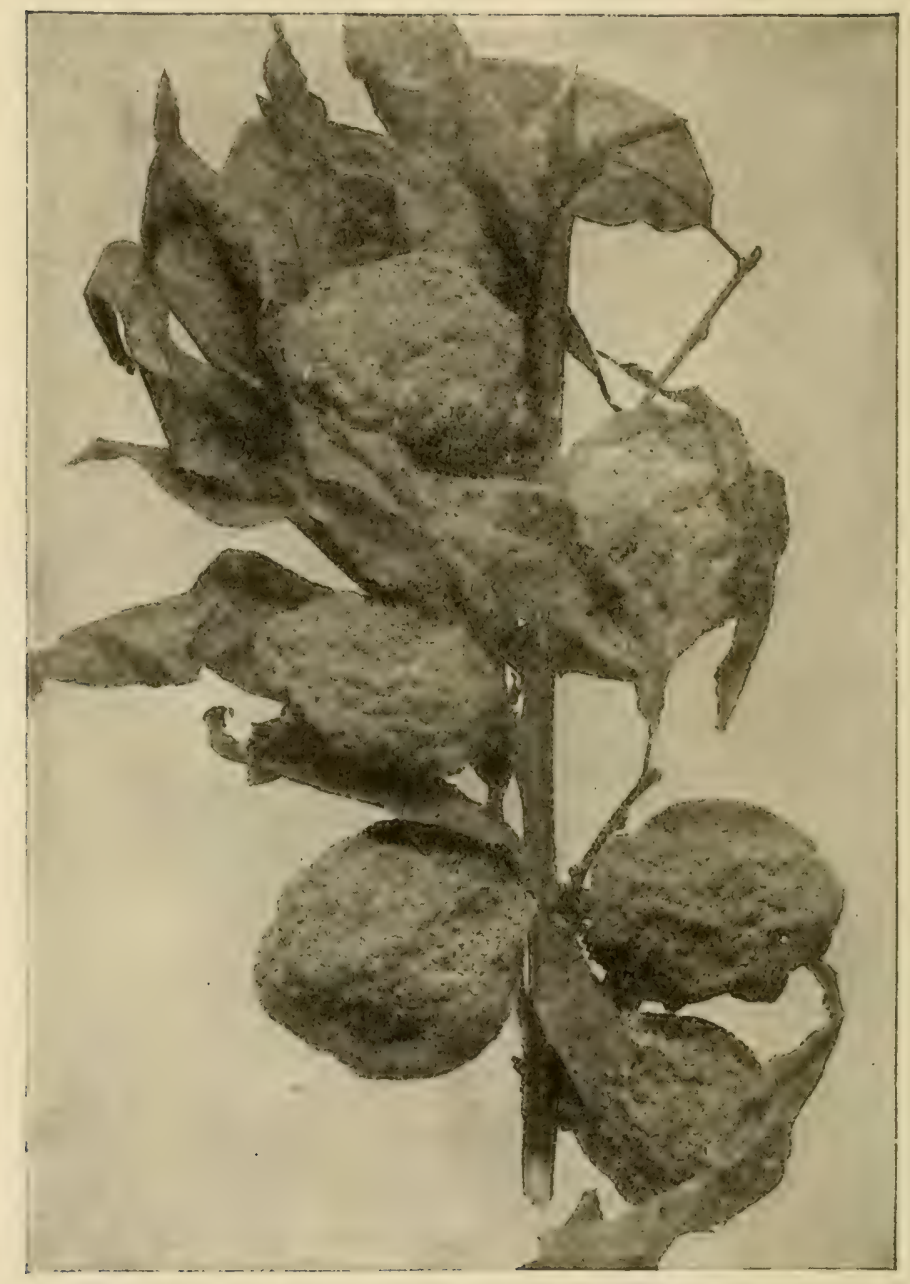

Peaches destroyed by brown rot, showing gray masses of spores of the fungus. 
1. Demonstrate how to can the various kinds of local fruits by use of the cold pack method.

2. Demonstrate and explain the use of other methods of canning fruits, and of glass and tin containers for the canning of surplus fruits of the garden and orchard.

3. The proper method of scalding, blanching, paring, coring, stemming, hulling and seeding of various kinds of fruits.

4. Show how to grade and crate the various kinds of fruits for the market, and the use of parcel-post packs. Show how to prepare exhibits of fruit for fairs, club festivals, educational meetings, etc.

\section{Fruit Play Contests}

Among the most interesting play contests in connection with the agricultural and home economic work of the school are the fruit play contests. These contests will not only serve to create interest in the study, but will actually teach valuable lessons on how to do the important things related to the project.

1. Fruit judging contest.

2. Paring, seeding and stemming contests.

3. Oral recipe giving contest.

4. Fruit pie guessing games.

5. Spelling contest, in which the fruit terms, names and related interests are used.

6. Apple coring and paring contest. This is especially valuable in teaching skill in the handling of knives, and in encouraging practise in rapid paring and coring without too much loss of food material.

7. Apple or fruit races. These can be conducted very much on the same plan as potato and egg races, which are known to all. 


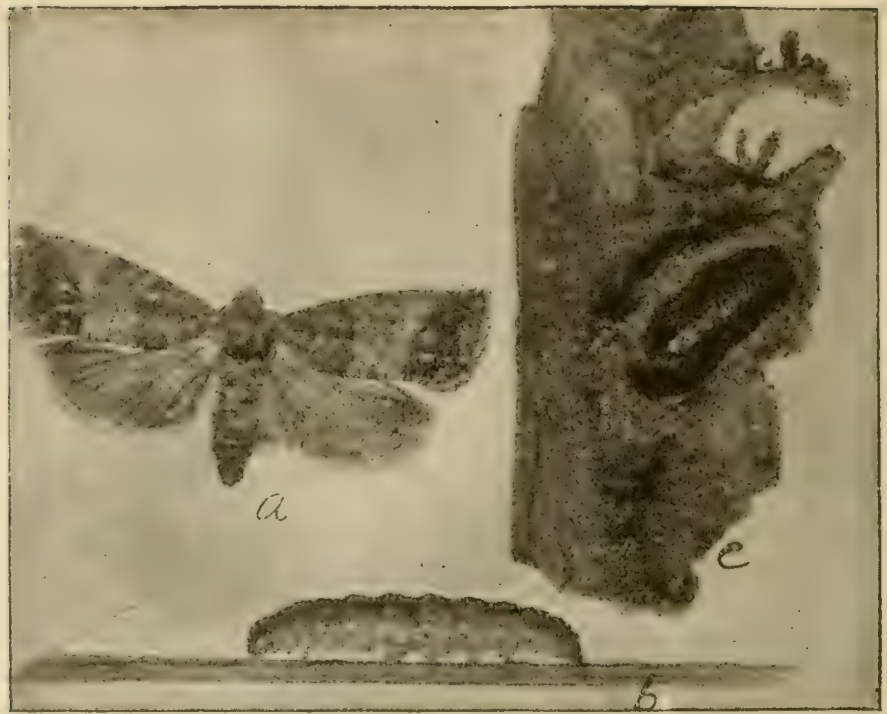

Stages of the codling moth; (a) moth; (b) larva; (c) pupa in its cocoon.

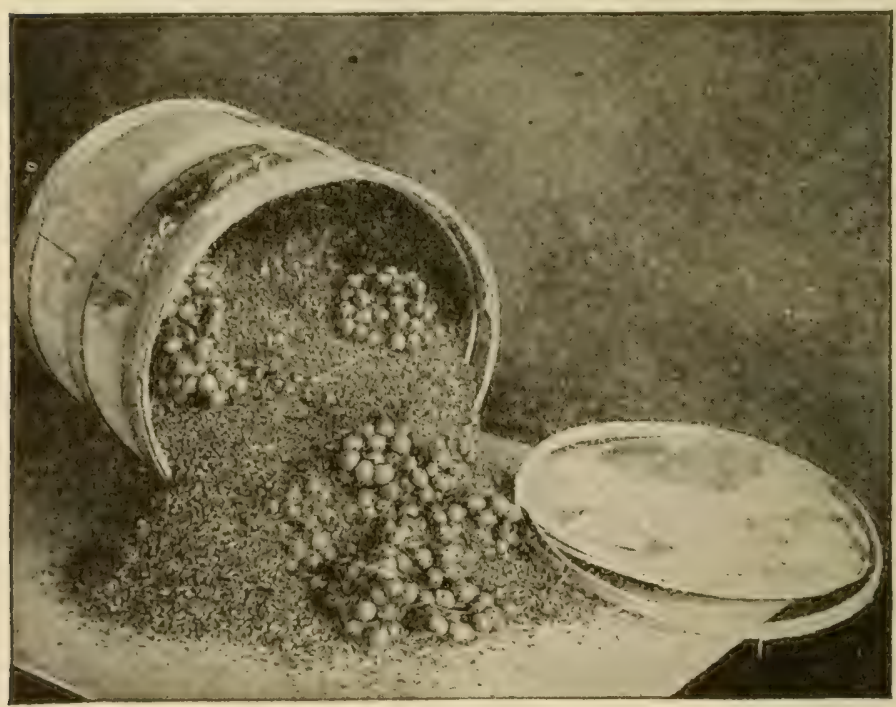

California grapes and packing for shipping. 
8. Variety naming contests.

9. Fruit art contests, in which the contestants are to draw free hand on paper the various types of fruit placed before them.

10. Fruit grading and packing contests, including preparation of parcel-post packages.

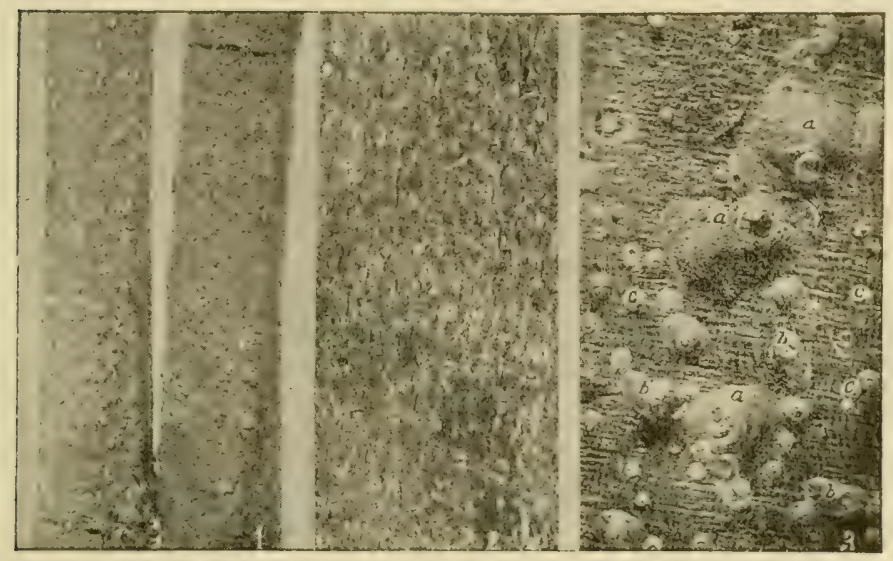

San Jose Scale.

(1) Natural size on apple trig. (2) Scales on rose stem enlarged. (3) Scales on apple twig, much enlarged. (a) Adult female scales; (b) male scales; (c) young developing scales. The depressed ring around the raised central dot is a characteristic of this species.

\section{Fruit Club Project}

The organization of a fruit club is not only possible but interesting and practical. This is illustrated in connection with apple clubs, in which each member takes charge for the entire season of a row or square of ten or twelve apple trees, keeps records, does all the pruning, spraying, plowing, trimming, picking, grading, crating, marketing, and 
camning of windfall apples. In some cases it may be advisable for the class to take entire charge of an orchard and apportion it into as many parts as there are members. The basis of award may be as follows:

1. Management of orchard

2. Condition of the orchard at clnse of season_._-_._-_...- 20

3. Net profit on investment-_-_-_-_-_-_-_-_-_-_-_-_-_- 20

4. Exhibit and quality of both fresh and canned products 20

5. Crop report and story of season's work-_-_-_-_-_-_-_-_- 20

Total score-_-_-_- 100

The above score can be modified to suit club projects with strawberries, peaches, pears and citrus fruits.

The fall fruit and vegretable festival held in connection with the school for the entire community should be one of the most interesting events of the year. At this time the demonstrations, exhibits and play contests can be successfully carried out with definite educational and recreative value to all. 


\section{CHAPTER XII}

\section{THE TOMATO}

TOMATOES are becoming so important a garden and 1 truck crop as to deserve special mention. They came originally from tropical regions, where the vines bear fruit all the year.

\section{Importance of the Tomato}

For a long time tomatoes were not known to have value as a food, but were thought to be poison. The plants were then cultivated for ornamental purposes and were known as "love apples."

Uses now as food.-The chief value of tomatoes as a food lies in the sugars and protein, and in a stimulating effect on digestion. More than three hundred recipes have been worked out in preparing tomatoes for our tables. Many more people than now use tomatoes as a part of their diet will do so when they come to know more of their value.

Tomato growing states.-Tomatoes will grow successfully in almost every part of the United States. Maryland is one of the largest tomato producing states, and has the largest number of tomato canning factories. New Jersey, Indiana, California and Delaware rank next.

Hundreds of thousands of cases of tomatoes are now being grown and canned annually by the girls of the canning clubs. It is estimated that, after paying the expenses of raising her crop, a club girl from ten to eighteen years of age can make from ten dollars to twenty-five dollars a day for the time she puts in canning the crop for market. 


\section{Varieties}

In selecting the varieties for the home garden the length of season, quality, y-ield and appearance of the crop should be considered.

Early varieties.-There are a great many varieties from which to select. Amons the favorites are: Earliana, Chalk's Early Jeacell, Bomic Best, Globe and Prince's June Pink.

Late varieties.-The chief late varieties are: Stone, Matchless, Beauty, Ponderosa, Dicarf Stone, Acme and Trophy.

\section{Raising the Crop}

Where the seasons are short it is neccssary to start the plants in a hotbed and transplant them when all danger of frost is past. In northermmost states it is well to use the cold-frame for hardening off the plants before setting in the garden. This process strengthens the plants and enables the crop to mature before freezing in the fall.

Transplanting.--IIave the seed bed well prepared by deep spading or plowing, thoroughly manured with a wellrotted barnyard manure, and well pulverized. The plat should be marked off in rows three or four feet apart, according to the variety of tomatoes grown. The large hardy varieties will require a distance of four feet each way, while the dwarf varicties will do well three fect apart. In transplanting, have the holes opened up, remove the plants from cold-frames or hotbed without injuring the roots. Allow enough soil to accompany the roots so that the plant may go on growing without pause.

Pruning.- Much of the success of the tomato crop depends on proper pruning and staking. Tomatoes are especially liable to fungous and bacterial diseases, and therefore need to be kept from the ground and given an abun- 
dance of sunlight. The vines should be pruned at the time of transplanting or afterward by pinching off the suckers,

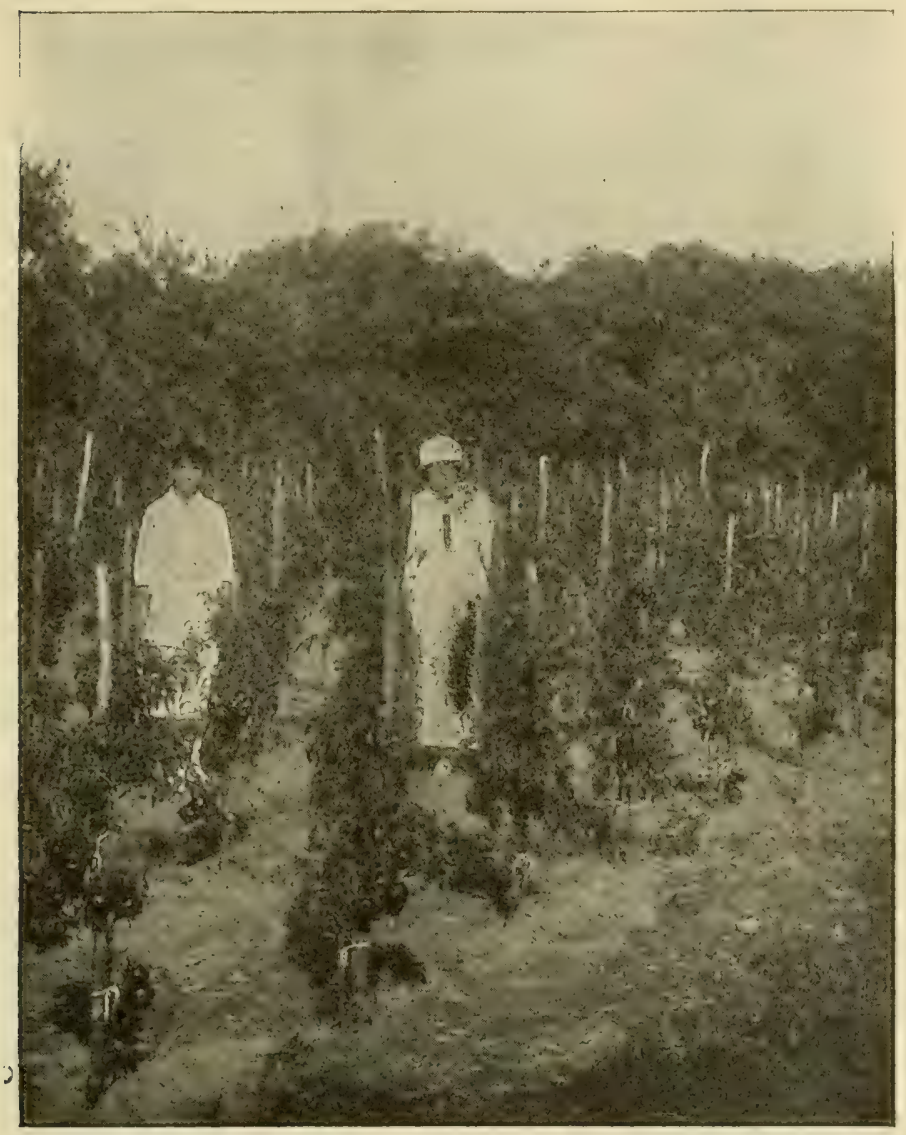

A plot of tomatoes showing the result of careful pruning and staking.

or secondary leaf buds, found in the axils of the leaves. This will cause the plant to grow tall instead of spreading out. After each vine has developed four or five clusters 
of fruit the top but should be pinched off to prevent the plant from growing too high.

Staking.-The method of pruning described requires staking to support the vines. For this purpose a single stake may be driven beside each hill, or a continuous meshed wire or other form of fence may be used. Soft twine or cloth should be used for tying the vines. No loop should be drawn tightly around the plant.

Spraying.--The tomato vines should be thoroughly sprayed with Bordeatux mixture several times during the season. The first spray should be given about the time the first fruit begins to form, or even earlier if the season is warm and moist. This will prevent the plants from being attacked by mildew. Remove at once any tomatoes that show a brownish discolored area about the blossom end. This will prevent the spread of disease.

\section{Harvesting and Marketing}

Gathering the crop.-Tomatoes should be gathered when ripe and firm and should be handled with great care to prevent crushing or bruising. For marketing they should be graded in three classes, prime, medium and culls. The more nearly uniform in size, shape and color, the more will the market offer for the product.

Canning.-Tomatoes for canning purposes should be thoroughly ripened and be of the deep red color, smooth and firm. They should be canned whole so as to permit the use of the tomato in as many different ways as is possible with the fresh tomato. Water should not be added to jars or cans when canning tomatoes, as this will dilute their flavor, destroy their color, and injure their purity. The culls may be put up for such purposes as puree, for tomato soup, breaded tomitoes, etc. 


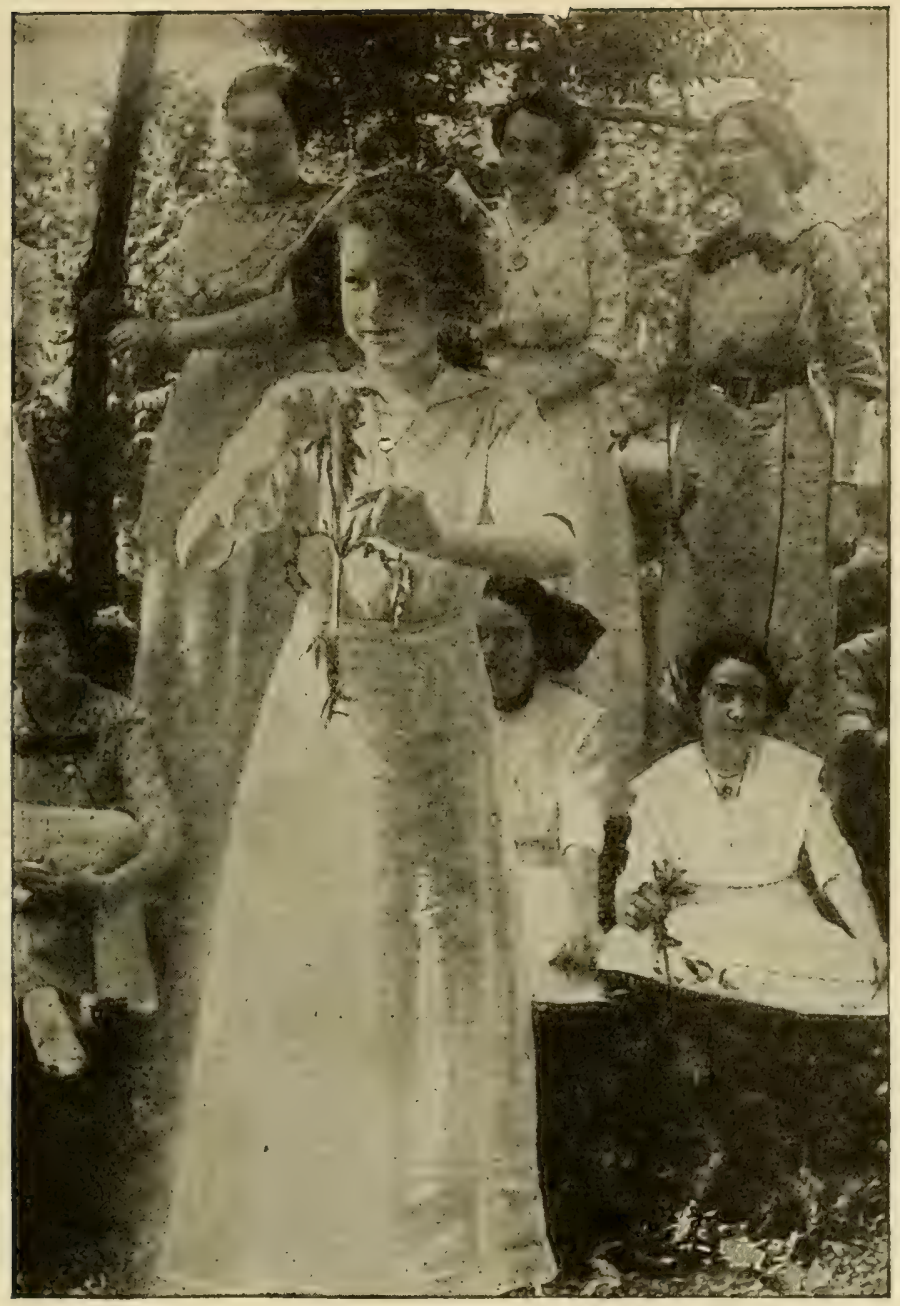

An Iowa club girl showing how to prune the tomato plant by pinching off the axillary bud. 


\section{TOPICS FOR INVESTIGATION}

1. Write a brief history of the tomato. Name the different uses to which the tomato is put in your own home. Can you suggest still other uses? Why should tomatoes be canned whole?

2. How many quarts of tomatoes did you raise and can last year? What kind of soil is best adapted to the culture of tomatoes?

3. Make a drawing of a hothed, giving all dimensions. iVrite out full directions for preparing and filling and caring for the bed.

4. Show how to keep a bookkeeping account of onetenth acre of tomatoes, covering items of cost and cash received from the time of preparing the hotbed to the canning and marketing of the crop.

5. Show on the map of the United States the greatest tomato states, and the approximate location of the territory in which the early varieties should be grown and the territory in which the late varieties should be grown.

\section{Demonstrations with the Tomato}

1. Demonstrate how to scald, pare and core the tomato.

2. How to can tomatoes.

3. How to grade and crate for parcel-post shipment, prime grade tomatoes.

4. Demonstrate how to use the tomato in the home by preparing certain dishes.

5. Demonstrate the proper method of pruning and staking of tomato vines.

6. Other demonstrations of cultivation. hoeing, spraying, thinning, etc., can be undertaken in connection with tomato culture.

\section{Tomato Play Contests}

1. Tomato race, conducted on very much the same plan as the potato race. 
2. Tomato judging contest.

3. Tomato canning contest.

4. Can labeling contest.

5. Essay writing contest on the origin and history of the tomato.

6. Tomato problems contest.

7. Tomato recipe giving contest.

\section{Tomato Club Project}

One of the most interesting club projects is the growing of a club plat of tomatoes and studying all of the interesting lessons from the selection of the variety of seed, through the hotbed, cold-frame, transplanting, pruning, staking, cultivating, gathering, grading, crating, marketing and home canning of the surplus product. To this can be added finally the working up of the product into various dishes for the table. For the rural communities one-tenth of an acre should be the acreage basis, and for city and village work, not less than a square rod.

The basis of award should be:

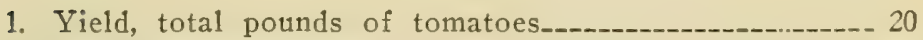

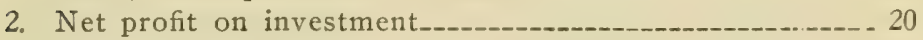

3. Quality, both fresh and canned products_._._._._._._... 20

4. Variety of canned and prepared tomato products on exhibit

5. Cost record and story "How I Made, Canned and Mar-

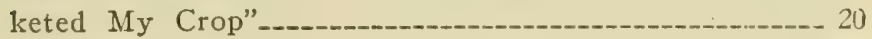

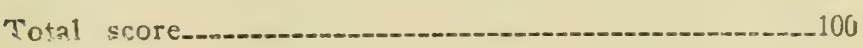




\section{CHAPTER XIII}

\section{GARDEN AND ORCHARD SPRAYS}

DOISONOUS sprays for the destruction of insect and I fungi of garden and orchards have come into general use. Upon their successful application often depends the value of the crop, both as to quantity and quality. Not infrequently an entire failure of yield results from the attacls of these pests when they are not destroyed in time. Worm' and scabby apples, rotting peaches and plums, blighted berrics and diseased vegetableș prove the necessity for somi: means of stopping their ravages.

The purpose of the two classes of mixtures, fungicides and insecticides, is indicated by the name applied; the cide in each word means to kill. Only the more important and common fungicides and insecticides will be described here

\section{Bordeautr Mirture}

Bordeaux mixture is one of the most successful and widely used fungicides. Used at proper strength it is harmless to most plants, though it has been found injurious to some, especially plums and, in less degree, peaches. It will ilso stain foliage and fruit upon which it falls.

Composition.-Bordeaux mixture is made when needed, of copper sulphate (blue vitriol) and lime. The strength may be varied, depending on the required use. The proportions most generally accepted are:

4 pounds of copper sulphate.

6 pounds of fresh lime.

50 gallons of water. 


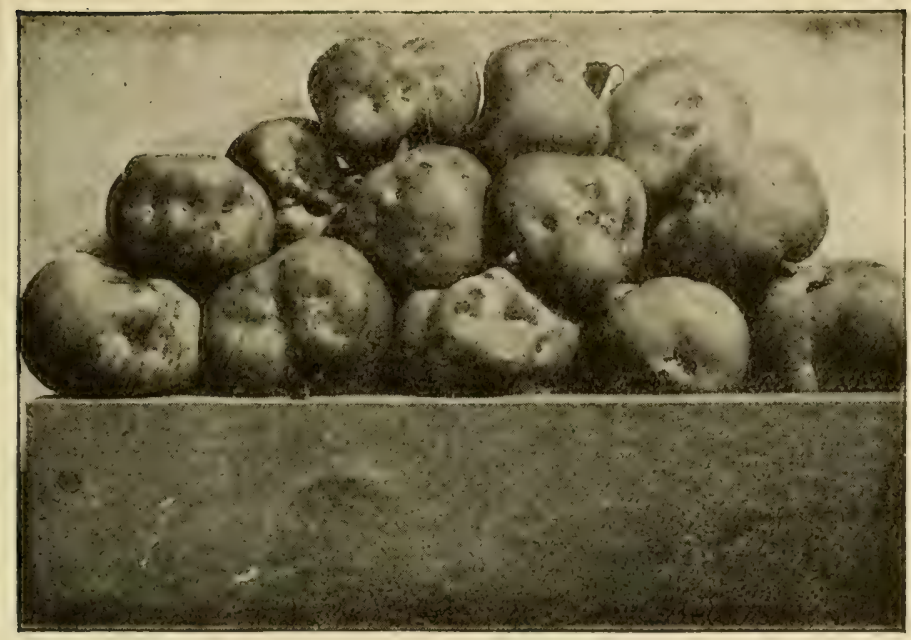

Duchess apples, showing results of punctures of the plum curculio. This injury could have been saved by proper spraying.

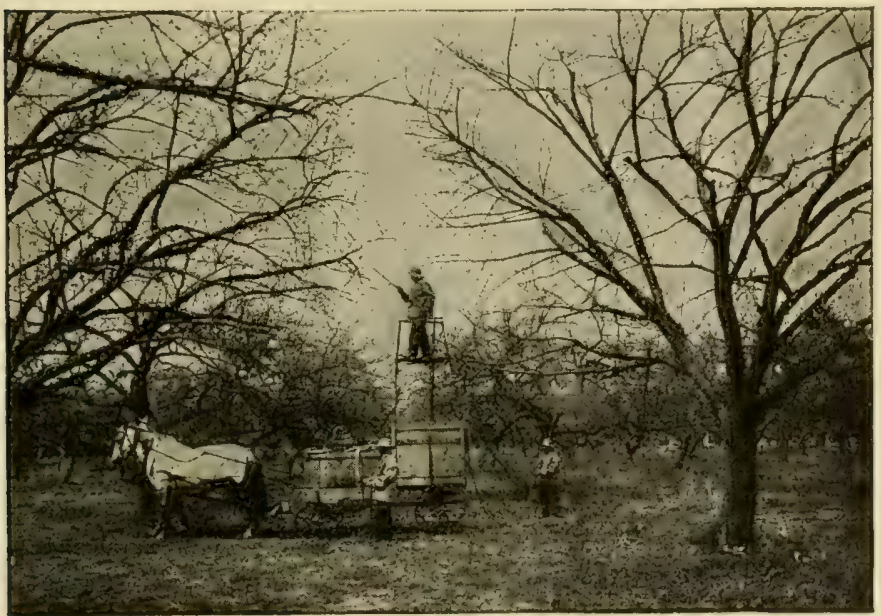

Spraying apple trees. 
The copper sulphate is the active agent in killing the fungi, while the lime prevents injury to the plant. Besides this "4-6-50" mixture, other formulas frequently used are of the proportions 4-4-50, and 5-5-50.

Making the mixture.-When but a small amount of spraying is to be done the only equipment required for making Bordeatx mixture is a fifty-gallon barrel, two twenty-five gallon tubs, buckets and a fine-mesh sieve.

Fill one of the smaller tubs with water, and suspend just below the surface four pounds of copper sulphate in a loose bag, giving it time to dissolve. This will require about an hour, though the process can be hastened by using hot water. Slake six pounds of lime in the other tub, using hot water and reducing the lime to a paste. When the lime has cooled, dilute to twenty-five gallons.

Now stir the contents of the tubs, and pour bucketfuls of each mixture simultaneously through a sieve into the larger barrcl, making sure that the streams mix. Stir well, and the compound is ready for the spraying machine.

Use.-The amount neerled for a garden can be judged from the fact that a tree in full leaf and having a spread of twenty-five feet will require about four gallons of the mixture. Most beginnners use too little, and hence fail to get the best results.

Bordeaux mixture is not effective against insects. If, however, arsenate of lead in the proportion of two pounds to each barrel of the mixture be combined with it, the compound will serve as a check on both insests and fungous diseases. Scab, apple blotch, bitter rot, wilt, mildew and brown rot are controlled by Bordeaux mixture.

\section{Lime-Sulphur Mixture}

The lime-sulphur mixture, besides being an insecticide for certain plant insects, is also a fungicide serving the same 
general purpose as Bordeaux mixture. It has the advantage of not injuring certain plants, such as peaches and plums, to which Bordeaux mixture is not adapted. Some fruit growers are coming to employ it as their principal fungicide.

Composition.-The strength of the mixture may vary, the proportion of the ingredients commonly being:

8 pounds of flour of sulphur.

8 pounds of fresh lime.

50 gallons of water.

iNaking the mixture.-The lime-sulphur compound may be made by several different processes, one of the simplest of which is the self-boiling process. To make the selfboiled mixture, put eight pounds of lime to slake, and while the slaking process is going on, sift over the lime eight pounds of finely powdered sulphur. Stir constantly, adding water until a thin paste is secured. Dilute to fifty gallons, and strain before using.

Lime-sulphur may be also bought ready for use. Although it costs slightly more than the home-made product, the time saved makes the. commercial form cheaper if but a small amount is required.

Use.-Lime-sulphur controls scale insects and curculio, as well as such fungous diseases as scab, leaf curl, brown rot, etc. Arsenate of lead may be used with this mixture also.

\section{Arsenate of Lead}

Arsenate of lead is one of the most important stomach insecticides known, and has largely taken the place of Paris green with most fruit growers. It seems to be palatable to all garden insects. It adheres well to foliage, and hence does not easily wash off in showers as does Paris green. It will not injure plants no matter how strong the solutic?. 
And it also acts as a fungicide, especially when mixed with lime-sulphur.

Composition.-Arsenate of lead is easily compounded, the usual formula being:

22 ounces acetate of lead dissolved in 2 gallons of warm water.

8 ounces arsenate of soda dissolved in 1 gallon of water. (Use wooden pail in each case.)

The two solutions are now poured together and diluted with water to make a mixture of fifty gallons, when it is ready to spray.

Arsenate of lead may also be procured in the form of a paste ready to dilute for the spraying machine. Three pounds of the commercial paste will make fifty gallons of spray. It will hardly pay to go to the trouble of mixing the compound at home, since the ready-made product usually costs no more than the ingredients for making the mixture.

Use.-The arsenate of lead mixture may be used either alone or with fungicides for destroying nearly the whole range of biting insects attacking garden fruits. It has proved of the greatest service, especially in the spraying of apples.

\section{Paris Green}

Paris green is one of the oldest and best known of the insect poisons. Several thousand tons are used each year for this purpose.

Composition.-Paris green is often prepared for spraying by simply dissolving from four to eight ounces in fifty gallons of water. The standard formula, however, is:

4 ounces of Paris green.

$1 / 2$ pound of lime.

50 gallons of water.

The lime is to be slaked and mixed with the water. The 


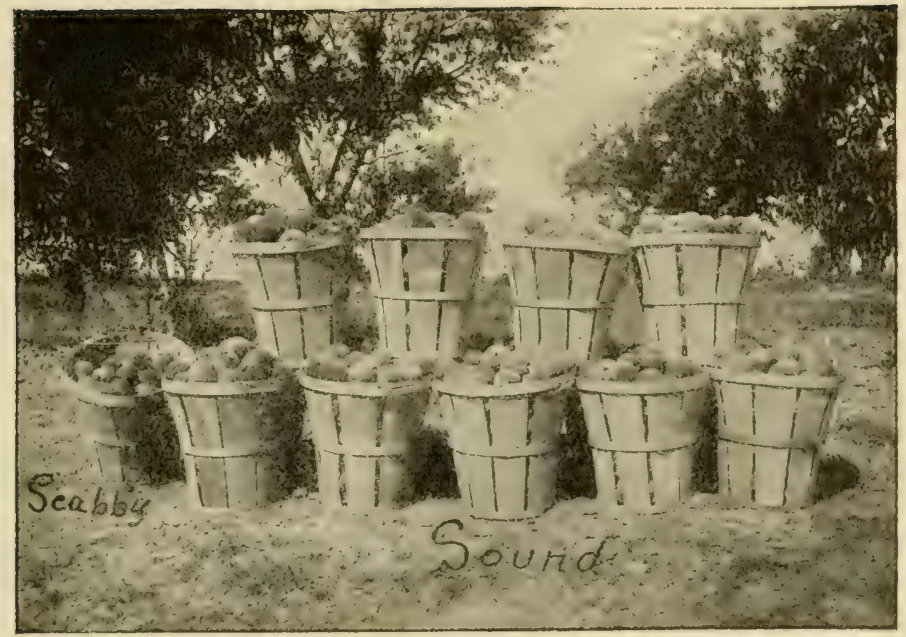

Crop from four sprayed peach trees; one basket of scabby fruit at the left; the remainder sound.

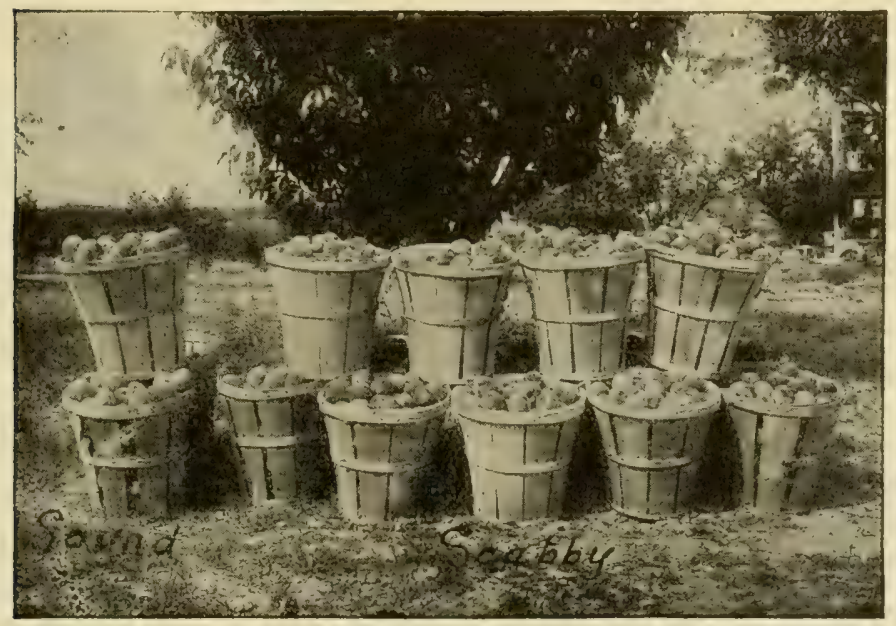

Crop from four unsprayed peach trees. Sound fruit in three baskets at left; the remainder scabby. 
Paris green is mixed to paste form in a small quantity of water, and then adder to the water.

Use.-Paris green may be used in combination with the Bordeaux mixture, but not with lime-sulphur. When mixing it with Bordeaux, the Paris green should be combined with the diluted lime before it is brought in contact with the copper sulphate.

\section{Kerosene Emulsion}

Kerosene is one of the best of contact insecticides. A small particle of it on any part of the bocly means certain death to any insect. Pure kerosene, however, will injure most plants, and hence must be used in a mixture. The best of these is what is known as kerosene emulsion.

Composition.-The formula for the mixture commonly used is :

$1 / 2$ pound hard laundry soap shaved fine.

1 gallon of soft water.

2 gallons of kerosene.

Making the emulsion.-One of the advantages in the use of this spray is the ease with which it can be made. Dissolve the soap in one gallon of boiling water; remove from the stove and at once add two gallons of kerosene. Stir while cooling until a soft, butter-like mass is obtained. Dilute one part of this stock solution with ten or twelve parts of water as needed for spraying.

Use.-Kerosene emulsion may be used on all kinds of tender foliage without injury. It will control the various kinds of plant lice, slugs, etc.

\section{The Resin-Lime Mixture}

One of the difficulties in using many of the insecticides and fungicides is that they do not adhere well to the smooth foliage of the plants. The resin-lime mixture is often used 
in combination with other compounds to insure their sticking to the plants until they have done their work.

Composition.-The formula employed is:

5 pounds of pulverized resin.

1 pound of concentrated lie.

1 pint of fish or some other animal oil.

5 gallons of water.

This mixture is the stock solution, which is still further diluted as used.

Making the mixture.-The oil, resin and one gallon of cold water are to be put into an iron kettle and heated until the resin softens. Add the lime and stir well. Then add four gallons of hot water and boil until a little mixed with cold water gives a clear amber-colored liquid. Add water to make up for what has boiled away, making five gallons of the compound.

Use.-This spray, besides causing other mixtures to adhere to the foliage of plants, is itself an excellent contact insecticide. Its principal effect is through making a smothering coating over the body of the insect. It is used in some regions as a dormant wash for the control of scale insects. When used with Paris green or Bordeaux, two gallons of resin-lime compound are mixed wiin eight gallons of water, and this added to forty gallons of the spray.

\section{TOPICS FOR INVESTIGATION}

1. Copper sulphate costs from seven to ten cents a pound, and lime, when bought in small quantities, about fifteen cents a pound. What, then, should be the outlay in making fifty gallons of Bordeaux mixture? What would it cost for material to spray ten apple trees averaging a twenty-five-foot spread?

2. Under the direction of the teacher and with great care in handling both before and after mixing, let the class 
join in making up a Bordeaux mixture, substituting one ounce for each pound of the ingredients in the formula, and a corresponding amount of water. What is the color of the compound? Will it keep indefinitely if covered to save evaporation?

3. Nake a lime-sulphur mixture, reducing the amounts as before to one ounce for each pound of ingredients.

4. Make up a kerosene emulsion, using one pint of kerosene and a corresponding amount of other ingredients.

5. Secure catalogs describing spraying machines, examine the different makes, and decide which is best for the use you would require in your home garden and orchard. If uncertain write your state agricultural college about it. 


\section{CHAPTER XIV}

\section{HOME CANNING OF FRUITS AND VEGE- TABLES}

T is both practicable and economical to can the surplus 1 vegetables, fruit, sweet corn, greens and other such products that commonly go to waste in the orchard, field and garden.

\section{Home Canned Products and the Table}

When the farm home has learned to can its surplus fresh food products, then the family can have a balanced ration every day in the year, and the cost of living will be greatly reduced.

Home canned foods.-The average farm family should plan to have for table use from the home-canned supply one quart of zegetables, one quart of fruit and one quart of greens for every day in the year when these foods are not available in the garden. The ration based on these foods and supplemented by meats is better balanced and less expensive than one based on meats with a scarcity of fruits and vegetables. Such a system will have a tendency to cut down both the doctor's bills and the grocery bills, and will furnish a more palatable diet.

The elimination of waste.-The importance of home canning is still more fully realized when we stop to consider that in most states probably one-half of all the fruit and vegetables raised are allowed to go to waste. They are not needed for immediate consumption, and methods of grading, crating and marketing are not understood. Home canning will save all of this waste. 
Successful canning not difficult.-By following simple recipes and time-tables for sterilization, even children can successfully can anything that grows in the garden, field or orchard. Once canned the product has a money value, and is as standard in the market as sugar or nails.

Canning fruits.-The list of receipts and time-tables given in this chapter are made to be used in connection with the usual home canning utensils, and with four distinct types of canning outfits. Such outfits are not expensive. They can be bought all the way from eighty-nine cents up to twenty dollars, depending on type and size. All kinds of glass jars, bottles and tin cans commonly used in the old methods of canning can be used with these newer devices. (Write for Farmers' Bulletin 521 and other circulars of instruction on canning, for description of canning outfits, and full directions for their use.)

\section{Canning Recipes for Fruits and Vegetables}

These recipes have been carefully planned and tested by experts, and should be followed with great care if the best results are to be obtained.

Tomatoes.-Grade for ripeness, size and quality. Scald to loosen skins. Dip in cold water; remove skins; pack whole. Fill with tomatoes only and add 1 level teaspoonful salt to each quart. Place rubber and partially seal. (Cap and tip tins.) Sterilize thirty-two minutes in hotwater bath, twenty-two minutes in water-seal outfit, fifteen minutes under five pounds of steam, or ten minutes in pressure cooker. Remove jars, tighten covers, and invert to cool.

Strawberries.-1. Can fresh, sound berries same day picked. Hull (twist berries off hull) ; place in strainer, pour water over to cleanse. Pack in jar or tin without crushing. Four hot sirup over berries to top. Place rubber and top and partially tighten. (Cap and tip tins.) Sterilize sixteen 


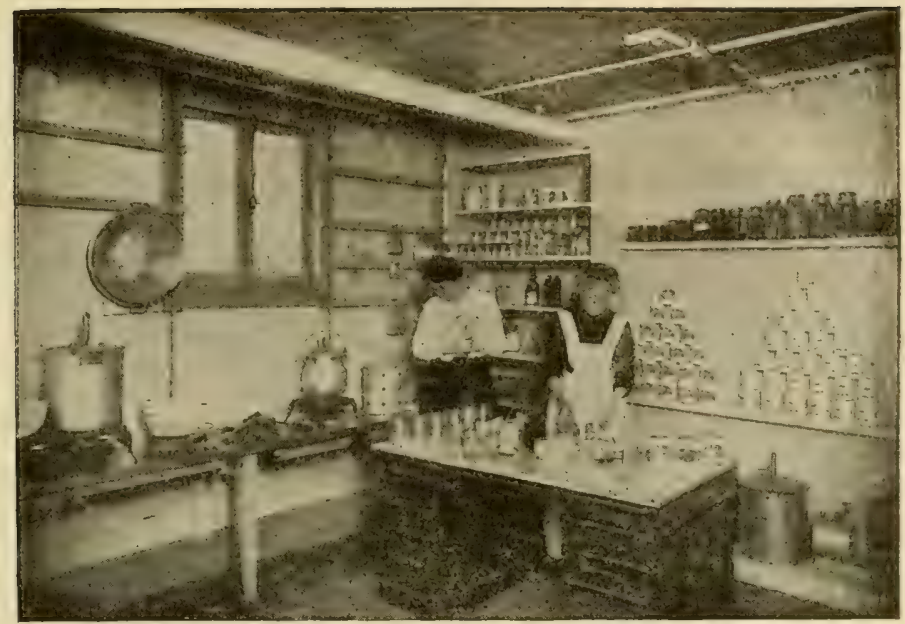

A practical canning kitchen.

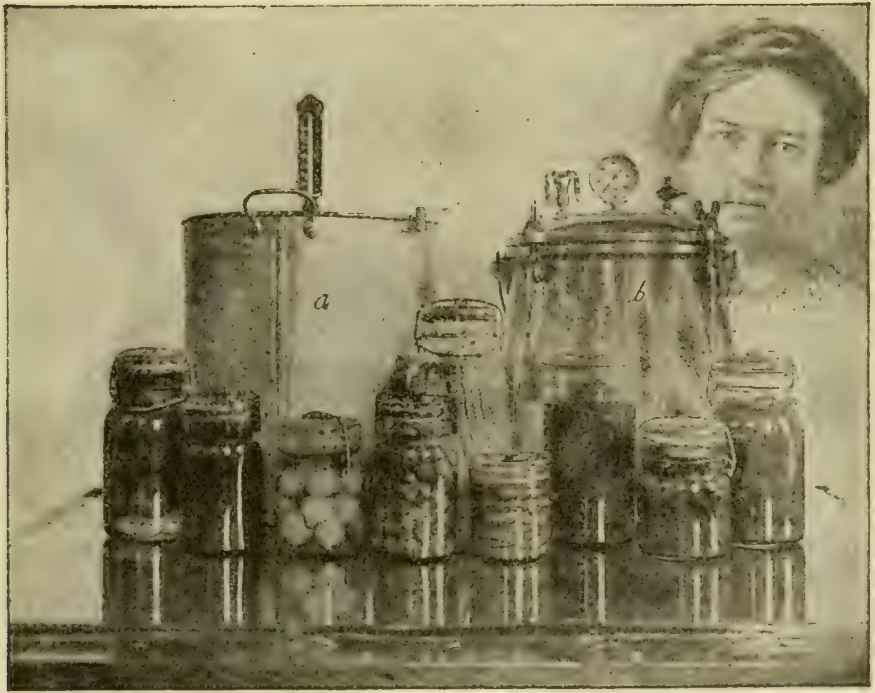

Two types of canning outfits: (a) the water seal; (b) the steam pressure type, used by a canning club girl. 
minutes in hot-water bath, 6 minutes under 5 pounds of steam, 10 minutes in water-seal outfit, or 5 minutes in pressure cooker.

(Sirup: $11 / 2$ qts. sugar to 1 qt. water, boiled to medium thick.)

Strawberries.-2. Same as above except sirup. Sirup : Crush berries for 1 quart natural juice, add 1 qt. sugar, boil to medium thick sirup. Add as in No. 1.

Strawberries.-Sun preserves. Select ripe, firm berries. Pick and preserve same day. Hull and rinse as in No. 1. Place in shallow platter in single layer; sprinkle sugar over them; pour over them 40-degree sirup (same as No. 1 boiled thicker). Cover with glass dish or window pane. Hllow to cook in hot sun 6 to 10 hours. Pack in glasses, jars, or cups; tie paper over tops. (Paraffin or sealing wax.) Keep in cool dry place.

Carrots, parsnips, sweet potatoes, etc.-Scald from 1 to 5 minutes in boiling water. Plunge in cold water. Remove slins; pack whole or sliced; add boiling vater and 1 level teaspoonful salt to each quart. Place rubber and top and partially tighten. (Cap and tip tins.) Process 11/2 hours in hot-water bath, 1 hour, 15 minutes in water seal, 1 hour under 5 pounds of steam, or 30 minutes in pressure cooker.

Eggplant.-Scald 5 minutes in slightly salt boiling water; plunge in cold water; remove skins. Slice crosswise and pack; add boiling water and 1 level teaspoonful of salt to each pint. Place rubber and top and partially tighten. (Cap and tin tins.) Process 1 hour in hot-water bath, 50 minutes in water-seal outfit, 45 , in 5 lbs. of steam pressure, or 30 minutes in pressure cooker. Remove jars, tighten covers, and invert to cool.

Sweet corn, on the cob.-Blanch in boiling water 10 minutes, plunge quickly in cold water. Pack, alternating butts and tips; add boiling water and 1 level teaspoonful of salt to each quart. Place rubber and top and partially tighten. (Cap and tip tins.) Process 180 to 240 minutes in hot-water bath, $11 / 2$ hours water-seal outfit, 60 minutes under 5 pounds of steam, or 45 minutes in pressure cooker. Remove jars, tighten covers, invert and cool.

Sweet corn, off the cob.-Same as above, except cut 
from cob after blanching. Pack and fill jars with boiling water, adding 1 level teaspoonful salt to each pint. Proceed as above.

Peas, beans, etc.-Blanch 3 minutes in boiling water; plunge in cold water. Pack and add boiling water and 1 level teaspoonful salt to each quart Place rubber and top and partially tighten top. (Cap and tip tins.) Process $11 / 2$ hours in hot-water bath, 1 hour in water-seal, 1 hour under 5 pounds of steam, or 35 minutes in pressure cooker.

Chards, beets, turnips, etc.-Scald 1 to 6 minutes in boiling water; plunge in cold water, remove skins. Slice and pack; add boiling water and 1 level teaspoonful salt for each pint. Place rubber and top and partially tighten. (Cap and tip tins.) Process 11/2 hours in hot-water bath, $11 / 4$ hours in water-seal, 1 hour under 5 pounds of steam, or 40 minutes in pressure cooker. Remove jars, tighter covers, and invert to cool.

Greens, (spinach, dandelion, mustard, beet tops, etc.) -Blanch in boiling water 10 minutes, plunge in cold water. Cut ready for table use. Process 10 minutes in open kettle to shrink; season with slice of bacon or chips of dried beef for each pint. Pack, add hot water and a little salt to each quart. Place rubber and top and partially tighten. (Cap and tip tins.) Process 60 minutes in hot-water bath or water-seal outfit, 40 minutes under 5 pounds of steam, 30 minutes in pressure cooker. Remove, tighten covers, and invert to cool.

It is always advisable to cook the greens a short time before packing in order to reduce the bulk.

Windfall apples.-For the canning of whole apples select firm, not over-ripe apples. A great difference in the canned products will be noted in the different varieties of apples. The recipe is intended for firm and preferably tart varieties. Some varieties will require less time and some more. Experience will teach adjustment of time.

Remove blemished, cut out core. Blanch for 2 minutes in boiling water; plunge in cold water. Pack in tin cans or glass jars and add just a little very thin sirup. Place rubber and top and partially tighten. (Cap and tip tins.) Process 20 minutes in hot-water bath, 15 minutes in water- 
seal, 10 minutes in stcam pressure outfit, or 4 ninutes in pressure cooker. Remove jars, tighten covers, and invert to cool.

Windfall apples for pie filling.- Peel and core. Slice; scald 1 minute in boiling water; plunge in cold water. Pack in glass or tin, and add about one teacupful of hot, thin . sirup to each quart. Place rubber and top, partially. tighten. (Cap and tip tins.) Sterilize 16 minutes in hotwater bath, 12 minutes in water-seal outfit, 10 minutes under 5 pounds of steam, or 4 minutes in pressure cooker. Remove jars, tighten covers, invert to cool.

Blanching.-After blanching plunge in cold water and pack quickly.*

1. Blanch peas, beans, etc., 5 minutes.

2. Blanch corn on cob, 5 to 15 minutes.

3. Blanch pumpkin, squash, mangoes, about 5 minutes.

4. Blanch okra, cabbage, sweet potatoes, 5 minutes.

5. Blanch asparagus, spinach, kale, etc., 5 to 10 minutes.

6. Ilanch rhubarb, beet tops, etc., 1 to 3 minutes.

7. Blanch or scald beets, carrots, turnips, etc., 6 minutes.

8. Scald tomatoes, plums, pears, etc., 1 to 2 minutes.

9. Scald peaches, apricots, 1 to 2 minutes.

Reasons.-Scalding: (1) To remove skins without loss of pulp; (2) to eliminate objectionable acids; (3) to arrest flow of coloring matter.

Blanching.-(1) To eliminate objectionable acids; (2) to set coloring matter; (3) to make texture firm for sterilization.

Cold Dip.-(1) To separate skin from pulp; (2) to set color bodies; (3) to render packing easier.

\section{Time Table for Home Canning of Foods}

To be followed in the use of the four different types of portable home canners. For altitudes of,+ 000 feet or more above sea level, add about 20 per cent. or 25 per cent. more time to this schedule.

* Cook greens, cabbage, chard, etc., about 20 minutes before packing to reduce bulk. 
Time Schedule for Canning.

Products to be Canned.

\begin{tabular}{|c|c|c|c|c|}
\hline 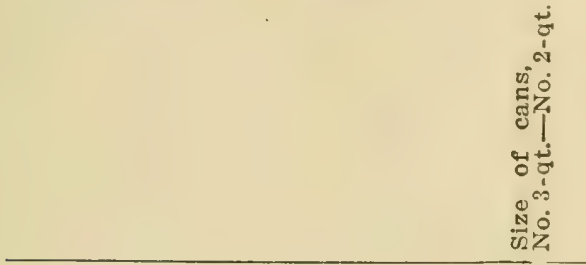 & 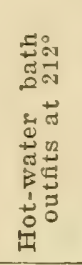 & 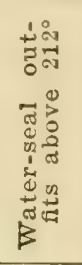 & 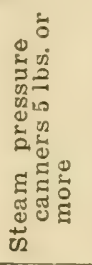 & 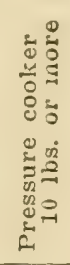 \\
\hline Apples & $\begin{array}{c}\text { Min. } \\
15\end{array}$ & $\underset{15}{\text { Min. }}$ & $\begin{array}{c}\text { Min. } \\
10\end{array}$ & $\underset{4}{M}$ \\
\hline Apricots ....... & 15 & 12 & 10 & \\
\hline Asparagus - & 60 & 60 & 40 & 30 \\
\hline Apple cider & 20 & 15 & 12 & 6 \\
\hline Beans, lima and string & 120 & 90 & 60 & 30 \\
\hline Blackberries, Dewberries_-_...-- 2 or 3 & 12 & 8 & 6 & 4 \\
\hline Cherries, Peaches _- & 15 & 12 & 10 & 5 \\
\hline Corn, on or off cob-_. & 240 & 180 & 60 & 40 \\
\hline Grapes, Pears, Plums & 20 & 15 & 10 & 6 \\
\hline Hominy - & 60 & 50 & 40 & 35 \\
\hline Huckleberries - & 10 & 8 & 6 & 5 \\
\hline Okra & 60 & 60 & 40 & 35 \\
\hline Okra and tomatoes combined_- 2 or 3 & 50 & 50 & 40 & 35 \\
\hline Oysters & 60 & 50 & 40 & 35 \\
\hline Peas (field) - & 90 & 90 & 40 & 35 \\
\hline Peas (garden or English) & 90 & 60 & 40 & 35 \\
\hline Pineapple -..- 2 or 3 & 30 & 25 & 10 & 6 \\
\hline Raspberries - & 15 & 10 & 6 & 4 \\
\hline Sauerkraut _- 3 & 50 & 50 & 40 & 25 \\
\hline Sausage ……- & 60 & 60 & 40 & 35 \\
\hline Sweet potatoes - & 180 & 90 & 60 & 40 \\
\hline Strawberries - & 12 & 10 & 8 & \\
\hline Succotash - 3 or 3 & 60 & 60 & $4 C$ & 30 \\
\hline Tomatoes - 3 & 32 & 22 & 10 & 6 \\
\hline Tomatoes and corn & 80 & 70 & 60 & 40 \\
\hline Grape juice - & 15 & 15 & 10 & 5 \\
\hline Quince - - & 30 & 25 & 15 & 10 \\
\hline Tomato juice - & 20 & 20 & 15 & 10 \\
\hline Pumpkin & 50 & 50 & 40 & 30 \\
\hline Fish, Pork & 200 & 200 & 1.20 & 60 \\
\hline
\end{tabular}


Time Schedule for Canning. Products to be Canned.

\begin{tabular}{|c|c|c|c|c|c|}
\hline & 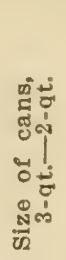 & 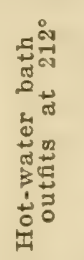 & 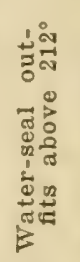 & 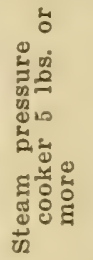 & 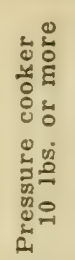 \\
\hline Chicken, beef & 3 & $\begin{array}{l}\text { Min. } \\
250\end{array}$ & $\begin{array}{l}\text { Min. } \\
240\end{array}$ & $\begin{array}{l}\text { Min. } \\
180\end{array}$ & ${ }_{40}$ Min. \\
\hline Figs & 3 & 30 & 20 & 10 & 5 \\
\hline Squash & 3 & 50 & 40 & 30 & 20 \\
\hline Spinach & 3 & 90 & 60 & 40 & 30 \\
\hline Other greens _... & 3 & 90 & 60 & 40 & 30 \\
\hline Rhubard & 3 & 25 & 25 & 15 & 10 \\
\hline Beets …n. & 3 & 60 & 60 & 45 & 30 \\
\hline
\end{tabular}




\section{PART III. SOIL}

\section{CHAPTER XV \\ NATURE OF SOIL}

$T^{N}$ our discussion of plants and crops we have constantly 1 referred to the soil. What is soil? Whence does it come? What relation does it bear to plant life, and hence to our own lives? Take a handful of "dirt" and crumble it between your fingers; of what does it consist, what is its nature?

\section{Origin of the Soil}

Soil did not always exist as it is to-day. When the earth was young and the crust was forming there was no soil. There was only rock. And it is out of the weathering of this surface rock that the soil has come; and the process is still going on whenever rock is exposed. Soil is but particles of rock, to which has been added organic matter coming from the plants and animals that have lived on it or in it.

The weathering of rock.-Rock is made into soil by two different processes, disintegration and decomposition. By disintegration is meant the breaking up of rock into small particles without changing their nature. By decomposition is meant such breaking up by chemical action that the nature of the particles is changed.

The chief agencies causing the disintegration of rocks are sudden changes of temperature and the action of frost. 
When masses of rock are heated by the sun they expand; sudken cooing at night or from change of weather causes so rapid a contraction that they are rent asunder. Water freczing in crevices also constantly breaks masses of rock into smaller pieces.

Rocks undergo decomposition largely through changes due to the action of chemicals carried in water. The mincral substances in the rocks are dissolved, and new products formed.

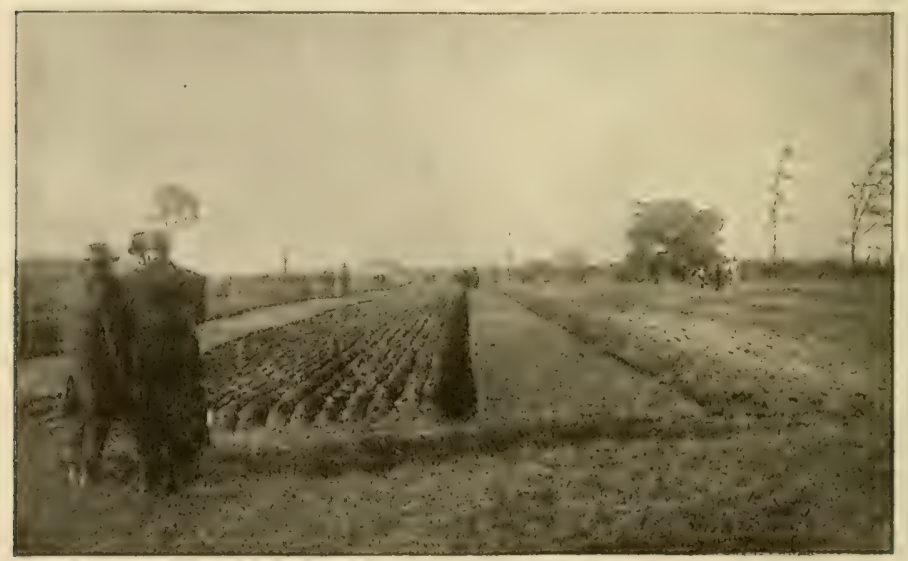

A plowing contest.

Surface and subsoil.-The terms soil and subsoil are often used to distinguish the top portion from the soil that lies underneath. The line between the dark humus-colored part and the lighter soil below is sometimes spoken of as the division between soil and subsoil. Another distinction made is to call all that lies below the depth of tillage subsoil. No such dividing line can be sharply drawn, however, as much organic matter is found below the humus line, and the depth of tillage does not mark a natural division in layers of the 
soil. Surface soil differs from subsoil chiefly in the organic matter it contains.

\section{Organic Matter in Soil}

Examine carefully a lump of common field soil. Pulverize it and spread it out on a paper. In addition to the grains of sand, silt and clay which represent the rock portions, note all the different organic particles, such as pieces of roots, fibers of plants, and parts of insects. Place it under a magnifier, and see whether you can make still further discoveries.

Need of organic matter.-Although the rock particles make up far the greater part of the mass of the soil, organic matter is of the highest importance to plants. Indeed, it is practically impossible to raise crops on soil lacking organic constituents. All the upper layers of ordinary soil contain from two to five per cent. of organic material, corning chiefly from the roots and stems of plants.

Humus.-When vegetation decays on top of the ground it is really burned up as effectually as if put into a stove, only more slowly. The gases pass off into the air and only a slight ash remains on the soil. From this process the soil receives comparatively little benefit. If, however, decay takes place under the surface, where but little oxygen is present, a substance is produced which is called hummus. All soil on which plants are grown is therefore constantly producing humus from the roots, and from the stubble and stems if these are turned under. Dig up a piece of timothy sod and note the mass of roots-about two tons of roots to the acre on a good field. Blue-grass yields some six tons of roots to the acre. Soils that are cropped continuously with the common cereals and the crops removed without returning manure to the field become deficient in humus, and the yield is decreased. 
Effects of humus in the soil.-The most easily noted effect of humus is in the darkening of the soil. The socalled "black" soils get their color from the abundance of humus they contain. The coloring is accomplished by the partially decayed and partially preserved black organic matter coating over the small particles of the soil. The depth to which humus extends, ranging from a few inches to several feet, can be noted at any wayside ditch by the line between the dark soil on top and the lighter soil beneath.

Humus serves several very important uses in the soil: (1) it acts as a storehouse for different kinds of plant food; (2) it increases the capacity of the soil to hold water; (3) it aids in conserving heat in the soil; (4) it favors the growth of bacteria helpful to plants; (5) it improves the physical condition of the soil, making it more porous and easily cultivated.

Living organisms.-Reference has already been made to the influence of certain bacteria in the fixing of nitrogen in the soil. The soil harbors many different kinds of bacteria and other organisms. It is fairly teeming with life, some of which is hostile to plant growth, but more of which is necessary to successful plant development.

Other organic matter.-Besides living organic matter and that which has undergone chemical changes converting it into humus, most soils contain a certain amount of vegetable matter in the form of roots and stems of plants which have not yet begun the process of decomposition. These affect the soil chiefly in making it more accessible to air and light, and more permeable to water.

\section{Texture of Soils}

Secure samples of three different field soils, (1) a clay soil, (2) a silt soil, and (3) a sandy soil. Place one inch deep of each of these in a bottle. Now fill all three bottles 
with water and shake for several minutes. Set the bottles in a quiet place and let the contents settle. Note which soil settles to the bottom most quickly. Keep a record of the time required for water to become clear in each bottle.

Meaning of texture-By texture of soil is meant the degree of fineness or coarseness of the particles of which it is composed. The finest soil particles, which will remain in suspension clouding water for hours, are called clay. The next finest, which will settle in about one hour, are silt. The coarser particles, which will settle almost at once, are called sand or gravel.

Most crop soils have all three of these grades or sizes of particles in their make-up. The texture of the soil depends on the proportion of each in the mixture. Soils are named in accordance with the particular one of these elements that preponderates.

If the very fine particles are in excess, we speak of a clay soil; if the texture is intermediate, of a loam soil ; and if coarse, of a sandy or gravelly soil. We also use the terms clay loam, silt loam and sandy loam to describe the texture.

Composition of three soil types.-A mechanical analysis of three types of soil texture made by the United States Department of Agriculture shows the following proportions of soil particles in each:

\section{Very}

Fine C'se Med. Fine fine

Type of soil gravel sand sand sand sand

Silt Clay

\begin{tabular}{lrrrrrrr}
\hline Norfolk sand (truck soil)_-_-3\% & $15 \%$ & $22 \%$ & $38 \%$ & $10 \%$ & $8 \%$ & $4 \%$ \\
Wabash clay (river bottom)_0 & $1 \%$ & $1 \%$ & $3 \%$ & $7 \%$ & $49 \%$ & $37 \%$ \\
Silt Loam (corn soil)_---_0 & $1 \%$ & $1 \%$ & $2 \%$ & $8 \%$ & $73 \%$ & $15 \%$
\end{tabular}

From this table it is seen that Norfolk sand, which is an excellent ?il for truck gardening on the Atlantic, is eighty-eight per cent. sand and gravel, and only twelve per 
cent. silt and clay combined. Midile western silt loam, such as grows most of our best corn, is three-fourths silt, and fifteen per cent. clay and twelve per cent. sand. Riverhottom, clay soils are slightly more than one-third clay, and almost one-half silt.

\section{Structure of Soils}

Take a piece of clay in your hand. Try to crumble it into small particles. Do the same with a piece of loam; with a lump of sandy soil. Note that some soils plow up in great clods, while others break up into small pieces, producing what is called a mellow condition. Have you noticed that in some places the ground cakes and cracks open when it becomes very dry, while in other places it remains soft and unbroken no matter how dry it becomes? These differences are a matter of soil structure.

Soil structure.-By soil structure is meant the mode in which particles adhere to one another, causing them to cling together in solid masses hard to break up, or forming but loosely joined lumps easily pulverized.

Clay soils are of a heavy, dense, clinging structure, difficult to break apart, and hence hard to plow. Silt loams and sand loams, on the other hand, are friable; that is, they are easily broken up. They plow or pulverize easily because they are not so adhesive. All soils that are lacking in humus tend to become dense and resisting in structure.

Causes affecting soil structure.-The chief adhesive force holding soil particles together in clusters, grains, or lumps is the water films that surround the particles. Each separate particle is covered by a thin film of water, whose effect is much the same as a film of rubber. Let a number of small soil particles, each surrounded by its water film, come into contact, and their individual films all merge into 
one, which by its tension unites these particies in a single granule, or cluster. These clusters are in similar way joined into still larger clusters, and so on until, in fine clay soils, one continuous mass is formed. As clay soils dry out the films break, shrinkage occurs, and cracks open.

The greater adhesive power of clay soils is because of the fineness of their particles. The larger the number of particles in a given mass of soil, the greater the aggregate surface of these particles, and hence the greater the amount of water films to bind the particles together. Sandy soils do not form into granules, or lumps, because the aggregate surface of the particles is not sufficient to supply the binding force of water films necessary to hold them together.

It has been carefully estimated that the particles of a cubic foot of soils of different textures have the following amounts of surface:

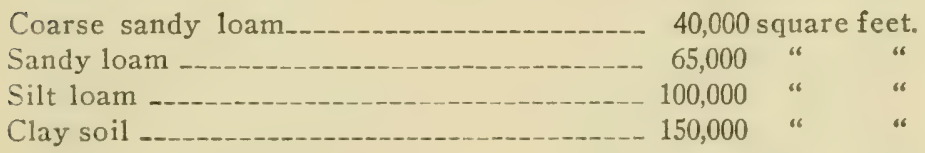

From these comparisons it is clear that the water films are several times greater in area in clay soils than sandy soils, and hence the tendency to adhesiveness in clay soils is correspondingly increased.

Soil structure and tilth.-You have seen some seed beds that were granular or full of lumps, with very little fine earth for packing about the secds. Others are finely pulverized, and favorable for plant growth. The condition presented by the soil with reference to plant growth is called its tilth.

Tilth depends chiefly on soil structure. Dense heavy soils that have a tendency to form into lumps when plowed, or that easily bake after rain, make it difficult to maintain a 
good tilth. On the other hand, a good tilth is equally hard to maintain on soils that easily burn out in a drought, or that for any reason are not good reservoirs of water.

\section{Erosion of the Soil}

Note the color of the soil on some cultivated hilltop and on the lower ground at the foot.

1. Why is the color on the hilltop lighter? Why is the crop yield less? Are there any slopes near by with gullies washed out?

2. Have you seen sheets of soft earth which have been carried by the wash from heavy rains and spread over low ground or along the courses of streams? Where does this soil come from? What is its texture, fine or coarse? What is the structure of this overflow soil, heavy and dense, or friable? Is such soil fertile? Must this fertility be lost from the ground from which the wash came?

3. Have you ever seen banks of soil built by the carrying of soil particles in the wind? Great masses of windbuilt soil, called locss, are to be found in Illinois, Wisconsin, Iowa, eastern Kansas and Nebraska, and northern Missouri. These loessial soils consist chiefly of silt.

4. Which loses more soil from the action of the wind, hilltops or valleys? In certain western plains regions as much as an inch of top soil is sometimes removed in a single dust storm lasting twelve hours.

Nature of erosion.-By erosion is meant the wearing or carrying away of soil by the action of running water and the wind. Erosion by running water takes place in some degree on all slopes; the hills are gradually but constantly being carried into the valleys. But it is on the steep hillsides where the velocity of the water is greatest that most damage is done. The reason for this is easily seen when it is remembered that the transporting power of water increases 
as the sixth power of its velocity. This means that doubling its velocity increases the carrying power sixty-four times; trebling its velocity increases the carrying power seven hundred and twenty-nine times, and so on.

The texture of the soil has much to do with erosion. All soils that permit ready aisorption of water, as from rains or melting snow, leave less to run over the surface, and so are less subject to erosion than dense clay soils.

Effects of water erosion.-Erosion by running water

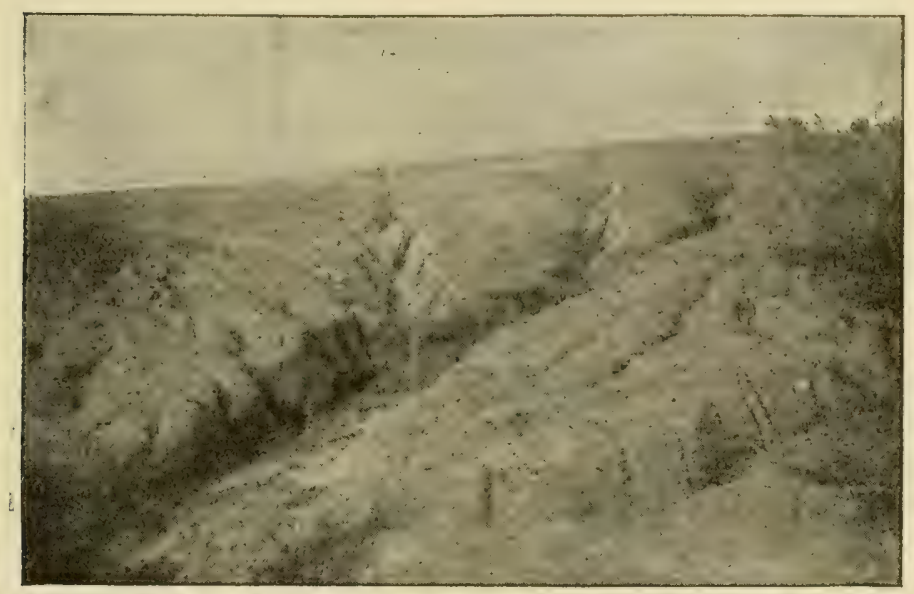

An Illinois field, showing the effects of water erosion.

not only produces gullies and ditches that interfere with cultivation, but greatly reduces the fertility of hilltops and slopes by general surface washing. For it is the best parts of the soil that are carried away by erosion. Organic matter is relatively light, and so floats off; the finer clay and silt particles which, as we have seen, will remain long in suspension in water, are carried away, and the coarser 
portions left behind. And it is just this organic matter and the finer soil particles that contain the best part of the plant food. No wonder then that the hilltops have a thin poor soil, and that the valleys are noted for their fertility.

Prevention of erosion.- While soil erosion can not be wholly prevented, it can be greatly checked. And nature suggests one effective remedy in covering all soil with vegetation. It is bare soil that washes and blows away. Even a steep hillside when covered with grass is reasonably free from erosion. For the stems tend to delay the downward rush of water, thus causing it to soak into the ground, and the roots bind the soil together. This indicates that steep slopes should be used for pasturage and meadows rather than for cropping. The addition of organic matter in the form of manure also lessens the danger from washing, since it increases the capacity of the soil to absorb water, and also tends to bind the soil together.

Hillsides when tilled should be plowed along the slope rather than $u p$ and down, and in some sections it is necessary to terrace the hillsides. This delays the forming of rivulets and favors absorption of water. Every furrow leading down the hill is the beginning of a gully in heavy rains. Even the marks left by the wheels of a corn planter, unless leveled over by harrowing, will serve as water channels and result in waste of soil and washing out of the seed or plants.

Gullies once started should be leveled immediately by use of the plow or other form of cultivation. Packs of straw, hay, or manure at the head of the channel, or at intervals along its course, will do much to stop the erosion, if used in time. Sheet, or surface, washing is, however, a source of greater damage than the formation of gullies. For sheet erosion, though gradual, is constant on the slopes of all tilled fields. 


\section{TOPICS FOR INVESTIGATION}

1. Select a spot on ycur home farm representing its typical soil, dig down with a spade or soil auger and take two samples, one from a depth of six inches, and one of twenty inches. How do the samples differ (1) as to texture, (2) as to organic matter, (3) as to structure? How deep does the humus extend? Bring samples to school, and compare with those from the different farms represented.

2. Place some of each sample in a bottle or glass of water and mix well. Allow the sand to settle (How long?), and pour the water off the top into a third receptable. Allow the clay to settle until the water becomes clear. (How long is required?) Now determine as nearly as you can what is the proportion of clay, silt and sand in the soils. How would you name the texture of the soil on your farm?

3. Secure a sample of the soil from some cultivated hilltop, and examine it for its texture, structure and the amount of organic matter. Compare with another sample taken from the foot of the hill. Explain the difference in color. Dig down with a spade and compare the depth to which the humus extends in each case.

4. Are there any cultivated hills on your farm steep enough that erosion is considerable? If so, how does the yield on the hill compare with the lower land? Are there any gullies forming? If so, how long have they been washing out? What is being done to stop them?

5. Determine what kind of soil there is in your school yard, such as silt loam, clay soil, or sandy loam, and compare the aggregate surface of the particles of a cubic foot of it with the area of the school grounds.

6. What is a soil auger and for what is it used? What is a soil survey, and how and why is it made? Consider the possibility of joining with your classmates in making a soil survey and a soil map of your district. 


\section{CHAPTER XVI}

\section{SOIL FERTILITY AND PLANT GROWTH}

BOTH plants and animals depend on the soil for their exI) istence. Since animals can not draw food immediately from the soil, they are dependent on plants, which have the power to live chiefly from the soil elements. Plants ray therefore be looked upon as minute factories, each at work making living tisste out of soil materials. All human fooci comes either from the plants themselves, or from animals which feed on plants.

\section{Plant Food and Soil Fertility}

The soil is the home of the plant; there it must find the conditions necessary to its growth and development. The plant must have air and water for its roots, and for its food all the elements that enter into the tissues in its growth. The ability of the soil to supply the elements necessary for plant growth is called its fertility.

Food required by plants.-Agricultural plants require, in all, ten different chemical elements for their growth. These are:

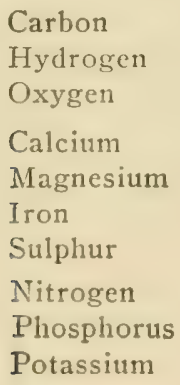

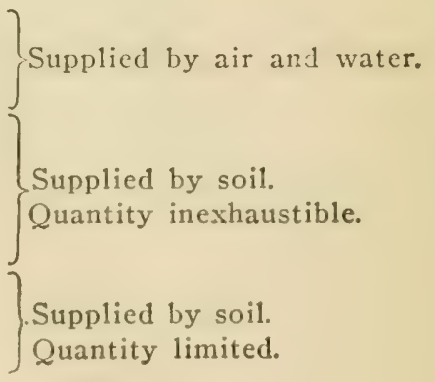

236 
The first of these ten plant elements, carbon, is supplied in the form of carbon dioxid by the atmosphere, and hence forms no part of the soil's fertility. Hydrogen and oxygen, which are the elements that compose water, are taken up by the plant directly from the water of the soil. The next four of the list, calcium, magnesium, iron and sulphur, are found in practically all soils in quantities sufficient for ordinary plant growth. The fertility of the soil therefore depends chiefly on the supply of the last three, nitrogen, phosphorus and potassium.

Rich or fertile soils are those that contain an abundance of these three elements. Every crop removes some amount of each of the seven elements supplied by the soil; but since calcium, magnesium, iron and sulphur are practically inexhaustible, they do not have to be replaced in order to maintain the soil's fertility. Nitrogen, phosphorus, and potassium, however, must constantly be returned to the soil if it is not to become exhausted and the crops reduced. Like the strength of a chain is measured by its weakest link, so the fertility of the soil is measured by the plant element of which it has the least.

Danger of loss of fertility.-One of our chief agricultural problems is to maintain the fertility of the soil. We must all live from its products, no matter what our occupation. Most of the tillable land of the United States is now occupied. Our people must be fed from this land; there is no other source of supply.

This means that we should not only keep up the fertiity of the soil, but actually increase it as time goes on. It is estimated that our population is increasing five times as fast as our food supply. This fact explains in part, at least, the high cost of living.

Much land, particularly in the East and South, has been rendered almost valueless through careless methods of 
farming which have robbed the soil of its nitrogen, phosphorus and potassium. Farms located within a hundred miles of the great eastern markets have recently been bought for from ten dollars to twenty dollars an acre, when middle western land is selling for one hundred dollars to two hundred dollars an acre. Much of this eastern land was originally as good as the western, and would be worth three hundred dollars an acre if it had been properly farmed to conserve its fertility.

There are thrce principal methods of maintaining the fertility of the soil or increasing it when it has run down. These are: (1) manuring, either with barnyard manure or by plowing under such plants as clover, alfalfa, cow-peas, or some other grecn crop; (2) using commercial fertilizers; (3) rotation of crops.

\section{Barnyard Manure as a Fertilizer}

One of the best evidences of careful farming and good management is a well kept and well used manure heap. Manure should no more be wasted than any other farm product.

The value of barnyard manure.-Barnyard manure is rich in all three of the elements in which the soil is likely to run short-nitrogen, phosphorus and potassium. It has been estimated by experts that if animals are kept in stalls or pens throughout the year, given a reasonable amount of litter for bedding and all the manure saved, the annual value of the manure from each animal will be: horses or mules, twenty-seven dollars; cattle, twenty dollars; hogs, eight dollars; sheep, two dollars. Differently stated, the value of the manure produced during the seven winter months on a farm keeping four horses, twenty cows, fifty sheep and ten hogs would be at least two hundred and fifty dollars. These 


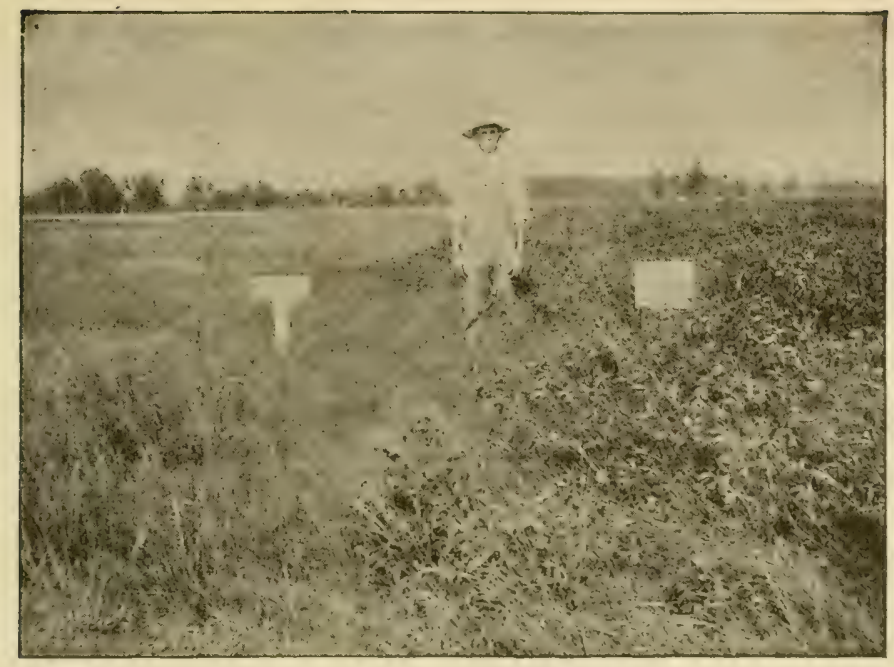

Field showing the effect on lesumes of proper trestment of the soil. On the left, manure was used; on the right, limestone, rock-phosphate and manure.

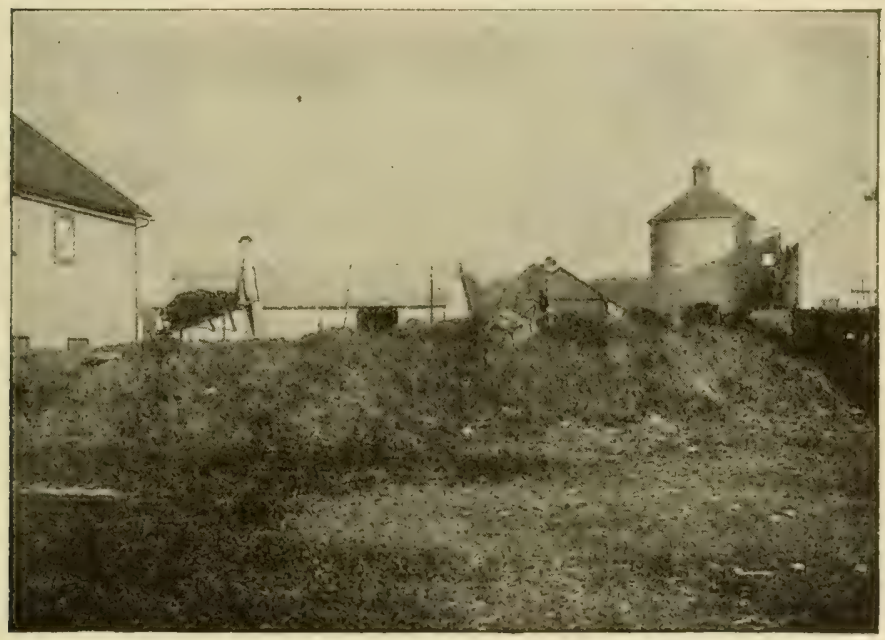

The wrong way to handle barnyard manures. 
figures are based on the cost of an equal amount of commercial fertilizer.

It is true that not all the fertility taken from the soil by farm crops can be returned by using the manure from the feeding of crops, but the greater part of it can be. The manurial value of different farm products, based on the cost of commercial fertilizers, is shown in the following table: (Farmers' Bulletin 193, U. S. Dept. of Agriculture.)

Value of fertilizer in ton

\begin{tabular}{|c|c|c|c|c|}
\hline \multirow[b]{2}{*}{ Product } & \multicolumn{3}{|c|}{ Phosphoric } & \multirow[b]{2}{*}{ Total } \\
\hline & Nitrogen & acid & Potash & \\
\hline Meadow hay & $\$ 3.47$ & $\$ 0.57$ & $\$ 1.06$ & $\$ 5.10$ \\
\hline Clover hay & 6.83 & .78 & 1.46 & 9.07 \\
\hline Wheat bran & 8.35 & 3.82 & 1.14 & 13.31 \\
\hline Linseed meal & 17.87 & 2.25 & .99 & 21.11 \\
\hline Cottonseed meal & 23.06 & 3.96 & 1.17 & 28.16 \\
\hline Wheat & 6.38 & 1.11 & .42 & 7.91 \\
\hline Oats & 6.21 & .87 & .35 & 7.43 \\
\hline Corn - & 5.62 & .83 & .30 & 6.75 \\
\hline
\end{tabular}

We see from the above table that the farmer who sells a ton of meadow hay loses from his, farm, fertilizer that would cost about five dollars if purchased in commercial form. If he sells clover hay, he loses almost as much value in fertilizer as his hay brings him. If he pays twenty dollars a ton for wheat bran he gets over thirteen dollars' worth of fertilizer, leaving the feeding cost about seven dollars.

Of course it is evident that these values will not be obtained from the feeding of farm crops unless the manure is carefully saved and properly used. Not only has manure great chemical value because of supplying the elements needed in plant growth, but it has bacteriological vaiue as well. For manure contains an enormous number of bac- 
teria, many of which aid in plant growth. Attention has already been called to the fact that the addition of manure improves the physical condition of the soil, making it more porous, and increasing the supply of humus.

Preventing loss from manure-Loss of fertilizing qualities from manure is due principally to two causes: (1) fermentation, or heating, which reduces the supply of nitrogen; and (2) weathering, or leaching from rains, in which all the valuable elements suffer.

The fermentation of manure is caused by two different kinds of bacteria, one of which works near the outside of the heap where there is air, and one farther in where the air is excluded. A certain degree of fermentation is necessary to the best rotting of the manure, yet overheating, or the "fire-fanging" so common in horse and sheep manure, greatly reduces its value.

The rapidity of fermentation can be controlled in part by packing. If the heap is too loosely built, the air-working bacteria become active, the heat grows intense and nitrogen and humus-making material are lost. If, on the other hand, the heap is packed too closely, the decomposition is slow and the manure does not have the best effect when spread on the soil. Frequent sprinkling with water will aid in checking too rapid fermentation.

Great loss is suffered from leaching when manure is exposed to the weather. It has been found that six months' leaching of horse manure reduces its value fully one-half. The remedy lies in collecting manure under cover, so that it is not exposed to rains. It should also be provided with a water-proof floor for the heap, so that the liquid parts, which are fully as valuable as the solid, may not drain away into the soil. The profits from open-yard, badly leached manure are so small as hardly to pay for spreading it on 
the field. It is a careless, shiftless method of farming that allows this great waste, which is so easily prevented.

The application of manure.-For heavy soils, which need to be made porous by the addition of vegetable matter, it is well to spread manure on the field fresh from the stalls without waiting for it to rot. It should not, however, be allowed to lie long before being plowed under, as much of its strength is lost in this way. For all lighter soils, and especially such as have a tendency to dry out, the manure should be rotted before being applied.

The practise of throwing the manure in heaps on the field and later spreading it is a mistake. For here also the leaching takes place. Some of the best elements of the manure are drained into the ground immediately under the heap, and some are lost by passing off in the air. The most economical and satisfactory method of spreading manure is by use of the manure spreader. This machine saves labor, and distributes the manure more evenly than is possible by hand.

The amount of manure to be used will depend on the strength of the mantre and the condition of the soil. Five tons to the acre is a light application, ten or twelve tons average, and twenty tons a heavy application.

\section{Green Mamıring}

As already suggested, the returning of the barnyard manure to the soil, no matter how skilfully done, is not enough to maintain the fertility. Our soils are everywhere being gradually worn out. One of the most successful methods of supplementing barnyard manure is by green mamuring.

Meaning of green manuring.-By green manuring is meant plowing under any green crop for the purpose of im- 
proving the soil. Green manures improve the soil both by adding to its fertility and bettering its physical condition. If the soil is light and sandy, green manure prevents it from drying out. On heavy clay soil green manure has quite the - opposite effect, because of admitting the air, loosening the soil, and improving its drainage.

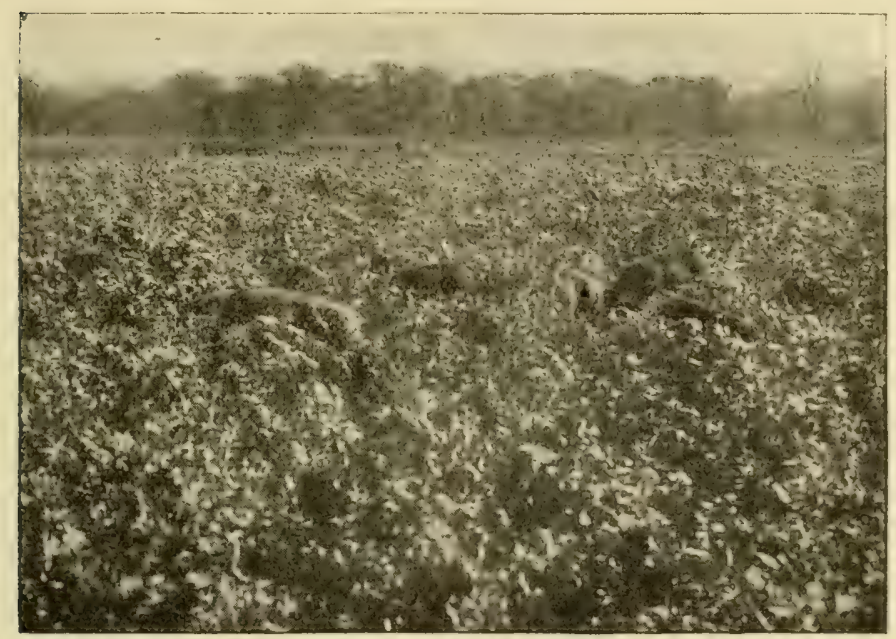

Hogs in clorer. After pasturing, this clover will be turned under as green manure.

Green manure crops.-For most purposes the best green manure crops are the nitrogen gatherers already discussed-the clovers, alfalfa, cow-peas, soy-beans, the vetches and other legumes. Rye, buckwheat, rape and turnips are among other crops used as green manures. This group, however, lacks the advantage of gathering nitrogen.

\section{Commercial Fertilizers}

Although proper systems of manuring and rotation of crops will insure fertility on naturally good soil for many 
years, the land will finally become.exhausted under such ireatment. This is for the simple reason that the crops remove from the soil each year more of the elements necessary to their growth than are returned to it. The deficiency must finally be made up if permanent fertility is.to be maintained. This is accomplished by supplementing manuring and rotation with what are called the commercial fortilizers.

Increased use of commercial fertilizers.-Commercial fertilizers have long been used in a small way, but it is only recently that they are coming to be employed on a large scale. The farmers of the United States are now paying out considerably more than $\$ 100,000,000$ a year for such fertilizers. There are at present more than five hundred manufacturers selling the various fertilizing products.

Since, as we have seen, only three of the elements necessary to plant production are likely to run short, commercial fertilizers are commonly limited to these three-nitrogen, phosphorus and potassium.

Commercial nitrogen fertilizers.-Nitrogen is the most expensive of the three essential fertilizers. Commercial nitrogen fertilizer is sold chicfly in three different forms: (1) nitrate of soda (Chile saltpeter); (2) sulphate of ammonia, which is a by-product of the manufacture of coke and gas; and (3) dried blood, ground or steamed bone, or other animal products from packing houses.

The nitrogen fertilizers cost from fifteen to fifty cents a pound. Instead of depending on them the intelligent farmer will therefore use every effort to maintain the supply of nitrogen in his soil through the nitrogen-fixing legumes, occasionally plowing under a crop of clover, alfalfa, cowpeas, vetches, or soy-beans. Where these can be grown successfully, there will be little need to buy nitrogen ; it can be obtained from the seventy million pounds of free nitrogen in the atmosphere ahove each acre. 
Commercial phosphorus fertilizers.-Phosphorus fertilizers are supplied commercially in the form (1) of the bones of animals killed at the slaughter-houses; (2) of mincral deposits in phosphate rock, immense beds of which are found in Tennessee, South Carolina, Florida, 'Wyoming, Utah, Idaho and Montana; and (3) of slag from the furnaces where certain ores containing phosphorus are smelted.

Bone phosphate is sold either as ground bone, which is raw bone ground up; or bone meal, which is made by grinding after the bones have been steamed under high pressure to remove the fats and oils.

Mineral phosphate is sold in two forms, (1) that first treated with sulphuric acid, and (2) the natural rock finely ground. The first form has the advantage of being more immediately available for plant use. The second form is considerably less expensive and, when mixed with organic matter like some form of manure, proves equally as valuable as the more expensive compound.

Commercial potassium fertilizers.-Potassium fertilizers are available in several commercial forms, none of which is produced in large quantity in this country. The potash mines of Germany are the chief source of supply.

The crude potash may be used on the soil directly as mined, or it may be made into more concentrated form. It is sold commercially as a fertilizer (1) as muriate of potash, (2) as saltpeter of potash, and (3) as kainit. Since this product has to be imported it is naturally more expensive than if produced at home. From one hundred to two hundred pounds to the acre, applied at intervals of from one to three years, will, however, usually prove sufficient to keep up the supply.

The application of commercial fertilizers.-Because commercial fertilizers are so expensive, and also for the reason that the application of a fertilizer when it is not 
needed may do positive harm, the advice of your county agricultural agent or some other agricultural expert should be sought before purchasing. An expert, after a survey of

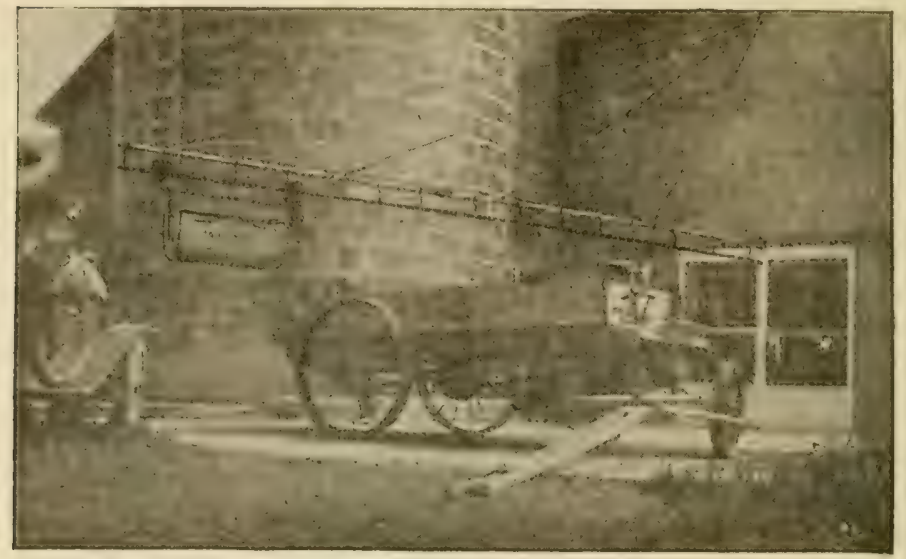

The better may. Manure carrier and spreader.

your soil, will be able not only to suggest the best kind for local needs, but also the amount that should be used.

\section{The Use of Lime on Soils}

Lime can hardly be called a fertilizer, since it does not contain any of the elements in which the soil is generally lacking. Yet because of its action on certain other elements of the soil it is necessary to plant production. When lime does not already exist in the soil it must be added in commercial form if the fertility of the soil is to be maintained. The purpose of lime is to cure the soil of its acid condition.

Acid soils.-All soils have a tendency to become sour, or acid. This acidity comes about in several different ways: in the decay of organic matter in the soil, certain acids are 
produced; hence the soils rich in humus are likely to be acid. Plant roots give off acid in the process of their growth, and this acid remains in the soil. The action of the nitrifying bacteria also adds to the acidity of the soil. Heavy, non-porous clay soils which do not allow the entrance of fresh air are usually sour.

The degree of acidity of soils can be judged (1) by the refusal of certain plants to grow in them; for example, the legumes will not thrive in acid soils, and the failure of clover or alfalfa to do well should arouse a suspicion of too much acid. (2) The presence of such woeds as sheep-sorrel, horsetail rush, corn spurry, and wood horsetail indicate acid. (3) Blue litmus paper turns red when placed in contact with a soil containing acid.

Liming acid soils.-Lime is a certain remedy for acid soils. In some regions, especially where limestone abounds, the natural supply of lime in the soil is sufficient to overcome the surplus acid. In other regions, lime needs to be applied in commercial form. This is the only cure for acid soil within reach of the farmer.

Nearly all prairie soil is in some degree acid, especially on slopes where leaching of the soil has carried away the original deposits of lime, and wherever large supplies of humus have formed from the decay of organic matter. Thousands of acres of acid land would well repay the cost of liming by increased yields. Many farmers now look on liming as a regular and necessary requirement. Of course lime should not be applied unless needed, but the tests are so simple that this is easily determined.

Forms of lime used.-Lime is available for application to the soil in several forms: (1) Quicklime, or lime ready for use in making plaster, when finely ground may be applied at the rate of about one ton to the acre. (2) Airslacked lime, or ordinary lime that has been exposed to the 
air, is an excellent form, and may be applied at the rate of two or more tons to the acre. (3) Ground or finely crushed limestone direct from the quarries is widely used in regions where it is easily obtainable. From one to two tons to the acre will usually correct the acidity.

The form of lime to be used will depend chiefly on which is most easily available and cheapest. The amount required is determined by the degree of acidity in the soil.

\section{Crop Rotation and Fertility}

The rotation of crops can not properly be said to increase the fertility of the soil. For every crop removes from the soil some quantity of each of the elements required for plant growth. Certain advantages come from rotation, however, which at least save the rapid soil exhaustion resulting from growing one crop continuously. Rotation also brings increased yields. In this sense a proper rotation may have the same effect as the application of a fertilizer, though it can never serve as a substitute.

What is meant by rotation of crops.-By rotation of crops is meant a regular order followed for a period of years, and alternating on different fields. If this order is hit-andmiss, or the result of whim or chance, it can not be called a rotation. Rotations may be planned on a two-year, threeyear, four-year, or any other cycle.

What is accomplished by rotation.-Rotation of crops improves the physical condition of the soil. Grasses and legumes have a larger supply of roots than most cereals, and so increase the organic matter. Different crops send their roots to different depths, and so use new portions of the soil. The cultivation of inter-tilled crops clears the soil of weeds, and opens it up to air and moisture.

Rotation also aids in destroying insects and other ene- 
mies of plants, as we have already seen. The pests that attack one kind of crop die out when another crop is raised on the field. The growing of the nitrogen-gathering legumes on every part of the farm in succession is allowed by rotation, thus saving the necessity of buying commercial nitrogen fertilizers.

The crops to use in a rotation.-It is evident that no universal standard rotation can be prescribed. Both the particular crops and the order must be decided by local conditions and requirements. The rotation is usually based on some one principal crop, the other crops being arranged to favor this. For example, corn is the basis of rotation in the states constituting the "corn belt." A five-year rotation with corn occupying about forty per cent. of the farm might be something as follows:

\begin{tabular}{llllll}
\hline Year & Field A & Field B & Field C & Field D & Field E \\
\hline First & Corn & Corn & Oats & Clover & Pasture \\
Second & Corn & Oats & Clover & Pasture & Corn \\
Third & Oats & Clover & Pasture & Corn & Corn \\
Fourth & Clover & Pasture & Corn & Corn & Oats \\
Fifth & Pasture & Corn & Corn & Oats & Clover \\
First & Corn & Corn & Oats & Clover & Pasture \\
\hline
\end{tabular}

It will be noted that this arrangement provides for two fields of corn each year, and one field each of oats, clover, and pasture. Of course other crops might be inserted in the rotation. With alfalfa in the rotation, a longer cycle is needed, since it does not pay to plow alfalfa up so soon after planting.

\section{TOPICS FOR INVESTIGATION}

1. Has the yield of the principal crops increased or decreased in your region within the last ten or twenty years? To make sure of this, ask your father, or some one who has farmed in the vicinity for some time.

2. Are there run-down farms in the neighbnrhood? If so, is the land naturally poor, or has it been depleted by 
single cropping or poor methods of farming? Learn the history of all such farms as accurately as possible, with reference to cropping, rotation, manuring, and so on.

3. Based on the figures given in section two, what was the approximate value of the manure produced on your home farm last year? (See p. 240.)

4. What care is given to saving the manure on your home farm? Is it collected under cover? Does it ever "fire-fang"? Is there a water-tight floor under the heap? How closely is the manure gathered up from the yards? What is the method of distributing it on the fields? How many loads are used to the acre?

5. How much hay, oats, corn and other farm products were sold from your home farm last year? What was the approximate manurial value loss to the farm?

6. What commercial fertilizers are used in your region? In what form is the fertilizer applied? What is the quantity used per acre? The cost? To what extent is green manuring employed? What crops are chiefly used? What is meant by a "5-8-7" commercial fertilizer?

7. To make the litmus-paper test for acid in soils, take a small piece of blue litmus paper and place it between pieces of thoroughly dampened soil, pressing the soil close and leaving it in contact with the paper for five minutes. If the paper turns red, the soil is acid and needs lime. Secure samples of soil taken at a depth of six inches from several different parts of your farm, including both upland and lowland areas, and make the litmus-paper test.

8. Draw a diagram of your home farm showing the different fields. Now work out several different crop rotations based on your principal crop, and taking into account the necessity for growing some legume for improving the soil. Compare with the rotations suggested by other members of the class. 


\section{CHAPTER XVII}

\section{SOIL MOISTURE}

WATER is as necessary to the growth of plants as fertile soil. All the food taken by plants from the soil must first be dissolved in water. The tiny root-tips suck in this food-laden water which circulates to every part of the plant, producing its growth.

The amount of water required by a growing crop is enormous. For every pound of dry matter made by the plant, from three hundred to eight hundred pounds of water must be drawn in by its roots and circulate throigh it. To produce a ton of dry hay on an acre of ground demands that approximately five hundred tons of water be pumped by the grass stalks from the soil. When the soil lacks water, plants are cut off from both necessary food and drink.

\section{Forms of Soil Water}

Gravitational water.-Soil that is thoroughly saturated contains a certain amount of free water that will drain off if there is some outlet. That is, the force of gravity pulls it down through the soil; hence its name, free, or gravitational water.

To watch how this works, place some soil in a funnel closed with a stopper. Pour water over the soil until it is completely soaked. Then remove the stopper and allow what will of the water to drain off. All the water that thus escapes is free, or gravitational water.

Plants can not use gravitational water for their supply. 
This is to say that they can not grow in a soaked soil. "Water-logged" soil excludes air from the roots, and the plants soon suffer for want of oxygen. Standing water also keeps the roots of most plants too cold for good growth. Hence the necessity of conditions that will allow the soil to drain readily after rains, so that the free water may escape.

Capillary water.-Soils will not drain entirely dry. After your funnel of earth has lost all the water that will run from it, it is still wet. This wetness is caused by what is called capillary water.

Capillary water exists in the form of thin films around the soil particles and in the spaces between them, as described in an earlier chapter. Each separate particle is surrounded by its own film, while larger films bind the separate particles together in granules. Since the particles of a given weight of soil of fine texture present a larger surface area than the particles of a soil of coarse texture, it is evident that the finer the soil the greater the amount of capillary water required to make up the films.

Plant growth and capillary water.-It is the capillary water of the soil that plants use in their growth. Their root tips come in contact with the water films surrounding the soil particles and drink this water in. One of the first requisites of a productive soil, therefore, is its ability to act as a reservoir for a large amount of capillary water.

\section{Capacity of Soils of Capillary Water}

Soils differ greatly in their capacity for capillary water. This can easily be shown by a simple experiment. Bake a pint of sand and a pint of clay until all the water is dried out; then place the samples in separate funnels over the lower end of which is tied a piece of cheese cloth. Now slowly pour water from a graduate over each soil until the 
water begins to drip from the bottom of the funnel. Note carefully how much water was required in each case.

Soil texture and capillary water.-Because of the fineness of their texture, clay and silt soils have much greater capacity for capillary water than sandy or gravelly soils. Under average field conditions the difierence in the amount of capillary water held in the first two feet of fully saturated soil is about as follows:

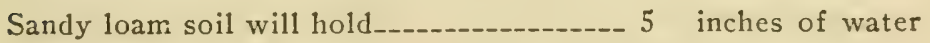
Clay loam soil will hold Muck soil will hold. $71 / 2$ $121 / 2$

This is to say that it would require a sheet of water five inches deep to supply the capillary water for the first two feet of saturated sandy soil ; a sheet of water seven and onehalf inches deep for the first two feet of saturated clay soil; and a sheet twelve and one-half inches deep for the first two feet of saturated muck soil.

Drawing ground water by capillarity.-A very simple experiment will test the capacity of different soils for drawing capillary water from below. Take four glass tubes at least one inch in diameter and from fifteen to twenty inches long, or four chimneys from student-lamps, and arrange them suspended in a rack. Tie over the lower end of each a piece of cheese-cloth. Fill the tubes with soils of different texture, from fine clay to coarse sand. Place a pan beneath the tubes, and pour water into it until the water stands half an inch above the bottom of the tubes. Now watch the water rise in the different soils. Keep accurate track of the time required, and of the height reached in each. What are your conclusions?

Humus and capillary water.-The capacity of any soil for holding capillary water is greatly increased by the presence of decaying organic matter. It has been care- 
fully estimated that one ton of humus will absorb two tons of water and give it up as needed by growing plants.

\section{Tillage and Soil Water}

One of the chief problems of agriculture is to conserve the capillary water of the soil and make it available for plant growth. Capillary water is removed from the soil in two ways, (1) by evaporation, and (2) by being absorbed by the roots of growing plants. What is lost by evaporation is wasted so far as crops are concerned.

Tillage for conserving capillary moisture.-All loosening of the soil increases its absorbing power, and thus causes rain to soak into the ground instead of running off the top. The deeper the plowing the greater this effect will be. Fall plowing, by opening the soil for the absorption of the winter snows, adds to the amount of soil water.

The most effective tillage for conserving capillary water, however, is the frequent cultivation during the growing season which results in a fine soil mulch over the surface. To see the truth of this, make the following experiment:

Effect of a soil mulch.-Fill two glasses nearly full of the same soil; if the soil is dry, add an equal amount of water to each, making the soil fairly damp, but not soaked; pack them equally by striking the glass gently down on the table. Now put a half inch of fine, dry road dust over the top of one, leaving the other without covering. Set the two glasses side by side, and note the time it requires for each to dry out by losing its capillary water through evaporation.

The fine mulch made by frequent harrowings and cultivatings has precisely the same effect on our fields. In dry regions summer fallowing is used for the purpose of collecting a supply of capillary water. Whatever rain falls is 


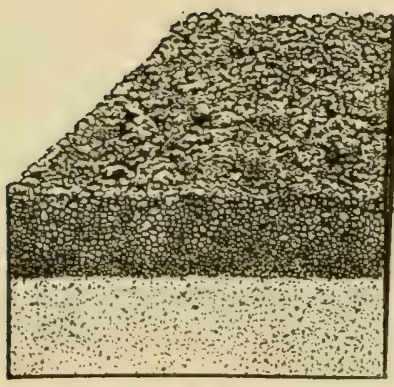

The right kind of mulch for moisture conservation is granular-that is, the dirt should not be pulverized too finely.

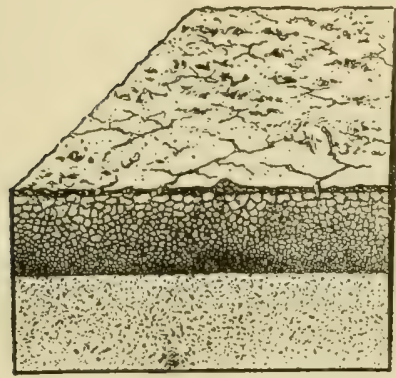

The granular mulch rained upon and left standing for a number of days. Observe that the ground is cracking and that moisture is escaping through these cracks. The crust can be easily broken.

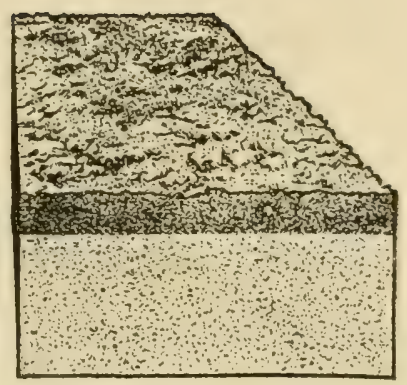

The wrong lind of mulch. The ground is almost dust. Such mulch blows away easily.

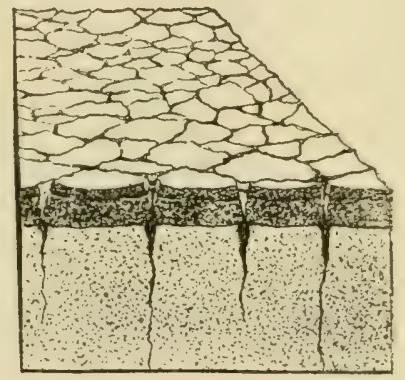

Dust mulch rained upon and left standing in the hot sun. Note that the crust has cracked, and that the moisture is escaping very rapidly. It is impossible to work up this seed bed properly. 
saved by keeping the surface covered with a fine soil mulch, and what moisture is drawn up toward the surface from the ground water by capillary attraction is also conserved for the crop that is to follow.

\section{Soil Drainage}

Necessary as water is to plants, however, much of our soil needs drainage to rid it of an oversupply of free or gravitational water. There are some eighty million acres of marsh lands in the United States. The greater part of this waste territory would make excellent farm land if properly drained.

Lut perhaps fully as important is the occasional small piece of wet ground on farms now under tillage. In certain regions there is hardly a farm that does not have its low marshy places where crops drown out in wet times, or which are allowed to lie without cultivation. In nearly all cases this land could be made the equal of the remainder of the farm by drainage and a little care.

Surface drainage.-Surface drainage is never so thorough and satisfactory as underdrainage, yet it will often improve conditions enough to pay. By surface drainage is meant the opening of runs or ditches to allow the escape of surface water that otherwise would stand on the soil. flood over lower ground, or percolate down to add to the gravitational water already in the subsoil.

1.ow ground is sometimes plowed in narrow strips, the frequent dead furrows allowing surface drainage. If there is a slight slope and the furrows can open freely at the end. this will prove of great benefit. Where such simple drainage will not serve, it is sometimes necessary to construct open ditches, though these should give way to underdrainage when this is possible. For underdrainage is under most 


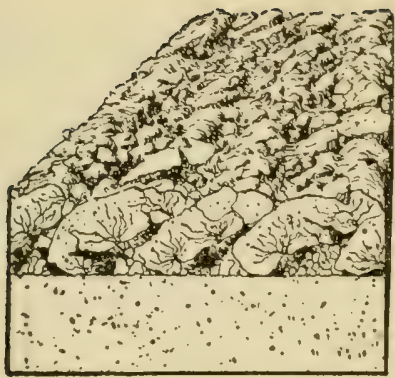

Undisked stubble plowed. Observe that the ground is turned up in lumps; that there are open spaces at the bottom of the furrow which prevent the close compactness of the lower portion of the turned furrow with the soil beneath.

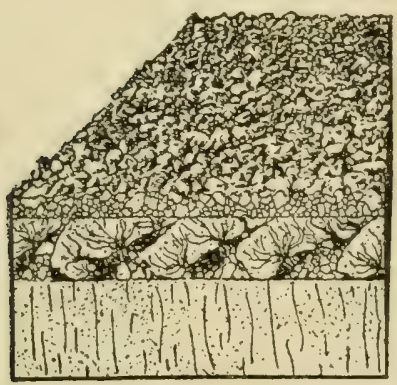

This illustration represents the field above treated with a pegtooth harrow after plowing. The surface is in comparatively good condition, but the bottom is not compact.

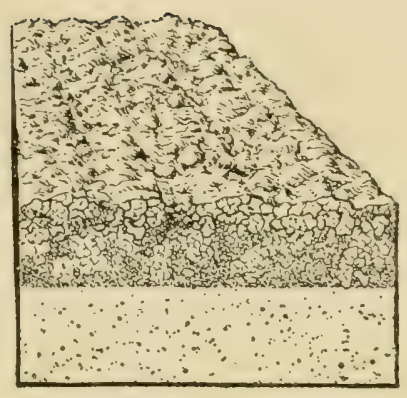

Disked stubble plowed. The mulch formed by the disk harrow fills up the open spaces at the bottom of the furrow, thereby forming a close conection with the subsurface.

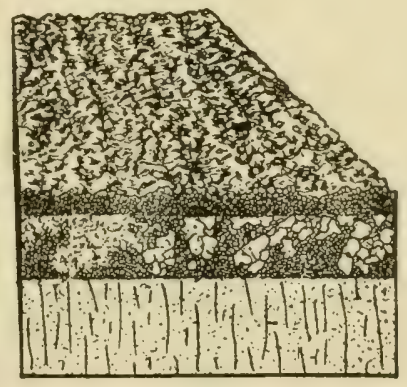

This illustration represents the field above harrowed with a pegtooth harrow. The air spaces are still at the bottom of the furrow. 
conditions a more successful way of removing the water, and it saves much loss of ground and the cutting up of fields.

Making surface drains.-Surface runs which are only required to remove surplus water during flood seasons may be made one and one-half feet deep and ten feet wide at the top at a cost of about twenty-five cents a rod, using a road grader for the excavating. Such shallow runs are often seeded, and the edges leveled off and cultivated, thus aroiding waste of land. Open ditches of this kind are often desirable in connection with underdrainage. They also serve as an cares-trough to prevent flood water of surrounding uplands from entering lower areas.

Deeper ditches are required when the main drain is to receive the discharge of lateral drains. The size and depth will depend on the territory to be drained, and the fall of the ditch. In the Middle Viest, open ditches, many of them miles in length, are being constructed, cach farm served paying its share of the expense. Open lateral ditches or mndersround tile then emnty into this main drain. Under averagre conditions, the cost of opening a ditch seven feet deep and twenty feet wide at the top by means of a dredging machine is about one thousand dollars a mile.

Underdrainage.-Underdrainage has the advantage of carrying off the ground water to any desired depth. This is an important matter in the growth of most crops. For where the level of ground water is near the surface, plants will not strike their roots (leep in the soil, but spread them ont near the top. This leaves the crop at the mercy of irought later in the season, when the upper layers of soil dry out. Deep rooting is also necessary to make full use of the plant food of the soil.

Tile underdrains.-Burnt clay and cement are the materials chiefly used for underdrains in most regions. 
These materials are made into cylinders from three to thirty-six inches in diameter, and from twelve to thirty inches in length. For lateral drains, tiles four or five inches in diameter are most used. The main outlet drain usually requires tiles from eight to twelve inches.

Placing the drains.-Moderately heavy clay soils require laterals about four rods apart to carry off the rainfall. If the subsoil is sandy, the laterals may be as much as eight rods apart. Sometimes the marshiness of a piece of ground is caused by seepage leading to it from some higher area. In this case, there should be a line of tile at the edge of the lower ground to receive the seepage.

Several lines of parallel drains are more economical than one central line into which diagonal laterals run. This is because with parallel drains there is less area receiving double drainage. Several parallel lines can often be carried into one line of larger tile, and all discharge through the same outlet, thus saving trouble and expense.

Depth of tile.-Tile should be placed deep enough that the level of ground water will not stand too near the surface, and yet not too deep to carry off the gravitational water without allowing it to stay too long in the soil. In clay subsoil the most common depth is about three feet. In partially sandy subsoils, the depth may be four feet. All tile meant to catch seepage should be as deep as four feet.

Gradient, or fall.-The larger tiles may be laid with a fall of an inch to one hundred feet. Laterals should have from two to three times this much fall. Lines for catching seepage should have still greater slope; as much as five inches to one hundred feet, if this is possible.

Cost of tiling.-The cost of tiling will, of course, vary with the size of tile used, the depth it is laid, and the character of the soil. The average cost under middle western conditions is about as shown in the following table: 


\begin{tabular}{|c|c|c|c|c|}
\hline \multirow[b]{2}{*}{ Size of tile } & \multicolumn{4}{|c|}{ Depth tile is laid } \\
\hline & 3 feet & 4 feet & 5 feet & 6 feet \\
\hline 4 inch & $\$ .30$ & $\$ .50$ & $\$ .80$ & $\$ 1.25$ \\
\hline 5 inch & .35 & .55 & .85 & 1.30 \\
\hline 6 inch & .40 & .60 & .90 . & 1.38 \\
\hline 8 inch & .45 & .65 & .95 & 1.40 \\
\hline 10 inch & .50 & .70 & 1.00 & 1.45 \\
\hline 12 inch - & .55 & .75 & 1.05 & 1.50 \\
\hline
\end{tabular}

\section{TOPICS FOR INVESTIGATION}

1. Is there any ground on your home farm too wet or marshy for cropping successfully? If so, measure carefully the amount of land in such areas. Do any patches break the regularity of cultivated fields? How much land is practically wasted as far as any return in crops is concerned?

2. What is the value of your farm per acre? What is its rental value per acre? What is the value of all the land lost by being too wet to cultivate? What is its rental value? Have you any land under cultivation that is too wet at times to produce good crops? What do you estimate is the loss?

3. Draw a diagram of any pieces of marsh land on your home farm, showing the outlet for drainage and the distance the drain would have to run in each case. Are there any places where a shallow run would serve? Have you any low ground troubled with rain floods from higher land? If so, could a shallow ditch be made to serve as an eavestrough to save the flooding?

4. Taking the cost of tile drainage as shown in the table, figure what it would cost to tile out wet places on your farm, using four-inch tile for parallels laid four rods apart. The parallels are to connect across the lower end with a six-inch line, and this is to empty into the nearest available ditch or stream. Would it pay to put in tile or: your home farm?

5. By digging down in several different places on your 
farm, see whether you can discover the level of ground water. Have you ever seen water gather in the bottom of a post hole? What does this indicate?

6. Study the texture of the soil in your school yard, and compute the approximate weight of the capillary water contained in the first two feet of its depth when the soil is well saturated.

7. Show how you can make a soil survcy of your father's farm by the use of the soil auger and a diagram of the farm, indicating the top soil, subsoil, elevations, lowlands, and drainage possibilities.

8. Upon an outline sketch of the United States indicate the various regions of distinct types of soil, such as the black loam, sandy loam, clay loam, mountain silt, limestone, and other types of soil representative of a region.

\section{Soil Demonstrations}

In connection with the study of the soil there is abundant opportunity to make some very interesting demonstrations which will also have direct application to the management of the soil on the farm or in the garden.

1. Show how to determine the kind and depth of soil of any particular spot.

2. Show how to test the soil for acidity. Show two methods if possible.

3. By the use of a tumbler of muddy water and the application of a little lime, show the value of lime to soils.

4. Demonstrate the value of shallow cultivation for the conservation of moisture in soils by the use of loaf-sugar and powdered sugar, a solid or well packed piece of earth and a dust mulch placed on top. Apply water to each at the bottom.

5. Demonstrate how to test the capillarity of soils.

6. Demonstrate by the use of various types of soil and the same kind of seed the relations of types of soil to the germination of seed and its subsequent plant growth. 
7. Show by demonstration how legumes tend to conserve the fertility of the soil.

8. Show by the use of different types of soil their respective merits in the conservation of moisture.

\section{Soil Play Contest}

1. Soil type naming contest.

2. Soil analysis contest.

3. Soil guessing games.

4. Soil sample getting contest.

5. Stone naming contest, in which samples of various types of native stones are placed before the contestants and the one who can name the largest number in a given time is to be judged the winner.

\section{Soil Fertility Club Projects}

The object of this club project is to organize the boys and girls into a cooperative group for the purpose of building up the soil fertility of a community. The pupils should pledge themselves to manage at least one acre of land during the season with the idea of not only making a net profit on the investment for the season, but of starting and carrying on a three to five-year rotation of crops with a distinct plan of growing leguminous crops such as clover, alfalfa, cow-peas, etc. This kind of a club project can be easily combined with the other club work outlined in connection with corn, small grains and forage crops.

Combined club projects.-The project may also contemplate the raising of some live stock such as a thoroughbred pig, a baby becf, a pen of chickens, or any other live stock which rightfully belongs to the economy of the farm. Club members in this project should keep a definite record with a view to showing the bookkeeping account and records 
including observations, receipts and expenditures, not only for the first year, but for the entire period of three or four years covering a rotation scheme for the upbuilding of the soil.

Club membership.-This particular club work should be maintained for the members of the agricultural class and should not be open to the boys and girls who are, as a rule, too young to appreciate and undertake properly this line of work. The teacher, in cooperation with the county superintendent and county agricultural agent, may assist in making up a definite three or four-year rotation plan which can be uniformly followed by all members of the club.

The basis of award for a soil fertility club may be as follows :

1. The plan and management of rotation___________ 20

2. The average yield per acre_-___-_ 20

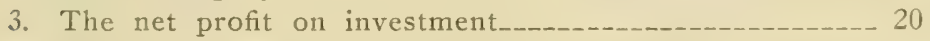

4. The fertile condition of the soil at the end of a three or four-year period-_-__-_-_- 20

5. Soil and crop records, story and soil chart of work_--- 20

Total score-_-_ 100

\section{Class Demonstrations}

In order to stimulate interest in the work and give greater zest to study and the mastery of subject-matter, we would recommend holding a class demonstration contest. The three class members who give the best demonstration will make up the official demonstration team of the class on "soils." They will enter the inter-class, inter-city; intercounty or inter-state demonstration and in this way you can put the "football spirit and philosophy of education" into the school work through the agricultural class.

Subjects for demonstration work may be any or all of 
those given on page 261. Other subjects for both individual and team demonstration may be suggested by members of the class and by the teachers.

Invite the county agent from the County Farm Bureau, county club agent, or some soil expert, to give an address or a demonstration on "Soils and Their Management" before the class, and if agreeable to the school management, let this be done before the entire school. All need a greater knowledge of soil as the source of all that we eat, drink and wear.

It might be well here to go into some of the more elemental things in regard to the chemistry of soils. Every student should bring samples of soil, know different types and their relation to crop production and their ability to drain well, hold fertility and moisture as well as the causes for "c'ashing," "crosion," "blozving," and "running out."

Students may well take field trips to study types of low or high priced land in the neighborhood. To be a good judge of land or soil will prove a great asset for the student through life regardless of rocation or the profession he intends to follow.

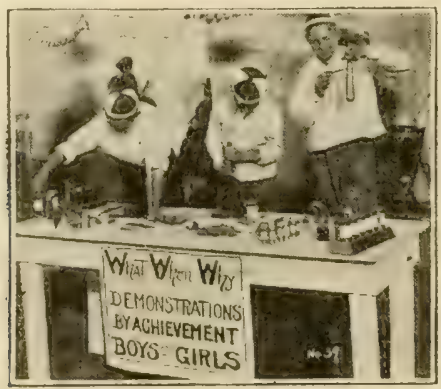

Parlin (N, J.) team demonstrating before an inter-state fair audience. 


\section{PART IV. FARM ANIMALS}

CHAPTER XVIII

\section{FARM ANIMALS AND AGRICULTURE}

$\mathrm{F}^{\mathrm{ARM}} \mathrm{M}$ animals form one of the most important sources of I wealth in the nation. The five most important groups of animals, ranked according to their market value, are horses, cattle, hogs, mules and sheep. If these animals should all be sold, they would bring the enormous sum of nearly six billion dollars, or sixty dollars for every man, woman and child in the United States.

\section{Work Animals}

Farm animals serve several important uses: (1) they provicle food for man, (2) they work for him, and (3) they supply various useful products. The total market value of the working animals, horses and mules, is slightly greater than that of the food producing group, cattle, sheep and hogs.

Using animals for work.-Centuries ago man had not yet domesticated the animals and trained them to work for him. Since the uses of steam and electricity had not been discovered, all labor had to be done by men themselves. The implements used for cultivating the soil were all crude and ineffective, and could only be operated by hand. It 
then required much more time and effort to secure a living by agriculture than it does now.

One of the greatest lines of progress in America has been the substitution of animal power for man power in doing farm work. In this we are far ahead of most other nations, even those of Europe. For example, we have in the United States almost twenty-five million horses, or approximately one to every four persons. In France, one horse has to serve ten people; in Germany, thirteen, and in Great Britain, twenty-six.

Saving in time by work of animals.-The use of work animals has resulted in great saving of time. It has been estimated that in 1830 each bushel of wheat grown in the United States required three hours of a man's time; it now requires less than ten minutes. In 1850 it took a man four and one-half hours on an average to grow, harvest and shell a bushel of corn; it now requires less than forty minutes. The greater part of this saving has come through the use of improved farm machinery drawn by horses or mules.

Where the peasants of European countries use shovels, hoes, scythes or other primitive implements, we employ gang-plows, disk harrows and self-binders. The great saving in human energy and time growing out of this difference is seen when it is remembered that one lorse hitched to modern machinery can do the work of at least ten men with hand tools. Many an American boy with his fourhorse team is therefore accomplishing the labor of forty European peasants with their hand work and poor tools!

The animals used for work.-Among the various animals that men have trained to work for them are horses, cattle, mules, buffalo, reindeer, camels, dogs and elephants. No animals, except horses, mules and cattle, have ever been extensively used for farm work in this country. The use of oxen for work has now been almost wholly discontinued. 
During recent years, horses and mules have found a competitor in the automobile and the traction-engine. Thousands of farmers now own their cars, and the gasoline tractor is a common sight on many of the larger western farms. In spite of these facts, however, the number of horses and mules on our farms is constantly increasing, and the market for them is growing better and more uniform. The price of work animals is considerably higher than it was when automobiles and traction-engines began to come into use. Horses will always have an important place in the economy of the farm.

\section{Animals That Supply Food}

Meat and other animal products form a very important part of our food supply. Even vegetarians, who are opposed to the eating of flesh, depend largely on such foods as butter, eggs and milk.

Meat as food.-A great proportion of all our farm crops goes to the feeding of meat producing animals. The most progressive nations of the world are those that in addition to fruit and vegetables for the diet make much use of their domestic animals in supplying food products. Meat is a more expensive food than grains and vegetables, and people of the poorer classes can not aftord to eat it. Millions of those living in oriental countries seldom taste meat in any form. Lack of nutrition and a balanced ration are shown in absence of ambition and enterprise.

According to careful estimates the food stuply in American homes is divided among the different foods in approximately the following proportions (Farmers' Bulletin 391) :

Meats and poultry $16 \%$

Dairy products $18 \%$ 
Cereals and their products__-_____._. $31 \%$

Vegetables and fruits________________ $25 \%$

All other foods_____- 10\%

It is therefore seen that we derive more than one-third of all our food in this country from animals, either by consuming their flesh or other products from them, such as milk, butter, cheese, etc.

Animals used for meat.-The animals whose flesh is chiefly used for food are cattle, hogs and sheep. So great has the industry of preparing their flesh for food become, that every city has its great stock-yards and slaughterhouses, where hundreds of thousands of animals are lilled every year. Cold storage vaults are provided in which meats can be kept at a temperature below freezing for months at a time. Nuch of the meat that is now used on the farms is first shipped to the city packing houses for slaughter, and then bought back from retail dealers as needed, in the form of bacon, ham, canned or dried beef, or as fresh meats shipped in refrigerator cars. Many small towns also have their local slaughter-houses, where animals purchased from the farms are killed for home consumption.

Other food products from animals.-The other food products from animal life, such as mill, butter, eggs and cheese, are even more important. Milk and eggs contain more of the different food elements needed by the human body than any other foods; and butter is as necessary as meat.

The dairy and poultry industries are therefore among the most important connected with agriculture. Milk and butter are shipped to the cities in refrigerator cars or special trains. Hundreds of creameries are operated to save time for the farmer and insure him greater profit. Many trainloads of eggs and butter are collected during the summer 
months and put in cold storage and kept for the winter supply.

\section{Other Animal Products}

The farm animals are useful in other ways than doing work and providing food for man. Many practical necessities are supplied by them.

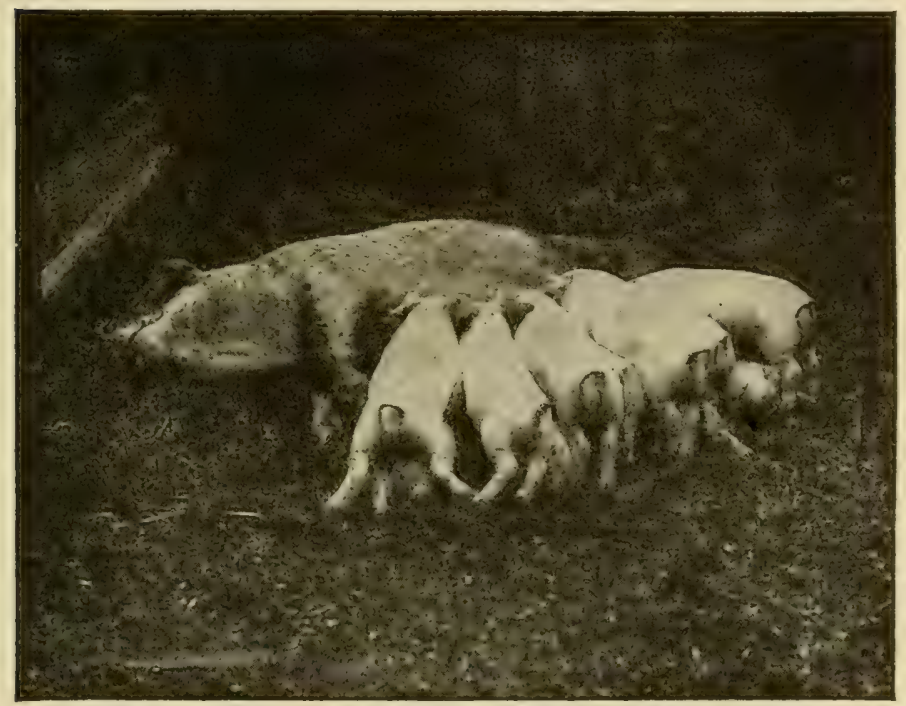

A promising family.

Leather.-The skins of all the common farm animals are saved for leather. Cattle, horses, sheep and even pigs, contribute to the making of our shoes, gloves, mittens, harnesses, saddles, cushions and many other articles in common use.

Wool.-Sheep furnish one of the most valuable clothing materials known. Many sheep ranches are maintained 
chiefly for the flecees, mutton being of secondary considcration. More than thirty-eight million sheep annually give up their wool in the United States for the making of clothing and other articles for the household.

Other products.-We orve many other articles of common use to some form of animal product. Our brushes are made from bristles. Buttons are cut from bone. Gelatin and glue are both animal products. Many soaps are made from animal parts not suitable for meat. Blood and bone, as we have already seen, are used for fertilizers. So completely are all parts of siaughtered animals saved for some useful purpose that it is said nothing is lost of the pig when it is killed, except the "squeal."

It is estimated that the value for fertilizing purposes of the manure of all farm animals in the United States, if properly saved and applied to the soil, would annually reach the stupendous amount of more than two billion dollars.

\section{TOPICS FOR INVESTIGATION}

1. Make a careful list of all animals belonging on your home farm. Have your father help estimate what each one is worth, and compute the value of all live stock, and find the annual interest on this amount at six per cent.

2. How many bushels of corn were raised on your farm last year? On the basis of the time required for producing a bushel of corn in 1850, how many days of nine hours each would have been required to produce this crop with machinery then in use? Make the same computation with the wheat raised on your farm, comparing with the time required to produce a bushel in 1830 .

3. Talk with your mother, and see whether you can estimate what proportion of the food used on your table comes from each of the classes shown in section two.

4. Nake an investigation by reading and inquiring among people of the amount of meat, butter, eggs and milk used by the farming class in England, Germany, 
France, Spain, Russia, China. Compare with our own country.

5. Is there any country where the buffalo is now used as a work animal? The elephant? The camel? Where are reindeer used, and for what purpose? What are the different lines of work in which dogs are employed?

6. Show on the map of the United States the most important regions for the production of the various types of domestic animals, such as the horse, dairy and beef cattle, the sheep, the hog and the goat. Consult the last census report with reference to increase or decrease of farm animals in the various states. 


\section{CHAPTER XIX.}

\section{CATTLE}

ATTLE rank second only to horses in market valuc in C the United States. Our farms support some twentytwo million dairy cows, or one to approximately every four people. In addition, there are about thirty-seven million other cattle, chiefly calves and beef stock. The value of each of these two great groups is about the same, nearly a billion dollars, or almost two billion dollars for the whole.

\section{Dairy Cattle}

Dairying is one of the leading American industries Each of six states, Wisconsin, New York, Iowa, Minnesota, Inlinois and Texas, has more than a million dairy cows, and four other states, Pennsylvania, Ohio, Michigan and Missouri, have more than three-quarters of a million each. These ten states supply fifty-three per cent. of all our dairy cattle.

The following chart shows the percentage of all the farm dairy cows of the United States found in each of these ten leading dairy states:

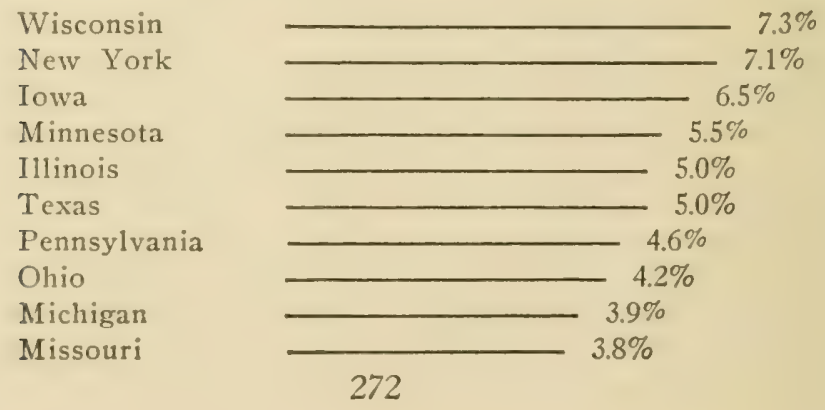


Profitable and unprofitable cows.-Whether a dairy herd yields a profit or a loss depends first of all on the milk and butter-fat producing capacities of the individual cows. A poor cow may require as much feed as a good one, and demands as much labor and attention.

It has been estimated that one-third of the dairy cows in the United States are kept at an actual loss. Twice

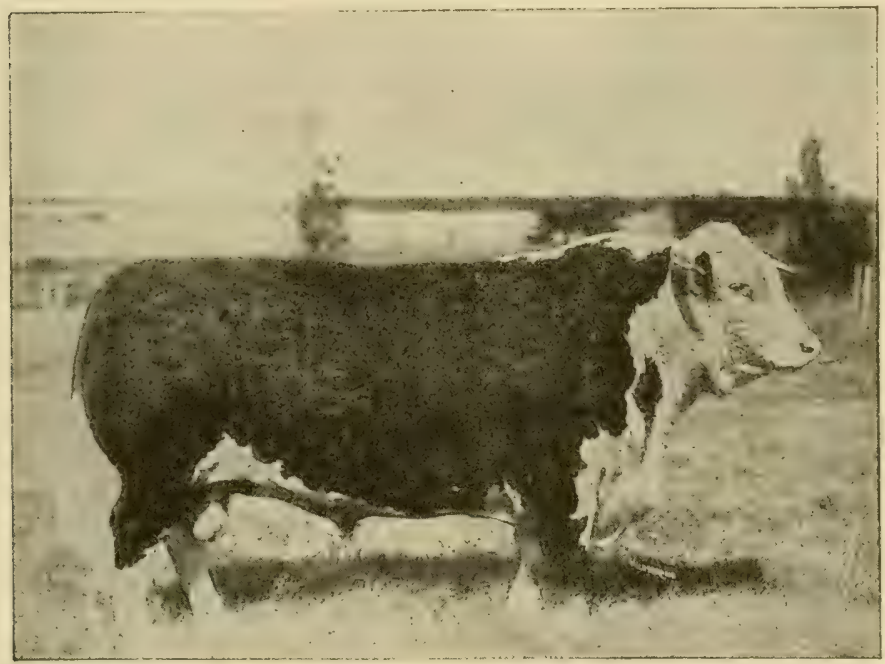

A champion Hereford.

every day, therefore, there are milked some seven million cows, mere "boarders," that not only return no profit, but use up the profit from good cows. How many cows of this kind are kept on your farm?

Profit differences in herds.- It is estimated that the skim-milk, calf and manure from a dairy cow are worth the cost of caring for her. This leaves the milk to balance against the value of the feed. The difference 
between the best and the poorest cow in almost any herd is surprising. This difference is well shown in the following record of fifteen cows for one year in an Illinois herd:

\begin{tabular}{|c|c|c|c|c|c|}
\hline $\begin{array}{l}\text { No. } \\
\text { cow }\end{array}$ & $\begin{array}{l}\text { Lb. } \\
\text { milk }\end{array}$ & $\begin{array}{l}\text { Lb. } \\
\text { fat }\end{array}$ & $\begin{array}{l}\text { Per cent. } \\
\text { fat }\end{array}$ & Profit & Loss \\
\hline 1 & 1204 & 49 & 4.07 & ---- & $\$ 27.52$ \\
\hline 2 & 1236 & 50 & 4.05 & ---- & 27.20 \\
\hline 3 & 2944 & 88 & 2.99 & $\ldots$ & 15.17 \\
\hline 4 & 2597 & 91 & 3.50 & $\ldots$ & 15.38 \\
\hline 5 & 2548 & 98 & 3.85 & --- & $13.1 \mathrm{~S}$ \\
\hline 6 & $24 / 5$ & 99 & 4.00 & -...- & 13.18 \\
\hline 7 & 2569 & 105 & 4.09 & $\ldots$ & 10.98 \\
\hline 8 & 3164 & 117 & 3.70 & $\ldots$ & 8.37 \\
\hline 9 & 2829 & 123 & 4.34 & $\ldots$ & 8.67 \\
\hline 10 & 3380 & 149 & 4.41 & $\therefore-$ & 1.58 \\
\hline 11 & 4582 & 158 & 3.45 & $\$ 1.41$ & \\
\hline 12 & 4146 & 174 & 4.20 & 3.41 & -- \\
\hline 13 & 4103 & 177 & 4.31 & 5.41 & $-\ldots$ \\
\hline 14 & 4993 & 191 & 3.82 & 8.40 & --- \\
\hline \multirow[t]{3}{*}{15} & 4435 & 200 & 4.51 & 10.21 & --- \\
\hline & & & & $\$ 28.84$ & $\begin{array}{r}\$ 141.23 \\
28.84\end{array}$ \\
\hline & & & & Loss & $\$ \overline{112.39}$ \\
\hline & $\overline{3147}$ & $\overline{124}$ & $\overline{3.94}$ & & $\$ 7.49$ \\
\hline \multicolumn{6}{|c|}{$\begin{array}{l}\text { Av. } \\
\text { Difference in profit between best and poorest cow. } \$ 37.73\end{array}$} \\
\hline
\end{tabular}

This was an exceptionally poor herd, so poor that it lost the owner $\$ 112.39$ for the year-an average loss of $\$ 7.49$ per cow. Either of the two poorest cows lost almost as much as the best five made their owner. Even the best cow of this herd is poor enough, but there is a difference 
of $\$ 37.73$ in the year's record between the best and the poorest.

\section{Sclecting Dairy Corus According to Type}

Dairy cows may be selected by two different methods: (1) keeping a record of the amount of milk produced, with the percentage of butter-fat it contains; and (2) judging whether the cow conforms to the physical type known as good dairy stock. The first of these is the only absolutely sure method. The second is also of great value, for cows are often bought without any possibility of learning their milk record. Every farmer should, therefore, know the points of a good dairy cow.

The dairy type of cow.-Dairy cattle and beef cattle present two rather distinct types as to form, or build, and appearance. In general, the frame of the beef animal is the shape capable of taking on the largest amount of flesh, while that of the dairy cow is adapted to the production of milk. Both types must be good eaters, for only the food above the amount required for maintaining the body can go to the production of either beef or milk.

The good dairy cow is spare of flesh, for the surplus food must be turned into milk instead of fat. She appears somewhat loose-jointed, but the muscles are well developed. The coat is smooth and soft, the eyes are bright, and the disposition is wide-awake and active. The jaw is strong, the stomach and other organs of digestion are capacious. The circulatory system needs size and strength, as it must supply abundance of material for the production of milk. The udder is well shaped and large.

Shape of the dairy cow.-The typical dairy cow has what is called a wedge conformation, or shape. The body outline, whether viewed from side, top, or front, roughly resembles a wedge. 
The side wedge has its base in a line formed by the depth of the body through the hips to the lower extremity of the udder, with the point of the wedge at the head. The top wedge has its base in a line across the width of the hips, and its point at the withers. The front wedge has its base

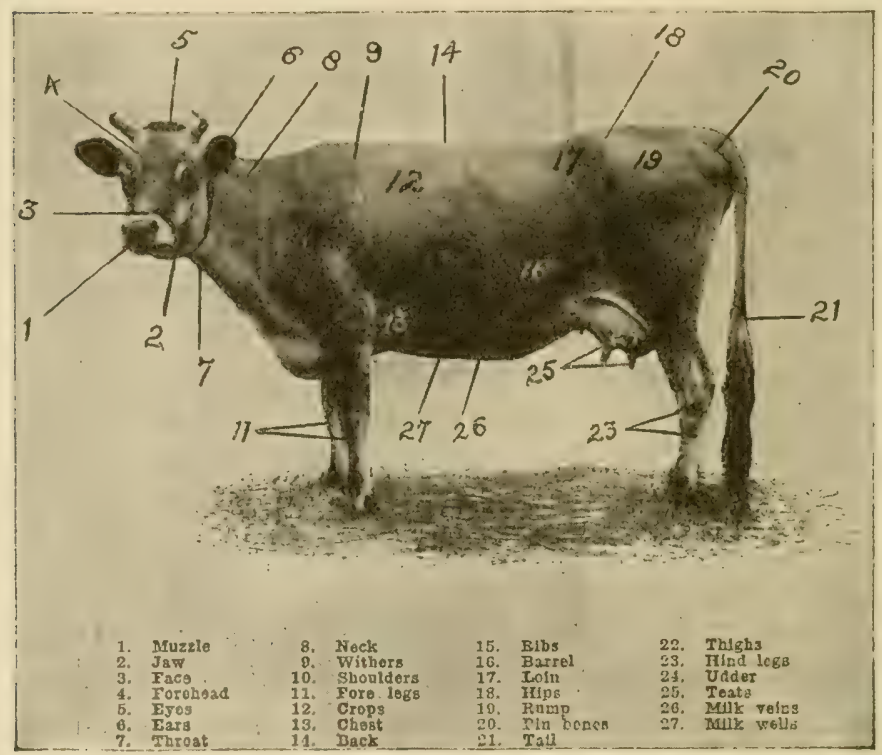

Parts of a dairy cow shown as an aid in judging.

in a line across the floor of the chest, and its point at the top of the withers.

It is readily seen that the shape given the body by these three wedge conformations allows a generous amount of room for the digestive and circulatory systems and the udder. This form does not, however, give a frame capable of taking on a large amount of flesh, and is therefore not adapted to beef cattle. 


\section{Judging the Dairy Cow}

Various score-cards are in use for the judging of dairy cows. Judging by use of the score-card trains in accurate observation and judgment, and shows the relative value of the different points. Secure a score-card from your state college of agriculture or the United States Department of Agriculture and learn to use it in judging cattle.

\section{Selecting the Dairy Cow by Milk Tests}

The profit from a dairy cow depends on two factors, (1) the amount of milk produced, and (2) the percentage of butter-fat in the milk. The first of these questions can be determined by weighing the milk; the second, by testing the milk with the Babcock milk test.

Testing the milk of different cows.-In order to determine the record of each cow of the herd, the milk must be weighed and tested regularly throughout the season. The testing and weighing may be done daily, though this frequent a test is hardly necessary for practical farm purposes. A plan followed by many farmers is to woigh the milk daily, and test the butter-fat of both night's milk and morning's milk once a month.

Making the Babcock test for butter-fat.-It is not the quantity of milk alone that determines the value of a cow. Practically all milk and cream now sold from the farm for butter-making purposes are paid for, not by weight or bulk, but by the amount of butter-fat they contain. The purpose of the Babcock test is to measure the percentage of butter-fat in milk. Every dairy farm should regularly use this test.

The materials for making the Babcock test are (1) a hand-power centrifugal tester; (2) two or more milk testbottles; (3) a pipette to measure the milk; (4) a small glass 
measure for acid; (5) sulphuric acid with specific gravity of 1.82: (6) hot water. The necessary apparatus can be bought for about five dollars, theigh a fuller equipment may cost as much as twenty dollars. Full directions for making the test come with each set of apparatus.

Steps in the Babcock test.-The Babcock test is not difficult to make, nor does it require much time. Yet great

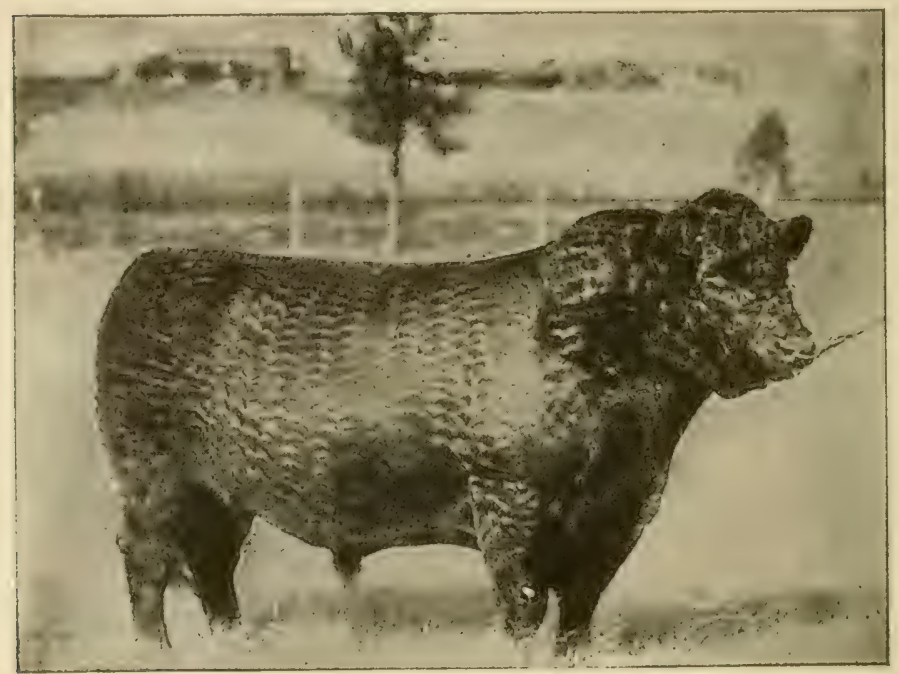

A Galloway prize winner.

care must be taken if the results are to be trustworthy. The following are the steps required in making the test:

1. Stir the milk thoroughly before taking the sample.

2. Fill the pipette to the height shown by the mark.

3. Empty the pipette into the test-bottle, blowing to drive all the milk out.

4. Fill the acid measure to the mark shown with sulphuric acid, and add to the test-bottle.

5. Shake the bottle to mix the milk and acid thoroughly. 
6. Place the bottles in the machine, and whirl five minutes.

7. Add hot water to each bottle until filled to bottom of neck, and whirl one minute.

8. Add more hot water to bring the top of the fat nearly to the top of the marks on the neck of the bottle, and whirl one minute.

9. Read the per cent. of fat in the neck of the bottle; this indicates the quality of the milk.

10. Empty the test bottles and wash.

The percentage of butter-fat ought to be not less than three and five-tenths, and should range up to five or occasionally even six in the milk of the better cows.

\section{Dairy Breeds}

Dairymen are not agreed as to the type of cow that is most profitable. Some prefer what they call a "generalpurpose cow," combining as far as possible the qualities of both dairy and beef breeds. Such animals are usually of large frame, take on flesh readily, and so are easily converted into beef when this is more profitable than milking. Other dairymen select the pure dairy breeds, preferring to get their profit out of the milk produced, rather than from the beef. Which is the better plan will depend on local conditions and demands.

Choosing the dairy breed.-It is impossible to select any one breed of dairy cattle as the best under all conditions. Some are noted for producing large quantities of milk, and others for producing milk rich in butter-fat. Some do best when allowed a wide range for foraging, and others when they are kept close and fed high. Some give a large flow of milk for a short season, and others a smaller flow for a longer time. The dairyman should decide what particular qualities are best adapted to his needs, and then select the breed that will meet these needs.

Leading dairy breeds.-Among the best-known 


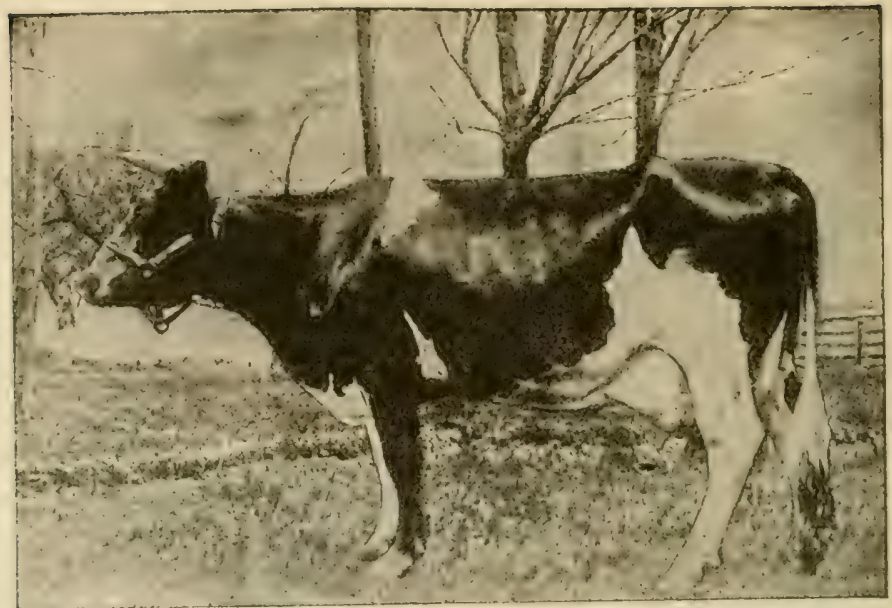

"Bimilstiue Belle de Kol," a champion Holstein cow with a record of $1,058.34$ pounds of butter-fat in 365 days.

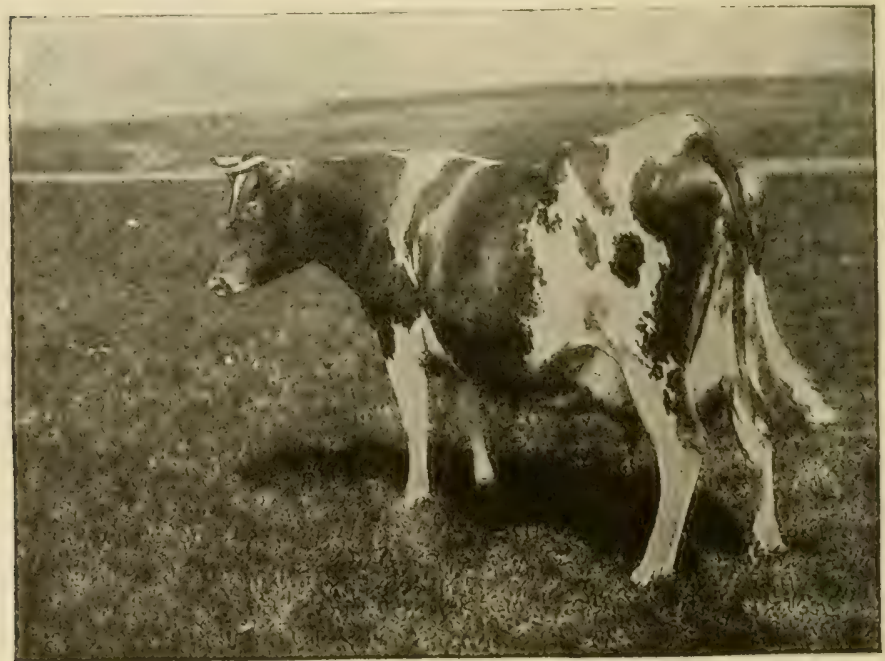

Another dairy champion of the United States, "May Rilma," a Guernsey. Her record for 365 days was $19,639.5$ pounds of milk and 1,059.59 pounds of butter-fat. 
breeds of dairy cattle are the Holstein, or Holstein-Friesia as they are officially named; the Jersey; the Guernsey; and the Ayrshire. The Shorthorns are also a favorite class, combining in large degree both dairy and beef qualities. Records kept for one year in various experiment stations of the United States Department of Agriculture show the following average ratings as milk producers of the first four of these breeds in the. station herds:

\begin{tabular}{|c|c|c|c|c|}
\hline Breed & $\begin{array}{l}\text { Pounds } \\
\text { of milk }\end{array}$ & $\begin{array}{c}\text { Per cent. } \\
\text { of fat }\end{array}$ & $\begin{array}{l}\text { Pounds } \\
\text { of fat }\end{array}$ & $\begin{array}{l}\text { Per cent. } \\
\text { total solids }\end{array}$ \\
\hline Holstein & 8699 & 3.45 & 300 & 12.99 \\
\hline Jersey - - & 5508 & 5.14 & 283 & 14.2 \\
\hline Guernsey _-_- & 5509 & 4.98 & 274 & 14.2 \\
\hline Ayrshire - ....-. & 6533 & 3.85 & 252 & 12.98 \\
\hline Average -..- & 6562.25 & 4.355 & 277.25 & 13.5925 \\
\hline
\end{tabular}

\section{Feeding Dairy Cows}

Just as the soil must contain the food elements needed in the growth of the plant, so the dairy cow's rations must contain the elements required to produce milk and upbuild the body. If proper food is not supplied, either the amount of milk or its quality will be sure to suffer. Only three different food elements, or uutricnts, are likely to run short in the ordinary rations of the cow; these are (1) protein, (2) carbohydrate, and (3) fat.

Protein.-Protein is required in the animal body for the making of all muscular parts, blood and connective tissue. It supplies nearly one-third of the solid part of milk, going to form the curd and albumen.

It is fortunate that the nitrogenous plants so valuable in building up the soil are also rich in protein. Alfalfa, clover, cow-peas, soy-beans, the vetches and other legumes are therefore desirable as a part of the dairy ration. Bran, 
linseed meal, cottonseed-meal, gluten feed and oats are also rich in protein. Protein should make up approximately onesixth of the cow's ration during the milking season; no other food can take its place. It is the most expensive part of the ration, and should be secured as far as possible from home-grown legumes.

Carbohydrates.-The carbohydrates are necessary to supply energy, heat and fat for the animal body, and sugar and fat in the milk. All the common grains are rich in carbohydrates, which are the cheapest nutrient of the cow's rations. Among the more common carbohydrate feeds are corn, corn silage, corn stover, oats straw, millet hay, sugar beets and dried beet pulp. Timothy hay should not form a part of the dairy ration, as it has few of the elements required in producing milk.

Fat.-Fat is used for practically the same purposes as the carbohydrates in maintaining the body and producing milk. It is contained in some degree in all feeds, though in smaller quantities than carbohydrates, and in more concentrated form. It has been found that one pound of fat will scrve the same purpose in the dairy ration as two and one-fourth pounds of carbohydrates.

The balanced ration.-By a balanced ration is meant a ration which contains the right digestible proportion of each kind of nutrient demanded by the animal. The term nutritice ratio is used when speaking of the relation of protein to carbohydrate and fat in the ration. The nutritive ratio of the dairy ration is $1: 6$; this is to say, one part of digestible protein to six parts of carbohydrates and fat combined. The following tables show several balanced and economical rations for dairy cows:*

*(Purdue Ext. Bul. No. 21.) 
Ration I.

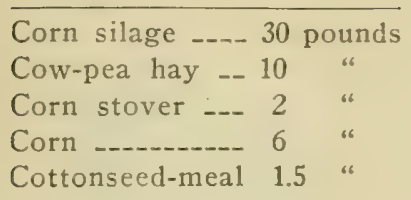

Ration III.

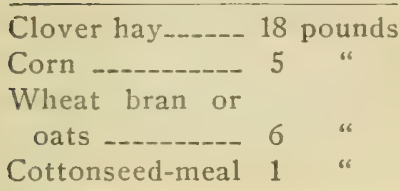

Ration II.

\begin{tabular}{|c|c|}
\hline & \\
\hline $\begin{array}{l}\text { Sugar beets_._._. } \\
\text { Alfalfa hay }\end{array}$ & $\begin{array}{r}\text { pou } \\
\text { “ }\end{array}$ \\
\hline Corn stover & “ \\
\hline Corn & “ \\
\hline Dried brewers' & \\
\hline grains _..--..- 5 & "s \\
\hline Ration IV. & \\
\hline orn silage _... 30 & pc \\
\hline $\begin{array}{l}\text { Canadian pea and } \\
\text { oat hay }\end{array}$ & 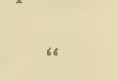 \\
\hline - & “ \\
\hline feed._....... & “ \\
\hline
\end{tabular}

It must be remembered that, no matter what the feeds used to supply the protein, carbohydrate and fat, there must also be a certain amount of ronghage in the ration. All browsing or grazing animals require bulky feed, and can not thrive on concentrated material alone.

\section{Producing Clean Milk}

Milk is perfectly clean as it comes from the cow. It is easily tainted, however, either by filth that may 'fall into the pail during the milking, or from dirty utensils. Dirty milk makes dissatisfied customers, endangers the health of users, especially children, hastens souring, makes a lower grade of butter, and indicates shiftlessness and low standards of dairying.

The cow barn.-The cow barn should be constructed for the comfort, cleanliness and hygienc of its occupants. It should be well ventilated and have plenty of light. The floor should be of some hard material, preferably cement, and water-tight. The stalls should be the right length for the cows, and have a shallow sutter at the rear with slope 


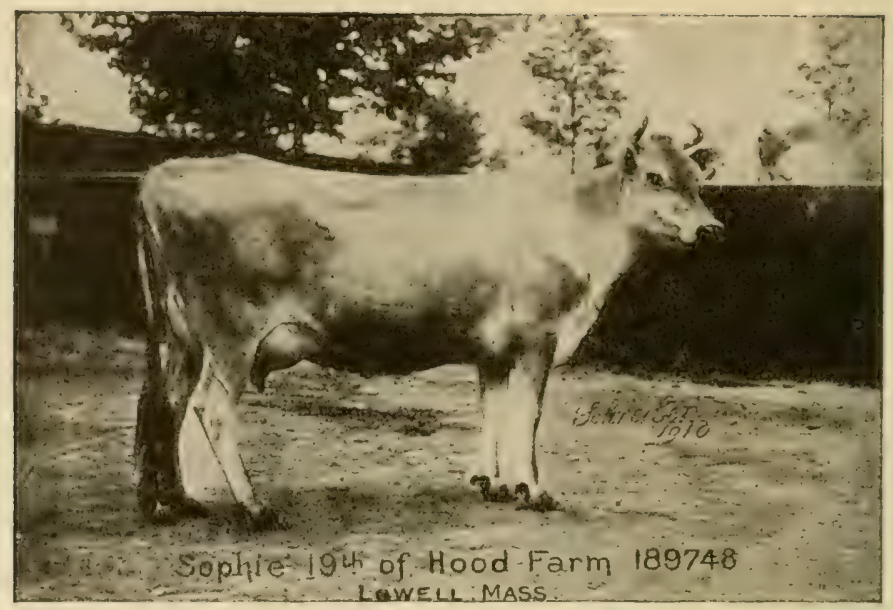

A chamrion . Tersey cow with a butter-fat record of 929.14 pounds in 365 days.

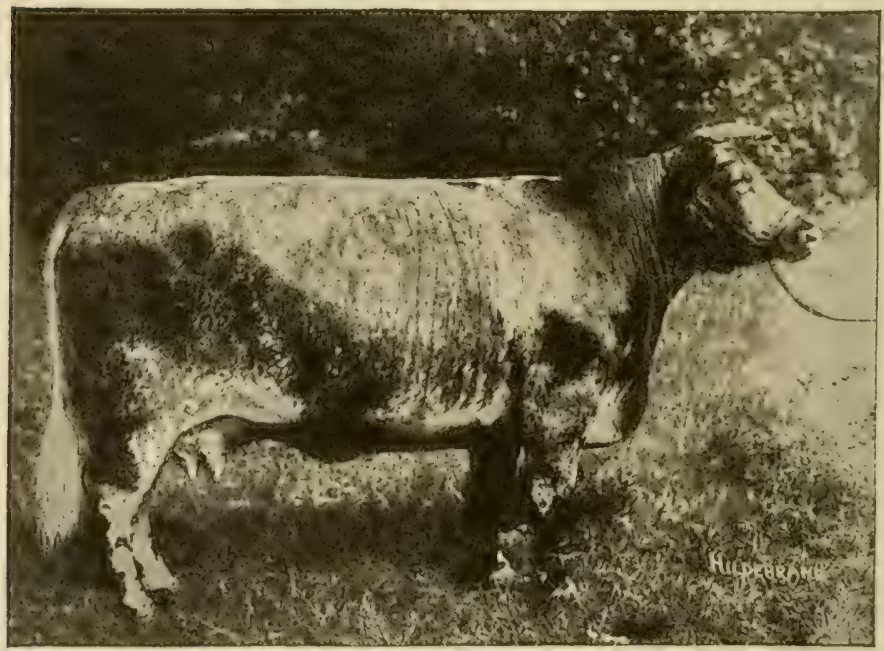

A champion Shortholn cow. a general murpose breed adapted both to beef and milk production. 
enough toward one end to permit drainage. Instead of a feed manger in front, there should be a liquid-tight trough, also with a slight slope, that it may be washed out. All floors should be kept thoroughly washed by means of a hose and stiff brushes.

Cleanliness in milking.-Before the milking is begun, both the cow and the milker should be clean. If the cow is dusty, the dust should be well brushed out. The udder should be wiped clean, washed, or sponged off, as may be required. The milker's hands should be freshly cleansed, as it is almost impossible to keep the milk from touching them.

Special suits should be kept for milking, and should be frequently washed. The practise of putting on old, greasy and unwashed clothes, simply to save soiling other garments while milking, is too filthy to be permitted in any dairy. All utensils should be kept in a perfectly clean place, and well scalded once each day.

A careful analysis of the dirt contained in milk shows about nine-tenths of it to be cow manure. The other tenth is hair from the cow, dirt from the cow or the millier, particles of the feed used, and disease germs from the cow or hands of the milker. No dairyman should ask a consumer to eat such an array of filth as this.

Straining the milk.-Much of the dirt that gets into the milk can not be strained out, since it fully dissolves and will pass through the strainer as easily as the milk itself. A good strainer will, however, remove a considerable portion of the insoluble matter.

A wire mesh strainer should never be used. The strainer should be cone-shaped, with gauze and absorbent cotton forming the outlet. One thickness of the cotton is placed between four thicknesses of gauze, two on each side, and held in place by a ring which fits over the edges and attaches it to the bottom of the recentacle. The cotton should 
be destroyed after each straining, and never used a second time. The additional expense for this type of strainer is slight, and should keep no progressive dairyman from using it.

Cooling the milk.-After cleanliness, the next essential to good care of milk is quick cooling. So important is quick cooling to prevent souring of milk and keep it in

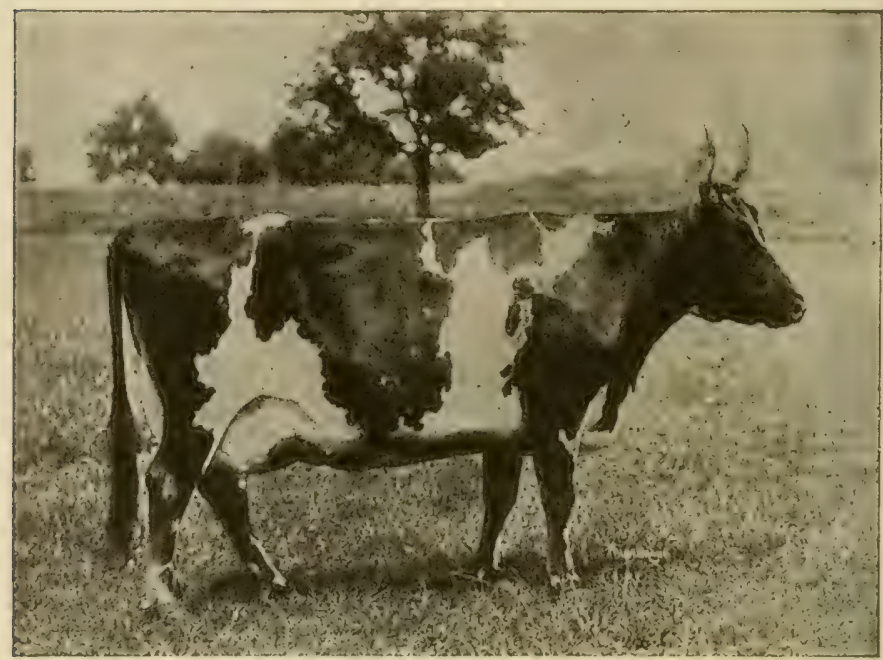

Auchenbrain Brown Kate 4 th, Ayrshire cow with a 365-day butter-fat record of 917.5 pounds.

good condition that a higher price is often paid for milk properly cooled than for uncooled milk.

For the best results some form of cooling apparatus is necessary. Various machines for this purpose can be had for from ten to twenty-five dollars. An average of about five cents' worth of ice is required for each hundred pounds of milk during the warm months. Milk should be cooled down to forty-five degrees in a few minutes of time. 


\section{Becf Breeds}

Larger profit can be secured from dairy than from beef cattle with the same amount of feed, but dairy animals require a much greater amount of labor and a more costly equipment. The work necessary to care for fifteen or twenty dairy cows will be sufficient to tend two hundred beef animals. Properly managed, the raising and feeding of cattle for beef can be made highly profitable.

The beef-producing type.-Beef and dairy cattle differ widely in their type. For the production of beef, the animal must be able to use a large proportion of its food in the putting on of flesh; it must also have a form capable of holding a large amount of muscle and fat.

The beef animal should have a conformation that (1) favors the production and carrying of flesh; (2) supplies the best proportion of good cuts of meat on the block; (3) indicates good constitution and feeding capacity.

The form of beef animals.-Instead of the wedge conformation of the dairy cow, beef cattle should in their shape present a series of rectangles; that is, they should be "blocky." The body is reasonably long, and deep, with short sturdy legs. The whole form presents a plump, fullshaped appearance. The back is broad and straight, with ribs well arched to give breadth to the body. The quarters are well filled and thick. The skin is pliable, rather thick, and the coat smooth and glossy.

Judging beef cattle with the score-card.-Because of the difference in type between dairy and beef cattle, it is best to use separate score-cards in judging them. Secure a score-card from your state college of agriculture or the United States Department of Agriculture. After studying it and judging one or more animals under the direction of the teacher, each member of the class should judge several 


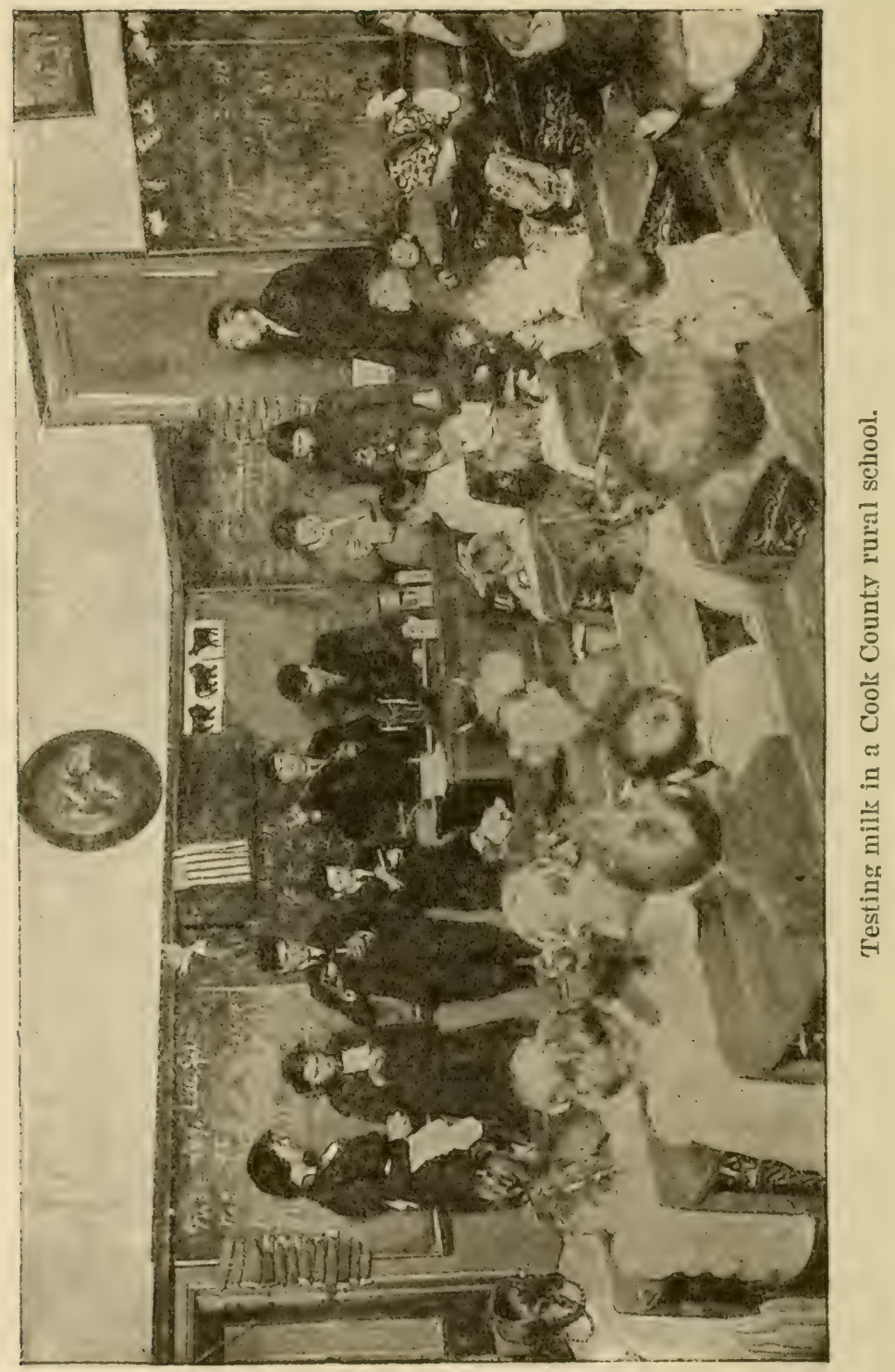


beef animals from the home herd, asking his father to help in the judging.

Beef breeds.-Among the chief breeds of beef cattle in the United States are Shorthorns, or Durhams, Herefords, Aberdeen-Angus, and Galloways. Several different breeds have also developed a polled, or hornless, type. Except for the lack of horns, the polled breeds closely resemble the parent breed from which they were derived.

Feeding beef cattle.-Feeding grain and roughage to beef cattle is a more profitable way to market them than to sell them off the farm. In this way the fertility of the soil is also conserved, and better crops produced.

The fattening ration for cattle is slightly different from the dairy ration, the mutricnt ratio for beef being $1: 7$, as against $1: 6$ for milk production. This is to say, that the fattening animal should have a balanced ration consisting of one part protein food for every seven parts of carbohydrates and fats.

\section{Tuberculosis in Cattle}

Tuberculosis is a common disease among cattle. It is more common among dairy cattle than beef cattle. This is probably because dairy cows are kept to a greater age than beef cattle, and are more closely confined in barns. The effects of tuberculosis in a dairy herd are (1) lowered milk production and final loss of the tuberculous animal by death, and (2) danger of giving the disease to people, especially children, who use the milk.

Prevalence of tuberculosis in herds.-There is no way of telling the exact number of cattle affected by tuberculosis, as comparatively few herds are examined for the disease. It is not uncommon to find as high as seventy to eighty per cent. of the cows in a herd diseased, some with 
the disease just starting, others with it well along, and still others in the last stages. Since tuberculosis is contagious, it is evident that when it once gets started in a herd it is hard to stamp out.

The tuberculin test.-It is impossible to make certain of the presence or absence of tuberculosis in a herd by any set of symptoms. The only sure way is by the tuberculin test. This test is required by law of all dairy herds in a number of states. Experts have shown that tuberculin, if properly used, will reveal the presence of tuberculosis in at least ninety-eight per cent. of the cases.

Tuberculin is a fluid in which tubercle germs have been grown, but from which they have all been removed. This fluid is injected with a hypodermic needle under the skin of all the animals of a herd which is being tested. It will not injure well animals nor give them the disease. Animals that have tuberculosis reveal this fact by a feverish condition. which arises from eight to twelve hours after the tuberculin is administered. Well animals show no such reaction.

Suppressing tuberculosis in cattle.-Little can be done in the way of treatment to cure tuberculosis in cattle. Those that have contracted it in a mild form often recover. Animals found to be well advanced with the disease should at once be slaughtered. All diseased stock should be separated from well animals, and kept in different barns and pastures.

The milk from mildly diseased cows may be used, providing it is first carefully pasteurized. To pasteurize milk, it is kept at a temperature of one hundred and forty-nine degrees for twenty minutes, or one hundred and seventysix degrees for five minutes. This heating is sufficient to kill the germs of the tuberculosis. 


\section{TOPICS FOR INVESTIGATION}

1. Are the cattle on your home farm of dairy breed, beef breed, or "general purpose" breed? Talk with your father and learn the lineage of each of your milk cows. Are they "blooded," "grade," or "scrub" stock? Is your herd being "selected" toward any pure breed?

2. Is the milk produced by your cows weighed and tested for butter-fat? If so, how does the record of the herd compare with the herds referred to in the chapter? If no tests are being made, talk with your father about getting the apparatus for the Babcock test. After making the test under the direction of the teacher, bring samples of milk from home and make the test for several of your cows with the school tester.

3. Weigh the milk produced by each of your cows for a week, keeping a careful record. Now have your father help you estimate what each cow will produce during one year, taking into account the length of time each one milks, and the changes due to season, etc.

4. Weigh carefully the feed that is regularly given one of your cows for one day. Compare with the sample rations shown in the chapter. Are you feeding a balanced ration? If not, in which nutrient is it short? What should be done?

5. Make a careful study of the distinguishing marks of each of the chief dairy breeds, and learn to identify different breeds at sight.

6. Consider the conditions of your home dairy barn. Has it plenty of light? Is it well ventilated? Are the stalls the right length for the cows? Is the floor tight? Are the rear gutter and the feed trough of a good type? Is the barn clean? Does it smell bad?

7. What steps are taken in your dairy toward cleaning the cows each time before milking? Do the cows get soiled from the stalls? Are the milkers' hands washed before milking? What kind of a strainer do you use? Is your milk clean when it is ready for cooling.

8. Has your state a law requiring the tuberculin test for dairy herds? Has your father's herd had the test? 
If so, how often is the test applied? With what results? Have you any cows with a cough? With coats that look rough and dead? Are any of your cows losing in flesh or amount of milk without seeming cause? Have any of them lumps in their udders? All these things are symptoms of tuberculosis.

9. Write an essay on how to improve dairy conditions and profits in your region.

10. Show how to keep a book account with the cattle interests of the farm.

11. Indicate on the map of the United States the dairy and beef producing sections. Consult the last census report and insert in each state the amount of beef and dairy production.

\section{Demonstrations as Related to Cattle}

1. Demonstrate how to make a butter-fat test with a milk-testing machine.

2. Demonstrate by the use of the blackboard or chart a good and a poor dairy type of cattle.

3. Show by drawing or chart a good type of beef cattle. Diagram the beef unit so as to show the various grades of meat.

4. Show how to keep a record of the Babcock test for butter-fat for five cows.

5. Demonstrate how to cool milk and cream.

Other demonstrations can be carried on in connection with the cattle industry, such as butter making, cheese making, showing the use of milk in various kinds of food, pasteurizing milk, cleaning cows, mixing various types of feed and making tuberculin tests.

\section{Cattle Play Contests}

1. Cattle judging contest.

2. Breed naming contest.

3. Record keeping contest. 


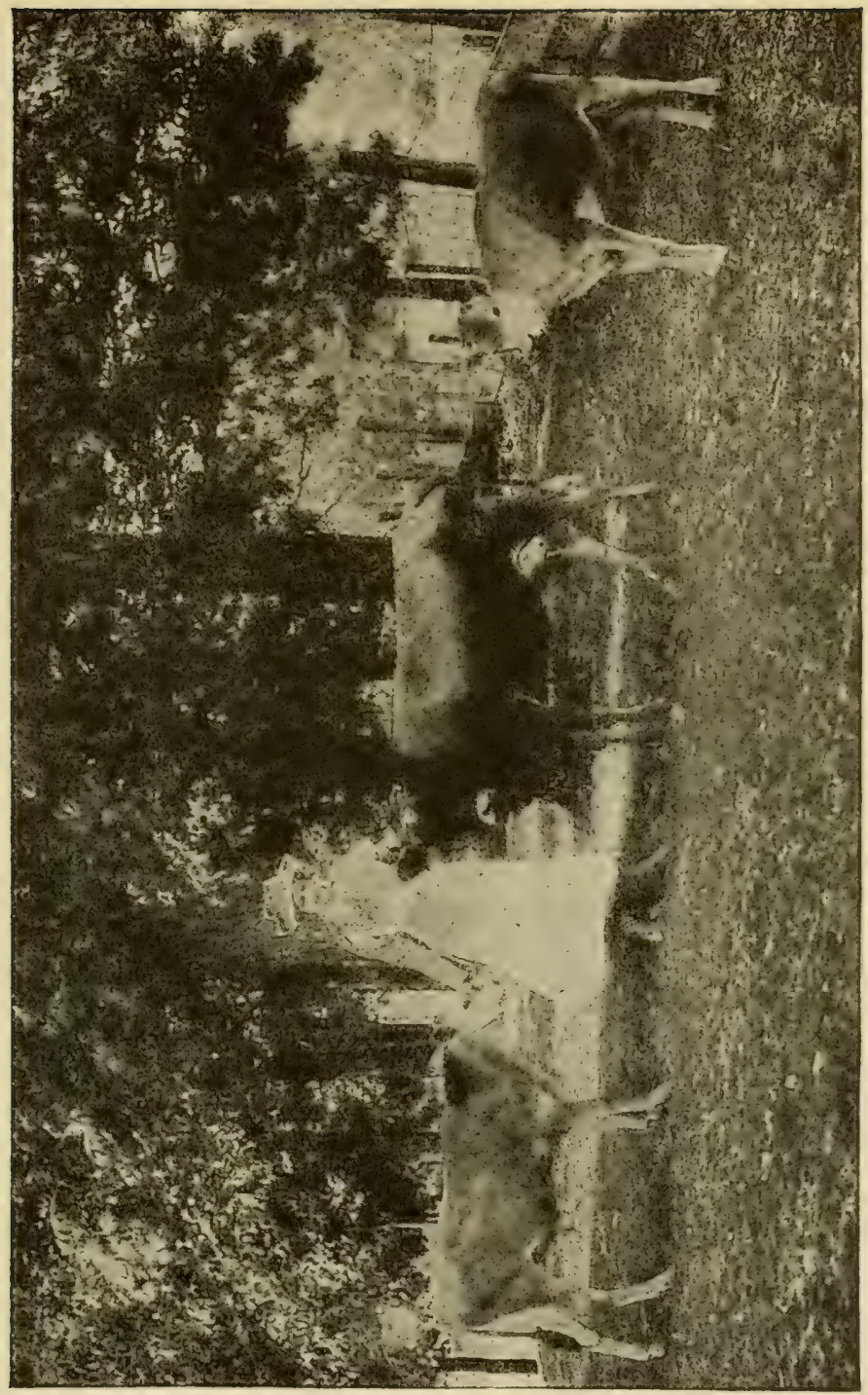

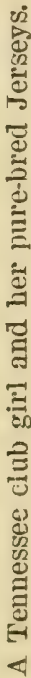


4. Milking contest.

5. Story writing contest on "Origin and History of Cattle" and other kindred subjects.

\section{Cattle Club Projects}

There are three very practical and interesting club projects possibie in connection with this subject. The first and most important perhaps is the dairy club, where club members agree to test for butter-fat a certain number of dairy cows or the entire herd on their father's farm. The basis of award may be as follows:

1. Number of cows tested 30

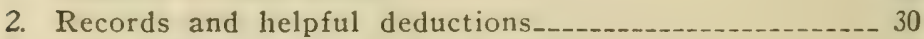

3. Skill in making test, shown in demonstration______-_ 20

4. Essay "How To Make the Test, Its Importance to Dairy Farmers"

Total score

The baby beef club project.-The object of this project is to encourage the production of beef cattle and to teach the proper methods of management and feeding of beef stock so as to secure the maximum returns for money, time and energy expended. The baby beef club member should be required to take a calf at a certain age, a yearling, or two-year-old, and care for it, keeping a record of all expenditures, daily rations, and cost of feed for six months or a year, with a view to showing maximum results from the management for the beef market. It is advisable as far as possible to have members grow their own feed, or at least a part of it, and to keep an accurate account of the cost of production of this feed as applied to the baby beef club project work. The basis of award may be as follows: 
1. Condition of beef at end of period, judged by score-card

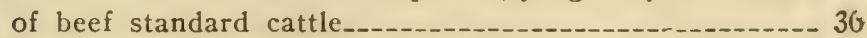

2. Net profit and cost of production

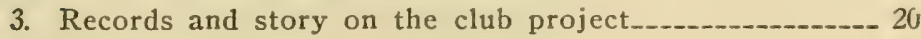

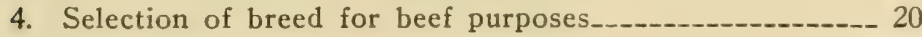

Total score-_-_-_- 100

Dairy record club project.-The object of this club project is first to teach methods of keeping accurate records of cost of management, feed, pastures, and milk production for each individual cow in the dairy herd, and to teach through these records the difference between a profitable dairy cow and a "boarder."

It is possible to combine the dairy herd club project with the butter-fat testing work. The basis of award in this particular club project may be:

1. Number of cows of which complete records were kept_---- 30

2. Condition of records, neatness, accuracy, etc.-_-_-_-_-_-_ 30

3. Conclusions and valuable recommendations_-_-_-_-_-_- 20

4. Oral or written discussion of "How I Kept My Records" -

Total score 


\section{CHAPTER XX}

\section{HORSES}

MORE than twenty million horses are to be found on 11 the farms of the United States. These horses on the farms alone are worth the enormous sum of two and a quarter billion dollars, or more than all our cattle, both dairy and beef. The raising of horses is therefore one of the leading industries connected with agriculture.

\section{The Leading Horse Raising States}

Slightly more than fifty-two per cent. of all the horses found on the farms of this country are raised in the following ten states: Iowa, Illinois, Texas, Kansas, Missouri, Nebraska, Ohio, Indiana, Minnesota and Oklahoma. The farms of Iowa and Illinois support approximately one and one-half million horses for each state; Texas, Tansas, Missouri and Nebraska have more than a million each, and Ohio, Indiana, Minnesota and Oklahoma, more than three-fourths of a million each.

Proportion supplied by each state.-The proportion of all the horses found on our farms which is supplied by each of these ten leading horse states is shown in the following chart:

Iowa

Illinois

Texas

Kansas

Missouri

Nebraske

Ohio

Indiana

Minnesota

Oklahoma

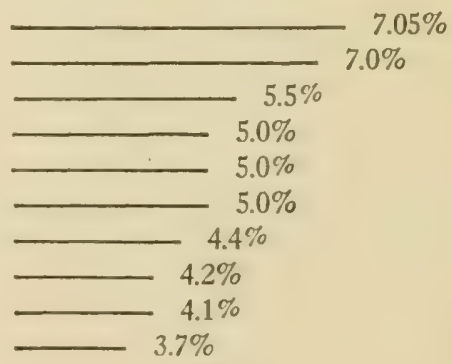

296 
Horses are adapted to a wide range of climates, and can be successfully produced in every state. The market for horses is good and, under skilful management, they can be be raised with profit on almost all farms.

1. Nake a list of all the horses on your farm, and have your father help you estimate the value of each. Now compare the value of your horses with the value of your cattle; your hogs; your sheep.

2. After each member of the class has made the computation asked in No. 1, put all the results together and make similar comparisons for the value of different farm stock for all farms represented. Compare the relative values of horces, cattle and hogs for your region with the relative values of these animals for the entire country, taking the necessary figures from the respective chapters of this book.

\section{Classes of Horses}

Class and grade.-Regardless of breed, horses are classed in the markets according to the uses to which they are suited. The different classes are: draft horses, chunks, avagon horses, carriage horses, road horses, saddle horses and ponies. Animals are graded within each class as choice, good, medium, common and inferior. The class to which a horse belongs depends on (1) weight, (2) height, and (3) conformation, or build, and (4) quality.

Draft horses.-To be in the draft class a horse in good flesh must weigh from one thousand six hundred pounds to more than a ton. The height ranges from 15-2 to 17-3 hands. The form of draft horses is broad, compact and rugged, with legs short as compared with the depth of the body. This build brings the weight close to the ground, where it can exert the greatest power in drawing a load. Draft horses are used largely for city teaming, for logging and the like. 
Chunks. - The form of this class of horses is indicated by their name. Chunks are heavy-set, short legged, compactly built horses, of lighter weight than draft horses. Their weight varies from eight hundred pounds among the lightest of the southern chunks to one thousand five hundred and fifty pounds in the North and East. The height is from

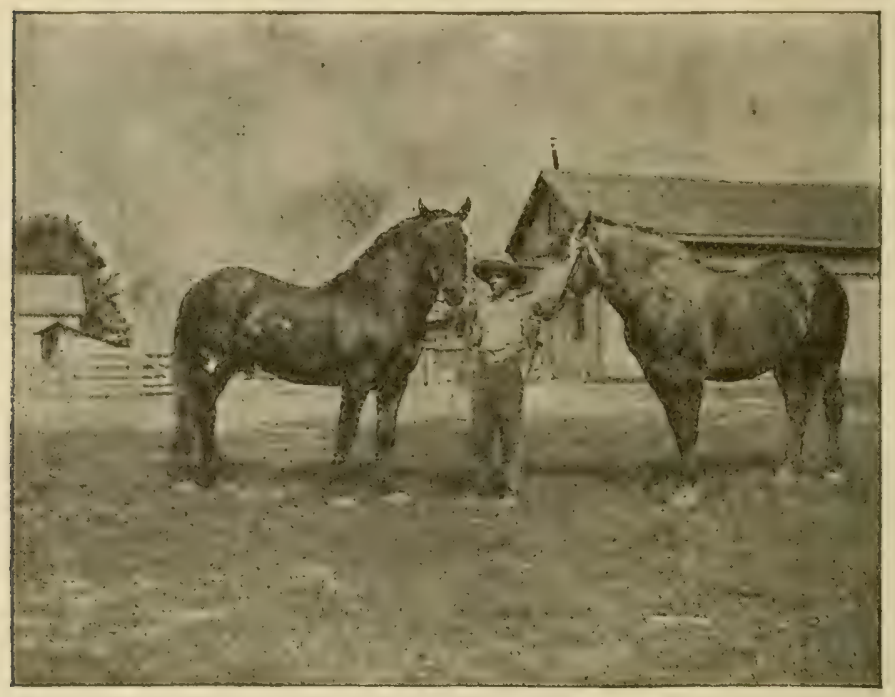

A pair of draft horses.

15 to 15-3 hands. The typical farm horse belongs to the cinunk class.

Wagon horses.- TTagon horses are required to combine weight with action and cndurance. City delivery and express, fire and artillery horses are selected from this class. They must have sound feet; strong clean legs; broad deep chests ; and show good constitution and quality. Their weight is from one thousand and fifty pounds to one thou- 


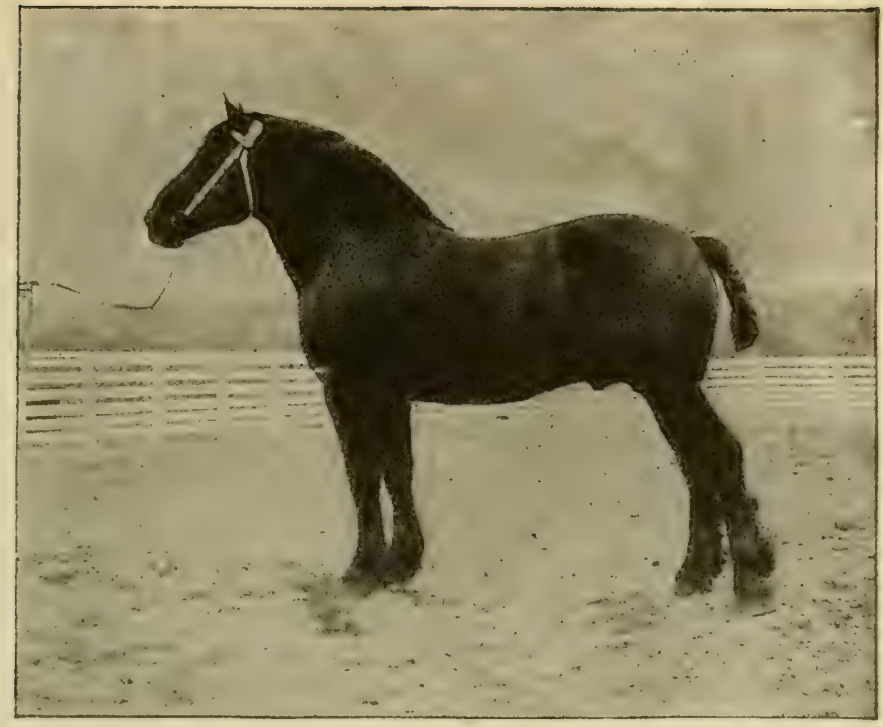

A fine type of draft horse.

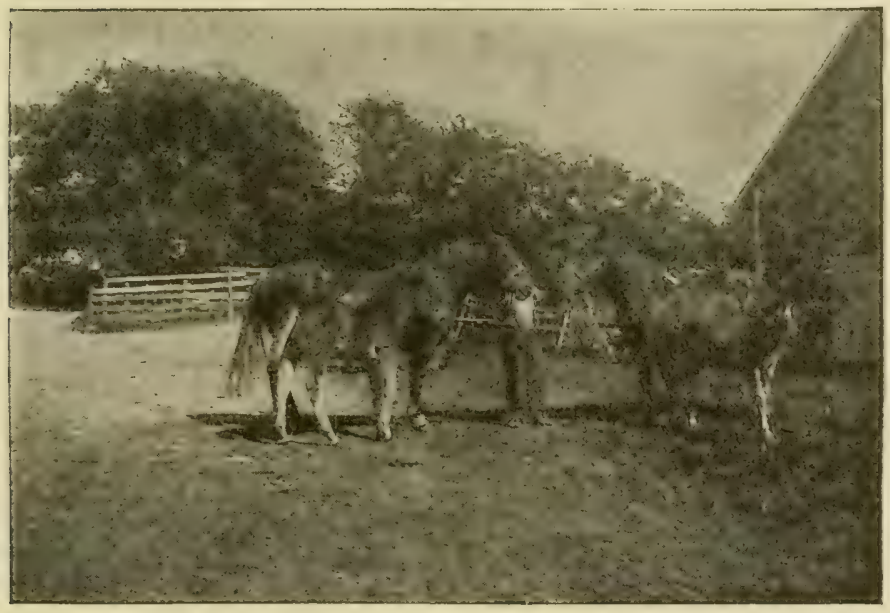

A good pair of chunks, and their offspring by pure-bred sires. 
sand seven hundred pounds; and their height from 15 to 17-2 hands.

Carriage horses.-The carriage, or heary harness, class are required to have good action, a fair amount $\dot{f}$ speed, and to be of a pleasing, stylish form and carriage. The head should be small, and well-set, on a long arching neck. The body should be smooth and rounded, the back short and well coupled, with a long level croup, and the

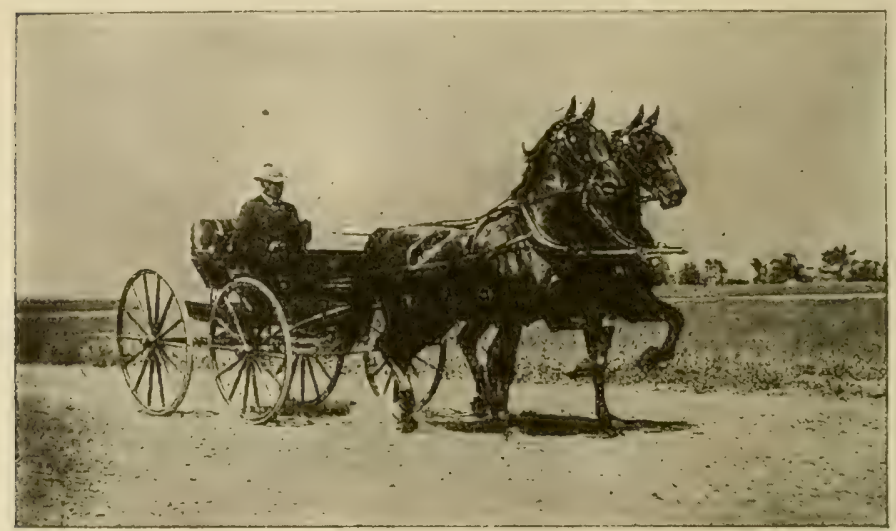

A good team of heavy carriage horses, showing fine chalracter and action.

hindquarters strong and well developed. The height ranges from 14-1 to 16-2 hands, and the weight from nine hundred pounds to one thousand two hundred and fifty pounds. The carriage class supply the coach, park and cah horses.

Road horses.-Road or light harness horses ari lighter in build, more angular in form, and possess better action than the carriage class. They must have good speed, life and quality. They are used for light and fancy driving, and for racing. Their weight is from nine hundred to one 
housand one hundred and fifty pounds, and their height from $14-3$ to 16 hands.

Saddle horses.-Saddle horses are built for ease of action, strength and sureness of foot. They are also required to have mettle, coupled with a good disposition and intelligence. The withers are high and thin, and the shoulders oblique. The back must be short, well muscled, and

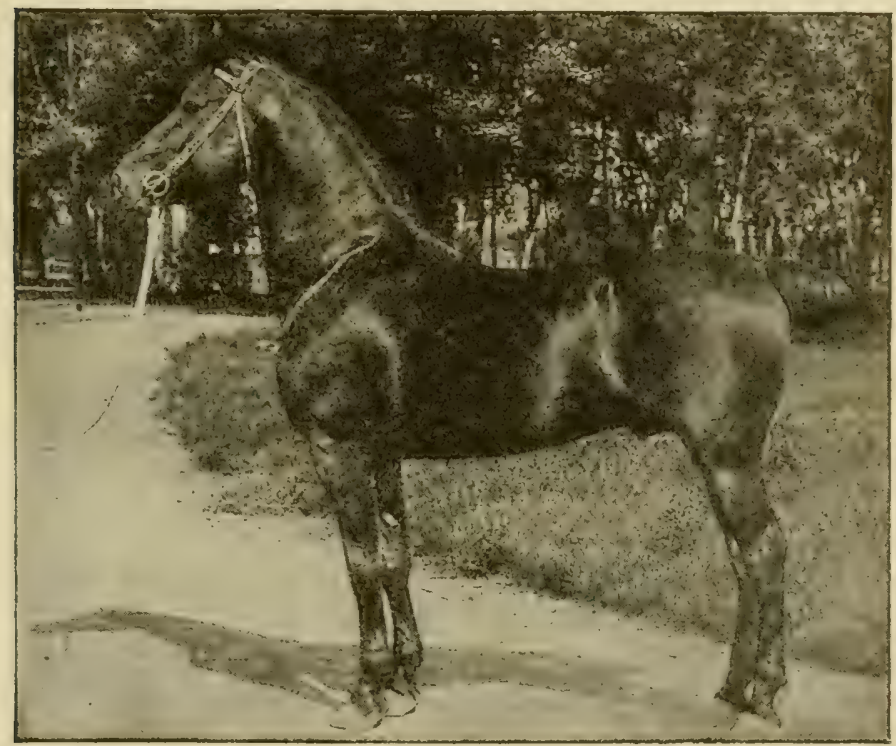

A good saddle horse.

strongly coupled, and the gait easy. The height runs from fourteen hands for polo ponies to sixteen hands for hunters or cavalry horses. The weight may vary from eight hundred and fifty to one thousand two hundred and fifty pounds.

Ponies.-Ponies are chiefly used for children, and must therefore first of all have good dispositions. To be in the pony class, the height must be under fourteen hands. 
The body is deep and well rounded, the legs and neck are short, the croup is level, and the quarters are strong and well developed.

These different classes of horses often merge into one another so that it is difficult to tell in which of two classes a certain animal belongs. For market purposes it pays to breed for well marked classes, as these always bring higher prices than mixed stock.

1. Study each horse on your home farm, and decide the class to which it belongs. If the type is not clearly marked in any case, decide what two classes it resembles.

2. Also grade each horse as choice, good, medium, common, or inferior in its class. Remember that to be "choice" the animal must be entirely sound, in good condition, and possess in the highest degree the ideal qualities of its class. The "inferior" grade is the very worst of its class. The other grades lie in between these two extremes.

\section{Breeds of Horses}

While the breed to which a horse belongs has little bearing on its market value if the class marks are strong and the grade high, yet the only way to secure class and grade is by pure breeding. Millions of dollars are being lost by American farmers every year through the breeding of grade or scrub horses.

The value of breeding.-An excellent illustration of the difference in market value between pure-bred and gradebred horses is shown in the case of Wisconsin horses (Bul. 186, Wis. Ag. Exp. Sta.) :

\begin{tabular}{|c|c|c|c|c|c|}
\hline & \multicolumn{5}{|c|}{ Average value of horses by ages } \\
\hline & $\begin{array}{l}4 \text { to } 6 \\
\text { months }\end{array}$ & 1 year & 2 years & 3 years & 4 years \\
\hline From pure-bred sires. & $\$ 78.77$ & $\$ 132.84$ & $\$ 196.84$ & $\$ 218.00$ & $\$ 303.00$ \\
\hline From grade sires & -51.25 & 85.00 & 127.50 & 156.45 & 200.20 \\
\hline $\begin{array}{l}\text { Difference in favor } \\
\text { pure-bred sires }\end{array}$ & 27.52 & 47.84 & 59.34 & 61.55 & 102.80 \\
\hline
\end{tabular}


This table is very convincing when it is remembered that it costs no more in care and feed to raise a well-bred horse than a scrub. The farmer who uses only pure-bred sires for his breeding will get almost fifty dollars more for his colts as yearlings than if he uses grade sires, while if he

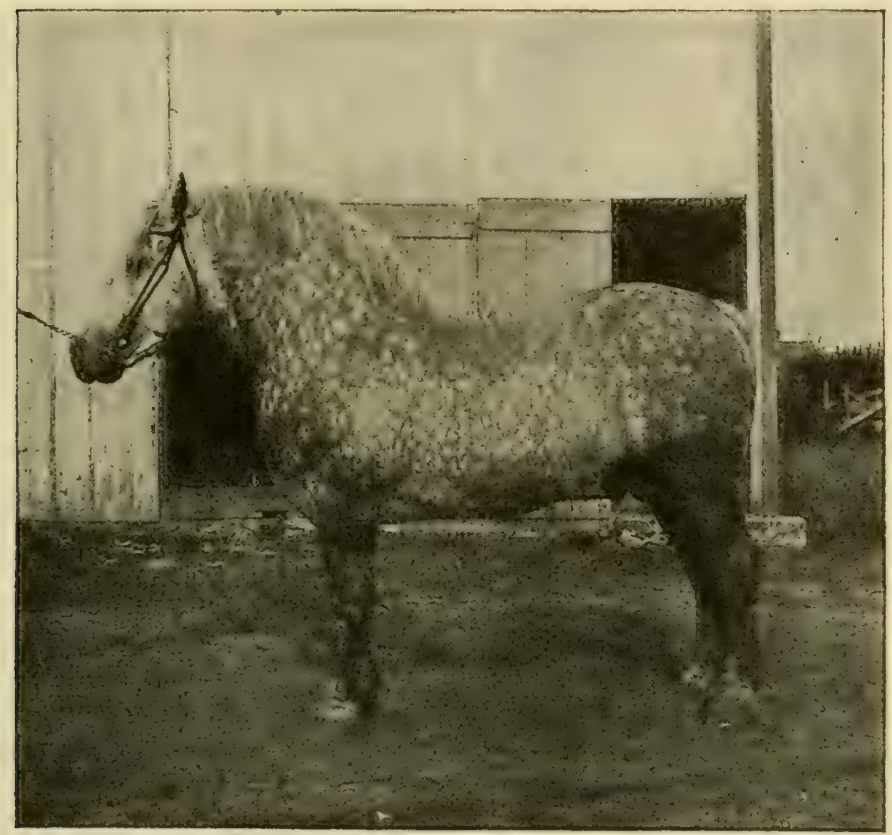

A typical Percheron.

does not sell until the colt has reached maturity he will receive at least one hundred dollars more. If pure-bred dams are also used, the difference will be greater still. Will it not pay well to "breed up" our horses?

Draft breeds.-The chief breeds of draft horses in the United States have been imported from Europe. The favorite of these is the Percheron, which comes from France. 
The Percherons have good spirit, are strong-boned, and have sound feet. They show good action, have a high degree of intelligence, and respond well to training.

The Cly'desdales come from Scotland. They are longer in build than Percherons, have smaller bodies, and less rug-

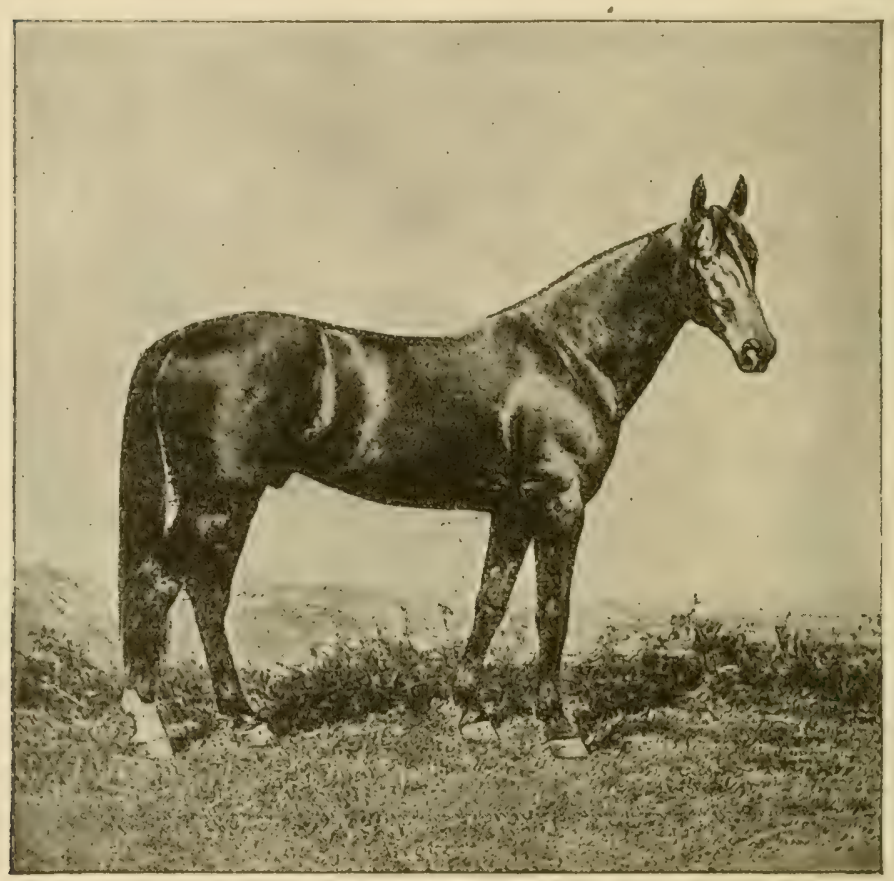

Typical of the American trotter breed.

ged constitutions. They are strongly marked by a heavy growth of hair on the lower part of the leg, especially at the fetlock. For use in wet and muddy times this excess of hair is a disadvantage, since it is hard to keep dry and clean.

The Belgians come to us from Belgium, and the English 
Shires from England. Both are excellent breeds, though they have not yet come into the favor enjoyed by the Percherons, or even the Clydesdales.

It is chiefly from the heavier breeds that come all our draft horses, chunks, wagon horses, and carriage, or heavy harness horses. A comparatively small proportion of horses in any of these classes is as yet pure bred, most being a cross with grade or common stock.

The lighter breeds.-Relatively few farmers have undertaken the raising of the lighter and speedier breeds of horses. This has been left to special breeders and stock farms that make a specialty of horses. The heavier breeds are better adapted to the farm, since the dams can then be used for general farm work, and thus serve a double purpose and thereby add to the profit.

Among the lighter breeds raised in this country, the English Hackney, the French Coach, and the German Coach are the favorites for the carriage class. For lighter road use the breeds most favored are the American Trotter, the American Saddle horse and the English Thoroughbred.

\section{Judging Horses}

The horse is to many people the most interesting animal on the farm. The satisfaction and profit from horse raising depend very largely on the breed, class and grade. For these reasons all who are interested in farm animals should learn to judge horses readily and accurately.

The score-card.-Before undertaking to use the scorecard in actual judging, the pupil must become thoroughly familiar with all its points, understanding fully the requirements for a perfect score under any point. With this ideal in mind, the animal is to be examined, and the score ptit down on the card. Do not be afraid to mark nff for 
all bad points. It takes a good animal to grade eighty per cent. when marked by an expert judge, and an exceptional one to grade ninety per cent. 'Judges do not usually mark closer than ${ }^{\circ}$ one-fourth per cent. on any point.

\section{Common Defects and Unsoundness in Horses}

Any defect or unsoundness lowers the value of a horse. All who have to do with horses should be able to identify the more common faults, and know their causes. (See Purdue Circular, No. 29.)

Defects of head, eyes and ears-

1. Poll evil; sore on top of head, caused by bruises.

2. Blindness; either with or without defects of eyeball.

3. "Bluc-cyed"; a peculiar bluish color, may indicate blindness.

4. Over-mobile ears; showing viciousness or blindness.

5. Immobile ears; showing deafness or lockjaw.

\section{Defects of the mouth-}

1. Nose discharge; indicating catarrll, glanders, diseased molars.

2. Bit sores, showing tender mouth, or abuse.

3. Diseased molars; affect health and interferc with cating.

4. "Parrot" mouth; upper jaw too long, front tecth project over lower.

5. Undershot jav; lower jaw short; front tecth do not meet.

6. Clipped tongue; tip cut off to prevent lolling.

Defects of neck, withers and shoulders-

1. Neck sores; caused by collar wear on top of neck.

2. Fistula; running sore on withers on shoulders.

3. Collar sores and boils; dirty and ill-fitting collars.

Defects of feet and legs-

1. Shoe boil; sore at ellow from injury by shoe while lyings down; also sore from harness band.

2. Splint; (describe.)

3. Broken knee; bent backward from injury.

4. Buck knee; bent forward from stiffening of tendons.

5. Capped knec; (what is meant?)

๑. Greased heel; sores which refuse to heal. 
7. Scratches; sores under fetlocks from filth or dampness.

8. Windgalls; puffs around fetlock joint from hard driving or standing on hard floors.

9. Cocked ankles; ankles bent forward from misuse.

10. Navicular disease; contracted foot, favored in action.

11. Toe cracks; transverse checks across the hoof.

12. Quarter racks; split in hoof extending up to heel.

13. Corns; (what? where?) (describe cause.)

14. Thrush.

15. Knocked-down hip; one hip lower than the other from blow.

16. Spavin; either bog, or bone, indicating sprain or injury.

17. Thorough-pin; (describe cause.)

18. Curb; enlargement at back of hock from sprain.

General defects-

1. St. Vitus's Dance; twitching of muscles.

2. Crampness; tendency for muscles to cramp.

3. Stringhalt; one or both hind feet lifted too high.

4. Roaring; a wheezing, roaring sound in breathing; from bad wind.

5. Heaves; spasmodic breathing. Vices-

1. Cribbing; habit of biting mangers, posts, etc., caused by teeth trouble.

2. Windsucking; habit of biting, and at the same time sucking in air.

3. Halter pulling; habit of pulling back when tied.

4. Biting; vicious tendency to bite people or other horses.

5. Balking; refusing to move when commanded.

6. Rolling in stall; likely to become "cast" and cause injury.

7. Kicking; showing vicious temper.

8. Striking; with front feet to injure attendant.

\section{The Care of Horses}

The horse is the most intelligent and companionable of the farm animals. It quickly shows the effects of ill treatment or lack of care and, on the other hand, easily responds to training and good usage. 
Unsoundness due to ill usuage.-Not a few of the defects common to horses should be blamed to their owners or users. For example, poll cuil is frequently caused by striking the head against a door or stall beam that is too low. Bit sores indicate either a careless or a cruel driver, or a bit unsuited to the horse on which it is used. Neck and shoulder sores seldom occur if the collar is a good fit, and if kept clean. Fistula on withers on shoulders comes from collar bruises. Sivecny is the result of a wrench or strain, often due to ill-fitting collars.

In similar way, splints, spavins, curbs, thorough-pins and other injuries to the legs are often caused by excessive driving or pulling, especially of young horses. Misshapen knees and ankles are an evidence of hard usage. Greased heel, thrush and scratches come from damp and filthy stalls. Roaring is the result of driving until the wind is "broken"; heares usually come from eating dusty feed; cribbing is a sign of the neglect of teeth that need attention.

The effect of training.-The vices which reduce the value of many horses and make them unpleasant to handle are usually due fully as much to training as disposition. Halter pulling commonly begins in the colt being frightened and made to break loose when tied, or else being tied with an old and easily broken halter that encourages pulling on it. Balking often indicates lack of intelligence and patience on the part of the trainer fully as much as stubbornness on the part of the horse. Biting may be started by teasing; and kicking often has its beginning in fright from something loose about the harness or vehicle before the colt is well broken.

Ireatment of horses.-The horse should be treated with kindness and firmness. The driver who strikes or jerks because of his anger or petulance deserves the con- 
tempt of all lovers of animal life, and should not be entrusted with horses. One who will work a team in the heat and dust and then allow them to stand over night without cleaning shows either lack of intelligence about horses or cruelty. To drive a team until they are sweaty and then allow them to stand in a cold wind unblanketed reveals not only heartlessness but bad business management.

The horse can not be taught like a person. Therefore,

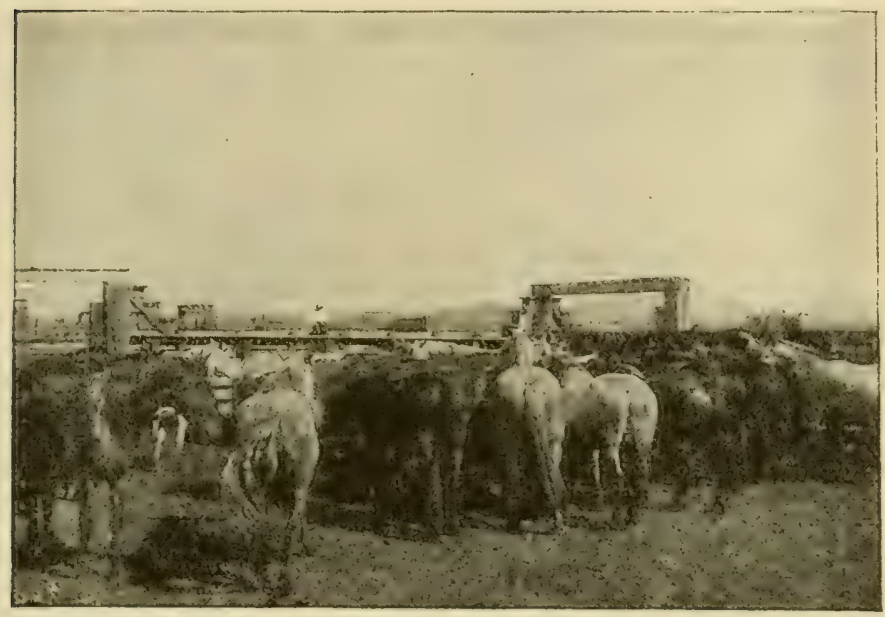

A horse market, showing a type of horse for which there is a good demand.

only one single word of command should ever be used for the same act. Whoa should always mean an immediate and dead stop; back should mean to step backward, and not merely to stop. Some one signal alone should be used to start, and the horse never allowed to start without this signal. Care in such simple points as these would result in much better broken and safer horses. 


\section{Feeding Horses}

The feeding of farm work horses is a different problem from the feeding of most other farm stock. This is because the horse is fed for work, while other animals are fed for meat, milk, eggs and so on.

The ration for horses.-The ordinary farm ration for working horses is some form of hay for roughage, and one or more cereals, such as oats or corn. The particular kind of hay fed is not important, so that it is in good condition and free from dust. If dusty hay must be used, it should be sprinkled with water as it is fed. Horses seem to find timothy hay more palatable than most other kinds, but red clover, alfalfa, meadow fescue and other meadow grasses have been found satisfactory. It is thought that less grain is necessary to keep up the weight of horses at hard work when alfalfa is fed instead of some other hay.

Grain ration for farm horses.-Oats are the choice of the cereals for horses wherever they are obtainable. They are relished better than most grains, and seem especially stited to the horse as a nutrient. Horses fed on oats also seem to show better mettle than those fed on other grains.

In the corn producing region corn is usually a more economical feed for horses than oats, and has therefore come into quite general use as a part of the ration. Corn and alfalfa hay make a satisfactory ration, at least for a limited time, and are cheaper than oats and timothy hay. A very satisfactory and rather heavy daily ration for a horse weighing from one thousand two hundred to one thousand three hundred pounds, and employed at general farm labor is:

$71 / 2$ pounds of whole corn.

$7 \frac{1 / 2}{2}$ pounds of whole oats.

1 pound of oil meal.

3 pounds of wheat bran. 
$7 \pi / 2$ pounds of timothy hay.

$7 \mathrm{~T} / 2$ pounds of clover hay.

Other rations that have been proved satisfactory by experiment are as follows:

1. Corn, 6 pounds; gluten feed, 6 pounds; bran, 2 pounds; timothy hay, 10 pounds.

2. Corn, 8 pounds; bran, 7 pounds; timothy hay, 10 pounds.

3. Oats, 6 pounds; corn, 4 pounds; bran, 2 pounds; hay, 12 pounds.

These rations are the amount that should be fed daily to a horse weighing from one thousand two hundred to one thousand three hundred pounds when at work. Larger horses should receive more, and smaller horses less, according to weight. It is also to be noted that some horses require more feed than others of the same weight.

How to feed.-For horses with good teeth it is not essential whether the grain is ground or fed whole, except that the same amount will yield somewhat more nourishment if ground. This difference may sometimes be as much as one per cent. in favor of ground feed. On days when work horses are allowed to stand idle the amount of grain should be reduced about one-half. If the idleness continues beyond three or four days, the amount of grain may gradually be increased, but should not reach the full work ration.

Most of the hay should be fed at night and in the morning, as there is not time at noon to secure the necessary nourishment from roughage. The noon feed of grain may be slightly heavier than that for night or morning. About twice as long is required for horses to eat ground grain fed dry as when it is dampened.

Watering horses.-Much prejudice exists concerning the best time for watering horses, some preferring to water before feeding, and others after. Careful experiments have 
shown that the time of watering is not highly important. If horses come from the field thirsty, it is reasonable to suppose that they will relish their meal better if they have had a drink. If the feed consists largely of dry roughage it also seems best to water before feeding. Whatever system is adopted should be followed regularly, as changing about often injures the appetite or produces some other derangement. Horses should never be given a large amount of water when highly heated from working or driving.

\section{TOPICS FOR INVESTIGATION}

1. What breeds of horses are favored in your region? Let each student find out just what breeds are represented in the horses on his home farm, with the percentage of pure-bred blood in each animal. Sum up the results for the entire district.

2. If it costs fifteen dollars more to sire from pure-bred than grade horses, what would be the net gain by using pure-bred rather than grade sires in raising for market two teams and selling them at four years of age on the basis shown in the table on page 302 ?

3. After studying the score-card for judging draft horses and judging one or more animals under the direction of the teacher, judge independently at least two other horses, having your work tested and criticized by the teacher or other competent judge.

4. Master thoroughly the list of defects common to horses, and then watch for an example of each on different animals until you have learned to identify any unsoundness at sight. Examine carefully each horse at your home for unsoundness.

5. Write a detailed account of the care that should be given a working team each day, including stall, feeding, watering, cleaning, blanketing, and so on.

6. Weigh the ordinary daily ration fed one of your working horses and compare with the rations suggested in 
the chapter. At current prices, just what does it cost a day to feed one of your work horses?

7. Show how to keep a bookkeeping record of the cost of keeping, feeding, and use of a team of heavy draft horses for farm purposes, covering a period of six months through the working season.

8. Show upon the map of the United States the approximate number of horses in each state. Secure records from the last census report on horses. Where were the wild horses originally found? Where are horses now raised on ranges?

\section{Demonstrations With the Horse}

1. Demonstrate how to halter-break a colt.

2. The proper method of judging a horse.

3. Show how to handle a buggy horse; harness, hitch and start.

4. Demonstrate the proper method of mounting a saddle horse, with or without the saddle.

5. The proper method of currying a horse, training the mane, and tying up the tail for muddy roads.

6. Demonstrate miscellaneous interests in horsemanship. In this particular case contestants may be allowed to bring their own horses and demonstrate values and tricks such as prompt obedience to master's command, and peculiar and valuable traits of their animals.

7. Demonstrate the practical rope knots and splicings of especial value in the handling of horses, such as the halter-hitch, clove-hitch, slipknot and timber-hitch.

8. Demonstrate how to harness and hitch a team to a double wagon.

All of the above demonstrations should not only show skill, accuracy and speed. but kindness in the handling of the animals. 


\section{The Horse Play Contests}

1. Horse mounting contest, judged by skill, largest number of mountings in five minutes and showing of kindness to animal in mounting.

2. Horse judging contest, driving contest in single, double, or four-horse team.

3. Oral story, giving the life history of the horse.

4. Essay writing contest on the subject: "The Horse and Its Relation to Agriculture."

5. Recipe and remedy giving contest, showing the proper methods of treatment for unsoundness, defects, blemishes and vices of the horse.

6. Description and recognition of defects and blemishes with causes.

\section{Colt Club Project}

The object of organizing a colt club is to get bovs and girls interested in the raising and proper management of colts as an economic factor on the farm. The work should cover a period of not less than twelve months in the management, feeding and keeping of records of a colt. The basis of award should be as follows:

1. Management shown by training of colt_-_-_......-- 25

2. The cost of keeping-_-

3. Condition of the colt or horse-_-_-_- 25

4. Story of "My Year's Work with the Colt"-_..._._._._. 25

Total score 


\section{CHAPTER XXI}

\section{SWINE}

TH OGS outrank every other farm animal in number in the 1 United States, and are exceeded in value only by horses and cattle. There are more than sixty million hogs on our farms, or nearly two porkers for every three of the population. The aggregate market value of swine is about two-thirds that of dairy cattle, and not far from equal to the value of beef cattle. American farmers own more than six hundred million dollars' worth of hogs.

\section{The Pork Producing Region}

A large proportion of our hogs is produced in the states forming the corn belt. This is natural, since corn is one of the cheapest and best grains for raising pork. Many other regions can grow hogs as successfully as the corn ctates, however, and the industry is spreading.

Hogs in the South.-Southern farmers have not yet entered very largely upon the raising of hogs, though they can probably be produced fully as cheaply in the South as the North. The southern people consume more meat per capita than the people of any other section. Millions of pounds of fresh meats are annualiy shipped to southern markets from northern and western farms. This means a double loss to the South, hence the importance of a more general study of the swine industry. For money is paid out for what could well be raised at home, and a most profitable industry is thus omitted irom the farms. 
The leading states in hog production.-Sixty per cent. of all our pork is raised in ten states. In the order of their importance in pork production these states are: Iowa, Illinois, Missouri, Nebraska, Indiana, Ohio, Kansas, Texas, Wisconsin, Georgia. The percentage each of these supplies of all hogs produced in the United States is shown in the following chart:

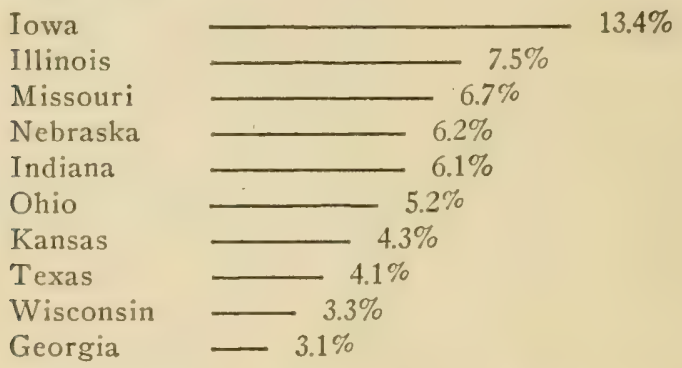

The number of swine in these states runs from about two million in Georgia to nine million in Iowa.

\section{Breeds of Hogs}

Many of our important breeds of cattle and horses originated in Europe, but we have ourselves developed nearly all our chief breeds of hogs. The breeds most favored in the United States are Poland-China, Duroc-Jersey, Chester-White and Berkshire. The Berkshire, the only imported breed, came from England. Other less well-known breeds are the Yorkshire, Cheshire, Suffolk, Hampshire and Essex.

Poland-China.-Poland-China has long been a favorite brecd of hogs, especially in the corn states. They are black in color, with irregular white markings on almost every part of the body. The ears are drooping. The PolandChinas make a rapid growth, and reach good size. They are rather small of bone, and not so good foragers as some 
other breads. Some fault has been found with them for not producing larger litters.

Duroc-Jersey.-The Duroc-Jerseys are easily recognized by their reddish color. They are one of the most prolific and vigorous breeds, somewhat slow in developing, and strong of frame. Their bones are large, and

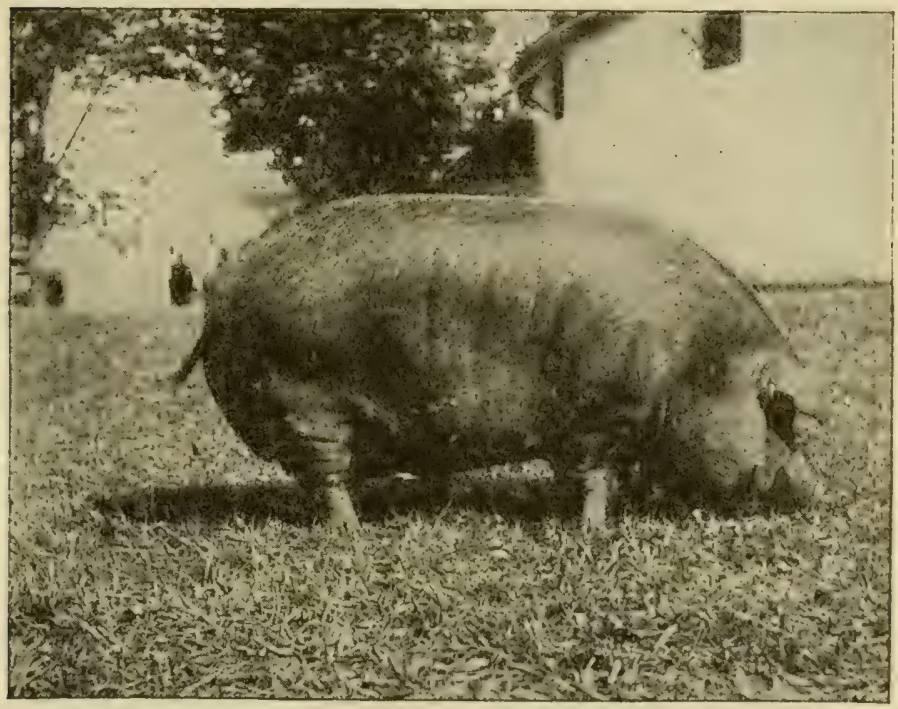

A fine Duroc-Jersey sow.

they reach good size and weight. They have large drooping ears, are good foragers, and thrive well on pasturage, or when following a herd of fattening cattle.

Chester-White.--The Chester-White breed are of large frame, rather slow in maturing, and possess good constitutions. They are white without markings, and have drooping ears. They are raised more in New England than in the corn region. 


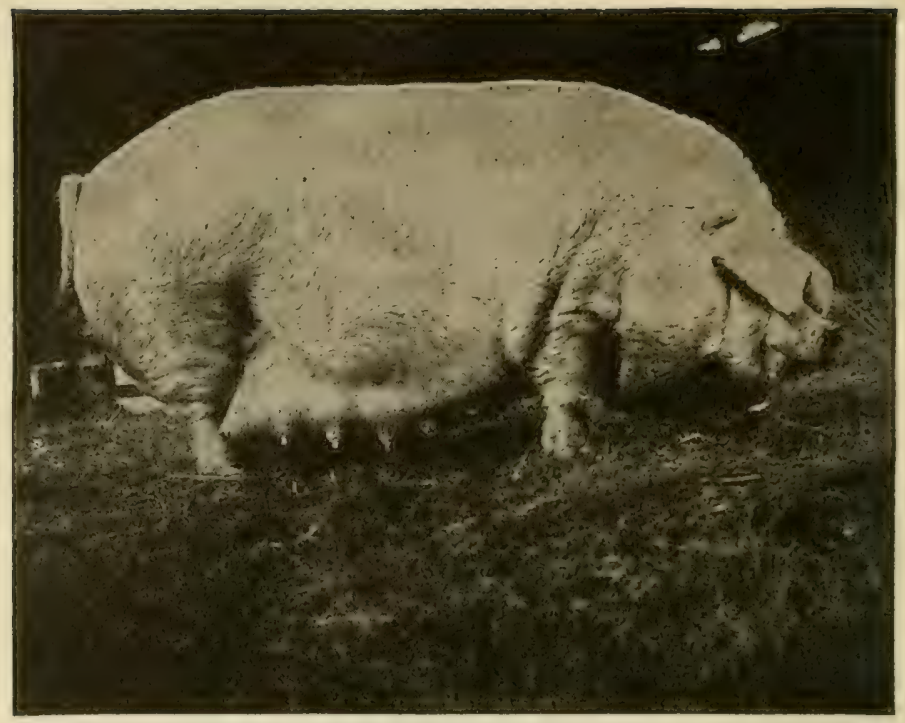

A Chester-Thite sow in show condition.

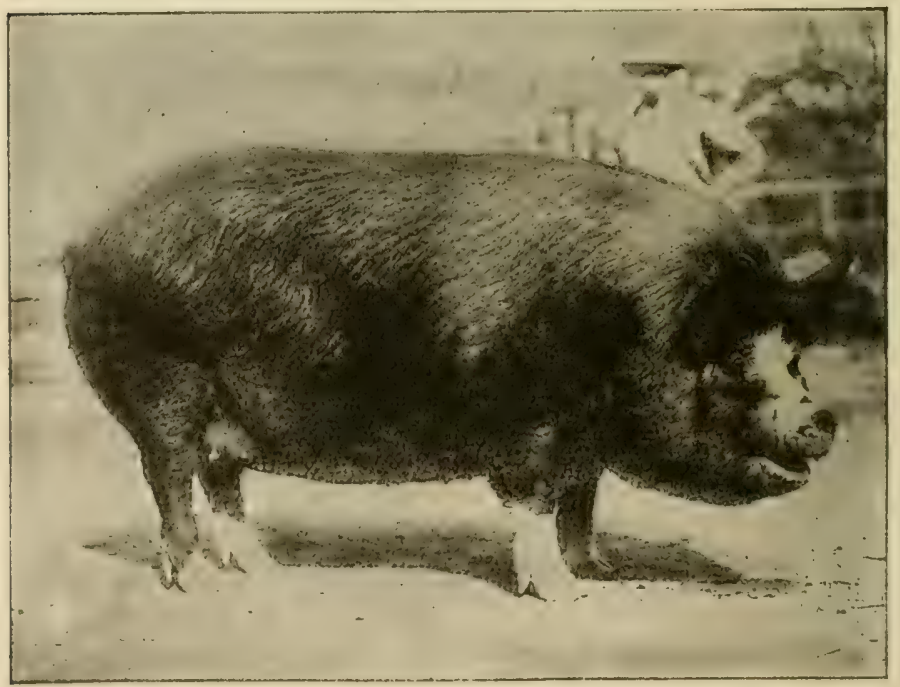

A Perkshire. 
Berkshire.-Berkshires resemble the Poland-China breed in color and markings, being black with white markings. They may be distinguished by their erect ears. They have a compact frame, are good feeders, and make a quicker growth than most other breeds. The Berkshire has long been a favorite breed, especially throughout the Middle West.

\section{The Care of Hogs}

Pigs are not so cleanly in their habits as some other farm animals. This seems to make many farmers think that it does not matter how they are kept. Nothing could be a greater mistake. Hogs thrive only under hygienic conditions of feeding and housing. Millions of dollars are thrown away every year by failure to give hogs the care they require.

Need of good housing.--Hogs are the most poorly housed of any farm animal. Any kind of place is thought good enough for them on many farms. Yet hogs are far more sensitive to cold than horses or cattle, which have thick coats to protect them, while the hog has almost none. Hogs lie down more than most animals, and need a better bed. They live close to the ground, and easily breathe in dust and impurities. They need sunshine more than do horses and cattle, yet little is provided for them.

Hogs take cold very easily. Little pigs, especially, need to be kept warm, dry and away from drafts, if they are not to have their growth checked, or even lose their lives by catching cold. Neglect of these simple rules indicates shiftless farming, and causes great loss.

Hog-houses.-Every farm that makes a business of raising pigs will find a well-built hog-house a paying investment. The most economical and convenient hog-house has a row of pens along each side of a central alley which, in 
larger buildings, should be wide enough to drive through. This allows the hauling in of straw for beclling, and corn or slops for feeding, thereby saving much labor. It also provides for the easy removing of manure.

The separate pens should be from five to eight feet wide, and from eight to twelve feet long; depending on the use to be made of them. Pens for brood sows need not be larger

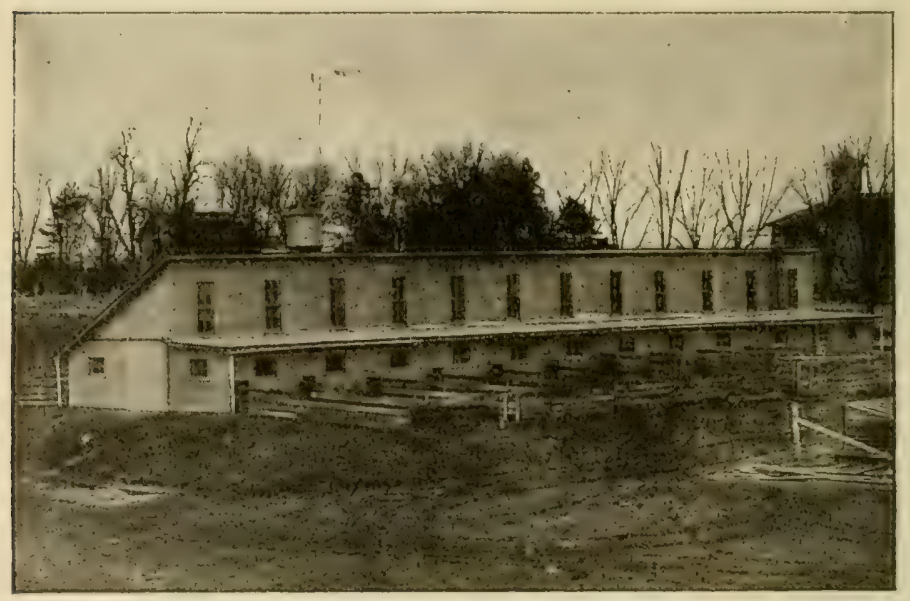

An excellent type of hog-house with outdoor pens.

than five or six by eight feet. If feeding is to be done in the pens they should be larger, or, better still, the partitions should be removable. The floor may be of cement, though for farrowing sows a temporary board floor should be laid over the cement, because of the coldness of a cement floor. Woven wire stretched over the top of the ground to prevent rooting is sometimes used as a floor. Such a floor is likely to be either dusty or wet, however. Board floors are expensive and drafty if above the ground. They also har- 
bor rats, which not infrequently kill young pigs. A double trough may supply each pair of pens. Young pigs should have their own troughs outside the main pens.

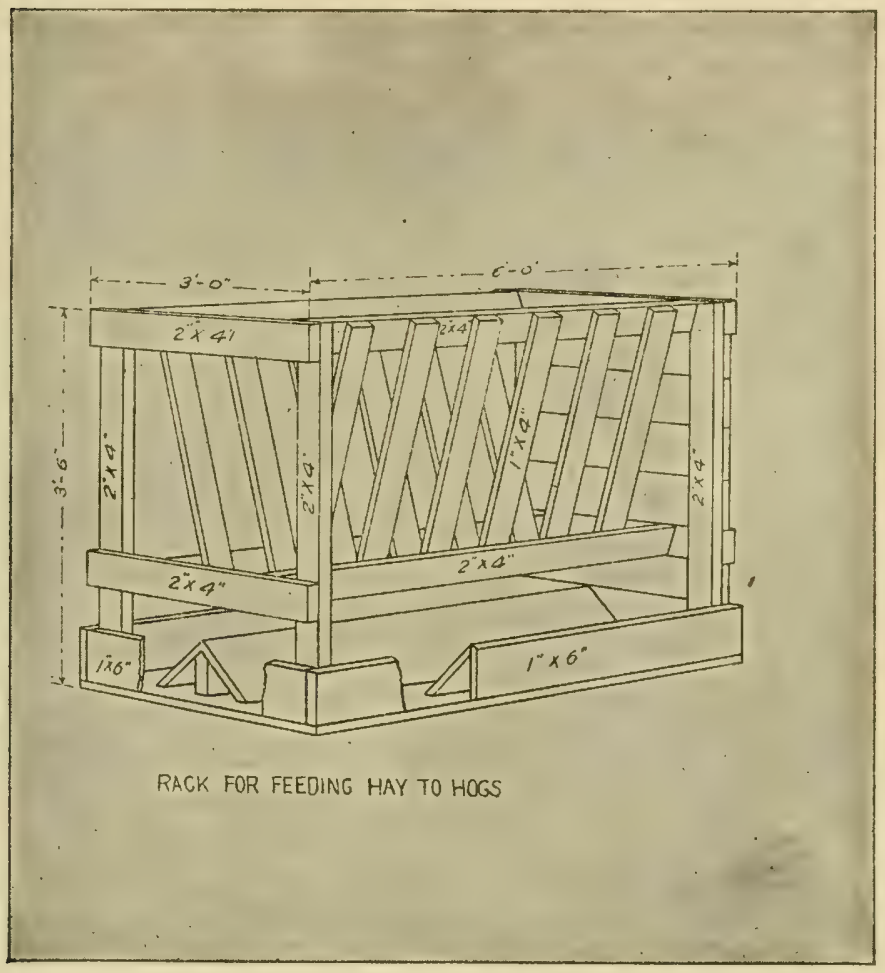

Lighting and ventilating hog-houses.-It is not uncommon to find hog-houses that cost several thousand dollars built almost without windows or other means of admitting light, air and sunshine. Other houses are built with windows in unfavorable positions, so that the sunlight car. 
not fall on the floor of the pens where it is needed by the pigs.

The hog-house should run east and west, so that it may have one full side exposed to the sun. This arrangement will necessitate having one row of pens along the north side. In order to get sunlight into the north pens, the "broken roof" style of building is used. Care must be taken to place both upper and lower windows at such a height that the sunlight will reach the floor during the winter and early spring months, or during the farrowing season.

To do this, the angle of the sun, say in February and March, and the width of the building must be carefully computed. At the latitude of southern Iowa, or central Illinois, Indiana, Ohio and Nebraska, the tops of the upper windows of a hog-house twenty feet wide should be ten and one-half feet from the ground. If the north pens are eight feet long, and the alley is four feet wide, the sunshine will just reach the back line of the pens at ten o'clock and at two o'clock on the first of March. Care to such details will save the lives of many young pigs farrowed in the early spring.

Individual hog cots.-Many hog raisers are now providing two types of hog-houses, the large permanent house for farrowing purposes, and the small individual cot for the sows and their litters as soon as the latter are old enough to be put out-of-doors. The individual cots may be scattered about the lot or pasture, and moved as often as necessary to keep the quarters clean. For winter service the cots can be collected side by side in a sheltered place, banked and used for sleeping quarters.

The feeding floor.-The use of a sanitary feeding floor should be much more common than it is. It is a great waste of grain to scatter it in the mud or dust of a lirt yari. This mole of feeding is also injurious to the health of the pigs, for it compels them to breathe in a great 
amount of dust and to eat impurities in order to get the grain. The effect is seen in such diseases as "thumps" and "wheezes," and in the greater liability to colds, tuberculosis and other troubles.

The best feeding floor is made of concrete, slightly raised above the level of the ground, if made outside the hog-house,

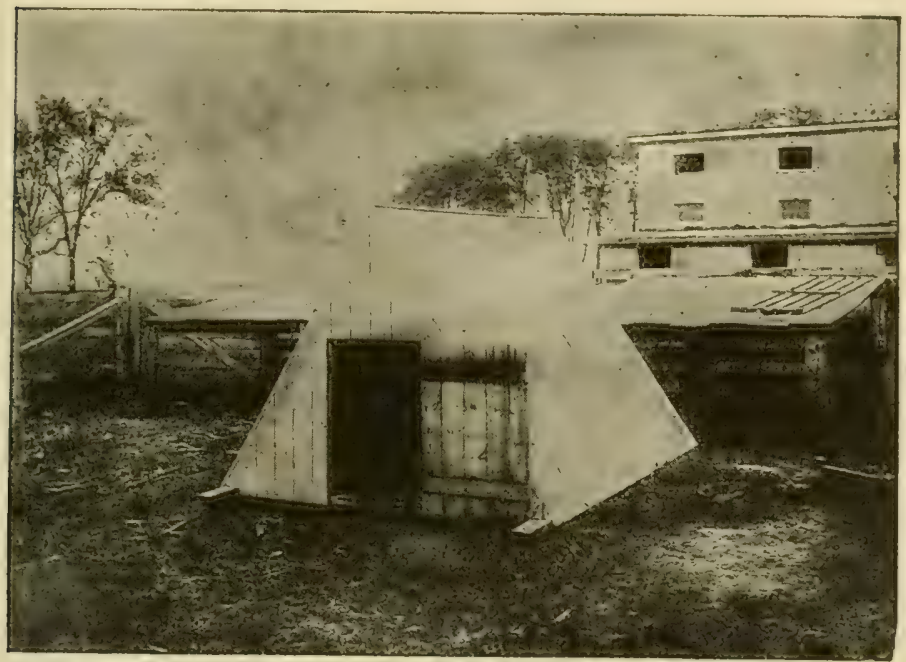

Individual hog cot, on runners, so that it can be drawn from place to place.

and sloping slightly so that it can easily be washed off. Such a floor is not expensive, and will pay for itself many times over in the feeding of hogs.

\section{Feeding Hogs}

Hogs are probably the best money makers on the farm, if properly handled. The same amount of feed will produce a greater value of pork than any other meat. The returns also come in sooner than with most other farm animals. 
Money invested in hogs can be turned rapidly, as pigs are marketable when eight months old. The yearly sales from a herd of hogs should be from two to four times the original investment. Much of the profit depends on intelligent feeding.

The feeding of pigs requires the consideration of three stages in their development, (1) from farrowing to weaning, (2) from weaning to fattening, and (3) fattening for market.

Feeding young pigs.-Little pigs do not need any food other than their mother's milk for the first two or three weeks of their life. When they have reached this age, they will begin to nibble on shelled corn. A little of this should be fed them in a place outside the pen. By the time they are from three to four weeks old, they may be fed a small amount of skim-milk, in which has been mixed a little ground feed, such as shorts. They should have a trough of their own where it can not be reached by the mother.

The amount of mixed feeds and shelled corn given small pigs may be increased till they are ten weeks old, when they should be weaned. When they are deprived of their mother's milk, which up to weaning time supplies the basis of their nourishment, it is very important that they be fed a ration capable of producing the most rapid growth and best health.

Feeding pigs after weaning.-At the time of weaning, the feed should not be greatly changed, except to increase the amount, until the pigs have become accustomed to the loss of the mother's milk. If pasture is available, the quantity of corn may be increased. If the pigs must be kept in a dry lot, a larger proportion of soft feeds should be used.

It is to be remembered that the purpose in feeding pigs 
from the age of two months up to the age of six or seven months is not to fatten them, but to cause them to grow large frames and develop good constitutions. If they are fattened too early, it stops their growth, and reduces their vitality, thereby making it unprofitable to continue feeding them up to full maturity.

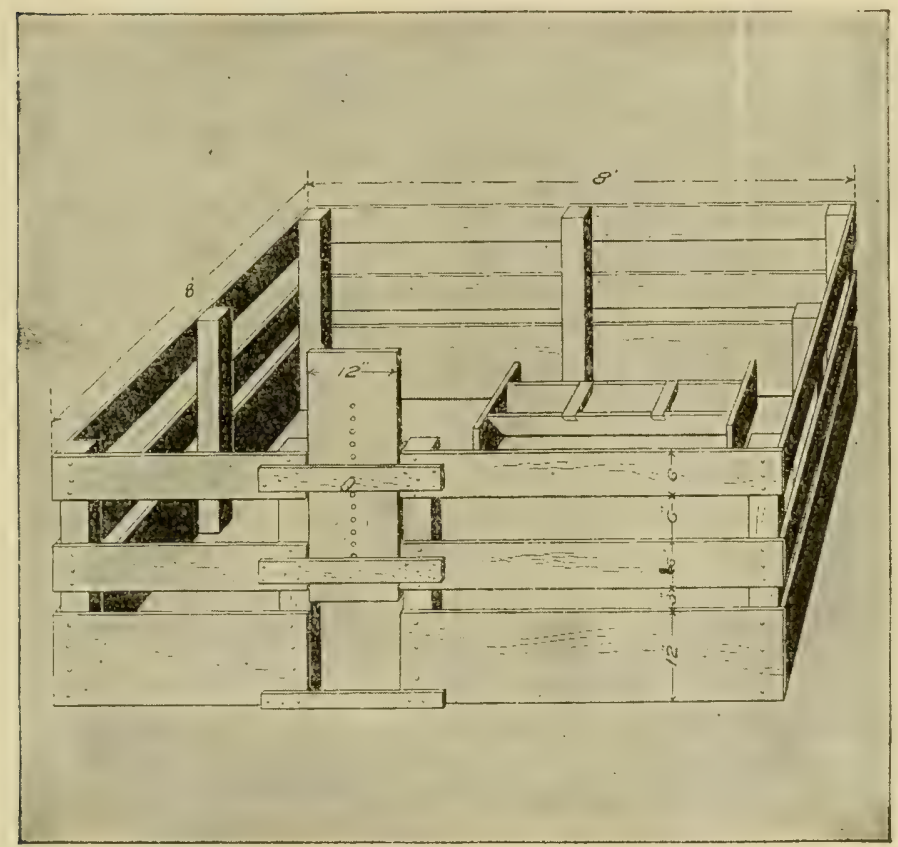

A good type of feeding pen for small pigs.

Pasturage for growing pigs.-Growing hogs, therefore, require muscle and bone making food, instead of a ration that will fatten them. They need exercise to promote their growth, and give them strong vigorous frames for the taking on of fat. For these reasons, pasturage 
should supply the basis of the young hog's ration. Clover, alfalfa, peas, rape, vetch and other succulent plants are the cheapest and best feeds for the period between weaning and fattening time.

To this green feed will need to be added a certain proportion of corn, or other grain, in order to make a balanced

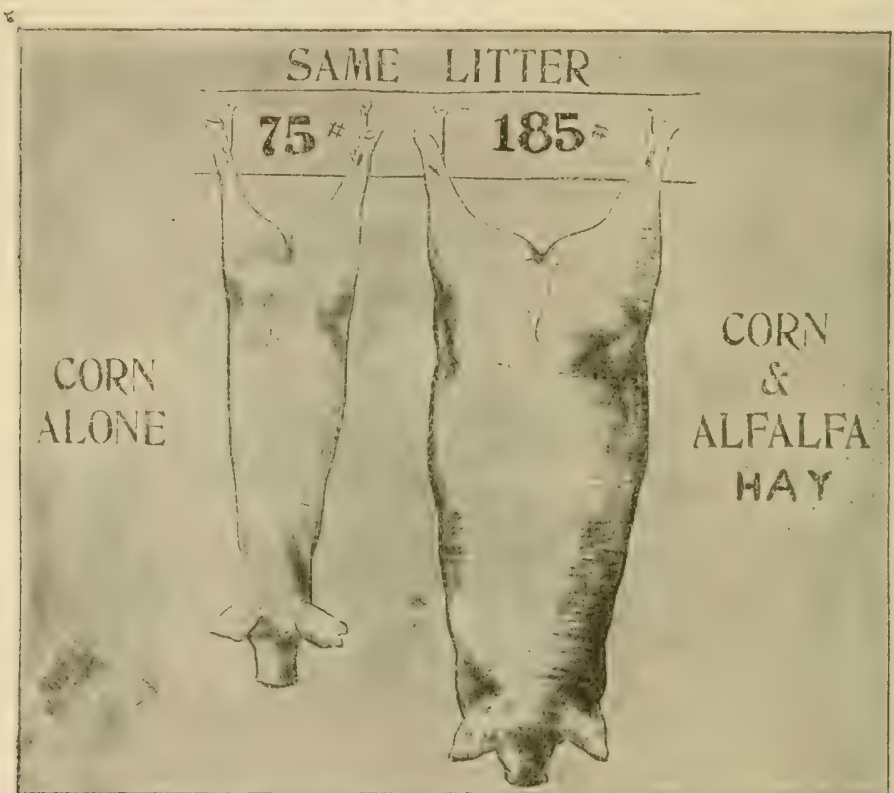

ration. But the poorest and most expensive way to grow pigs is to shut them in a dry lot and feed them a ration of corn alone, as is so often clone. The farm lacking in well arranged hog pastures is not ready for the business of making money out of pork.

Balanced rations for young hogs.-No matter what other ration may be fed pigs, milk is always desirable. For milk is highly palatable to hogs, and it contains more of 
the necessary food elements than any other food. The following are suggested as rations suitable for growing hogs that have, in addition, access to good pasturage:

1. Corn, $60 \%$; shorts, $30 \%$; tankage, $10 \%$; or

2. Corn, one-third; wheat, one-third; oats, one-third, ground; or

3. Corn, one-half; shorts, one-half; or

4. Corn, $60 \%$; shorts, $20 \%$; linseed-oil meal, $20 \%$; or

5. Corn, one-third; milk, two-thirds.

It has been shown by careful tests that if pigs must be fed in dry lots, ratio. vne, consisting of corn sixty per cent., shorts thirty per cent. and tankage ten per cent., will produce double the gain that can be secured from corn alone.

Fattening hogs.-Pigs should be ready for fattening by the time they are from six to six and one-half months old. When fattening begins, the ration should have a much larger proportion of corn. In fact, hogs may be profitably fattened on corn alone, through the addition of milk to the ration pays.

While being fed for fattening, the hog does not require the amount of exercise needed during the growing period. It is not best, however, to shut feeders up in a close pen, for a certain amount of exercise is necessary to keep the hog in a healthy condition and good appetite.

Snapped corn is preferable to husked ears on account of the greater amount of work demanded of the hog, and the slower eating required. Where the fields can be properly fenced off, the best of all ways to feed corn to hogs is to allow them to do their own harvesting. This method of feeding, called "hogging down" corn, gives the hogs about the right amount of exercise, allows them to eat whenever they desire, and saves the farmer the labor of husking, hauling and feeding. The same amount of corn will also produce more pork. 


\section{Diseases Affecting Hogs}

Young pigs are not particularly liable to any one disease, but easily fall prey to troubles arising from improper care. Cold, wet, dirty pens cause the death of many newfarrowed pigs. Dusty floors, filthy mud-holes and uncleaned troughs are always harmful. Exposure to extreme cold or to burning heat is sure to tell in loss of health or weight. It is safe to say that half the troubles attacking

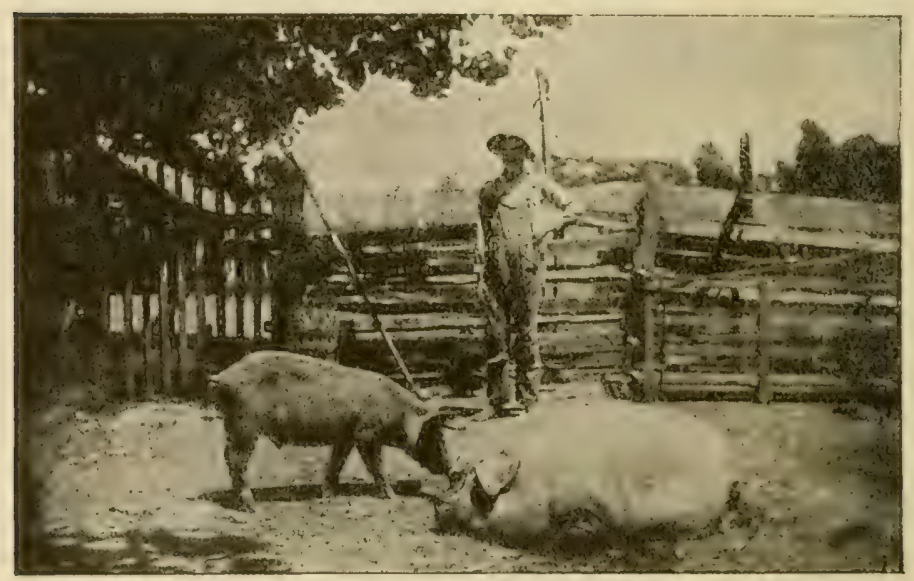

A razor-back and a pure-bred. The large one was owned and raised by the club hoy, receiving good care and a balanced ration. The razor-back, owned by the father, had no management, a narrow ration, produced pork slowly and unprofitably.

the younger pigs, at least, could be saved by providing them with more sanitary surroundings.

Thumps.-This is a disease that manifests itself in a spasmodic manner of breathing, which suggests the name. It is usually a digestive trouble caused by over-feeding and lack of exercise. Certain worms may also cause thumps. The best preventative for thumps, especially with 
young hogs, is plenty of pasture with green feed. The treatment for thumps is to reduce the amount of feed, give a laxative, and make sure that the pigs get exercise.

Scours.-Scours, or too great laxness in the digestive tract, are caused in young pigs by overfeeding, a feverish condition of the mother sow, soured feeds, dirty troughs, or some other insanitary condition connected with their feeding. The first step in applying a remedy is to find and remove the cause. If the trouble continues, each pig may be given a few drops of laudanum.

Worms.-Worms are a source of great trouble in raising pigs. Through rooting in the dirt, and being fed on dirt floors, young pigs pick up certain kinds of worms which continue to live in their digestive organs. Pigs never thrive when afflicted with worms. The coat shows rough, growth is hindered, the general health affected, and a large proportion of the feed wasted. A simple remedy is to give one teaspoonful of turpentine to sixty or eighty pounds of hog, and repeat the dose in three days. Another remedy is five grains of santonin combined with three grains. of calomel for each sixty or eighty pounds of hog. This should be followed by an effective physic. Whatever the remedy employed, the pigs should be starved for twelve hours before being dosed.

Lice.-Many hogs are lousy. The lice can easily be detected by looking between the legs or behind the ears. Hogs suffering with lice will make a slower growth and fatten less easily than clean hogs. So important is this matter that many hog raisers provide as a part of their equipment a dipping tank, in which some form of crude oil or coal tar is used as a bath. Where the dipping tank is not available, or in the case of young pigs, the remedy should be sprayed or rubbed on.

Tuberculosis.-Hogs, like various other animals, are 
subject to tuberculosis. Many hogs have this disease in some form. Its effects are seen in a stoppage of growth, a general run-down appearance, loss of appetite, and in some cases, death. Because hogs are kept so short a time, and tuberculosis is so slow a disease, there is comparatively

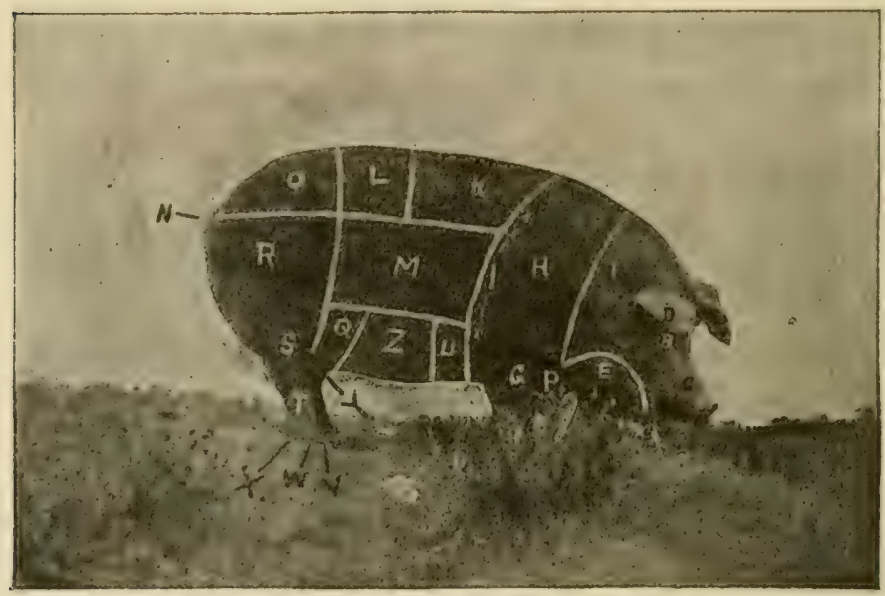

Parts of a hog

$\begin{array}{lll}\text { A. Snout } & \text { K. Back } & \text { S. Hock } \\ \text { B. Eye } & \text { L. Loin } & \text { T. Hind leg } \\ \text { C. Face } & \text { M. Side } & \text { U. Fore flank } \\ \text { D. Ear } & \text { N. Tail } & \text { V. Foot } \\ \text { I. Jowl } & \text { O. Rump } & \text { W. Pasterns } \\ \text { T. Neck } & \text { P. Breast } & \text { X. Dew claw } \\ \text { G. Fore leg } & \text { Q. Hind flank } & \text { Y. Stifle } \\ \text { H. Shoulder } & \text { R. Ham } & \text { Z. Belly } \\ \text { I. Chest line } & & \end{array}$

little loss owing to cleaths from tuberculosis. But many animals when slaughtered are found to be unfit for food because of the disease.

Tuberculosis is caught either from diseased pigs, or from drinking the milk of tubercular cows. It is probable that most of the tuberculosis in swine comes from the latter 
cause. Many hog raisers now pasteurize the milk before feeding it to the pigs. This is the only sure preventative against tubercular milk.

Hog cholera.-By far the worse disease scourge affecting hogs is cholera. It not infrequently wipes out entire herds within a few weeks. The average yearly loss from hog cholera in Indiana is estimated at three million dollars. In one single "cholera year" Iowa lost at least twenty million dollars from this cause. Other states suffer in like proportion. It is, therefore, of the highest importance that the causes of cholera, and the modes of prevention be well understood.

Hog cholera is a germ sickness caught by infection from hogs that have the disease. It is not necessary for well animals to come in direct contact with cholera hogs in order to catch the infection. The germs may be carried by dogs; by pigeons, crows, or other birds that alight in the hog lot to pick up grain; by men who have tramped through a lot where cholera hogs have been; by new stock brought into the herd; and by streams that have become infected. When hog cholera is in the region, therefore, it is necessary to observe every precaution to keep infection away from the herd.

Effects of cholera.-The disease is so marked in its symptoms that it is not hard to distinguish from most other hog sicknesses. In hog cholera, the lymphatic glands, lungs, intestines, kidneys and liver are highly inflamed. Red blotches appear on the skin. Appetite is lost, the gait becomes staggering, the eyes inflamed. Not infrequently bleeding at the nose and vomiting occur. The temperature is usually from one hundred and seven to one hundred and eight degrees Fahrenheit. The first ones of the herd to be stricken commonly die within a few days; those that take the disease later may live for several weeks, or even recover. 
Treatment.-No absolute cure has been discovered for hog cholera. Nearly all animals that take the disease usually die. A method of preventing well herds from contracting cholera has, however, been discovered. This is to give well hogs anti-cholera serum; or, in effect, vaccinate them, as is done with people for smallpox and diphtheria.

The hog cholera serum is secured by drawing blood from

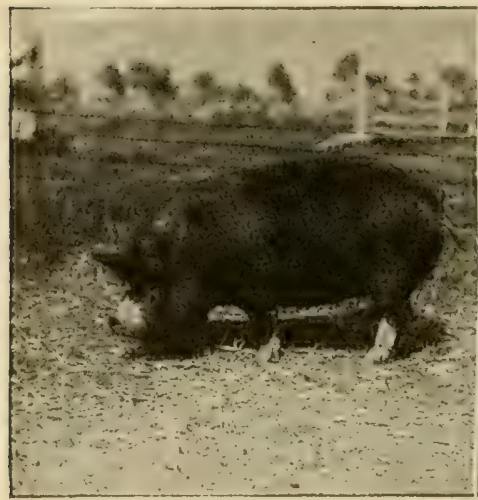

I had serum.

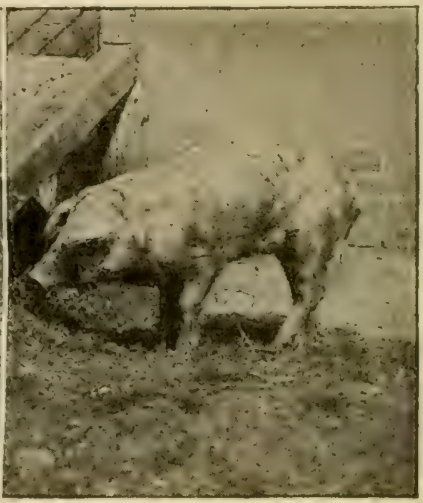

I wish I had.

a hog which has first been rendered immune to cholera, cither by having had the disease or being given a special treatment for the purpose of immunizing, and then having had cholera germs injected into his veins. Each animal of the herd to be treated is given by hypodermic injection a certain quantity of this serum in accordance with its size.

If the treatment is successful, it will immunize the herd against cholera for several weeks. When the scrum is given to well herds, a cholera hog is sometimes brought among them, or its carcass even fed them, at the time the treatment is given. This method is thought to make the immunity more certain. 
Success of the serum treatment.-The success of the serum treatment is still questioned by many. It seems reasonably certain, however, that where failure has followed its use, it was because the serum was improperly prepared or not skilfully administered. Various experiment stations have found that there is a loss of only about ten per cent. of the hogs treated in herds already infected, and of only one or two per cent. in well herds where the serum treatment has been carefully used. The manufacture of serum by the state, or official inspection of its manufacture by private plants, will make its use as a cholera preventative still more effective. No one is justified in failing to treat his herd with the serum when hog cholera threatens.

\section{TOPICS FOR INVESTIGATION}

1. Make a census of all the hogs on your home farm, classifying them into the following groups: brood sows, suckling pigs, young shoats, and fattening hogs. Have your father help you estimate the value of each group, and compute the value of all.

2. What different breeds are represented on your farm? Are the breeds pure or mixed?

3. At what time of the year are the pigs farrowed? At what age are they weaned? At what age is fattening started? Are your young pigs allowed the range of a pasture? If so, what is the grass used? What feed is used in addition?

4. Is attention given on your home farm to feeding hogs a balanced ration? If so, what are the feeds used? What is the ration used for fattening?

5. If, when pigs are allowed to "hog down" corn it takes eight pounds of corn to produce one pound of pork, but requires ten pounds of corn to make a pound of pork when the corn is fed in a pen, what will be the difference in the value of the corn fed twenty hogs while they are making an average gain of seventy-five pounds each, corn being worth fifty-five cents a bushel? 
6. Have you any hogs that do not seem to be thriving? If so, can you judge what is the matter? Do they cough? Do they lack appetite? Do they look rough coated, and run down? Is it likely that they have tuberculosis? That they have worms? Have they the thumps?

7. Examine several hogs out of your herd for the presence of lice. Are your hogs ever treated for lice? Why is it that lousy hogs never thrive well?

8. Compare all the different types of hog-houses used in your neighborhood. How many are clean, light, well ventilated, and have the windows so placed that the pens receive the sunlight during the spring farrowing season?

9. Discuss the value of the cholera serum as a preventative for hog cholera. How would you proceed to get state and government help for the care of hogs if any of them showed symptoms of hog cholera? What are some of the symptoms?

10. Show how to keep a book account of a pen of pigs, five in number, for a season of six months. The items should include labor costs, feed and equipment.

11. Show upon the map the relative standing of the hog states of the Union. Has there been a falling off or an increase in hog production during the last ten years? Refer to the last census report of the United States Department of Agriculture.

\section{Demonstrations}

1. Demonstrate upon the blackboard or with pasteboard or paper, how to make a hog-house; also a hog pen with feeding floor; then make a miniature outfit for the club festival or school fair.

2. How best to move hogs from place to place. Would you drive, lead, or coax them?

3. Demonstrate by diagram the proper divisions of a hog for the butcher's meat block.

4. Demonstrate the proper method for the vaccination of hogs for hog cholera. (Consult Farmers' Bulletin No. 379.) 
5. How to make feeding and watering troughs for hog pens, in a simple inexpensive way.

\section{Play Contests}

1. Contest in hog judging.

2. Naming and giving five characteristics of each of the various types or breeds of hogs.

3. Spelling contest, in which words relating to the hog industry are used.

4. Essay writing contest on one or more of the following subjects: "The Origin of the Hog"; "The Care and Feeding of Hogs"; "Treatment for Diseases of Hogs."

5. Drawing contest of hogs, hog pens, equipment, etc.

\section{Pig Club Project}

The pig club work can easily be combined with the corn or grain club. Each club member takes thoroughbred pigs to raise in connection with the corn or grain crop, keeping, of course, separate records of each interest and charging against the hog all grain or other feed, from the club acre. Careful records of observation, receipts and expenditures should be kept in connection with the pig club work and the project should cover at least twelve months of work.

The basis of award in this particular project should be as follows:

1. The exhibit of the hog and relation to its purpose judged by score-card -.-.-_-_-_-_- 25

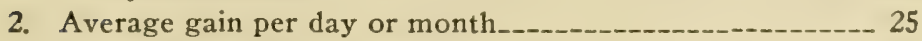

3. Net profit and cost of production

4. Records and story on "How I Raised My Hog"-........ 25

Total score 


\section{CHAPTER XXII}

\section{SHEEP}

T'HE raising of sheep has never received the attention it 1 deserves in most regions. There are at present only a little more than fifty million sheep on the farms of the United States. Almost sixty per cent. of our sheep are found in ten states, seven of which are in the far West, one in the South, and only two in the middle and eastern states. According to their importance in sheep raising, these states are: Montana, Wyoming, Ohio, New Mexico, Idaho, Oregon, California, Michigan, Texas and Ctah. Other middle western states having important sheep interests are Missouri, Indiana, Kentucky, Iowa and Illinois.

\section{Importance of Sheep on the Farm}

Sheep could be raised with good profit on thousands of farms where they are now unknown. They are among the most hardy of the domestic animals, and will thrive in almost every part of the country.

Sheep as foragers.-Shcep have no equal among the farm animals as foragers. They will eat a wide range of roughage, much of which is not available for other stock. Certain weeds not palatable to most animals are eaten by sheep, and they therefore aid in keeping pastures, meadows and fields clean. Sheep will graze steep hillsides not accessible to horses or cattle, and will feed from the foliage and twigs of brushland pastures. They find a good living 
on stubble-fields, and will clean up the waste leaves, husks and stalks of corn-fields, being able to thrive in fields where cattle and horses have gleaned all that they can well find. Sheep can therefore obtain a considerable part of their living from material that would otherwise go to waste.

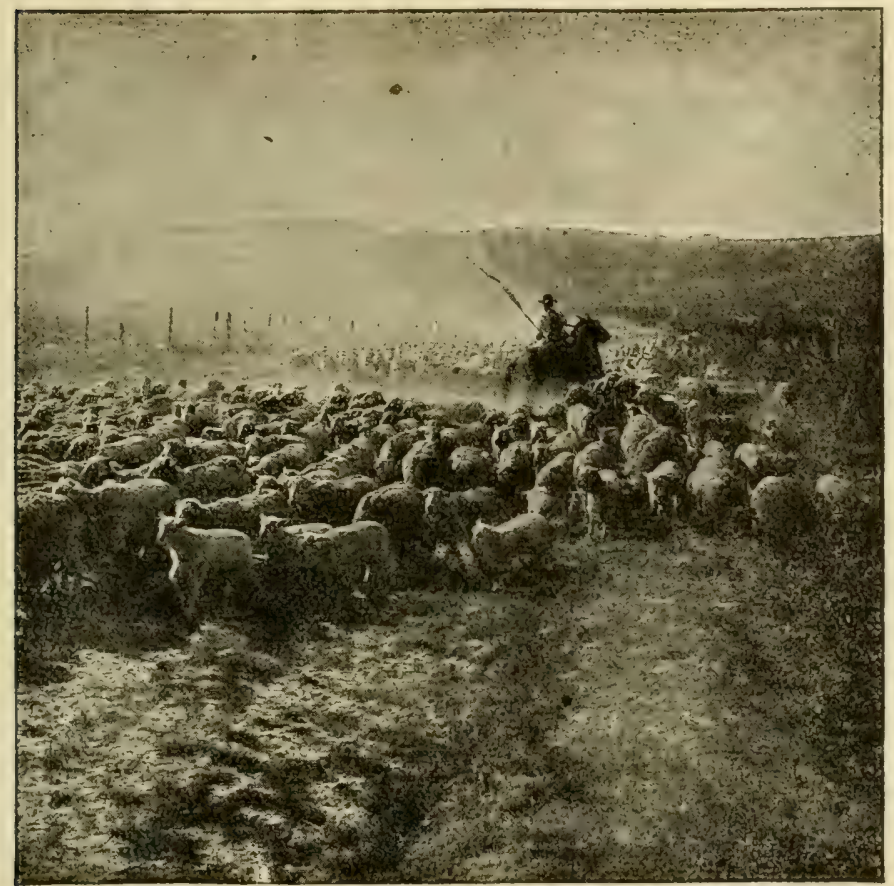

Sheep grazing in Washington.

Sheep require little labor.-Comparatively little labor is required in caring for sheep. In order to maintain the fertility of the soil, we need to raise more stock on our farms. Half a dozen sheep will produce as much income as a dairy cow, and demand much less labor for their care. 
Their heavy coats enable sheep to live in relatively open sheds in the winter, providing they are kept dry. The cost of shelter is therefore low.

One of the chief practical difficulties in sheep raising is that the fences suitable for horses and cattle will not hold sheep. The present tendency, however, is to build closer fences, so that fields will be available for both hogs and sheep. In some regions serious loss of sheep occurs from vicious dogs, wolves and coyotes. Sheep-killing dogs should be relentlessly shot.

Sheep bring quick returns.- Sheep are almost as good as poultry for quick returns. For ordinary farm purposes breeds are usually selected to produce both wool and mutton. In this way a double yield can be secured-fleeces from all the flock, and either lambs or mutton in addition.

It is estimated that the fleece from good sheep should pay for their feed, thereby leaving the lambs raised or the mutton produced as profit. Lambs are ready for market at from seven to twelve months of age, thus allowing the money invested in them to be turned quickly.

\section{Breeds of Sheep}

Sheep, like cattle, are kept for two purposes. Just as cattle include both the beef and the dairy breeds, so sheep comprise mutton breeds and merino, or w'ool, breeds.

Mutton breeds.-Mutton breeds of sheep correspond to beef breeds of cattle-their forms must be such as to yield the best results on the butcher's block, and they must be able to change their feed profitably into mutton.

Mutton breeds are divided into two classes in accordance with the length of their wool: (1) medium wool, or down type, of which there are eight different breeds; and (2) long wool, of which there are three breeds. 


\section{Medium wool breeds-}

Shropshire

Southdown

Oxford

Hampshire

Dorset-Horn

Cheviot

Tunis
Long wool breeds-

Leicester

Cotswold

Lincoln

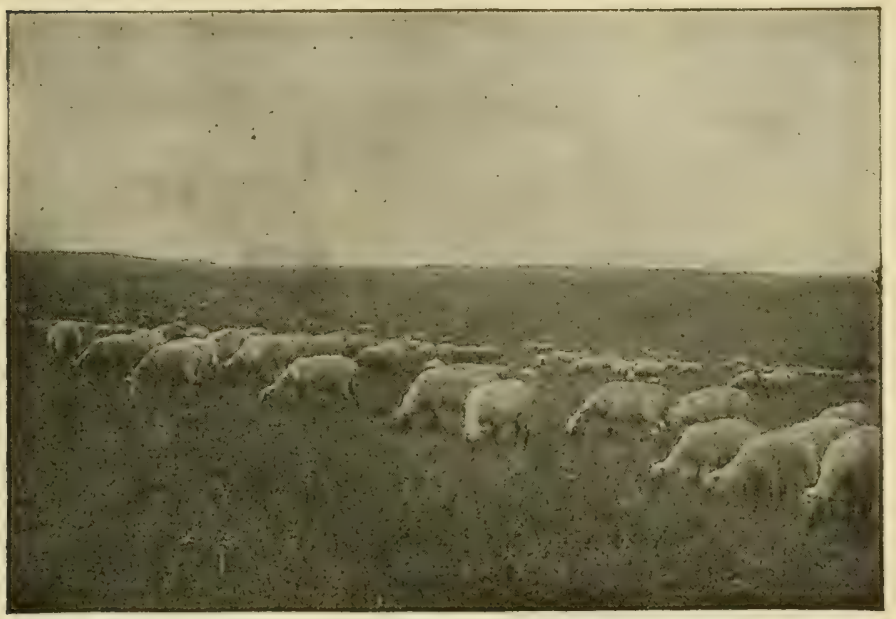

Sheep grazing, typical of western states.

The mutton breeds are more commonly used for the general purposes of the farmer than are the breeds that are classified as merino.

Merino breeds.-The merino breeds of sheep correspond to the dairy breeds of cattle. The build is more angular than that of the mutton breeds, and the general form such as to give the largest surface for the attachment of fleece. On the pure wool breeds the skin often hangs in folds on certain parts of the body, thus increasing 
the area for the growth of wool. The three chief merino breeds are:

\section{American Merino \\ Delaine Merino \\ Rambouillet}

Market classes of sheep.-Wholly regardless of breed, market demands divide sheep into three groups or classes. These are (1) fat, or mutton sheep, or those ready for slaughter; if the animals are less than one year old, they are called lambs; (2) feeders, or animals ready to be fattened; and (3) breeders.

\section{Feeding Sheep}

What has been said about the ability of sheep to forage for a great part of their food must not be understood to mean that it does not matter what sheep are given to eat. For sheep are exactly like all other animals in requiring the right proportion of nutritive elements in their food. Lacking a proper ration, they will be checked in growth, delayed in fattening, or short on the quantity and quality of wool.

Feeding ewes kept for breeding.- Ewes that are to produce lambs in the spring may be fed through the winter on a cheaper ration than that required for the feeders. The cwes need more of the muscle-forming, and less of the fatproducing foods. Their rations may therefore consist more largely of roughage, and less of grains than for the fattening lambs.

For breeding ewes weighing from one hundred and twenty-five to one hundred and fifty pounds, the following daily rations have been tested by the Minnesota Experiment Station and have been found to be economical and satisfactory: 
Ration No. 1.

3.5 pounds of corn stover.

2.0 pounds of roots.

.4 pounds of oats or shelled corn.
Ration No. 2.

2. pounds of clover hay.

1.4 pounds of corn stover.

.4 pounds of oats and corn mixed.

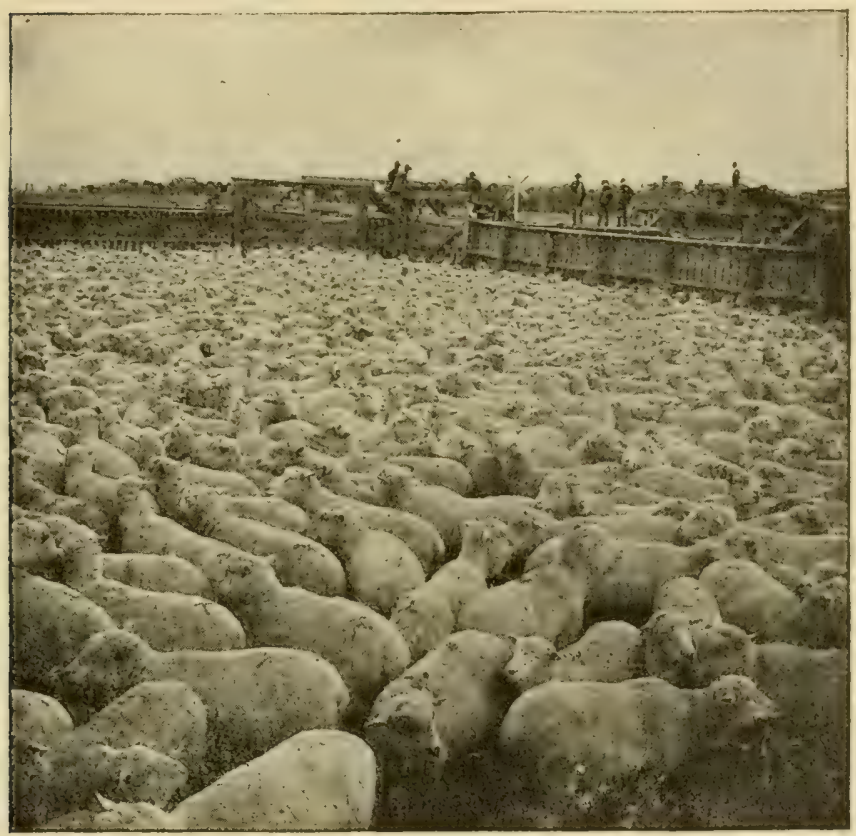

IIontana sheep ready for shipment.

Feeding for market.-The ration for fattening requires a larger proportion of fats and carbohydrates than the ones just described. It has also been found that lambs fatten best with a mixture of succulent food along with the usual roughage and grain.

The Cornell University Experiment Station has tried extensive experiments in fattening different lots of lambs 
during a period of one hundred and ten days. Each of the following rations served fifty lambs for one day:

Ration No. 1.

60 pounds of silage.

50 pounds of mixed hay.

35 pounds of corn.

13 pounds of oats.

5 pounds of brewer's grain.

Ration No. 3.

65 pounds of mixed hay.

10 pounds of corn.

20 pounds of brewer's grains.

20 pounds of gluten.

5 pounds of oats.
Ration No. 2.

65 pounds of mixed hay.

35 pounds of corn.

15 pounds of oats.

5 pounds of brewer's grains.

Ration No. 4.

60 pounds of silage.

50 pounds of mixed hay.

10 pounds of corn.

20 pounds of brewer's grains.

20 pounds of gluten.

5 pounds of oats.

It should be understood in studying these rations that at the beginning of the feeding period a larger proportion of roughage and a smaller proportion of grain were fed. By the end of the one-hundred-and-ten-day period this proportion had been reversed. The rations as given are the daily average for the whole time.

The actual amount of nutrients is the same for each of these four rations, yet the results differ considerably both as to cost and the amount of fat produced, as is shown by the following comparisons:

\begin{tabular}{ccc}
\hline Ration & $\begin{array}{c}\text { Average gain per sheep } \\
\text { in } 110 \text { days }\end{array}$ & $\begin{array}{c}\text { Cost per pound } \\
\text { of gain }\end{array}$ \\
\hline 1 & 22.7 pounds & 10.6 cents \\
2 & 15.7 " & 15.9 " \\
3 & 18.9 " & 13.2 " \\
4 & 25.1 "6 & 9.6 " \\
\hline
\end{tabular}

It will be noted that the most rapid gains, and at the lowest cost per pound were from the rations that contained 
silage. It is also seen that the lowest gain, and at the highest cost per pound, was from ration No. 2, where all succulent food was lacking, and most of the grain ration consisted of corn and oats.

\section{TOPICS FOR INVESTIGATION}

1. Make a study of the sheep raising industry in your vicinity, determining (1) how many sheep are kept, (2) what breeds are most used, (3) whether mutton or wool is depended on for the chief source of profit, and (4) what method of feeding and housing is principally followed.

2. Which would probably add more labor on your farm, increasing your dairy herd by five cows, or keeping a flock of thirty sheep? How would the profits probably compare? What is the basis for your judgment?

3. Suppose the cost of the nutrients making up the fattening rations shown on page $3+2$ was as follows: Hay, ten dollars a ton; silage, two dollars and fifty cents a ton; corn, sixty-five cents a bushel; oats, forty-five cents a bushel; distiller's grains, thirty dollars a ton; gluten, twenty-five dollars a ton. Figure what it cost to feed fifty lambs with each ration for one hundred and ten days.

4. After judging one or more sheep under the direction of the teacher, judge several animals independently, and then have your markings criticized and corrected.

5. Write an argument of three hundred words showing why sheep raising should be extended as an industry in your neighborhood and county.

6. Show how to keep a record of labor costs, pasture rent, feed and shearing of ten sheep.

7. Indicate on the map of the United States the sheep areas and the approximate number of sheep in each state as shown by the last census report.

8. Enumerate in your note-book the various products supplied by sheep.

\section{Sheep Demonstrations}

1. Demonstrate the proper method of shearing sheep.

2. Show how to make a balanced ration for sheep for the month of January in your locality. 
$\therefore$ Demonstrate how to judge the sheep. Use drawing, photograph or chart.

4. Demonstrate how to judge a lamb for mutton purposes. Use an animal in this case if possible.

5. Show how to judge sheep for wool purposes. Use the animal in this case.

\section{Sheep Play Contests}

1. Breed naming contests.

2. Wool fabric judging contest. A number of small pieces of various kinds of wool cloth, mixed with half wool and half cotton pieces, and some cotton pieces can be placed before the pupils with a view to teaching them how to distinguish between all-wool, part-wool, or cotton goods.

3. Essay writing contest on "The Life History of Sheep."

4. Sheep judging contest.

5. Five-minute extemporaneous speaking contest. In this contest have club nembers obtain ail kinds of information with a view to making a speech either for or against the production of sheep on the average farm of the community. The object of this is to have them use the information obtained from the text, investigations, etc., and apply this to their own farming conditions.

\section{Sheep Club Projects}

There are two practical club projects in connection with this line of work: The mutton production club, and the wool production club.

Mutton production club.-In connection with this club project the members are to take from one to a dozen spring lambs and care for them, keeping a record for a definite period of time, with a view to preparing them for 
the mutton market. The basis of award for this project may be :

1. Net profit or cost of production______- 30

2. Condition of lamb, judged by score-card_________._._. 30

3. Records of cost of labor, feeding, etc.--_-_-_-_-_-_-_-- 20

4. Story of "How to Produce Good Mutton"-_.-_-_-_-_-_-_ 20

Total score 100

Wool production clu.J.-This may consist of taking care of one or more s'reep Ior a year's time, and may require the club member tc select the sheep on the basis of high wool production. Keep records and accounts of labor and feed, as well as wool receipts. The net profit on investment is to come from the returns from the wool rather than the mutton. The basis of award may be:

1. Net profit or cost of production___- 30

2. Condition and quality of wool produced_-_-_-_-_-_-_- 30

3. Exhibit of samples of wool__-__-__- 20

4. Records and story of "How to Produce High-grade

Wool Economically" -...-_- 20

Total score-_. 100 


\section{CHAPTER XXIII}

\section{POULTRY}

$T^{H E}$ raising of poultry is considered of rather incidental 1 importance on most farms. A few chickens are kept for supplying the table with fresh eggs and an occasional fowl. Perhaps a flock of turkeys, ducks or geese are added for the sake of variety. Little attention is usually given to the possibility of large profits from the sale of eggs and poultry.

Yet, in spite of this somewhat haphazard method of treating the poultry industry, its aggregate returns are very large. For more than five and one-half million farms have a flock of chickens or other fowl. In addition, not a few people in villages and towns keep enough fowl for home use.

1. Take a census of all the fowls on your home farm, dividing into chickens, ducks, geese, etc.

2. How many of each class are in their first year; second year; third year, etc.?

3. Carefully estimate the value of each class of fowls, and compute the value of all.

\section{Distribution of Poultry Production}

Nearly five hundred million fowls are kept on the farms in our population. Considerably more than one and onehalf billion dozen eggs are produced annually. This is enough to supply every man, woman and child with fifteen 
dozen eggs each year. The value of the eggs is in excess of three hundred million dollars a year, or sufficient to pay about three-fourths of the running expenses of all our public schools. The fowls themselves are worth above two hundred million dollars.

The ten leading poultry states.-Ten states supply about fifty-four per cent. of all the eggs we produce. These states are Missouri, Iowa, Ohio, Illinois, Kansas, Indiana, Texas, Pennsylvania, New York and Michigan.

The percentage of the entire egg crop produced by each of these ten states is as follows:

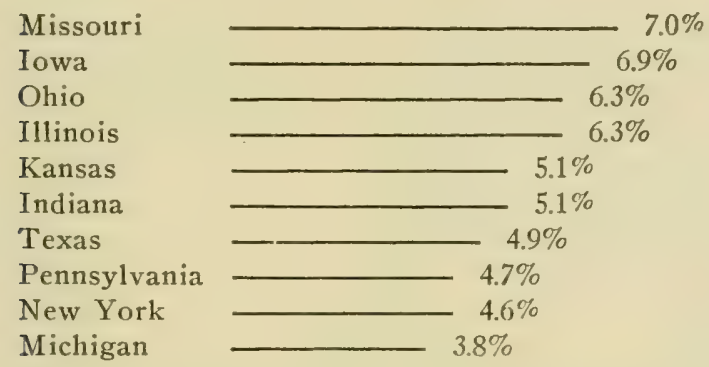

\section{Poultry Raising as a Farm Industry}

There are several good reasons why the raising of poultry should occupy a more important place than it now does on most of our farms.

Increasing demands for eggs and poultry.-Eggs form one of the most necessary and palatable articles of food. With improved methods of shipping and cold storage they have increasingly become a staple on almost every table, city as well as country. The prices are high, a dozen of eggs bringing the farmer about as much as a pound of butter. The demand for fowl as a supplement to other kinds of meat has also greatly increased, and there is now 
a ready market throughout the year for all kinds of poultry suitable for the table.

Low cost of feeding poultry.- $\Lambda$ fair-sized flock of poultry can be kept on the farm with but little expense for feed. This is because fowl will gather up the greater part of their living from material that would otherwise be wasted. Scattered grain from the feed lots; undigested grain from farm animals; weed and grass seeds; grass and various

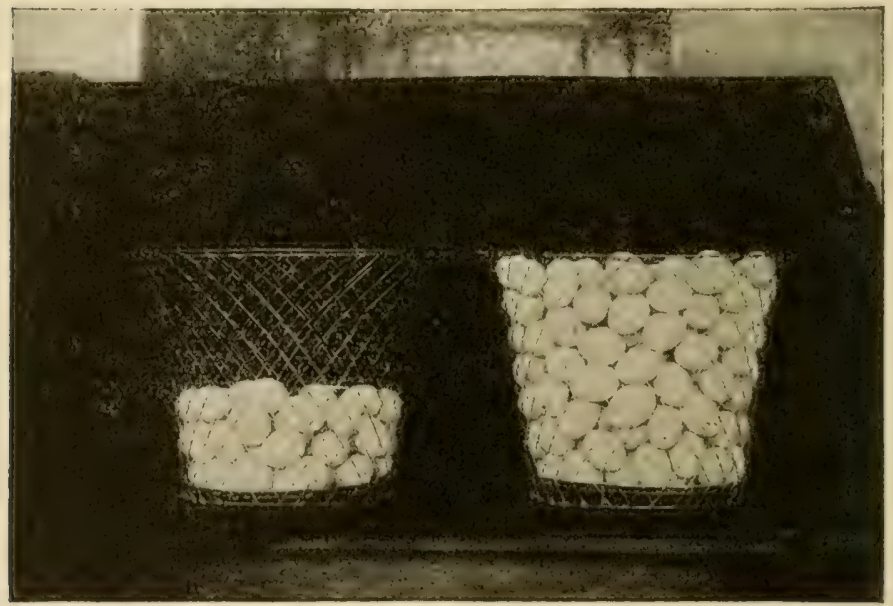

A year's product of an average hen and a good hen. The average hen laid 75 eggs, the good hen 223 eggs.

green plants about the barn lots, worms, bugs, grasshoppers and other insect pests form a large part of the diet of farm poultry during most of the year.

The labor of caring for poultry is light.-The labor connected with poultry raising is much lighter than with other farm animals. Much of the work is suited to the strength and interest of children, and gives the training in responsibility which every child needs. With a little over- 
sight, children of from ten to eighteen years can successfully take almost entire charge of poultry raising and make it highly profitable. This has been fully demonstrated in many boys' and girls' poultry clubs in nearly every state.

Quick profits are realized.-The profits from a well managed flock of chickens are not only liberal and certain, but quick. Chickens are ready for market within a few months from the time they are hatched, and hens are at their best as layers during the first and second years of their life. And the eggs afford a continuous source of income to meet the expense of any feed or other supplies that are bought, or to add to the bank account.

Almost all farm boys and girls could become expert chicken raisers and, by making arrangements with their parents to receive a share of the income from the flock, earn their own money for clothes, books, schooling, travel or whatever else they may desire.

\section{Breeds of Chickens}

According to experts there are one hundred and four standard varieties of chickens raised in the United States. There are many other varieties not sufficiently developed to be called standard. For practical purposes the standard varieties may all be grouped in four classes: (1) General purpose breeds; (2) meat or table breeds; (3) egg breeds; (4) ornamental breeds.

General purpose breeds.-The general purpose breeds are the result of an attempt to combine egg-laying with good table qualities. The favorites of these breeds are:

Plymouth Rocks, Barred, White and Buff.

Wyandottes, Silver, Golden, White, Buff, Black, etc.

Javas, Black and Mottled.

Dominiques, Rose-comb.

Rhode Island Reds, Single-comb and Rose-comb. 


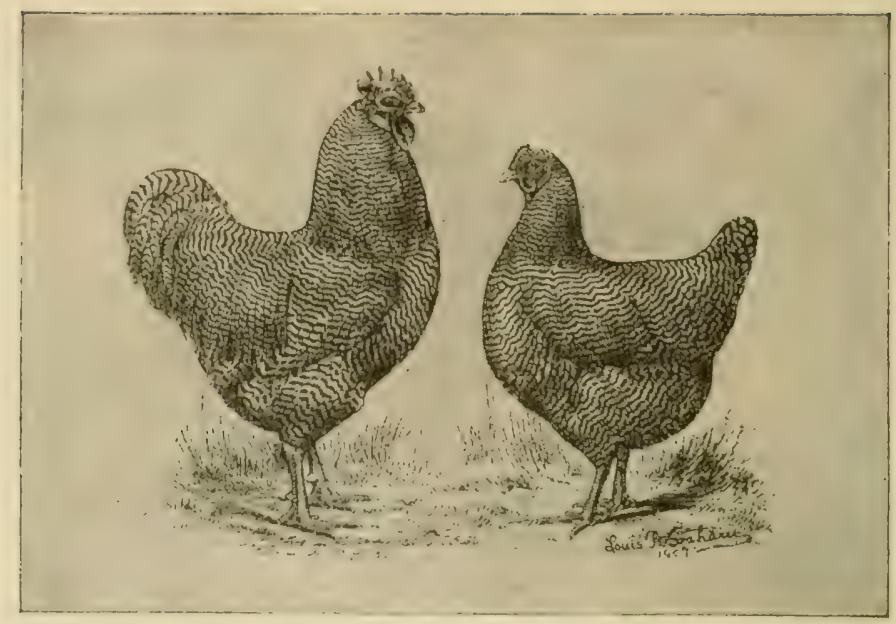

Barred I'lymouth Iocks.

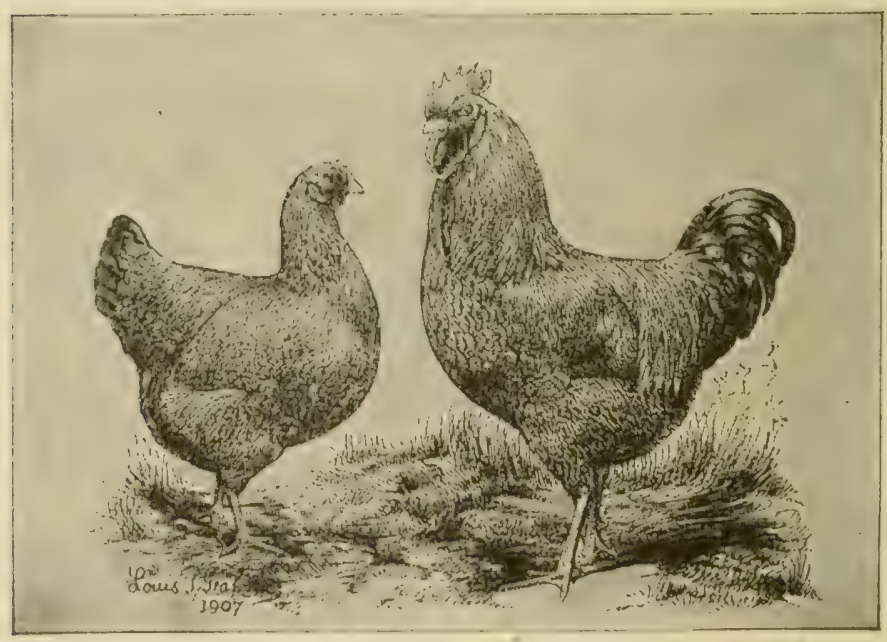

Single-comb lilode Island Reds. 
Buckeyes, Pea-comb.

Orpingtons, Buff, Black and White.

Houdans, Mottled.

Meat breeds.-The meat, or table, breeds are chiefly raised for the large markets. They must be of good shape and size, quick growers and ready fatteners. The principal breeds of this class are:

Brahmas, Light and Dark.

Cochins, Buff, Partridge, White and Black.

Langshans, Black and White.

Dorkings, White, Silvër-gray and Colored.

Indians, White Game.

Egg breeds.-The prime consideration in the egg breeds is that they shall be good layers, begin laying young, and continue for a considerable period of time. The chief breeds are:

Leghorns, Brown, Buff, White, Black, etc.

Minorcas, Black and White.

Spanish, White-faced Black.

Andalusians, Blue.

Anconas, Mottled.

Hamburgs, Gold and Silver Spangled, White and Black.

Redcaps, Rose-comb.

Ornamental breeds. - The ornamental breeds are not important for practical farm purposes. Sume of the favorites of these breeds are:

Polish, White-crested Black, Golden, Silver, White, Golden.

Crevecoeurs, Black.

La Fleche, Black.

Bantams.

Games.

It is best not to mix bree ls of chickens. First one should decide what class is desirea, whether egg, meat, or general 


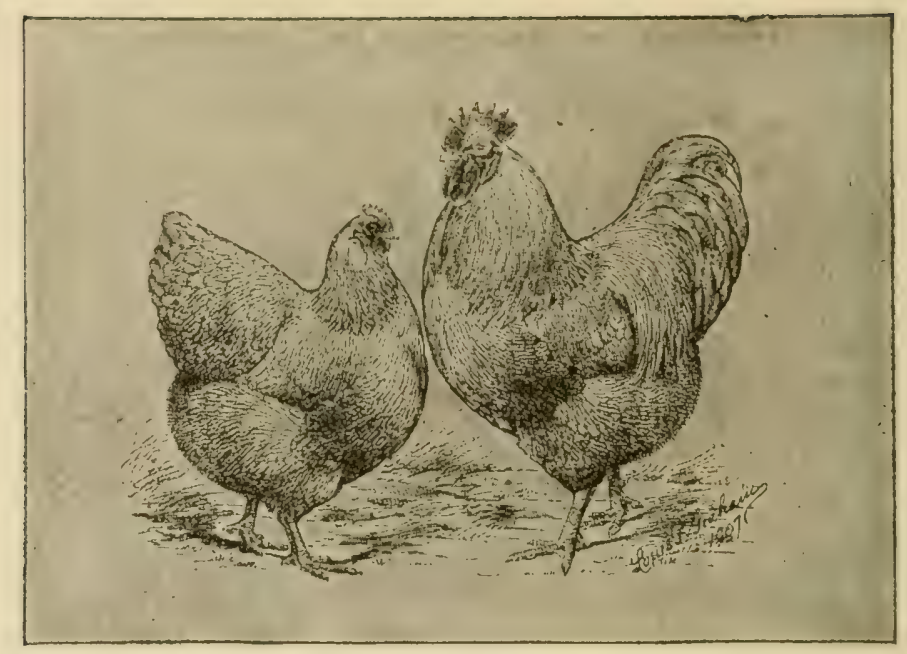

Single-comb Buff Orpingtons.

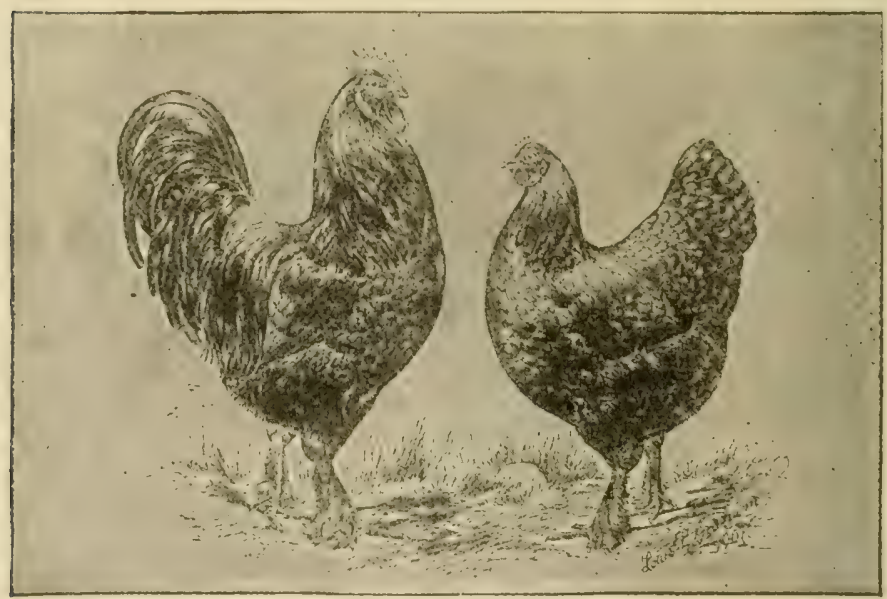

Black Laugshans. 
pirpose. Then a pure breed of this class should be selected, and the strain kept free from mixture with other breeds.

1. Are the chickens on your farm pure bred, grade, or scrub? What breed or breeds do you use? Is this an egg, meat or general purpose breed?

2. What steps could be taken to improve the breed?

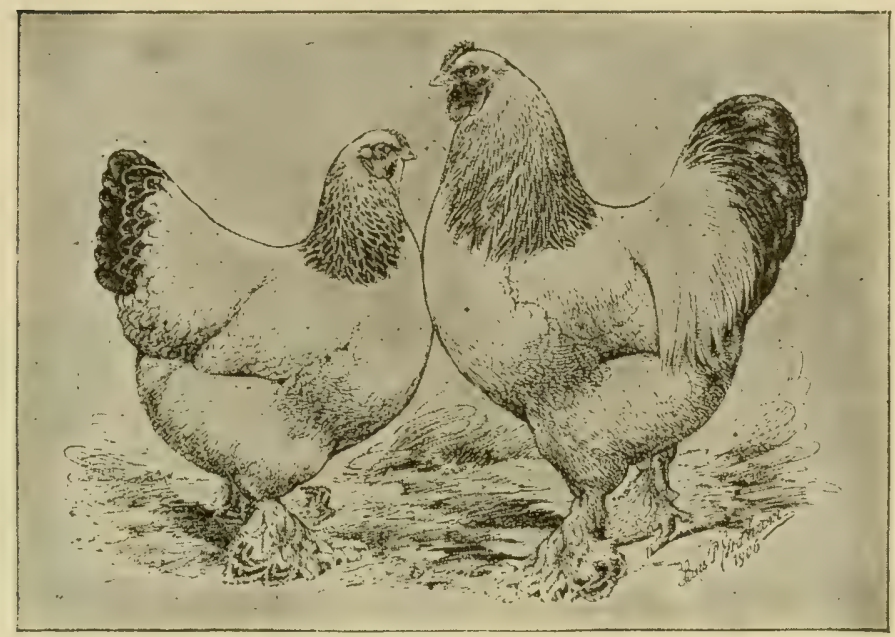

Light Brahmas.

Would this not pay? Do egg or table breeds return most profit under farm conditions?

\section{Producing Chickens}

A successful hatch depends (1) on securing fertile uninjured eggs, and (2) on proper incubation.

Eggs for hatching.-Heredity has its effect in fowl as well as other animals. The eggs for hatching should therefore come from the choicest and most vigorous members 
of the flock. The best plan is to separate from the main flock a sufficient number of desirable hens to produce the eggs required for setting. These can be kept by themselves until the hatching season is over.

In order that eggs may hatch at all they must be fertile. They are made fertile by the presence of a male bird in the flock during the laying season. One male should be supplied for every ten or twelve hens. Since one-half of the heredity of the entire flock is dependent son the male bird, he should be pure bred, the best of his kind, young and vigorous.

Care of eggs before setting.-Eggs should be fresh when they are set, never more than two weeks old, and better if not more than a few days from the nest. They should be kept rather cool, a suitable temperature being between fifty and sixty degrees Fahrenheit. Eggs that have been badly chilled will not hatch. It is necessary, therefore, that eggs intended for hatching shall be gathered at frequent intervals during cold weather. Many poultry men think it is best to turn the eggs over every day or so during the time they are stored before setting. They should never be jarred or shaken.

Hatching with the hen.-Eggs may be successfully hatched either with a hen or an inculbator. If the hatch is not to consist of more than from one hundred to two hundred chicks, and if the hens come of a breed of good setters, it is doubtful whether it pays to use an incubator.

Only quiet, motherly hens of good disposition should be used for setting. The nest should be made of a box from fourteen to sixteen inches square, and six inches deep. Four inches of earth should be placed in the box, hollowed slightly, and covered with chaff or straw. The broody hen should be removed to the nest at night and given a few china eggs 
for a ady or two to make sure that she is in earnest about sitting. From thirteen to fifteen eggs may then be given her for the hatch. It is well to dust both hen and nest with insect powder to destroy vermin. The sitting hen should be well fed on such grains as corn, wheat, or oats, have

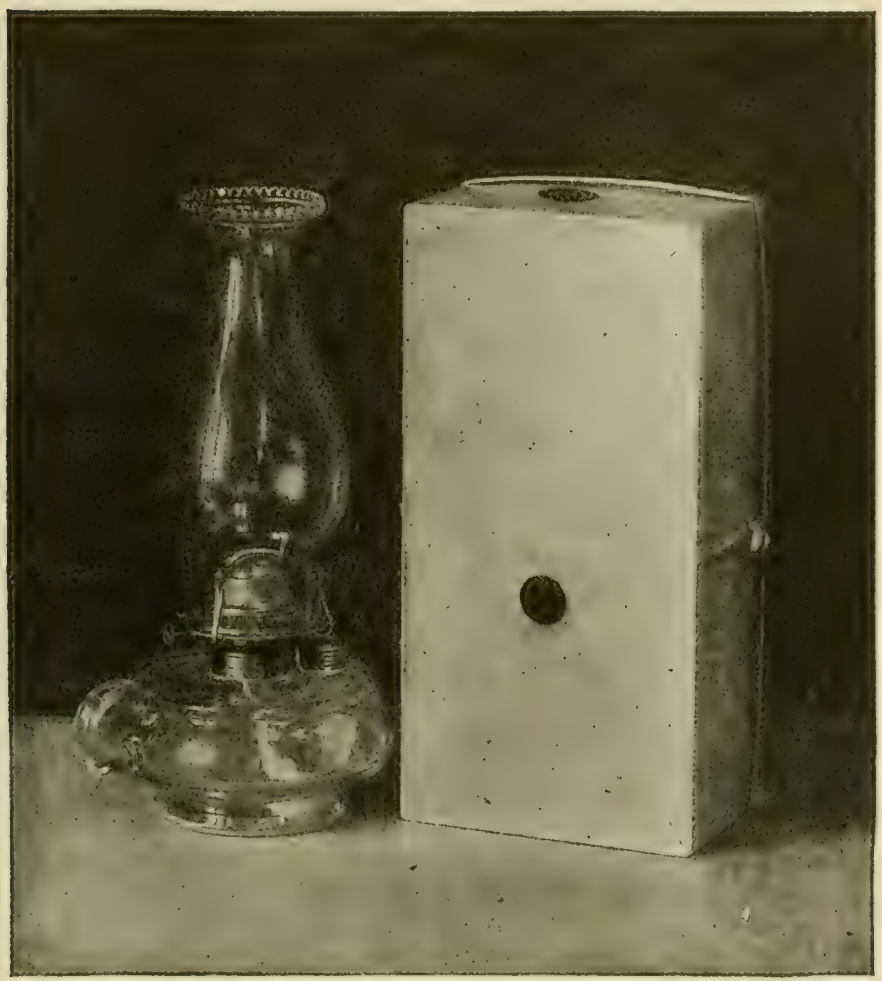

A home-made egg tester.

plenty of fresh water, and be let off the nest a short time sach day for exercise and a dust bath. 
Hatching with the incubator.-Although there are many different makes of incubators, they all supply the heat necessary for hatching by one of two methods, either hot air, or hot water. All of the standard makes will be found satisfactory, though the hot-air type seems less likely to get out of order.

Success with the incubator depends much more on the operator than the machine. For unless the temperature and ventilation are kept right, the eggs properly turned, and other necessary conditions met, the hatch is sure to fail. The directions supplied with the machine must be faithfully followed, else one need not hope for success.

Testing for infertile eggs.-About the sixth day after setting the eggs should be tested and the infertile ones re. moved. The testing may be done by placing a small lamp or a lantern in a box through one side of which just opposite the light a hole has been cut somewhat smaller than an egg. The testing should be done in the dark, preferably at night. The egg is held against the opening in front of the light. As the light shines through, the infertile eggs will appear clear, while the fertile egg will show a network of threads leading out from a center, and floating about as the egg is turned. If a number of hens were set at the same time, and many infertile eggs are found, one hen may be released, or given a new supply, and the fertile eggs distributed among the others.

Care of newly hatched chicks.-The chicks first hatched from a setting should be removed from the nest in about twenty-four hours. If they are not, they will begin to leave the nest themselves, and the hen is likely to desert the nest before all the eggs are hatched. The chicks must be kept warm and comfortable until the mother is ready for them. 
When the hatching is done in an incubator, the chicks are left for twenty-four hours after hatching and then removed to the brooder, which must be at a temperature of from ninety to ninety-five degrees Fahrenheit. By the time the chicks are a month old the brooder may be brought gradually down to seventy degrees.

1. Is any care taken in raising chickens on your farm toward selecting eggs from the best hens for setting? Is care taken to use only the best male birds?

2. Draw a plan for a suitable nest for a sitting hen, showing covered runway.

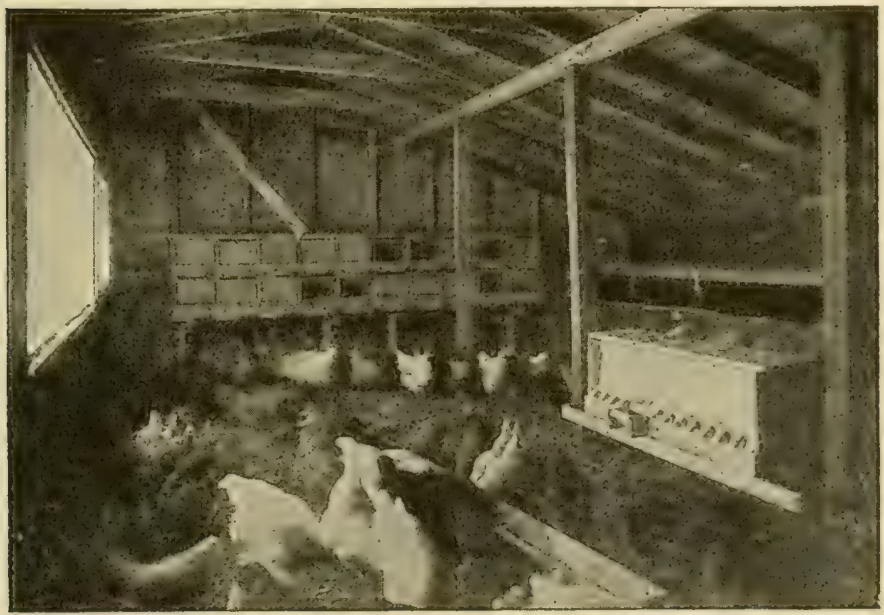

A well-arranged interior, showing nests and feeding equipment.

3. Do you make the test for infertile eggs after the hens have been set about a week? How do you tell whether the egg has started to hatch?

\section{Feeding Chickens}

Feeding young chickens.-For the first forty-eight 
hours after hatching the young chick needs no feed of any kind. Nature had provided for this period by having the yolk of the egg absorbed into the abdomen of the chick just before it is hatched. This food must be used up before the chick is ready for more.

The first food given the chicks may be stale bread soaked in milk and squeezed dry; hard boiled eggs chopped fine, shell and all; or cracked corn, wheat or oats. A good grain ration for chicks is made of equal parts of cracked corn, cracked wheat and cut oats fed five times a day. An cxcellent supplementary ration to hasten growth is the following: Bran, ten pounds; shorts, ten pounds; cornmeal, five pounds; meat scraps, five pounds; charcoal, two and onehalf pounds. This mixture may either be fed wet or dry. Plenty of sour milk will add greatly to the effectiveness of the ration. Green foods should also be supplied irum the first.

Feeding laying hens.-Hens, like other animals, do best on a ration balanced to meet their needs. There is no one best ration, since the necessary food elements can be obtained from many different sources. It is certain, however, that fowls require grain, meat, or milk, mill feeds such as shorts, or bran, green foods, sharp grit, shell and water.

The following is recommended as a well balanced laying ration, though wheat may be left out and more corn and oats added, or milk supplied instead of the meat scraps. (Purdue Extension Bulletin, 10.)

Grain

10 pounds of corn.

10 pounds of wheat.

5 pounds of oats.

\section{DRY MAsIT}

5 pounds of bran.

5 pounds of shorts.

$3 \frac{1}{2}$ pounds of meat scraps.

The grain is fed in a litter of straw night and morning, 
and the mash left before the fowls the greater part of the day. Green food, grit and shell are, of course, added to this ration.

Feeding chickens for fattening.-Chickens should be specially fattened for market. Not only is weight added, but the quality of the meat greatly improved by fattening, and a higher price obtained. When unfattened chickens are selling at ten cents, the same fowls when fattened will bring fifteen cents in the city markets.

Both the pen and the crate metlod of fattening are used. Pen fattening requires less time and attention than crate fattening. The fattening pen should be kept darkened except at feeding time, in order that the chickens may remain quiet. A suitable ration is fed at regular intervals, and in as large quantities as the fowls will eat in from twenty to thirty minutes.

Crate feeding.-Nore rapid fattening is possible by placing from six to nine chickens in a crate. The fowls are given a regular ration, and kept from all exercise. tbout two weeks is the average time required for fattening. An excellent fattening ration may be compounded as follows:

10 pounds of cornmeal.

5 pounds of shorts.

5 pounds of ground oats.

40 pounds of buttermilk.

Cramming.-Poultrymen who make a business of fattening for city markets often use the cramming system of feeding. This method is based on the fact that chickens will not eat so much as they can assimilate and use in making fat. The fowl is taken from the pen or crate and held while soft food is pressed down the throat into the crop, or passed into the crop by means of a tube attached to a cramming machine. This forcible feeding will considerably hasten the fattening process. 


\section{Producing and Marketing Eggs}

Properly handled eggs are the most profitable part of the poultry business on the farm. It is therefore well to study the conditions necessary to the largest production of eggs. The number of eggs produced by a flock depends (1) on the breed, whether of the laying, or meat, type; (2) on the feed, whether it consists of a balanced ration containing the elements required by the egg; and (3) the housing and care.

Profitable layers.-There is a great difference in the laying qualities not only of different breeds, but also of individual hens. An average grade or scrub hen will lay about seventy-five eggs in a year; a high-class hen of a laying breed, more than two hundred. These two hens eat the same amount of food, take the same amount of room, and require the same amount of care. The one hardly pays for her keep, the other yields a handsome profit. It will pay every farmer to weed out the poor layers from his flock, and fill their places with productive hens.

Age and egg production.-Young hens are the best layers. Only in the case of exceptional layer's should hens be kept after they are two years old. Hen: that have passed their second year will continue laying anc produce a fair number of eggs, but younger hens will produce more eggs, and should therefore take the place of the older ones.

Pullets should begin laying in the fall of their first year. In order that they may do this, it is necessary to have them hatched out early in the preceding spring, preferably not later than March or April. They should then lay throughout the winter, and be at their best the following summer.

The quality of eggs.-Eggs are rated commercially according to size as c.rtras when they weight from twenty-six to twenty-eight ounces to the dozen; as firsts when they weigh from twenty-four to twenty-six ounces to the dozen: 
and as seconds when they weigh less than twenty-four ounces. In some places eggs are now sold by weight. For these reasons the size is of great importance.

To command the highest price, eggs should also be uniform in shape and color, the shell smooth and free from spots, and clean without having been washed. Tested with the candler the air cell should be no larger than a dime, thus indicating freshness; the contents must appear opaque, the yolks barely visible, and free from any discoloring; the white must show thick and compact, the yolk not floating about.

1. Make a candler test as described in the text, and learn to tell fresh from stale eggs; fertile from infertile.

2. Score the eggs collected for several days from your farm hens. How many extras; firsts; seconds? How many were dirty? What was the average score?

Effect of infertility on quality.-No eggs except those intended for hatching should be fertile. This is because infertile eggs keep much longer and in better flavor than fertile eggs. If a fertile egg is allowed to stand in a warm temperature for two or three days it begins to develop blood-rings; that is, it begins to hatch. This process is sture to go on during the marketing and shipping, thus greatly reducing the value of the eggs. The infertile egg is free from all this difficulty, and will keep fresh much longer.

It is estimated that the loss from allowing eggs to become fertilized is more than fifteen million dollars annually in the United States. All male birds should therefore be kept away from laying hens when the eggs are to be used or sold. This will have no effect on the number of eggs produced.

Rules for egg production.-The following rules for egg production are given by the United States Department of Agriculture: 


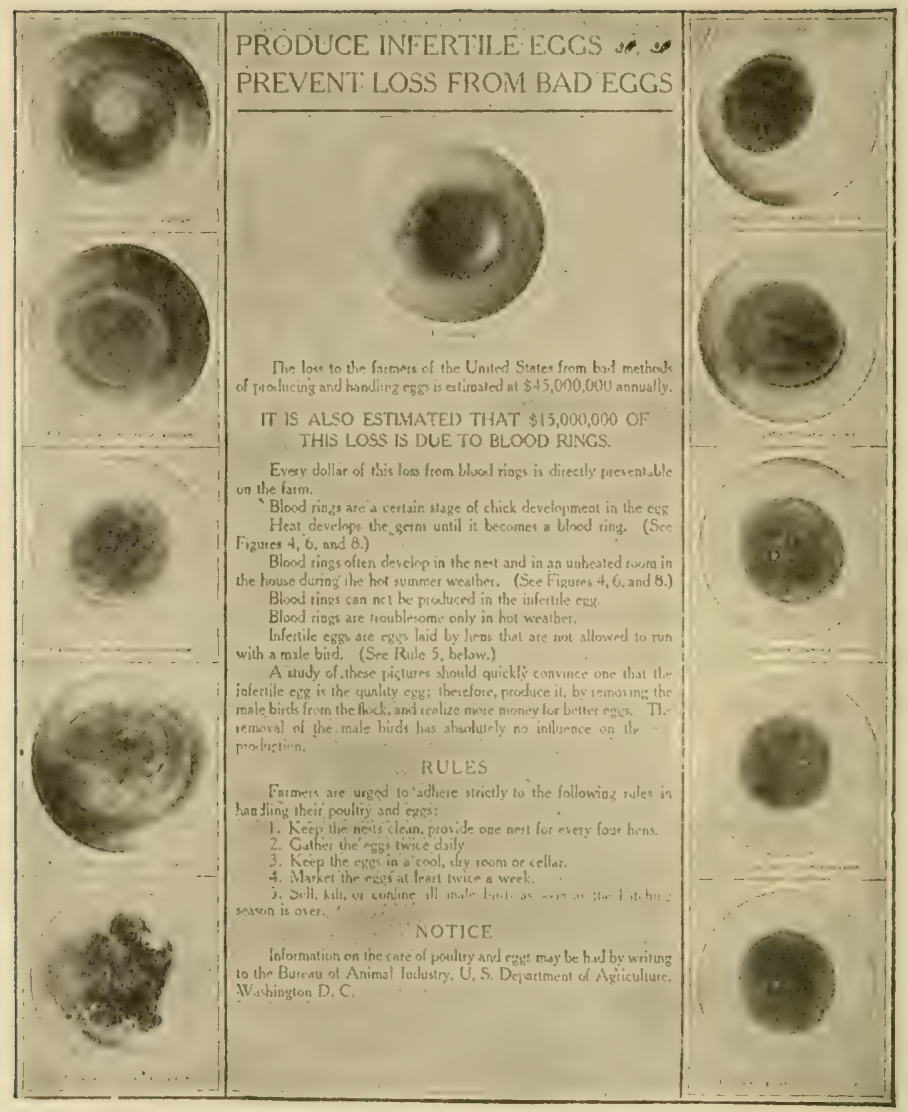

Fertile and infertile eggs. 
1. Keep the nests clean; provide one nest for each four hens.

2. Gather the eggs twice daily.

3. Keep the eggs in a cool dry room or cellar.

4. Market the eggs at least twice a week.

5. Market, kill or confine all male birds as soon as the hatching season is over.

\section{Housing the Poultry}

There are almost as many different styles of poultry houses as dwelling houses. The exact form of the poultry house is not important, though some types are more pleasing in appearance and less expensive than others. Every state agricultural college has plans for poultry houses adapted to the region and will be glad to supply these to citizens of the state. No matter what the style, however, certain fundamental requirements should be met by all poultry houses.

Drainage.-Poultry are especially sensitive to unhygienic surroundings. Impurities arising from ground saturated with unclean seepage, and dampness coming from undrained soil are sure to injure the fowls. The poultry house should be built on well drained ground. Drain tile should be used to carry the water away if necessary.

Room.-In many instances a flock of chickens are crowded into a space far too small for them, and the owner then wonders why they do not thrive well or lay eggs. The amount of floor space should be from four to five square feet for each bird. If there is free access to a sheltered yard, somewhat less than this may serve, but better sell part of the flock than overcrowd them in small pens.

Ventilation-Chickens require far more air according to their weight than larger animals. Confinement in close, ill-smelling rooms is certain to lower their vitality, bring on diseases, and interfere with laying. In climates 


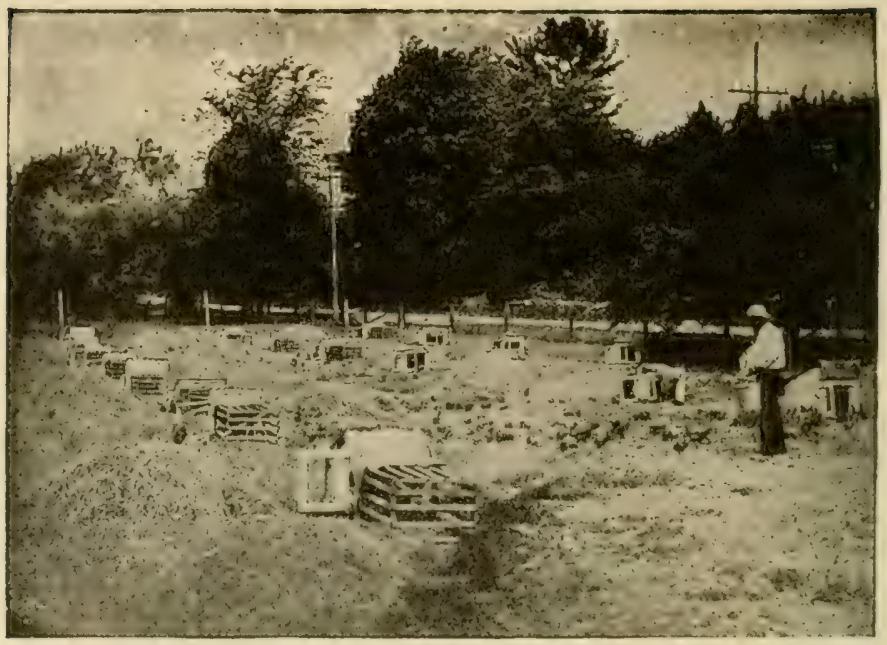

Brood coops set on clean fresh ground. This flock is in little danger of disease.

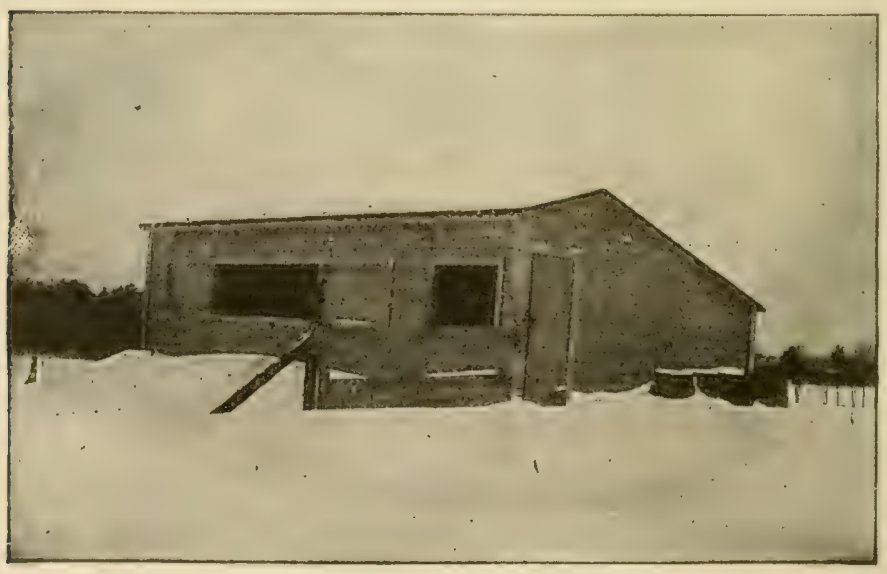

A practical ben house for the farm. 
where the poultry house can not have an open front, two or more sashes should be covered with muslin instead of being glazed, and hung on hinges so that the window may be thrown open in good weather. In bad weather the sash may be closed and yet admit sufficient air. Drafts should never strike chickens either while they are on the roost or the floor.

Sunlight.-Suniight is the best of disinfectants. The poultry house should front the south, and have a reasonable number of glazed windows besides the muslin sashes. Too much glass makes the house excessively hot in the summer and very cold in the winter; too little glass leaves the quarters dark and gloomy, hinders the chickens in feeding, and encourages disease.

Freedom from dampness.-When frost gathers heavily inside the poultry house in cold weather it shows too great a degree of dampness. This may come from the ground floor, or lack of ventilation and sunlight. If a soil floor is used, there should first be filled in several inches of broken rock. On top of this may be placed a coating of cinders, and over the cinders a layer of soil. The soil floor at its best is hard to keep clean, dry and free from odors. Cement makes an excellent floor, as it can easily be washed. Over the cement should be spread an inch or two of straw or hay.

Comfortable roosts.-Fowls spend much time on the roosts. It is therefore important that the roosts be comfortable. Roosts may be made from two-by-two-inch stuff, rounded on the upper edges; they should be placed about two and one-half feet from the floor. Eight inches below the roosts should be a removable board or floor to catch the droppings.

Nests.-One nest should be supplied for every four hens. The nests may be built in a series along the side, 
just under the eaves if these are not too high. Hens lay best in a secluded place. The nests should therefore be covered, and sufficiently enclosed to make them partially dark. Openings through the outer wall large enough to admit the hand into the nests will allow the gathering of the eggs without entering the building. Care must be taken, however, to provide a way to close these holes so that drafts may not strike the nests.

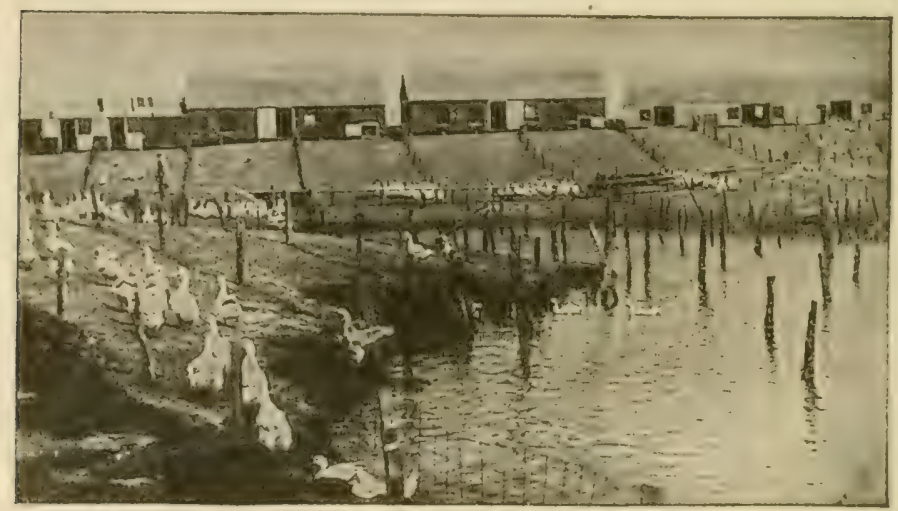

Colony houses and runs for ducks.

Colony houses.-Colony houses are small buildings intended for from fifteen to twenty-five fowls, and are movable. They may be constructed on the same plan as the larger building, and are placed on sills or runners so that that may be dragged from place to place with a team. Poultrymen who use colony houses move them frequently, thus securing better hygienic conditions. The colony house is especially desirable for hens with broods of chickens. Many large poultry raisers use both the permanent building and the colony house for their flocks. 


\section{Poultry Diseases}

Thie poultryman's aim should be to prevent diseases rather than cure them in his flock. For a fowl sick with any serious disease is hard to treat, and should usually be killed at once to save time in caring for it and the danger of infecting others.

Sanitation in the poultry yard.-Chickens are subject to a number of diseases that depend chiefly on lack of cleanliness around the premises. Lice and various parasitic mites attack little chicks or older fowls alike. Frequent whitewashing of the poultry house, washing the roosts with kerosene, and spraying with kerosene emulsion such as is used for fruit trees, are some of the preventatives for these pests.

A simple and effective lice powder is made of one pint of tobacco dust mixed with two quarts of fine road dust. Sulphur may be used in place of the tobacco dust, and finely sifted hard coal ashes in place of the road dust. The soil of a poultry yard should occasionally be sprayed with kerosene emulsion, or coated with whitewash after all refuse has been removed. If the ground is plowed or spaded late in the fall and allowed to freeze during the winter many parasites and disease germs will be destroyed.

White diarrhea.-This is a disease affecting young chicks within the first four days of their life. They are n.ost subject to attack the first twenty-four hours, and immune after ninety-six hours. The disease is caused by a bacterium found in the egg laid by a hen that carries the germs in her body. It may also be caught by contagion from chicks that have the disease, or from contact with incubators where the germs have lodged. There is no successful remedy. A good measure of prevention is to keep incubators, brooders and all feeding utensils disinfected. 
Gapes.-Gapes is another disease attacking young chicks. It is caused by a small worm picked up from the soil. The worms attach themselves to the inner walls of the windpipe, where they draw their food from the blood of the chick, thereby weakening it, and also clogging the passage so hat the chick gasps for breath.

Here again prevention is a question of sanitation. If the soil is free of the worms, there will be no gapes in the chickens. It is well, therefore, to keep the young chicks on clean new ground on which former broods have not been raised.

Cholera.-Several different kinds of germs commonly found in the intestines of chickens may, under certain conditions, cause diseases known as cholera. True chicken cholera is caused only by one particular germ, however. Cholera is contracted by contact with fowls sick with the disease, by germs carried by new birds brought into the flock, by germs brought by wild birds that alight in the poultry yard, or dogs or other animals that roam from place to place.

It does not pay to try to cure fowls that $\mathrm{r}$ ave contracted the disease. It is best to kill them at once, burning or deeply burying the bodies. Care should all center on prevention. First of all, the flock must have sanitary surroundings-good air, sunshine, quarters that are dry and clean, and should have suitable food.

The poultry house and yard must be frequently disinfected. New fowls brought into the flock must be kept by themselves for a week to make sure they do not carry infection. Stray animals should be shut from the chicken yard. The careful following of these simple precautions will greatly lessen the danger from chicken cholera.

Roup.-This is but another name for a kind of contagious catarrh among poultry which closely resembles in- 
fluenza, or grippe, in man. Roup is thought to be contracted only by contact with infected birds. It attacks the mem-

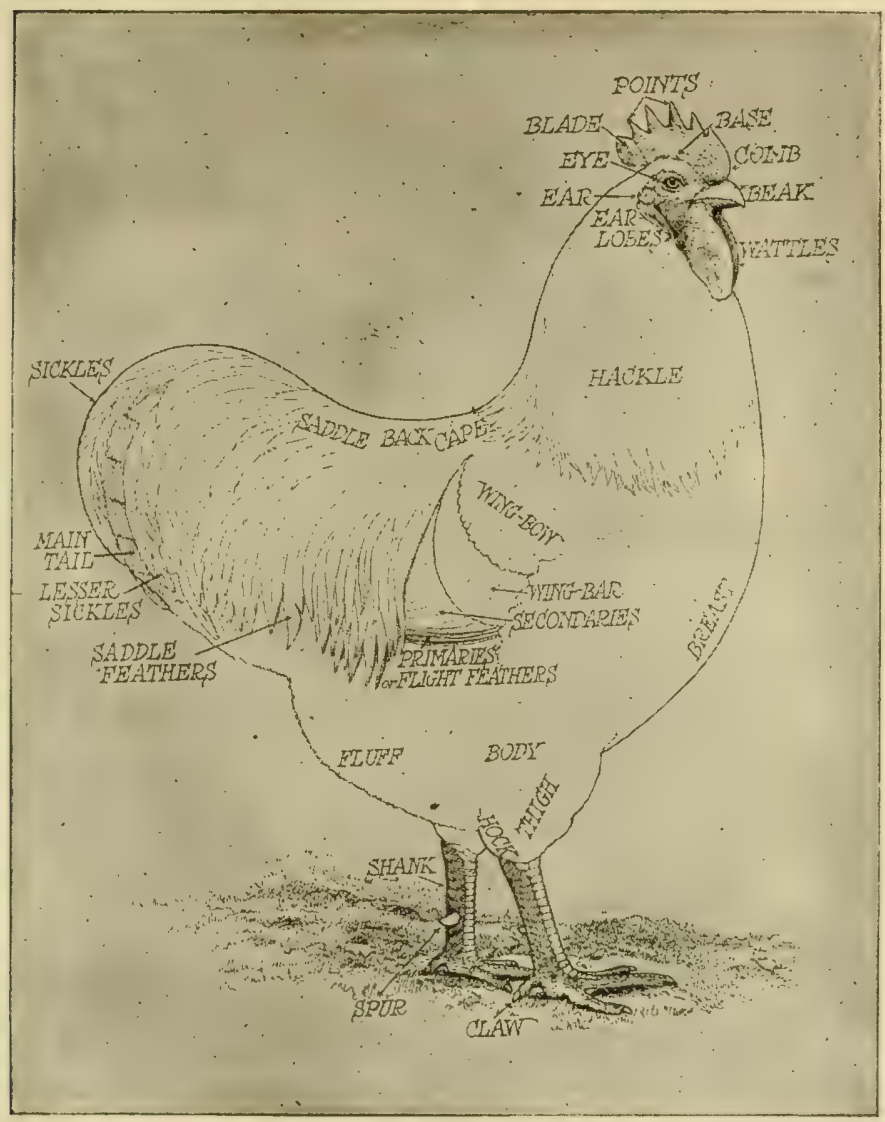

The parts of a chicken.

branes of the eye, mouth and throat, causing inflammation and a sticky discharge. The disease is accompanied by high fever. Roup may be brought into the flock by newly 
purchased birds, by fowls that have been taken to poultry shows, or by pigeons or other wild birds.

Roup is one of few poultry diseases that may be successfully treated. The sick fowl should be separated from the flock and given a warm, dry, well-ventilated place. All the affected parts, should be washed with some antiseptic mixture. This may be done with a spray, or by plunging the head into the liquid wash. The following are suitable washes:

1. Boric acid, 1 ounce; water, 1 quart, or

2. Permanganate of potash, 1 dram; water, 1 quart, or

3. Peroxide or hydrogen 1 ounce; water, 3 ounces.

\section{TOPICS FOR INVESTIGATION}

1. Taking into account both what the chickens on your farm are fed and what they pick up, make a list of what goes into the ration of your flock. Compare with the rations given in the chapter. Is any element lacking in what your chickens are getting?

2. Estimate as carefully as you can the value of the feed given your chickens in one year; now estimate the value of the eggs and meat yielded by your flock. What do you conclude? Would it pay to keep a strict account of the expense and income of your flock for several months or a year, so you would know how you are coming out?

3. Estimate as closely as you can the number of eggs produced in a year by your flock. How many eggs does this average per hen? Is this a good average?

4. If the average egg production from your flock is low, what is the cause: breed, age, care, or feeding? What would need to be done to improve the record? How many hens have you more than two years old?

5. Suppose you have for market fifty chickens that, without special fattening, will avẹrage five pounds each, and will bring ten cents a pound. Now also suppose that by two weeks of crate or close-yard feeding you can increase the average weight one pound for each bird, and get 
fifteen cents a pound for the lot. If the feed used is just balanced by the increase in weight, what would be the gain from fattening?

6. Select several fertile and several infertile eggs, and place them where they will keep at a temperature of eighty: to ninety degrees; examine with the candler after twentyfour hours: after forty-eight hours; after seventy-two hours: after ninety-six hours. What do you conclude as to the keeping qualities of fertile eggs, and of infertile eggs?

7. Make a drawing of your farm poultry house, showing all doors, windows, roosts, dropping boards, nests, etc. How does the building compare with the requirements given in the chapter? What needs to be done?

8. Talk with your father and mother about allowing you to take charge of a part or all of the chickens for a season, sharing the income. Then study all the helps you can find, and make a record for yourself and high profits for both.

9. Show proper methods of keeping poultry records. Include in the items, cost of labor, feed, marketing, parcelpost cases, egg production, receipts from spring settings of eggs, cold storage costs, and poultry equipment.

10. Show on the map of the United States the poultry sections, and indicate the poultry production both in number of poultry of various kinds and the egg production, as shown in the last census report.

\section{Poultry Demonstrations}

1. Demonstrate how to make equipment of various kinds, such as water and feeding troughs, colony house, trap nests.

2. Demonstrate how to test eggs by candling, using a pasteboard box and a lamp.

3. How to pack eggs to ship by parcel-post and for cold storage.

4. How to operate an incubator.

5. How to handle a sitting hen. 


\section{Poultry Play Contests}

1. Egg race, conducted on the same plan as potato race.

2. Poultry judging contests. Use score-card.

3. Egg scoring contest. Use commercial score-card.

4. Breed variety naming contest.

5. I)rawing contest. In this contest all kinds of equip-

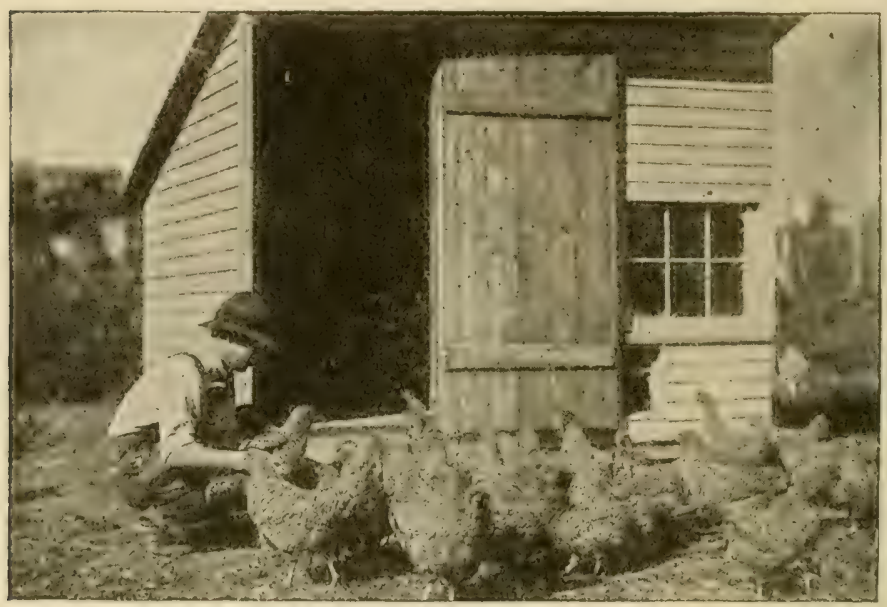

A Minnesota club boy with his fock and colony house.

ment, different breeds of poultry, poultry houses, runs, etc., may be used as a basis.

\section{Poultry Club Project}

One of the most interesting club projects to be undertaken by the boys and girls is the poultry club work. The - project may start with a setting of fifteen eggs, or the management of a pen of chickens consisting of seven pullets and one cockerel for a season or a year. 
A four-year project.-The poultry club work should include, if possible, a four-year project in order to encourage the use of the first year's results to the greatest possible advantage. The second year club members should raise at least fifteen pure-bred pullets and two cockerels, and hatch at least three settings of eggs from the fifteen pullets. The third year the project should be based on twenty-five pullets and two cockerels and the hatching of at least five settings of eggs. The fourth year, fifty pullets and three cockerels and the hatching of at least six settings of eggs.

Exhibit and award.-For the first year club members must agree to exhibit one dozen eggs from the club poultry and a pen of at least five chickens-four pullets and one cockerel-and each subsequent year, two dozen eggs and a pen of at least four pullets and one cockerel at the state, district or county fair. The basis of award for each succeeding year may be as follows:

1. Number hatched (1 point to each egg in first course, or

1 point for 3 chicks in second course)

2. Number of live chicks at end of 10 weeks (1 point for each chick in first course, or 1 point for 3 chicks in second course)

3. Number of cockerels marketed, at --.-months of age;

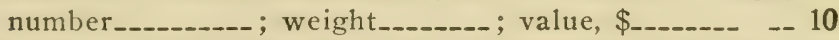

4. Number of birds remaining and total weight of birds_.- 15

5. Profit on investment (total value at local market price, less cost of feed, setting of eggs, labor and equipment) 15

6. Score-card applied to birds with reference to quality,

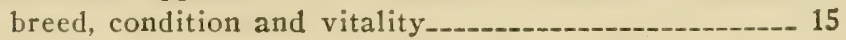

7. Equipment: character of lot, pens, fence, feeding and

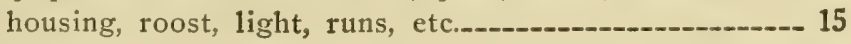

Total score.

It is recommended that whenever possible a pen of chickens be kept on the school grounds as property of the school, and turned over to the care of certain club members during the summer vacation period. 



\title{
PART V. FARM ECONOMICS
}

\author{
CHAPTER XXIV
}

\section{FARM AND HOME MANAGEMENT}

FARMING, like banking or running a railroad, requires good business management. Not hard work alone, but careful planning is necessary to success. Brains are coming to be quite as essential as muscle on a modern farm.

\section{Planning the Farm and Its Work}

In Europe, land is high and labor cheap; in the United States, land is comparatively cheap and labor expensive. The first principle for the American farmer therefore is so to select his farm and its enterprises as to make the best possible use of the labor available upon it. This is to say that the work should be so diversified as to give the largest possible number of working days during the year to the family, hired help, teams and machinery. Idleness soon eats up the profits of labor, whether it be man, beast or machine that is idle.

Selecting and planning the farm.-The farm should be carefully selected with reference (1) to its soil; (2) its adaptability to the enterprises to be entered into, such as stock raising or cropping; (3) its nearness to markets, school, church and neighbors; (4) the length of season and 
favorable climate; (5) its general suitability for being made into a pleasant and profitable homestead where an attractive home can be established.

The equipment.-With the nature of the farm enterprises in mind, the buildings, fences, divisions of fields and all other improvements should be planned with great care to fit into the general project. The machinery should be adapted to the soil and the crops and should receive the best of care. Too much machinery means too large

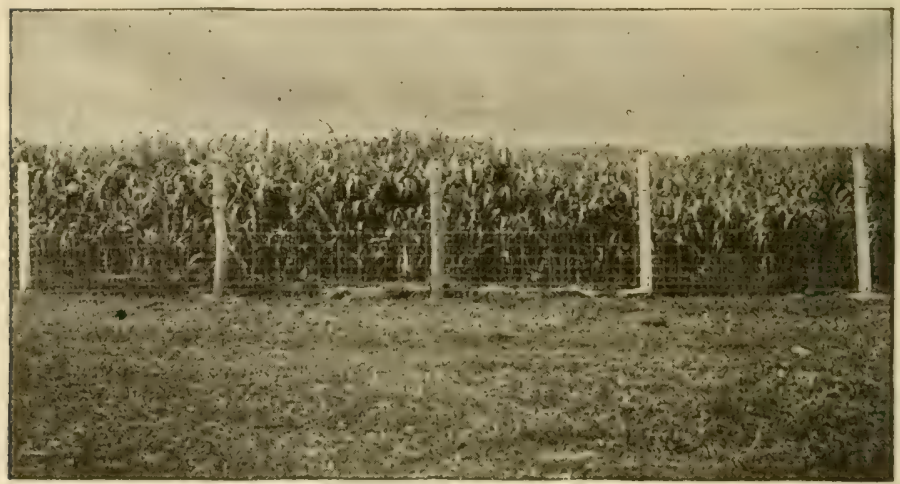

It pays to build good fences.

an investment, and too little means poor farming and loss of labor.

Crops and animals.-Many farmers are wearing out their soil and obtaining poon crops because of lack of sufficiently diversified farming. They do not manage well if they neglect to include in their system the legumes, orchard, garden and wood-lot products, or other crops adapted to their locality. Or, perhaps certain crops are raised or animals kept even at an actual loss, thus neutralizing the profits on other crops or animals. This all suggests the need of better management on such farms. 


\section{Administration of the Farm}

The general tendency among American farmers is to introduce the handling of too many enterprises and the cultivation of too much land. Our farms are larger than those of any other country, and the amount produced per acre less, than in most other countries.

Planning to get the most out of labor and soil.-Good administration gets the most out of every day of labor and out of every acre of land. Each piece of work is carefully planned. Fields are tilled and crops harvested at the right time. A faulty machine is repaired before it breaks down. Unprofitable cows and horses are disposed of and not kept at a loss. Fertilizers are used whenever they will pay. Gardens and orchards are sprayed when necessary. No poor seed is ever planted. Herds and flocks are kept in good health by care and sanitary conditions. The home is comfortable, convenient and well equipped. Members of the family are given opportunity for recreation and amusement as a rest from labor.

Farm bookkeeping.-Every enterprising farmer should keep a system of records or book accounts. These need not be elaborate, but they must be accurate. Without this it is impossible to determine the sources of profits or losses, and hence impossible to manage crops or stock intelligently.

A system of book accounts will show whether the farm is returning to the owner fair wages and reasonable interest on the investment. A farmer who can make average day wages, and in addition five per cent. interest on the money invested, is ranked as a good farmer. Many make much more than this, while others make less.

The set of farm books should show an inventory at the beginning of the year of all stock, grain, roughage and the like on hand. At the end of the year another inven- 


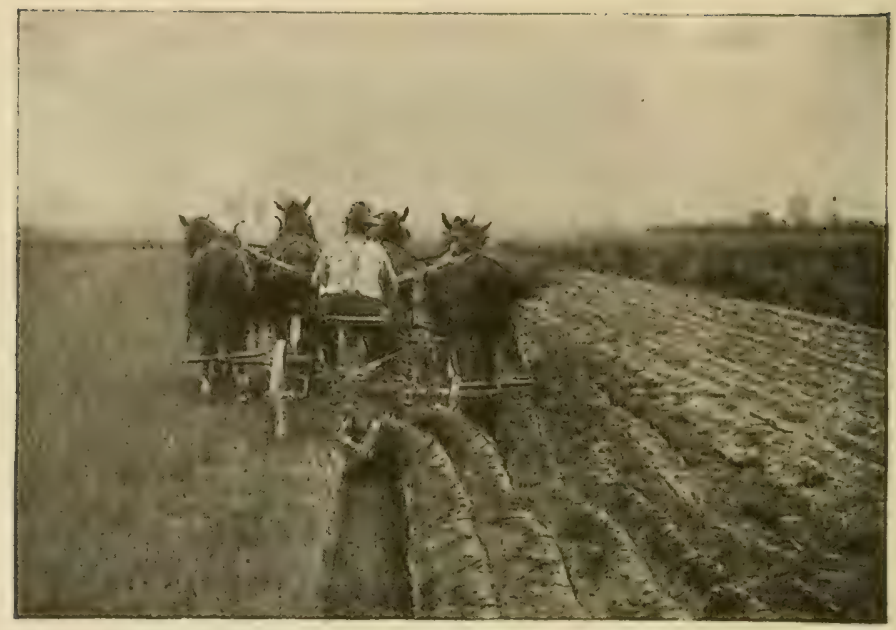

Good machinery is a profitable investment.

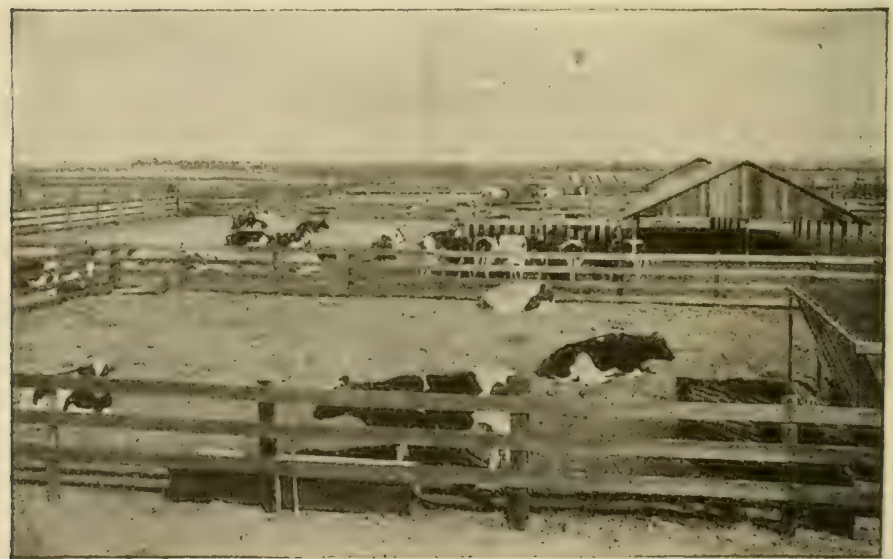

Well-arranged cattle yards. 
tory, with an itemized cash record, one list of bills orced others, and another list of bills due from others will serve the purpose very well on the average farm.

Marketing farm products.-Farmers find that it pays well to give careful attention to the grading, crating and standardizing of farm products for the market. It is good business as well as a matter of pricle to establish a uniformity of standard, using a particular type of box, crate or parcelpost pack marked with the owner's special label or trade mark. Merchants, packers or customers will soon show their appreciation of a standard product by being willing to pay more for it than for ungraded products.

The farmer's need of information.--Intelligent handling of farm business requires that the farmer should be thoroughly abreast of the times in information. He will need a daily paper giving market quotations and crop reports. He should also be familiar with the best farm journals, a few standard books on agriculture, and the bulletins and circulars of the United States Department of Agriculture and his state college of agriculture and by means of these be able to obtain much of daily value for all farm enterprises.

Ten important points in farm administration.-Doctor IV. J. Spillman, of the United States Department of Agriculture, gives the following factors as underlying successful farming:

1. Low real estate prices for the land cultivated.

2. Production of commodities for which the supply is less than the demand.

3. Management of the business on as large a scale as capital and managerial ability will permit.

4. Production of commodities of the highest quality.

5. A reputation for reliability.

6. Location for good markets, and ability to buy and sell profitably. 
7. Keeping only animals of highest productive capacity.

8. Large yields with relatively little labor and fertilizer.

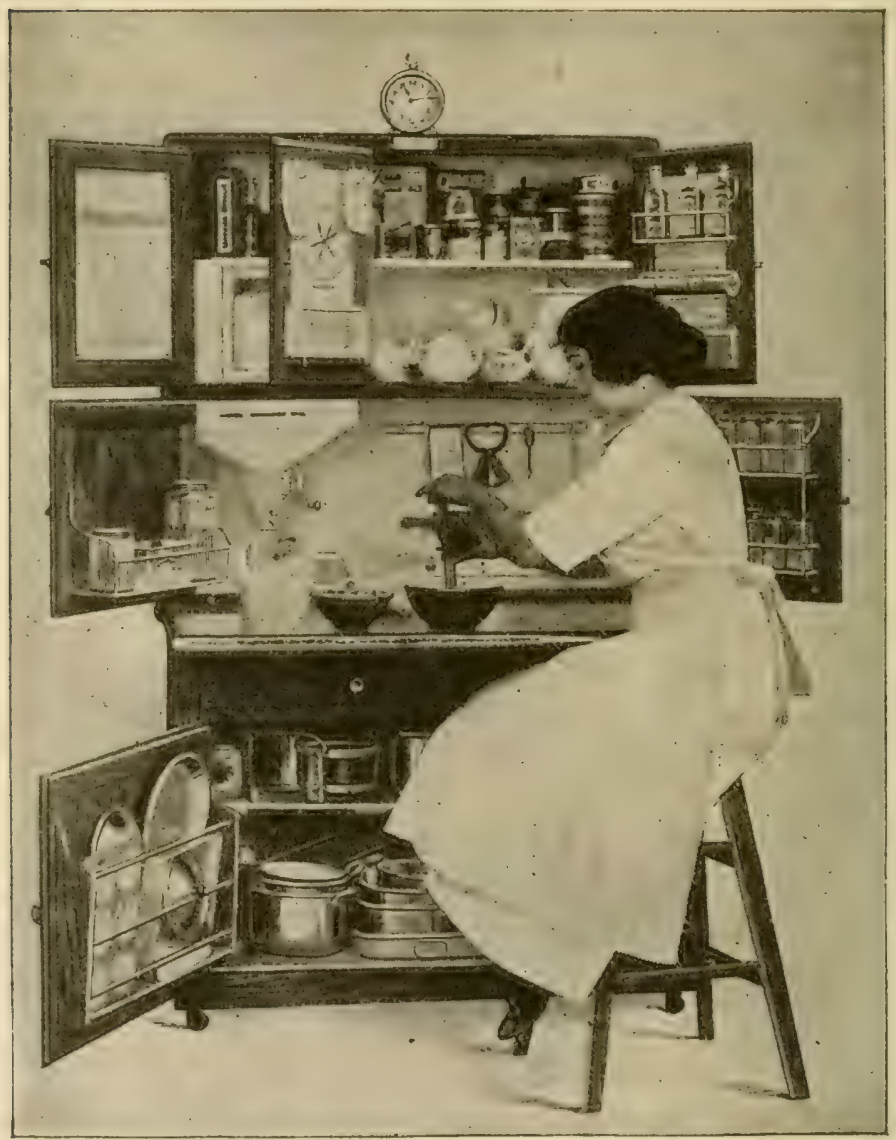

A kitchen cabinet and young bouse mistress.

9. Production at low cost.

10. Production of staple commodities for permanent profits. 
The following ten commandments for southern agriculture, as taught by the late Doctor Seaman A. Knapp, will be of value to all who are interested in southern farm management.

\section{TEN COMMANDMENTS UF AGRICULTURE}

"At an early period it was found necessary to evolve from the mass of ethical teaching a few general rules for living, called The Ten Commandments, by which a man could be moral without going through a course of theology. Just so, in order to instruct the average farmer how successfully to conduct his farm operations so as to secure a greater net gain from the farm, it is necessary first to deduce from the mass of agricultural teachings a few general rules of procedure. They are called The Ten Conmandments of Agriculture, by the practice of which a man may be a good farmer in any State without being a graduate from a college of agriculture."

1. Prepare a deep and thoroughly pulverized seed bed, well drained; break in the fall to the depth of eight, ten or twelve inches, according to the soil with implements that will not bring too much of the subsoil to the surface (the foregoing depths should be reached gradually).

2. Use seed of the best variety, intelligently selected and carefully stored.

3. In cultivated crops, give the rows and the plants in the rows a space suited to the plant, the soil and the climate.

4. Use intensive tillage during the growing period of the crops. 
5. Secure a high content of humus in the soil by the use of legumes, barnyard manure, farm refuse, and commercial fertilizers.

6. Carry out a systematic crop rotation with a winter cover crop on southern farms.

7. Accomplish more work in a day by using more horse power and better implements.

8. Increase the farm stock to the extent of utilizing all the waste products and idle lands of the farm.

9. Produce all the food required for the men and animals on the farm.

10. Keep an account of each farm product, in order to know from which the gain or loss arises.

\section{TOPICS FOR INVESTIGATION}

1. Name all the different enterprises on your home farm.

2. What is meant by seasonal distribution of labor: Name some of the things that a farmer and his men can do on rainy days in the summer and on stormy days in the winter.

3. Make an inventory of your farm supplies at thc present time, such as stock, machinery, grain, hay, etc. Make a list of purchases in these lines during the last year. Make a list of the sales. Talk with your father about lieeping under his direction a set of farm records for a year.

4. Choose some farm in the neighborhood and, under the teacher's direction, make a plan for reorganizing its management as to cropping, stock, machinery, buildings. drainage, laying off of fields, fencing, etc., with a view to better results.

\section{The Farm Home}

Successful farming must make the home the center of all interest and effort. The final purpose of increasing the fertility of the soil, raising good crops, and producing fine 


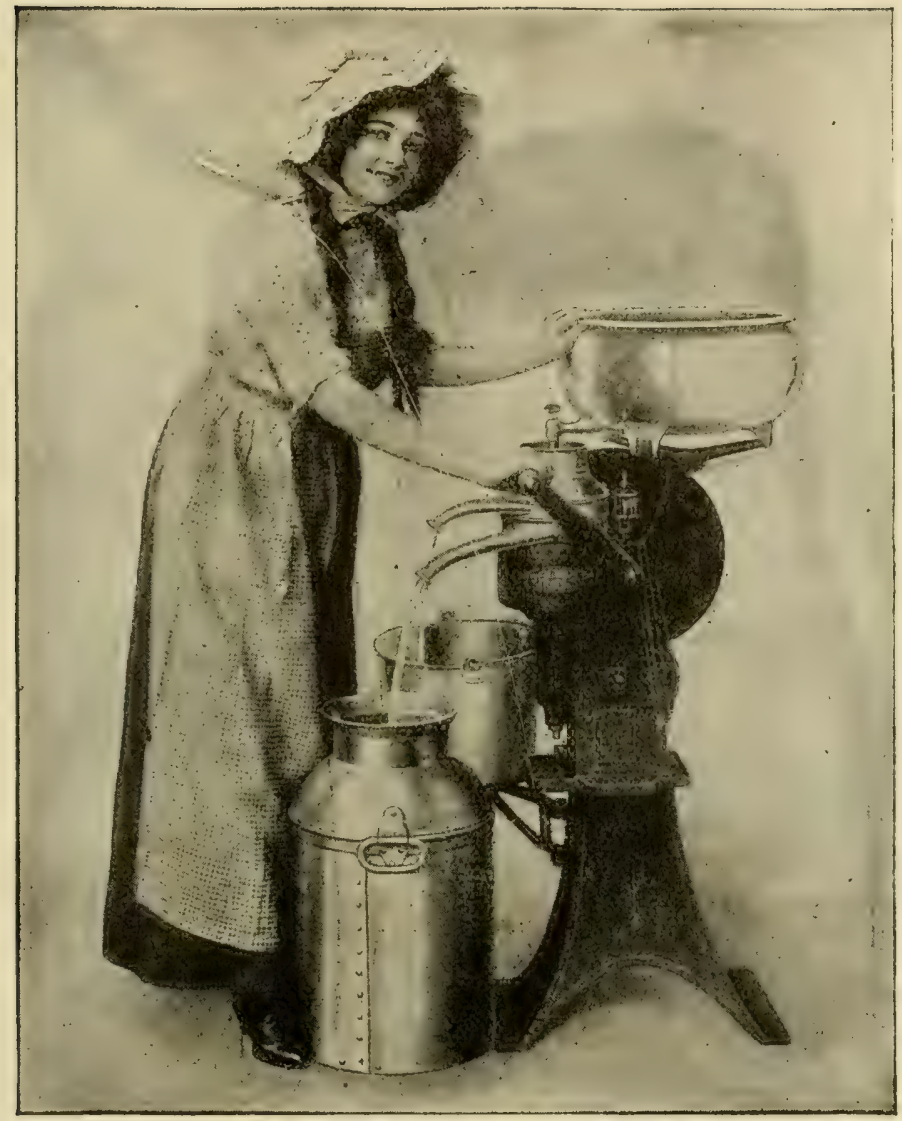

A hand separator. 
herds and flocks is to make a better home thereby. Little is gained by making more money, buying more land and raising more stock if the home is not made to share in the prosperity.

The farmhouse.-The farmhouse should be comfortable and attractive. There is little excuse in this day for building houses that are ugly and repellent; for even modcrate priced buildings can be planned to look well and at the same time be convenient and homelike. The home, whether large or small, should be one in which every member takes pride, and where happiness and contentment may reign.

Plan and equipment.-The farmhouse should be planned for convenience. For there is much hard work to be done by the housewife, and every care should be taken to save her time and strength. A well organized kitchen, with running water, a good sink with drainage, a movable kitchen cabinet, plenty of table space, cupboards, oil or gas heater for summer use, and a fireless cooker, is one of the first requirements in planning a house.

Practical conveniences.--The farm home should have a well lighted basement with cement floor, a fully equipped laundry with water-pipes and stationary tubs connected with a drain, to save the lifting and carrying of water. Suitable vegetable bins should be provided and so arranged that they may be cooled from the outside. A bathroom is a practical necessity on the farm as well as city home and can be supplied with water from an elevated windmill or cistern tank. A toilet and lavatory should also be a part of this equipment. The telephone now belongs to the farm as much as to the town, and electric lighting and power, even, are now being made available to many farms through the extension of trolley lines. All these things can be had with- 
out great cost. They require chiefly a spirit of enterprise and a little careful planning.

Labor-saving devices.-The wise farmer buys good machinery to till his land and harvest his crops. His wife should also have the advantage of modern labor-saving devices in her work. The best of cooking utensils, fruit and

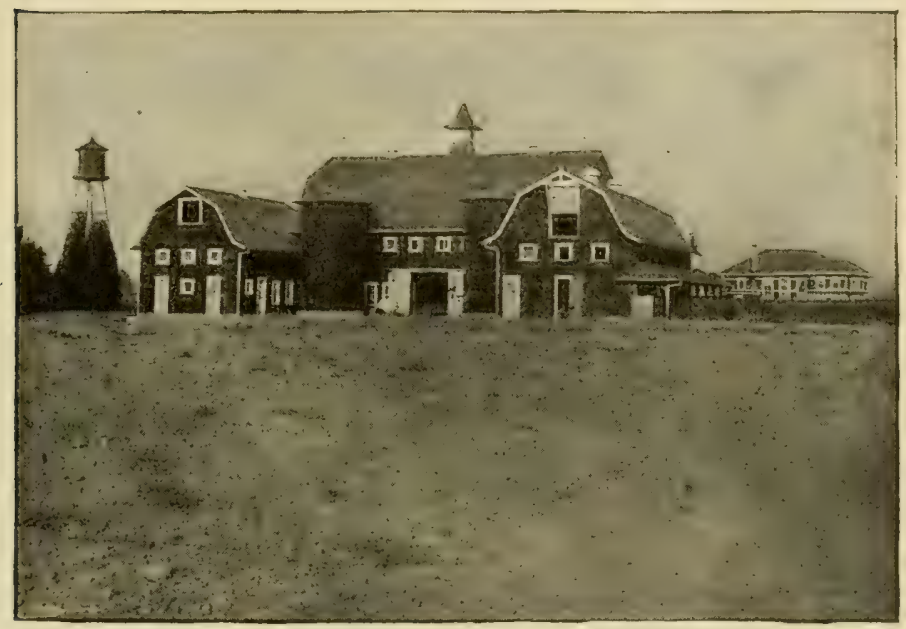

A fine homestead, but lacking in trees.

vegetable canning outfits, automatically heated flat irons, cleaning devices, hardwood floors, rugs and other similar helps to good housekeeping should not be wanting. For such equipment now belongs in every modern home, and will save much time and drudgery.

Recreation and culture.-Most farm homes can afford a supply of good books and magazines. These lead both to education and enjoyment. Good pictures and well decorated rooms also add much to the home spirit. Musical instruments are within the reach of thousands of farm homes, 
and prove one of the best of investments. Many interesting games can also be had at little cost.

The back yard.-The back yard should be quite as clean and attractive as the front yard. No refuse or litter, chicken coops, garbage heaps or mud-holes should be tolcrated. Closed garbage cans should be used, and everything done away with that will attract flies or mosquitoes, or be the breeding place for disease germs.

Drainage.-No farm house is complete without a drain leading out through the basement and on to a cesspool some distance from the house. Cesspools can be constructed at almost no expense except for the labor, and so made as not to endanger wells in the vicinity.

\section{Other Farm Buildings}

Much time and labor can be saved by a proper arrangement and placing of farm buildings. While barns should not be located too near the house, neither should they be so far away to cause unnecessary steps in going back and forth.

Making a plan.-Before barns, poultry houses, hoghouses or corn cribs are erected a plan for the whole system of buildings likely to be needed should be made. The distance of carrying feed, water and milk should be carefully considered, and all other conditions taken into account in placing the structures. The buildings themselves should be planned with the greatest convenience and economy of labor in view.

Barnyards.-The appearance of a barnyard is one of the best tests of a good farmer. The yard should, first of all, be clean and free from filth. All low places that collect pools of water should be filled. Manure should be cleaned up and spread on the fields. No old machinery, 
piles of boards, and scraps of rubbish should litter the place. The entire set of farm buildings, yards and fences should show taste and good management and be pleasing to the eye. To accomplish this does not add materially to the expense of operating the farm; in the long run it does not even require more time than to allow the homestead

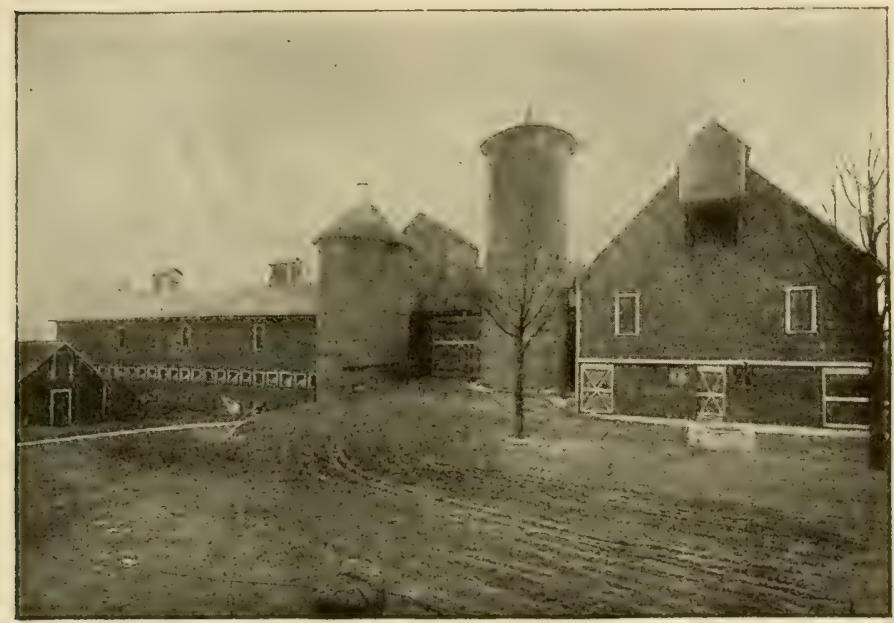

Well-kept barns.

to run at loose ends. A well kept homestead is largely a matter of thoughtful planning, and a desire to make the farm home attractive as well as profitable.

\section{TOPICS FOR INVESTIGATION}

1. Make a study of the plans for several farm homes, and discuss the advantages and disadvantages of each plan, finally selecting your favorite plan.

2. Take a look at your home door yard, and decide whether any improvement is necessary. Do the same for your barnyards. Is there old machinery or rubbish about 
that needs cleaning up? Are there any fences or gates that ineed repairing?

3. Make a plan of your farm homestead, locatirgs all! of the buildings. Now suggest any rearrangement that would make the homestead more convenient or attractive.

4. Make a plan showing how water could be brought by underground pipes from an elevated tank on yout windmill or silo, (1) to the kitchen of your house, and (2) to your barns. Also make a drawing of a drain leaking from your basement to a cesspool; show a plan also of the cesspool. What is a septic tank?

5. Consider carefully what practical project you could carry out for the improvement either of the appearance or the convenience of your farm homestead, and talk with your father about undertaking it. Show a detailed estimate of any expense involved, including dabor. 


\section{CHAPTER XXV}

\section{THE HOME GROUNDS AND WOOD LOT}

NO home place is complete without trees, plants and 1 shrubs. Even with costly and pretentious buildings, a homestead may look barren and inhospitable from lack of the decorative and comfortable effect of shade trees, groves, climbing vines and blossoming plants. One should learn not only to make his farm pay but to make it interesting and attractive.

\section{Beautifying the Home Grounds}

The house lot and lawn of the farm home can be made especially beautiful and interesting. For there is more room on the farm than in the town or city, and the trees and plants needed for its decoration will cost but little except a reasonable amount of care. Well kept grounds add a great deal to the market value of a farm, and contribute even more to the peauty and comfort of the home.

Plan for setting.-To produce the best results, the setting of trees and shrubbery should follow some complete and well devised plan. The effect of the most beautiful vegetation may be lost by careless or improper placing. When used for decoration or shade, trees should usually not be set in rows, unless along a driveway or boundary line; nor should they be so blocked together that they shut off the view of the house. They may stand as single isolated specimens, or in irregular groups. Trees often are 
placed too near the house, thus excluding the sun and causing dampness.

Shrubs, likewise, appear to best advantage when set in clumps, or irregularly to make a border for the lawn. Climbing vines can be used to screen porches, cover garden fences, hide unsightly sheds and outbuildings, or clamber over stumps, rocks or banks.

Selecting varieties.-One can select from an almost

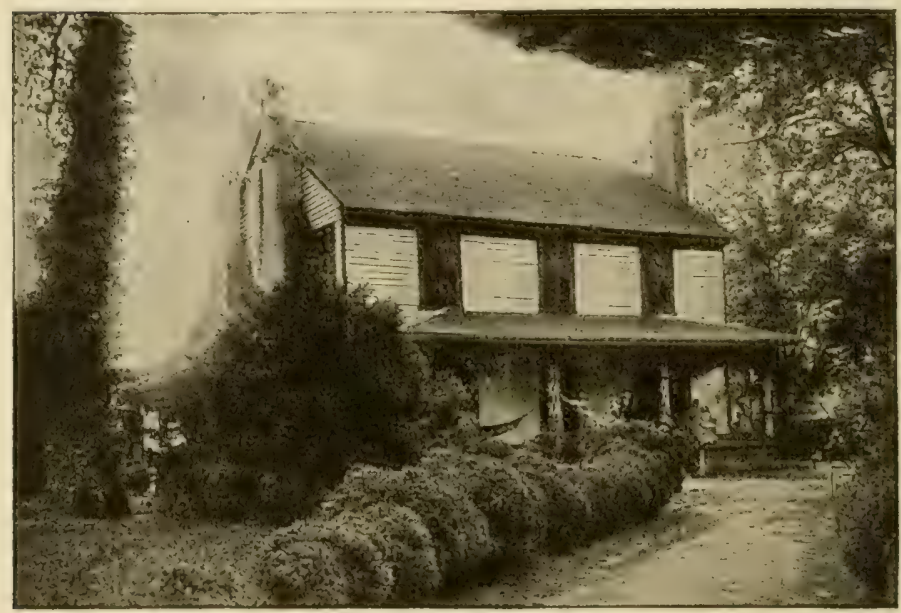

The shrubs and trees add much to this farm home.

endless variety of trees, shrubs and vines. Each variety has its own peculiar individuality, which should be studied and known before the selection is made. A plant, once given a place on the grounds, becomes a permanent part of the home-place, and should therefore be chosen with as much care as are our friends.

Shade trees should be hardy, well-shaped, broad leafed, grow to a good size, and attract no troublesome insects. Elms, maples, oaks, ashes, basswood, catalpa, locusts, nut 
and fruit trees, and, in the South, magnolias, the redbud and live oak, are among the favorites.

Shrubs are to be selected both for thes ioliage and flowers. With care, provision can be made for the appearance of blossoms during each month of the summer, and for an attractive variety of foliage throughout the season.

Flowering plants.-The plan for the home grounds

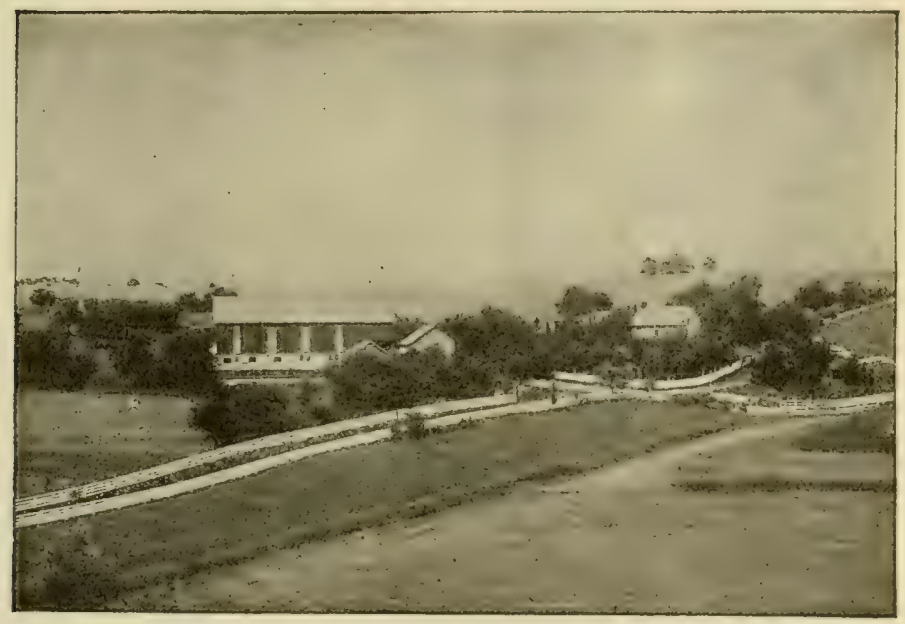

A fine homestead management, showing wood lot, orchard and a good set of buildings.

should include a few beds of flowering plants. Most of these may be perennials, which will require almost no care after the bed has become well established. With the addition of a few varieties of hardy bulbs for annual planting, beautiful effects can be produced with practically no cost and with the expenditure of very little time.

The lawn.-Nothing adds more to the appearance of a homestead than a well kept lawn. The lawn should first of all be well smoothed, the low places being filled and all 
obstructions removed. The soil should be rich and well drained. For the greater part of the United States, a mixture of blue-grass and red-top, with perhaps a small amount of white clover, makes a good lawn covering.

The lawn must be close-mown if it is to produce a pleasing effect. If allowed to grow up, the grass becomes tufted and coarse, besides looking ragged and unkempt. Farm stock should not be pastured on the lawn. Their trampling will produce unevenness that interferes with the lawnmower, and plants, shrubbery and young trees are sure to suffer from being browsed.

\section{TOPICS FOR INVESTIGATION}

1. Draw a plan of your home grounds, locating all the trees, vines and shrubs, and giving the names of varieties.

2. In your drawing also show the position, size and shape of all the flower beds, specifying the varieties of plants, and whether annuals or perennials.

3. Make a complete plan for the decoration of your home grounds, taking into account the trees, shrubs, and plants already set out. What varieties should be added? Are any trees or shrubs in such positions that they should be removed?

4. Make a plan for decorating the school grounds, specifying by variety each tree and shrub, and showing its location.

\section{The Farm Wood Lot}

Every farm place should have its own wood lot. It costs little to start, requires almost no care after the first year or two, and yields large returns.

Uses of the wood lot.-Poles, timbers and posts are constantly needed on every farm. When there is no wood lot to supply them, they must either be bought, or the farm suffer for their lack. And lumber, posts and timbers of every sort are becoming more expensive from year to year 
as our forests are being depleted. Fire-wood raised on the farm costs very much less than if bought in the matket, and so scarce is it becoming in many regions that it can not be had at all unless produced at home.

The wood lot can often be so placed as to serve for a

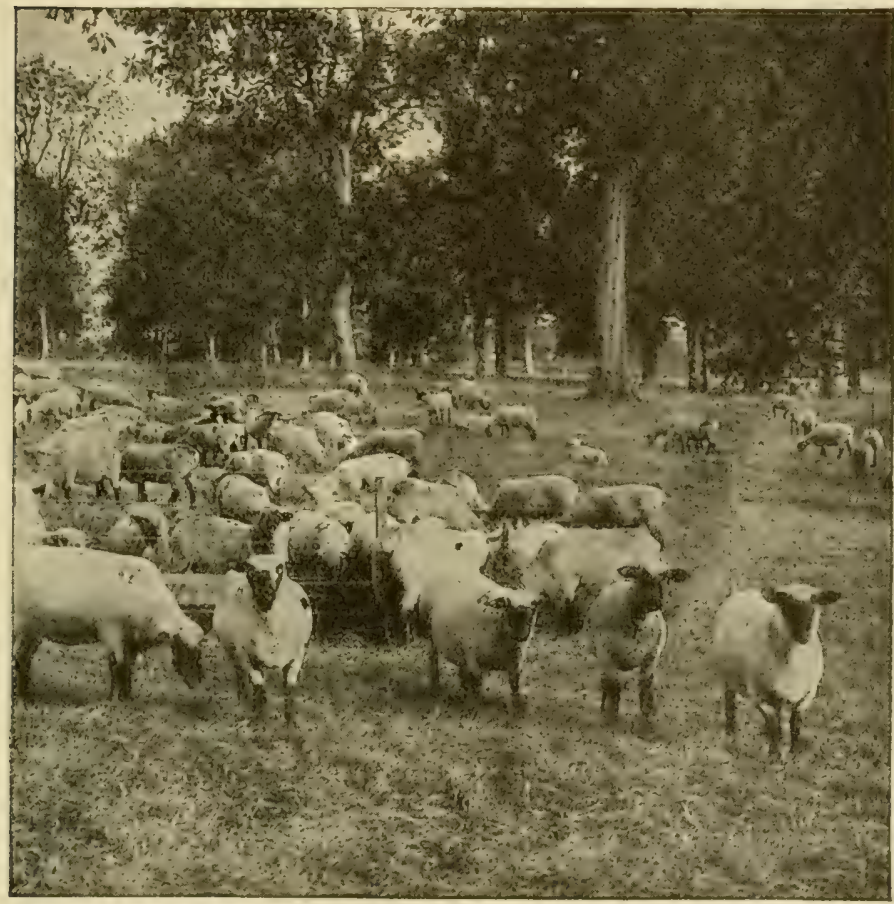

A good lot of Hampshire Downs and a fine wood lot. windbreak for the farm buildings, and at the same time add to the beauty and value of the homestead. When the trees are grown they afford welcome shade for animals, contributing both to their comfort and profit.

Birds are attracted to the wood lot, and from this shelter make sallies out upon the harmful insects that prey on 
crops or gardens. From the friendly tree-tops they also pour out their tribute of song.

The location and size of the wood lot.-It may not always be desirable to plant a large wood lot near the buildings. When such is the case, low wet places, steep hillsides, or small irregular pieces of ground not suitable for cultivation can often be utilized.

From one-half an acre to several acres of ground can profitably be set to trees on a fair-sized farm. While the

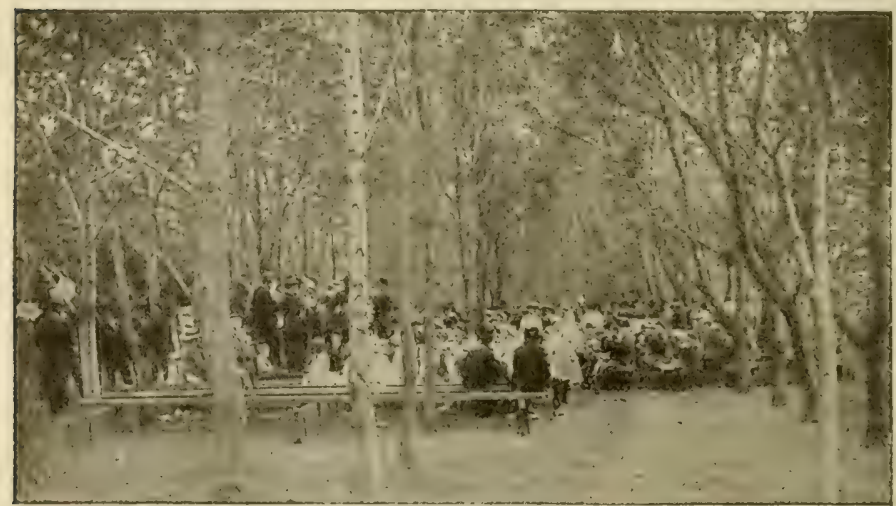

Using the wood lot for picnics and club festivals.

returns are not immediate as with other crops, yet the profit is reasonably sure in the end. Many far-sighted farmers are now providing for the fence posts and timbers they will need ten or twenty years hence by setting out and caring for trees in a wood lot. It is estimated that Minnesota farmers set ont a million trees in 1913 and in many other regions the movement is quite as marked.

Varieties of trees for the wood lot.-It is impossible to recommend definite varieties of trees for the wood lot, 
since this depends on the region and the use to be made of the timber. Some prefer to plant the faster-growing soft wood trees, while others are willing to wait longer for the harder woods to grow. An excellent plan is to plant a number of varieties. Not only will this allow a mixture of the slow and the fast growing trees, but provide a variety of timber suitable for different purposes of utility and comfort for the farm.

From the eastern to the middle western states the favorite trees seem to be the different varieties of maple, elm, oak, locust, ash, fir, basswood, hickory, walnut, boxelder, cottonwood, yellow poplar, catalpa, etc.

In the drier regions such as western Kansas and $\mathrm{Ne}$ braska, Oklahoma, Texas and Colorado, it is difficult to start successfully some of these varieties. Among the best drought resisting trees are the black locust, green ash, Osage orange and Russian mulberry. In the southern and far western states practically all varieties suitable to the North and East can be grown and many others besides.

Starting the wood lot.-The wood lot may be started, in the case of most trees, either by planting the seed, or by setting out young trees. A common method of starting a grove of hardy catalpa, for example, is to prepare the seed bed as if for corn. Catalpa seed is then planted, and the field cultivated for several years. The young trees are sometimes cut back to the ground after two years of growth for the purpose of producing straighter and more sturdy trees. The growth of the tree is not retarded by this process.

A seed bed for trees can easily be started, and the rrees transplanted to the desired positions when the seedlings are from one to three years old. A small seed bed will supply trees for a large wood lot. 


\section{Tree Enemies}

While most of the common trees are not subject to a large number of enemies, yet they must have reasonable care and protection if they are to thrive.

Farm animals.-One of the most common mistakes in starting young trees is to allow them to be exposed to stock. Cattle, sheep or hogs are sure to injure the trees by grazing upon the leaves and branches, by trampling them, or by rubbing against them. The wood lot should be fenced, and all stock excluded until the trees are well grown. Horses should never be tied to trees.

Weeds and sod.- Young trees are as easily injured as any other plant by weeds or grass. Many people seem to think that because large trees can take care of themselves against these encmies young trees can do the same. But trees once checked in their growth by the choking of weeds or sod will never fully recover.

Insect and fungous enemies.-Shade and timber trees are, on the whole, less subject to insect and fungous attacks than fruit trees. Yet occasionally even the most hardy trees succumb to such enemies. The elm, one of the healthiest of our trees, has recently suffered greatly in certain regions. The chestnut has also been seriously aflicted with a bark discase. Whole forests of fir have died in southern localities. Even the catalpa is subject to a fungous trouble at certain stages of its growth. Whenever a considerable number of trees in a locality show signs of disease, an expert should be consulted and his directions followed.

\section{TOPICS FOR INVESTIGATION}

1. Join with the teacher and class in making a collection of all the woods in your locality. Use seasoned woods for specimens when possible, selecting sticks two or three 
inches in diameter, and sawing them about four inches long. Split each specimen, then smooth and sanclpaper the flat side and ends and spread a coat of shellac over the fin-

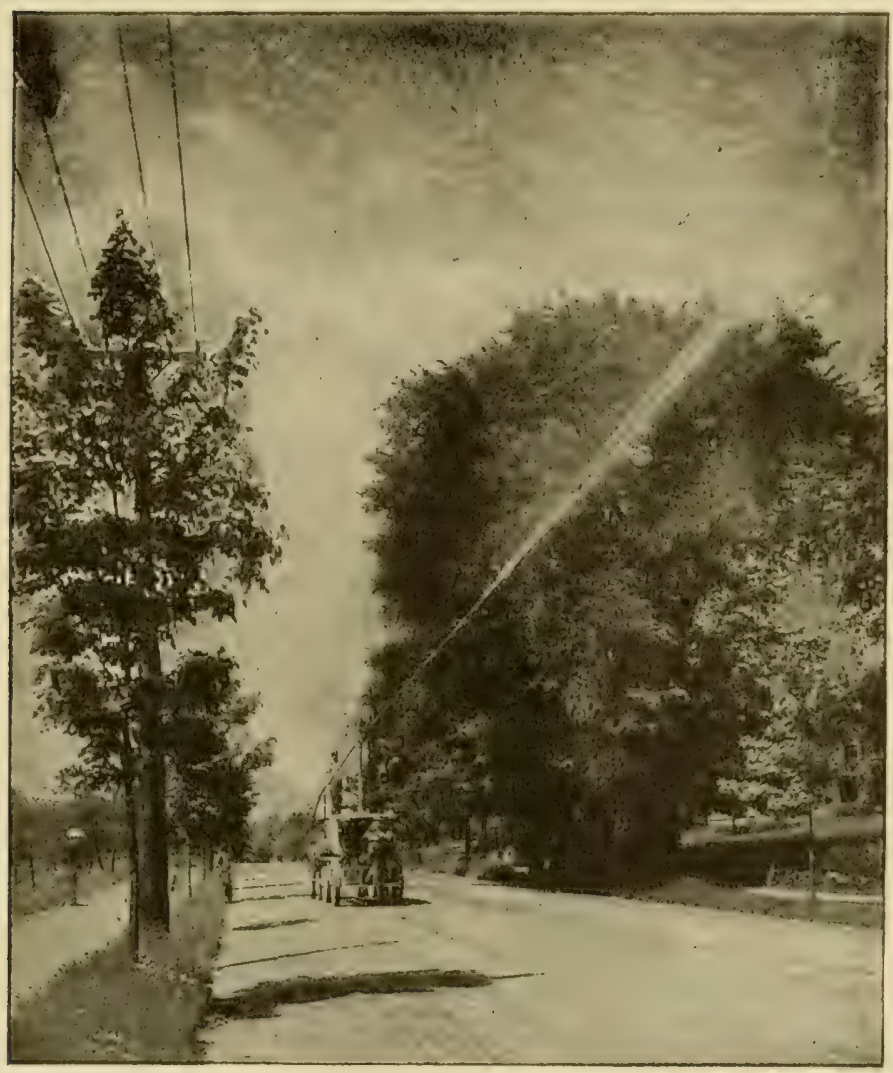

Power spraying of trees.

ished parts. Learn to identify each specimen both by the bark and by the texture and grain.

2. Gather and preserve in wide-mouthed bottles samples 
of the seeds of all the trees in your vicinity. Learn to identify these seeds. Plant some of each, and learn to identify the young plant of each variety. Consider the possibility of starting a tree seed bed on the school ground, where the seeds of the different trees can be planted and seedlings raised for study or replanting, either on the school grounds or at the homes.

3. How can you tell the age of a trec after it is cut down? Find some freshly cut tree and discover its age. Can you tell from the annual rings any years when the tree did not make a good growth?

4. Make a collection of the leaves of all the different trees available, and learn to identify them.

5. What is the difference between plain-sawn and quarter-sawn lumber? Look at different pieces of oak furniture, and decide whether the lumber was plain or quarter-sawn. Why does some hard pine flooring have a tendency to splinter up, while other does not?

6. Locate on the map of the United States the forest reserves of our country; the lumber producing sections.

7. Estimate the cost of producing a ten-acre wood lot of some prevailing trees of your section.

8. Write down the names of all the different trees you can think of common to your state, in the order of their importance to the farm.

\section{Demonstrations on Home Grounds and Wood Lot}

1. Demonstrate how properly to remove and transplant a shrub or bush.

2. Demonstrate how to make a tree graft; how to make a bud graft.

3. Demonstrate how to prune the different kinds of trees.

4. Show the proper method of spraying for different insects, diseases and blights.

5. Show how to treat the tree-trunk to prevent insects from passing from the ground into the tree.

6. Demonstrate different methods of tree surgery, such 
as repairing injured limbs and diseased and decayed spots. How does this compare with medical and surgical treatment of human beings?

7. Demonstrate how to lay off a lawn with a view to artistic arrangements for the lawn itself and as related to the home, buildings, pathway and roadway.

8. Demonstrate how to sharpen and set a fence post.

9. Show how to set a corner post and brace it.

10. Demonstrate how to make bird houses, bird baths, watering troughs, feeding platforms, etc., on the lawn or in the shrubbery, trees, and out in the wood lot, to encourage and help the conservation of bird life.

\section{Play Contests for Home Grounds and Wood Lot}

There can be no better way to arouse interest in the improving of home grounds and the planting and care of wood lots than to inaugurate a large number of play contests, related to this work. Practically all of the demonstrations outlined above can be so organized as to become very interesting play contests. Illustrations:

1. Tree naming contest.

2. Spelling contest from a list of names of tiecs, shrubs, plants and flowers.

3. Drawing contest, showing the plan and arrangement of lawns, wood lots and farm home grounds.

4. Wood collection and exhibit contest.

5. Manual-training contests, in which the pupils are to contest in making articles from wood, leaves, bark, buds and flowers.

6. Tree judging contest.

7. Lawn mowing contest, the same to cover a season and to involve not only the mowing of the lawn but its proper up-keep, repair and improvement.

8. Essay writing contest on the home grounds and wood lot. 


\section{Home Grounds and Wood Lot Club Projects}

A number of very interesting club projects can be organized in connection with the care and management of the home grounds, front yard, back yard, wood lot, trees, shrubbery, etc. The basis of award for these clubs will have to be modified to suit conditions. In general the award may be based on the following five points:

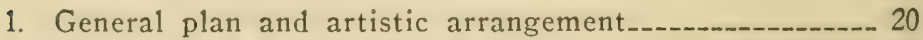

2. Management and methods employed during the season 20

3. Profit on investment or results based upon object of the project ---_---_-_- 20

4. Exhibit of products or appearance and results shown at close of project period--_-_-_-_-_- 20

5. Written story on "How I Did My Club Work"-_........- 20

Total score.--_-_-_. 


\section{CHAPTER XXVI}

\section{THE COUNTY AGRICULTURAL AGENT}

TWO new agencies have recently entered the field of ag1 ricultural education and rural development: These are (1) the county agricultural agent, and (2) the county farm burcau. The latter consists of an organization of the farmers of a county for the purpose of furnishing a kind of clearing house for agricultural information. The county agent is an agricultural leader whose business is to organize, lead, instruct and give expert advice to the farmers or to pupils and teachers of agriculture in the schools of the county.

\section{The Work of the County Agent}

First work in the South.-The advent of the bollweevil in the cotton-fields of Texas was responsible for the beginning of this work. So great were its ravages that in 1906 the United States Department of Agriculture put Doctor S. A. Knapp in charge of demonstration work showing how the pest could be exterminated. From this beginning there has been a very rapid growth of this type of work, until at the present time county agricultural agents are scattered all over the United States.

The county workers.-Men employed as county agricultural agents are required to be possessed of scientific information on the problems of agriculture. They are expected also to have had practical farming experience. Plans have already been made by which the county agent is assisted by a woman agent who will be thoroughly trained 401 
and fitted to advise and direct the girls and women in all matters relating to the making of better homes. Several hundred women agents are now at work in as many counties.

Organization of the county work.-The county agents live in the county and are supplied with an office where they may be consulted. They usually are furnished with some means of transportation so that they may travel about the county, from farm to farm and from school to school. In this way the county agents carry to the very door of the farm home and the public school the services of specialists. They are able to bring to those who can not go to college the help, advice and leadership of the best scientific investigators, and really make the farms a part of the campus, class rooms and laboratories of the agricultural college and demonstration centers of the United States Department of Agriculture.

Character of help rendered.-The work of the county agents is calculated to increase the profits of farming, and the comforts and efficiency of the farm home; to aid in conserving and building up the soil; and to encourage the advancement of community education and social interests. Like the physician or surgeon, the county agents are to be called when advice, treatment or preventative measures are needed. They plan for a system of demonstrations to show the best methods of managing the soil, preparing the seed bed, selecting and caring for seed, management and care of farm animals, organization and care of gardens and orchards, and the handling and conservation of farm buildings and machinery.

If a herd is stricken with tuberculosis, the hogs with cholera, or the corn-field with cutworms, the county agent should be notified and his help secured. If he is not able directly to give information and aid he will know where to secure assistance on short notice. In like manner the 
county agent will be of special assistance in planning the proper management of soils and crops when the seasons are too dry or too wet; in the best organization of farm enterprises; and in the management of all of the efficiency factors important to the success of American agriculture.

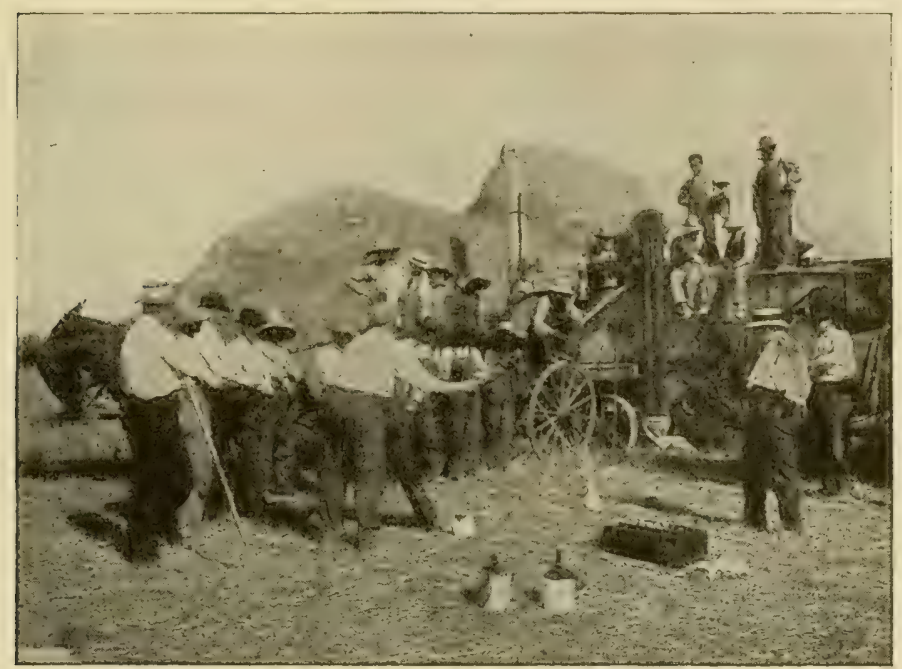

The county agricultural agent is discussing grain problems with the farmers at thrashing time.

\section{Financial Support}

The Smith-Lever law.-The county agent is usually supported in part by federal and in part by local funds. The Smith-Lever law passed by Congress made federal aid available for every state in the union beginning with the year 1914. The entire amount appropriated for the first year was four hundred and eighty thousand dollars, to be divided equally among the forty-eight states. The appropriation is gradually to increase until the federal government is con- 
tributing some four and one-half million dollars annually for the encouragement of agriculture.

The Smith-Lever law contemplates that the greater part of this immense fund shall be spent in supporting county agricultural agents, state and clistrict leaders, boys' and girls' club work, demonstration work in home economics, and other assistance in shaping and building up agricultural interests throughout the nation. The agricultural colleges and the United States Department of Agriculture are to cooperate in carrying out the provisions of the act.

Steps to be taken in securing a county agent.-The matter of securing an agent for a county should first be taken up with the state leader, whose headquarters are with the agricultural college of each state. $\mathrm{He}$ is in a position to assist in planning and conducting the campaign for an agent and can give information in regard to available sources of county, state and federal funds, and the amount of funds necessary properly to finance the movement. TVhen the county is ready for the appointment of an agent, the state leader will be able to recommend a man qualified for the work.

\section{The County Agent and the School}

The county agents seek not only to help the farmers in their immediate problems, but also to advance agricultural education in every possible way.

Help for the school.-Every agent desires to assist the work in agriculture in the schools of his county. In many instances the county agents and the county superintendents plan and carry on their work together. Teachers and pupils can always feel free to call on the agent for help or advice in connection with any agricultural club or individual project.

When it is impossible to reach the agent for a personal 
interview, the telephone or mail can be employed. Pupils and teachers should become acquainted with the agent personally, attend the demonstrations and public meetings, and study the experiments and investigations he makes. Think over carefully the work of the farm and if either you or your parents have problems that are annoying-troubles of any kind with soil, crops, or stock-seek the advice and help of the agent at once.

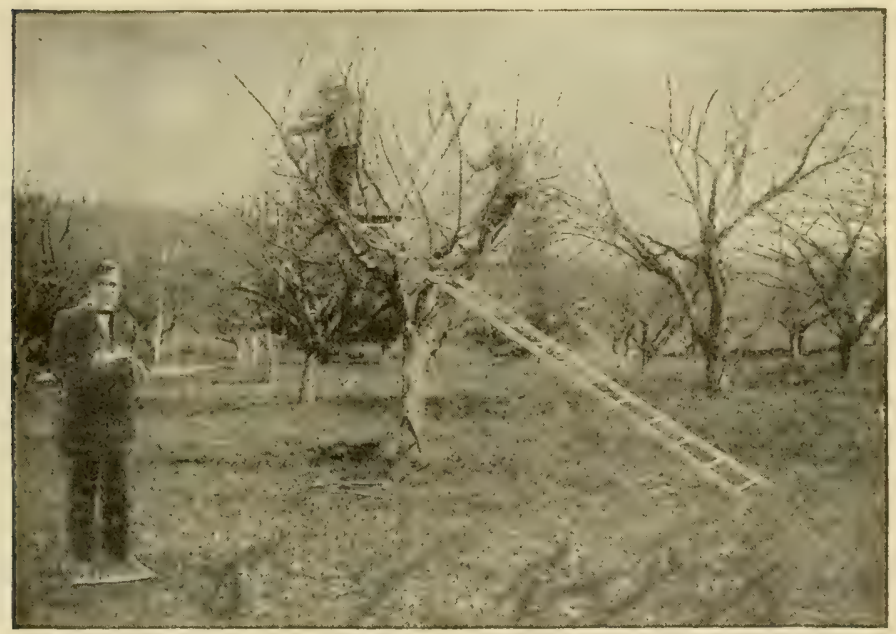

Apple club boys pruning orchard under direction of the county agent, Cortland County, New York.

Advice on club projects.-Club projects should be selected with great care. The county agent should be consulted as to the best project for the boys to undertake, and the best one for the interest of the girls and the home. All of the club projects outlined in this book will be of especial interest to the county agricultural agents and they will be glad to give encouragement and assistance to the work. They will help plan also the work of the manual- 
training classes in the rural and village schools so that it will fit into the needs of the farm, the garden and the home.

Special programs.-The county agent should be invited to the school, and especially in connection with the special programs of an industrial and agricultural nature. His help can be secured in the conducting of agricultural demonstrations, the judging of grains, fruits, vegetables and stock, and the organization of rural games and contests. His advice will be valuable in determining the basis of award and the methods of judging a contest. He should also be consulted with reference to suitable circulars and Farmcrs' Bullctins for correlation reading in connection with the agricultural and home economics studies of the school.

\section{TOPICS FOR INVESTIGATION}

1. Have you a county agricultural agent in your county? If so, who, and how long has he served the county? Where is his office located? Who pays his salary?

2. It was estimated that in one county the work of the agent increased the yield of corn by five bushels an acre in a certain year. The county is twenty-four miles square and eighty per cent. of the area is under cultivation. Of that under cultivation forty-five per cent. was in corn. What was the agent's help on the corn crop worth to the county, figuring corn at fifty cents a bushel?

3 . If your county has no agent, has the matter of securing one been discussed? Do you know what steps would have to be taken to secure an agent? How would the expenses have to be met? If you are not certain on these questions inquire of your state agricultural college or the United States Department of $\Lambda$ griculture.

4. What farm projects in your community need the advice of a county agent? Do you know of land that is foul or run down? Pastures that are weedy or dying out? Swamps that need. drainage? Orchards that do not bear 
profitably? Flocks or herds that are not profitable? Ravages of insects or diseases that cause severe loss? Hogs dying from cholera?

5. On what farm or garden project would you especially like advice from an agricultural agent in order to make sure of success the first year?

6. How much money is available this year from the Smith-Lever act for the county agent and farm demonstration movement? Upon what conditions is this secured and how is it administered? What part of this does your county get? (Secure a copy of the law from your congressman.)

7. Does your state college of agriculture have an extension department? If so, name the officers and leaders, such as director of extension, state agent in charge of club work, state agent in charge of county agents and demonstration work. (Write for its literature on club and extension work.)

8. To what extent do the Department of Education and the normal schools of your state encourage agricultural and home economic education? Do they have officials who supervise this type of work? If so, name them.

9. What is the County Farm Bureau? Do you have one in your county? Name its officers and agents.

10. What is the American Federation of Farm Bureaus? Where are the national headquarters? Who are its officers?

11. Name the secretaries of agriculture since its founding. How is it supported and what services can farmers secure from the Department of Agriculture?

12. Tell the history of some important agricultural movement, organization, or institution, such as "Boys" and Girls' Club Movement," "County Farm Bureau," "United States Department of Agriculture," "Farm Granges," "Farmers' Unions," "International Institute of Agriculture," Rome, Italy, "Rural Credit Societies of Canada," etc. 


\section{CHAPTER XXVII}

\section{FARM IMPLEMENTS AND MECHANICS}

\section{Importance of Implements and Tools}

NE of the most important and interesting phases of agriculture is the study of farm implements, their origin, history, utility, value, proper care and up-keep.

Tillage and tools.-Good crops and large profits usually depend upon wise management and proper tillage; and good tillage requires the use of tools adapted to the soil, the particular crops, and the condition under which the farming is done. It is poor economy to farm with unfit tools, or implements in poor repair. On the other hand it is possible to have too large an amount of money invested in farm implements and machinery. A number of the larger farm machines, such as corn harvesters, thrashing machines or shredders, can be owned cooperatively in a community and made to do the work of four to ten farmers instead of one. This will reduce both the first cost and the up-keep.

The care of machinery.-It is generally considered that a machine kept in good repair, and well housed when not in use, will last as long doing the work of five farmers as a machine owned by a single farmer and doing but onefifth of the work, if neglected and allowed to stand outof-doors in rain, snow and all kinds of weather when idle. There is no better test of the progressiveness and good management of a farm than the way the farm tools and machinery are treated. 


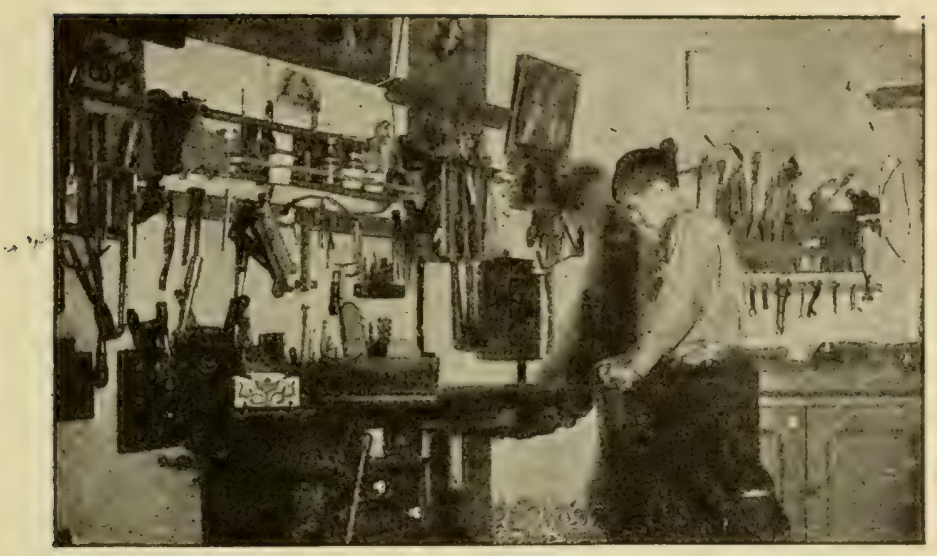

A young farmer mechanic with a well-equipped shop.

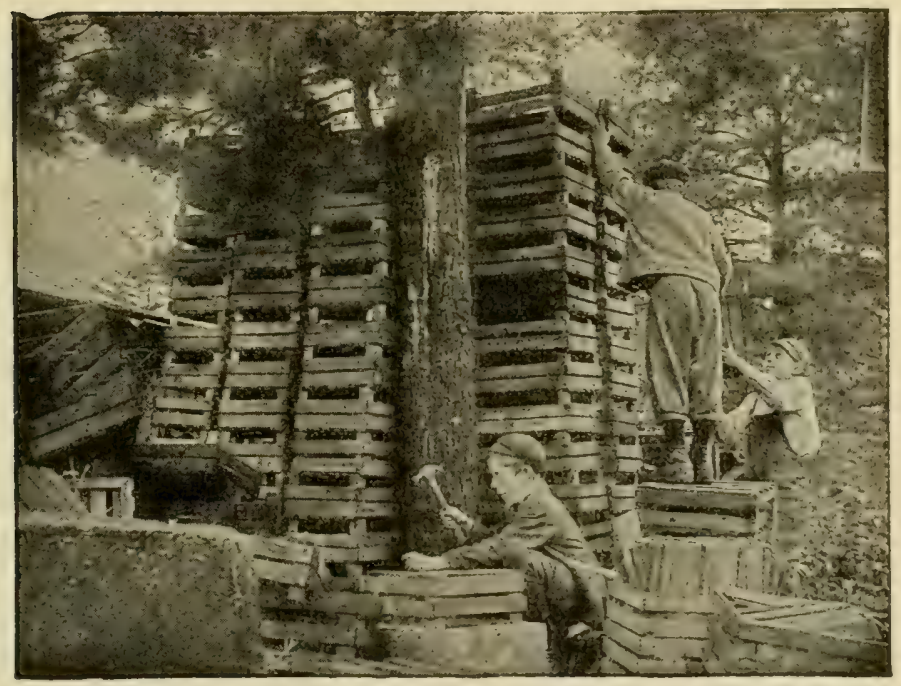

Practical f:rrm mechanics. 


\section{The Farmer as a Mechanic}

Every farmer should, at least to a degree, be a mechanic. This is not with a view to manufacturing implements, or even to the building of his own barns and houses, but to enable him to keep the implements, barns and houses constantly in good repair.

The farm work-shop.-A great many dollars can be saved on the average farm if the farmer has equipped himself with a little work-shop and a number of the necessary repair tools. A loose bolt, a broken rivet, a loosened board, or a brace out of position can easily be repaired by a practical farmer, while if it is neglected it may result in greater breakage, with the consequent loss of time and money. A large number of minor pieces of farm equipment, such as watering and feeding troughs, feed racks, seed trays, test boxes, fireless cookers, bins, shelving, wagon boxes and hog racks can profitably be made in the farm shop.

There are always plenty of rainy days and occasionally periods of time when the rush and heavy work of the fields have been completed and an opportunity given for repair work and the making of practical necessities belonging to the farm.

Manual training and the farm boy.-A farmer boy's education has no more important part than training in the use of farm tools and the application of the ordinary mechanical work needed about barns, fences and machines. This phase of training should be correlated with the manual-training courses in the public school. The manual training learned by the farmer boy should relate to farm needs. Every farmer boy should master the practical principles of painting, the mixing and use of paint, and the relation of color schemes. For the use of paint not only. beautifies, but conserves buildings, fences and machinery.

The use of cement.-Cement has come to be one of 


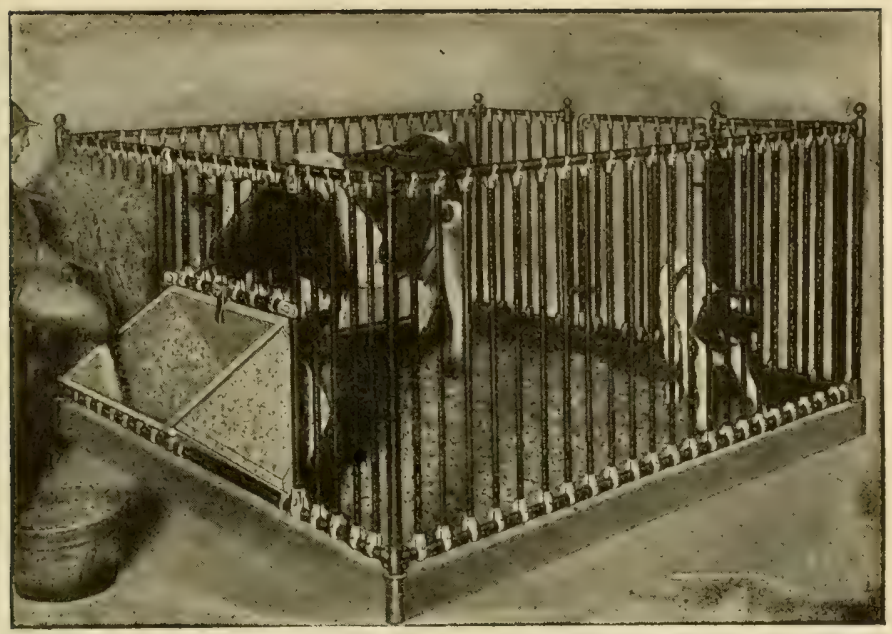

A modern type of cow pen.

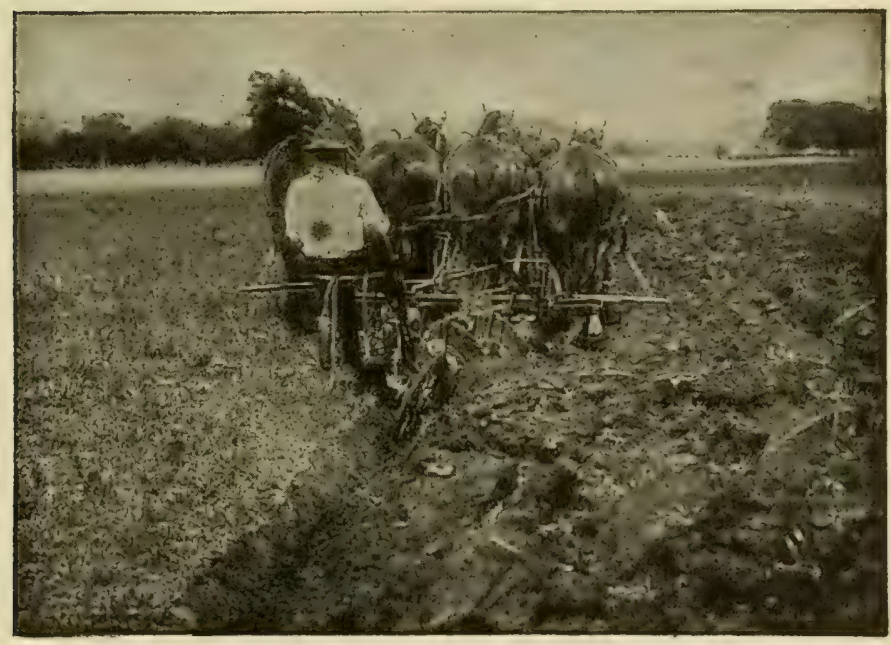

A deep tilling plow, with two disks. 
the most important economies of a farm homestead. Every boy will want to know something about the making of concrete, and the proper methods of mixing and surfacing. $\mathrm{He}$ should understand the making of molds, the laying of foundations for cement structure, and the application of cement to the construction of silos, water-tanks, fence posts, bridges, feeding floors, etc.

\section{Rope Tying and Splicing}

One of the elementary yet most interesting divisions of farm mechanics is rope tying and splicing. The place of the rope in farm management is very much the same as the relation of the nail to the builder. Ropes are also widely used in other occupations, and the lives of many workmen often depend on the strength of a rope or the security of a knot.

The uses of ropes.-Long before farm machinery was invented or useful implements projected, rope tying and splicing bore a very important relation to the work of agriculture. The first harness was made of rope. Joints and splicings were made with rope long before the day of bolts, rivets, and other metal devices for the joining of parts in farm machinery. In spite of the fact that we have to-day all manner of improved farm machinery we still need the convenience and economy made possible by the use of the rope.

Some knots useful on the farm.- Some of the practical rope knots are as follows: the clove-hitch; bowline; never-slip noose; slipknot; Beckett hitch; reef-knot, or square knot, which never slips but is always easily untied; the two half-hitches often used for the halter-hitch; weaver's knot for the joining of small cords; fixed knot; anchor bend; timber-hitch, which can be easily untied but never slips; and the carrick-bend for joining ropes. 


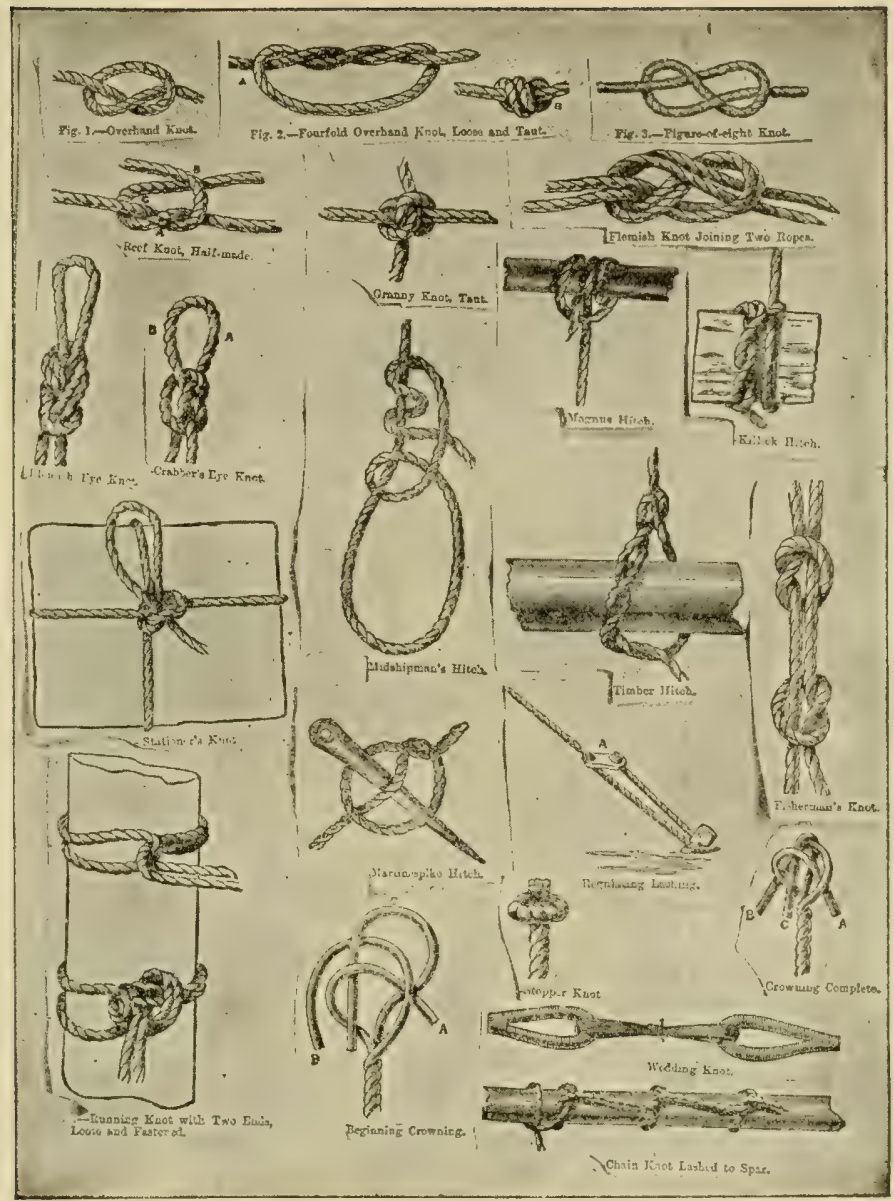

Some useful knots. Learn to identify and tie. 
Making the right knot.-Different knots are required for different purposes. A simple knot that will serve in one use is not adapted to another; knots that will untie

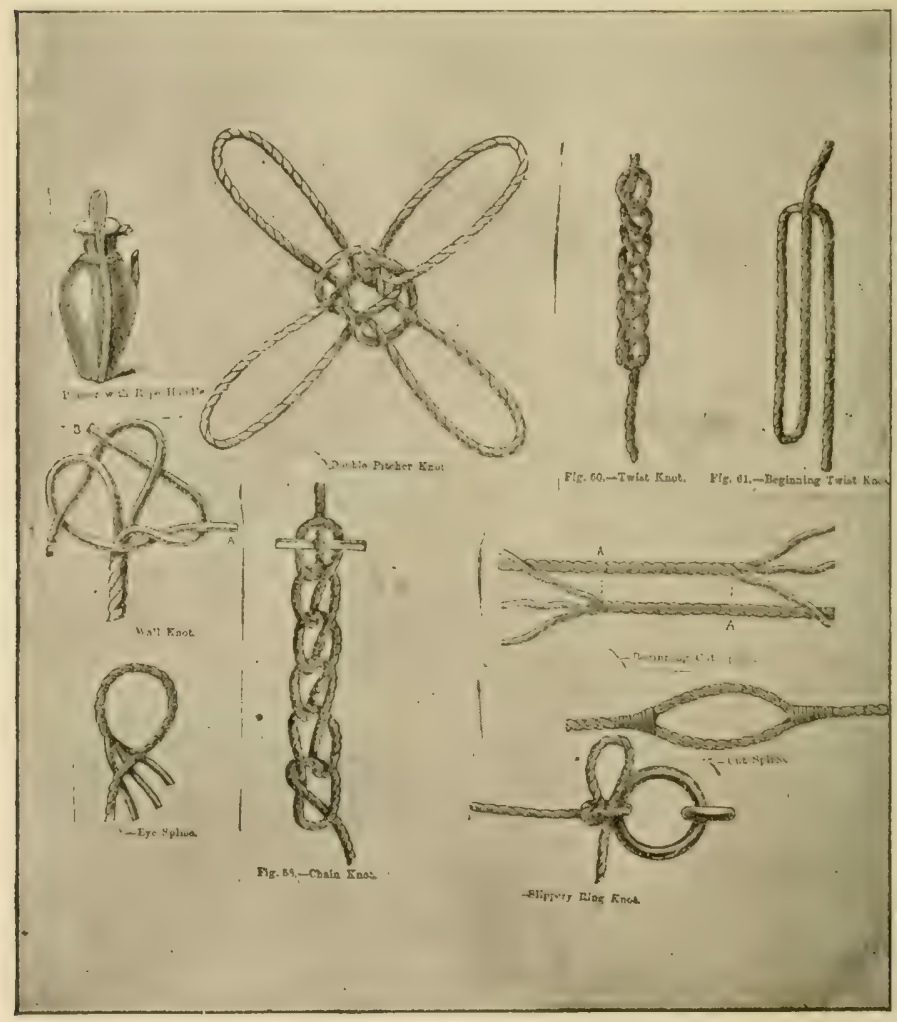

More knots.

under certain conditions may be impossible to untie under other conditions. ${ }^{1}$

1. A most interesting little book on rope knotting and splicing is one published by David McKay, Philadelphia. 50 cents. A number of the drawings here shown are taken by permission of the ompany from this set. 


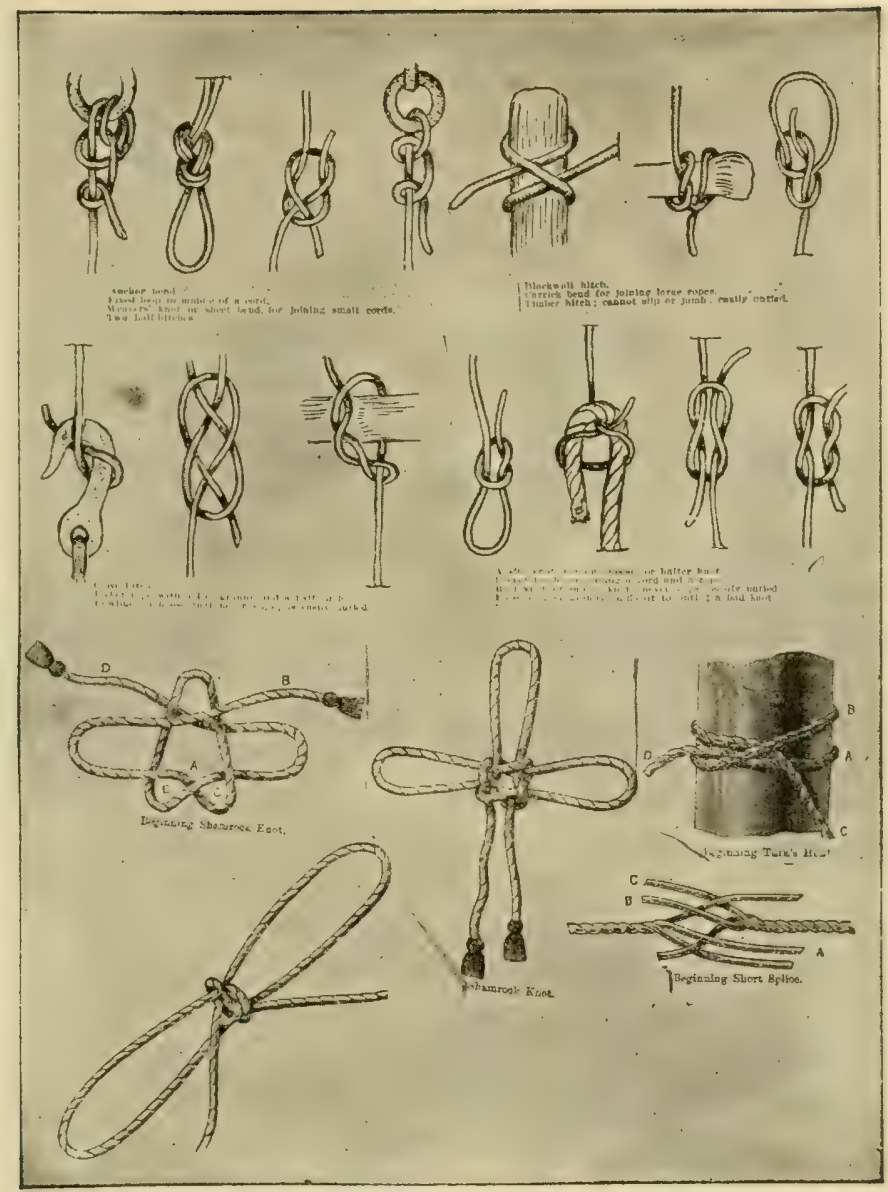

Still more knots. 
Principles of knot tying.-Certain principles apply to the tying of all knots. The efficiency of the knot does not depend on the number of turns or hitches, but on the position of the "nip." The bend or hitch must be so formed that the part of the rope under strain nips securely some portion of the knot, either against itself or the object to which it is attached. The nip of each different knot should be studied.

Rope materials.-While a large part of our rope and cordage is made of hemp, many other materials are now coming to enter into their manufacture. The coil rope is made from cocoanut fiber, which is used because it is so light and pliable. This rope is useful for warps, rocket lines, life-buoy lines, nets, etc. Manila grass is adapted to the construction of coarse ropes and hawsers requiring great strength and hard wear, and where tar can not be used on the rope.

Strips of hides are used for ropes where great st ength and pliability with small diameter are needed. Cotton is employed for ropes and cordage used for fancy work of all kinds. Wire is used for rope making whenever very great strength is needed, as in connection with dredging machinery, suspension bridge cables and the like.

Rope making.-Yarns are formed by twisting the hemp right-handed, while the "strands" are made by twisting or laying up the yarns left-handed, and the rope by laying it up in strands right-handed. Three small ropes laid up left-handed form a cable-laid rope. Four-stranded ropes are laid round a heart. In using hemp for rope making, great care should be exercised not to twist the hemp more than necessary, as this weakens the rope. A threestranded rope will bear a greater strain in comparison to its size than any other rope of the same material. This ac- 
counts for the fact that most of our rope is made of three strands. Cable-laid and four-stranded ropes are as a rule about one-fifth weaker.

\section{TOPICS FOR INVESTIGATION}

1. Make a list of all your farm machinery and estimate the value. Talk with your father and determine the annual expense of this machinery in deterioration and interest on the investment. How is your machinery housed? Is it kept in good repair?

2. Make a similar list of all your shop tools. Have you all that are needed for the up-keep of your farm buildings and machinery?

3. Make a list of all the knots you have ever seen used on the farm. Tie all these knots. What other knots would be serviceable? Learn to tie other useful knots from the pictures shown in this chapter.

4. If you wanted to draw a plank from the ground up to the gable window of a barn by use of a rope, what knot vould you use? Think of several other such uses for knots and show the knots to be employed.

5. Make a rope halter for a horse or calf. Show how to tip a halter rope.

6. Locate on a map of the world the places where the different rope materials are produced. Make a collection of all the different kinds of rope available, and tell of what they are made.

\section{Rope Play Contests}

1. Knot naming contest.

2. Rope judging contest.

3. Knot tying and splicing contest, to see who can tie and name accurately the largest number of rope knots in a period of ten minutes. Contest to be judged on skill, accuracy and number of knots tied.

4. Rope spelling contest, to be conducted from the list 
of words used in connection with rope, cordage and splicing work, with the object of making pupils familiar with the terms.

5. Knot drawing contest.

\section{Rope Club Projects}

It is possible to organize a group of boys into a rope club with a view to the mastery of rope tying, splicing,

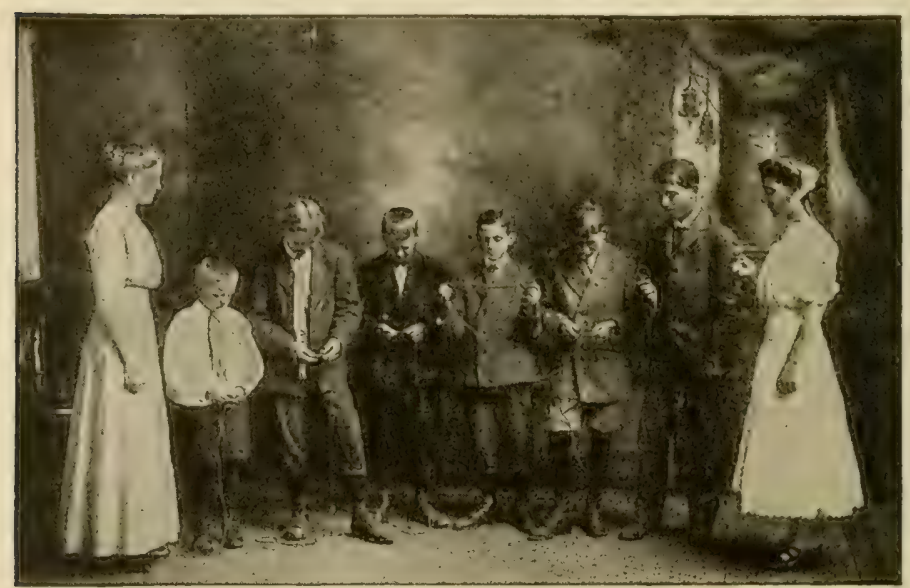

Rope tying contest: 36 knots tied, named and untied in 6 minutes.

cordage work, etc. The requirements should be to study in connection with geography the various fibers used, such as hemp, cotton and cocoanut. The method of production of the plants, a study of uses of rope, and their practical application to farm and home mechanics should be taken up. The basis of award of a club project of this sort may be as follows :

1. Knowledge of origin, development and methods of manufacture in the rope industry 
2. Ability to name and tell the use of knots and splicings-- 20

3. Exhibit of knots and splicings named and mounted on

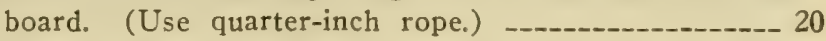

4. Skill shown by actual test in the tying and naming of rope knots_..-_-_-_._- 20

5. Written story of "Rope Tying and Splicing as Related to

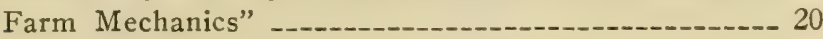

Total score 


\section{CHAPTER XXVIII}

\section{ROAD BUILDING AND MAINTENANCE}

V,OD public roads are a prime necessity to successful (I agriculture and rural development. They add to the pleasure, profit and convenience of the farm.

\section{Importance of Public Roads}

There are in the United States about two million two humired thousand miles of roads. Of this immense stretch of pizblic highway, two million miles are classed as earth roads. This is to say that we have enough earth roads to circle the globe eighty times at the equator.

Gciod roads and prosperity.-A study of history shows that every great and prosperous nation has built a good system of public roads, while primitive and unprogressive peoples are satisfied with poor roads. In our own cutntry we find the most prosperous and progressive communities are those that are giving attention to their roads.

Need for good roads.-Because good roads allow the farmer to haul his produce to market at a minimum of expense in time and energy, he can make more profit out of his crops and stock. And the prosperity of the farmer tends to increase the prosperity of all business men and lower the cost of living to consumers. The success of the rural schools also depends much on improved roads. Especially is this true where the schools are being consolidated and the pupils transported to the school by the dis- 


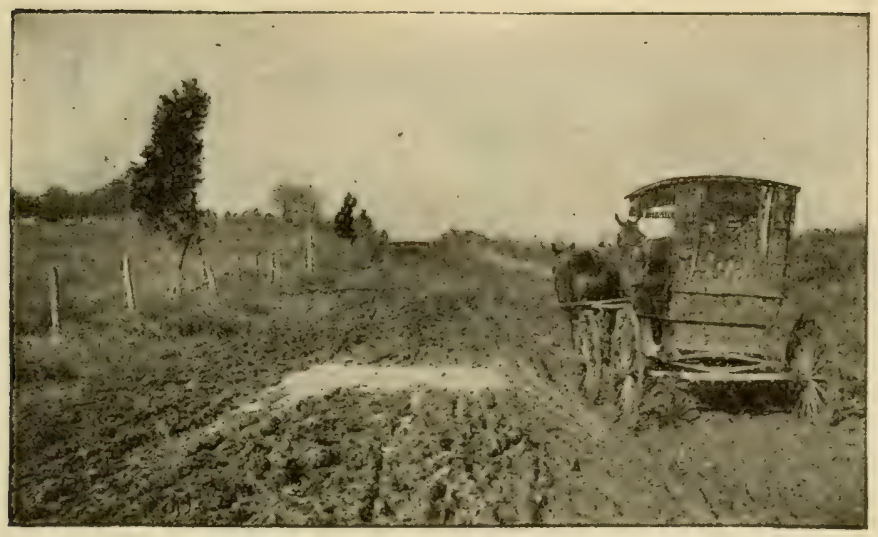

An earth road that needs imnroving.

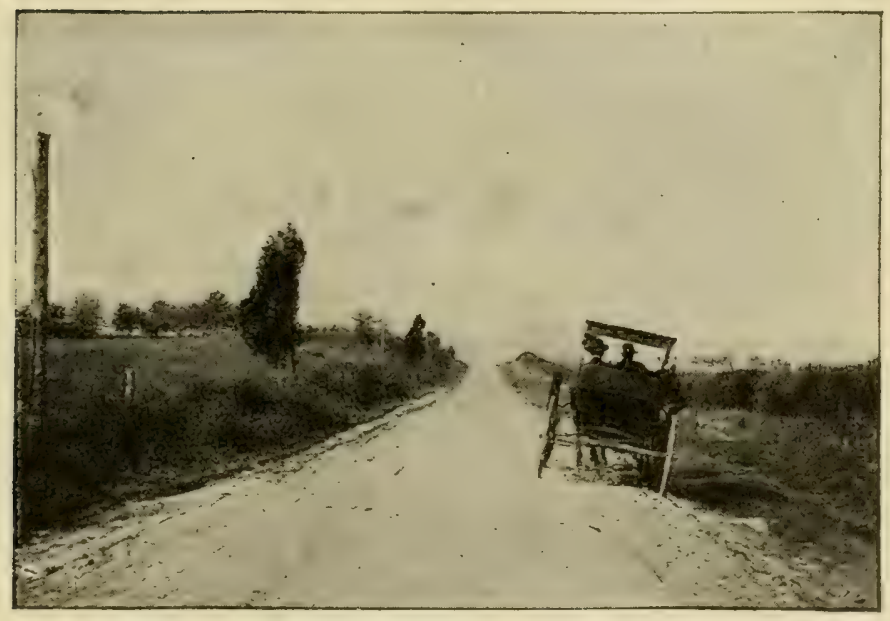

The sume road improved. 
trict. Rural mail delivery and the extension of the parcel. post system further demand the improvement of country roads. And, not least important, the making of country life interesting and attractive rests in no small degree or good roads, for they allow rural people easily to travel about the community for social or business purposes.

Growing movement for good roads.-In nearly every part of the Unitec States there is at present a growing interest in good roads. New laws are being passed and millions of money appropriated to improve our roads. Commercial clubs, business concerns and other organizations are working together to encourage road building. And farmers are coming to demand improved roads for teaming and automobiles.

\section{Types of Roads}

Roads are generally considered under the following types: (1) earth roads, (2) sand clay roads, (3) gravel roads, (4) macadam roads, (5) bituminous macadam roads, (6) brick roads, and (7) concrete roads. The discussion in this chapter will be confined to the earth roads, since these are the most necessary and practical study for the public schools.

Earth roads.-A chain is no stronger than its weakest link; so, also, a road is no better than its poorest part. This means that the heaviest load that can be drawn over a public highway is the load that can be drawn up the steepest hill, through the worst ruts or mud-holes, or over the deepest stretch of sand. Hence the importance of lowering or going around the hill, and eliminating the mudholes, ruts and stretches of sand.

\section{The Location of a Road}

Public roads should, as far as possible, be located in straight lines. In hilly or mountainous regions, however, 


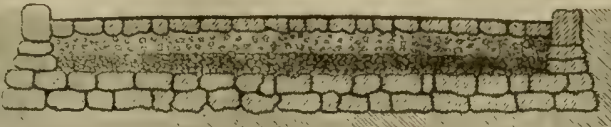

Cross Section Roman Rood (Appian Woy).

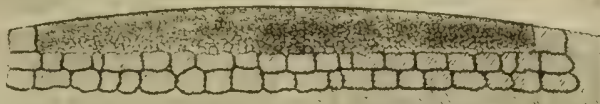

Cross Section French Rood (Roman Method), previous to 1775 .

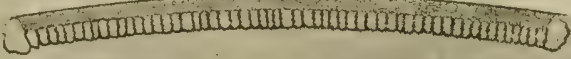

Cross Section of Tresaugues Rood, 775 .

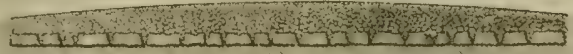

Cross Section Telford Road 1820

7.

Cross Section Macodom Rood, 181G.

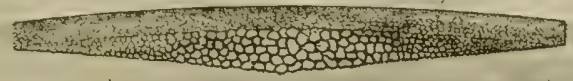

Cross Section of Modern Mocadom (Mussachusetts) Rocd with V shaped foundation.

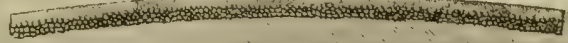

Cross Section of Modern Mocodom Raod.

Cross-sections of different types of roads. 
this rule must often give way to avoid the climbing of too heavy grades.

Straightness and grade.-To lift a ton one foot high requires two thousand foot-tons of energy. On a road surface requiring one hundred pounds traction per ton, the same energy would roll the ton a horizontal distance of twenty feet. As far as the actual amount of energy used is concerned, therefore, to save one foot of grade, or up-hill

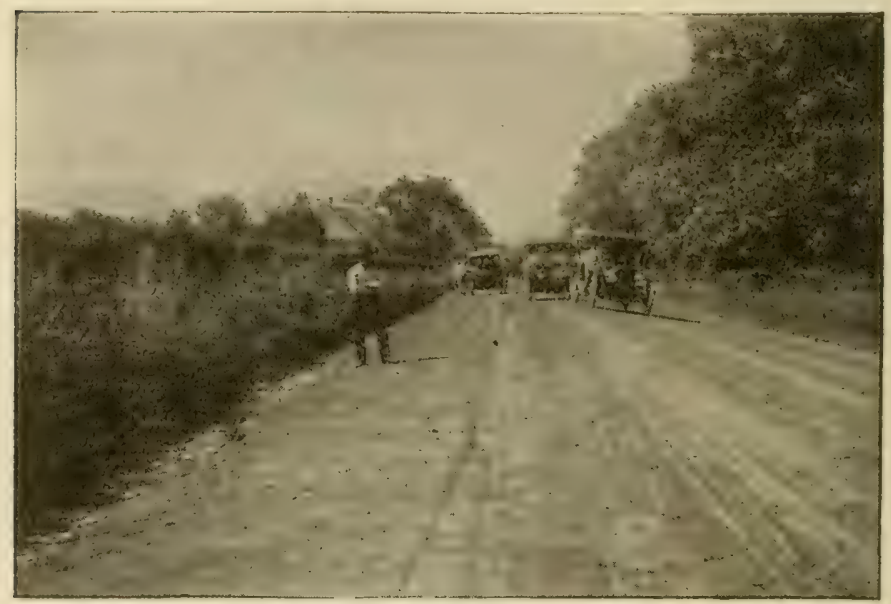

Earth road in Kansas.

climb, the road may be lengthened twenty feet. Public road grades should avoid a rise of more than six feet in a distance of one hundred feet. The hills should be cut down and the material used to fill in the hollows or else the road relocated to go around the hill and to avoid the steep grades.

The necessity of sunlight.-Every road bed should have at least six hours of sunlight each day. Brush, trees or hedges that interfere with this requirement should be cleared away or sufficiently thinned out. On the other hand, 
suitable trees, shrubbery, grass, vines and flowers should be encouraged along the roadway, as they add both to the beauty of the road and the value of farms.

Drainage.-As a rule the only ditches needed for the proper drainage of the road can be made by the road grader. Deeper ditches are necessary where the adjoining land is low and level. In the building of culverts care should be taken to make them large enough to handle the overflow. They must also be sufficiently durable to resist the spring

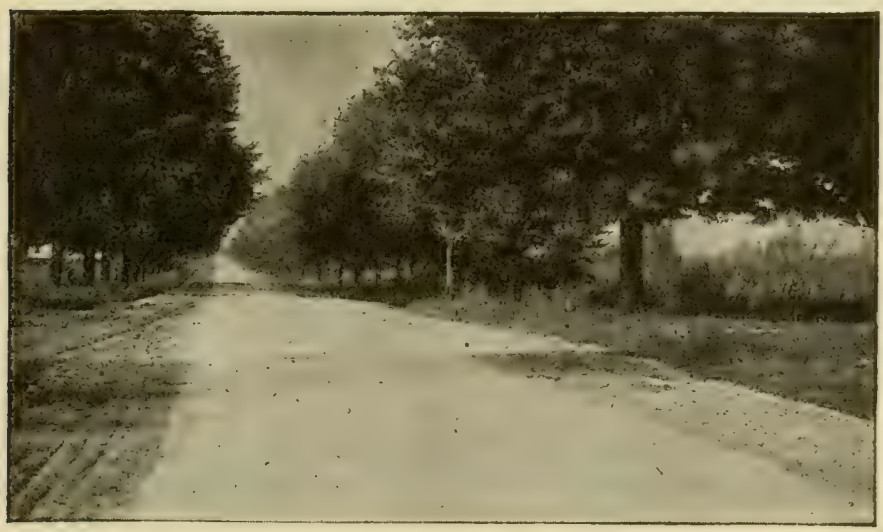

Concrete road near Detroit.

freshets and not be injured by the maximum flow caused by storm water. They should have sufficient slope so that the wash will keep them clean. All the spillways should be paved, if necessary, and the outlet and inlet protected by suitable head and wing walls.

\section{The Construction of Earth Roads}

Shaping the road bed.-Earth roads should not be made too wide. Twenty-four to thirty feet is sufficient unless the road is to be macadamized or otherwise permanently 
improved. All roads should be properly crowned or rounded in order to aid them in disposing quickly of surface water. An earth road twenty-four feet wide should not be less than six inches nor more than twelve inches higher at the center than at each of the borders. The total fall from center to side should be about an inch to the foot.

The work of construction. - The earth roads can best be crowned and ditched by a reversible road grader. The use of picks, shovels, scoops and plows should be avoided. One road machine with sufficient power and a good operator will do the work of a large number of men and do it much better. Graders as a rule should be used when the soil is damp. This will make the soil pack well while drying. If it is worked when dry and hard it takes more power to draw the machine and in addition the dry earth and dust will absorb and retain moisture and soon develop ruts. All clods, sod, weeds and vegetable matter should be remsved.

\section{Maintcnance of Earth Roads}

Necessity of constant care.-The greatest problem of earth road building is that of maintenance, and any earth road which carries a great deal of traffic requires almost constant attention. Repairs should be made when needed. A few days spent upon the road at different times throughout the year will accomplish a great deal. It is a serious mistake to devote all of the time in road building to a paricular season, leaving the road without care the remainder of the year. Most communities need a few men and teams spending their entire time in keeping roads in repair.

Dragging earth roads.-One of the most useful devices for the maintenance of public earth roads is the split$\log$ drag. This works with great efficiency on both earth and gravel roads. To obtain the best results the roads 
should be dragged once each way after every heavy rain. This must be done while the soil is moist but not sticky.

It is not necessary to employ the direct supervision of skilled engineers for the maintenance and repair of earth and gravel roads, providing the rules and suggestions they lay down are carefully and intelligently followed. A dif-

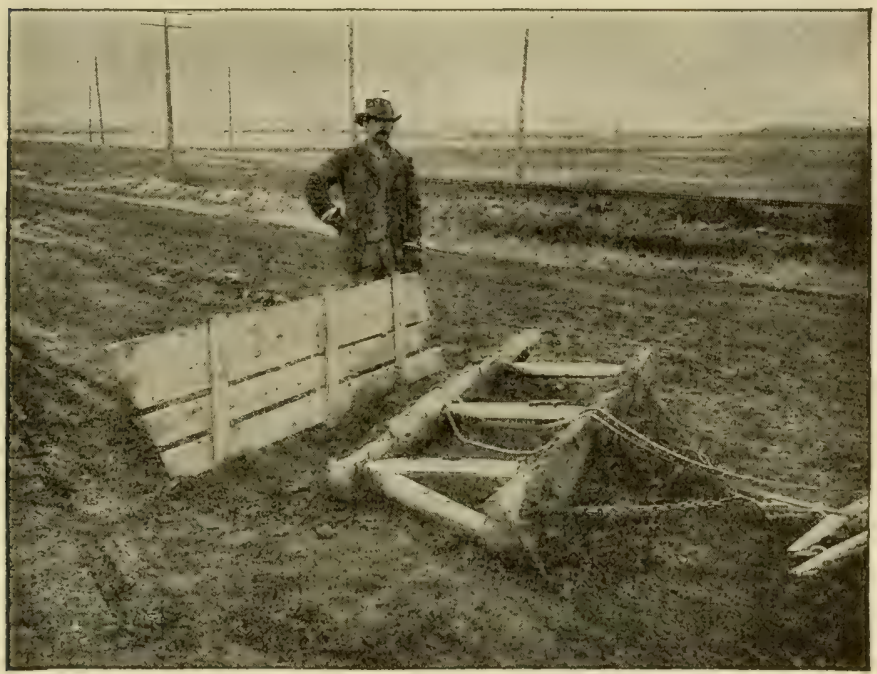

The split-log drag at work on an Iowa road.

ficult piece of construction or fixing of grades should, however, always be carried out under the supervision of an expert.

\section{TOPICS FOR INVESTIGATION}

1. What is the prevailing type of road in your locality? How many miles of public roads in your school district? In your county?

2. What roads do you know which climb steep hills? Can you devise a method by which you can measure the 
grade of the incline, and find how many feet rise to each one hundred feet?

3. How many split-log drags in your school district? What road machinery is owned by the township or road district?

4. Under what management is the care of roads in your locality? Name the road officials of your district and county. Give a statement of the road laws of your state.

5. What different materials are used in constructing bridges, culverts and road drainage systems in your locality? Which seems to be the most satisfactory?

6. Do any transcontinental or state highways pass through your state? If so, locate them on a state mas and name them.

7. For whom was the macadam road named? Describe how such a road is built.

8. Look up the story of each of the following men and learn what he did to help the cause of good roads: PierreMarie Fresaguet, J. L. MacAdam, Thomas Tilford, Eli Whitney Blake.

\section{Demonstrations}

Many of the demonstrations should be conducted out on the public highway and when possible under the supervision or direction of the road supervisor, commissioner or expert.

1. Demonstrate how to make a split-log dirag, either full size or miniature.

2. Demonstrate by means of drawing, paper or wood construction, the various types of drainage used in road building.

3. Show how properly to crown a road.

4. Demonstrate how to repair a rut in a permanent roadway.

5. Demonstrate by drawing a roadway showing correct perspective, crowning, drainage, etc. 


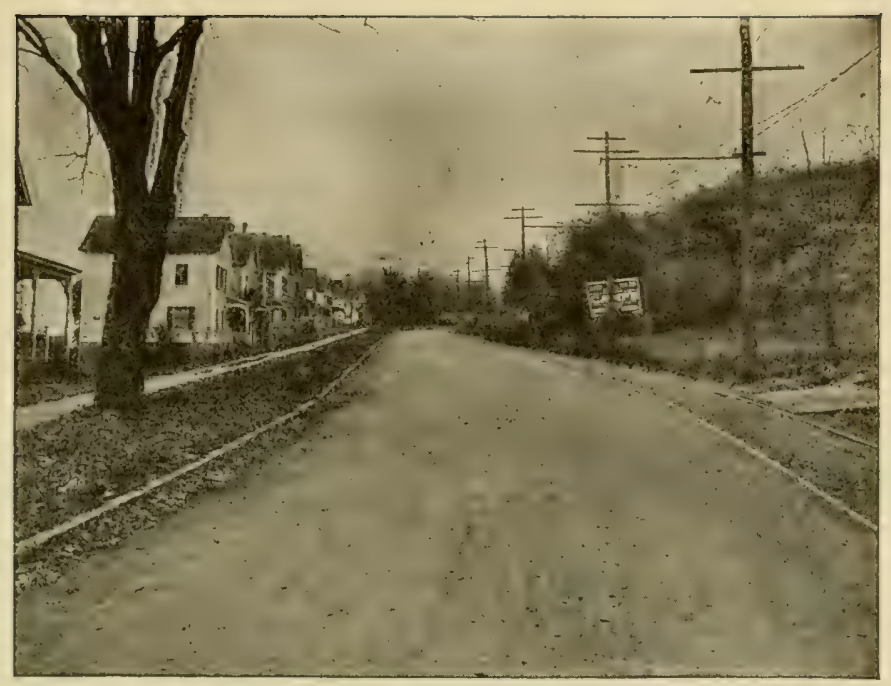

A good macidam road.

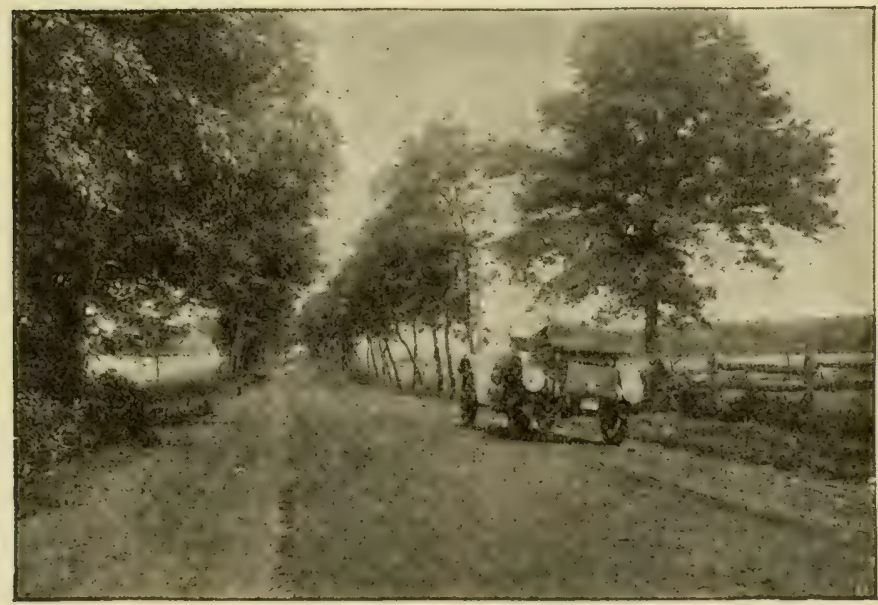

Bituminous macadam road in New Jersey. 


\section{Road Play Contests}

1. Road dragging contest.

2. Split-log drag making contest.

3. Road drawing contest.

4. Essay writing contest on subjects relating to roads.

5. Spelling and drawing contests, as related to the words and interests of road work.

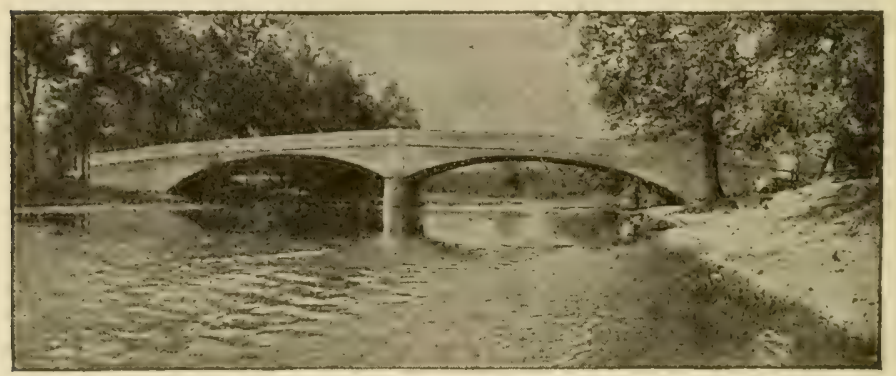

A concrete bridge. This type of structure should replace the old wooden bridge.

\section{Road Club Projects}

Permanent road building as a rule is not the work of boys and girls. But the building, maintenance and repair of common earth and gravel roads is quite within the reach of the boys ranging in age from twelve to nineteen. Two different road projects are suited to club work.

One project is known as the "School Road Dragging Club," in which the pupils, under the leadership of the teacher and with the advice of the road officer, take charge of one mile of public highway near the schoolhouse, keeping it well dragged and in repair for the season. A second project permits individual pupils to take charge of one mile of road in front of the homestead, keeping it carefully dragged and in good repair churing the summer. 
Awards.-The basis of award in either of these club projects may be as follows:

1. General improvement in road during period of club project, based upon trueness, alignment, regularity and clearness of ditches, amount and shape of crown, betterment of surface and drainage

2. General condition of improved section at end of club project period with reference to clearness of ditches, waterways, trueness, and shape of borders, freedom from ruts and depressions, smoothness, compactness, regularity of width

3. Economy of methods used, based on ten cents per hour for time of horse, and ten cents per hour for member_. 15

4. Written report and story of "The Road Work of the Season"

5. Faithfulness of maintenance during club project period with reference to freedom of flow in ditches and waterways, repair of borders and washes, rapidity of drying out and hardening after rains, and the regularity and systematic use of the split-log drag-_-_-_---- 40

Total score

The authors are indebted to Mr. Maurice O. Eldridge, of the office of Good Roads, Washington, D. C., for able assistance in the preparation of this chapter, and to the office of Public Roads for photographs used. 


\section{CHAPTER XXIX}

\section{BIRDS AND OTHER INSECT DESTROYERS}

THE farmer is greatly assisted in his war against the

insects that prey on crops, orchards and gardens by birds and other creatures that use these pests for food. Every farm boy and girl should learn the most useful of these small friends and protect them in every way.

\section{Birds and Their Food}

Whether certain birds are helpful or harmful to the farmer depends almost wholly on what the bird eats. If its diet consists chiefly of farm grains and domestic fruits, or if the bird kills other useful birds, it is an enemy; if, on the other hand, its food is made up mainly of harmful bugs, beetles, grasshoppers, caterpillars and worms, it should be counted as a friend. It is also to be remembered that many birds that eat grain or fruit as a part of their diet may kill enough noxious insects in return to pay far more than for damage they do. Besides devouring insects, many species of birds eat immense quantities of weed seed, thus reducing the weed crop of the next season.

Food of some common birds.-The United States Department of Agriculture has examined the stomachs of many birds to determine the nature of their food, and thus discover their relation to agriculture:

The quail or bobwhite eats weed seed, potato beetles, squash beetles, the boll-weevil, chinch-bug, grasshoppers, cutworms, etc. 


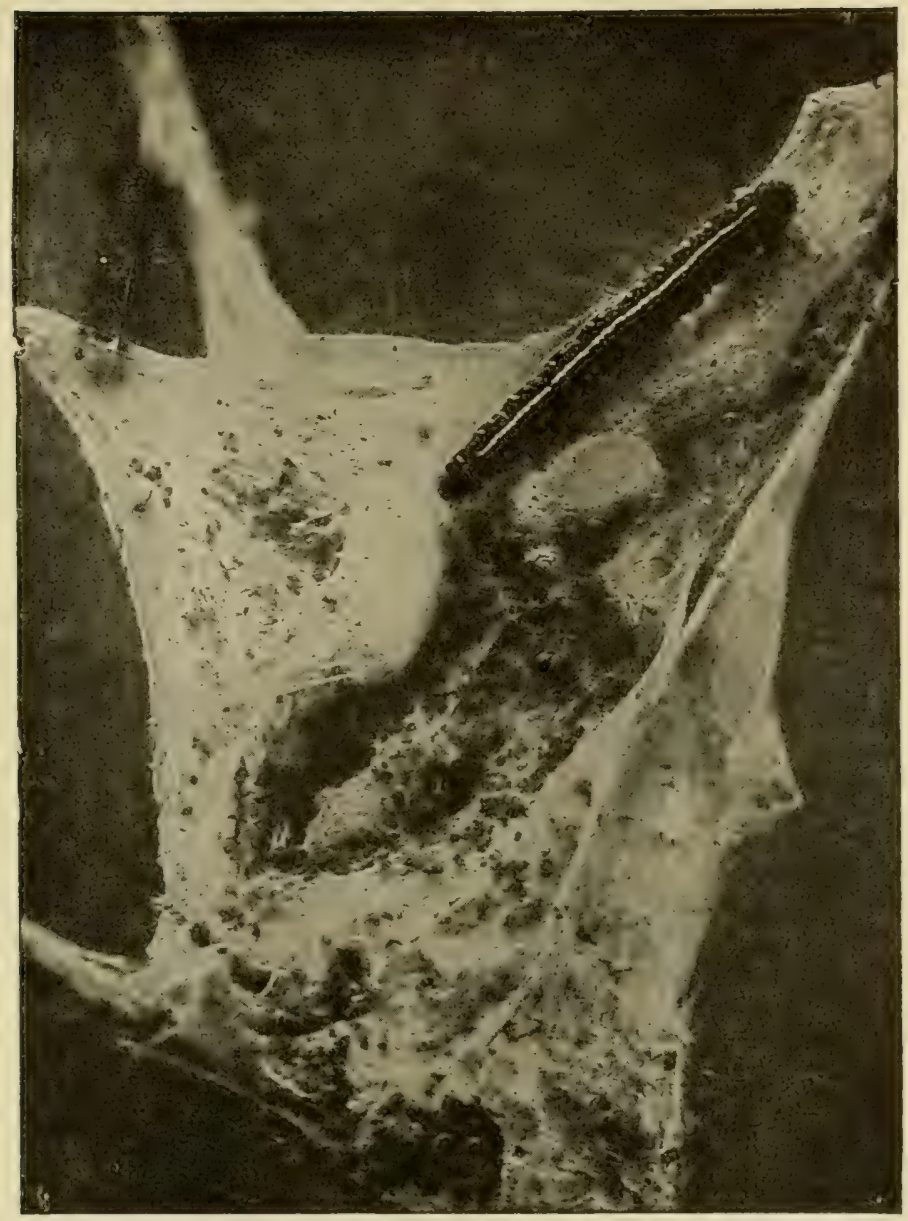

A favorite food of the birds. 
Mourning dor's live principally on weed seed, with a small proportion of waste grain.

Cuckoos live chiefly on caterpillars, grasshoppers, beetles, moths and other harmful insects.

The red-headed woodpecker makes three-quarters of his diet consist of harmful insects, and most of the rest of weed seed and wild fruit.

The night harck is especially fond of flying ants, but also eats grasshoppers, beetles and bugs.

Bank sacillor's and barn siallow's live almost entirely on flies, various species of flying beetles, ants and weevils.

The grosbcaks are among the most useful of our birds. They are particularly fond of potato beetles, and have done much to rid the farmers of this pest. They also eat other harmful insects.

The barn oril lives principally on mice, rats and rabbits. While he captures an occasional chicken, he does far more good than harm and should be protected.

The crow is usually looked upon as a thief and a robber. There is no doubt that the crow does pull up young corn, rob birds' nests and occasionally kill chickens. Yet the crow is so fond of beetles, grasshoppers, bugs and other crop enemies that his virtues exceed his vices and he should be counted as a friend.

Other useful birds.-It will not be necessary to extend this list, which might be made to include scores of birds that join with the farmer in his efforts to rid the crops of insect pests. Among the many species that should be encouraged and protected are: meadowlark, house wren, song sparrow, oriole, scissor-tail fly catcher, mocking-bird, blue jay, red-winged blackbird, cardinal, red-headed woodpecker, killdeer, screech owl, robin, bluebird, snow bird, warbler, kinglet. In general, the birds are the farmer's friends and deserve his good will. 


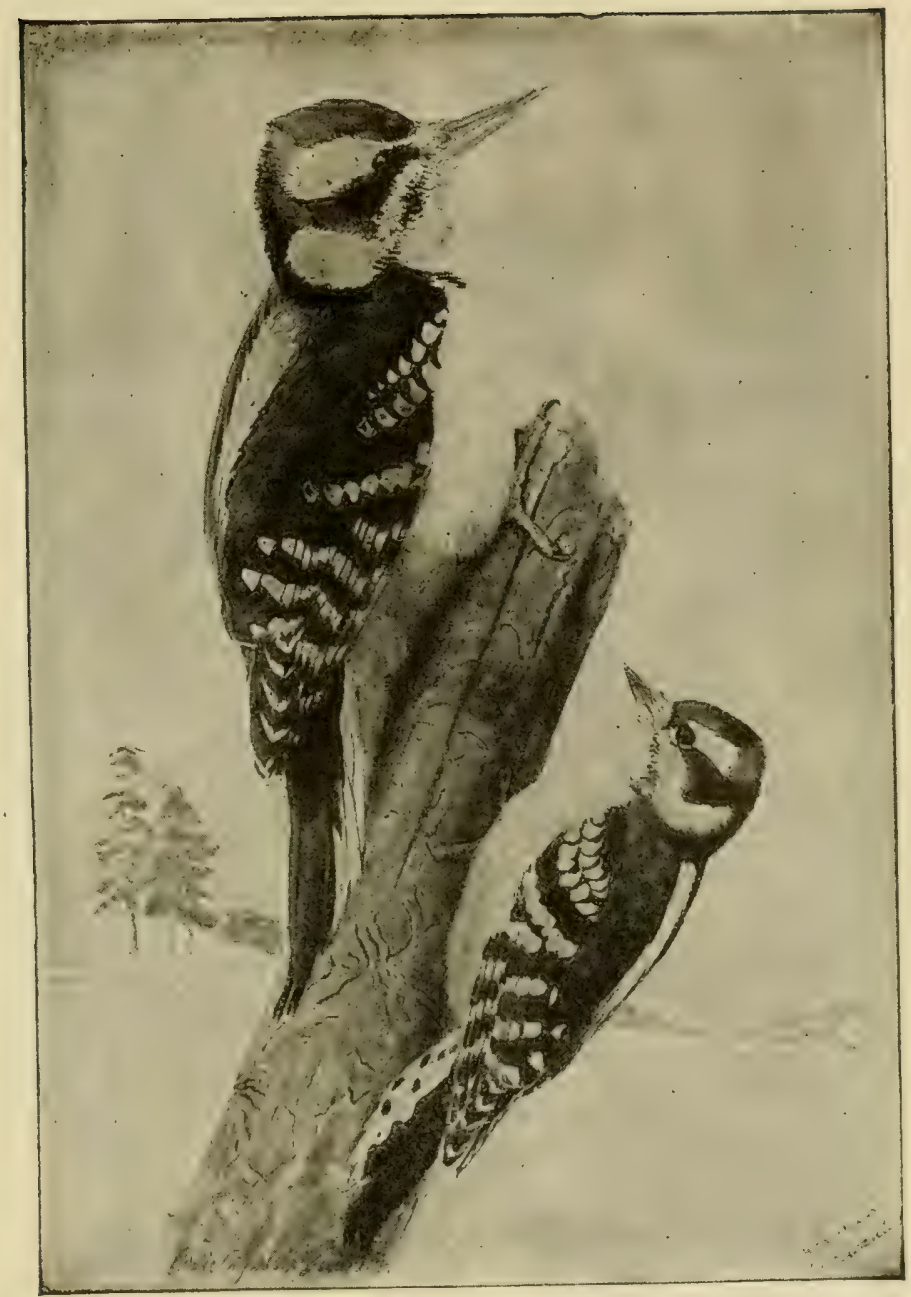

The hairy and downy woodpeckers. 


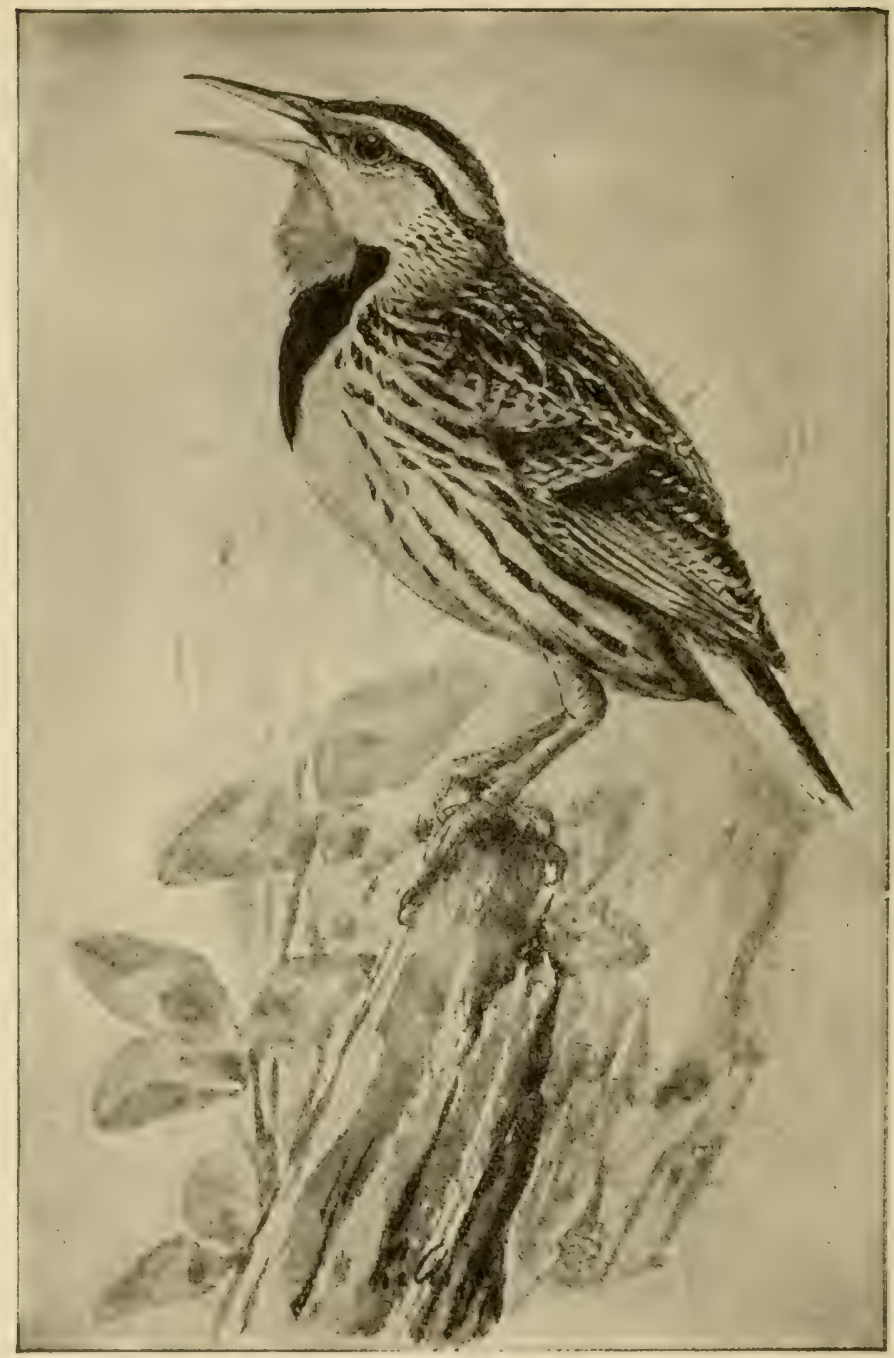

The meadowlark. 
Harmful birds.-A few species of birds do much more harm than good and therefore do not merit protection.

The English sparrow has been declared a pest and should be exterminated. While in some regions it eats a certain proportion of weed seed and harmful insects, on the whole its diet consists of orchard fruits, young garden vegetables and field grains, especially wheat. It also eats the eggs and attacks the young of a score of useful birds, thus reducing their number. Campaigns of extermination have been waged against the English sparrow in various parts of the country.

The house finch and the sapsucker also do sufficient damage that they have no claim to the farmer's good will or protection.

\section{Other Enemies of Harmful Insects and Animals}

Besides birds a number of other creatures, most of them so lowly as all but to escape observation, are good friends of the farmer.

The toad.-The common ugly toad, which we often either avoid or kick out of our path, deserves better treatment. Its food consists of flies, caterpillars, cutworms, June-bugs and other harmful insects.

The horned lizard fancies almost the same bill of fare and joins with the toad to protect our gardens.

Snakes.-The small snakes common to most regions are entirely harmless, and live on our enemies, such as mice, various beetles and weevils. It is therefore a mistake to kill them.

\section{Protecting Our Friends}

Boys and girls should make a study of the life and habits of the humble friends who do their best to rid our fields and gardens of their enemies, and should always encourage and protect them. 


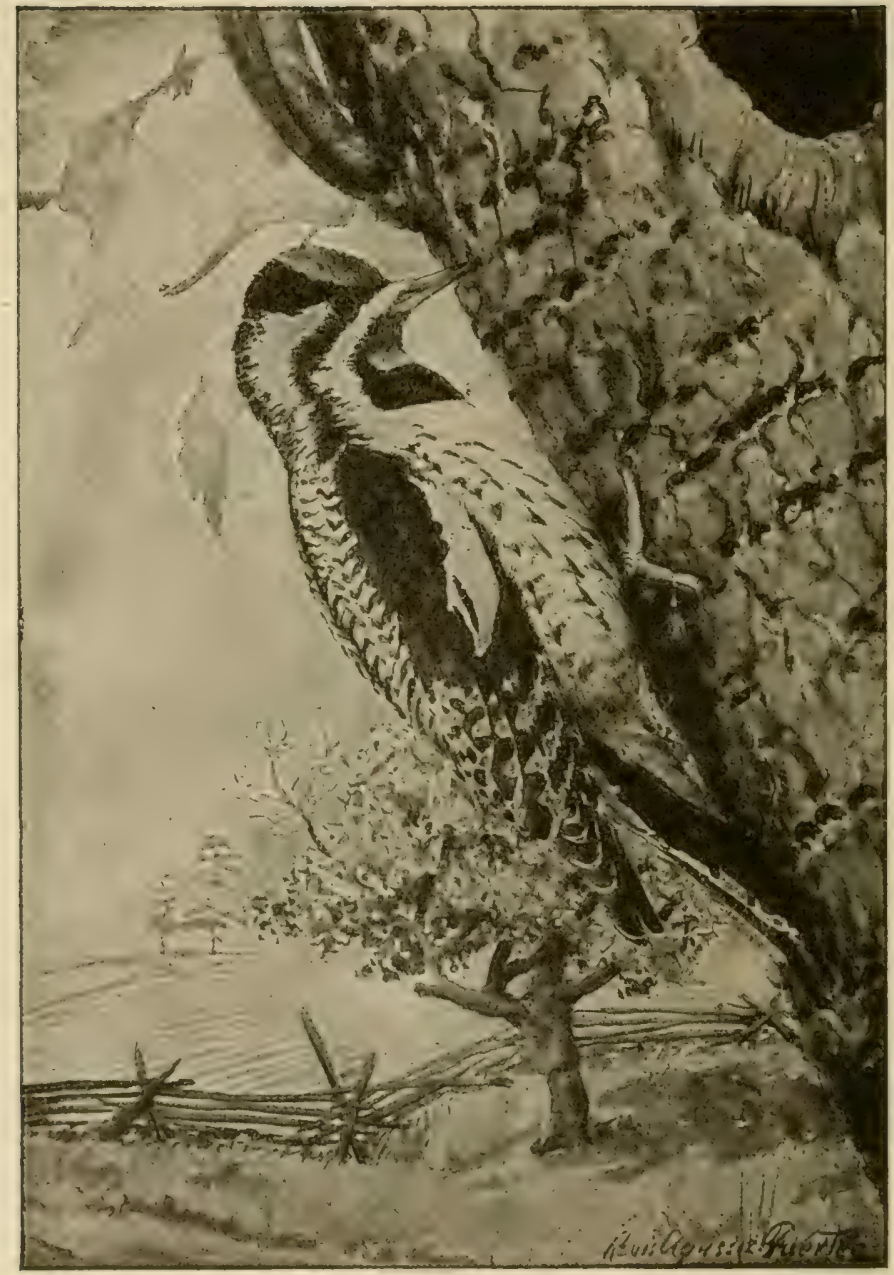

The yellow-bellied sapsucker. 
Attracting the birds.-Bird houses consisting of small boxes roofed over, cans open at one end, or other suitable receptacles placed in trees or on posts in secluded places will do much to attract certain birds. When deep snow covers the ground in winter, hiding the seeds and other food, it will pay well to scatter a little grain each day where the non-migrating birds will find it.

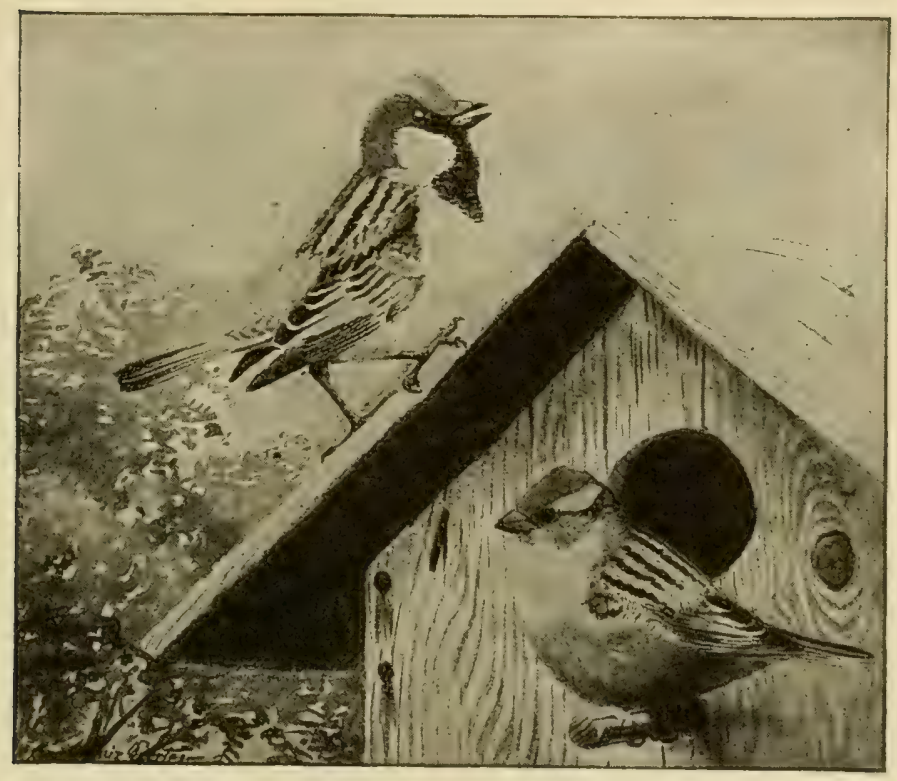

English sparrows, male and female.

How to treat a friend.-Bird hunting should not be with a gun, but with a camera, field glass or alert eyes for the purpose of becoming acquainted with our feathered friends. Birds' nests should never be disturbed, the eggs handled or the young worried during nesting time. The fashion which decorates hats with the plumage of birds, 
thus requiring their destruction, should be severely condemned. We should even come to look upon toads, lizards, snakes and frogs as our friends and treat them well.

\section{TOPICS For INVESTIGATION}

1. Malie a list of the birds you are able to identify at sight. Do you know the nesting habits of each of these?

2. Make a list of all the birds' eggs you are able to identify. Do you know the hatching time of each?

3. Secure a copy of Farmers' Bulletins Nos. 54 and 506 , and make a table of the food of each of the commo: birds of your locality.

4. What birds remain over winter in your region? What ones migrate and where do they go?

5. Watch for toads, lizards and snakes and observe their feeding habits.

6. Keep a lookout for birds you do not recognize, and find out their names and habits. 


\section{CHAPTER XXX}

\section{MISCELLANEOUS INFORMATION}

\section{How to Remove Stains}

Iron rust.-Apply salt and lemon juice to the dampened spots. Place in the sun or near the fire. Then rinse or wash thoroughly.

Fruit stains.-Pour over stained cloth, boiling water, letting it fall a distance of four or five feet, or wring article out of cold water and leave out-of-doors over a cold night.

Blood stains.-All fresh blood stains can be easily rubbed out after soaking in cold or tepid water. After the blood has been dried, use javelle water or peroxide of hydrogen. Kerosene is sometimes used with success.

Paint spots.-Use equal parts of ammonia and turpentine. Wash or rub until clean.

Grass stains.-Remove grass stains by the use of alcohol, naphtha soap, or ammonia and water.

Ink.-The commercial ink eradicator will remove ink stains from all white goods. If used on colored goods it will probably bleach or remove color. Another practical recipe is to wet the spot with warm water and sapolio, rub or polish between the hands, wash in a solution of hydrochloric acid and rinse in ammonia water.

Mildew.-Mix equal parts of soap and starch, half as much common salt, and juice of half a lemon. Spread over the spots and lay garment upon the grass until the stain disappears.

Perspiration.-Soak in cold water, wash with borax and spread garment to dry in sunlight. Under-arm stains 
usually require an acid such as a weak solution of muriatic acid.

Burned cooking utensils.-To clean granite ware where mixtures have been burned on the surface, fill container half full of water, add good soap, washing powder, or baking soda. Bring water to a boiling point and scrub with a small brush.

Tea, coffee or cocoa.-Wash with cold water, pour glycerine over spots and let stand for a few hours. Then wash with cold water and hard soap. If stains are fresh, pour over the stains boiling water from a height of four or five feet, after soaking.

Tar or wagon grease.-Use cold soap-suds.

Pit stains.-Grease with lard before using soap and water. Turpentine will usually remove the stains if other remedies fail.

2. Location of Colleges of Agriculture, Extension Departments and Experiment Stations

Letters addressed to any of these institutions, requesting information on agriculture or home economics subjects will be answered with courtesy. Help will be rendered or farm bulletins supplied when possible. 


\begin{tabular}{|c|c|c|c|}
\hline STATE & $\begin{array}{l}\text { College of } \\
\text { Agriculture }\end{array}$ & $\begin{array}{c}\text { Ertension } \\
\text { Department }\end{array}$ & $\begin{array}{l}\text { Experimell } \\
\text { Station }\end{array}$ \\
\hline Alabama_ & Auburn -- & -- & $\begin{array}{l}\text { Auburn } \\
\text { Uniontown (Sub.) } \\
\text { Tuskegee (negru) }\end{array}$ \\
\hline Arizona & Tueson & Tucson_-...... & Tueson \\
\hline Arkansas_-_._- & Fayetteville_._. & Fayetteville_..... & Fayetterille \\
\hline California___. & Berkeley_......... & Berkeley_-_..... & Berkeley \\
\hline Colorado_............ & Fort Collins & Fort Collins & Fort Collins \\
\hline Connecticut ........ & Storrs__- & Storrs_-_- & $\begin{array}{l}\text { Storrs } \\
\text { New Haven }\end{array}$ \\
\hline Delaware_-__-__- & Newark_____-_-_ & Newark_- & Newark \\
\hline Florida_... & Gainesville & Gainesville_....... & Gainesville \\
\hline Georyia $\ldots \ldots$ & Athens & A thens & Experiment \\
\hline Hawail_.......... & Honolulu__._. & Honolulu__._- & tolula \\
\hline Idaho_-__. & Moscow & Boise & $\mathrm{MI}$ \\
\hline Illinois_. & Urbana__._. & Urbana_._. & IIr \\
\hline Indiana__-_... & Lafayet te & Lafayette_-_...... & Lafayetto \\
\hline Iowa_-_- & Ames_-_. & Ames_........ & Ames \\
\hline Kansas_-_-_-_-_-- & Manhattan_._... & Manhattan_- & Manhattan \\
\hline Kentucky_-_-_... & Lexington & Lexington_..._-_- & Lexington \\
\hline Louisiana_.... & $\begin{array}{c}\text { Baton Rouge } \\
\text { New Orleans...-. }\end{array}$ & $\begin{array}{l}\text { Baton Rouge.-.... } \\
\text { New orleans.... }\end{array}$ & $\begin{array}{l}\text { Baton Rouge } \\
\text { Auburn Park (brch.) } \\
\text { Calhoun (branch) } \\
\text { Crowley (branch) }\end{array}$ \\
\hline Maine_-_-_-_-n- & Orono & Orono & Orono \\
\hline Maryland__._. & College Park -. & College Park_---- & College Park \\
\hline Massachusetts_.... & Amberst_........ & Amberst_-_-_-_--- & Amherst \\
\hline Michigan_-_-_-_- & East Lansing-...- & East Lansing--- - & East Lansing \\
\hline Minnesota_---+--- & St. Paul_____. & Sť̀. Paul & St. Paul \\
\hline Mississippi_-_-_... & Agric. College-...- & Agric, College---- & Agric. College \\
\hline Missourín-_._. & Columbia_-_. & Columbia___- & Columbia \\
\hline Montana_-_. & Bozeman__-_- & Bozeman_-_-_-_-- & Bozeman \\
\hline Nebraska_t_ne-n & Lincoln__-_-_- & Lincoln_-_-_-_--- & Lincoln \\
\hline Nevaua____ & $\begin{array}{l}\text { Reno_-_-_--nom } \\
\text { Durham }\end{array}$ & & Reno \\
\hline New Hampshire--- & $\begin{array}{l}\text { Durham } \\
\text { New Brunswiek }\end{array}$ & $\begin{array}{l}\text { Durham } \\
\text { New Brunswick }\end{array}$ & Durham \\
\hline New Jersey_m.n & $\begin{array}{l}\text { New Brunswiek-... } \\
\text { State College. }\end{array}$ & $\begin{array}{l}\text { New Brunswick-. } \\
\text { State College }\end{array}$ & New Brunswick \\
\hline New Mexico__._. & Ithaca............. & $\begin{array}{l}\text { State College- } \\
\text { Ithaca }\end{array}$ & State College \\
\hline New York_-_...- & & & $\begin{array}{l}\text { Ithaca } \\
\text { Geneva }\end{array}$ \\
\hline North Carolina_..- & West Raleigh_-_.. & West Raleiglı_-.-- & West Raleigh \\
\hline North Dakota.... & Agric. College_-_- & Agric. College---- & Agric. College \\
\hline 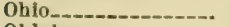 & Columbus______. & Columbus & Wooster \\
\hline Oklahoma_n_._. & Stillwater_._._. & Stillwater____. & Stillwater \\
\hline Oregon & Corvallis______ & Corvallis_____ & Corvallis \\
\hline Pennsylvania__-_-_. & State College-_-_- & State College & State College \\
\hline Porto Rico & Mayaguez_._..... & Mayaguez_...... & $\begin{array}{l}\text { Mayaguez } \\
\text { Rio Piedras (Sub.) }\end{array}$ \\
\hline South Carolins_..... & Clemson College-_- & Clemson College... & Clemson College \\
\hline South Dakota..... & Brookings & Brookings_. & Brookings \\
\hline Tennessee-_._. & Knoxville & Knoxville__. & Knoxville \\
\hline Texas_-_-__- & College Station & College Station & College Station \\
\hline Utah & Logan & Logan_-..... & Logan \\
\hline Vermont _... & Burlington & Burlington & Burlington \\
\hline Virginia_........... & Blacksburg & Blacksburg & Blacksburg \\
\hline & Hampton & Hampton (negro) - & Norfolk (branch) \\
\hline Washington & Pullman & Pullman & Pullman \\
\hline West Virginia & Morgantown & Morgantown & Morgantown \\
\hline Wisconsin_-_-_. & Madison_........ & Madison_................ & Madison \\
\hline Wyoming-_-_- & Laramie........... & Laramie ........... & Laramie \\
\hline
\end{tabular}


3. Distances Apart for Planting Fruits and Vegetables

Feet

Apples --_-_-_-_--- 30.0-40.0

Apricots

Cherries

Oranges

Peaches

Pears

Plums

Quinces

Blackberries

Currants

Raspberries

Strawberries

Asparagus

Beans, bush and pole

Beets
$15.0-20.0$

$15.0-25.0$

$25.0-30.0$

$15.0-20.0$

20.0-30.0

$15.0-20.0$

$10.0-12.0$

$4.5-7.0$

$4.0-4.5$

$3.5-5.0$

$1.0-4.0$

$2.0-4.0$

$1.0-4.0$

$.5-2.0$
Feet

Cabbage -_-_._.... 2.0-3.0

Carrot --_-_-_-_-_.- $\quad .5-2.0$

Corn, sweet -_-_-_- $3.0-3.5$

Celery -_-_-_-_- $3.0-4.0$

Lettuce - -

Onion -

Parsley -_-_-_-_.- 1.0- 2.0

Peas -

Potato -............ 2.5- 3.0

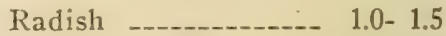

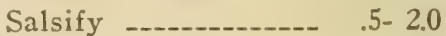

Squash and pumpkin $6.0-8.0$

Turnip -

Tomato - $3.0-4.0$

4. Quantity of Secd per Acre and Legal Weights per Bushel

Alfalfa

Barley

Blue-grass

Buckwheat

Clover

Corn, shelled, check row

Corn, ensilage

Cotton, upland

Cow-pea

Oats

Potato

Rye

Timothy -..-_-_._.-. 10 to $20 \mathrm{lbs}$.

Wheat
Seed
per acre

$30 \mathrm{lbs}$.

8 to 10 pks. 20 to $25 \mathrm{lbs}$.

3 to 5 pks. 10 to 15 lbs.

6 to 8 qts.

10 qts.

4 to 8 pks.

4 to 7 pks.

2 to 3 bu.

6 to $18 \mathrm{bu}$.

3 to $8 \mathrm{pks}$.

6 to 9 pks.

Weight per bu. 60 lbs. 48 lbs.* 14 lbs. 48 lbs.* 60 lbs.* 60 lbs. 32 lbs.* 60 lbs. 32 lbs. 60 lbs.* 56 1bs." 45 lbs.* 60 lbs.

*Varies in a few states. 
TO THE TEACHER 



\section{TO THE TEACHER}

\section{The Point of View}

SUCCESSFUL teaching of agriculture, more than that of $\checkmark$ any other subject, depends on the spirit and methods of the teacher. Agriculture is so thoroughly concrete a sulsject that only a small part of it can be effectively taught by textbook and in class room without the assistance of field and farm. The teacher of agriculture must remember first of all that there is no real agriculture in the text-book.

The place of the text.-Real agriculture is out in the fields, gardens and pastures, and among the herds and flocks of the farm. The text-book can only serve as a guide to point the way, showing the pupil what to look for, and teaching him to understand what he finds as he meets the problems of preparing the soil, planting and tilling the crop, or feeding and caring for the stock. Agriculture can therefore not be taught from the text alone, no matter how complete or well arranged it may be, nor how generous the illustrations. The text-book is very important in class room and laboratory, but it must be supplemented by the immediate interests of the farm.

\section{Public School Extension Work}

This point of view suggests a method for comnecting the work of the school with the home. The children should actually do the things they study about. For a number of years the colleges of agriculture have been engaging in 
various forms of crtension work, with a view to offermy the services of the elucational institution to those who can not so to college. The time has come when the public school should also offer some such form of extension service reaching the homes of its patrons.

Plans for extension projects.-Agricultural extension work can be carried out by the public schools according to two different plans: (1) the setting of certain definite home or farm "projects," or specific pieces of work, to be carried out by the individual pupils as a part of the course in agriculture; or (2) the organization of agricultural clubs, which provide for group, or coordinated, work of specified nature, usually in conjunction with state or national club organizations. In either case a certain amount of school credit should be allowed for home and club work satisfactorily done.

Agricultural club projects. - The United States Department of Agriculture has undertaken the organization of hoys and girls' clubs in every state in the Union, and, wherever posible, works in connection with the public chools. Covermment experts, state club managers, county agricultural agents and the state agricultural colleges all stand ready to help organize, promote and direct these clubs.

The teacher of agriculture will find the club a great incentive to pupils, and an invaluable adjunct to text-book and class-room work. Through the club it is possible to ranslate book and laboratory information into real action in the field, with the herds, and in the home. Agricultural (lub work will also do much to bridge the gap that has so long existed between the home and the school.

The number of club projects. - The club idea must nut. however, he overdone. It is possible to start so many jrojects that none of them can be well supervised or suc- 
cessfully carried out. Probably no school should encourage the formation of more than two different club projects for the same season. Club work is outlined with almost every chapter in this text, but not with the expectation that any school will organize at one time all the clubs suggested.

The teacher, with the cooperation of county, state or national agricultural club leaders, should select for boys the project of greatest agricultural significance and value to the community, and for the girls the project of greatest economic and social value to the community home life. Every rural school, especially, should have two such club projects. This plan will carry the benefits of the school to the homes, and offer the boys and girls real interests in agriculture and home economics not only for the school year, but for the summer vacation as well.

\section{Equipment for Teaching Agriculture}

The amount and nature of the equipment required for the teaching of agriculture will depend largely on the time allotted to the study, the age and grade of the pupils, and the scope of the work undertaken. But every school, no matter how small or elementary, must have certain necessary equipment if the work is to be most successful. Much of this material can be made by the pupils in the school, if they are properly directed.

Tables and cabinets.-It is essential to have suitable table space so as to permit study or demonstration in a group. This will be much more satisfactory than undertaking to do the work from the individual desks of the pupils. For successful class work the pupils should always be seated together for observation and instruction, and there must be room for the display and distribution of material to be used by the entire class. Adequate cupboard or cabinet space for the storing of material and specimen; is 
important. These may be separate pieces, or built permanently in or against the wall. They should be mouse-proof, "therwise the specimens are likely to be destroyed. The inper section of the cabinet may be of glass and the lower doors of wood. The doors should be locked throughout the night and the vacation periods.

\section{Individual Equipment}

A few pieces of litmus paper.

cmall glass vials for the selection of weed seerls and samples of soil.

Two pieces of quarter-inch hemp rope for use in the suly of the relation of the rope to agriculture.

I few blotter testers, a rag-doll tester, and at home, a box seed-corn tester.

Seel racks and seed trays used for drying and exhibiting purposes.

I small thermometer for the testing of temperatures of water, soil, etc.

I few simple garden tools like hoes, rakes, small hamd males, potato fork, etc. Most of the garden tools can, if course, he supplied from the home to be used both at home and at school.

Snme simple carpenter tools for use in the making of molel hen houses, feed and watering troughs, single-trees, seed boxes, cold-frames, etc.

\section{General Equipment for the School}

Secel trays, seed-testing equipment, soil capillarity tubes. a sct of large-mouthed bottles for exhibits of types of soil, a : imilar set for exhibita of seeds, a Babcock milk tester, amming equipment, a few miniature models of farm machinery. When room las been provided and func's are available 
regular farm machinery, cream separators, fanning mills, etc., will be of great value in the teaching of the various strbjects of agriculture.

\section{Laboratory Matcrial}

A great deal of the material for instruction can be obtained as needed from the homes, and adjoining farms and fields. It is not possible, however, to make the course in agriculture follow the seasons exactly, and some material therefore needs to be stored for class use. Other material may not be easily found when required. Samples of still other products may not be available in the region, and should be kept for comparison.

Samples of soils.-Samples of all the different rarieties of soils to be found in the region should be collected and kept in laboratory bottles, jars or common fruit jars. These samples should include soils rich in humus, clays, sands, lava, and soils in which organic matter is lacking. Each sample should be labeled, telling the type represented and where obtained.

Specimens of cereal plants and grains.-Samples of all the commori cereal grains, including the different local varieties, should be collected and stored in wide-mouthed bottles. These will serve for comparison with samples brought by the pupils from their farm crops. Specimens of the cereal plants should also be collected and stored when the crop is ripening. This will allow the class to study the different types and rarieties of wheat, oats, etc., and to identify each from the plant, even if the study can not be taken up when the crops are available in the fields. It is also desirable to make a collection of types or varieties not common to the region and use them for comparison. The state agricultural college can msially help in securing such a collection. 
Specimens of grasses and legumes. $-\Lambda$ complete collection of the native grasses and legumes should be made in every school. The pupils will delight in helping in this work, which may be made one of the most valuable parts of their instruction. Wherever possible the roots should be saved with the stem, so that the entire plant will be represented. The specimens should be clearly labeled and tied in bunches or attached to pieces of cardboard. It is not intended that these dried samples shall be used for study instead of the growing plant, but they are often useful for occasional illustration when there is no time to collect the new material. They also serve as a standard for identification of specimens brought by the pupils to the school. The list should include the chief varieties grown in other sections of the country.

Specimens of weeds.-A collection of the noxious weeds of the region should be made and labels attached. Here again the class may be used in making the collection of all specimens that are available at the time school is in session or even during vacation. A collection of weed seeds should be saved in bottles like those used for the cereals. Pupils should become able to identify at sight both the weed plant and its sced, and should know the labits of growth, the injury done crops and the method of eradication.

Specimens of injurious insects and worms.-The insect pests common to the region should be collected anri preserved for study by attaching them to cardboard by means of laboratory pins or other device. The school should have a cyanide insect bottle for killing specimens, and insect cases for preserving them. Each specimen should be clearly labeled and the time of its appearance and disappearance given. These specimens will then serve as a guide for the class in making their own collection, or 
identifying the insects at work. The proper place to study insects is, of course, in the field in connection with the soil and plant life whenever they are available.

Specimens of woods.-A collection of native woods is one of the most interesting and easy to make. Every pupil will be glad to take part in the work. Samples of the leaves should also be collected and preserved. Such a collection will supply the basis for a study of trees, and should result in each pupil being able to identify native trees at sight, either by their leaves or wood and habits of growth. Pupils should not be permitted to destroy useful plants for the sake of school specimens.

\section{Method of Instruction}

It is not possible or desirable in this place to give detailed discussion as to the methods of teaching agriculture. Certain broad and fundamental principles may, however, be stated.

Seeking knowledge at first hand.-From the very first day, the pupils should be made to feel that the study of agriculture is the study of the actual problems of the farm -crops, soils, animals, and all else that goes to make up the life of the farm. To "get a lesson," is therefore not to commit to memory what the text may say on a certain subject, but to use the text-book and all other available helps to master fully the problem at hand in the study of an ear of corn, the preparation of the seed bed, the fertilizing of a field, or the feeding and management of a rock or herd.

Use of the text-book.-The text-book is arranged to give as natural and interesting an approach as possible to each chapter or topic. There is hardly a text-book lesson for a single day which does not provide for some practical bome and field study in connection with the subject under 
consideration. The lesson assignment should usually first ic studied from the text, the field, laboratory or home work on the topic then being taken up. The topics for iniestigation and the questions throughout the text should alicay's be acorked out fully and thoroughly. In many instances the teacher will desire to add questions or topics to supplement those of the book. Only in such practical ways can the work be made interesting and vital.

Use of note-books.-The pupils should be provided with note-books of uniform size. In these should be kept a record of all demonstrations, experiments, field trips and excursions and observations. Here should also be worked out all the exercises and problems required in the text, and those assigned by the teacher. Drawings, diagrams, tables or any other matter brought into the course should find their way into the note-hook. Pictures of farm animals, crops, machines, farm buildings and the like, should be assembled and form a part of the record of the course. Every note-book should be neat and well kept, and arranged in a businesslike manner.

Correlation with other subjects.-Agriculture may well be made in many schools to serve as the basis of correlation with other subjects. Much of the arithmetic can be taught more efficiently and naturally from the lessons in agriculture than in any other way. Language work, including composition and letter-writing, can be related to much of the work of the agriculture course. Industrial geography is suggested hy every chapter in the text. Frechand and mechanical drawing, manual training and domestic science all connect easily and naturally with the lessons and problems of the course.

Connection with home work.--Constant reference is made in the text to the crops, gardens, stock, soil and other interests found on the farm or at hame. This is not by 
accident. The purpose is to make the study of agriculture interesting and helpful by connecting it immediately with the homes. The teacher who will faithfully carry out this concrete method of instruction will find growing $n_{1}$ his pupils a firm and abiding enthusiasm in the subject never to be hoped for in mere text-book study. The sreat purpose and the highest success is to get the lessons of the te.t translated into life and action. The work on agricultural projects assigned in connection with the course should, as far as possible, be done under the guidance of the teacher and should receive school credit.

Demonstrations and experiments.--The difference between demonstrations and cxperiments should he clearly understood by the class. The iclea in an experiment is to investigate, discover or verify some truth. In a lemonstration some well-known truth is illustrated, shown or demonstrated to others, with the purpose of convincing them of its merits and leading them to adopt it in practise.

\section{Seasonal Order of Study}

Seasonal order impossible in text.-It is wholly impossible to arrange any text on agriculture so that the topics will follow the seasons throughout the year. If this could be done it would make the teacher's work much simpler and easier. But seasonal variations do not come at the same time in different regions, nor loes the order of the crops and gardens follow the arrangement of the school year.

Order to be based on crop sequence.-Because of these facts, it must be left to the teacher to select such an order from the text as best fits the crops and seasons of his region. It is not necessary that the chapters be taken in succession as they occur. For northern schools opening in the late summer, the corn chapter undoubtedly will be best for 
a beginning. The potato chapter should be taken up before the (rop is harvested if possible. It may be icferred to again at planting time in the spring. The gas ien chapters should be studied during the late winter or early spring, and again referred to as the planting, spraying or tillage is under consideration. The teacher need not be afraid even to divide a chapter, using a part at two or more different seasons if this seems best. For example, the field study of corn should be beginn in the fall with the ripening crop, but the testing and grading of seed corn should be reserved for winter study.

The greater part of the study of farm animals can be successfully carried on during the winter, though certain of the features should be taken up in the fall or spring. Some of the work on soils can also be utilized for winter stuly. Actual field study and demonstrations will, of course, be carried on when the ground is not frozen. The great point is to base the lessons on the immediate activities of the farm during just as much of the year as possible, making the assignments from the text conform to the seasonal order of the locality.

\section{Reference Material}

Every school where agriculture is taught should be stocked with a number of standard texts on each of the divisions of the subject. The library should contain a standard cyclopedia of agriculture. It is also desirable to have the Igricultural I ear Book of the United States De. partment of Agriculturc, and the Census Reports that deal with the subject of agriculture. Arrangements can be made for the receipt of the current crop reports.

Government publications.-The United States Department of Agriculture, Washington, D. C., is in position to give help to all citizens on the subject of agriculture. 
A large number of Farmers' Bulletins, circulars, reports and special instructions on almost every conceivable agricultural or home economics subject, can be secured by addressing the Secretary of Agriculture. Most of the publications are free and are intended for the use of the public. This material makes a very necessary and helpful supplement to the text-book, and should be constantly referred to. It is well to provide some library or filing arrangement to contain such material, so that it can be properly classified and cared for.

State agricultural colleges and experiment stations.Every state has its agricultural institution. These colleges publish a great deal of valuable material on the agricultural problems of their respective states. In most cases the ma1erial is free to all citizens of the state, and should be freely drawn upon for school use. A list of the agricultural colleges and experiment stations will be found in the chapter on "Miscellaneous Information." 

INDEX 



\section{INDEX}

Aifalfa,

as forage,

as soil renewer,

chapter on,

chief region of,

enemies of,

feeding value of,

harvesting of,

soil requirements for,

study of plant,

Animals,

farm and agriculture,

farm, section on,

food supplying,

work of farm,

Ants,

Aphis,

corn root,

Arsenate of Lead Spray,

BABCOCK,

steps in test,

278

test for butter fat,

BACTERIA,

nitrifying,

BeEF,

breeds of cattle, 


\section{INDEX}

\section{BIRDS,}

and their food,

chapter on,

harmful,

methods of protecting,

useful varieties of,

Blotter Seed Testers,

Bordenux Mixture,

BREAD,

Canning Fruits and Vegetables,

chapter on,

recipes for,

time table for,

217

218

222

Cattle,

beef, breeds of,

287

chapter on,

272

club projects,

294

dairy,

$2 \div 2$

feeding beef,

play contests with,

289

tuberculosis in,

293

289

Chickens,

breeds of,

chapter on,

diseases of,

feeding for eggs,

feeding of,

houses for,

the raising of,

Chinch-Bugs,

Clovers, The,

alsike,

as forage, 
Clovers, The (Continucd).

as soil renewer,

chapter on,

crimson,

enemies of red,

harvesting of,

impurities of seed,

red-clover plant,

successful growing of,

Club Work,

cattle,

corn,

forage,

fruit garden,

hogs,

horses,

potato,

poultry,

roads,

sheep,

soil,

tomato,

vegetable garden,

Commercial Seed'Tester,

CORN,

barren stalks,

binder,

chapter on,

club work,

cultivation of,

demonstrations, 


\section{INDEX}

CoRn (Continued).

for silo,

grading seed,

harvesting and storing,

judging,

plant,

play contests,

preparing seed for planter, $\quad 11$

root aphis,

roots and moisture,

root worm,

seed bed,

seed saving,

14

seed selection bed,

24

seed testing box,

33

shocker, the,

53

smut,

stand of,

stover, value of,

suckers,

testing seed,

time for gathering seed,

5

52

8

31

time for planting,

20

types of,

uses of,

uses of stalk,

varieties of, yield of,

County Agent,

and the school, financial support of, 403 the agricultural, 


\section{INDFX}

Cow,

dairy type of,

feeding of dairy,

281

judging the dairy,

2ii

milk tests of the,

Cow-Peas,

as forage,

148

as soil renovator,

148

plant,

CROPS,

forage,

rotation of,

CUTWORAIS,

DAIRY,

breeds,

profitable and unprofitable cows,

types of cows,

Demonstrations,

cattle,

corn,

forage,

fruit garden,

hogs,

horses,

potato,

poultry,

3i1

roads,

sheep,

$34+$

soil,

tomato,

vegetable garden, 


\section{INDEX}

DRAINAGE,

cost of,

strrface,

under,

EGGS,

for hatching,

producing and marketing,

rules for production of,

FARM,

administration of, and home management,

buildings for the, implements and mechanics, chapter on,

selecting and planning,

the liome,

Farm Economics,

section on,

Fertilization of Plants,

Fertilizers, Commercial,

Forage Crops,

chapter on,

club project,

region of,

Fungicides,

Garden, The Fruit,

care of,

club projects,

demonstrations, 


\section{INDEX}

Garden, The Fruit (Continued),

plan of,

play contests,

pruning of,

soil and location for,

spraying,

varieties in,

Garden, The Vegetable,

chapter on,

clubs,

cultivation of,

demonstrations,

insect enemies of,

location and soil for,

plan for,

planting time,

play contests,

Grasses,

for meadows,

for pastures,

uses of,

varieties of,

Grasshoppers,

I ARVESTING,

alfalfa crop,

by "hogging down" corn,

red-clover crop,

the corn crop,

the potato crop,

102

the wheat crop,

with corn binder,

Hessian Fly, The, 


\section{INDEX}

Hogs,

balanced ration for,

breeds of,

316

care of,

chapter on,

315

chief region for,

315

club projects,

- 335

demonstrations with,

334

diseases of,

feeding,

328

houses,

323

play contests,

prevention of cholera in,

Home,

and farm management,

375

beautifying the grounds,

grounds and wood lot,

389

Horses,

breeds of,

302

care of,

307

chapter on,

classes of,

296

297

clubs,

314

defects of,

306

demonstrations with,

313

feeding of,

310

judging of,

305

leading states for,

296

play contests,

314

Horticulture,

section on,

Hotbed, Tine,

Humus, 


\section{INDEX}

IMPLEMENTS,

farm and mechanics, chapter on,

408

INOCULATION,

of soil for alfalfa,

140

INSECTICIDES.

208

Kerosene Emulsion,

214

LEGUATES,

chapter on,

146

for meadows,

155

for pastures,

159

uses of,

115

varieties of,

114

Lime,

use of on soils,

246

Lime Sulphur Spray,

210

Manure,

application of,

242

barnyard,

238

green,

242

preventing loss from,

241

MeAdows,

care of,

156

chapter on,

154

grasses for,

155

permanent,

158

requirements of,

154

seed mixtures for,

156

봬드,

cooling of,

producing clean,

tests for the dairy cow, 
Nitrogen,

gathering bacteria,

OAts, Chapter ON,

PARIS GREEN SPRAY,

PAstures,

care of,

grasses for,

mixtures of seed for,

requirements of,

PEANUT, THE,

uses of,

Phosphorus FERTILIZERS,

38

Planter,

grading seed for,

41

testing the,

Play Contests,

292

cattle,

61

corn,

fruit garden,

hogs,

horses,

potato,

poultry,

roads,

sheep,

soil,

vegetable garden, 


\section{INDEX}

Pollen,

Potassium Fertilizers,

Potatoes,

as a farm crop,

99

chapter on,

98

cutting the seed,

106

clubs,

111

demonstrations,

111

enemies,

107

play contests,

111

region,

selection of seed,

103

soil and seed bed for,

100

storing of,

102

the plant,

Poultry,

chapter on,

clubs,

372

demonstrations,

371

diseases of,

housing of,

363

increasing demands,

347

leading states for,

play contests,

Pruning,

of fruit trees,

tomatoes,

"Rag-Doll" Seed Tester,

Ration,

balanced for dairy cows,

balanced for hogs,

for fattening chickens, 


\section{INDEX}

RATION (Continued).

for laying hens,

358

for sheep,

Resin Lime Spray,

214

ROADS,

chapter on,

420

construction of earth,

425

club projects,

430

demonstrations with,

428

importance of public,

420

location of,

maintenance of earth,

play contests,

types of,

Rope-Tying,

Rotation of Crops,

and fertility,

plan for,

RUsT,

wheat,

Saivdust Seed Testers,

SCAB,

in wheat,

potato,

SEED,

bed and planting,

bed for wheat,

care of 'shelled,

cleaning red clover,

curing of corn,

cutting potato,

germination box,

grading for planter, 


\section{INDEX}

SEED (Continued).

loss from poor,

mixtures for meadows,

saving of,

selecting wheat,

selection bed,

70

selection of potato,

24

testing,

103

various testers for,

Seed Bed,

preparing the,

Sheep,

agricultural importance of,

336

breeds of,

338

chapter on,

336

club projects,

$3+4$

demonstrations,

$3+3$

feeding of,

$3+0$

play contests,

$3+4$

Shocker,

the corn,

Silo, The,

Sinut,

corn,

treatment for wheat,

SoIL,

acid and liming,

barnyard manure and,

capacity of for water,

252

chapter on,

225

club projects,

262

cultivation of,

102

demonstrations,

drainage, 


\section{INDEX}

Sorl (Contimued).

erosion of,

fertility and legumes,

fertility of,

forms of water in,

$2: 1$

for potatoes,

inoculation for alfalfa,

moisture, chapter on,

$2 \div 1$

organic matter in,

227

origin of,

225

play contests,

262

requirements for alfalfa,

138

structure of,

230

texture of,

228

tillage and water,

Soy-BEAns,

feeding value of,

152

Spraying,

machines for,

101

mixtures for,

208

of fruit gardens,

IS8

tomatoes,

204

Stover, Corn,

Tilth of Soils,

231 'Jomato, The,

as a garden crop,

201

chapter on,

201

club project,

culture,

demonstrations with,

harvesting and marketing,

play contests, 


\section{INDEX}

Tomato, The (Continued).

pruning and staking,

varieties of,

Tuberculosis,

in cattle,

in hogs,

suppressing in cattle,

tuberculin test for,

TUbers,

Vegetables,

enemies of,

garden,

transplanting of,

VETCH,

common,

hairy,

types of,

WATER,

capillary,

gravitational,

WeEDS,

as enemies of alfalfa,

killing in corn-field,

soil and tillage,

Whe八T,

chapter on,

diseases and enemies of,

harvesting,

i1

importance of,

planting,

seed bed for, 


\section{INDEX}

IVuE.tT (Continued).

selecting seed,

7)

spring,

69

types of,

(6)

winter,

WIREW ORMS,

WOOD LOT,

chapter on,

389

enemies of,

396

the farm,

392

IVORMS,

corn root, 






\section{LIBRARY OF CONGRESS}

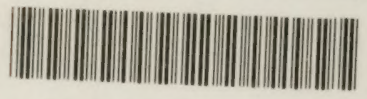
00027733190 